TESIS DOCTORAL

\title{
MODELIZACIÓN DE LA INTERRELACIÓN ENTRE LAS VARIABLES DE SERVICIO \\ Y LA DEMANDA DE VIAJEROS \\ DE AUTOBUSES DE TIPO INTERURBANO
}

\author{
UNIVERSIDAD DE BURGOS
}

ESCUELA POLITÉCNICA SUPERIOR

AUTOR: MARTA ROJO ARCE

DIRECTORES DE TESIS:

HERNÁN GONZALO ORDEN Y LUIGI DELL'OLIO

JUNIO 2011

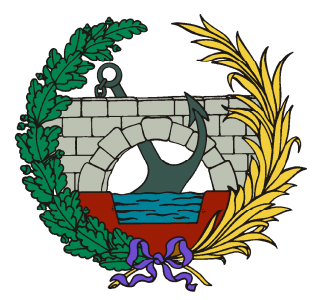





\section{Resumen}

Es un problema cada día más grave, tanto en el ámbito urbano como en el interurbano, la congestión que sufren las infraestructuras. Por ello, todas las soluciones pasan por fomentar el uso del transporte público y/o penalizar al vehículo privado motorizado. El objetivo de la presente investigación es, en primer lugar, tratar de encontrar cuál es la relación existente entre los parámetros de calidad de los servicios de transporte interurbano de viajeros en autobús con la demanda de los mismos.

Para ello, se ha analizado la situación actual real del transporte público interurbano de viajeros por carretera, y se han recopilado diversos estudios existentes hasta la fecha para intentar modelizar correctamente cómo los usuarios perciben la calidad del servicio, así como su elección modal. También se han examinado diferentes metodologías que tratan de integrar las condiciones de calidad del servicio dentro de los contratos con los concesionarios, para así fomentar su empleo, reduciendo a la vez las subvenciones.

A continuación, se procedió a una exhaustiva labor de recolección de datos, realizando en total más de 800 encuestas. Tras determinar el perfil tipo de los actuales usuarios del autobús y las características de los viajes realizados por éstos, se procedió a la etapa de modelización, calibrando sendos submodelos de satisfacción de los usuarios y de elección modal, mediante técnicas de elección discreta -los primeros de tipo ordinal y los segundos de tipo logit multinomial o jerárquico-. La relación entre las variables relevantes en uno y en otro es un punto crucial para el conocimiento de cómo potenciar el empleo del servicio.

Finalmente, se ha propuesto una nueva metodología de aplicación de los resultados anteriores a los contratos de transporte en la Comunidad Autónoma de Castilla y León. Mediante sendas pruebas piloto, y a partir de una adecuada modelización previa, se ha aplicado dicha metodología, planteando la posibilidad de introducir incentivos a los operadores que lleven a cabo mejoras en la calidad del servicio de transporte interurbano en autobús. De este modo, sin aumentar el coste para la Administración, se pueden reducir las cuantían de subvención por déficit de explotación, al aumentar la demanda si hacemos el transporte público más "apetecible" al usuario. Así, de un modo sencillo y factible de ejecutar, se puede conjugar la mejora de calidad con la viabilidad económica de las concesiones, con la consecuente ganancia para todos. 



\section{Abstract}

It is a more serious problem each day, both in the urban area and in the long distance, the traffic congestion in our infrastructures. Therefore all solutions try to promoting the use of public transport and/or penalize private motorized vehicles. The objective of this research is, first of all, finding the relationship between the parameters of quality of the services of intercity passenger bus with the demand for them.

So, the real situation of interurban public transport of passengers by bus has been analyzed, and various existing studies which model how users perceive the quality of the service, as well as its modal choice, have been gathered. Also, we examined different methodologies which try to integrate the conditions of quality of the service under the contracts with the operators, in order to promote its employment, while reducing subsidies.

An exhaustive work of data collection has been made, with more than 800 surveys. We determined the profile type of current users of the bus and the characteristics of the journeys made by them. After that, the stage of modeling began, calibrating two separate sub-models of satisfaction of users and their modal choice, using techniques of discrete choice -ordinal type for the first sub-model and multinominal logit or hierarchical type for the second one-. The relationship between the relevant variables in each sub-model is a crucial point for the knowledge of how to enhance the use of the service.

Finally, it has been proposed a new methodology for the application of the above results to transport contracts in the region of Castile and León, Spain. Applying the prior modeling to two pilot tests, we used this methodology, considering the possibility of introducing incentives to operators which carry out some improvements in the quality of the service of interurban bus. In this way, without increasing the cost for the Administration, we may reduce the amounts of subsidy for the operating deficit, since the demand of the service should rise if we make the public transport more attractive to the user. Thus, in a simple and feasible way, we can combine the improvement of the quality of public transport with the economic viability of the concessions, with the consequent gain for all. 



\section{Agradecimientos}

Quiero agradecer a mis directores de Tesis D. Hernán Gonzalo Orden y D. Luigi dell'Olio su apoyo y ayuda para la realización de la investigación llevada a cabo. Sus explicaciones y conocimientos me han servido fuertemente para continuar adelante cada día.

También quiero citar aquí a los profesores D. Jesús Sánchez Alonso y D. Jesús Ángel Alonso García, y a D. Javier Monar Lomana, por acogerme en nuestro pequeño Área con su fuerte calor y cercanía. Además, deseo indicar mi agradecimiento al profesor D. Ángel Ibeas Portilla, quien, junto con mis directores de Tesis, me animó hace unos años a embarcarme en esta tarea.

Deseo así mismo agradecer a las investigadoras $D^{\mathrm{a}}$. Alaitz Linares Unamunzaga y $\mathrm{D}^{\mathrm{a}}$. Lara Velasco Carrera su colaboración en la realización de encuestas, cuya ayuda fue crucial para el desarrollo de la presente investigación.

También quiero agradecer a la Universidad de Burgos la concesión de una de sus Becas Predoctorales para la Formación de Investigadores, y por hacerme recientemente un hueco entre su profesorado. Espero poder responder ante la confianza depositada en mí.

Así mismo, hago constar la colaboración de la Consejería de Educación de la Junta de Castilla y León, a través de sus Ayudas para la Formación de Personal Investigador de la Comunidad de Castilla y León, cofinanciadas por el Fondo Social Europeo.

Por último, se lo agradezco en especial a mis padres, por todos esos años apoyándome sin más recompensa que el ver a su hija cumplir sus aspiraciones. Y a Fran, sin cuya ayuda y perseverancia, y su fuerza en los momentos difíciles, no hubiera podido seguir adelante. Quiero agradecerle aquí su comprensión y paciencia para calmarme cuando los nervios me atacaban y empujarme cuando me quedaba estancada.

Sin todos ellos, no hubiera sido posible. 



\section{Índice}

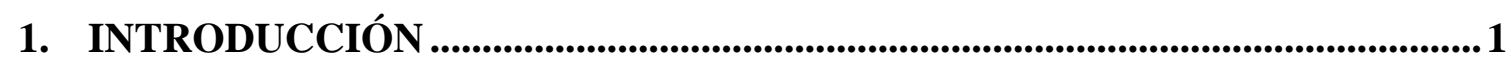

1.1. Antecedentes y Justificación ......................................................................... 3

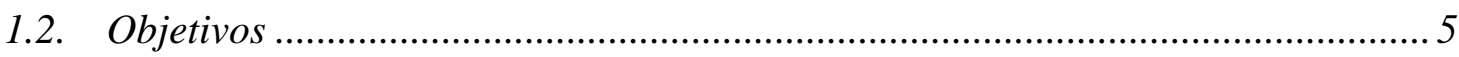

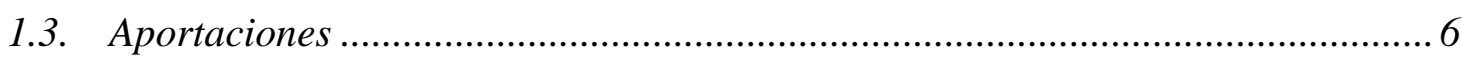

2. SITUACIÓN ACTUAL DEL TRANSPORTE INTERURBANO DE VIAJEROS POR AUTOBÚS ...................................................................................... 7

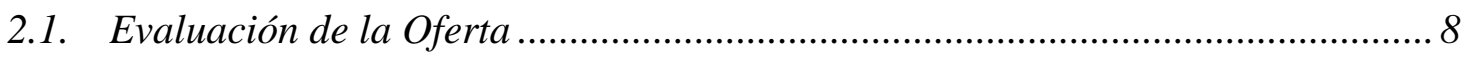

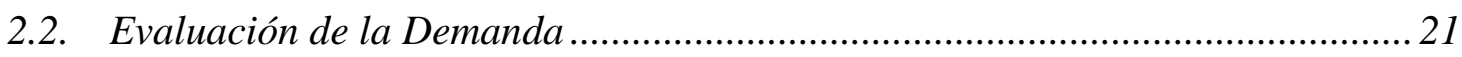

2.3. La Gestión de los Servicios Públicos de Transporte .......................................... 28

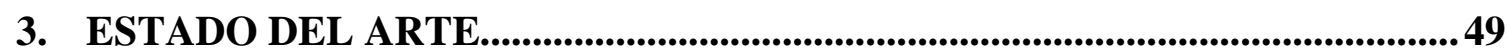

3.1. Revisión Bibliográfica de Modelos de Calidad y Demanda ............................... 50

3.2. Incorporaciones de Parámetros de Calidad a los Contratos de Transporte...... 76

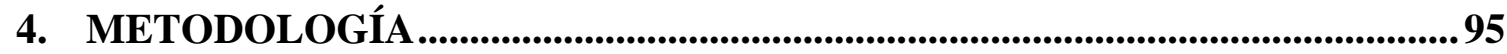

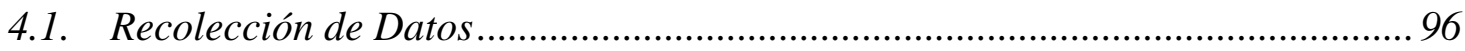

4.2. Modelización de la Satisfacción Global del Usuario y su Relación

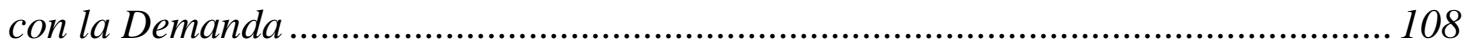

4.3. Aplicaciones a los Contratos de Transporte .................................................... 139

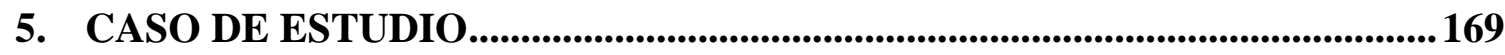

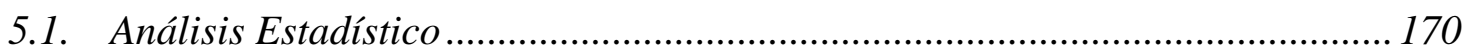

5.2. Modelización del Comportamiento del Usuario ............................................... 180

5.3. Inclusión de Variables de Calidad en los Contratos de Transporte.................. 225

6. CONCLUSIONES Y FUTURAS LÍNEAS DE INVESTIGACIÓN .................259

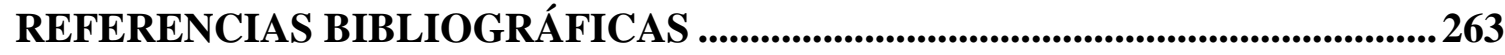

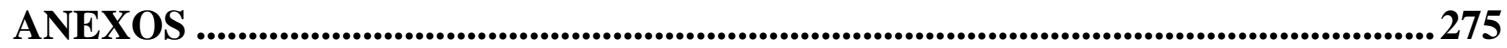





\section{Índice de Tablas}

Tabla 2-1. Autobuses autorizados por el Ministerio de Fomento (servicio público) ............ 9

Tabla 2-2. Autobuses autorizados por el Ministerio de Fomento (servicio privado) ............ 9

Tabla 2-3. Variación bianual del total de autobuses autorizados por el Ministerio de Fomento

Tabla 2-4. Vida media de los autobuses dados de baja .................................................... 13

Tabla 2-5. Número medio de autobuses autorizados por empresa (servicio público)......... 16

Tabla 2-6. Número medio de autobuses autorizados por empresa (servicio privado)......... 16

Tabla 2-7. Distribución de empresas en función del número de autobuses

(serv. público)

Tabla 2-8. Distribución de empresas en función del número de autobuses

(serv. privado)

Tabla 2-9. Tráfico total de viajeros (millones de viaj-km)

Tabla 2-10. Tráfico total de viajeros en autobús interurbano (miles de viajeros) ............... 23

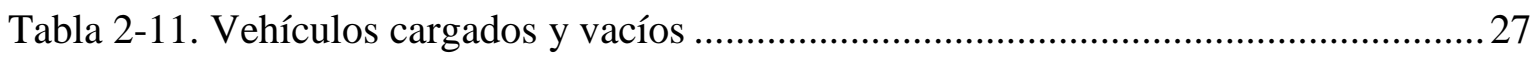

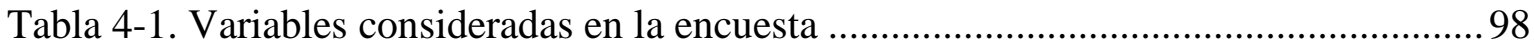

Tabla 4-2. Tamaño muestral mínimo para las encuestas de preferencias reveladas ............99

Tabla 4-3. Selección inicial de variables para los experimentos PD .................................. 101

Tabla 4-4. Diseño preliminar del experimento PD autobús - vehículo privado ................. 101

Tabla 4-5. Diseño preliminar del experimento PD autobús - ferrocarril ........................... 102

Tabla 4-6. Selección definitiva de variables para los experimentos PD............................ 103

Tabla 4-7. Diseño definitivo del experimento PD autobús - vehículo privado................... 103

Tabla 4-8. Diseño definitivo del experimento PD autobús - ferrocarril ............................ 104

Tabla 4-9. Reglas de buena práctica de inclusión de variables en los modelos

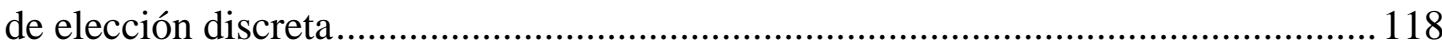

Tabla 4-10. Costes anuales de explotación tipo del servicio de autobuses interurbanos .. 156

Tabla 4-11. Costes del transporte en la Comunidad de Madrid ....................................... 160

Tabla 5-1. Matriz (resumen) de correlación entre variables exógenas (satisfacción) ........ 182

Tabla 5-2. Relación de variables incluidas en los modelos de satisfacción ....................... 183

Tabla 5-3. Modelos de satisfacción genéricos para todos los usuarios

(5 rangos de elección)

Tabla 5-4. Modelos de satisfacción genéricos para todos los usuarios

(4 rangos de elección)

Tabla 5-5. Relación de variables incluidas en los modelos de satisfacción

con variaciones sistemáticas en los gustos de los usuarios. 
Tabla 5-6. Modelos de satisfacción incorporando variaciones en los gustos de los usuarios 190

Tabla 5-7. Modelos de satisfacción - test de ajuste general ..............................................193

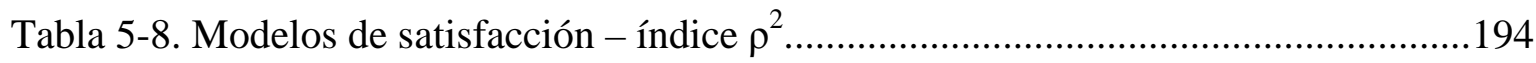

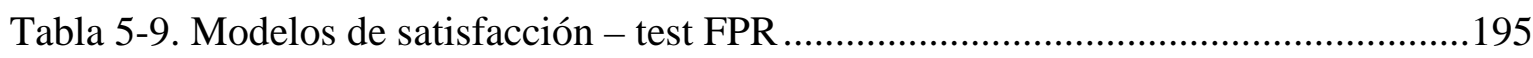

Tabla 5-10. Modelos de satisfacción - resumen de test de bondad ....................................196

Tabla 5-11. Matriz (resumen) de correlación entre variables exógenas (demanda) ...........199

Tabla 5-12. Relación de variables adicionales incluidas en los modelos de demanda ......200

Tabla 5-13. Modelos de demanda (logit multinomial) genéricos para todos los usuarios

Tabla 5-14. Relación de variables incluidas en los modelos de demanda con variaciones sistemáticas en los gustos de los usuarios .204

Tabla 5-15. Modelos de demanda (logit multinomial) con variaciones en los gustos de los usuarios

Tabla 5-16. Modelos de demanda (logit jerárquico) con variaciones en los gustos

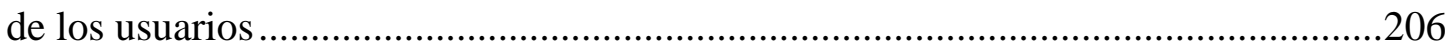

Tabla 5-17. Modelos de demanda - test de ajuste general.............................................209

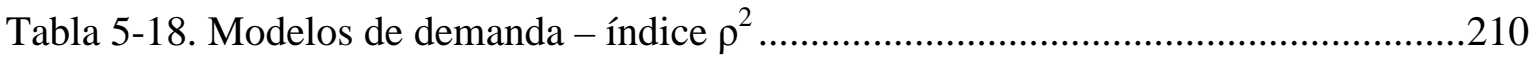

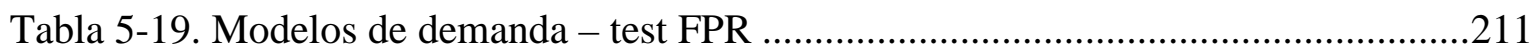

Tabla 5-20. Modelos de demanda - índice de éxito predictivo ..........................................212

Tabla 5-21. Modelos de demanda - resumen de test de bondad......................................212

Tabla 5-22. Disponibilidad al pago (usuario medio) por mejoras en las variables

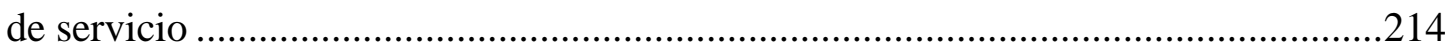

Tabla 5-23. Disponibilidad al pago (variaciones en los gustos) por mejoras en las variables de servicio

Tabla 5-24. Proporciones estimadas de elección modal .....................................................218

Tabla 5-25. Elasticidades de la demanda del servicio de autobuses interurbanos .............219

Tabla 5-26. Comparación de modelos de satisfacción y demanda genéricos para todos los usuarios .222

Tabla 5-27. Líneas incluidas en la aplicación de modificación de concesiones .................226

Tabla 5-28. Demanda y situación inicial de las líneas metropolitanas y provinciales.......228

Tabla 5-29. Costes de explotación iniciales de las líneas metropolitanas y provinciales ..230

Tabla 5-30. Procedencia de la nueva demanda captada por el autobús interurbano..........232

Tabla 5-31. Prueba 1: Alfoz metropolitano. Maximización beneficio social + operador.

Punto óptimo de explotación 
Tabla 5-32. Prueba 1: Alfoz metropolitano. Maximización beneficio social + operador.

Resultados económicos

Tabla 5-33. Prueba 1: Alfoz metropolitano. Maximización beneficio social.

Punto óptimo de explotación

Tabla 5-34. Prueba 1: Alfoz metropolitano. Maximización beneficio social.

Resultados económicos

Tabla 5-35. Prueba 2: Tray. Provinciales/Regionales. Maximización beneficio social

+ operador. Punto óptimo de explotación (valores finales)

Tabla 5-36. Prueba 2: Tray. Provinciales/Regionales. Maximización beneficio social + operador. Punto óptimo de explotación (incrementos relativos).

Tabla 5-37. Prueba 2: Tray. Provinciales/Regionales. Maximización beneficio social + operador. Resultados económicos (valores finales)

Tabla 5-38. Prueba 2: Tray. Provinciales/Regionales. Maximización beneficio social + operador. Resultados económicos (incrementos)

Tabla 5-39. Prueba 2: Tray. Provinciales/Regionales. Maximización beneficio social.

Punto óptimo de explotación (valores finales)

Tabla 5-40. Prueba 2: Tray. Provinciales/Regionales. Maximización beneficio social.

Punto óptimo de explotación (incrementos relativos).

Tabla 5-41. Prueba 2: Tray. Provinciales/Regionales. Maximización beneficio social.

Resultados económicos (valores finales)

Tabla 5-42. Prueba 2: Tray. Provinciales/Regionales. Maximización beneficio social.

Resultados económicos (incrementos) 



\section{Índice de Figuras}

Figura 1-1. El "círculo vicioso" del transporte interurbano en autobús 3

Figura 2-1. Evolución del total de autobuses autorizados por el Ministerio de Fomento ... 11

Figura 2-2. Antigüedad de los autobuses según su tamaño a finales del año 2007 ............. 12

Figura 2-3. Parque nacional de autobuses a finales del año 2008 ................................... 12

Figura 2-4. Evolución del número de autobuses con edad mayor a 10 años ........................ 14

Figura 2-5. Parque de autobuses según número de plazas................................................ 15

Figura 2-6. Evolución del $n^{\circ}$ de autobuses autorizados (s. público) según el tamaño

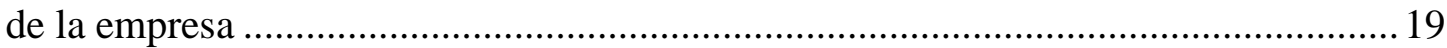

Figura 2-7. Distribución porcentual de tráfico (viaj-km) en transporte público................... 22

Figura 2-8. Evolución mensual del tráfico en autobús ...................................................... 24

Figura 2-9. Kilómetros medios de recorrido anual por autobús ......................................... 25

Figura 2-10. Variación mensual del recorrido medio por autobús .......................................26

Figura 2-11. Evolución de porcentajes de vehículos cargados y vacíos............................... 27

Figura 2-12. Modalidades de Gestión del Transporte Público ............................................ 43

Figura 3-1. Esquema del modelo empleado en Taiwan.................................................... 58

Figura 3-2. Evolución de la calidad esperada y percibida por los usuarios............................ 61

Figura 3-3. Ciclo de la calidad en el transporte público de pasajeros ................................. 85

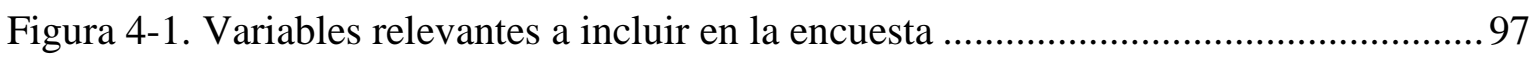

Figura 4-2. Formulario de encuesta (versión reducida) ...................................................... 106

Figura 4-3. Metodología de interrelación calidad-demanda para las variables

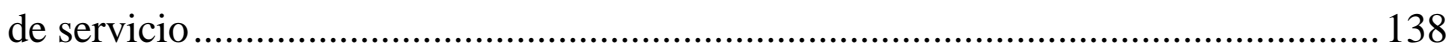

Figura 4-4. Pendiente de la variable compuesta en función de la demanda ...................... 149

Figura 5-1. Distribución de los entrevistados en función de su sexo ................................ 170

Figura 5-2. Distribución de los entrevistados por rangos de edad.................................... 171

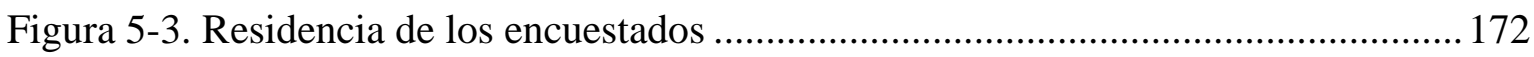

Figura 5-4. Disponibilidad de carnet de conducir y vehículo privado

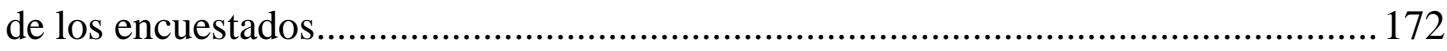

Figura 5-5. Distribución de los entrevistados según su actividad ................................... 173

Figura 5-6. Status económico familiar de los encuestados........................................... 173

Figura 5-7. Frecuencia habitual de viaje de los encuestados .......................................... 174

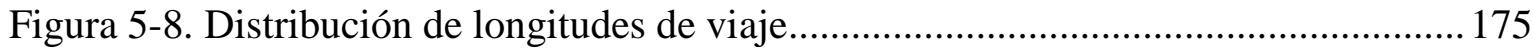

Figura 5-9. Motivos de viaje de los entrevistados .......................................................... 175

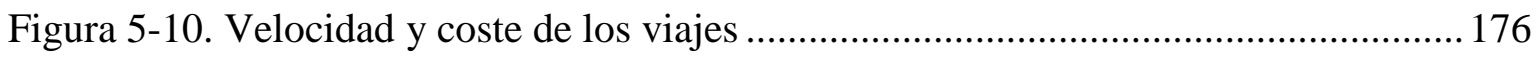

Figura 5-11. Retrasos y número de paradas de los viajes................................................ 176 


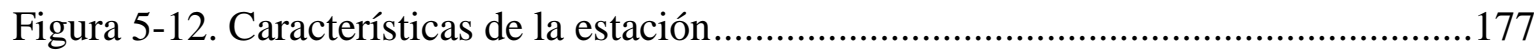

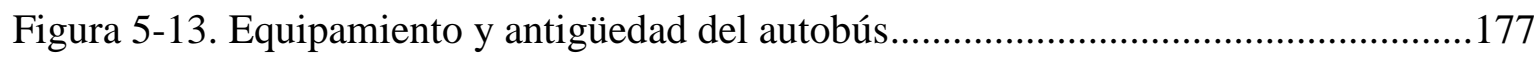

Figura 5-14. Satisfacción global y fidelidad de los usuarios ............................................178

Figura 5-15. Comparación satisfacción-fidelidad ..............................................................179

Figura 5-16. Resultados de interrelación calidad-demanda para las variables de servicio

Figura 5-17. Prueba 1: Alfoz metropolitano. Maximización beneficio social

+ operador. Variaciones en el presupuesto

Figura 5-18. Prueba 1: Alfoz metropolitano. Maximización beneficio social

+ operador. Variaciones en el beneficio industrial

Figura 5-19. Prueba 1: Alfoz metropolitano. Maximización beneficio social.

Variaciones en el presupuesto

Figura 5-20. Prueba 1: Alfoz metropolitano. Maximización beneficio social.

Variaciones en el beneficio industrial 


\section{INTRODUCCIÓN}

Es evidente que, hoy en día, en las carreteras se está produciendo una clara tendencia de congestión, debida principalmente al exceso de intensidad de tráfico que deben soportar. Por ello, los sistemas de transporte público se configuran como una alternativa de reducción de los costes externos que general esta situación: accidentes, ruido, contaminación ambiental...

Debido a esta situación, en los últimos años se está tratando de promover el transporte público frente al privado, ya que, la cuota de mercado del transporte público es cada vez menor, debido a la necesidad de desplazamiento cada vez a mayor distancia, además del proceso de motorización existente. Por ello, existen numerosas propuestas y metodologías de fomento del transporte público, de entre las cuales hay algunas incluso con formulación matemática cuantitativa.

En el presente documento, se tratará primordialmente de potenciar el transporte público interurbano por carretera en nuestro país, y de forma más centrada en la Comunidad Autónoma de Castilla y León, a través de la actuación sobre las principales variables de calidad del servicio. Para ello, se revisarán en primer lugar las distintas experiencias nacionales e internacionales hasta la fecha en cuanto a cómo se puede modelizar la relación calidad del servicio - satisfacción del usuario e interrelacionar dichas variables con la demanda final del mismo.

El objetivo final del estudio es, en resumen, tratar de modelizar cuáles son los parámetros que realmente valora el usuario a la hora de evaluar la calidad global del servicio de transporte interurbano de pasajeros en autobús, para poder calcular posteriormente la demanda estimada del mismo. Además, se tratará de inferir una formulación aplicable a nuestra región, que se pueda introducir en los contratos del transporte público interurbano de viajeros en autobús, a fin de garantizar una mayor demanda del servicio, que reduzca las posteriores subvenciones, y que maximice el beneficio social común.

Además, se pretende que sirva a su vez como Tesis Doctoral de la autora Marta Rojo Arce, dentro del Programa de Doctorado "Ingeniería Civil e Industrial" de la Universidad de Burgos, dirigido por D. Hernán Gonzalo Orden y codirigido por D. Luigi dell'Olio. 
El trabajo se compone de seis capítulos, estructurados de forma cronológica, según la metodología de realización del estudio.

El primer capítulo corresponde a una breve introducción al problema. En él se presenta el planteamiento del problema de estudio, junto con los objetivos perseguidos en el mismo y un resumen de las principales aportaciones de la presente investigación.

En los capítulos segundo y tercero se exponen los antecedentes del estudio, en cuanto a la situación actual del transporte público interurbano de viajeros en autobús, y sus modalidades de gestión, y también se revisan las experiencias previas recogidas en la principal bibliografía relacionada con el tema.

El cuarto capítulo recoge la metodología propuesta, diferenciando tres etapas principales: recolección de datos, modelización del comportamiento del usuario -incluyendo los análisis de satisfacción y elección modal- y aplicación a los contratos de transporte público interurbano. A continuación, en el quinto capítulo se presentan los resultados de la metodología expuesta al caso de estudio, a partir de las encuestas realizadas en la etapa anterior.

Finalmente, el capítulo sexto recoge las posibles líneas futuras de investigación que quedan abiertas, junto con las principales conclusiones del estudio. 


\subsection{Antecedentes y Justificación}

En el ámbito del transporte, tanto urbano como interurbano, es evidente el problema -cada día más grave- de insostenibilidad que sufren las infraestructuras. La solución aparentemente más sencilla sería fomentar el uso del transporte público, de modo que el vehículo privado quedara relegado a una posición menos relevante.

Sin embargo, suele ser habitual que los servicios de transporte público de viajeros de tipo interurbano sean altamente deficitarios, siendo necesaria la inclusión de cuantiosas subvenciones que permitan mantener dichos servicios, dado su carácter de servicio público. Unida esta circunstancia a la insuficiente calidad de algunos servicios de transporte interurbano de viajeros, en términos de frecuencias, rutas y estado de los autobuses, se produce una especie de "círculo vicioso".

Dada la baja calidad del servicio, se genera poca demanda, lo que no mejora la situación económica del mismo, que precisa de grandes subvenciones de la Administración para mantenerse, y que hace, por tanto, que las inversiones para mejorar su calidad no resulten rentables para los operadores. El "círculo" descrito se refleja en la Figura 1-1:

Figura 1-1. El "círculo vicioso" del transporte interurbano en autobús
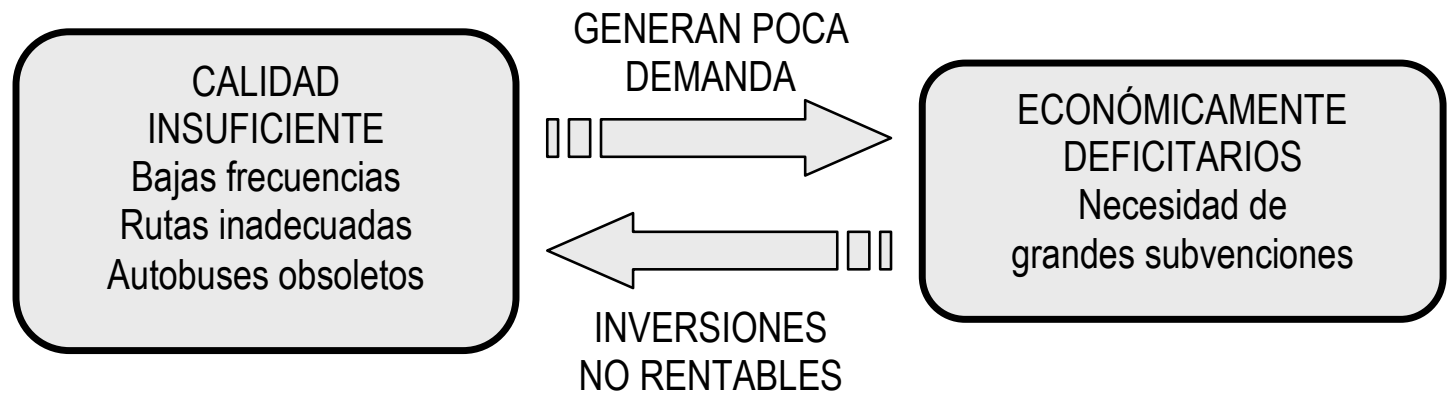

Además, se suma la tendencia de los últimos años de que, a pesar de que aumenta el número de viajes interurbanos efectuados, la proporción de los mismos que se realiza empleando el transporte público es cada vez menor, debido a la mejor disponibilidad económica, y a que cada vez son mayores las distancias a salvar. Así, los costes del transporte que soporta nuestra sociedad son cada vez mayores, considerando no sólo los internos, sino también los externos, correspondientes a los accidentes, el ruido, la congestión, el deterioro medioambiental, etc.

Por todo ello, las distintas Administraciones tratan de potenciar el transporte público frente al vehículo privado, bien promocionando el primero o penalizando el empleo del segundo. 
Sin embargo, las acciones de penalización del transporte en vehículo privado no gozan de buena percepción por parte de los usuarios, que sienten que se les está privando de un derecho adquirido. Es por esto que las autoridades tienen, en numerosas ocasiones, "miedo" a aplicar este tipo de medidas, por las consecuencias políticas que ello pueda acarrear. Así, las acciones habitualmente empleadas están encaminadas a mejorar el servicio de transporte público, con el objetivo de aumentar su cuota de utilización.

Sin embargo, a menudo sucede que las medidas aplicadas no dan el resultado esperado, bien porque los usuarios no las perciben o valoran suficientemente, o porque no se está actuando sobre sus verdaderas necesidades. Y además los operadores suelen ser reacios a invertir en mejorar la calidad del servicio, ya que con frecuencia es deficitario, y los costes añadidos (de inversión o de explotación) no se prevén suficientemente rentables, debido al bajo incremento de recaudación esperado, correspondiente, a su vez, a la poca demanda captada.

Por todo ello, resulta muy importante conocer los siguientes aspectos que caracterizan la demanda del servicio de transporte de tipo interurbano de viajeros en autobús:

- Los criterios de calidad que siguen los usuarios a la hora de valorar el servicio.

- La metodología más adecuada para incidir en la demanda.

- La posibilidad de incorporar estas medidas a los contratos de servicios de transporte regular, sin afectar negativamente a los operadores, en un ámbito geográfico piloto.

Con este fin surge la investigación cuyo resultado es el presente documento, con el objetivo último de encontrar cuáles serían las posibles acciones que potenciarían el uso del transporte público en autobús en ámbito interurbano, para proponer una metodología de aplicación a los contratos con los concesionarios. 


\subsection{Objetivos}

Una vez justificada la necesidad de llevar a cabo la investigación propuesta, en el presente apartado se reflejan los principales objetivos que se persiguen con ella. En resumen, los principales fines buscados en la Tesis Doctoral son los que siguen:

- Modelizar correctamente la percepción de calidad por parte de los usuarios del servicio de transporte interurbano en autobús, detectando cuáles son las características del mismo más relevantes desde el punto de vista del individuo.

- Obtener una metodología que permita estimar la demanda del citado servicio, en función de sus variables de funcionamiento, de modo que seamos capaces realizar prognosis de futuro, modificando los actuales valores de las características del servicio consideradas.

- Relacionar las variables relevantes para la calidad del servicio percibida por los usuarios con las que influyen en su elección modal, clasificándolas de este modo en diferentes categorías, según a qué criterio afecten.

- Proponer un nuevo sistema concesional para los servicios interurbanos de transporte regular de viajeros, que incorpore criterios de calidad, y que asegure una demanda mínima del servicio y, por tanto, un límite máximo a las subvenciones, añadiendo incentivos económicos adicionales a los operadores que mejoren su calidad y que aumenten el volumen de demanda captada, siguiendo una metodología analítica para ello. 


\subsection{Aportaciones}

En la Tesis Doctoral que se propone, se emplearán como base de partida algunas de las experiencias previas descritas en los capítulos 3 y 4 . Sin embargo, se han incorporado una serie de variaciones innovadoras, entre las que cabe destacar las siguientes:

- Las características del servicio de transporte interurbano en autobús han sido clasificadas en función de su relevancia desde el punto de vista de la calidad percibida por los usuarios, de su correspondiente elección modal, o de ambas cuestiones simultáneamente. Además, dicha categorización se ha expuesto gráficamente, herramienta sencilla pero que puede resultar muy útil a la hora de exponer los resultados de las modelizaciones a públicos no expertos.

- Se ha propuesto un nuevo sistema concesional, en este caso en un ámbito territorial reducido, novedoso en nuestro país -a pesar de que existen Administraciones que de forma más o menos indirecta también consideran la calidad del servicio de transporte público interurbano en autobús-. Este nuevo sistema, manteniendo el equilibrio económico de cada concesión, permitiría mejorar de forma importante la calidad del servicio, promoviendo el empleo del mismo y reduciendo, por lo tanto, las externalidades negativas asociadas.

- Los beneficios aportados al usuario han sido calculados considerando todas las variables de calidad que han resultado relevantes en los modelos asociados, a través de las técnicas de disponibilidad al pago (WTP). Ello aporta mayor riqueza y variabilidad al problema expuesto, permitiendo así mismo la optimización de la calidad del servicio, pero manteniendo el equilibrio económico de cada concesión.

- Se ha incorporado a la propuesta de aplicación la valoración de los costes externos del transporte. Así, una visión global del sistema de transportes permitiría una mejor redistribución de las subvenciones necesarias para los distintos operadores, repercutiendo positivamente a aquéllos que inviertan en mejorar la calidad del servicio que ofrecen.

Así pues, se han aportado una serie de innovaciones novedosas en nuestro país, en este caso orientadas al transporte público interurbano en autobús, que mejorarían la calidad del servicio y reducirían las externalidades del transporte. Además, se desea hacer notar la fácil transferibilidad de las metodologías propuestas también a otros ámbitos de estudio, lo que amplía aún más la posible aplicación práctica de las mismas. 


\section{SITUACIÓN ACTUAL DEL TRANSPORTE INTERURBANO DE VIAJEROS POR AUTOBÚS}

Resulta evidente que el primer paso para poder analizar correctamente cómo se puede influir sobre el sistema de transporte público interurbano por carretera es representar la situación actual, evaluando además la utilización del mismo, a fin de comprobar en qué medida se pueden mejorar las estadísticas.

En primer lugar, se analizará la oferta de transporte público en el ámbito general español, y más concretamente en el de la Comunidad Autónoma de Castilla y León, que es sobre la que finalmente se pretende realizar el análisis final.

A continuación, se introducirán una serie de cifras de tráfico, en los dos ámbitos territoriales considerados, para comprobar si el grado de utilización del servicio es susceptible de ser mejorado y, en caso positivo, en qué medida.

Finalmente, se revisará brevemente las actuales posibilidades de gestión de los sistemas de transporte público en autobús, tanto desde el punto de vista normativo como de las modalidades de contratación existentes. 


\subsection{Evaluación de la Oferta}

En el presente apartado, se analizará brevemente el servicio de transporte público interurbano de viajeros por carretera, empleando fundamentalmente datos del Observatorio del Transporte de Viajeros por Carretera del Ministerio de Fomento [102], correspondiente al mes de Agosto de 2010, y de la Dirección General de Tráfico [34].

En primer lugar, se comentará una serie de datos sobre el número total de autorizaciones de transporte público en autobús interurbano existentes, para continuar con la edad media y número de plazas de los vehículos. Por último, se realizarán unos breves apuntes sobre la estructura empresarial de los concesionarios.

\subsubsection{Autorizaciones de Transporte de Viajeros en Autobús}

En primer lugar, es necesario comentar que, en España, el 1 de Julio de 1998 se liberalizó el otorgamiento de las autorizaciones, de tal modo que:

- Las autorizaciones para la realización de servicios de transporte público discrecional y privado complementario, pasan a ser adjudicadas a la empresa, mientras que antes de esta fecha se otorgaban por autobús.

- Además, las autorizaciones de servicio público de tipo regular pasan a considerarse como discrecionales, de modo que los datos sufren un vuelco a partir de la citada fecha.

- El ámbito de las autorizaciones correspondiente al Ministerio de Fomento se ajusta casi únicamente a los trayectos de tipo nacional, quedando también algunos de tipo limitado.

Teniendo en cuenta cómo esta situación influye en los datos globales, en la Tabla 2-1 se presentan los datos de los últimos años en cuanto a total de autobuses autorizados para servicio público y, en la Tabla 2-2, para servicio privado: 
Tabla 2-1. Autobuses autorizados por el Ministerio de Fomento (servicio público)

Fuente: Ministerio de Fomento [102]

\begin{tabular}{|c|c|c|c|c|c|c|c|c|c|}
\hline & \multicolumn{9}{|c|}{ SERVICIO PÚBLICO } \\
\hline & \multirow{2}{*}{ TOTAL } & \multirow{2}{*}{$\begin{array}{l}\text { SERVICIO } \\
\text { REGULAR } \\
\text { (VR) }\end{array}$} & \multicolumn{7}{|c|}{ SERVICIO DISCRECIONAL (VD) } \\
\hline & & & TOTAL & NACIONAL & COMARC. & LOCAL & AUTONÓM. & PROVINC. & LIMITADO \\
\hline 1.993 & 30.949 & 7.438 & 23.511 & 11.868 & 1.279 & 9.048 & 1.035 & 281 & 0 \\
\hline 1.994 & 30.627 & 6.672 & 23.955 & 11.583 & 1.235 & 9.663 & 1.172 & 302 & 0 \\
\hline 1.995 & 30.007 & 6.101 & 23.906 & 11.627 & 1.272 & 9.357 & 1.308 & 342 & 0 \\
\hline 1.996 & 29.466 & 5.399 & 24.067 & 11.442 & 1.216 & 9.488 & 1.580 & 341 & 0 \\
\hline 1.997 & 30.576 & 5.325 & 25.251 & 11.618 & 1.231 & 10.034 & 1.990 & 378 & 0 \\
\hline 1.998 & 30.486 & 4.864 & 25.622 & 11.424 & 1.178 & 10.405 & 2.247 & 368 & 0 \\
\hline 1.999 & 34.415 & 1.013 & 33.402 & 29.129 & 208 & 3.135 & 887 & 40 & 3 \\
\hline 2.000 & 33.999 & 328 & 33.671 & 30.655 & 102 & 2.435 & 455 & 15 & 9 \\
\hline 2.001 & 36.318 & 320 & 35.998 & 33.255 & 100 & 2.213 & 409 & 11 & 10 \\
\hline 2.002 & 35.745 & 302 & 35.443 & 33.794 & 3 & 1.299 & 335 & 6 & 6 \\
\hline 2.003 & 38.013 & 301 & 37.712 & 36.206 & 1 & 1.213 & 280 & 6 & 6 \\
\hline 2.004 & 37.503 & 301 & 37.202 & 35.759 & 1 & 1.176 & 254 & 6 & 6 \\
\hline 2.005 & 39.800 & 301 & 39.499 & 38.095 & 1 & 1.145 & 246 & 6 & 6 \\
\hline 2.006 & 38.486 & 299 & 38.187 & 36.841 & 1 & 1.093 & 240 & 6 & 6 \\
\hline 2.007 & 40.258 & 296 & 39.962 & 38.694 & 1 & 1.035 & 229 & 6 & 7 \\
\hline 2.008 & 40.077 & 295 & 39.782 & 38.556 & 1 & 1.008 & 203 & 6 & 8 \\
\hline 2.009 & 42.435 & 295 & 42.140 & 40.918 & 1 & 1.005 & 202 & 6 & 8 \\
\hline 2.010 & 40.997 & 279 & 40.718 & 39.499 & 1 & 1.003 & 201 & 6 & 8 \\
\hline
\end{tabular}

Tabla 2-2. Autobuses autorizados por el Ministerio de Fomento (servicio privado) Fuente: Ministerio de Fomento [102]

\begin{tabular}{cccc}
\hline & \multicolumn{3}{c}{ SERVICIO PRIVADO (VPC) } \\
\cline { 2 - 4 } & TOTAL & NACIONAL & AUTONÓMICO \\
\hline $\mathbf{1 . 9 9 3}$ & 1.139 & 1.139 & 0 \\
\hline $\mathbf{1 . 9 9 4}$ & 1.068 & 1.068 & 0 \\
\hline $\mathbf{1 . 9 9 5}$ & 1.035 & 1.035 & 0 \\
\hline $\mathbf{1 . 9 9 6}$ & 952 & 952 & 0 \\
\hline $\mathbf{1 . 9 9 7}$ & 1.025 & 1.023 & 2 \\
\hline $\mathbf{1 . 9 9 8}$ & 854 & 845 & 9 \\
\hline $\mathbf{1 . 9 9 9}$ & 986 & 977 & 9 \\
\hline $\mathbf{2 . 0 0 0}$ & 988 & 987 & 1 \\
\hline $\mathbf{2 . 0 0 1}$ & 1.106 & 1.099 & 7 \\
\hline $\mathbf{2 . 0 0 2}$ & 1.184 & 1.173 & 11 \\
\hline $\mathbf{2 . 0 0 3}$ & 1.333 & 1.315 & 18 \\
\hline $\mathbf{2 . 0 0 4}$ & 1.298 & 1.269 & 29 \\
\hline $\mathbf{2 . 0 0 5}$ & 1.429 & 1.402 & 27 \\
\hline $\mathbf{2 . 0 0 6}$ & 1.322 & 1.272 & 50 \\
\hline $\mathbf{2 . 0 0 7}$ & 1.487 & 1.433 & 54 \\
\hline $\mathbf{2 . 0 0 8}$ & 1.386 & 1.327 & 59 \\
\hline $\mathbf{2 . 0 0 9}$ & 1.531 & 1.470 & 61 \\
\hline $\mathbf{2 . 0 1 0}$ & 1.452 & 1.395 & 57 \\
\hline
\end{tabular}


De este modo, se puede comprobar que el número total de autorizaciones de servicio público discrecional tenía una ligera tasa anual de crecimiento hasta el año 1999, en el que se experimenta un importante aumento, motivado por una doble causa (debida en resumen a la nueva LOTT): la liberalización del sector, que indujo un mayor número de solicitudes, y la transformación de las autorizaciones de servicio regular en discrecional. A partir de esta fecha, sigue un crecimiento algo mayor que el anterior a 1998, especialmente en los años impares, que coinciden con los de visado de las autorizaciones.

Por otra parte, el transporte privado complementario, fue disminuyendo ligeramente hasta 1998, año en el que se revierte la tendencia, comenzando una etapa de ascenso que nunca ha parado. En la Tabla 2-3 y en la Figura 2-1, se reflejan estas tendencias porcentual y gráficamente.

Tabla 2-3. Variación bianual del total de autobuses autorizados por el Ministerio de Fomento

\begin{tabular}{|c|c|c|c|c|c|}
\hline & \multirow[b]{2}{*}{ TOTAL } & \multicolumn{3}{|c|}{ SERVICIO PÚBLICO } & \multirow{2}{*}{$\begin{array}{c}\text { SERVICIO } \\
\text { PRIVADO } \\
\text { (VPC) }\end{array}$} \\
\hline & & TOTAL & $\begin{array}{c}\text { SERVICIO } \\
\text { REGULAR (VR) }\end{array}$ & $\begin{array}{c}\text { SERVICIO } \\
\text { DISCRECIONAL (VD) }\end{array}$ & \\
\hline 1.995 & $-3,3 \%$ & $-3,0 \%$ & $-18,0 \%$ & $1,7 \%$ & $-9,1 \%$ \\
\hline 1.997 & $1,8 \%$ & $1,9 \%$ & $-12,7 \%$ & $5,6 \%$ & $-1,0 \%$ \\
\hline 1.999 & $12,0 \%$ & $12,6 \%$ & $-81,0 \%$ & $32,3 \%$ & $-3,8 \%$ \\
\hline 2.001 & $5,7 \%$ & $5,5 \%$ & $-68,4 \%$ & $7,8 \%$ & $12,2 \%$ \\
\hline 2.003 & $5,1 \%$ & $4,7 \%$ & $-5,9 \%$ & $4,8 \%$ & $20,5 \%$ \\
\hline 2.005 & $4,8 \%$ & $4,7 \%$ & $0,0 \%$ & $4,7 \%$ & $7,2 \%$ \\
\hline 2.007 & $1,3 \%$ & $1,2 \%$ & $-1,7 \%$ & $1,2 \%$ & $4,1 \%$ \\
\hline 2.009 & $5,3 \%$ & $5,4 \%$ & $-0,3 \%$ & $5,5 \%$ & $3,0 \%$ \\
\hline
\end{tabular}

A partir del año 1998, con la entrada en vigor de la LOTT, las Comunidades Autónomas adquieren las competencias sobre las líneas pertenecientes por completo a su territorio. De este modo, ya se ha observado en las tablas anteriores que las autorizaciones de tipo autonómico disminuyen considerablemente a partir de esta fecha. En concreto, en Castilla y León, durante el año 2010, se registraron el 6\% del total de autorizaciones del Estado, dividiéndose este dato entre 2.476 de servicio público y 83 de servicio privado [102]. Estas cifras porcentuales se pueden considerar bastante bajas, teniendo en cuenta la vasta extensión de nuestra región, aunque también se dé una muy baja densidad de población, especialmente en las áreas rurales.

Además, comparando estos datos con los correspondientes al año 2005, se puede comprobar que el número total de autorizaciones en la Comunidad se mantiene prácticamente constante (disminuyendo las de servicio público y disminuyendo las de 
servicio privado). Con esta tendencia, el porcentaje respecto del total estatal ha disminuido ostensiblemente [100, 102].

Figura 2-1. Evolución del total de autobuses autorizados por el Ministerio de Fomento Fuente: Ministerio de Fomento [102]

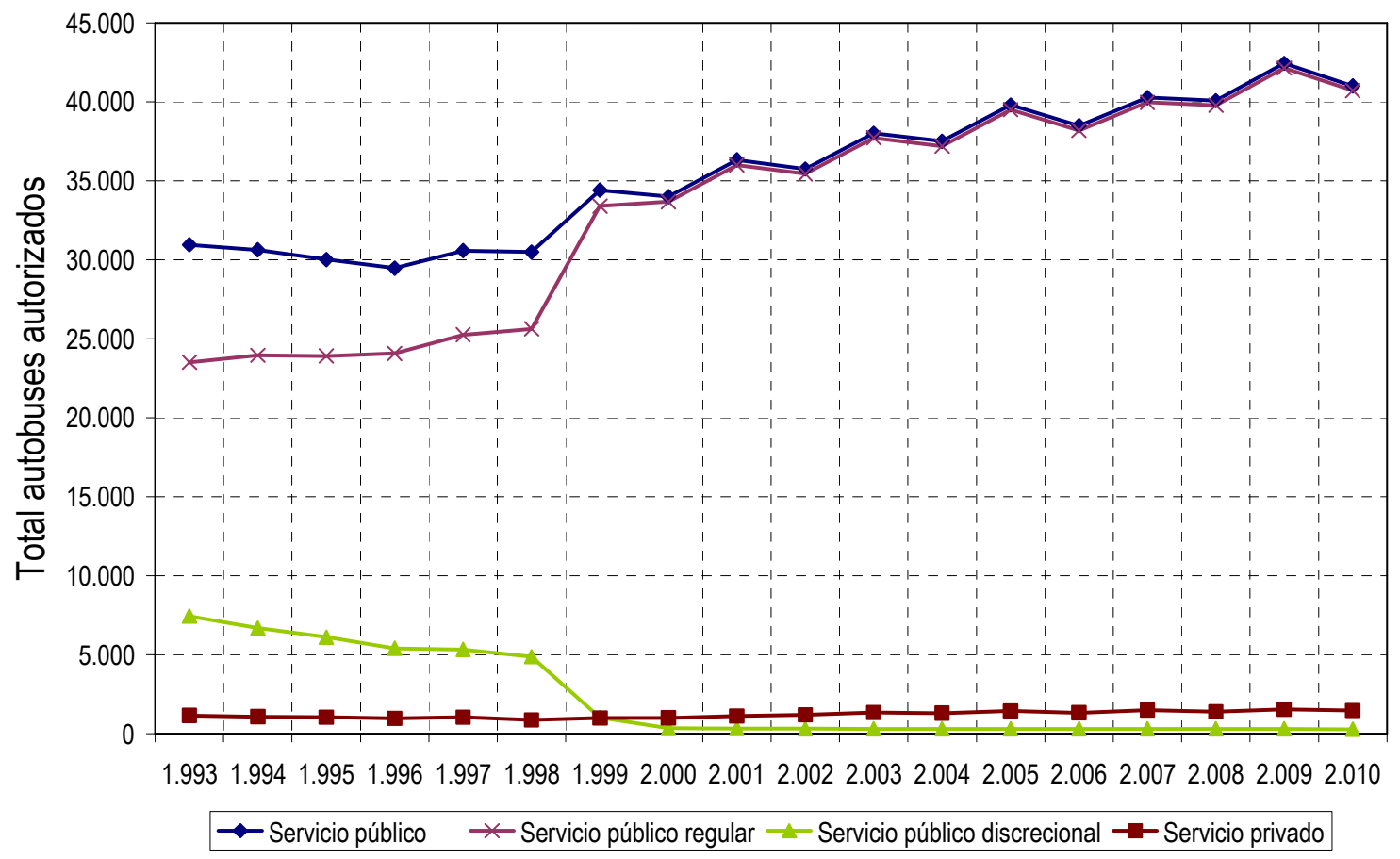

\subsubsection{Edad Media de los Autobuses en Servicio}

En el presente apartado, se indicarán brevemente ciertas cifras sobre la media de edad del parque de autobuses español.

El problema existente es que no existen datos de la fecha de matriculación de los autobuses anteriores al año 1987, por lo que hay un cierto grado de incertidumbre. Sin embargo, sí es posible obtener la mediana de edad de los autobuses autorizados, resultando un valor de unos 9 años, correspondiente al percentil 50 de la Figura 2-3.

A continuación, la Figura 2-2 refleja la antigüedad del parque español de autobuses, en función del año de matriculación de los y, la Figura 2-3, en porcentaje de vehículos matriculados cada año, tanto respecto del total como acumulado. 
Figura 2-2. Antigüedad de los autobuses según su tamaño a finales del año 2007 Fuente: Dirección General de Tráfico [34]

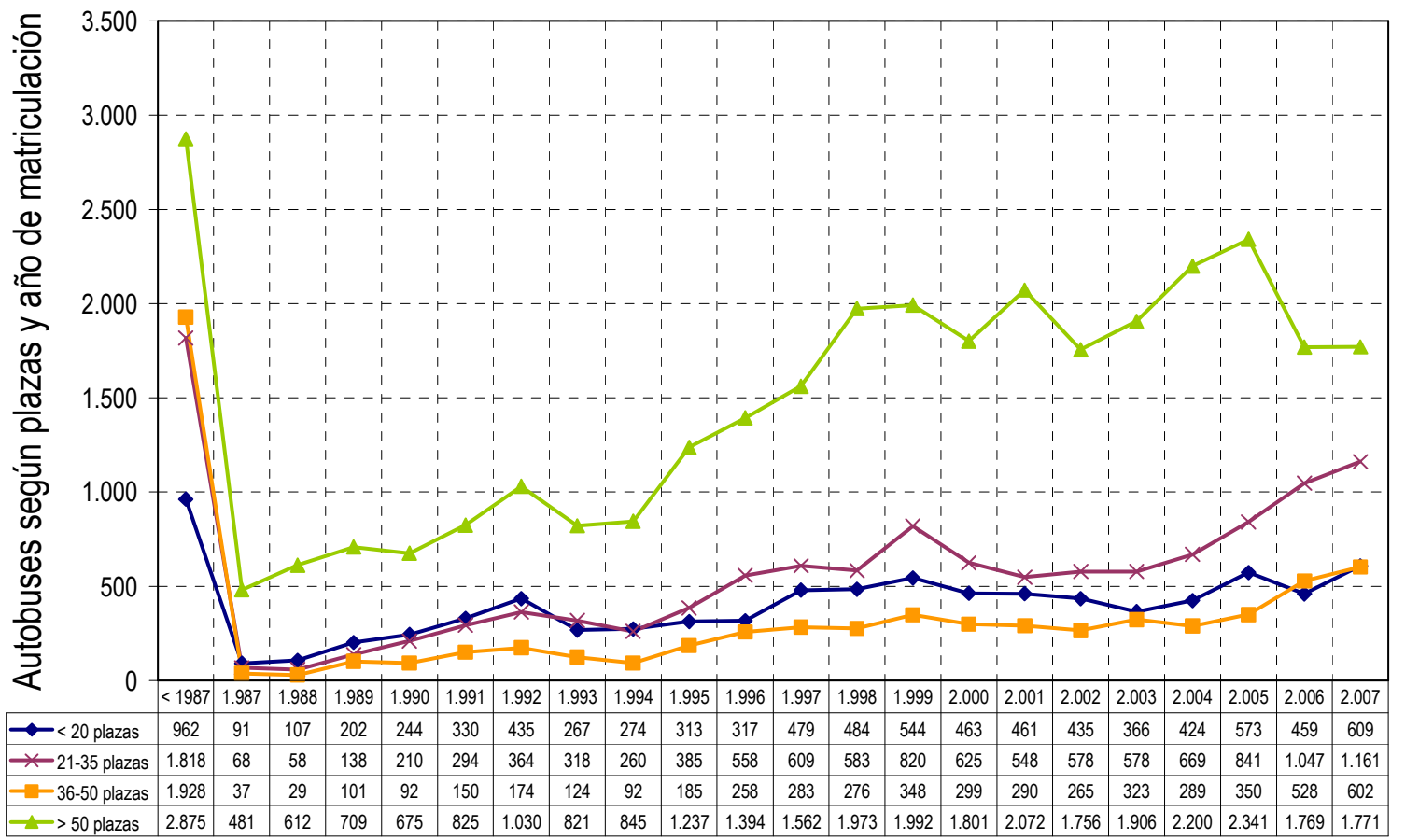

Figura 2-3. Parque nacional de autobuses a finales del año 2008 Fuente: Dirección General de Tráfico [34]

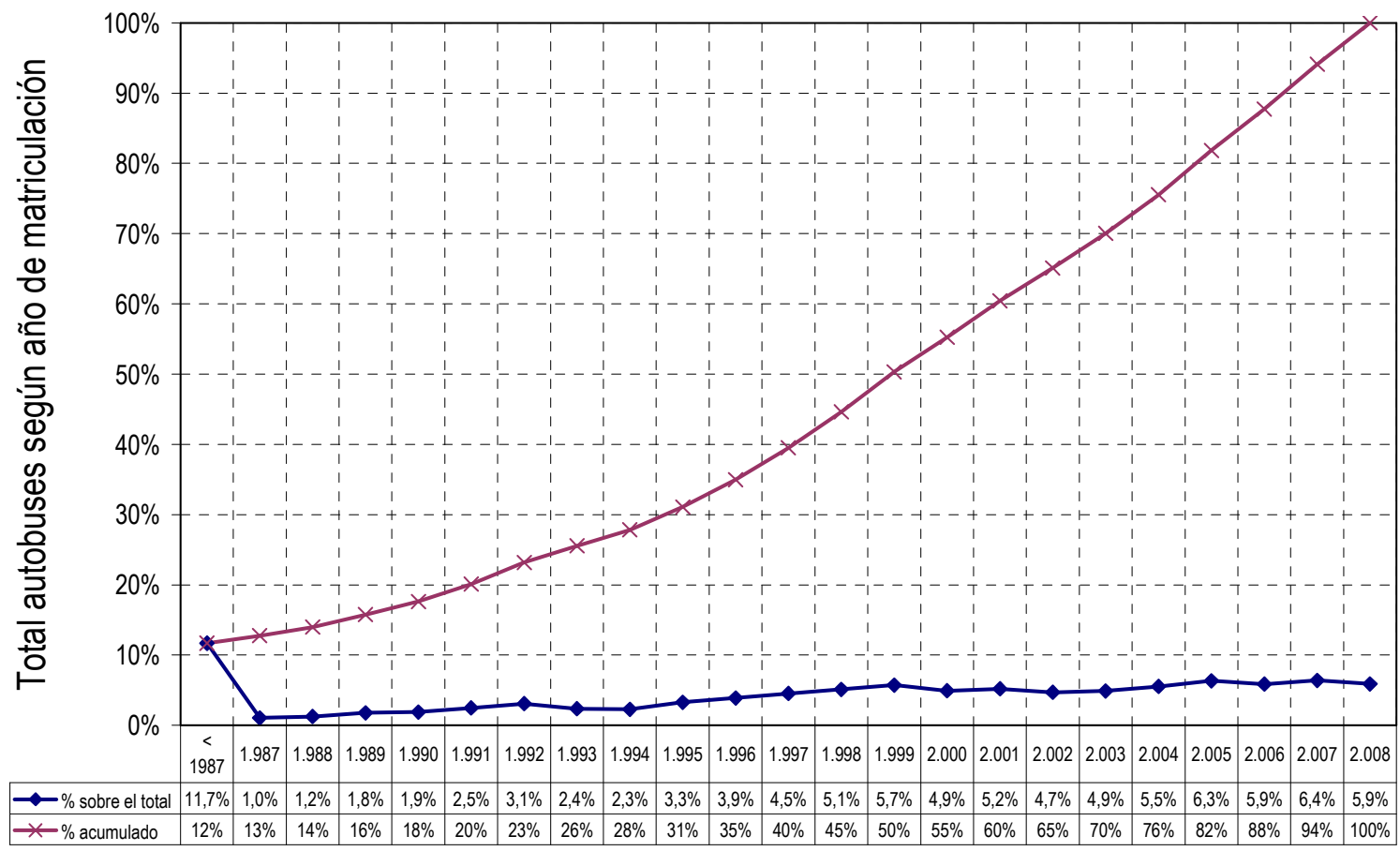


Se observa una distribución similar en cuanto a la edad para todos los rangos de tamaño considerados. Además, es especialmente destacable que los autobuses de más de 50 plazas superan ampliamente al resto, como se verá en apartados posteriores.

Puede también resultar interesante comparar las edades medias de los vehículos que se dieron de baja en los últimos años, a fin de determinar su vida útil aproximada. Dichos datos se reflejan en la Tabla 2-4. En ésta, se aprecia una cierta tendencia a disminuir la vida útil de los vehículos a partir del año 2000, finalizando en el año 2008 en algo más de 16 años por autobús.

Para terminar con este estudio de la edad del parque de vehículos, puede ser representativa la evolución anual del número de autobuses con antigüedad superior a 10 años. Dicha evolución se presenta en la Figura 2-4.

Tabla 2-4. Vida media de los autobuses dados de baja

\begin{tabular}{ccc} 
Fuente: Ministerio de Fomento [102] \\
\hline AÑO & N $^{\circ}$ BAJAS & $\begin{array}{c}\text { VIDA } \\
\text { MEDIA } \\
\text { (AÑOS) }\end{array}$ \\
\hline $\mathbf{1 . 9 9 5}$ & 2.425 & 18,4 \\
\hline $\mathbf{1 . 9 9 6}$ & 1.696 & 18,3 \\
\hline $\mathbf{1 . 9 9 7}$ & 1.784 & 18,7 \\
\hline $\mathbf{1 . 9 9 8}$ & 1.899 & 18,1 \\
\hline $\mathbf{1 . 9 9 9}$ & 2.141 & 18,3 \\
\hline $\mathbf{2 . 0 0 0}$ & 2.012 & 17,5 \\
\hline $\mathbf{2 . 0 0 1}$ & 2.249 & 16,1 \\
\hline $\mathbf{2 . 0 0 2}$ & 2.274 & 16,0 \\
\hline $\mathbf{2 . 0 0 3}$ & 2.583 & 16,7 \\
\hline $\mathbf{2 . 0 0 4}$ & 2.698 & 16,7 \\
\hline $\mathbf{2 . 0 0 5}$ & 1.626 & 16,7 \\
\hline $\mathbf{2 . 0 0 6}$ & 2.582 & 16,0 \\
\hline $\mathbf{2 . 0 0 7}$ & 3.408 & 15,1 \\
\hline $\mathbf{2 . 0 0 8}$ & 2.528 & 16,2 \\
\hline & &
\end{tabular}


Figura 2-4. Evolución del número de autobuses con edad mayor a 10 años Fuente: Ministerio de Fomento [102]

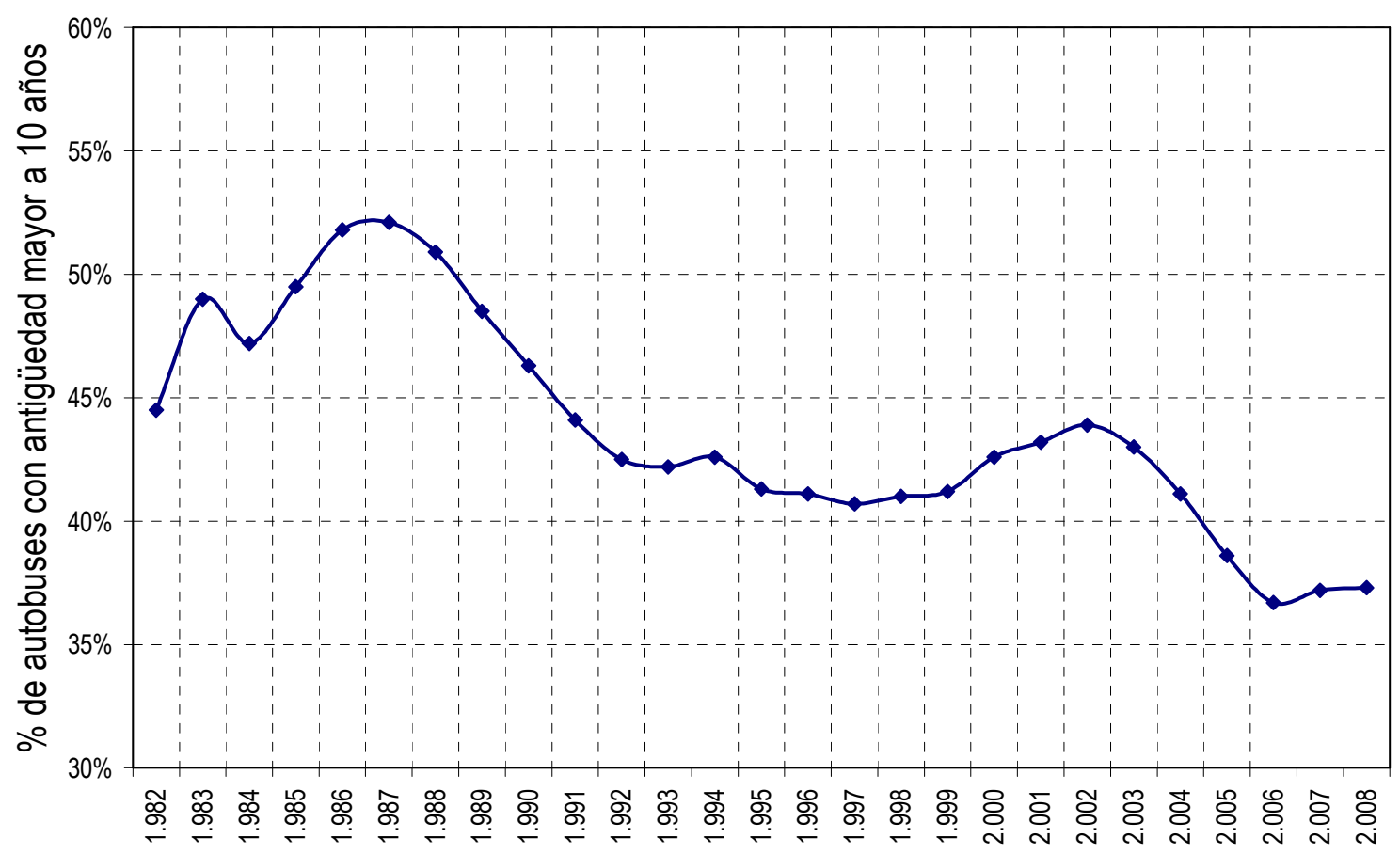

A pesar de las oscilaciones que se pueden apreciar claramente en la gráfica, sí se detecta una clara tendencia a disminuir el número de autobuses antiguos dentro del parque, especialmente acusada a partir del año 2005.

\subsubsection{Número de Plazas por Autobús}

Otro factor importante desde el punto de vista de calidad y eficiencia del servicio es el número de plazas ofertadas, íntimamente relacionado con la capacidad de los autobuses.

En el epígrafe anterior se indicaron los autobuses matriculados en cada año, según su número de plazas.

Pero también es interesante conocer la evolución de la distribución del parque de autobuses, considerado su número de plazas como variable estratificadora. Dicha evolución se presenta en la Figura 2-5: 
Modelización de la Interrelación entre las Variables de Servicio y la Demanda de Viajeros de Autobuses de Tipo Interurbano

Figura 2-5. Parque de autobuses según número de plazas

Fuente: Ministerio de Fomento [102]

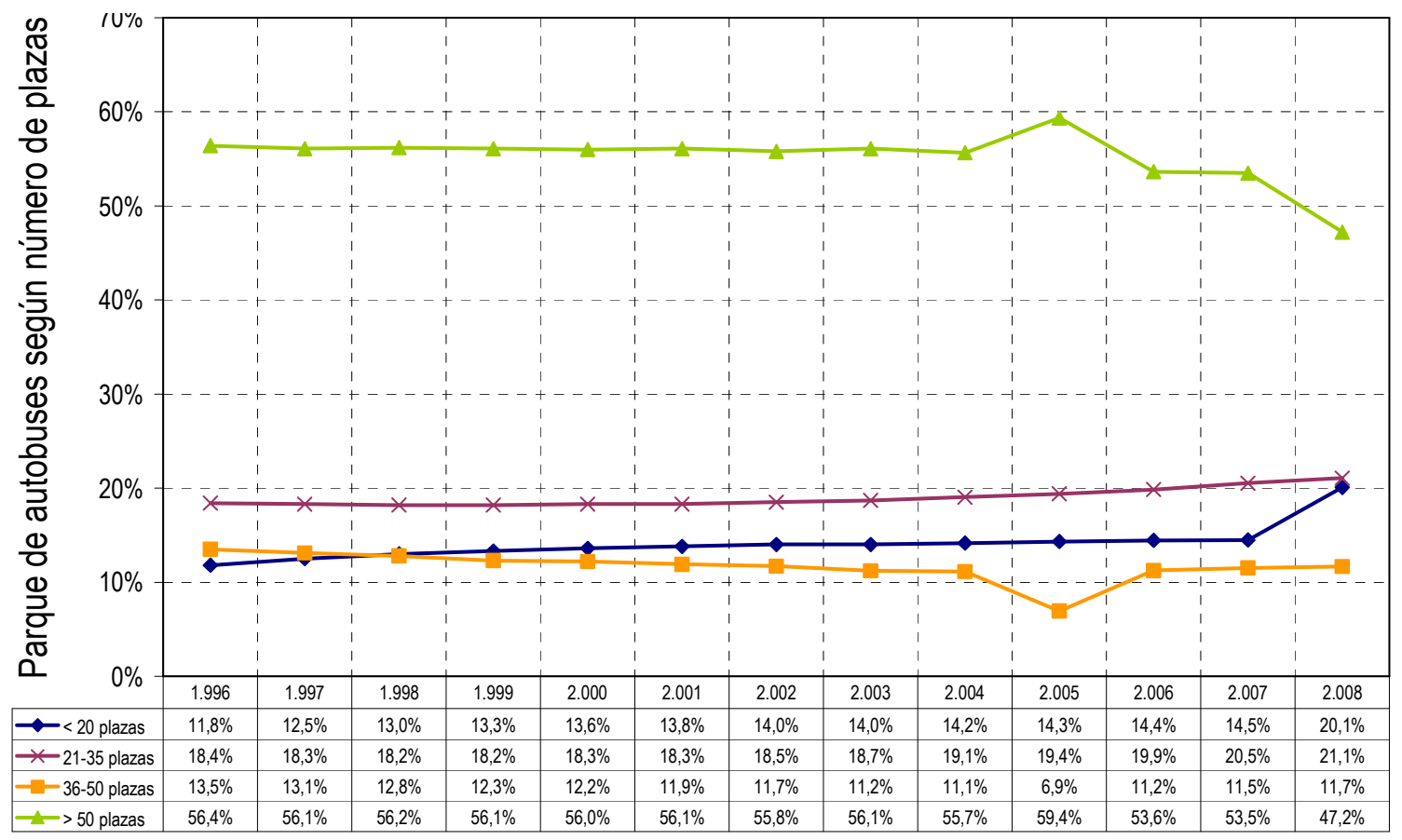

De nuevo, se observa que cerca del $50 \%$ de los autobuses tienen un tamaño superior a las 50 plazas, aunque la tendencia en este aspecto es ligeramente decreciente en los últimos años. Por el contrario, los autobuses menores (hasta 35 plazas) están experimentando una fase de ligero ascenso en cuanto a su proporción sobre el total de vehículos, frente a los de tamaño intermedio, con evolución negativa.

\subsubsection{Estructura de las Empresas Concesionarias}

Para finalizar este resumen de la oferta existente, en el presente apartado se analizará brevemente la estructuración de las empresas de transporte de viajeros en autobús, principalmente desde el punto de vista del número de autorizaciones concedidas, y del tipo de servicio que realizan.

Comenzaremos estudiando el número medio de autobuses por empresa. A primeros del año 2009, los valores medios de autobuses de servicio público y privado eran de 10,9 y 1,8 autobuses por empresa, respectivamente, con incrementos del $4,9 \%$ y $1,7 \%$ respecto del año anterior [102]. 
Además, se observa la circunstancia de que, a partir del año 1998, con la liberalización del sector, el número medio de autobuses autorizados por empresa en servicio público ha aumentado considerablemente, creciendo desde dicha fecha en casi un 65\% [102].

En la Tabla 2-5, se representa el número medio de autobuses autorizados por empresa, desde el año 1998, para servicio público y, en la Tabla 2-6, para servicio privado:

Tabla 2-5. Número medio de autobuses autorizados por empresa (servicio público) Fuente: Ministerio de Fomento [102]

\begin{tabular}{|c|c|c|c|c|c|c|c|c|}
\hline & \multicolumn{8}{|c|}{ SERVICIO PÚBLICO } \\
\hline & \multirow{2}{*}{ TOTAL } & \multirow{2}{*}{$\begin{array}{l}\text { SERVICIO } \\
\text { REGULAR } \\
\text { (VR) }\end{array}$} & \multicolumn{6}{|c|}{ SERVICIO DISCRECIONAL (VD) } \\
\hline & & & NACIONAL & COMARCAL & LOCAL & AUTONÓMICO & PROVINCIAL & LIMITADO \\
\hline 1.998 & 6,4 & 8,1 & 3,3 & 1,5 & 3,7 & 6,0 & 2,2 & -- \\
\hline 1.999 & 7,3 & 9,8 & 7,2 & 1,2 & 3,9 & 4,4 & 1,3 & 1,5 \\
\hline 2.000 & 7,6 & 13,7 & 7,9 & 1,6 & 4,6 & 3,2 & 1,4 & 3,0 \\
\hline 2.001 & 8,1 & 15,2 & 8,5 & 1,7 & 4,6 & 3,0 & 1,6 & 3,3 \\
\hline 2.002 & 8,4 & 20,1 & 8,5 & 1,5 & 5,4 & 2,9 & 2,0 & 3,0 \\
\hline 2.003 & 8,9 & 21,5 & 9,0 & 1,0 & 5,4 & 2,8 & 2,0 & 3,0 \\
\hline 2.004 & 9,2 & 21,5 & 9,3 & 1,0 & 5,4 & 2,6 & 2,0 & 3,0 \\
\hline 2.005 & 9,7 & 21,5 & 9,8 & 1,0 & 5,3 & 2,5 & 2,0 & 3,0 \\
\hline 2.006 & 9,7 & 24,9 & 9,9 & 1,0 & 5,1 & 2,5 & 2,0 & 3,0 \\
\hline 2.007 & 9,7 & 26,9 & 10,3 & 1,0 & 5,0 & 2,4 & 2,0 & 3,5 \\
\hline 2.008 & 10,4 & 29,5 & 10,6 & 1,0 & 4,9 & 2,3 & 2,0 & 4,0 \\
\hline 2.009 & 10,9 & 29,5 & 11,2 & 1,0 & 4,9 & 2,3 & 2,0 & 4,0 \\
\hline 2.010 & 10,9 & 31,0 & 11,2 & 1,0 & 4,9 & 2,3 & 2,0 & 4,0 \\
\hline
\end{tabular}

Tabla 2-6. Número medio de autobuses autorizados por empresa (servicio privado) Fuente: Ministerio de Fomento [102]

\begin{tabular}{cccc}
\hline & \multicolumn{3}{c}{ SERVICIO PRIVADO (VPC) } \\
\cline { 2 - 4 } & TOTAL & NACIONAL & AUTONÓMICO \\
\hline $\mathbf{1 . 9 9 8}$ & 1,4 & 1,4 & 1,0 \\
\hline $\mathbf{1 . 9 9 9}$ & 1,5 & 1,5 & 1,0 \\
\hline $\mathbf{2 . 0 0 0}$ & 1,6 & 1,6 & 1,0 \\
\hline $\mathbf{2 . 0 0 1}$ & 1,6 & 1,6 & 1,2 \\
\hline $\mathbf{2 . 0 0 2}$ & 1,7 & 1,7 & 1,1 \\
\hline $\mathbf{2 . 0 0 3}$ & 1,7 & 1,7 & 1,1 \\
\hline $\mathbf{2 . 0 0 4}$ & 1,7 & 1,8 & 1,1 \\
\hline $\mathbf{2 . 0 0 5}$ & 1,8 & 1,8 & 1,1 \\
\hline $\mathbf{2 . 0 0 6}$ & 1,7 & 1,7 & 1,3 \\
\hline $\mathbf{2 . 0 0 7}$ & 1,7 & 1,8 & 1,3 \\
\hline $\mathbf{2 . 0 0 8}$ & 1,7 & 1,8 & 1,3 \\
\hline $\mathbf{2 . 0 0 9}$ & 1,8 & 1,8 & 1,3 \\
\hline $\mathbf{2 . 0 1 0}$ & 1,8 & 1,8 & 1,3 \\
\hline
\end{tabular}


Se puede deducir, por tanto, que las empresas que realizan servicios de transporte privado son las más "pequeñas", es decir, con menor número de autobuses, como media (entre 1 y 2 autobuses por empresa), mientras que las que realizan servicios de transporte público regular son las mayores, con un valor constante en los últimos años superior a 20 autobuses por empresa (y cercano a los 30 ). En cuanto a las cifras globales, tanto en servicio público como en privado se está observando una clara tendencia creciente en cuanto al número medio de autobuses por empresa, tendencia especialmente acusada en las autorizaciones de servicio público.

De hecho, y evidentemente asociado al dato anterior, observando las tendencias de los últimos años [102], se puede apreciar claramente cómo está disminuyendo fuertemente el número de empresas autorizadas para realizar servicios de transporte público, destacando, por ejemplo, que en el año 1999 había 4.742 empresas, frente a las 3.753 del 2010.

Visto a la inversa, se puede relacionar el tipo de servicio realizado con el número medio de autobuses por empresa, de modo que resulta la Tabla 2-7, en la que se indica la distribución de las empresas de transporte, en función del total de autobuses autorizados para cada una, a principios del año 2010, para servicio público y la Tabla 2-8, con los mismos datos para servicio privado:

Tabla 2-7. Distribución de empresas en función del número de autobuses (serv. público) Fuente: Ministerio de Fomento [102]

\begin{tabular}{ccccccccc}
\hline & \multicolumn{7}{c}{ SERVICIO PÚBLICO } \\
\cline { 2 - 9 } No VEH. & TOTAL & $\begin{array}{c}\text { SERVICIO } \\
\text { REGULAR } \\
\text { (VR) }\end{array}$ & \multicolumn{7}{c}{ SERVICIO DISCRECIONAL (VD) } \\
\cline { 3 - 9 } & & NACION. & COMARC. & LOCAL & AUTON. & PROVINC. & LIMITADO \\
\hline $\mathbf{1}$ & $15,1 \%$ & $22,2 \%$ & $14,2 \%$ & $100 \%$ & $40,2 \%$ & $62,8 \%$ & $33,3 \%$ & $0 \%$ \\
\hline $\mathbf{2}$ & $11,3 \%$ & $11,1 \%$ & $11,0 \%$ & $0 \%$ & $17,2 \%$ & $15,1 \%$ & $33,3 \%$ & $0 \%$ \\
\hline $\mathbf{3}$ & $7,7 \%$ & $33,3 \%$ & $7,2 \%$ & $0 \%$ & $11,3 \%$ & $9,3 \%$ & $33,3 \%$ & $0 \%$ \\
\hline $\mathbf{4}$ & $4,3 \%$ & $0,0 \%$ & $4,0 \%$ & $0 \%$ & $6,9 \%$ & $2,3 \%$ & $0 \%$ & $100 \%$ \\
\hline $\mathbf{5}$ & $12,4 \%$ & $0 \%$ & $12,8 \%$ & $0 \%$ & $4,9 \%$ & $2,3 \%$ & $0 \%$ & $0 \%$ \\
\hline $\mathbf{6}-\mathbf{1 0}$ & $23,6 \%$ & $0 \%$ & $24,4 \%$ & $0 \%$ & $10,3 \%$ & $4,7 \%$ & $0 \%$ & $0 \%$ \\
\hline $\mathbf{1 1 - 2 0}$ & $15,1 \%$ & $11,1 \%$ & $15,5 \%$ & $0 \%$ & $5,4 \%$ & $2,3 \%$ & $0 \%$ & $0 \%$ \\
\hline $\mathbf{2 1 - 4 0}$ & $6,4 \%$ & $0 \%$ & $6,6 \%$ & $0 \%$ & $2,9 \%$ & $1,2 \%$ & $0 \%$ & $0 \%$ \\
\hline $\mathbf{4 1 - 6 0}$ & $1,9 \%$ & $0 \%$ & $2,0 \%$ & $0 \%$ & $0 \%$ & $0 \%$ & $0 \%$ & $0 \%$ \\
\hline $\mathbf{6 1 - 1 0 0}$ & $1,0 \%$ & $0 \%$ & $1,0 \%$ & $0 \%$ & $1,0 \%$ & $0 \%$ & $0 \%$ & $0 \%$ \\
\hline$>\mathbf{1 0 0}$ & $1,2 \%$ & $22,2 \%$ & $1,2 \%$ & $0 \%$ & $0 \%$ & $0 \%$ & $0 \%$ & $0 \%$ \\
\hline
\end{tabular}


Tabla 2-8. Distribución de empresas en función del número de autobuses (serv. privado)

\begin{tabular}{cccc}
\multicolumn{3}{c}{ Fuente: Ministerio de Fomento [102] } \\
\hline $\begin{array}{c}\mathbf{N}^{0} \\
\text { VEH. }\end{array}$ & \multicolumn{3}{c}{ SERVICIO PRIVADO (VPC) } \\
\cline { 2 - 4 } & TOTAL & NACIONAL & AUTONÓMICO \\
\hline $\mathbf{1}$ & $70,6 \%$ & $70,2 \%$ & $77,8 \%$ \\
\hline $\mathbf{2}$ & $17,4 \%$ & $17,4 \%$ & $17,8 \%$ \\
\hline $\mathbf{3}$ & $5,5 \%$ & $5,6 \%$ & $4,4 \%$ \\
\hline $\mathbf{4}$ & $1,8 \%$ & $2,0 \%$ & $0 \%$ \\
\hline $\mathbf{5}$ & $1,6 \%$ & $1,7 \%$ & $0 \%$ \\
\hline $\mathbf{6 - 1 0}$ & $2,2 \%$ & $2,3 \%$ & $0 \%$ \\
\hline $\mathbf{1 1 - 2 0}$ & $0,6 \%$ & $70,0 \%$ & $0 \%$ \\
\hline $\mathbf{2 1 - 4 0}$ & $0 \%$ & $0 \%$ & $0 \%$ \\
\hline $\mathbf{4 1 - 6 0}$ & $0 \%$ & $0 \%$ & $0 \%$ \\
\hline $\mathbf{6 1 - 1 0 0}$ & $0 \%$ & $0 \%$ & $0 \%$ \\
\hline$>\mathbf{1 0 0}$ & $0,1 \%$ & $0,1 \%$ & $0 \%$ \\
\hline
\end{tabular}

Además de estos datos, es interesante evaluar la tendencia de crecimiento o decrecimiento de cada tipo de empresa. De este análisis se extraen las siguientes conclusiones [102]:

- El número de empresas de servicio público con un único autobús sufre una clara tendencia decreciente, ya que ha disminuido casi un 58\% desde que entró en vigor la LOTT. En cambio, en servicio privado, este tipo de "pequeñas empresas" con un solo autobús representan la clara mayoría del sector.

- También ha disminuido, significativamente, aunque no de forma tan drástica, el número de empresas que tienen de 2 a 4 autobuses autorizados para servicio público, de modo que a principios de 2010 hay un $46 \%$ menos de este tipo de empresas que en el 1998. Es de destacar que existan menos empresas con 4 autorizaciones que con 5, debido principalmente a la exigencia en la nueva ley de un número mínimo de autobuses (que resulta ser 5 en el caso general), para las empresas de constitución posterior a 1998.

- Por otra parte, las empresas con 5 ó más autobuses autorizados son cada vez más numerosas, aumentando alrededor de un $32 \%$ desde la entrada en vigor de la LOTT.

En resumen, se puede concluir que la entrada en vigor de la LOTT ha reducido bastante la atomización de la estructura empresarial, imponiendo restricciones a la creación de pequeñas empresas, de modo que el total de empresas de servicio público se ha reducido en un $20 \%$, mientras que el número de autobuses autorizados ha aumentado un $36 \%$ [102]. 
Ya centrados en el transporte público, a continuación se adjunta la Figura 2-6 con la evolución temporal del número de autobuses autorizados, distribuidos en función del tipo de empresa con que se corresponden:

Figura 2-6. Evolución del $n^{o}$ de autobuses autorizados (s. público) según el tamaño de la empresa Fuente: Ministerio de Fomento [102]

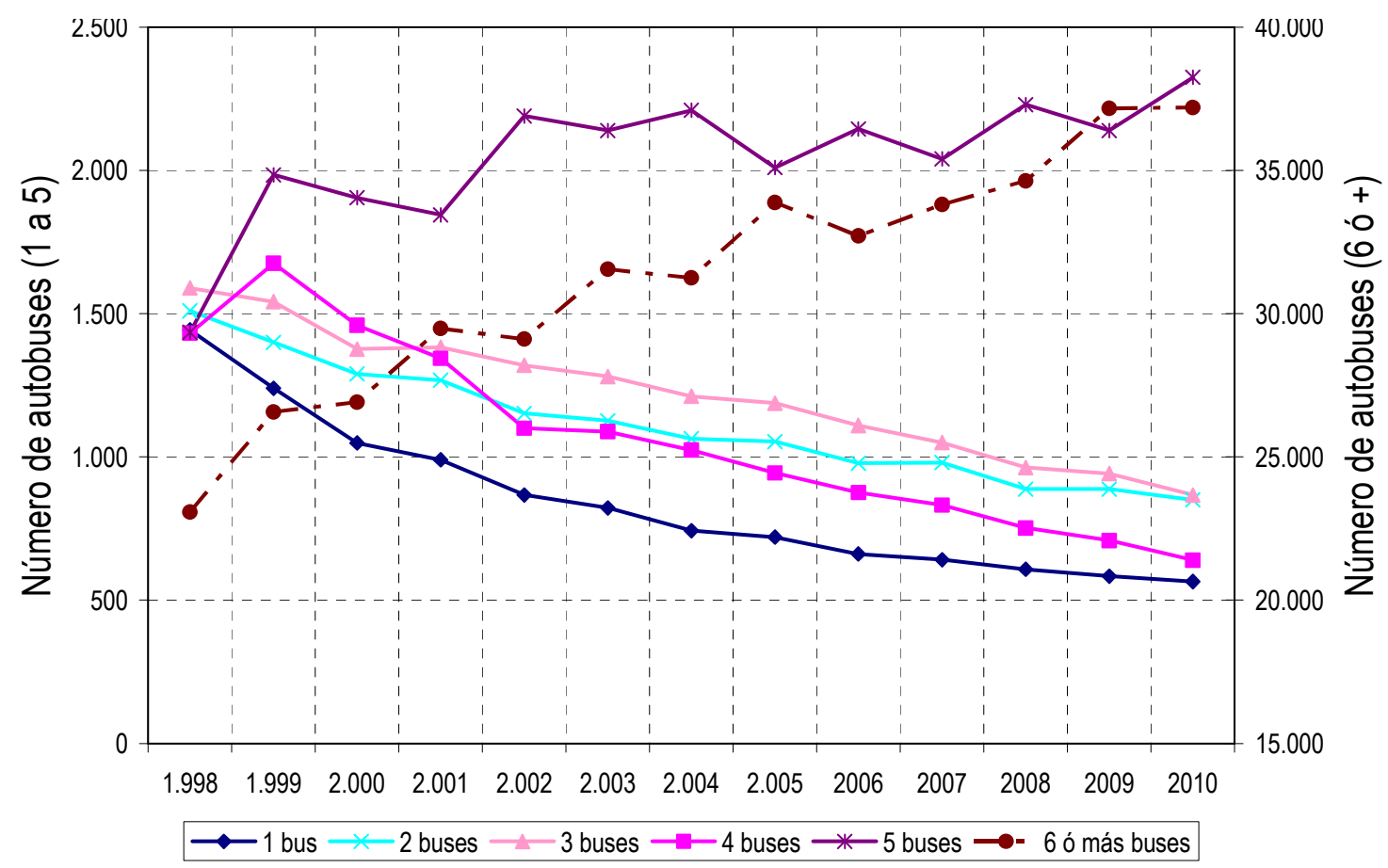

En esta gráfica se observa claramente cómo disminuyen gradualmente las autorizaciones de autobuses en empresas con menos de 5 vehículos, mientras que las de empresas con 5 vehículos aumentan ligeramente, aunque con una tendencia final a la estabilización. Por otra parte, en otra escala, se representa también la evolución de autorizaciones en empresas con más de 5 vehículos, con unos valores globales mucho mayores, y también con una tendencia creciente mucho más acusada.

De este modo, ha quedado de nuevo patente la tendencia que está generando la nueva legislación, favorecido la creación de grandes grupos empresariales y limitando la atomización del sector, de modo que sólo el $12 \%$ del total de empresas autorizadas tiene de 1 a 5 buses, mientras que cerca de la mitad poseen más de 20 vehículos [102].

Por último, y concluyendo ya con esta parte del estudio de la oferta, se analizará a continuación una división de las empresas en función del tipo de sociedad que las rige y del número de autobuses. En este caso, se puede observar que, en las empresas con un 
único vehículo, predomina claramente la persona física. Por el contrario, en las empresas con más de 20 autobuses, las fórmulas más comunes son las sociedades anónima y limitada, prácticamente a partes iguales. En los rangos intermedios, la fórmula más habitual es la sociedad limitada. Considerando las cifras globales, más de la mitad de las empresas son sociedades limitadas (cerca del 67\%). Para más información al respecto, se puede consultar el Observatorio del Transporte de Viajeros por Carretera [102]. 


\subsection{Evaluación de la Demanda}

En el presente apartado, se pretende analizar cuál es la situación actual del transporte público interurbano en autobús, desde el punto de vista del grado de utilización del servicio ofertado, con el fin de poder disponer de un marco global de estudio, en el que se considere tanto la oferta como la demanda.

En primer lugar, se analizará la distribución de tráfico entre modos de transporte, para continuar con una serie de datos estadísticos sobre viajeros y viajeros-km transportados en autobús interurbano, y en comparación con el resto de modos. Además, se reseñarán los datos más recientes sobre kilómetros recorridos anualmente, y sobre la distribución de los autobuses según su grado de ocupación.

Los datos que se reflejarán provienen de dos grupos distintos: por una parte, de la estadística mensual de Instituto Nacional de Estadística "Transporte de Viajeros" [77], y, por otra, del "Observatorio del Transporte de Viajeros por Carretera", del Ministerio de Fomento [102].

\subsubsection{Distribución Modal del Tráfico Interurbano de Viajeros}

Si se representa conjuntamente la distribución de tráfico entre los distintos modos de transporte, queda evidentemente reflejada la absoluta preferencia de la carretera frente al ferrocarril, avión o transporte marítimo. Los datos globales se adjuntan en la Tabla 2-9:

Tabla 2-9. Tráfico total de viajeros (millones de viaj-km)

Fuente: Ministerio de Fomento [100, 102]

\begin{tabular}{cccccc}
\hline AÑO & TOTAL & CARRETERA & FERROCARRIL & AÉREO & MARÍTIMO \\
\hline $\mathbf{1 . 9 9 8}$ & 354.169 & 320.972 & 18.875 & 13.116 & 1.206 \\
\hline $\mathbf{1 . 9 9 9}$ & 376.785 & 341.329 & 19.659 & 14.493 & 1.304 \\
\hline $\mathbf{2 . 0 0 0}$ & 391.395 & 352.889 & 20.150 & 17.020 & 1.336 \\
\hline $\mathbf{2 . 0 0 1}$ & 399.569 & 359.667 & 20.827 & 17.770 & 1.305 \\
\hline $\mathbf{2 . 0 0 2}$ & 404.080 & 364.269 & 21.206 & 17.314 & 1.291 \\
\hline $\mathbf{2 . 0 0 3}$ & 414.277 & 373.065 & 21.147 & 18.784 & 1.281 \\
\hline $\mathbf{2 . 0 0 4}$ & 428.174 & 385.494 & 20.786 & 20.458 & 1.436 \\
\hline $\mathbf{2 . 0 0 5}$ & 438.851 & 392.596 & 21.604 & 23.244 & 1.407 \\
\hline $\mathbf{2 . 0 0 6}$ & 441.935 & 392.450 & 22.105 & 25.861 & 1.519 \\
\hline $\mathbf{2 . 0 0 7}$ & 452.572 & 405.083 & 21.856 & 24.021 & 1.612 \\
\hline $\mathbf{2 . 0 0 8}$ & 452.300 & 405.386 & 23.968 & 21.286 & 1.660 \\
\hline
\end{tabular}


De este modo, se observa una distribución de alrededor de un $90 \%$ del tráfico total por carretera, un $5 \%$ en ferrocarril y en avión y un $0,4 \%$ por vía marítima. Sin embargo, este tráfico por carretera no es comparable directamente con el resto, ya que incorpora las cifras del vehículo privado, que lógicamente distorsionan el resultado, debido al gran empleo de este modo de transporte.

Por ello, conviene dividir este dato global entre la utilización de los distintos vehículos, de modo que tengamos una distribución entre modos de transporte público. Así, la Figura 2-7 refleja esta distribución, considerando únicamente transporte público. Los datos de ésta, ya comparables entre sí, nos indican que el transporte en autobús supone alrededor del 56\% del total del tráfico en transporte público, y alrededor de un $13 \%$ del total (público y privado).

Figura 2-7. Distribución porcentual de tráfico (viaj-km) en transporte público Fuente: Ministerio de Fomento [102]

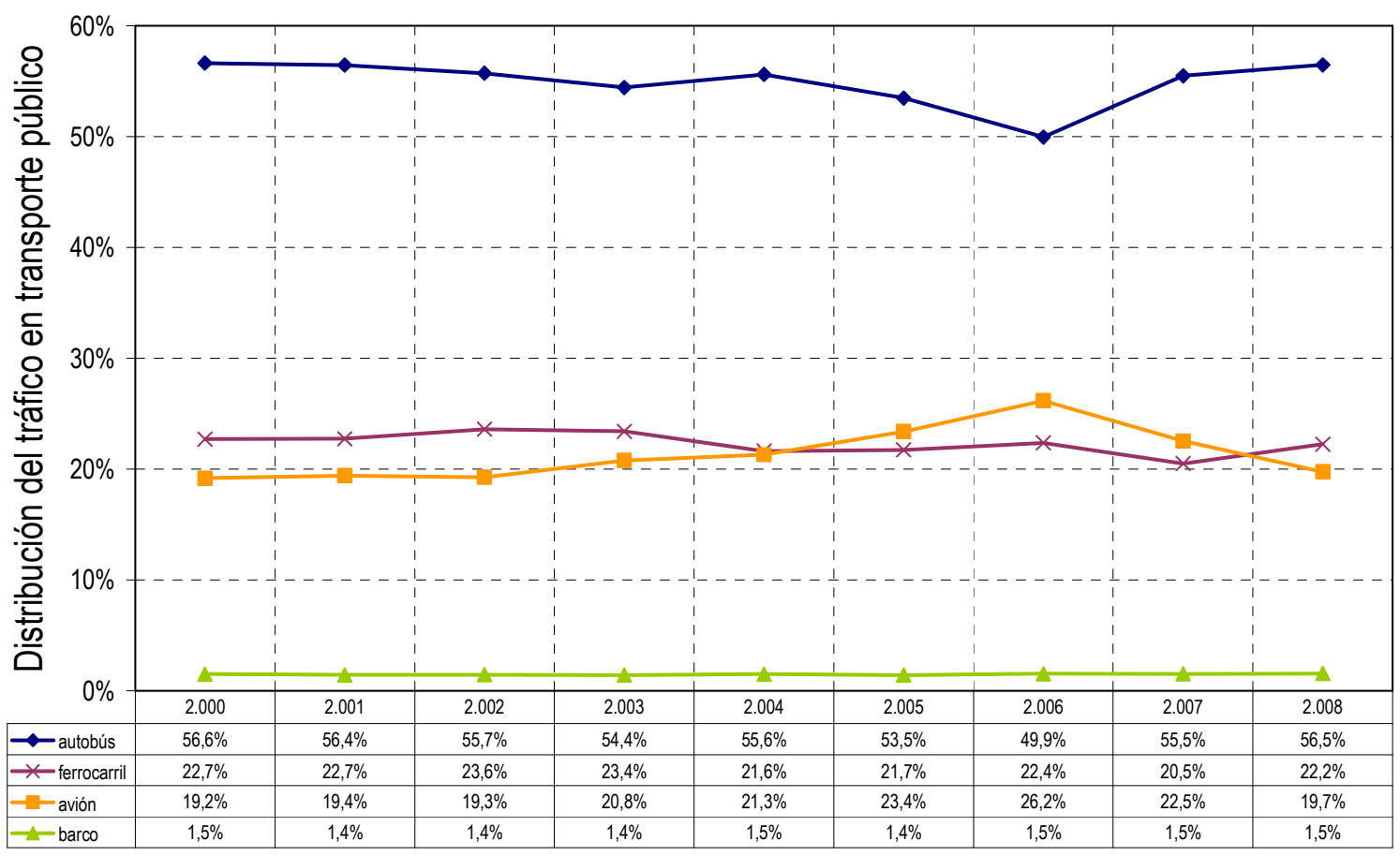




\subsubsection{Tráfico Interurbano de Viajeros en Autobús}

Una vez establecida la posición del transporte público interurbano en autobús con respecto al total del sistema de transporte y con el resto de modos públicos, a continuación, se indicará la evolución anual del tráfico de viajeros en autobús interurbano.

En primer lugar, en la Tabla 2-10 se indicarán las series anuales de vehículos transportados desde el año 2006 hasta la actualidad (el 2010 no está completado por falta de datos). No se han incluido valores anteriores al año 2006, ya que el INE modificó la metodología de redacción de sus estadísticas, incorporando un nuevo cuestionario, y diversas novedades en el diseño muestral, como: actualización del directorio de empresas de transporte por carretera, cambios en las variables de estratificación o un importante incremento del tamaño muestral. Con estos cambios, los resultados de las encuestas a partir de esta fecha no son comparables con las anteriores, a no ser que se aplique un coeficiente de enlace, que se debe multiplicar a los valores anteriores a 2006, para que sean equivalentes a los posteriores a la citada fecha. Dichos coeficientes, que tienen variación mensual, de acuerdo con los periodos de elaboración de las encuestas, son algo superiores a la unidad para transporte regular, y algo inferiores para transporte discrecional.

Tabla 2-10. Tráfico total de viajeros en autobús interurbano (miles de viajeros)

Fuente: INE [77]

\begin{tabular}{|c|c|c|c|c|c|}
\hline \multirow[b]{2}{*}{ AÑO } & \multicolumn{3}{|c|}{ REGULAR } & \multirow[b]{2}{*}{ DISCRECIONAL } & \multirow[b]{2}{*}{ TOTAL } \\
\hline & GENERAL & $\begin{array}{c}\text { ESP. } \\
\text { ESCOLAR }\end{array}$ & $\begin{array}{c}\text { ESP. } \\
\text { LABORAL }\end{array}$ & & \\
\hline 2.006 & 718.885 & 244.279 & 113.698 & 221.607 & 1.298 .469 \\
\hline 2.007 & 701.902 & 227.990 & 102.945 & 190.479 & 1.223 .316 \\
\hline 2.008 & 708.834 & 217.608 & 91.083 & 177.613 & 1.195 .138 \\
\hline 2.009 & 700.011 & 216.692 & 84.864 & 167.721 & 1.169 .288 \\
\hline
\end{tabular}

Así, se observa que la proporción de tráfico regular frente al total es bastante alta (alrededor de un 86\% en el año 2009). Además, se observa una tendencia de leve decrecimiento en los valores totales de tráfico en autobús, debida en parte a la cada vez mayor tasa de motorización, y a la mayor participación de modos emergentes, como el aéreo.

Por otra parte, en la Figura 2-8 se presentará la variación mensual media en los citados años de los valores de tráfico regular y discrecional. 
Figura 2-8. Evolución mensual del tráfico en autobús Fuente: INE [77]

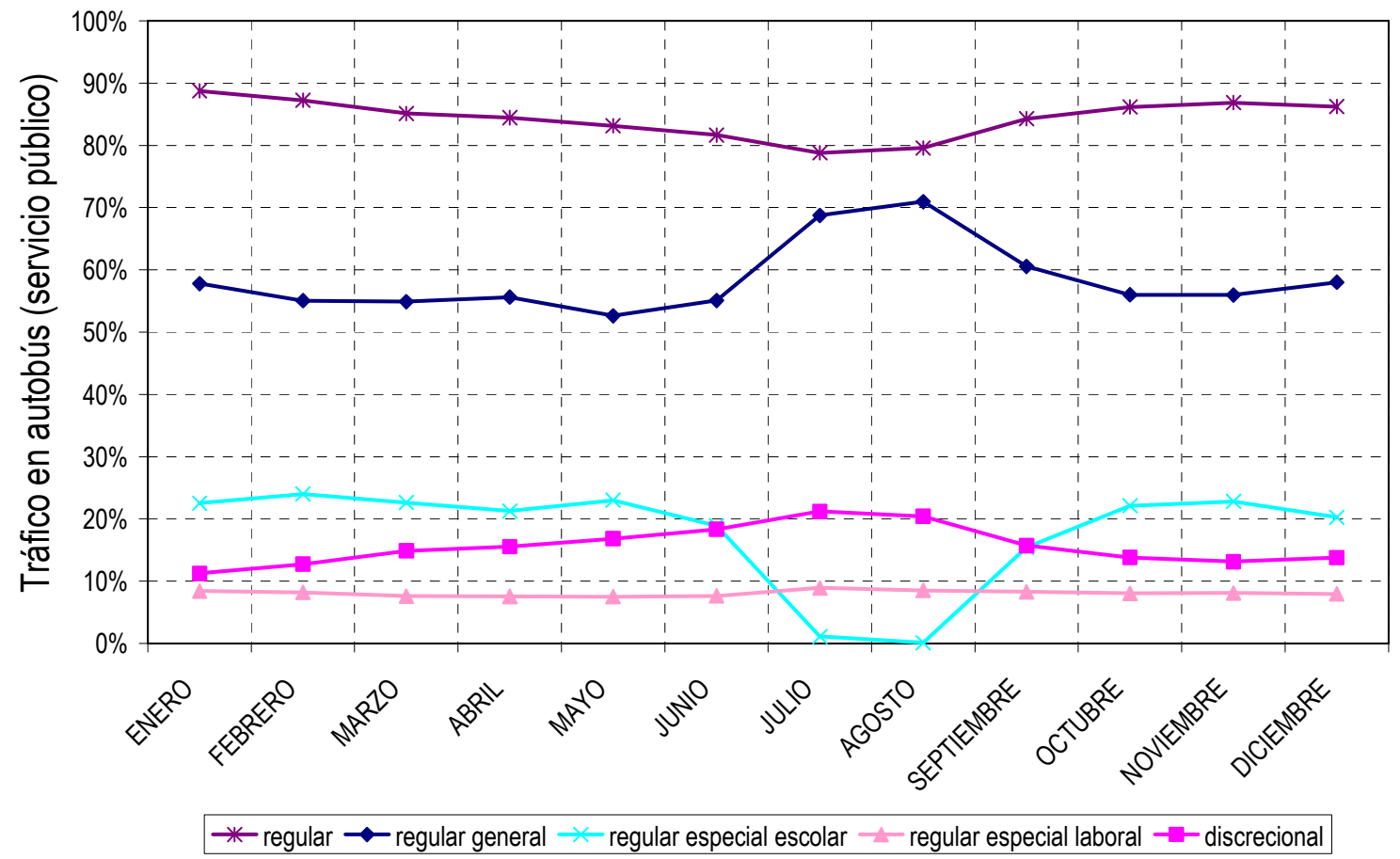

Así pues, se observa que el transporte regular especial laboral se mantiene aproximadamente constante a lo largo del año, mientras que el especial escolar sufre una fuerte caída en verano, como resulta lógico correspondiendo al periodo de vacaciones. En cuanto al regular general, se observa un gran aumento en el período estival. Sin embargo, computando en cifras globales todo el servicio de transporte regular, existe un leve descenso en verano.

Por otra parte, en cuanto al servicio discrecional, toma valores mínimos en invierno, mientras en los meses de Julio y Agosto adquiere su mayor auge, lógicamente influenciado por la mayor cantidad de viajes de tipo vacacional. 


\subsubsection{Recorrido Medio Anual de los Autobuses}

En este apartado, se analizará brevemente el número de kilómetros recorridos anualmente, como media, por los autobuses de transporte público interurbano. Los datos se obtienen a partir de los controles de los discos tacógrafos instalados en los vehículos.

A continuación se presenta Figura 2-9, con los recorridos medios anuales por autobús y el número de vehículos controlados, entre los años 2002 y 2009.

Figura 2-9. Kilómetros medios de recorrido anual por autobús Fuente: Ministerio de Fomento [102]

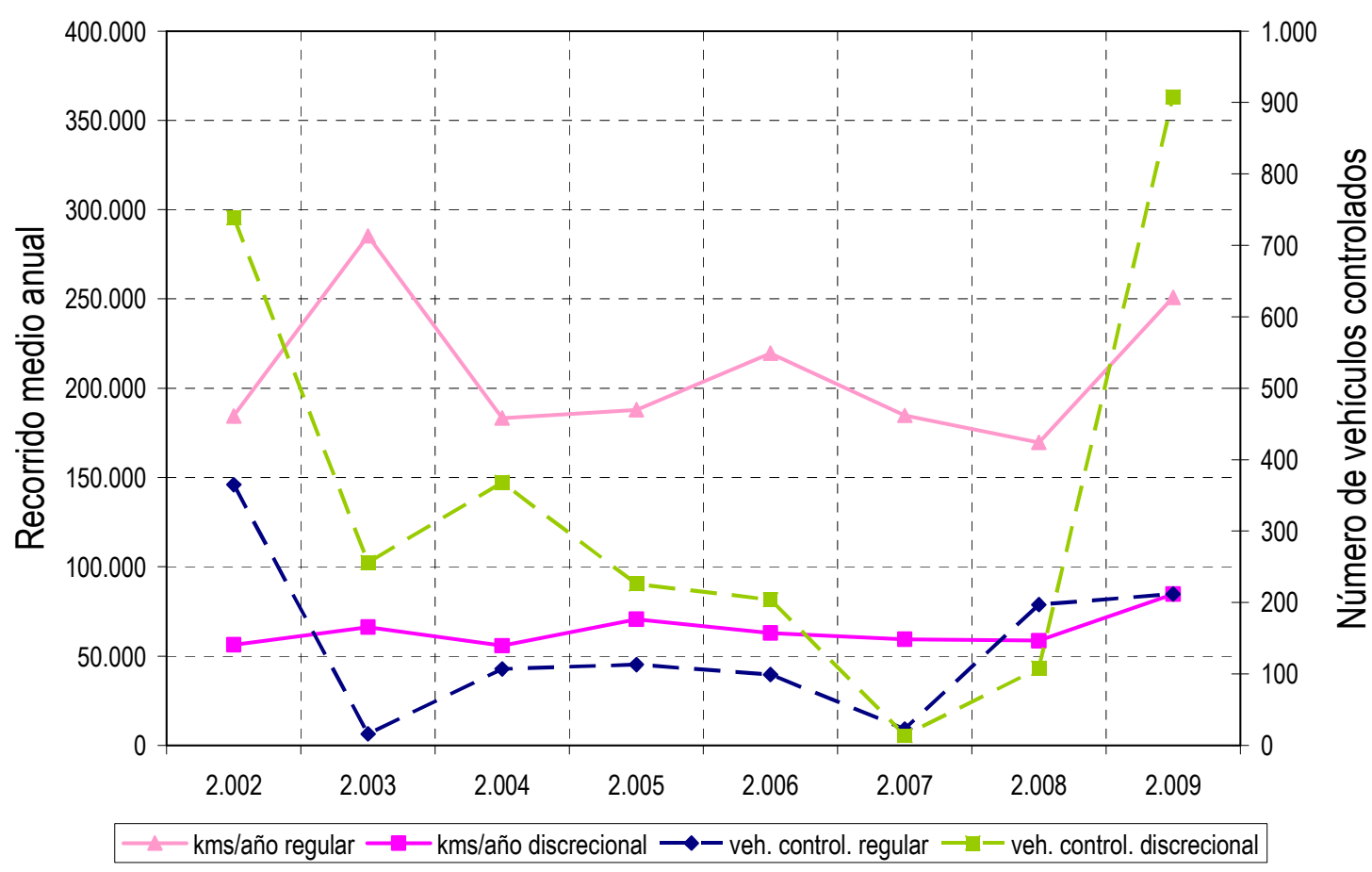

Observando la gráfica, se concluye que los autobuses que realizan servicios regulares realizan un mayor número de kilómetros anuales que los de tipo discrecional, como podíamos presuponer a priori.

Al igual que se ha realizado con las estadísticas de tráfico, la Figura 2-10 muestra la distribución mensual del número de kilómetros recorridos, promediando los datos existentes hasta el año 2000. 
Figura 2-10. Variación mensual del recorrido medio por autobús Fuente: Ministerio de Fomento [100]

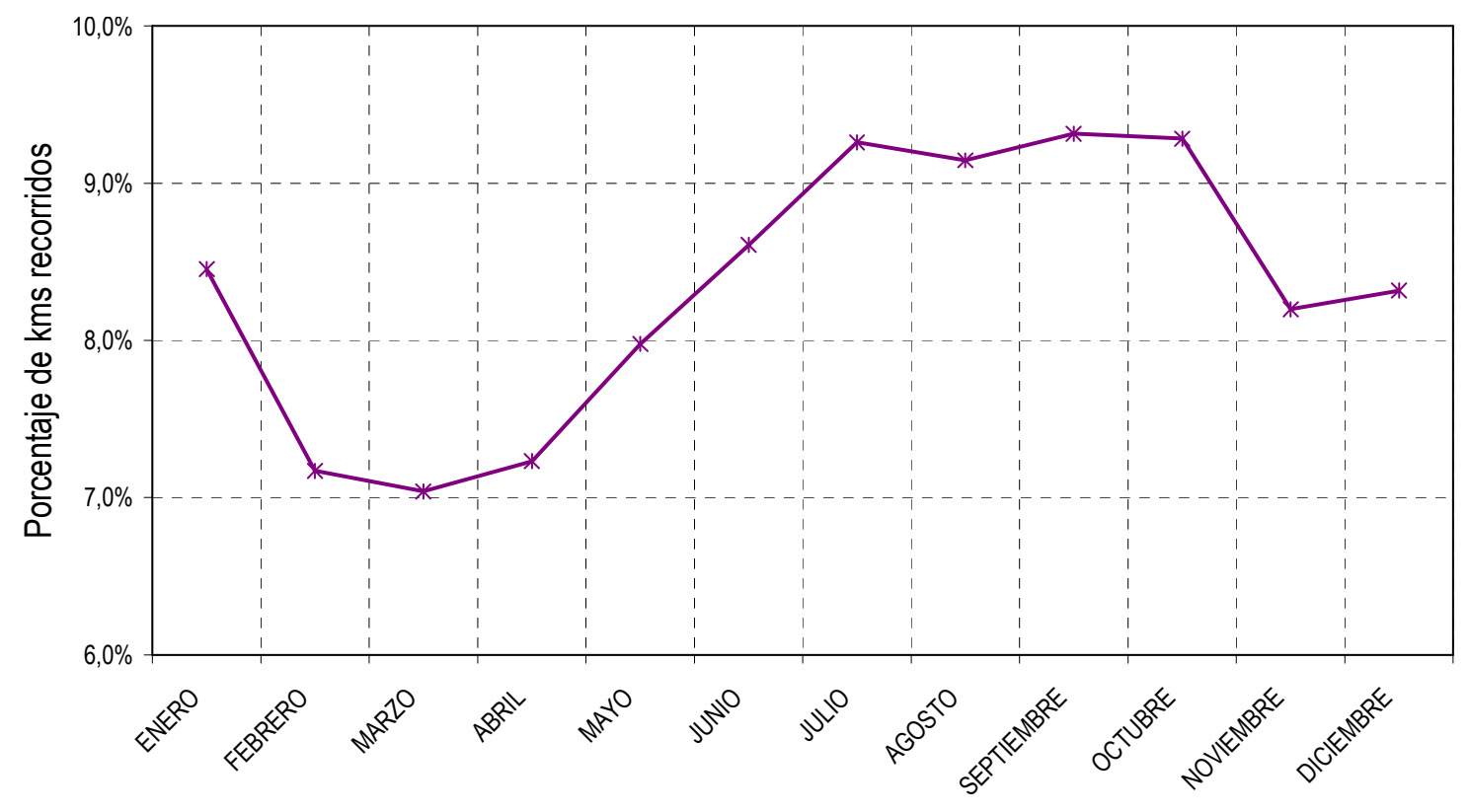

Se puede observar en la gráfica que el mayor recorrido medio por autobús tiene lugar en verano y otoño, con un fuerte descenso en los meses de Febrero a Abril. A partir de estos datos, junto con los de tráfico de viajeros, se puede deducir que, aunque la distribución del número de viajeros-kilómetro sea aproximadamente lineal, en verano hay menor número de viajes pero de mayor longitud, mientras que en primavera son predominantes los viajes cortos, pero más numerosos.

\subsubsection{Distribución de Vehículos Cargados y Vacíos}

En el presente apartado, se expondrán los datos proporcionales de autobuses circulando vacíos y cargados, a fin de determinar si la eficiencia del sistema es adecuada. Los datos proceden de los controles realizados por la Guardia Civil en las carreteras españolas, y constituyen un muestreo bastante aceptable, ya que se realiza de manera aleatoria, y además el número de datos es muy elevado (más de 2,5 millones de vehículos controlados entre los años 1996 y 2009).

A partir de estas series de datos, se puede realizar una evolución anual diferenciando los vehículos nacionales y extranjeros, de modo que, considerando los últimos cinco años, resultan unos porcentajes totales de vehículos cargados del $69 \%$ para los vehículos nacionales y del 78\% para los extranjeros. La Tabla 2-11 y la Figura 2-11 indican la evolución de estas proporciones entre 1996 y 2009. 
Tabla 2-11. Vehículos cargados y vacíos

Fuente: Ministerio de Fomento [102]

\begin{tabular}{ccccc}
\hline \multirow{2}{*}{ AÑO } & \multicolumn{2}{c}{ VEHÍCULOS NACIONALES } & \multicolumn{2}{c}{ VEHÍCULOS EXTRANJEROS } \\
\cline { 2 - 5 } & CARGADOS & VACÍOS & CARGADOS & VACÍOS \\
\hline $\mathbf{1 . 9 9 6}$ & 138.989 & 70.039 & 21.857 & 6.292 \\
\hline $\mathbf{1 . 9 9 7}$ & 128.242 & 64.197 & 23.301 & 7.154 \\
\hline $\mathbf{1 . 9 9 8}$ & 132.135 & 65.022 & 22.931 & 6.995 \\
\hline $\mathbf{1 . 9 9 9}$ & 144.307 & 77.501 & 23.823 & 7.936 \\
\hline $\mathbf{2 . 0 0 0}$ & 143.547 & 76.117 & 24.299 & 8.517 \\
\hline $\mathbf{2 . 0 0 1}$ & 154.581 & 67.205 & 18.380 & 5.125 \\
\hline $\mathbf{2 . 0 0 2}$ & 124.625 & 55.985 & 19.241 & 5.111 \\
\hline $\mathbf{2 . 0 0 3}$ & 140.208 & 70.565 & 21.159 & 5.515 \\
\hline $\mathbf{2 . 0 0 4}$ & 132.072 & 66.457 & 20.626 & 5.875 \\
\hline $\mathbf{2 . 0 0 5}$ & 110.593 & 51.582 & 18.294 & 4.625 \\
\hline $\mathbf{2 . 0 0 6}$ & 120.004 & 58.263 & 18.782 & 4.296 \\
\hline $\mathbf{2 . 0 0 7}$ & 127.728 & 57.446 & 18.200 & 6.150 \\
\hline $\mathbf{2 . 0 0 8}$ & 117.385 & 53.308 & 17.538 & 4.679 \\
\hline $\mathbf{2 . 0 0 9}$ & 129.951 & 53.333 & 17.090 & 5.210 \\
\hline
\end{tabular}

Figura 2-11. Evolución de porcentajes de vehículos cargados y vacíos Fuente: Ministerio de Fomento [102]

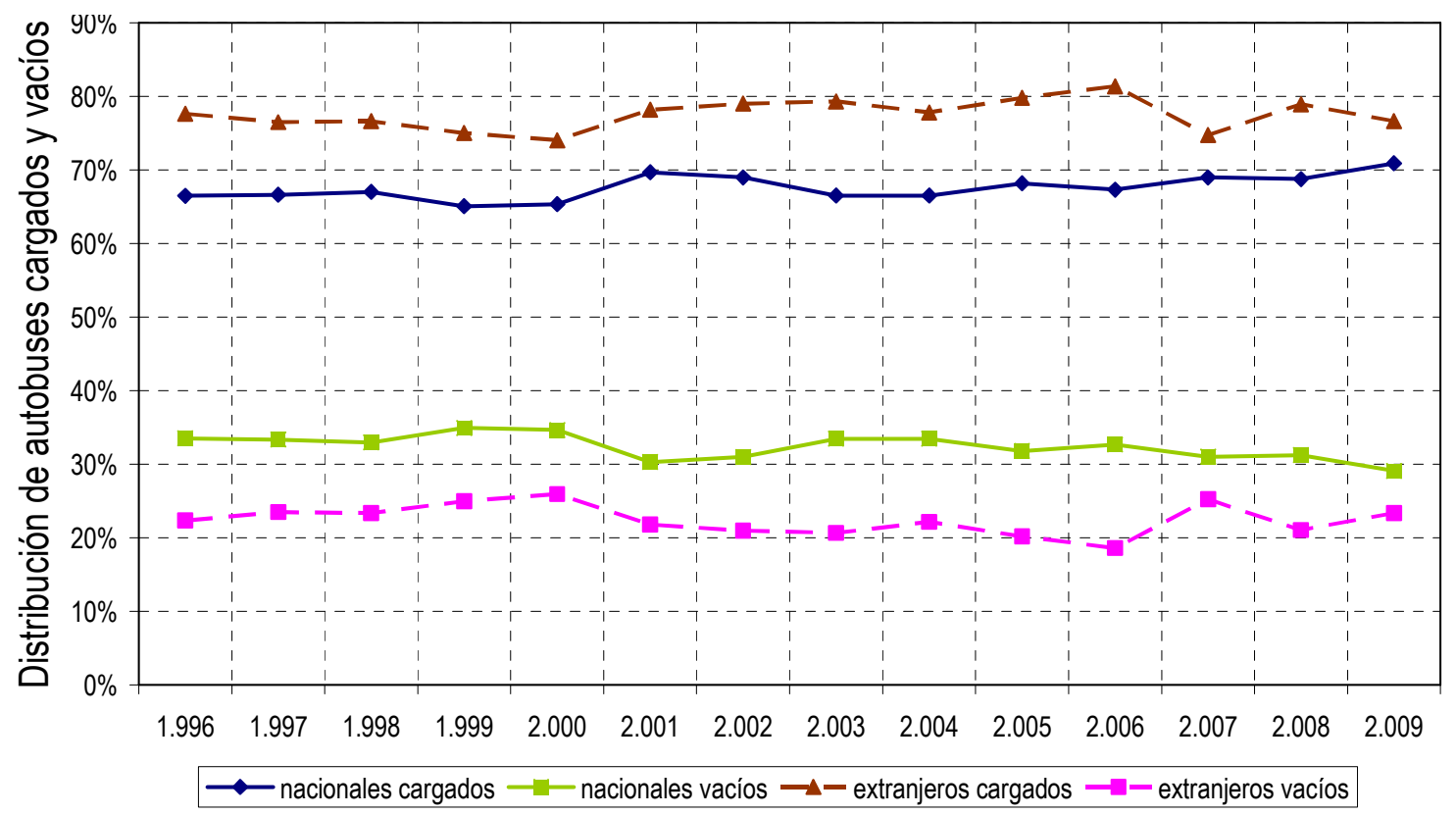

En general, se puede concluir que los vehículos extranjeros tienen un mayor índice de ocupación que los nacionales. También es interesante destacar que, especialmente en los autobuses nacionales, se percibe una ligera tendencia creciente en cuanto a la ocupación de los mismos, lo que denota una mejora en la eficiencia del servicio. 


\subsection{La Gestión de los Servicios Públicos de Transporte}

Como finalización de este capítulo referente a la situación actual de las concesiones de transporte público de viajeros por carretera, a continuación se hará un breve resumen del marco normativo existente al respecto, tanto a nivel nacional como regional, así como las principales modalidades de gestión. Ambos temas se desarrollarán en los apartados que siguen.

\subsubsection{Marco Normativo}

La principal legislación estatal en vigor que afecta al transporte público, por orden de importancia, se resume a continuación:

- Constitución Española (1978). En su artículo 130.1, dicta que el Estado es el responsable de "atender a la modernización y desarrollo de todos los sectores económicos a fin de equiparar el nivel de vida de todos los españoles".

- Ley de Ordenación de los Transportes terrestres (LOTT, Ley 16/1987). Es la única referente al sector del transporte, sin ser específica del transporte público.

- Ley Orgánica de Financiación de las Comunidades Autónomas (LOFCA, Ley Orgánica 8/1980). En su artículo 15.1 indica que "El Estado garantizará en el territorio español el nivel mínimo de los servicios públicos fundamentales de sus competencias".

- Ley de Contratos del Sector Público (LCSP, Ley 30/2007), que sustituye a la anterior Ley de Contratos de las Administraciones Públicas. Recoge, en su artículo 253, las modalidades de contratos de gestión de servicios públicos.

- Ley de Organización y Funcionamiento de la Administración General del Estado (LOFAGE, Ley 6/1997). Regula las posibles modalidades de gestión directa de los servicios públicos.

- Ley Reguladora de las Bases de Régimen Local (LRBRL, Ley 7/1985). En su artículo 86.3 dicta lo siguiente: "Se declara la reserva a favor de las Entidades locales de las siguientes actividades o servicios esenciales: (...), transporte público de viajeros". 
Sin duda, el principal exponente normativo es la Ley 16/87, de 30 de julio, de Ordenación de los Transportes Terrestres (modificada por la Ley 29/03, de 8 de octubre y por la Ley 39/03, de 17 de noviembre, del Sector Ferroviario), junto con el Reglamento que la desarrolla. En ellos, se fijan las principales definiciones pertinentes a los servicios de transporte público y privado, así como las condiciones básicas para su realización.

Además, en Marzo de 2003, el Ministerio de Fomento [99] editó su "Plan de Líneas de Actuación del Transporte en Autobús (PLATA)", en el que se realiza en primer lugar un diagnóstico del sistema de transporte público en autobús, tanto urbano como interurbano, para, a continuación, determinar las actuaciones críticas a realizar, con el objetivo principal de mejorar su calidad, seguridad, integración con el medio ambiente, y, en general, modernización y mejora del mercado.

Por otra parte, la Administración Regional ha elaborado su Ley 15/2002, de 28 de noviembre, de Transporte Urbano y Metropolitano de Castilla y León, en la que se establecen las normas de carácter general de los transportes urbanos y se determinan los modos y reglas de coordinación entre el transporte urbano e interurbano, entre otras. A pesar de que es una normativa en principio dirigida a los transportes de tipo urbano, tiene algunos apartados específicos de transporte interurbano.

Además de esta normativa, a nivel regional existen también las órdenes reguladores de las subvenciones a conceder a empresas deficitarias de los servicios de transporte público permanente regular de uso general de viajeros por carretera, que incluyen las condiciones a exigirles a los mismos.

A continuación, se revisa brevemente cada una de estas normativas.

\section{Normativa Estatal}

\section{a. Ley de Ordenación de los Transportes Terrestres y Reglamento}

La principal normativa existente a nivel estatal que regula los transportes públicos por carretera es la Ley 16/87, de 30 de julio, de Ordenación de los Transportes Terrestres (modificada por la Ley 29/03, de 8 de octubre y por la Ley 39/03, de 17 de noviembre, del Sector Ferroviario), junto con el Reglamento que la desarrolla, aprobado por Real Decreto 1211/90 (modificado por el Real Decreto 1225/06). En ellos, se fijan las principales definiciones pertinentes a los servicios de transporte público y privado, así como las condiciones básicas para su realización. 
Es una normativa de tipo general, que abarca todos los transportes terrestres (carretera, ferrocarril, transportes por cable o tubería...), y de aplicación tanto para transporte de viajeros como de mercancías. Es una ley de aplicación directa en los transportes que son competencia de la Administración Central.

Se divide en seis títulos más uno preliminar, junto con las correspondientes disposiciones adicionales, transitorias, derogatoria y final. El esquema simplificado de la citada ley es el siguiente (se citan títulos y capítulos):

- Título preliminar

○ Ámbito de aplicación

○ Principios generales

- Régimen de competencias y coordinación de las mismas

○ Órganos de coordinación interadministrativa

- Título I: Disposiciones comunes a los diferentes modos de transporte terrestre

○ Directrices generales

- Programación y Planificación

- Régimen económico-financiero de los servicios y actividades de transporte terrestre

- Coordinación entre los distintos modos de transporte terrestre y transporte combinado

- Coordinación del sistema de transportes con las necesidades de defensa y protección civil

- La Inspección del Transporte Terrestre

- El Consejo Nacional de Transportes Terrestres

- Juntas Arbitrales del Transporte

- Los usuarios del transporte

- Título II: Disposiciones de aplicación general a los transportes por carretera y a las actividades auxiliares y complementarias de los mismos

- Condiciones para el ejercicio del transporte y de las actividades auxiliares y complementarias del mismo

o Colaboración con la Administración y cooperación entre empresas 
- Título III: De los servicios y actividades del transporte por carretera

- Clasificación

- Los transportes públicos regulares de viajeros

- Los transportes públicos discrecionales de viajeros y mercancías

○ Los transportes privados

○ El transporte internacional

○ Los transportes turísticos

○ Los transportes urbanos

- Título IV: Actividades auxiliares y complementarias del transporte por carretera

- Actividades de mediación

- Centros de información y distribución de cargas

- Almacenistas-distribuidores

○ Transitarios

- Estaciones de transporte por carretera

- Arrendamiento de vehículos

- Título V: Régimen sancionador y de control de los transportes terrestres, y de sus actividades auxiliares y complementarias

- Régimen sancionador

- Documentos de control

- Título VI: El transporte ferroviario

○ Concepto y clases

- Los ferrocarriles de transporte público

- Los ferrocarriles de transporte privado

- Policía de Ferrocarriles

- La Red Nacional de los Ferrocarriles Españoles

- Disposiciones adicionales

- Disposiciones transitorias

- Disposición derogatoria

- Disposición final 
En primer lugar, en la distribución de competencias, no dicta con claridad cuáles de las mismas son atribuidas al Estado y cuáles a las Comunidades Autónomas. Sin embargo, en la región de Castilla y León, la normativa autonómica explicita que es de aplicación a las concesiones de competencia directa de la Administración Regional, que son aquéllas que transcurren íntegramente por los límites de la Comunidad.

Otro de los puntos más importantes de la citada Ley es el de las condiciones necesarias para el ejercicio del transporte público, que son las ya conocidas de: tener nacionalidad española, europea o de algún otro país que goce de Convenios o Tratados, y superar las condiciones de capacitación profesional, honorabilidad y capacidad económica.

Una de las clasificaciones más importantes que establece esta Ley es la correspondiente a los servicios de transporte por carretera, diferenciando:

- En función de su naturaleza:

- Transporte público: Si se lleva a cabo por cuenta ajena mediante retribución económica.

- Transporte privado: Si se lleva a cabo por cuenta propia.

- En función del objeto:

○ De viajeros: Si se desplazan personas con sus equipajes.

- De mercancías: Si se desplazan mercancías.

- Mixtos: Si se desplazan personas y mercancías en el mismo vehículo, mediante la adecuada separación.

- En función del ámbito:

○ Interiores: Si el origen y el destino están en territorio español.

○ Internacionales: Si el itinerario discurre parcialmente por países extranjeros.

- En función de su régimen jurídico:

○ Ordinarios: Son los habituales.

○ Especiales: Requieren una autorización específica, por razones de peligrosidad, urgencia, incompatibilidad con otros, repercusión social u otras causas.

Los transportes públicos de viajeros por carretera pueden ser regulares, si se realizan dentro de itinerarios preestablecidos, y con sujeción a horarios y calendarios prefijados, o discrecionales, en otros casos. Sin embargo, los transportes públicos de mercancías tendrán en todo caso la consideración de servicios discrecionales. 
Quizás el capítulo en más directa relación con el objetivo del presente estudio sea el $2^{\circ}$ del Título III, referido a los transportes públicos regulares de viajeros. En primer lugar, se clasifican los transportes públicos regulares de viajeros como sigue:

- Por su continuidad:

- Permanentes, si se realizan de forma continuada, para atender necesidades de carácter estable.

- Temporales, para atender tráficos de carácter excepcional y de duración limitada, aunque pueda ser repetida, tales como ferias, mercados, vacaciones...

- Por su utilización:

- De uso general, si son utilizables por cualquier interesado.

- De uso especial, si sirven específicamente a un grupo específico de usuarios, como trabajadores, escolares, militares...

A continuación, cita los mecanismos de establecimiento o creación de prestaciones de servicios de transporte público regular de uso general de viajeros por carretera, que puede ser promovido por iniciativa pública o privada. Se indica que la modalidad de gestión más usual será la concesión, aunque también permite la gestión pública directa en casos justificados. La concesión se realizará por concurso, a partir las bases que se establezcan en el correspondiente pliego de condiciones, debiendo ser consideradas en la resolución todas las circunstancias que se incluyan en las diferentes ofertas (es decir, no sólo las económicas), dando preferencia, en igualdad de condiciones, al anterior concesionario (si existe).

También en este apartado se permite la colaboración entre empresas concesionarias, y se cita de forma excepcional la posibilidad de realizar concesiones de tipo zonal y no lineal. Además, se indica la posibilidad por parte de la Administración, de unificar concesiones cuando, por razones de interés público, no sea viable o procedente el establecimiento de un nuevo servicio que sustituya los anteriores.

Después, se citan las causas de cancelación de una concesión, entre las que aparece el incumplimiento de los términos esenciales de la concesión. Esta es una causa que podría ser aplicable al tema objeto de estudio, ya que muchas de las autorizaciones no cumplen unos criterios mínimos de calidad, que se podrían exigir para mejorar el servicio.

En el resto de artículos, se citan las condiciones específicas de los restantes tipos de transporte, tanto público como privado, para finalizar con las disposiciones indicadas, que 
facilitan la adaptación de la anterior normativa a la actual, modificando las concesiones existentes en la fecha de aplicación de la Ley.

En cuanto al Reglamento que desarrolla la Ley de Ordenación de los Transportes Terrestres, como punto más importante del mismo dentro del estudio en realización, se especifica en él de forma más detallada el proceso de establecimiento, explotación y adjudicación de los servicios de transporte regulares permanentes y de uso general de viajeros por carretera, incluyendo las condiciones que se deben cumplir en cada caso, así como la documentación a exigir en los proyectos, y las condiciones básicas de los pliegos, que incluirán todas las características de: tráficos esperados, itinerarios, calendarios, número de vehículos, régimen tarifario, plazo de la concesión, etc.

Las condiciones exigidas en los pliegos pueden tener carácter de:

- Condiciones esenciales: se deben respetar sin introducir ninguna variación. Ejemplos de estas variables son el plazo de la concesión, los tráficos...

- Condiciones con carácter de requisito mínimo: pueden ser mejoradas por las distintas ofertas, respetando siempre el mínimo establecido. Las variables de calidad y de nivel de servicio entran claramente en este grupo.

- Condiciones de carácter orientativo: se pueden establecer en cada oferta. Algunas de ellas son las tarifas, plazos de amortización, instalaciones fijas (si no se establecen mínimos en el pliego)...

Se indica también todo el procedimiento administrativo a seguir para la resolución y adjudicación del concurso, citando expresamente que se deben considerar todas las características introducidas en las diferentes ofertas, "sin atender exclusivamente al contenido económico de aquéllas", debiendo valorar especialmente: régimen tarifario, frecuencias, características y antigüedad de vehículos e instalaciones, integración del personal ya existente y calidad y seguridad del servicio. Además, en caso de ofertas similares, tendrá preferencia la presentada por el actual concesionario, siempre que haya cumplido correctamente sus obligaciones hasta la fecha.

A continuación, se indican las características a respetar en la explotación, en cuanto a la obligación de aceptar a todos los usuarios que lo soliciten, dentro de una serie de condiciones, o sobre los mecanismos de modificación de la concesión. También se indican los tipos de régimen tarifario permitidos, y cómo se deben establecer y revisar, indicando expresamente, en su versión corregida por el Real Decreto 1225/06, que " $L a$ Administración deberá tener en cuenta la necesidad de compensar al concesionario, 
siempre que éste así lo solicite, por las obligaciones de servicio público que le sean impuestas con posterioridad a la formalización del título concesional y alteren la relación entre costes y tarifa que en éste se contempla. Cuando ello resulte posible, dicha compensación se instrumentará a través de una modificación de la tarifa de la concesión, (...). En caso contrario, la compensación se llevará a efecto de forma directa por la Administración.

Por, se tratan los mecanismos de unificación y extinción de las concesiones de servicios de transporte público permanente regular de uso general de viajeros por carretera, indicando los procedimientos a seguir en cada caso, y las causas que los pueden originar.

\section{b. Plan de Líneas de Actuación del Transporte en Autobús (PLATA)}

El Plan de Líneas de Actuación del Transporte en Autobús [99], denominado también mediante las siglas PLATA, es un documento elaborado por la Dirección General de Transportes por Carretera del Ministerio de Fomento, en Marzo del año 2003.

En realidad no es un documento de tipo normativo, sino unas recomendaciones para el desarrollo del sector del transporte público de viajeros por carretera en España. Su objetivo básico es la mejora de la competitividad del transporte público de viajeros por carretera, considerándolo de forma global.

El documento se estructura en 8 capítulos, que se indican a continuación [99]:

1. Planteamiento general

2. Objetivos del Plan

3. Aspectos clave en la elaboración del Plan

4. Factores críticos y áreas de actuación

5. Conclusiones del diagnóstico

6. Grupos de trabajo

7. Plan de acción

8. Gestión del Plan

Las áreas básicas de análisis son, dentro del transporte público de viajeros en autobús, las siguientes:

- Servicio público regular: de uso general interurbano, de uso especial (escolar y laboral) y regular temporal

- Servicio público discrecional

- Transporte urbano 
En el capítulo 2, se establecen los principales objetivos del Plan, que deben considerarse principios fundamentales a seguir, y que son los 7 siguientes: seguridad, calidad, modernización, comercialización, medio ambiente, organización del mercado e intermodalidad [99].

A partir de estos aspectos clave, en el capítulo 4 se extrajeron una serie de factores críticos, que son los que más afectan al sistema, realizando un análisis diferente para los distintos grupos de transporte considerados, y también un estudio global. Finalmente, se determinaron las grandes áreas de actuación del PLATA, que son similares para todos los grupos de análisis y que agrupan los factores críticos. En total, resultaron las 12 áreas de actuación siguientes [99]:

1. Organización del mercado

2. Estructura y gestión empresarial

3. Comercialización nacional e internacional

4. Servicios complementarios

5. Nuevos sistemas de transporte e intermodalidad

6. Socio-laboral

7. Formación

8. Nuevas tecnologías

9. Medio ambiente

10. Calidad

11. Seguridad

12. Ordenación normativa

Una vez preestablecidos los factores críticos y las áreas de actuación, se llevaron a cabo reuniones de trabajo con representantes de empresas del sector, y también miembros de la Administración. En ellas, se realizó la evaluación bajo dos criterios distintos:

- Los factores críticos fueron valorados en función de su importancia.

- Las áreas de actuación fueron valoradas siguiendo dos criterios: su importancia estratégica y su urgencia.

La valoración de los factores críticos aportó una serie de conclusiones interesantes [99]:

a. Desde los empresarios del sector del transporte público regular de uso general, los factores más valorados son los correspondientes a la renovación de concesiones, seguidos de los relativos a la relación con otros modos, la eficiencia de la gestión de las Administraciones, y las repercusiones de la nueva Ordenación Normativa de la 
Unión Europea. Por otra parte, los menos valorados son los relativos a los aspectos medioambientales y a las certificaciones de calidad y medio ambiente.

b. Desde los empresarios de los sectores del transporte público regular de uso especial y discrecional, el factor más valorado es la competencia dentro del mercado, seguido de las infraestructuras existentes y previstas, la imagen del sector y los aspectos socio-laborales. Los menos valorados son, de nuevo, los aspectos medioambientales y de certificaciones, junto con los servicios complementarios al usuario.

c. Muy al contrario, desde el punto de vista de las Administraciones, los aspectos relativos a la calidad del servicio y a la información suministrada por la empresas son muy relevantes, además de la posible coordinación en la explotación. Entre los menos valorados, están la competencia del mercado, el régimen de otorgamiento de autorizaciones y, de nuevo, las certificaciones de calidad y medio ambiente y los servicios complementarios.

En cuanto a las áreas de actuación, se realizó una evaluación combinada entre la importancia y la urgencia de cada una. Así, los resultados más destacables fueron los siguientes [99]:

- Desde los empresarios del sector del transporte público regular de uso general interurbano, las áreas más prioritarias son las relativas a los aspectos sociolaborales, ordenación normativa, calidad e intermodalidad, mientras que, las menos prioritarias, son las de comercialización, servicios complementarios y medio ambiente.

- Desde los empresarios del sector del transporte público regular de uso especial y discrecional, las áreas más prioritarias son las relativas a los aspectos sociolaborales, ordenación normativa, estructura y gestión empresarial y organización del mercado, mientras que, las menos prioritarias, son, de nuevo, las de servicios complementarios y medio ambiente.

- Por otra parte, desde las Administraciones, las áreas más urgentes son las relativas al servicio prestado a los usuarios, como la calidad y la seguridad, además de la formación en el sector, mientras que la menos prioritaria, es la de los servicios complementarios.

Tras este exhaustivo estudio, el capítulo 5 recoge las principales conclusiones del diagnóstico, obtenidas mediante diferentes metodologías, como: análisis cuantitativo y 
cualitativo de la oferta y la demanda (y la relación entre ambas), análisis externo del conjunto del mercado y metodologías de tipo D.A.F.O. [99].

A partir de estos resultados, se formaron diferentes grupos de trabajo temáticos, cada uno de ellos orientado a la mejora de una de las siguientes áreas de actividad:

- Grupo 1: Organización del mercado y gestión empresarial

- Grupo 2: Aspectos sociolaborales y formativos

- Grupo 3: Calidad, medio ambiente, seguridad y nuevas tecnologías

- Grupo 4: Ordenación normativa

- Transporte urbano

- Líneas regulares de débil tráfico

Cada uno de estos grupos tiene una serie de objetivos concretos, orientados a solventar los problemas de las áreas de actuación que les incumben, y a fomentar sus fortalezas.

En los capítulos 7 y 8, se presenta la programación de la ejecución del Plan. En primer lugar, se exponen las 11 líneas estratégicas del Plan, que se componen de un total de 28 Proyectos, cada uno de ellos englobando una serie de Medidas (123 en total). Los Proyectos se describen por sus objetivos, antecedentes y actuaciones a realizar, indicando en cada caso la entidad impulsora, su prioridad (muy alta, alta o media) y la comisión de trabajo que se encargará de su desarrollo. Además, se señalan las medidas que lo componen, con el cronograma de implantación de las mismas y los indicadores de control de cada caso.

\section{Normativa Regional}

\section{a. Ley de Transporte Urbano y Metropolitano de Castilla y León}

Tal y como se cita en la propia Ley, la Comunidad de Castilla y León, conforme a la normativa existente, y las sentencias habidas hasta la fecha, "ostenta la competencia exclusiva sobre los transportes terrestres, fluviales, por cable o por tubería que transcurran íntegramente por su territorio”.

Además, mediante Sentencia del Tribunal Constitucional, todos los artículos correspondientes a los transportes urbanos que contenía la Ley de Ordenación de los Transportes Terrestres quedaron derogados, apareciendo así un vacío normativo, que la 
Junta de Castilla y León ha solventado mediante su Ley 15/2002, de 28 de noviembre, de Transporte Urbano y Metropolitano de Castilla y León.

A pesar de que es una normativa en principio dirigida a los transportes de tipo urbano, tiene algunos apartados específicos de transporte interurbano, en especial en lo que se refiere a su coordinación con los urbanos.

Finalmente, el esquema de la Ley es el siguiente:

- Título 1: Disposiciones generales.

- Título 2: De los transportes urbanos.

○ Capítulo 1: Normas comunes.

○ Capítulo 2: Servicios regulares.

○ Capítulo 3: Servicios discrecionales.

- Título 3: Coordinación de servicios urbanos e interurbanos.

○ Capítulo 1: Normas generales.

○ Capítulo 2: Procedimientos de coordinación.

- Título 4: Transporte de viajeros en vehículos de turismo.

- Capítulo 1: Licencias de autotaxis.

- Capítulo 2: Vehículos afectos a las licencias.

○ Capítulo 3: Condiciones de prestación de los servicios.

- Título 5: Inspección, infracciones y sanciones.

- Capítulo 1: Normas generales.

○ Capítulo 2: Infracciones.

○ Capítulo 3: Sanciones.

- Disposiciones adicionales.

- Disposiciones transitorias.

- Disposiciones finales.

En el título 1 se indica el ámbito de aplicación de la Ley, que se corresponde con la gestión de los servicios que transcurren dentro de sus límites territoriales (dentro de la normativa general regional), y establece las competencias de los Municipios y del Gobierno Regional. 
A continuación, se definen varios conceptos, de manera muy similar a la de la Ley de Ordenación de los Transportes Terrestres. Así, se definen los transportes públicos y, dentro de éstos, los servicios regulares y discrecionales. A su vez, los servicios regulares se dividen en: permanentes o temporales, y de uso general o especial.

Por último, en este título se fijan las distintas posibilidades de financiación de los transportes públicos, así como la obligatoriedad de compensar económicamente a los concesionarios de servicios de transporte público que no alcancen el equilibrio económico de su explotación, bien monetariamente o mediante otras medidas (si ambas partes están de acuerdo).

En el título 2, se establece toda la normativa correspondiente a los transportes urbanos, definidos como aquéllos "que discurran íntegramente por suelo clasificado como urbano o urbanizable, de conformidad a la normativa urbanística, o estén exclusivamente dedicados a comunicar núcleos de población ubicados en dichas clases de suelo situados dentro de un mismo término municipal”. Como regla excepcional, también se permite en algunos casos la consideración de transportes urbanos a los que comuniquen zonas de otro tipo, pero siempre dentro de un mismo término municipal.

El título 3 es el correspondiente a la coordinación entre servicios de transporte urbano e interurbano, por lo que es el más directamente relacionado con el tema objeto del estudio.

En su capítulo 1, se establecen las normas generales que deben regir los procesos de coordinación, indicando expresamente la finalidad a buscar. Además, se citan los principios fundamentales que deben regir las estrategias, que son:

- "Eficacia en la gestión, con el mínimo coste económico y social.

- Autonomía de las Entidades Locales en la gestión de los servicios de transporte.

- Respeto a los derechos preexistentes de las empresas prestadoras de servicios públicos de transporte."

Respetando siempre las finalidades y principios básicos, se puede tratar de coordinar los siguientes tipos de servicio:

- Los de transporte público regular urbano de viajeros.

- Los de transporte público regular interurbano de viajeros de competencia de la Comunidad de Castilla y León.

- Los de autotaxis o similares. 
- Los de transporte público de viajeros de competencia estatal que se presten en el ámbito afectado, según la distribución de competencias actual.

- Las redes viarias y, en su caso, ferroviarias, si resultaran necesarias.

- Las instalaciones de transporte que sean necesarias $y$, en todo caso, las intermodales.

- Cualquier otro elemento, dentro de la distribución legal de competencias, y siempre que se cumplan las finalidades y principios.

Los principales modos de coordinación que se contemplan son tres: la constitución de una Entidad Metropolitana, la aprobación de Planes Coordinados de Explotación, y la fijación de los puntos de parada urbana de los servicios interurbanos.

Los Planes Coordinados de Explotación pueden organizarse mediante convenios entre las entidades competentes o a través de la creación de una entidad pública que realice de forma autónoma la ordenación conjunta de los servicios de transporte. Por otra parte, si son de ámbito municipal, corresponde a las autoridades locales su elaboración y aprobación, mientras que, si su ámbito es supramunicipal, precisan de la aprobación de la Consejería competente, dentro de la Junta de Castilla y León.

En cuanto a la ubicación de las paradas urbanas de los servicios de tipo interurbano, se indica expresamente que, en caso de disponer de estación de autobuses, al menos una de las paradas se debe disponer allí, con ciertas excepciones para trayectos de corto recorrido. Además, indica los mecanismos de aprobación de la ubicación de nuevas paradas o modificación de las existentes, siguiendo los criterios que se enumeran a continuación:

- "Número de usuarios afectados.

- Incidencia en la prestación del servicio y en las condiciones económicas de la explotación.

- Repercusión sobre la circulación urbana y la seguridad vial.

- Accesibilidad a los servicios de transporte urbano, y centros sanitarios, educativos y de trabajo."

El título 4 se refiere al transporte de viajeros en vehículos de turismo (taxi), siendo éstos los de capacidad igual o inferior a 9 plazas, incluida la del conductor. 
Por último, el título 5 indica los mecanismos de inspección, infracciones y sanciones correspondientes a los transportes urbanos, dividiendo las infracciones en tres grupos de diferente gravedad, y asignando a cada uno de ellos un rango de sanción económica.

\section{b. Bases Reguladoras de las Subvenciones a los Servicios Deficitarios}

Como último documento normativo a citar, la Consejería de Fomento de la Junta de Castilla y León convoca periódicamente convocatorias de subvenciones para la explotación de servicios deficitarios de transporte público permanente regular de uso general de viajeros por carretera. Así, en el año 2009, se preparó la Orden FOM/231/2009, de 9 de febrero, en la que se indicaban las bases reguladoras para la subvención, y su correspondiente convocatoria en la Orden 386/2009, de 24 de febrero.

En ellas, se establecen los servicios que son susceptibles de ser subvencionados, que son aquéllos que transcurran íntegramente en el ámbito territorial de la Comunidad Autónoma de Castilla y León, que pueden ser tanto existentes como nuevas propuestas.

Así mismo, se indica en cada caso la documentación necesaria y la tramitación a seguir, además de los criterios que se valorarán en la adjudicación, y los plazos para todo el procedimiento de presentación de solicitudes y de resolución de las mismas.

\subsubsection{Análisis de Modalidades de Gestión Existentes}

La principal distinción entre sistemas de gestión del transporte público en Europa se produce entre los regímenes de iniciativa pública y de mercado. Cuando un servicio se instaura por iniciativa pública, es la Administración quien tiene la responsabilidad de la explotación y la gestión, mientras que, cuando es la iniciativa de mercado la que rige el sistema, las empresas compiten entre ellas, mediante un proceso más o menos liberalizado según casos [129].

En España, la principal normativa que regula la contratación de los servicios de transporte público es la Ley de Contratos del Sector Público (LCSP, Ley 30/2007), que sustituye a la anterior Ley de Contratos de las Administraciones Públicas. En ella se indican las posibles modalidades de gestión indirecta existentes.

Así mismo, en la Ley de Organización y Funcionamiento de la Administración General del Estado (LOFAGE, Ley 6/1997), se indican las posibles vías de gestión directa. 
Por último, la Ley Reguladora de las Bases de Régimen Local (LRBRL, Ley 7/1985), indica los principios a seguir para los servicios de competencia de las Administraciones Locales.

En la Figura 2-12, se presenta un esquema resumen de los diferentes sistemas de gestión contemplados en la legislación española:

Figura 2-12. Modalidades de Gestión del Transporte Público

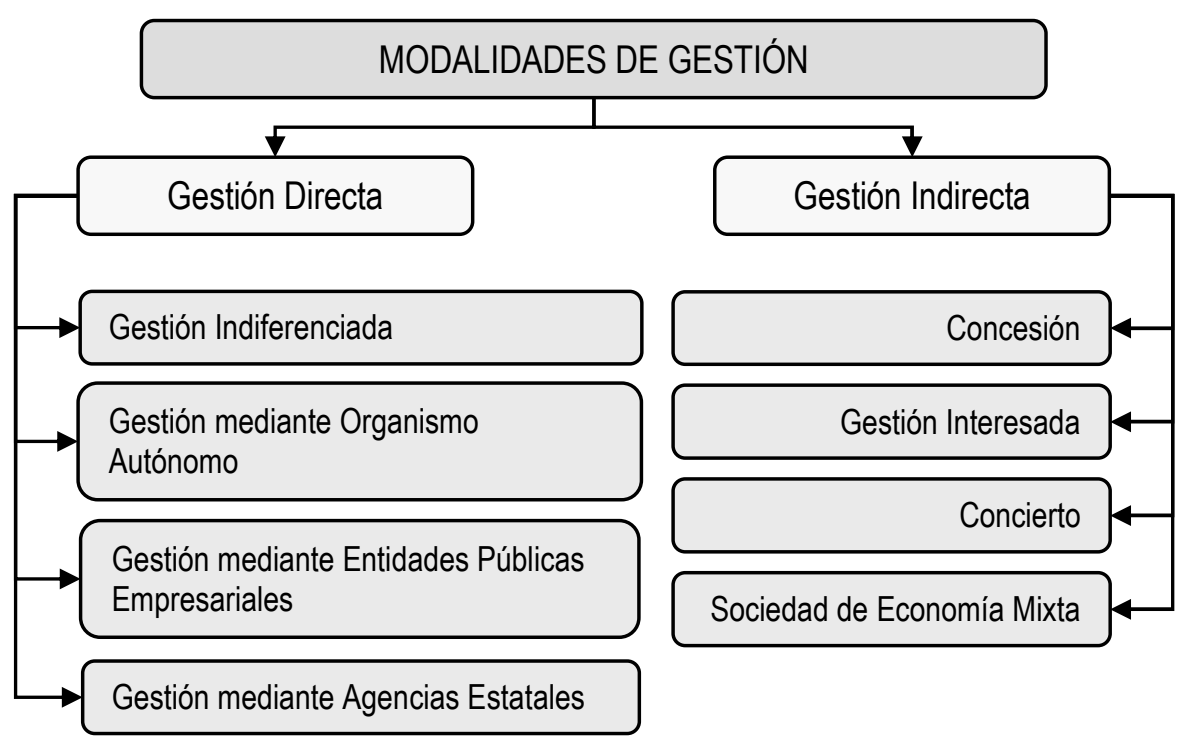

Las principales características de cada una de estas modalidades son presentadas brevemente a continuación:

\section{Gestión directa.}

La Administración ejerce el servicio mediante sus propios medios o bien a través de un ente público.

Al ser la propia Administración, empleando su personal, quien gestiona el servicio, se suprime cualquier actuación de terceros, y todo el capital es aportado por la Administración, quien asume, de igual forma, el riesgo mercantil de la explotación.

Dicho riesgo será diferente en función de la tipología de gestión directa que se sigua, de entre las que figuran a continuación. 
Gestión indiferenciada.

La Administración utiliza sus propios medios para la satisfacción de la demanda. El servicio público de transporte es una función a añadir en el organigrama de la Administración, ejecutándose por sus propios funcionarios.

\section{Gestión mediante Organismo Autónomo.}

La Administración crea un organismo especial que se encarga del servicio, dependiente de un Ministerio y que se rige por Derecho Administrativo. Corresponde al Ministerio la dirección, evaluación y control de su actividad.

Para su financiación, disponen de los ingresos propios que perciban, así como de las restantes dotaciones que se les asignen en los Presupuestos Generales del Estado.

Gestión mediante Entidades Públicas Empresariales.

Son organismos con personalidad jurídica propia, plena capacidad de obrar para la consecución de sus fines, y patrimonio propio.

Tienen una dependencia especial de la Administración, ya que están adscritos a un Ministerio, y están sometidas a un régimen jurídico-administrativo particular. Excepcionalmente, incluso pueden asumir la función de dirigir a otros entes de la misma o distinta naturaleza

Como ejemplo destacado, puede citarse a RENFE hasta el año 1987, cuando aparece la LOTT.

\section{Gestión mediante Agencias Estatales.}

Se trata de sociedades mercantiles en las que no hay participación del sector privado, siendo su totalidad de capital de carácter público. Según se indica en el artículo 2 de la Ley 28/2006 de Agencias Estatales para la mejora de los servicios públicos, "son entidades de Derecho público, dotadas de personalidad jurídica pública, patrimonio propio y autonomía en su gestión, facultadas para ejercer potestades administrativas, que son creadas por el Gobierno para el cumplimiento de los programas correspondientes a las políticas públicas que desarrolle la Administración General del Estado en el ámbito de sus competencias.” 


\section{Gestión indirecta.}

La Administración cede la gestión del servicio de transporte público a la empresa privada mediante un contrato (basado en la Ley de Contratos del Sector Público). El servicio es explotado mediante un contrato de gestión de servicios públicos.

Las Leyes de Contratos del Sector Público y de Ordenación de los Transportes Terrestres reconocen cuatro tipos de contratos:

\section{Concesión.}

Es la forma más habitual de contratación para los servicios de transporte público. Se otorga para servicios de carácter lineal (no forman parte de una red interconectada entre sí), y también excepcionalmente para servicios zonales.

La Administración podrá, de oficio o a instancia de parte, unificar servicios que fueron objeto de diferentes concesiones.

La empresa adjudicataria explota el servicio a su riesgo y ventura, bajo la supervisión de la Administración, soportando todo el riesgo mercantil, pero también el beneficio empresarial.

Las condiciones de la concesión se fijarán en el pliego de condiciones de la misma. De este modo, los beneficios se pueden ver reducidos por las imposiciones sociales, y se puede conceder al explotador una contribución financiera destinada a compensar sus obligaciones de servicio público.

Este modelo destacó en los últimos años. Con el paso de los años, el aumento del riesgo empresarial hizo que las empresas exigieran nuevas formas de contrato, comenzando a observarse en la actualidad un leve cambio en las tendencias.

\section{Gestión interesada.}

El titular del servicio (la Administración) y el empresario participan conjuntamente en los resultados de la explotación del servicio, en la proporción que se establezca en el contrato. El riesgo se asume de forma conjunta, e incluso se puede estipular contractualmente un beneficio mínimo a favor de cualquiera de las partes.

En España, están adquiriendo un gran auge los denominados contratos-programa. En éstos, la Administración se debe hacer cargo de los costes que el empresario deba soportar, y que no se vean compensados con los ingresos del servicio. Para 
asegurar el compromiso de la empresa con la eficiencia en la gestión y con la calidad, se puede medir el coeficiente de cobertura, e incluso se la pueden exigir unos valores mínimos en cuanto a determinadas variables del servicio, como horarios, antiguiedad y equipamiento de los autobuses, atención al cliente, etc... [94]

\section{Concierto.}

La Administración contrata a una entidad pública o privada, o a un particular, que ya esté prestando un servicio análogo al que se quiere contratar. De este modo, se aprovechan los locales e instalaciones de que ya disponga la empresa adjudicataria, y el contrato únicamente se refiere a la gestión del servicio.

$\underline{\text { Sociedad de economía mixta. }}$

Es una sociedad mercantil, anónima o limitada, quien gestiona el servicio. Sin embargo, la Administración participa, por sí misma o bien a través de una entidad pública, en dicha sociedad, junto con otra/s empresa/s privada/s.

Este tipo de modalidad incluye el caso de que la sociedad mercantil tenga un capital mayoritariamente público. Sólo queda excluido el caso de que el capital provenga en su totalidad de la Administración, ya que se trataría entonces de una gestión directa.

En general, se emplea este tipo de sociedad cuando se cree que la participación de la Administración puede hacer que el sector privado decida invertir, o también cuando la Administración no quiere hacerse cargo en solitario del servicio, pero tampoco quiere ceder completamente la gestión del mismo.

Además, la Ley de Bases de Régimen Local (LRBL) reconocía un tipo adicional de contrato: el arrendamiento. En éste, únicamente se contrataba la explotación del servicio, de modo que la Administración ponía a disposición del empresario las instalaciones y equipos necesarios para asegurar dicha explotación, aplicándole un canon por su utilización. Sin embargo, esta modalidad ha sido derogada, ya que no figura en la nueva redacción de la Ley de Contratos del Sector Público.

Como último apunte en este apartado, cabe destacar que, hasta la actualidad, la mayoría de los contratos de transporte público se han realizado por concesión. Sin embargo, están apareciendo en los últimos años nuevas formulaciones que permiten una mayor 
flexibilidad para la empresa concesionaria, con el fin último de que ésta se comprometa activamente con la mejora del servicio.

Así, pueden ser destacados los contratos-programa, que, como ya se ha indicado anteriormente, se basan principalmente en la idea de que la Administración sufrague todos aquéllos costes (no sólo los de explotación, sino también las inversiones para mejorar el servicio) que el empresario no compense con los ingresos percibidos. En concreto, en el caso de los transportes metropolitanos del área de Barcelona, el coeficiente de cobertura de gastos conseguido ha sido cercano al 80\% [94], exigiéndose además un compromiso de calidad a las empresas adjudicatarias.

Además, se está incidiendo en la necesidad de crear una competencia controlada entre las empresas que deseen prestar servicios de transporte público, introduciéndose también los contratos de gestión interesada, donde el empresario y la Administración comparten los riesgos y resultados de la explotación. En el área metropolitana de Barcelona, los nuevos contratos de gestión interesada obligan a las empresas a asumir un compromiso en cuanto al número mínimo de viajeros transportados, con lo que deben asegurar la calidad y fiabilidad del servicio. Así mismo, se han promovido incentivos y penalizaciones según determinados baremos de calidad y de nivel de servicio, adentrándonos de esta forma hacia una gestión eficiente y más sostenible [97].

En cualquier caso, en apartados posteriores se reflejarán con mayor detalle los principales intentos españoles para internalizar la calidad como una variable necesaria a la hora de conceder la gestión de los servicios de transporte público. 



\section{ESTADO DEL ARTE}

La preocupación por la mejora de la utilización de los servicios de transporte público en autobús no es nueva, sino que es un problema que se viene acentuando desde hace años. De hecho, ya en la década de los 80, Cherniack [30] promulgaba la necesidad de diversificar el servicio, creando dos niveles de explotación distintos: unos con precios bajos, pero también con un nivel de calidad básico, en cuanto a frecuencias, antigüedad de los autobuses, etc, y otro de mayor calidad, pero con una tarifa más elevada. Así, pretendía que, tanto los usuarios de bajos ingresos como los de alto poder adquisitivo, encontraran atractivo el empleo del autobús como modo habitual de transporte.

A continuación, se analizarán los principales exponentes en cuanto a la modelización de la calidad y demanda del transporte público en autobús, destacando especialmente aquéllos de ámbito interurbano, y finalmente los intentos detectados de incorporación de parámetros de calidad a los contratos de gestión. 


\subsection{Revisión Bibliográfica de Modelos de Calidad y Demanda}

Por todos es conocida la gran importancia que cobra cada día la congestión circulatoria en nuestra sociedad. Por ello, desde las distintas Administraciones, cada cual en función de la gravedad del problema que le concierne, se trata habitualmente de buscar soluciones que favorezcan el transporte en vehículo público frente al privado, basadas generalmente en la promoción del primero o en la penalización del segundo.

Sin embargo, las acciones encaminadas a penalizar el uso del transporte privado no gozan de la benevolencia de los ciudadanos, que, en general, sienten que se les está privando de un derecho adquirido. Por ello, suele ser habitual decantarse por soluciones de promoción del transporte público, mediante distintas actuaciones que tratan de mejorar su calidad, precio o ambas características. A pesar de las "buenas intenciones", se suele dar el caso de que estas acciones no dan el resultado esperado, bien porque los usuarios no las perciben correctamente o bien porque no son valoradas en suficiente magnitud.

Por ello, es imprescindible conocer cuáles son las variables que más aprecian los usuarios a la hora de evaluar la calidad global del servicio recibido, y también especialmente cómo influirían determinadas mejoras sobre la demanda del mismo. Así, en primer lugar, se analizará la experiencia internacional en cuanto a la modelización de la calidad percibida por los usuarios y respecto a la relación existente entre ésta y la demanda del servicio.

\subsubsection{Modelización de la Calidad Percibida y Satisfacción del Usuario}

En primer lugar, es importante destacar en este sentido que, mientras para transporte público urbano, la cantidad de estudios existentes es ingente, el transporte interurbano ha quedado relegado en cierto sentido. Por ello, se incluirán en el presente apartado no sólo estudios de ámbito interurbano, sino también los correspondientes al transporte de nuestras ciudades.

Se pueden encontrar interesantes colaboraciones en cuanto a la modelización de la calidad percibida y la correspondiente satisfacción del usuario, que, a efectos prácticos, dividiremos en el presente apartado en los siguientes grupos: aquéllos que relacionan la calidad y la importancia de cada variable de servicio, los que tratan de calcular un índice de calidad mediante métodos de regresión múltiple, los que emplean técnicas de elección discreta para identificar la importancia que cada usuario otorga a los diferentes atributos, aquéllos que se basan en análisis multicriterio para comparar diferentes alternativas de 
actuación, los que analizan las variables que influyen en la fidelidad de los usuarios, y los que emplean otras metodologías diferentes a las anteriores.

A continuación, se desarrollará brevemente los principales métodos empleados en cada grupo, junto con los resultados obtenidos.

\section{Relación calidad-importancia.}

Revisando la experiencia internacional al respecto, los estudios clásicos relacionaban la calidad de cada variable de servicio con la importancia que le otorga el usuario, a modo de ponderación $[43,55]$.

Así, por ejemplo, en la Red Metropolitana de County King (Seattle, Washington), tras detectar que los usuarios no percibían o no valoraban adecuadamente las actuaciones de mejora del servicio, se iniciaron una serie de investigaciones, desde el año 1995, por parte del Departamento de Transportes, para identificar cuáles son los factores clave, según los usuarios, para mejorar dicho servicio. Tras realizar reuniones del tipo grupo focal, se preparó un cuestionario con 22 parámetros, de los que los entrevistados -usuarios actuales y potenciales-, debían indicar la valoración que les otorgaban, junto con la importancia de los mismos. A continuación, se comparó, para cada variable, su valoración e importancia, resultando como variables prioritarias la frecuencia y tiempo de viaje entre las de diseño del servicio y la limpieza y la amplitud de horarios entre las de funcionamiento. [55]

Por otra parte, la Autoridad del Transporte de Chicago, tras observar el descenso de viajeros en autobús de los últimos tiempos, inició en el año 1995 la realización de una serie de encuestas bianuales sobre la calidad del servicio percibida por los usuarios. Se solicitaba a los usuarios que evaluaran la satisfacción con cada parámetro considerado y también su importancia, en escalas de 1 a 5 y de 1 a 10 , respectivamente. Finalmente, además de confrontar numéricamente ambos valores, se representaron en una gráfica que incluía, en su eje de abscisas, la importancia de cada parámetro, y, en el de ordenadas, su valoración. Dividiendo el área del gráfico mediante una línea vertical y otra horizontal, aparecían 4 zonas de diferente prioridad: la primera incluía variables muy importantes y mal evaluadas, con mayor prioridad de actuación; la segunda, variables importantes y bien evaluadas, a mantener en buena forma; la tercera, variables poco importantes y mal evaluadas, a mejorar ligeramente; y, la cuarta, variables no importantes y bien evaluadas, con la menor prioridad de actuación. [43] 
A partir de esta metodología gráfica de división en zonas, recientes estudios de la Universidad de Burgos $[123,124]$ han continuado trabajando en esta línea, con la gran diferencia de que la importancia de cada parámetro se obtuvo mediante técnicas de elección discreta, empleando modelos de tipo ordinal. Así, se elaboró una nueva determinación de los límites de zonas, mediante líneas diagonales -y no verticales y horizontales- que separan zonas de igual superficie. Con esta modificación, se evitan las difusas interpretaciones de la zona central del gráfico, donde los límites de las cuatro zonas concurrían en un mismo punto.

Para concluir este tipo de estudios, cabe destacar que, a pesar de su aparente simplicidad, tienen la gran ventaja de que, en un simple golpe de vista, se detectan los principales problemas, identificando también, por tanto, las áreas sobre las que actuar. Además, pueden constituir una metodología óptima para exponer ante un público no especializado los resultados de un estudio de calidad del servicio que puede llevar intrínseca una compleja formulación.

2. Índice de calidad mediante métodos de regresión.

En cuanto a la metodología existente para analizar cómo influyen las variables de servicio en la calidad percibida del mismo, puede observarse que los métodos empleados habitualmente suelen emplear modelos de regresión lineal o no lineal, donde se incluyen una serie de variables de servicio a fin de determinar la calidad global del mismo, y su comparación con la percibida por los usuarios.

En este sentido, cabe citar aquí la metodología seguida por el Ministerio de Transportes y Comunicaciones de Taiwan, el cual inició una investigación centrada en el corredor entre Taipei y Kaohsiung (cerca de $350 \mathrm{~km}$ ), localizado al Oeste de Taiwan, y fue realizado en el año 2003. Emplearon técnicas de regresión múltiple para modelizar la calidad del servicio, tomando como variables dependientes 4 grupos de parámetros, obtenidos mediante análisis factorial. Sin embargo, el objetivo último del estudio era modelizar la fidelidad de los usuarios, por lo que se hará más hincapié en puntos posteriores. [147]

3. Metodologías de elección discreta.

En los últimos años, está decayendo la utilización de los métodos de regresión a favor del empleo de técnicas de elección discreta, apareciendo numerosos estudios al respecto recientemente. 
Entre las primeras aplicaciones al respecto, podemos destacar la de Ortúzar et al [108], quienes emplearon modelos de tipo logit multinomial (MNL) sobre encuestas de preferencias declaradas (PD). Entre las conclusiones principales que arrojaron, citaron como pesos de cada variable sus correspondientes elasticidades sobre la demanda del servicio.

Otros autores, aun empleando también modelos logit multinomial (MNL) para el cálculo del índice de calidad, difieren respecto de los anteriores en que la función de utilidad resultante para cada usuario representa el valor de dicho índice [37], o también la analizan desde el punto de vista de cómo su mejora afecta al empleo del servicio [135]. Además, existen estudios que tratan de crear una función de desutilidad del servicio de transporte, como el llevado a cabo en la línea rural de autobús del distrito de Midnapur (India) [91], en el que se empleó un MNL para identificar el valor que el usuario asigna a cada variable.

Finalmente, existen también estudios que emplean otras tipologías de modelos de elección discreta, más adaptados a variables de elección discontinuas y con un claro orden de jerarquía entre las opciones. En concreto, destaca el empleo de los modelos ordinales, tanto de tipo probit [83] como logit [123], donde la función de utilidad es la satisfacción con el servicio, y las variables independientes son diversos parámetros de calidad

Especialmente destacables son las investigaciones llevadas a cabo por el Instituto de Estudios del Transporte [69, 119], no sólo para definir el índice de calidad del servicio, sino también elaborando propuestas de inclusión de parámetros de calidad en los contratos, como se verá en apartados posteriores.

En 1999, el ITS (Institute of Transport Studies) de Sidney comenzó a investigar distintas metodologías para que la industria del autobús de New South Wales (Australia) pudiera captar nuevos clientes a través del aumento de su satisfacción y de la mejora del servicio [119]. El objetivo era conseguir esbozar cómo la calidad podría ser introducida como un parámetro más dentro de un régimen de contratación distinto, incluso considerándola de forma económica. También se pretendía comprobar la efectividad de distintas medidas desde el punto de vista de los usuarios, e identificar qué aspectos del servicio funcionan mejor y cuáles precisan ser mejorados.

Como continuación de estas ideas, en el año 2000 comenzó la fase de desarrollo. Se identificaron dos parámetros clave a definir correctamente para la realización de la 
encuesta definitiva: los rangos de los distintos atributos sobre los que se debía consultar y la planificación de una correcta estructura para la muestra. Se invitó a participar a uno de los mayores operadores de transporte público, y a otro de los mayores de transporte privado. En total, se establecieron 9 segmentos de mercado distintos y, por agregación, se calculó un índice global para cada operador. [69]

La metodología empleada para ello fue la de preferencias declaradas, ya que muchas de las hipótesis que se pretendían considerar no existían en ese momento en los autobuses, e incluso no era viable su disposición. A partir de una serie de extensas discusiones con los operadores de transporte incluidos en el experimento, finalmente se eligió 13 atributos como los que mejor describían la calidad del servicio desde una perspectiva de los usuarios. [69]

A partir de estos trece atributos, cada uno de ellos con un rango de 3 niveles de variabilidad, resulta un total de $3^{13}$ combinaciones posibles de los mismos. Sin embargo, se restringió el número de combinaciones a un total de 81 , las cuales constituirían las distintas situaciones hipotéticas sobre las que se consultaría a los usuarios, a través de 27 formularios distintos de encuesta. De forma resumida, el plan de muestreo era distribuir alrededor de 500 encuestas en cada uno de los nueve segmentos (tres rutas distintas en tres distritos distintos), resultando en total 4500 muestras. Además, otro dato de desagregación del que se tomó nota fue si la encuesta se realizaba en períodos punta o valle. [69]

El formulario de la encuesta consistía en dos partes claramente diferenciadas. La primera tenía una serie de preguntas sobre el viaje que se estaba realizando y sobre el tipo de usuario (experimento de preferencias reveladas). Las posibilidades de elección respecto a los distintos atributos considerados fueron iguales que las que posteriormente se incluirían en el apartado de preferencias declaradas, excepto en el apartado del nivel de servicio. A continuación, se realizaban a cada usuario 3 experimentos de preferencias declaradas. [69]

En primer lugar, se realizó un análisis que revelara la importancia de cada atributo para cada segmento, mediante una metodología de asignación de pesos. Dichos pesos se obtuvieron mediante técnicas de elección discreta, empleando modelos de tipo logit multinomial (MNL) diferentes para cada segmento de mercado. A continuación se aplicó un factor de escala a cada segmento, con el fin de que fueran comparables entre sí, y obtener, a su vez, un índice SQI global. [69] 
Las percepciones de los usuarios respecto a los niveles de los distintos atributos, tanto actuales como en los escenarios hipotéticos presentados, junto con su elección final, constituyeron los datos básicos para identificar dichos pesos. Una vez se determinó el peso de cada factor, se multiplicó por el nivel asociado a cada uno de ellos en el viaje actual, y, sumando todas las multiplicaciones, se obtuvo un valor del índice de calidad del servicio para cada usuario. Además de estos pesos relativos, se obtuvo de forma adicional una estimación del valor del tiempo de los usuarios, que variaba entre 2 y 4,72 dólares por hora. [69]

Los parámetros que aportaron un mayor impacto negativo en la satisfacción fueron, como cabía esperar, el tiempo de viaje y la tarifa. Al contrario, la frecuencia de servicio y la posibilidad de ir sentado (se recuerda aquí que se trata de un estudio de tipo urbano) fueron los factores que provocaban un mayor impacto positivo. [69]

Esta tipología de estudios supone un importante desarrollo en la obtención de índices de calidad del servicio, con mejor nivel de organización que otros estudios previos. En cuanto a la posible utilidad de los resultados, se pueden detectar los atributos más importantes para los usuarios y, por tanto, saber sobre cuáles hay que realizar el mayor esfuerzo de inversión. Sin embargo, algunos de los parámetros relevantes no están bajo el control de los operadores, por lo que deben ser las Administraciones quienes los potencien para hacer los servicios de autobús más atractivos a los ciudadanos. En cualquier caso, el conocimiento de los factores que afectan la satisfacción del usuario es para todos los implicados en el sector una fuente de mejora importante.

4. Análisis multicriterio.

Una última tipología de estudios de calidad del servicio son los que incluyen análisis del tipo multicriterio. Éstos se caracterizan principalmente por la existencia de varios criterios simultáneos de valoración de alternativas, y su objetivo último suele ser la elección de la solución óptima.

Un primer ejemplo de aplicación al ámbito del transporte interurbano lo encontramos en el estudio elaborado para el operador ferroviario de Grecia: Hellenic Railways. [105]

Dentro del ámbito del transporte en autobús, aunque en ámbito urbano, es especialmente interesante el estudio realizado por Yeh et al [150] en Taiwan. En dicho documento, se analiza la calidad entre 10 líneas de transporte urbano de Taipei. Para ello, emplean una matriz de decisión, que representa cúanto satisface cada alternativa 
cada criterio o sub-criterio, y un vector de pesos, que indica cuán importante es cada criterio o sub-criterio.

Pero la característica diferenciadora de este estudio fue el empleo de las técnicas de análisis difuso o fuzzy, cuyo primer precursor fue Zadeh [151]. Dichas técnicas son especialmente útiles cuando la información de que disponemos es imprecisa y subjetiva. De hecho, cuando en una encuesta se pide a los usuarios que evalúen un determinado parámetro como "muy malo", "malo", "regular", "bueno" o "muy bueno", la puntuación numérica que cada entrevistado asocia a estos niveles no coincide. Entonces, cada posible elección queda determinada por una terna de valores formada por la puntuación más habitual de los usuarios, y sus valores máximo y mínimo, empleando una estructura triangular (y no en campana). [150]

La matriz de decisión incluirá en cada celda, por tanto, una terna. Aplicando sobre ella el vector de pesos, se obtiene la denominada matriz de funcionamiento del servicio, cuyos elementos serán también de tipo trinario. La bondad de una alternativa es función de la relación entre las celdas de su fila de la matriz de funcionamiento y el máximo difuso, que es igual al mayor ratio difuso de cada criterio, y ponderado para todos ellos. [150]

Como valor numérico a escoger, se pueden emplear los valores mayores de cada terna de las matrices, aunque también se pueden emplear los peores. $\mathrm{O}$ incluso se puede aplicar un índice denominado de optimismo, que oscila entre 0 y 1, e indica cuánto nos acercamos al peor o al mejor valor [153]. La bondad de una alternativa se mide considerando simultáneamente lo cerca que esté del óptimo ideal y lo alejada que esté del pésimo. [150]

Aplicando esta metodología a 10 líneas que prestan servicios de transporte público urbano en Taipei, consigue establecer un ranking entre ellas, e incluso una valoración cuantitativa de su calidad ofertada. [150]

5. Análisis de la fidelidad de los usuarios.

La fidelidad de los usuarios es a menudo definida como un lazo psicológico que une a los consumidores con el proveedor de un servicio en particular. Este "lazo" se refleja en la tendencia a emplear un determinado servicio frente al resto, resistiéndose al cambio, y a la identificación del usuario con el proveedor, demostrando una preferencia relativa frente a otros competidores. [26] 
La medida de la fiabilidad de los usuarios puede ser media a dos niveles: de comportamiento y de actitud. En la dimensión del comportamiento, se analiza la fidelidad mediante la cantidad o proporción de empleo de un determinado servicio frente al total. Sin embargo, cuando éste se combina con la actitud, una mejor definición de la fidelidad de los usuarios incluye la intención de utilizar el servicio de forma continuada. Ésta segunda es la metodología más habitual en los actuales estudios de fiabilidad de los usuarios del servicio de transporte. [26]

En cuanto a los estudios de fidelidad orientados al transporte público por carretera, como ya se ha indicado anteriormente, la CTA (Chicago Transit Authority), realiza de forma bianual encuestas de satisfacción a los usuarios del servicio de autobuses. La muestra de la encuesta fue determinada de forma aleatoria, según una cuota que representaba el número de encuestas a realizar en cada área geográfica (en función de diferentes características sociodemográficas de cada una). Además, así se permitió diferenciar los resultados entre zonas, consiguiendo una mayor información. [44]

Basándose en las metodologías de anteriores encuestas de satisfacción de los usuarios, se calculó un índice de lealtad (o fidelidad) de los usuarios del Corredor Norte. En general, este índice tiene tres componentes principales [44]:

- Nivel de satisfacción general.

- Predisposición a continuar empleando el servicio en el futuro.

- Predisposición a recomendar el servicio a familiares, amigos o compañeros de trabajo.

A partir de los datos anteriores (valorando cada uno de ellos de 1 a 5), se define a un usuario "leal" o "fiel" como aquél que asigna los mayores valores a cada uno de estos componentes (muy satisfecho, seguro que seguirá empleando el servicio y seguro que lo recomendará), es decir, es prácticamente "seguro" que este usuario continuará utilizando el servicio. Además, se determinan otras categorías de usuarios, en función de que se puntúe inferior al máximo alguno de los componentes, resultando así [44]:

- Usuarios "seguros". Son aquéllos que asignan la máxima puntuación a los tres componentes.

- Usuarios "potencialmente vulnerables". Son los que dan la máxima puntuación a dos de las componentes.

- Usuarios "vulnerables”. Asignan la máxima puntuación a un único componente.

- Usuarios "altamente vulnerables". No dan la máxima puntuación a ninguno de los componentes anteriores. 
Medido de esta manera, el índice de fidelidad de los usuarios se puede emplear como una medida más de calidad del servicio, ya que está íntimamente relacionado con la satisfacción de los usuarios, y de cómo éstos lo transmiten a sus conocidos.

Por último, en cuanto a los sistemas de transporte público interurbano en autobús, apenas existen estudios hasta la fecha, salvo quizás el del Ministerio de Transporte y Comunicaciones de Taiwan [147], ya citado anteriormente. En dicho estudio, se realiza un exhaustivo análisis sobre la fidelidad de los usuarios de un determinado corredor interurbano.

Como hipótesis de partida, se tomó la ya común medida de la fidelidad a través de las actitudes de los usuarios, y se identificó la satisfacción, valor del servicio, calidad del servicio, sacrificio por parte de los usuarios, costes del cambio, atracción de los competidores, e imagen como las variables más relevantes en la lealtad final de los consumidores, actuando cada uno con efecto positivo o negativo. [147]

Actualmente, existen escasos ejemplos de empleo de un índice estandarizado de calidad del servicio para los autobuses interurbanos. En el estudio de Taiwan [147], se empleó un índice empírico, que se basa en la escala SERVQUAL [112, 113], empleando 22 elementos de 7 variables, a los cuales se les asignó una escala de 5 puntos, variando de "muy insatisfecho" a "muy satisfecho".

La fidelidad de los usuarios se mide a través de una serie de variables, relacionadas con ésta y entre sí a través de una serie de modelos estructurales de ecuación, según el esquema de la Figura 3-1:

Figura 3-1. Esquema del modelo empleado en Taiwan Fuente: Wen et al [147]

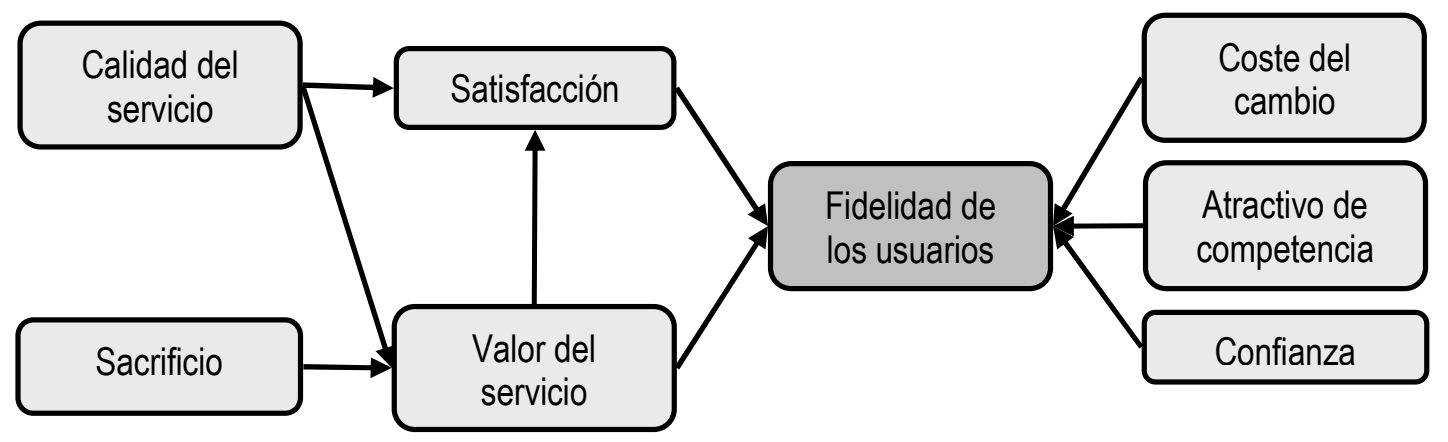

La metodología de obtención de las relaciones fue una técnica multivariable, combinando regresión múltiple y análisis factorial, para estimar una serie de relaciones 
de interdependencia simultánea entre las distintas variables. Tras el ajuste, cada relación queda finalmente representada por un valor numérico. Es especialmente relevante el hecho de que la máxima significancia directa se da entre satisfacción y fidelidad del usuario, siendo ésta la variable más fuertemente influyente. [147]

Además, tal y cabía suponer, el valor de servicio, coste del cambio y la confianza influyen de forma positiva, mientras que el atractivo de los competidores y el sacrificio son variables negativas. En cuanto a la calidad del servicio, también influye de forma indirecta sobre la fidelidad de los usuarios (a través de la satisfacción y del valor del servicio), siendo también una variable bastante significante. [147]

También se ha empleado metodologías similares a la SERVQUAL en otros estudios correspondientes al servicio de autobuses urbanos de Taipei, como en el trabajo de $\mathrm{Hu}$ y Jen [75]. Así mismo, estos autores [82] han empleado métodos de regresión múltiple, incluyendo los costes monetarios y no monetarios, así como la atractividad de otros modos en competencia.

6. Otras metodologías.

Dentro de esta última división incluiremos otros interesantes estudios, que no se asemejan a ninguna de las metodologías antes descritas.

Así, Garrido y Ortúzar [52], emplean una matriz de intensidad de ratio, donde confrontan las alternativas en filas y columnas. Cada elemento de la matriz es la relación entre las probabilidades de elegir la alternativa de la fila y la de la columna.

Por otra parte, Iakovou y Pachon [76] presentan un modelo de optimización de los servicios de lanzadera en la Universidad de Miami, combinando las herramientas estándar de mejora de calidad con estadísticas cuantitativas y herramientas de simulación. En concreto, destaca el empleo de una matriz de despliegue de actuaciones QFD (quality function deployment), que contiene en sus filas los parámetros a mejorar y, en columnas, las vías para mejorarlos. Los entrevistados debían marcar cada celda con una relación entre fila y columna nula, débil o fuerte.

Una última metodología diferente es la elaborada por Viton [140] para evaluar la mejora en la eficiencia del sistema global de transporte (todas las líneas y servicios) en Estados Unidos entre 1988 y 1992). Emplea la técnica del análisis de frontera (DEA, data envelopment analysis), identificando el conjunto de soluciones factibles existentes en la actualidad o no- de buen funcionamiento del sistema. La eficiencia del 
servicio es función en este caso de lo próximos que nos encontremos a las situaciones frontera, cuyo funcionamiento es el óptimo posible.

Además de estos estudios, diversas organizaciones han elaborado sus propias metodologías de evaluación de la calidad. Así, por ejemplo, el Transportation Research Board publicó en 1999 y 2003 sus dos ediciones del Transit Capacity and Quality of Service Manual [133, 134]. En ellas, se define la calidad del servicio fundamentalmente a través de la medida global del valor del servicio percibido por los usuarios, en contraposición con otros conceptos como eficiencia, impacto social, etc., que resultan de los puntos de vista de la sociedad, de la empresa y de los conductores. También se indica que los principales factores que afectan a la calidad percibida por los usuarios son dos: la disponibilidad del servicio, y el comfort y adecuación del servicio (ésta última incluye el equipamiento de los vehículos, la fiabilidad del servicio, coste y tiempo de viaje, seguridad y facilidad de transbordo).

Para culminar este apartado, también el Ministerio de Fomento [102] ha comenzado a elaborar encuestas bienales encaminadas a conocer las condiciones de calidad de las concesiones de competencia estatal. En este sentido, en su despliegue del año 2008, se realizaron más de 20.000 encuestas a usuarios, representantes municipales y estaciones de autobuses.

Tras elaborar un perfil general de los encuestados formado mayoritariamente por mujeres trabajadoras y que realizan viajes de tipo ocasional para realizar gestiones, se elaboró un índice global de calidad observada por los usuarios, considerando diferentes parámetros del servicio. El índice global de calidad resultó con un valor de 3,57 puntos (3 puntos implica valoración "normal”). [102]

Así mismo, se solicitó a los usuarios que indicaran las variables más importantes, destacando en este sentido la seguridad durante el viaje, la puntualidad de salida y llegada, el confort del autobús y, a continuación, la relación calidad/precio. [102]

Por otra parte, los entrevistados indicaron también la calidad esperada para cada variable y en términos globales. Es de destacar que este valor global sólo alcanza los 3,93 puntos, lo que hace suponer que en general los usuarios no exigen demasiado al servicio, lo que conlleva conclusiones positivas, ya que no quedarán en general insatisfechos, pero también negativas, ya que presuponen que la calidad será escasa. [102]

De hecho, la evolución de los índices de calidad esperada y observada en las encuestas posteriores refleja que la primera tiene una ligera tendencia descendente con los años, 
mientras que la segunda permanece relativamente estable, como se puede apreciar en la Figura 3-2:

Figura 3-2. Evolución de la calidad esperada y percibida por los usuarios Fuente: Ministerio de Fomento [102]

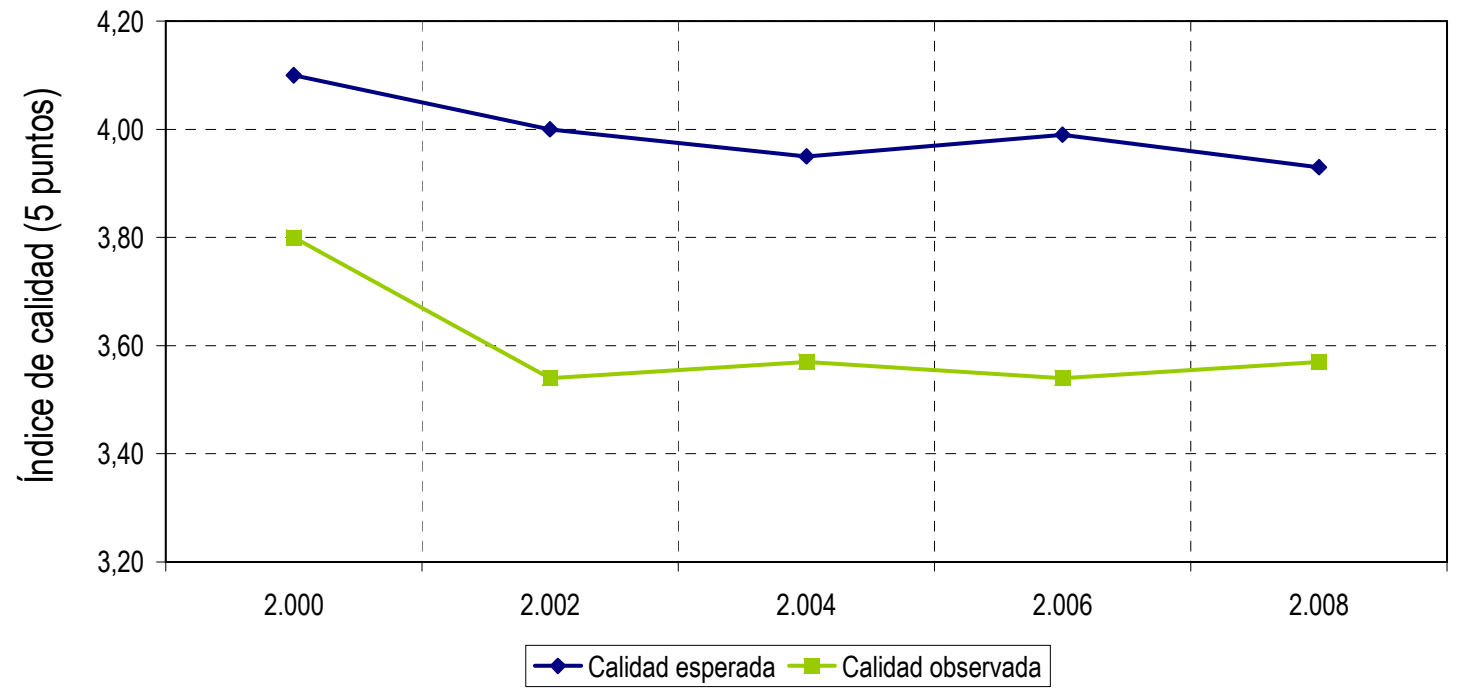

\subsubsection{Modelos de Demanda}

Dadas las ventajas que una adecuada modelización de la demanda de transporte, en cualquier ámbito del mismo, aporta a cualquier ente gestor y planificador al respecto, es evidente que la demanda de viajes de autobús de carácter interurbano no es una excepción, aunque, sin embargo, se dé el caso de que la modelización de dicho tipo de demanda no se encuentra desarrollada al mismo nivel que otros tipo de demanda de otras áreas del sector transporte.

Por tanto, bajo las ideas de conocer y resumir los actuales sistemas de modelización de demanda de viajes en autobuses de tipo interurbano, se ha iniciado una exhaustiva búsqueda de información, tanto nacional como internacional, sobre el tema.

Así, a continuación se presentan aquéllas colaboraciones que han resultado más interesantes, especialmente con la posterior orientación que se pretende encontrar hacia su posible aplicación de los contratos de transporte público interurbano en autobús. 


\section{Experiencias británicas.}

Hace ya más de dos décadas, el anteriormente denominado Transport and Road Research Laboratory (ahora TRL) editó uno de los documentos más interesantes sobre el tema de la demanda, dentro de su documento "The Demand for Public Transport" [145], denominado comúnmente como el "Libro Negro". Durante muchos años, este documento fue la herramienta base para los estudios de demanda del transporte público, pero, evidentemente, en la actualidad, muchos de los parámetros considerados entonces han cambiado, han aparecido nuevas metodologías y conceptos, y, sobre todo, las características socioeconómicas, institucionales, ambientales y legales son muy distintas.

Es por esto que, en el año 2004, las Universidades de Oxford, Leeds y Westminster, junto con el Colegio Universitario de Londres y el TRL editaron un nuevo documento actualizado, a modo de guía o manual para ser usados por las autoridades y técnicos encargados de la planificación del transporte público [16]. Esta "reedición" fue denominada "The Demand for Public Transport: A Practical Guide", en principio dedicada a los sistemas de transporte urbano de Gran Bretaña, aunque extensible a otros países y áreas geográficas. Paulley et al [114] realizan una interesante comparación entre los resultados de ambos estudios, especialmente destacando los efectos de la tarifa, calidad del servicio, nivel de ingresos y disponibilidad de coche de los usuarios.

El estudio se estructura en 13 capítulos. Tras una introducción al tema de estudio y a la descripción del escenario para el que inicialmente se ha diseñado, se presentan los principales resultados obtenidos en el estudio y se describe cómo se han obtenido los datos de partida y la calidad de los mismos. También se presenta la formulación matemática empleada, y se describen de forma exhaustiva los efectos aislados de los distintos factores considerados como influyentes en la demanda: tarifas, tiempos, calidad del servicio, cambios en otros modos, ingresos y disponibilidad de coche de los usuarios, ordenación del territorio, nuevos sistemas de transporte público y políticas de transporte. [16]

En primer lugar, tras definir los distintos sistemas de transporte público que se consideran en el documento, se identifican los principales parámetros de variación de la demanda de autobuses, a igualdad de condiciones del servicio. Dichas variaciones incluyen a menudo las siguientes causas [16]: 
- Tipo de usuario: edad y sexo.

- Situación temporal: hora, día de la semana y mes del año.

- Motivo del viaje: trabajo/estudio u otros motivos.

- Zona geográfica: centros urbanos o zonas rurales.

- Comportamientos individuales: status social, posición dentro de la familia, tamaño y estructura familiar, disponibilidad de coche...

La tarifa es el factor influyente en la demanda de transporte público que más intensamente se ha estudio, debido principalmente a dos razones: su valor numérico, así como sus cambios, son fácilmente identificables y cuantificables, y es el factor que más rápida y habitualmente se modifica para influir en la demanda. Aunque la elasticidad de la demanda con respecto a la tarifa siempre es negativa, su valor absoluto es un factor muy importante, ya que, cuando está entre 0 y -1, se da la circunstancia de que un incremento de tarifa supone una disminución de demanda, pero con aumento de beneficios para el operador. Por el contrario, cuando es inferior a -1, al aumentar la tarifa se produce un descenso tan fuerte en la demanda que hace que los ingresos sean menores. [16]

De hecho, dicha elasticidad es un factor variable con el tiempo, de tal modo que se distinguen elasticidades [16]:

- A corto plazo (1-2 años) $\rightarrow$ alrededor de $-0,4$.

- A medio plazo (5-7 años) $\rightarrow$ sobre -0,56.

- A largo plazo (12-15 años, o incluso hasta 20 años) $\rightarrow$ cercana a -1 .

Este incremento temporal de la elasticidad de la demanda con respecto a la tarifa se debe a que, cuando se incrementan las tarifas, cada vez hay menos usuarios, ya que éstos buscan otras soluciones. De hecho, el que la elasticidad a largo plazo sea cercana a -1, supone un grave problema para la industria del transporte público, ya que, al subir la tarifa, se provoca inmediatamente un aumento de los ingresos, por lo que las empresas suelen ser favorables a este tipo de medidas. Sin embargo, a largo plazo, la demanda cae en una proporción tan alta que los ingresos comienzan a ser inferiores a los que se obtenían con anterioridad a la subida. Además, revertir esta tendencia suele ser muy complicado, siendo habitualmente necesario volver a bajar las tarifas o mejorar el servicio, aunque, en ambos casos, la recuperación es muy lenta. [16]

Por otra parte, los valores numéricos medios de las elasticidades en cada viaje individual se ven afectados por una serie de influencias internas o externas al servicio, 
como son, además de las indicadas anteriormente: magnitud y signo del cambio de tarifa, nivel tarifario inicial, distancia de viaje, tipologías de billete y sistemas de tarificación, ausencia de tarifas o tarifas reducidas... [16]

Por otra parte, la calidad del servicio queda definida por una gran cantidad de atributos, sobre los que pueden actuar las autoridades del transporte. Algunos de estos atributos son cuantificables con relativa facilidad y por ello susceptibles de ser introducidos en los modelos, como: los tiempos de acceso, espera, y de viaje, el nivel de servicio... Sin embargo, hay otros atributos más "problemáticos", que, dada su difícil cuantificación, a menudo se sustituyen por "tiempo de viaje equivalente" o "coste equivalente", como pueden ser: características del vehículo, facilidad de intercambio modal, imagen percibida por los usuarios, información de horarios, promoción y marketing... [16]

A continuación, vemos brevemente las principales conclusiones que extrae el documento respecto a cada uno de estos factores [16]:

- Tiempo de acceso a la parada y desde la parada al lugar de destino. Se suele multiplicar entre 1,4 y 2,0 veces para igualarlo al tiempo de viaje.

Nivel de servicio.

- Con respecto a los veh-km en servicio, la elasticidad ronda entre -0,4 y -0,7 a corto y largo plazo, respectivamente.

- Con respecto al tiempo de espera, el valor medio de la elasticidad es cercano a $-0,64$, aunque es mayor cuando los viajes se realizan fuera de las horas punta y con destino distinto al centro urbano. En cuanto a la valoración del tiempo de espera, se suele multiplicar éste alrededor de 1,6 veces para hacerlo equivalente al tiempo de viaje en el vehículo.

- Por último, con respecto al total de vehículos-hora en servicio, el valor medio de la elasticidad es cercano a la unidad.

* Tiempo de viaje (en el vehículo). Los valores comúnmente aceptados de la elasticidad son, para viajes urbanos, entre $-0,4$ y $-0,9$, mientras que, para viajes largos interurbanos, sobre -2,1. Esto se debe a que, cuanto más cortos son los viajes, menor importancia tiene el tiempo dentro del vehículo respecto al total (más proporción de tiempos de llegada, acceso y espera), por lo que cobra menos valor.

- Coste generalizado del viaje. Al ser un concepto global, que incluye variables cuantitativas y cualitativas, existen multitud de estudios de elasticidades, dando valores medios entre $-0,4$ y $-0,7$. En cuanto a las técnicas habitualmente empleadas para su estimación, algunas de ellas son: 
- Cuando aumenta la distancia de viaje, el valor del tiempo en el vehículo aumenta, especialmente para el coche, mientras que los tiempos de espera y caminata se mantienen aproximadamente constantes. Además, la frecuencia suele perder importancia.

- Los usuarios del transporte público valoran menos su tiempo que los del vehículo privado.

- Los usuarios del vehículo privado tienen una particular aversión a caminar y a esperar al autobús, mientras que los de transporte público no valoran tanto estos atributos.

- En los viajes de tipo interurbano, el valor del tiempo suele ser mayor.

- En los viajes de negocios se suele valorar más el tiempo que en otro tipo de viajes. En cuanto al resto de viajes, en las zonas urbanas se valora más el tiempo cuando se trata de viajes de trabajo, mientras que en áreas interurbanas las diferencias son menores.

Zonas de espera. Los usuarios prefieren paradas que ofrezcan: comodidad (parada con marquesina, refugio y asientos), limpieza, seguridad (iluminación y presencia de personal), protección contra las inclemencias meteorológicas, información de horarios...

* Características de los vehículos. Es un factor difícilmente cuantificable, ya que son demasiadas las variables a considerar para poder realizar un análisis directo de sus efectos en la demanda. En cualquier caso, es evidente que los usuarios prefieren autobuses limpios, confortables y de fácil acceso, aunque ya no es tan fácil determinar cuánto influye cada característica. Por tanto, la metodología habitualmente empleada es la realización de encuestas a los usuarios, para, posteriormente, tratar de valorar monetariamente cada atributo. Un resultado habitual es que la valoración de un conjunto de actuaciones es inferior a la suma de las valoraciones individuales de cada actuación, por lo que resulta finalmente que las actuaciones de menor envergadura son, relativamente, las más beneficiosas, y que las mejoras sobre una situación inicialmente mala se valoran más que si las condiciones iniciales eran aceptables.

* Posibilidad de intercambio modal. Para introducir los transbordos en la modelización, se suelen valorar en términos de tiempo, los cuales tienen considerables variaciones, en función del motivo de viaje, área geográfica, frecuencia...

* Imagen del servicio. En general, la imagen que se suele tener del servicio de transporte público en autobús incorpora una percepción con grandes demoras, 
lentitud del viaje, incomodidad... En la modelización, estas variables se suelen asimilar a un tiempo equivalente.

* Información del servicio. Es evidente que un nivel básico de información es necesario para todos los usuarios actuales o potenciales del servicio de transporte público. Sin embargo, los usuarios ocasionales apenas utilizan los sistemas de información, ni tampoco los habituales, salvo para aconsejar a familiares y amigos. En general, este parámetro se suele incluir a través de su valoración monetaria por parte de los usuarios.

* Promoción y marketing.

$>$ Las campañas de marketing raramente se realizan de forma aislada, ya que, a menudo, van acompañadas con diversas medidas de mejora de calidad o de tarifa. Es por esto que el efecto aislado de las mismas apenas se conoce.

$>$ Además, en general, en el transporte público se pone poco énfasis en la promoción, salvo colocando esporádicamente carteles en las paradas, o anuncios en los propios vehículos, de modo que resultan ser campañas poco captadas por los no-usuarios.

Accesibilidad del servicio.

> Es un parámetro que resulta ser más problemático en las áreas rurales, con menor densidad de población. A causa de esta situación, disminuye la frecuencia, debido a la menor utilización del servicio, lo que limita su utilidad, fomentando el vehículo privado, a modo de "círculo vicioso".

Se puede resolver parcialmente disponiendo dos sistemas diferentes de autobús: mediante rutas fijas en las áreas más densas, y con transporte a la demanda en las más dispersas. Otras alternativas pueden ser la disposición de taxis o microbuses, cuya rentabilidad económica debe ser analizada en cada caso, pues es función del área de estudio.

Además de éstos parámetros propios del servicio, existen otros factores ajenos. Uno de ellos serían las interacciones con el resto de modos, en las que intervienen dos conceptos diferenciados: las elasticidades cruzadas, y la natural competencia entre modos. [16]

* En cuanto a la competencia entre transporte público y privado, el uso del transporte público es muy sensible a los costes del vehículo privado, mientras que el uso del vehículo privado es más independiente de los costes del autobús. Así, un pequeño cambio en los costes del transporte en coche particular puede suponer un gran incremento en la demanda de transporte público, no siendo igual al revés. 
Por último, también es importante la competencia entre los distintos modos de transporte público, e incluso existen diversos modelos que tratan de simularla. En éstos, los factores que se suelen incluir son el nivel de servicio, calidad del servicio y rangos de tarifa.

Otro aspecto relevante son los efectos de las distintas políticas de transporte, cuyos objetivos deben ser siempre más amplios que, simplemente, aumentar la demanda de transporte público, orientándose más hacia la mejora de la calidad de vida de los ciudadanos, en todos sus aspectos (que se puede conseguir fomentando el transporte público frente al privado). En general, las distintas acciones que pueden efectuar las autoridades del transporte se pueden agrupar como sigue [16]:

Sistemas de gestión de las infraestructuras.

> Gestión conjunta entre operadores del transporte y autoridades públicas: Convenios de transporte. Los primeros resultados obtenidos suponen una mejora de demanda del transporte público del 20 al 30\%, aunque no queda claro cuáles son las razones exactas, y aparecen grandes variaciones entre zonas.

$>$ Separación de tráficos. Es un concepto más orientado al tráfico urbano que al interurbano.

Políticas tarifarias.

$>$ Condicionar las subvenciones a los empresarios del transporte público. Se podría limitar las subvenciones a los empresarios si no adquieren tarjetas de transporte público para sus empleados.

> Impuesto a los vehículos que causan la congestión. Es una medida cada vez más "de moda", ya que las nuevas tecnologías emergentes lo hacen más fácil y eficiente. Se pueden establecer dos variantes: por rutas, aplicando un cargo al uso individual de la carretera, o por zonas, cobrando a los usuarios que entran en una zona.

$>$ Política de aparcamientos. Hay varias opciones posibles: limitar el espacio de aparcamiento disponible, aumentar el precio del aparcamiento, o sustituir las zonas de aparcamiento libre por otras de tiempo limitado.

Integración de las distintas políticas de transportes. Aplicando correctamente medidas procedentes de distintos grupos, se puede conseguir efectos conjuntos muy positivos. Por ejemplo, la disposición de un control de parking y de cargos por congestión suele aumentar la demanda de transporte público. 
Finalmente, en el citado documento [16], se presenta una metodología de aplicación de las elasticidades, de forma casi directa, a la estimación de las modificaciones previstas en la demanda a partir de una serie de medidas aplicadas al sistema de transporte público.

En primer lugar, es esencial definir las elasticidades correspondientes a cada variable considerada. Desde este punto de vista, se puede establecer una primera clasificación de las variables exógenas en: continuas, categóricas o discretas, y controladas por efectos dinámicos (se pueden introducir en el modelo mediante un parámetro que represente las modificaciones de la demanda a largo plazo). [16]

Así, cuando se aplican unas ciertas modificaciones en el sistema de transporte público, y siendo conocida la demanda en la situación inicial, se puede modelizar la demanda futura como sigue [16]:

$$
\frac{V_{t+1}}{V_{t}}=\left(\frac{X_{1, t+1}}{X_{1, t}}\right)^{\beta_{1}} \cdot\left(\frac{X_{2, t+1}}{X_{2, t}}\right)^{\beta_{2}} \cdot \ldots \cdot\left(\frac{X_{n, t+1}}{X_{n, t}}\right)^{\beta_{n}} \cdot\left(\frac{V_{t}}{V_{t-1}}\right)^{\theta} \cdot e^{\lambda_{1} \cdot\left(Z_{1, t+1}-Z_{1, t}\right)+\ldots+\lambda_{k} \cdot\left(z_{k, t+1}-Z_{k, t}\right)}
$$

Donde, V: demanda anual de transporte público

Situación t: año actual

Situación t-1: año anterior

Situación $\mathrm{t}+1$ : año próximo

$\mathrm{X}_{\mathrm{n}}$ : variables continuas

$\beta_{\mathrm{n}}$ : elasticidades de las variables continuas

$\mathrm{Z}_{\mathrm{k}}$ : variables categóricas o discretas

$\lambda_{\mathrm{k}}$ : efecto de la variación de las variables categóricas sobre la demanda

$\theta$ : efecto del largo plazo, con una valor alrededor de $-0,49$ (se debe aplicar a cada año, por lo que son necesarias varias iteraciones para años sucesivos)

De esta forma, conocida la demanda en el año base, los cambios relativos y las elasticidades de las variables exógenas, se puede obtener la relación entre la demanda de un año y del siguiente, considerando además el efecto del largo plazo. [16]

Para determinar el efecto de una medida concreta a partir del $2^{\circ}$ año desde su aplicación, basta con aplicar el factor descriptivo de las variaciones a largo plazo sobre la demanda del año después de la aplicación, y así sucesivamente para los años siguientes. Mediante esta metodología, las actuaciones sobre el servicio provocan modificaciones de la demanda cada vez menores (respecto del año inmediatamente 
anterior), hasta llegar a un período de "estabilidad", a partir del cual apenas son apreciables, a no ser que se incluyan nuevas actuaciones. [16]

Sin embargo, esta aplicación, casi directa, de las elasticidades se puede complicar cuando no se conocen todos los datos de las mismas, debiendo obtenerse los parámetros de unas en función de los de las otras y de relaciones entre las variables. En la propia guía se presentan las metodologías de obtención de unas elasticidades a partir de otras. [16]

2. Estudios que analizan el cambio de actitud de los usuarios.

Entre los estudios que analizan los factores que conducen a un determinado usuario a elegir uno u otro modo de transporte, podemos incluir en un grupo especial a aquéllos que contemplan lo que comúnmente se conoce como "Teoría del Cambio" o "Teoría del Comportamiento Planificado". [11, 120]

Dicha teoría divide el proceso de cambio de modo de transporte habitual mediante una serie de etapas (precontemplación, contemplación, preparación, acción y mantenimiento), en las que el usuario comienza por plantearse su actual problema de transporte. Tras analizar las posibles soluciones, proceso en que entran tanto la objetividad como los patrones de comportamiento habitual, si el usuario decide que otro modo es más conveniente, cambiará, primero de forma temporal, y finalmente de forma permanente. [120]

Además, según esta teoría, principalmente desarrollada por Ajzen [11] el comportamiento humano combina tres tipos de nociones subjetivas: de comportamiento (relativas a las consecuencias posibles de nuestros actos), normativas (función de la legislación existente) y de control (correspondientes a las diferentes restricciones que debamos soportar).

A partir de esta teoría, han surgido estudios aplicados, algunos de ellos orientados directamente al análisis del cambio desde el modo automóvil hacia el transporte público.

Así, por ejemplo, Bamberg et al [17] realizaron un experimento sobre 169 actuales usuarios del automóvil que planeaban cambiar de domicilio en un plazo de unos 6 meses hacia Stuttgart (Alemania) para determinar los efectos de una serie de actuaciones (entre las que destacó la combinación de una mayor información al usuario con la supresión de tarifas en el transporte público) sobre su posible cambio modal. La 
principal conclusión de dicho estudio fue que las conductas previas apenas influían sobre la posibilidad de cambio, siendo más bien los factores apuntados por Ajzen [11] los que condicionaban el transvase modal.

Experimentos similares fueron llevados a cabo con los estudiantes de la Universidad de Kyoto (Japón), eliminando igualmente la tarifa del transporte público durante un mes. Se observó entonces que numerosos conductores de coche comenzaron a emplear el autobús, y no sólo durante la etapa de gratuidad, sino también más tarde [45]. Se deduce, por tanto, que lo realmente importante (y no poco complicado) es iniciar el cambio modal de los usuarios, ya que, una vez han conocido y se han adaptado al transporte público, es menos probable que vuelvan a emplear su vehículo privado.

3. Estudios aplicados.

Frente a esta tipología de estudios que, aunque de tipo empírico, tratan de emular el proceso de cambio de actitudes y comportamientos humanos cuando se plantea un posible transvase modal, existen además numerosos estudios de modelización de la demanda de transporte.

Así, entre los ejemplos españoles más destacables, están los diferentes estudios de Espino et al [38-40]. Los autores han dedicado un importante esfuerzo a la modelización de la elección modal relativa al transporte interurbano, en el ámbito geográfico de la Isla de Gran Canaria. Para ello, se realizó una gran encuesta con preferencias reveladas y declaradas. Además, se trabajó en la determinación de la disponibilidad a pagar (WTP), entrando en el ámbito del valor subjetivo del tiempo. La especificación de los modelos incluyó variaciones sistemáticas en los gustos, siendo éstos de elección discreta. Finalmente, analizaron diferentes variaciones sobre la situación actual, tratado de determinar el efecto positivo de las mismas sobre la demanda del transporte público, determinando, en general, que las acciones de penalización al vehículo privado tenían un mayor efecto que las relativas a la mejora de calidad del autobús.

Otro ejemplo, pero orientado a un ámbito más urbano, podría ser el realizado a los estudiantes del área universitaria de Bilbao. Mediante el empleo de un modelo tipo logit jerárquico, se obtuvieron elasticidades tanto del tiempo como del coste del viaje, así como los efectos potenciales de determinadas acciones de promoción del transporte público frente al vehículo privado. [23] 
Entrando ya en estudios realizados en ámbito internacional, se puede destacar, por su relación indirecta, el estudio realizado por Cherchi y Ortúzar [29] sobre un nuevo servicio de tren en Cagliari (Italia), usando datos mixtos de preferencias reveladas y declaradas. El objetivo final fue la determinación del modelo de elección modal más adecuado, así como la obtención de las variables más relevantes a la hora de determinar el nivel de servicio.

Los estudios realizados desde Chile suponen un importante punto de partida para la modelización de demanda empleando técnicas de elección discreta. Así, Ortúzar [107] analiza la conveniencia del empleo del modelo logit jerárquico frente al multinomial cuando se trata de analizar la elección modal en ámbitos urbanos. Especialmente, cuando se dan determinadas características de intermodalidad en los viajes, las alternativas quedan íntimamente relacionadas entre sí, no siendo válida la suposición de su independencia. Discute diferentes tipologías de árbol, y lo aplica al estudio del corredor de West Yorkshire (Reino Unido), dando mejores resultados los modelos jerarquizados.

Por otra parte, los modelos probit también han sido empleados para la modelización de demanda, pudiendo destacar como ejemplo el estudio de los viajes con motivo trabajo en Seúl (Corea del Sur), a partir del cual se obtuvieron además elasticidades directas y cruzadas entre modos. [88]

Para finalizar, destacaremos a continuación dos estudios aplicados de demanda, elaborados para grandes áreas. Así, cabe destacar el análisis que, en 1995, realizó el WisDOT (Wisconsin Department of Transportation), mediante el proceso denominado Translinks 21, realizando encuestas a los usuarios para modelizar la demanda actual y predecir el futuro empleo de cada modo de transporte [148]. Otro ejemplo puede ser el elaborado por las Universidades de Calgary (Canadá) y Moratuwa (Sri Lanka) [149], que trató de encontrar un modelo de demanda válido para Sri Lanka (y, tras su generalización, para otros países del entorno) basado en datos agregados, y no individuales. La razón de dicha elección fue el menor coste necesario para la obtención de datos, y la confrontación de los resultados predichos y observados arrojo resultados con una desviación no muy elevada. 


\section{Otras metodologías.}

Ya en los años 70, Spear [126] trató de compatibilizar la modelización teórica de la demanda con la planificación real de nuevas vías, empleando modelos desagregados de elección modal individual, y preconizando su empleo a la hora de plantear las actuaciones de transporte.

Otros tipos de modelos de demanda no basados en encuestas a usuarios actuales o potenciales se han basado en conteos de tráfico. Así, Cascetta y Russo [28], emplean ténicas de máxima verosimilitud y regresión no lineal generalizada, contrastadas mediante estimación Bayesiana, para tratar de obtener un modelo de demanda aplicable a ciudades de tamaño medio, cuyos datos estiman de forma hipotética.

Volviendo con las técnicas de elección discreta Hensher y Reyes [66] idearon un método para emplear modelos de tipo logit multinomial, jerárquico y mixto con parámetros aleatorios para modelizar la impedancia que supone un intercambio modal. Así, sobre la secuencia total del viaje intermodal, y empleando datos obtenidos para el área de Sidney (Australia), determinaron que dicha impedancia es función de las características personales del usuario, destacando su edad, estructura familiar y nivel de ingresos, así como el motivo del viaje.

Otros estudios han analizado el patrón de viajes diarios, obteniendo un modelo para simularlo [89] o comprueban la eficiencia económica de diferentes compañías de transporte público urbano, elaborando un modelo de costes (con una formulación similar al de Cobb-Douglas), en función de la tarifa, longitud de la red y kilómetros recorridos [98].

Así pues, para finalizar este apartado, vemos que la existencia de aplicaciones para el estudio de la demanda es numerosa, si bien no tan amplia cuando nos adentramos en ámbito interurbano. De ahí la necesidad de potenciar el tema, ya que su influencia es también elevada en términos de contaminación ambiental y accidentalidad vial. 


\subsubsection{Disposición al Pago}

La disparidad de valores observados en diferentes estudios que calculan el Valor Subjetivo del Tiempo hace que sea muy difícil encontrar un valor promedio válido para cualquier situación. Sin embargo, tampoco parece razonable obtener valores específicos para cada situación y época de estudio. Por ello, y a pesar de la ya citada falta de regularidad, a continuación se presentan los resultados de diversos estudios encontrados tanto en ámbito nacional como internacional.

\section{1) Estudios del valor subjetivo del tiempo en España}

González Marrero [57] analizó la demanda de pasajeros entre las islas de Gran Canaria y Tenerife. Para ello, empleó técnicas de elección discreta, y, además del valor subjetivo del tiempo, determinó las elasticidades de las principales variables y la predicción de la demanda. Dentro de los resultados del estudio, se obtuvieron valores subjetivos del tiempo de unas 1834 pts/h, en cifras del año 1992, cuando se trataba de viajes por motivo trabajo, $1280 \mathrm{pts} / \mathrm{h}$ por motivo estudio u ocio y $1400 \mathrm{pts} / \mathrm{h}$ por otros motivos. Así mismo, determinó que dicha valoración crecía con el nivel de ingresos de los individuos, y que varía en función del modo de transporte empleado. En estudios posteriores [56], analiza también cómo influye la especificación del modelo sobre los valores obtenidos, arrojando interesantes resultados, al comparar los datos obtenidos con modelos de tipo logit multinomial, jerárquico o mixto, siendo en general éstos últimos los más concordantes con las observaciones.

En 1999, Barrios y Martínez [18] estimaron el valor del tiempo en los viajes al trabajo en Cádiz, a partir de modelos de elección discreta previamente calibrados, a partir de encuestas domiciliarias. Los resultados indicaban una valoración de unas 189 pts/hora, dando valores muy similares para modelos logit y probit. A pesar de que se trata de un valor bajo, los autores afirman que es consistente con el nivel de renta de la ciudad.

Por último, Amador et al realizaron un interesante estudio sobre la disponibilidad al pago de los estudiantes de la Facultad de Ciencias Económicas y Empresariales de la Universidad de La Laguna. Se emplearon modelos de reparto modal calibrados con técnicas de elección discreta, con variaciones sistemáticas y aleatorias en los gustos, basados en datos de preferencias reveladas. El resultado del mismo arroja unos valores de unas $21,4 \mathrm{pts} / \mathrm{min}$ (equivalentes a 7,7 €/h), en valores del año 2000. [12] 


\section{2) Práctica internacional}

Armstrong et al [14] analizan la necesidad de determinar los intervalos de confianza para el estimador del valor subjetivo del tiempo, ya que éste se obtiene a partir de parámetros también estimados. Así, establecen diversas metodologías para la determinación de dicho intervalo, para un determinado nivel de probabilidad. Además, analizan el efecto de determinados elementos del modelo sobre los límites de dicho intervalo, como puede ser la especificación del modelo, la distribución de ingresos en la muestra, y su tamaño.

En este mismo sentido, Hensher et al [71] estudian la variación de los resultados cuando se compara un modelo con otro en el que se han suprimido determinados atributos, empleando modelos de tipo logit mixto. Se empleó una muestra de 514 encuestas realizada en el área metropolitana de Sidney a usuarios de coche. La comparación entre el modelo completo y el restringido arrojaron resultados inferiores del valor del tiempo para éste último.

Sillano y Ortúzar [125], por su parte, analizan la dificultad de estimar correctamente el valor del tiempo cuando se emplean modelos de tipo logit mixto, en función del tipo de especificación de éstos. En concreto, comparan los resultados de aplicar a una misma muestra obtenida mediante encuestas de preferencias declaradas modelos logit mixtos con parámetros aleatorios, empleando los valores medios poblacionales de los parámetros o los individuales de cada observación. Concluyen en que, con determinadas condiciones, es mejor metodología el empleo de parámetros individuales, frente a las medias poblaciones, a pesar de la dificultad que ello conlleva. Sin embargo, los valores numéricos del tiempo de viaje son relativamente similares.

Ya centrándonos más en la recopilación de estudios cuantitativos de valores del tiempo de viaje, se pueden destacar algunos de ellos por sus interesantes y exhaustivos resultados:

- Quizás algunos de los resultados más interesantes en ámbito europeo se correspondan a los de sendos estudios realizados en Reino Unido y en los Países Bajos [62, 63]. Ambos comparten la principal metodología, así como las conclusiones más relevantes:

- Mayor importancia a las variaciones del tiempo de viaje cuando aumentan el valor habitual que cuando lo disminuyen, y mayor impacto cuando se trata de viajes por motivo trabajo. Este hecho sucede a menudo: el mayor impacto sobre la percepción del usuario de los cambios negativos que de los positivos. 
○ Relación monótonamente creciente (pero no proporcional) entre nivel de ingresos y valor subjetivo del tiempo.

- Mayor valor subjetivo del tiempo bajo condiciones de congestión, debido principalmente a la mayor incomodidad del viaje.

Wardman [143] comparó los valores del tiempo de viaje para los distintos modos de transporte, y en función del motivo del mismo. Así, definió un valor medio del tiempo de los viajes con motivo trabajo o estudio de unas $21 \mathrm{f} / \mathrm{h}$, siendo este valor, para el resto de viajes, de unas 6 £/h. Además, resaltó un patrón de comportamiento habitual: los valores del tiempo del coche y del tren son similares y menores que los valores del tiempo de autobús.

* Pero es obvio que no todos los intervalos de tiempo que intervienen en un viaje tienen igual valoración. De hecho, la experiencia refleja que los tiempos de acceso y espera suelen tener un mayor impacto que el tiempo de viaje en el vehículo. Así, en un análisis posterior realizado por Wardman [144], se encontró que los tiempos de acceso y espera equivalentes, en promedio y relativamente, a 1,66 y 1,47 veces el tiempo de viaje en el vehículo.

- Otros valores del tiempo internacionales los encontramos en un estudio elaborado con datos de Chicago y Philadelphia [146], en el que se aportan los siguientes valores promedio del tiempo de viaje en función del tipo de vehículo:

○ Turismos: sobre $14,3 \$ / \mathrm{h}$

- Furgonetas: $15,1 \$ / \mathrm{h}$

- Camionetas: $25,3 \$ / \mathrm{h}$

○ Vehículos pesados: entre 28 y $32 \$ / h$ 


\subsection{Incorporaciones de Parámetros de Calidad a los Contratos de Transporte}

Una vez analizados los estudios existentes hasta la fecha sobre la calidad y demanda de viajes de tipo interurbano por autobús, a continuación se resumirá los primeros intentos de integración de estas metodologías para poder aplicarlas de forma práctica a los contratos de servicio de transporte público.

El objetivo último es encontrar una metodología de aplicación práctica y eficiente a los pliegos de condiciones de las concesiones de transporte público, de modo que se puedan exigir al concesionario unos requisitos mínimos que aseguren una demanda de la línea, para así reducir las subvenciones posteriores.

\subsubsection{Revisión Bibliográfica Introductoria}

Además de las interesantes experiencias del Instituto de Estudios de Transporte y Logística de la Universidad de Sidney (antes llamado Instituto de Estudios del Transporte), al que, dada su ingente productividad en este campo se dedicará un apartado posterior, se han observado importantes aportaciones de diversos organismos, tanto europeos como del resto de continentes.

Así, se pueden destacar brevemente las que siguen:

\section{Reino Unido}

Ya en los años 80, aparecieron autores que propusieron la realización de un análisis coste-beneficio para la determinación de la subvención óptima para el transporte público en áreas urbanas $[35,54]$, aún sin incluir efectos de tipo medioambiental.

Desde la Universidad de Leeds, se han analizado de forma exhaustiva diferentes regulaciones de los sistemas de transporte en autobús. Así, citan como ejemplos destacados en la búsqueda de la optimización social de las subvenciones al transporte público los sistemas puestos en práctica en Noruega y el continente Australiano, los cuales se describirán en apartados posteriores. Además, hace una interesante recopilación bibliográfica en cuando a la eficiencia de las subvenciones al transporte público. [60]

Por otra parte, también se ha analizado la existencia de un posible círculo regulador de la gestión de los sistemas de transporte público. Así, desde un sistema inicial de 
monopolio público, se pasaría a una situación de competición controlada, después a una situación totalmente privatizada $\mathrm{y}$, por último, a una situación liberal pero regulada, para volver finalmente a la regulación pública. Las principales vías para buscar la solución óptima al problema (y no ir rotando de una a otra situación), serían básicamente: buscar unas expectativas realistas, implicar al sector privado, fomentar la mejora mediante incentivos y la implicación de las Administraciones en la búsqueda de la calidad. [61]

\section{Estudios realizados en los Países Bajos}

La Universidad de Delft es, sin duda, uno de los referentes internacionales en el tema objeto de estudio. Son numerosas las publicaciones de van de Velde en este sentido.

Por citar algunos ejemplos recientes, es interesante el análisis efectuado sobre la nueva Regulación Europea EC 1370/2007, la cual redefine, en su artículo 2, el nuevo concepto de "obligaciones de transporte público". En dicho estudio, se analiza también la evolución de la perspectiva europea en materia de contratación en los últimos años. [136]

Otros análisis interesantes se centran en el estudio de sistemas de contratación puestos en práctica donde se prima la calidad del transporte público, y también la demanda captada al vehículo privado. [137, 138]

También la Universidad de Amsterdam ha trabajado sobre el tema. Así, podemos destacar el estudio de Rietveld y Roson, en el que plantean la conveniencia de establecer dos tarifas diferentes para los servicios de transporte público: una para el sentido punta del movimiento de los viajeros y otra para el opuesto. Tras modelizar el efecto económico de la situación habitual (iguales tarifas) u otra donde se disminuye la tarifa en sentido punta, linealizando la demanda en función del precio, los resultados arrojan beneficios tanto para el operador como para los usuarios. [122]

\section{3. $\underline{\text { Otros estudios }}$}

Desde la Universidad de Pamukkale (Turquía), Haldenbilen y Ceylan realizaron un estudio sobre cómo fomentar el empleo del ferrocarril. Para ello, emplearon un algoritmo de tipo genético basado en otro de regresión lineal para modelizar la demanda del coche y el ferrocarril, cuando se imponían determinadas tasas al vehículo privado: peajes, impuestos... Según los autores, modificando el sistema de impuestos actual, los ingresos extra podrían ir dirigidos a mejorar el transporte público en 
ferrocarril, y además disminuirían los costes externos asociados al vehículo privado. [64]

Ya en los años 80, apareció en Japón una creciente preocupación por el descenso en el empleo del transporte público en autobús. Así, el Centro Nittsu de Investigación (Japón) analizó la tendencia del empleo del autobús en ciudades de tamaño medio, y estimó el efecto de determinados factores sobre su demanda. Uno de los principales resultados fue que la creciente tasa de motorización es el factor que más negativamente afecta al transporte público. [106]

Otros estudios interesantes sobre la relación entre el riesgo asumido y los beneficios obtenidos del transporte público son los de Stanley y Van de Velde [127] y Walters y Jansson [142]. Los primeros [127] indican la necesidad del control desde la Administración, la cual debe invertir en el sistema y en la formación de quienes van a lidiar con los operadores, así como la conveniencia de establecer agrupaciones o consorcios donde no sólo aparezca el sector privado. Los segundos [142] destacan el interés de los contratos negociados como vía intermedia entre el estricto cumplimiento de las obligaciones de servicio público y la libre competencia, en la que además priman los criterios de calidad y fiabilidad del servicio.

4. Propuestas del Instituto de Estudios de Transporte y Logística en Sidney

Una vez vista esta visión global introductoria, a continuación se reflejarán los principales estudios realizados por el Instituto de Estudios de Transporte y Logística de Sidney (Australia), dada su ingente producción en este tema. La citada institución es, quizás, uno de los organismos más especializados en técnicas de estudio de calidad del transporte público y de su relación con los contratos de concesión.

En concreto, han elaborado metodologías muy específicas, tanto para incluir un índice de calidad en los contratos [69], como fomentando de gran manera, e incluso proponiendo un sistema aplicable al país australiano de los contratos basados en la calidad -performance based contracts, PBC- $[68,70]$. Dado su especial interés, y gran relación con la metodología planteada en la presente investigación, se presentará en capítulos posteriores con mayor detalle las principales hipótesis del sistema propuesto.

A partir de estos pioneros estudios, han aparecido otros documentos más actuales, que desarrollan los conceptos introducidos con mayor detalle. Así, una serie de afianzados conocedores de la materia elaboraron un documento conjunto en el que expresaban su preocupación por la mejora de la calidad de los contratos, analizando a su vez su 
óptima formalización. La búsqueda de la eficiencia y la eficacia es un factor importante, según los autores, para conseguir dicho fin, y los roles de la Administración y del operador deben ser diferenciados, pero trabajar conjuntamente, ya que la calidad de un servicio público está en juego. [72]

En el año 2008, Hensher y Stanley [73] analizaron de nuevo las distintas modalidades de contratación de forma teórica y empírica, preconizando los contratos sobre un área de transporte, y no para una ruta determinada, e introduciendo de nuevo el concepto de la calidad. Ese mismo año, Hooper [74] elaboró un documento en el que resumía brevemente las principales tipologías de contrato existentes, diferenciando entre: coste extra (el operador recibe una cantidad fija adicional a los costes que sufre), coste bruto (el operador recibe íntegros los costes que sufre, quedando el beneficio o pérdidas restantes para la Administración), coste neto (se abona al operador el coste neto del servicio, y si hay beneficios, también revierten al operador), PBC (el operador recibe un incentivo en función de la calidad del servicio) y comercial (de libre mercado, el operador asume los costes y recibe todos los beneficios.). Incluso establece unas funciones de utilidad para la Administración y el operador, en función del riesgo que están dispuestas a asumir en la explotación del servicio, de modo que resulte el modo óptimo de contratación en cada caso.

Por último, tuvo lugar una mesa redonda sobre el contrato ideal [65], la cual extrajo una serie de conclusiones y recomendaciones, que se pueden resumir como sigue: 1 - La duración óptima de los contratos sería de unos 5-7 años, con posibilidad de renovación si se consiguen unos niveles mínimos da calidad, poniendo a cero en dicha renovación los cálculos de riesgo; 2 - Se proponen unos incentivos de calidad, bien con un sistema similar al peaje de sombra o bien compartiendo Administración y operador beneficios y costes; 3 - Para la obtención de los incentivos es crucial que el operador aporte datos e informes que validen su servicio; 4 - En cuanto a la contratación, sería conveniente un concurso competitivo en la primera concesión, con opción de renegociación en las sucesivas renovaciones; 5 - El rol de la Administración consiste en la planificación estratégica y social, el del operador, en el funcionamiento del servicio, quedando las variables del sistema para la colaboración entre ambos; 6 - Es necesario un acuerdo entre las partes para definir la calidad mínima y deseable.

Para finalizar este punto, simplemente destacar los grandes avances que este Instituto está llevando a cabo en el tema objeto del estudio, fomentando la competencia entre modos no desde un punto de vista comercial, sino desde la perspectiva de la mejora de 
la calidad del servicio, lo cual puede repercutir positivamente en toda la sociedad. De hecho, ya existen algunas experiencias pioneras, y tanto en España como en el resto de Europa está apareciendo intentos de incorporar la calidad en las concesiones de transporte público. Así, los apartados siguientes tratarán estas actuaciones.

\subsubsection{Algunas Experiencias Pioneras}

Desde los años 90, se ha observado un importante incremento en las tendencias competitivas en cuanto a un cierto número de servicios anteriormente gestionados por las Administraciones, a menudo ocasionado por diversas presiones para reducir el impacto presupuestario de los mismos. Por tanto, el enfoque habitual ha sido el tratar de minimizar los costes que deben soportar las autoridades, más que ajustar la calidad del servicio para fomentar su utilización.

El estudio de Preston [118] sobre las tendencias observadas en la competencia en Europa, nos devuelve la clara tendencia de sustituir el monopolio público en el servicio de transporte por la gestión de empresas privadas, existiendo además un cada vez más reducido número de competidores. Además, numerosos países europeos tienden en la actualidad a fomentar el libre mercado, entre los que podemos destacar los casos de Reino Unido y Suecia [138].

Analizando otros sistemas donde se premia la calidad del servicio, pero sin llegar al extremo de la total privatización, son especialmente interesantes los casos de determinadas regiones de Noruega y Nueva Zelanda. Ambos fueron países pioneros, y pueden servir como ejemplo de cómo estos nuevos sistemas de concesiones pueden ser empleados, tanto en ámbito urbano como regional y rural. El objetivo, en ambos casos, ha sido emplear de forma más racional las subvenciones existentes, orientando además a los operadores hacia criterios de índole social. Los beneficios obtenidos tanto por los nuevos usuarios como por los ya habituales son transmitidos desde la Administración hacia los operadores, desde una perspectiva general de reducción de costes externos.

Las premisas generales de este tipo de contratación son las siguientes [70]:

- Promover la competencia con objeto de reducir los costes, reconociendo cada vez más la necesidad de conseguir otros objetivos adicionales (mejoras del servicio), además de un mayor control sobre las subvenciones al concesionario. 
- Definir una estrategia diferente para cada área geográfica, adecuando esta contratación a los datos conocidos hasta la fecha de la zona en estudio.

- Colaboración transparente entre la Administración y el concesionario, asegurando que las subvenciones se asignen de forma óptima, desde un punto de vista global de todo el sistema de transporte, y no analizando de forma aislada una determinada concesión.

- Ambas partes deben compartir los riesgos y beneficios que una mejora en la calidad pueda suponer, ya que invertir en el servicio supone un coste que, inicialmente, puede acabar fomentando el uso del mismo y, por tanto, la recaudación del concesionario.

Ambos sistemas tratan de desarrollar estos tipos de contratación, mediante un sistema de remuneraciones que refleja los beneficios obtenidos cuando se mejora el sistema de transporte público. En particular, los dos prestan especial atención a una serie de criterios de tipo social, en la que los objetivos principales son los de generación de beneficios, tanto para los usuarios del transporte público como para la sociedad en general (por reducción de externalidades).

A continuación, se resumen brevemente las características de ambos sistemas pioneros.

\section{- Experiencias en la Región de Hordaland (Noruega)}

Hordaland es una de las áreas en Noruega donde los allí denominados "contratos de calidad" están siendo implementados para los sistemas de transporte público. Estos contratos surgieron bajo la idea de que es el operador quien mejor conoce el mercado y, por tanto, quien mejor puede diseñar un sistema de rutas apropiado. Sin embargo, para que este sistema pudiera ser operativo desde una perspectiva social, era necesario incluir una serie de incentivos.

El régimen de contratación de los performance based contracts (PBC) tiende, en resumen, a promover un nuevo desarrollo del sistema de transportes, en el que todos los operadores puedan mejorar el servicio, operando en el límite de sus costes admisibles, y teniendo en cuenta las reglas de "buena práctica".

La metodología implementada en Hordaland trata de internalizar tanto los beneficios para los actuales usuarios, por la mejora de la calidad, como sociales, por reducción de externalidades debidas al empleo del coche, en la estructura económica de los operadores, a través de una remuneración que será función del nivel de servicio y del volumen de pasajeros transportados. 
Las variables consideradas son la tarifa, los viajeros-kilómetro y la capacidad, las cuales se conjugan hasta lograr una combinación que maximice una función de beneficio social. De este modo, las subvenciones (determinadas en función de los viajeros-kilómetro) son calculadas bajo el objetivo de maximizar el beneficio global de la sociedad. Las tarifas son reguladas por la Administración, pero el ingreso total por pasajero que recibe el operador es la suma de estas tarifas más los correspondientes incentivos.

Para asegurarse de que el sistema de incentivos sea efectivo, existe la metodología, descrita por Larsen [92] y Johansen et al [84], de requerir al concesionario un cierto crecimiento cuantitativo, por encima de unos niveles de explotación (o de demanda) mínimos, con el establecimiento incluso de porcentajes anuales de mejora.

Por parte de los operadores, éstos gozan una gran independencia (y, por tanto, responsabilidad) en cuanto a la planificación y desarrollo del servicio. Ellos son los que deciden los horarios, frecuencias, tipos de vehículos empleados y tarifas, sobre los que las autoridades establecen unos mínimos a cumplir, pero permitiendo variaciones hacia arriba. Además, los operadores tienen libertad para establecer y modificar rutas, excepto en aquéllas orientadas al transporte escolar. En cualquier caso, lo que no pueden hacer es reducir el total de kilómetros a recorrer sin el consentimiento expreso de la Administración.

- Experiencias en Nueva Zelanda

Las autoridades de Nueva Zelanda han desarrollado una política de Subvenciones a la Demanda para los servicios de transporte público, que ofrece una serie de incentivos directos a los operadores que consigan un aumento de la demanda. Las subvenciones son otorgadas por el Gobierno Central a las distintas regiones, y no directamente a los operadores.

El sistema de incentivos a la demanda se basa en los dos mismos principios establecidos en Noruega, a saber: beneficios de los usuarios, y beneficios externos debidos a la ganancia de nuevos pasajeros, por mejora general del servicio. Wallis y Gale [141] indican que la reducción de externalidades incluye una menor congestión en las carreteras, además de un aumento de la seguridad y de los beneficios medioambientales.

Como consecuencia de esto, las subvenciones varían en función de la ciudad, el período de tiempo y la distancia recorrida. Por ejemplo, son mayores cuando se 
consigue aumentar la demanda del transporte público en los períodos punta en ciudades congestionadas. En definitiva, el sistema está claramente orientado a emplear las subvenciones principalmente en zonas donde la mejoría del transporte público puede reducir de forma importante los costes de congestión.

Wallis y Gale [141] presentan la metodología de valoración de los beneficios debidos a la reducción de externalidades empleada en Nueva Zelanda, que se resumen como sigue:

- Los beneficios en seguridad y medio ambiente están, por regla general, en un rango entre 8 y 13 céntimos por cada viajero-kilómetro.

- Los beneficios por reducción de la congestión varían en función de la ciudad, y sólo son significativos en períodos punta. Los valores habituales rondan los 40-50 céntimos por cada viajero-kilómetro trasladado al transporte público, para las grandes ciudades.

Además, los beneficios directos para los usuarios del transporte público, debido a la mejora general del servicio, son expresados como reducción del coste generalizado del transporte por pasajero, que sigue una formulación cuya única variable independiente es la distancia de viaje.

\subsubsection{Normativa de Calidad en los Servicios de Transporte Público de Pasajeros}

La normalización relativa a la búsqueda de la calidad ha ido evolucionando en los últimos años, incorporando mejoras y novedades en cada revisión.

Así, en el año 1994 apareció la Norma ISO 9002, con la incorporación del modelo para el aseguramiento de la calidad [1]. Incluso, a pesar de ir más dirigida al ámbito industrial o productivo, derivó en sendas normativas específicas publicadas en los años 1999 y 2001, para su aplicación en el transporte por carretera [2, 5].

Dichas normas fueron anuladas por la ISO 9001:2000 [3], a su vez posteriormente anulada por la ISO 9001:2008 [9]. En ellas, se plantea un nuevo modelo de gestión de la calidad, con el cual cada empresa debe definir su propia estrategia de mejora continua de la calidad, fomentando la implicación de los gestores, la planificación de los procesos y el conocimiento de la satisfacción del cliente. 
El siguiente paso "evolutivo" se corresponde con la aparición de la Norma ISO 9004:2000 [4], y su posterior revisión en 2009 [10], las cuales incorporan el modelo de calidad total, dentro del enfoque de gestión de la calidad propuesto en la 9001.

Finalmente, ya dentro del ámbito específico del transporte público de viajeros, se creó en 2003 la Norma UNE-EN 13816 [6] sobre "calidad del servicio, objetivos y mediciones", a su vez desarrollada por la Norma UNE-EN 15140 [7], que establece "requisitos básicos y recomendaciones para los sistemas de medición de la calidad del servicio producida", y posteriormente, a modo de guía de implantación por las Normas UNE 152001:2007 [8], con sus tres partes fundamentales:

1. Transporte regular de largo recorrido por carretera.

2. Transporte regional regular por carretera.

3. Transporte regular interurbano de cercanías por carretera.

A continuación, se describen brevemente los principales aspectos de cada una de estas tres normativas, todas ellas vigentes en la actualidad:

- Norma UNE-EN $13816[6]$

El principal objetivo de la Norma UNE-EN 13816 es “(..) fomentar el acercamiento de la calidad a la gestión del transporte público, poniendo especial interés en las necesidades y expectativas de los clientes (...)".

Una de las perspectivas más interesantes de esta norma es la diferenciación de los cuatro puntos de vista desde los que se puede evaluar la calidad:

- Calidad esperada. Es el nivel previsto o anticipado por parte del cliente.

- Calidad objetivo. Es el nivel que los prestadores del servicio desean ofrecer a sus clientes. Para cada criterio de calidad establecido, se debe definir con exactitud: un estándar de calidad (o valor objetivo a cumplir), su nivel de exigencia (porcentaje de clientes que lo disfrutan), y su umbral de inaceptabilidad (valor por debajo del cual el servicio no es prestado de forma adecuada).

- Calidad producida. Es el nivel realmente alcanzado por el servicio. Puede medirse directamente a partir de las prestaciones del servicio, con un tratamiento estadístico de los datos. 
- Calidad percibida. Es el nivel de calidad que el cliente siente y percibe. Dependerá principalmente de tres parámetros: su experiencia personal con el servicio y prestaciones asociadas, la información que reciba y sus características personales. Se mide a través de encuestas a los usuarios.

Los niveles de calidad objetivo y calidad producida son relativos al punto de vista del proveedor del servicio, mientras que, por parte del cliente, los niveles influyentes son los de calidad esperada y percibida. La interrelación entre estos cuatro niveles queda perfectamente reflejada mediante el ciclo de la calidad, que se presenta en la Figura 3-3:

Figura 3-3. Ciclo de la calidad en el transporte público de pasajeros Fuente: AENOR [6]

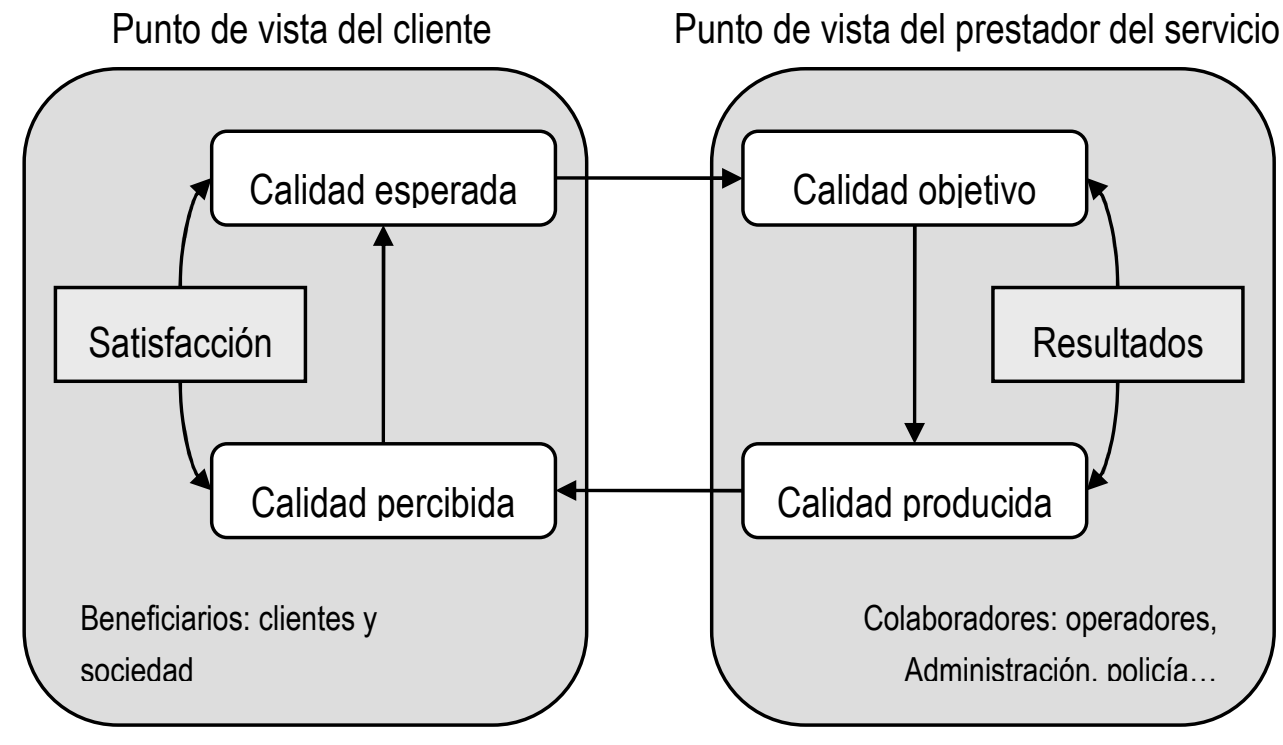

La relación entre la calidad esperada por parte del cliente con el objetivo por parte del operador es función de la capacidad del prestador del servicio para determinar cuáles son las necesidades de los usuarios. Por otra parte, la relación entre calidad objetivo y calidad producida está íntimamente ligada con la eficiencia del operador para lograr sus estándares de calidad. Es la relación entre calidad producida y percibida por el cliente la más difusa de las cuatro, al influir numerosos parámetros externos al servicio, lógicamente no controlables. Por último, la diferencia entre la calidad esperada por los usuarios y la realmente percibida es el principal factor que afecta a su satisfacción. Así, la calidad producida (visión por parte del operador) es un componente importante de la satisfacción de los usuarios, pero no el único [116]. 
Dado el interés de la Norma en la consecución de la calidad percibida por el cliente, se incluye en ésta un exhaustivo desglose de los parámetros que la configuran. Así, la Norma define 8 categorías de variables que influyen en la calidad. Además, para permitir diferentes niveles de detalle en los procesos de implantación, divide estas categorías en subniveles. Dichas categorías (niveles 1 y 2 ) son las que siguen (el desglose completo se recoge en la propia Norma [6]):

1. Servicio ofertado: modos de transporte, red, explotación, adecuación a las necesidades y fiabilidad del servicio.

2. Accesibilidad: externa, interna y de expendición/adquisición de billetes.

3. Información: general, relativa al viaje en condiciones normales y relativa al viaje en condiciones anormales.

4. Duración: duración del viaje y cumplimiento de horarios/frecuencias.

5. Atención al cliente: compromiso, relación con los clientes, personal, asistencia y adquisición de billetes.

6. Confort: funcionamiento del equipamiento de los pasajeros, asientos y espacio para los pasajeros, confort del viaje, condiciones ambientales, instalaciones complementarias y ergonomía.

7. Seguridad: protección contra las agresiones, prevención de accidentes y gestión de las emergencias.

8. Impacto medioambiental: contaminación, recursos naturales e infraestructura.

Además, la Norma hace también hincapié en la necesidad de compromiso por parte de todos los implicados en el funcionamiento del servicio, es decir, tanto del operador como de la Administración competente. Cada uno de ellos deberá asumir las responsabilidades que le sean asignadas, para que el sistema no sólo sea eficiente, sino que también lo perciban así los usuarios.

Por último, se indican en la Norma las etapas que deberían derivar en un correcto sistema de gestión de la calidad, las cuales se resumen a continuación:

1. Identificación de las expectativas explícitas e implícitas de los clientes. Se trata, en definitiva, de definir la calidad esperada por los usuarios. Las herramientas a emplear pueden ser grupos focales, entrevistas en profundidad, estudios de 
mercado, encuestas u otras, considerando no sólo los usuarios actuales, sino también los potenciales [116].

2. Contemplación de las limitaciones legales, políticas, financieras, técnicas o de otros tipos.

3. Identificación de los niveles de calidad existentes, y detección de las áreas potenciales de mejora.

4. Definición de los objetivos (estándares de calidad). Se deben seleccionar los factores a considerar, y, para cada uno de ellos, su valor de referencia, nivel de exigencia, umbral de inaceptabilidad y consecuencias en caso de no conseguirlo.

5. Medición del nivel de prestación. Ello va a conllevar: la selección de los métodos de medida, la decisión sobre la frecuencia de medición, la elección y validación de los métodos de cálculo de resultados, y el modo en que se documenten dichos resultados.

6. Puesta en marcha de acciones correctoras. Éstas podrán ser de tipo correctivo o, preferentemente, preventivo, y orientadas a eliminar las situaciones de no consecución del nivel objetivo o de inaceptabilidad.

7. Evaluación de la calidad percibida por los clientes. La Norma incluye algunas de las cuestiones que se podrían consultar a los usuarios en una encuesta de satisfacción, relacionadas con las 8 categorías de variables anteriormente citadas.

8. Elaboración y puesta en marcha de un plan de acción para disminuir las diferencias entre calidad producida, esperada y percibida.

Además de estas etapas, es importante establecer un proceso de revisión periódico, que permita asegurar la consecución de la calidad en cualquier momento. Así, podríamos añadir tres fases más al proceso, como indica Petit [116]: registro continuado de las actividades anteriores, y total definición de la documentación a elaborar, adecuación de la competencia profesional del equipo encargado de garantizar la calidad del servicio (incluye la inclusión y concienciación de todo el personal en el proceso de mejora de la calidad) y revisión periódica y eficiente del sistema de gestión. 
Como último apunte, simplemente indicar que la Norma incluye una metodología de medición tanto de la calidad del servicio percibida por los usuarios (a través de encuestas de satisfacción), como de la efectivamente producida (proponiendo una serie de indicadores a considerar para cada categoría). Las Normas UNE-EN 15140 [7] y UNE 152001:2007 [8] se refieren específicamente a la medición de la calidad producida y objetivo, por lo que su tratamiento se realizará a continuación.

\section{- Norma UNE-EN 15140 [7]}

La Norma UNE-EN 15140 recoge los requisitos básicos, y también una serie de recomendaciones y ejemplos, para la medición de la calida producida en los servicios de transporte público de pasajeros.

Como requisitos generales, se indica en primer lugar la necesidad de conocer previamente los criterios de calidad, en base a las categorías reflejadas en la Norma UNE-EN 13816 [6], preferiblemente dispuestos en forma de cuadrícula. Así, cada factor o criterio deberá poder ser declarado "conforme" o "no conforme", y se deben determinar ratios que reflejen el tanto por ciento de clientes afectados por la conformidad y la no conformidad.

En cuanto a la implantación del proceso, la medición debe ser revisada al menos una vez al año, con una recogida de datos y procesamiento transparente y verificable.

El último de los requisitos es variable en función de la tipología de medida que se vaya a realizar. Así, la Norma recoge los siguientes posibles métodos: con encuestadores o con medios técnicos (se deben comprobar puntualmente con otras metodologías de medida), y mediante medición continua o por muestreo (mediante reglas estadísticas adecuadamente escogidas).

Además de estos requisitos, la Norma incluye también una serie de recomendaciones, e incluso ejemplos cuantitativos, tanto para el diseño del sistema de medición como para la implantación del proceso, donde indica que se debe prestar una especial atención al equilibrio entre coste y resultados, ya que, por ejemplo, la realización de entrevistas personal tiene un alto presupuesto necesario. 
- Normas UNE 152001:2007 [8]

Las Normas UNE 152001:2007 son tres guías diferentes, todas ellas con el mismo objetivo: la determinación de un nivel de calidad de referencia para el transporte público de pasajeros en autobús. La primera parte se refiere a los servicios de largo recorrido (entre capitales de provincia, o con una longitud superior a los $200 \mathrm{~km}$ ); la segunda, a los de tipo regional (con una longitud de entre 50 y $200 \mathrm{~km}$, y sin unir capitales de provincia); y, la tercera, a los de tipo interurbano de cercanías (longitud inferior a $50 \mathrm{~km}$ y sin unir capitales de provincia).

Cada una de ellas, propone una serie de criterios de calidad, basados en la lista de categorías recogida en la Norma UNE-EN 13816 [6], indicando el parámetro a controlar, su nivel de exigencia y su umbral de inaceptabilidad. Se diferencian los criterios básicos y los optativos, aunque las propias Normas indican como situación objetivo aquélla en la que, al segundo año desde la implantación, se consigan todos los básicos y el $60 \%$ de los optativos. Dichos criterios se recogen en las respectivas Normas $[7,8]$.

Existen manuales de aplicación de estas normativas en España, los cuales se tratarán con más detalle en el apartado siguiente.

\subsubsection{Primeras Aplicaciones en España}

A partir de la normativa vista en el apartado anterior, el Ministerio de Fomento ha elaborado una serie de guías de aplicación y recomendaciones en los últimos años. Así, los cuatro ejemplos más recientes que podríamos citar, por orden cronológico de aparición, son los que siguen:

1. "Modelos para implantar la mejora continua en la gestión de empresas de transporte por carretera" [101]

2. "Buenas prácticas y recomendaciones para la mejora de la satisfacción del cliente de transporte público de viajeros por carretera" [46]

3. "Manual de apoyo para la implantación de la gestión de la calidad según norma UNE-EN 13816 en empresas de transporte de viajeros por carretera" [47]

4. “Calidad y corresponsabilidad en el transporte público por carretera” [48] 
La primera de ellas se refiere al proceso de creación de un sistema de gestión de calidad en empresas de transporte por carretera, pero no específicamente para el traslado de viajeros. En un primer lugar, establece los requisitos que se deben cumplir según las Normas ISO de calidad y gestión medioambiental, para, a continuación indicar los principios básicos de la gestión de la calidad, y de la orientación al cliente. Finalmente, presenta, según el modelo EFQM, las bases a seguir en una tendencia hacia la excelencia empresarial.

Las siguientes tres publicaciones tienen una clara orientación hacia el transporte público en autobús, por lo que tienen una incidencia más directa sobre nuestro ámbito de estudio. Así, a continuación se indicará brevemente las principales recomendaciones de cada una de ellas:

- "Buenas prácticas y recomendaciones para la mejora de la satisfacción del cliente de transporte público de viajeros por carretera" [46]

Este documento incluye tres partes principales, junto con otra última que aclara los conceptos y definiciones relativos a la calidad del transporte público por carretera.

En la primera de ellas, se establece el marco conceptual en que se desarrollará el documento. Así, tras hacer hincapié en las cuatro posibles definiciones de calidad, ya esbozadas en la Norma UNE-EN 13816 [6], diferencias las características del servicio en: básicas (se dan por esperadas, y su incumplimiento supone la total insatisfacción de los usuarios), proporcionales (se pueden evaluar de forma cuantitativa, y a mayor valoración mayor satisfacción), atractivas (no se presupone su cumplimiento, y, por tanto, resultan muy satisfactorias para el usuario si se dan) y neutrales (no tienen efecto ni positivo ni negativo). Además, establecen que las claves para garantizar la calidad del servicio son tres: eficiencia, con un sentido más económico, relativa a la capacidad de satisfacer la demanda con el menor número de recursos, eficacia, como capacidad para alcanzar las metas propuestas, y efectividad, más centrada en la orientación de los objetivos de la Administración hacia las necesidades reales individuales.

En la segunda parte se incluyen 70 buenas prácticas, extraídas de diferentes países, y divididas en dos grandes ámbitos, cada uno a su vez subdivido en áreas: provisión de servicios (servicio ofertado, accesibilidad, información, tiempo, atención al cliente, confort y medio ambiente) y gestión de servicios (coordinación y homogeneidad, participación ciudadana, captación de nuevos clientes, planes de movilidad, sostenibilidad y calidad de vida, educación infantil, prestigio del transporte público, 
transporte público de mercancías, financiación del transporte público, recursos humanos y nuevos sistemas de pago).

Por último, la tercera parte incluye una serie de recomendaciones y estrategias para mejorar la calidad de los sistemas de transporte público. Destacan, por ejemplo, el análisis DAFO y la estrategia de capas, la cual se basa en mejorar 10 ámbitos distintos que deben configuran un servicio de calidad y fiable.

- "Manual de apoyo para la implantación de la gestión de la calidad según norma UNE-EN 13816 en empresas de transporte de viajeros por carretera" [47]

Este documento incluye una serie de recomendaciones y pautas para implantar un sistema de calidad acorde con la Norma UNE-EN 13816 [6]. Tiene cinco partes principales, junto con una última de definiciones y conceptos.

En la primera de ellas, compara el modelo SERVQUAL de Parasuraman et al [112, 113] con el ciclo de la calidad expuesto en la Norma UNE-EN 13816 [6]. También realizan un repaso de las etapas recogidas en la citada Norma para implantar la calidad en el sistema.

El segundo capítulo se refiere a la orientación al cliente, recogiendo en primer lugar las principales variables ya referidas en el manual de Buenas Prácticas [46]. También se indica cuáles podrían ser los indicadores de calidad de servicio más habitualmente empleados: velocidad comercial, antigüedad del parque, frecuencia del servicio, porcentaje de vehículos adaptados a personas con movilidad reducida, porcentaje de vehículos con aire acondicionado y siniestralidad. Sin embargo, un parámetro relevante es el número (o porcentaje) de usuarios afectados por un incumplimiento de alguno de los valores objetivo anteriores.

En el tercero capítulo se proporcionan ejemplos y herramientas para elaborar un Manual de características básicas del servicio y una Carta de servicio. Un Manual de características básicas debe responder a cuatro preguntas fundamentales: quiénes somos (descripción de la empresa, marco competencial y compromiso con la calidad), qué servicio prestamos (descripción del servicio, conexiones y flota de vehículos), cómo realizamos el servicio (compromisos de calidad y descripción del sistema de gestión de calidad) y para quiénes lo hacemos (atención al cliente, idiomas y accesibilidad a personas con movilidad reducida). En cuanto a la Carta del servicio, debe contener una declaración de la calidad que puede esperar el cliente, formalmente dividida en: descripción del servicio, compromisos, formas de acceso, mecanismos de 
queja y reclamación y derechos de los usuarios. Otras características importantes son que esté actualizada, que sea pública, y que contenga compromisos relevantes para los usuarios y alcanzables, aunque exigentes, para el operador.

La cuarta parte se refiere a los procedimientos y documentos necesarios para implementar un sistema de gestión de la calidad, tanto desde el punto de vista de la Norma ISO 9001 [9] como de la UNE-EN 13816 [6].

Por último, uno de los capítulos más interesantes desde el punto de vista de la investigación presente es el quinto, relativo a la medida de la satisfacción del cliente. En primer lugar, indican diversos métodos de medida, como por ejemplo: focus group, informes del personal en contacto con los clientes, investigaciones de mercado, encuestas de satisfacción de clientes, cliente oculto o Mystery Shopping (uno o varios observadores independientes que se hacen pasar por auténticos pasajeros), seguimiento de las muestras de insatisfacción, análisis de indicadores operativos internos y medidas directas de la prestación. A continuación, recogen una serie de recomendaciones para medir la calidad esperada, objetivo, producida (a través de unos indicadores propuestos o de un índice de calidad interna), y percibida (mediante un índice de satisfacción del cliente, o ISC, el cual se recomienda elaborar mediante modelos de regresión).

\section{- "Calidad y corresponsabilidad en el transporte público por carretera" [48]}

Este último documento tiene una perspectiva diferente, más orientada a la distribución de compromisos y responsabilidades entre los distintos entes implicados en los servicios de transporte público. Incluye ejemplos nacionales e internacionales, y un resumen de buenas prácticas de referencia en este sentido.

Las Comunidades Autónomas más avanzadas en cuanto a la incorporación de parámetros de calidad a los contratos de transporte son Madrid y Cataluña. En lo que respecta a la Comunidad de Madrid, se están comenzando a incorporar cuestiones de calidad en los contratos relativos a las concesiones de transporte de competencia de su Consorcio Regional de Transportes. De hecho, algunas de ellas ya han visto mejorado su servicio [115], mientras que otras deben hacerlo antes de determinadas fechas para seguir manteniendo la concesión [31].

Además, en Cataluña, se ha comenzado la implantación de contratos-programa. En éstos, la Administración se compromete a hacerse cargo de todo el coste del servicio que no sea sufragado por los usuarios del servicio. Así, las empresas pueden emprender acciones de mejora de calidad o nuevas inversiones, inicialmente no recogidas en la concesión, sin 
asumir por completo el riesgo de la operación. La contraprestación es que la empresa se compromete a mantener el servicio en unas condiciones adecuadas de calidad: horarios, limpieza, atención al cliente, mantenimiento... [94]

Además, y como ya se ha indicado en apartados anteriores, se está incidiendo en la necesidad de crear una competencia controlada entre las empresas que deseen prestar servicios de transporte público, mediante los contratos de gestión interesada. En éstos, empresario y Administración comparten los riesgos y resultados de la explotación. En el área metropolitana de Barcelona, los nuevos contratos de gestión interesada obligan a las empresas a asumir un compromiso en cuanto al número mínimo de viajeros transportados, con lo que se deben comprometer en captar nuevos clientes, y también en cuanto a la calidad a ofertar. Así mismo, se han promovido incentivos y penalizaciones según determinados baremos de calidad y de nivel de servicio. De este modo, el contrato no es un elemento cerrado e inamovible, sino flexible y adaptable a las necesidades diarias del servicio. [97]

Además, la ciudad de Barcelona se ha incorporado al proyecto BEST, cuyo objetivo es compartir experiencias en cuanto a la gestión de calidad del transporte metropolitano. [13] 



\section{METODOLOGÍA}

En el presente capítulo se presentará la metodología empleada para la realización del estudio. En primer lugar, se indicará el modo de recolección de datos empleado, para, a continuación, plantear los modelos empleados tanto para la calidad percibida por los usuarios como para la demanda. Finalmente, se planteará la metodología propuesta de aplicación de los resultados obtenidos a los contratos de transporte público interurbano en autobús. 


\subsection{Recolección de Datos}

El primer paso para la realización del estudio consistió, lógicamente, en la recolección de los datos necesarios para el mismo. Los pasos del citado proceso fueron, en principio, la detección de las variables más relevantes, seguido por la elaboración del diseño experimental de la encuesta y, por último, la realización de la encuesta en sí.

Además, se recolectaron datos de los viajes disponibles en los servicios de transporte público interurbano en autobús de la Comunidad Autónoma de Castilla y León, con especial interés en aquéllos con parada en la Estación de Autobuses de Burgos, lugar donde se realizaron las encuestas definitivas $[15,121,139]$. El extracto de dichos datos se recoge en el Anexo 1.

\subsubsection{Detección de Variables Relevantes del Estudio}

Analizando la bibliografía y tras el análisis de las experiencias nacionales e internacionales citadas en el capítulo anterior, junto con los datos de estudios ya realizados hasta la fecha, se detectaron de forma preliminar las variables a introducir en los diseños experimentales de la encuesta.

La primera decisión fue la localización de los puntos de encuesta. En este sentido, dado que el principal objetivo de la presente investigación es determinar las variables que afectan a la calidad percibida por los usuarios del servicio de transporte público en autobús interurbano, se decidió realizar la práctica totalidad de las entrevistas en la estación de autobuses de Burgos. Para ello, tras unos contactos con el personal encargado, se obtuvo la pertinente autorización para realizar las encuestas durante los meses de Febrero y Marzo del año 2009.

Este hecho puede plantear problemas desde el punto de vista de la representatividad de la muestra. Sin embargo, mediante la realización de encuestas de control a usuarios habituales de otros modos de transporte, se determinó que el error inducido era muy leve, por lo que se consideró válido el resultado. De hecho, muchos de los entrevistados en la estación de autobuses, como se podrá comprobar en apartados posteriores, son usuarios ocasionales de autobús, que puntualmente empleaban dicho modo en el viaje considerado.

El siguiente paso fue descartar aquéllas variables que, aun pudiendo ser en cierto sentido relevantes para el estudio, alargarían de forma excesiva la duración de las entrevistas, con 
el consiguiente desagrado de los encuestados y la posibilidad de respuestas incoherentes. Por tanto, finalmente se optó por consultar a los usuarios sobre tres grandes grupos de cuestiones: sus características personales, los datos del viaje que acaban de realizar o van a realizar y, por último, la probabilidad de volver a elegir el autobús en próximos viajes, tanto con las mismas condiciones actuales como en otras diferentes.

De este modo, las variables a incluir finalmente en la encuesta son las que se reflejan en la Figura 4-1:

Figura 4-1. Variables relevantes a incluir en la encuesta

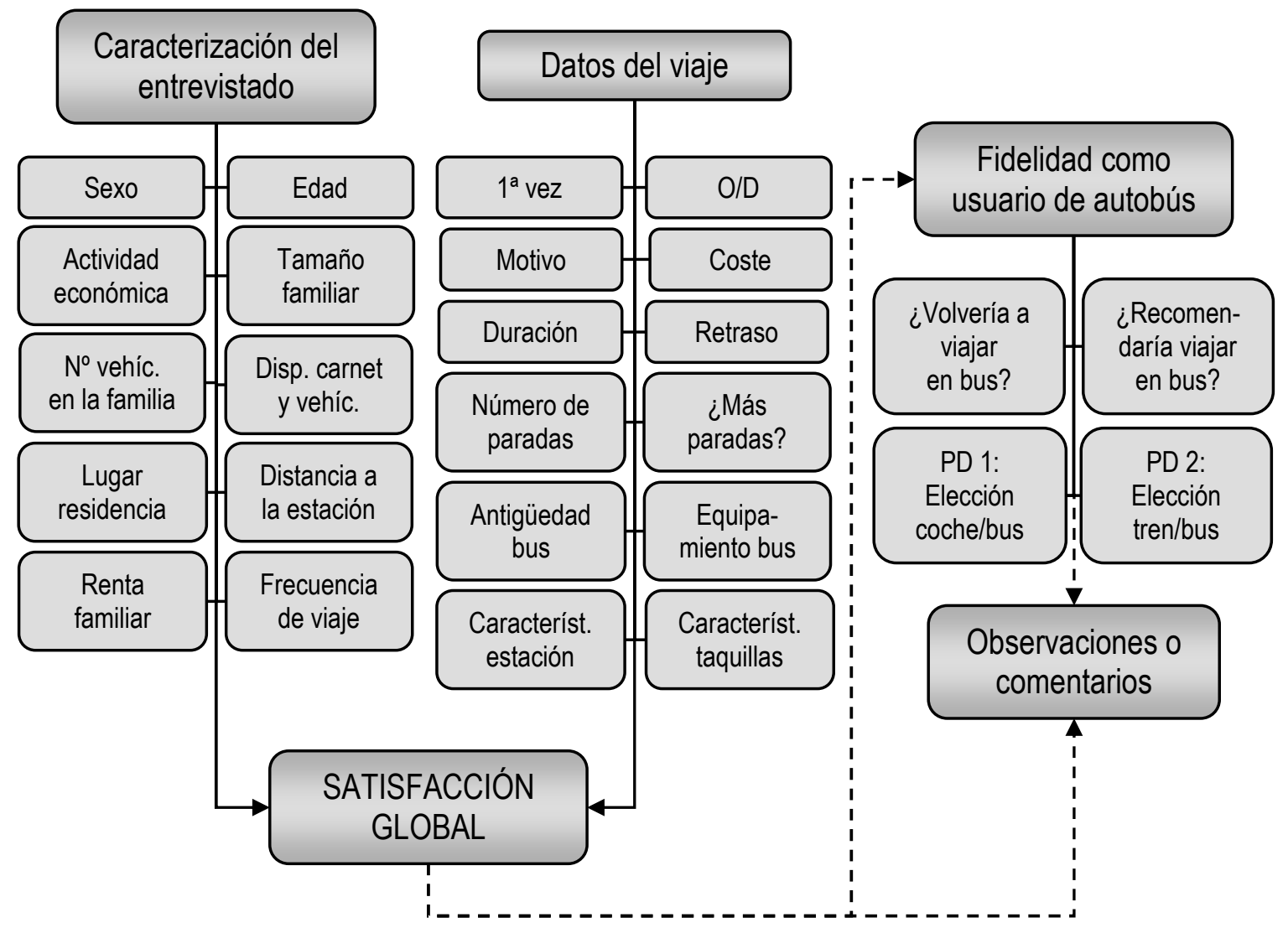

El siguiente paso fue la determinación de la mejor opción para incluir estas variables en la encuesta, de modo que se optimizara la duración de la entrevista, y consiguiendo la mayor facilidad de comprensión y de respuesta por parte de los usuarios. Estos temas se tratarán en el apartado siguiente, sobre el diseño experimental de la encuesta. 


\subsubsection{Diseño Experimental de la Encuesta}

En primer lugar, una vez determinadas las variables a incluir en la encuesta, se procedió a su inclusión en un primer formulario, del que se realizó un experimento piloto a una pequeña muestra de usuarios.

Así, para cada una de las variables anteriores, se determinó sus rangos de variación, los cuales quedan reflejados en la Tabla 4-1, diferenciándolas según los tres grandes grupos indicados en el apartado anterior:

Tabla 4-1. Variables consideradas en la encuesta

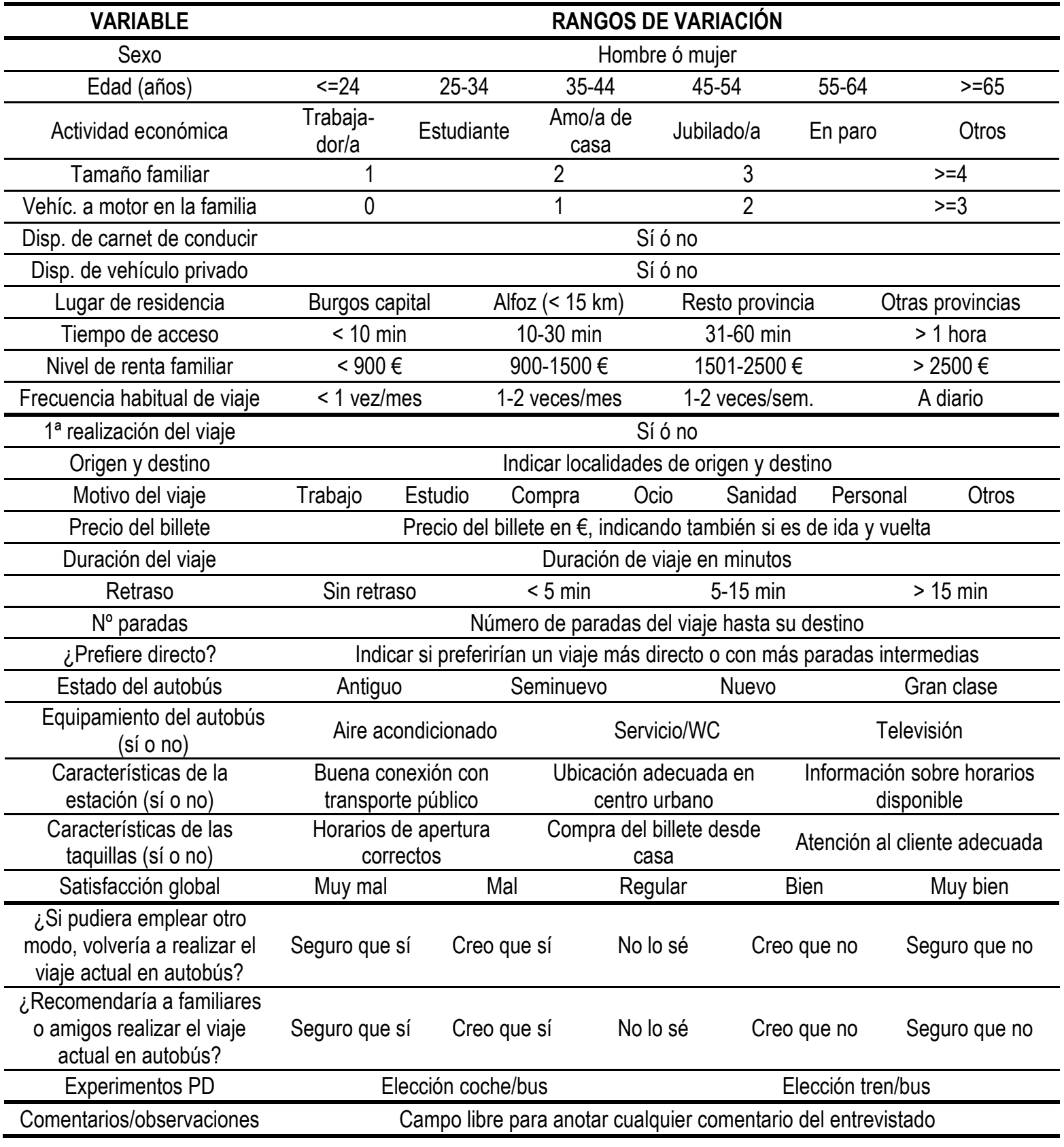


El siguiente paso fue la determinación del tamaño muestral mínimo para las encuestas de preferencias reveladas. Dado que se trata de encuestas fuera del hogar, la formulación siguiente nos da el tamaño muestral mínimo [111]:

$$
n \geq \frac{p \cdot(1-p)}{\left(\frac{e}{z}\right)^{2}+\frac{p \cdot(1-p)}{N}}
$$

Donde, n: número mínimo de encuestas a realizar

p: proporción de viajes con un destino determinado

e: nivel de error admitido

z: variable normal estándar para el nivel de confianza requerido

$\mathrm{N}$ : tamaño de la población (flujo de pasajeros por la estación, en este caso)

Se puede demostrar que el máximo valor de esta expresión se obtiene cuando se estima un valor de p igual a 0,5 .

Así, incluyendo un error máximo del $10 \%(\mathrm{e}=0,1)$ y un nivel de confianza del $95 \%$ $(\mathrm{z}=1,96)$, podemos calcular el número mínimo recomendado de encuestas a realizar, en función del total de viajeros diarios, que rondaría los 5.300 viajeros/día. Los valores resultantes se muestran en la Tabla 4-2:

Tabla 4-2. Tamaño muestral mínimo para las encuestas de preferencias reveladas

Fuente: Ortúzar y Willumsen [111]

\begin{tabular}{ccc}
\hline $\mathbf{N}$ (viajeros/día) & $\mathbf{n}$ (viajeros/día) & $\mathbf{n / N ~ ( \% ) ~}$ \\
\hline 2.000 & 92 & $4,6 \%$ \\
\hline 3.000 & 93 & $3,1 \%$ \\
\hline 4.000 & 94 & $2,3 \%$ \\
\hline 5.000 & 94 & $1,9 \%$ \\
\hline 6.000 & 95 & $1,6 \%$ \\
\hline 7.000 & 95 & $1,4 \%$ \\
\hline $\mathbf{5 . 2 7 0}$ & $\mathbf{9 4}$ & $\mathbf{2} \%$ \\
\hline
\end{tabular}

Así pues, con unas 94-95 encuestas completas sería suficiente para obtener los errores descritos anteriormente. Como se verá en apartados posteriores, este valor se supera ampliamente.

Como se indicará en apartados posteriores, la encuesta se realizó finalmente con soporte informático, empleando PDA's adecuadamente programadas al efecto. Ello permitió que los experimentos de preferencias declaradas (PD) fueran diseñados específicamente para cada usuario, sin necesidad de analizar los datos en gabinete y volver a contactar con éste. 
Sin embargo, debido a la obvia necesidad de obtención rápida de dichos experimentos, no fue posible el empleo de diseños eficientes, con métodos tipo D-error por ejemplo, ya que precisaban un elevado tiempo de cálculo. Por ello, se recurrió a un diseño experimental ortogonal y balanceado, minimizando la correlación entre los atributos presentados a los entrevistados.

De este modo, el proceso de elaboración de los experimentos PD constó de las siguientes etapas:

Preselección de las variables a incluir, basándonos en experiencias y encuestas previas, considerables como piloto, en la propia estación de autobuses de Burgos.

En este sentido, para no incluir un número excesivo de variables, y evitar que los entrevistados aplicaran reglas lexicográficas, se decidió incluir tan sólo 4 variables representativas del funcionamiento del autobús: tiempo de viaje, coste del billete, número diario de servicios y características del vehículo. Estas variables (únicamente cuando su sentido era lógico) fueron las mismas para las otras alternativas existentes: tren y vehículo privado.

Determinación inicial de los valores máximos y mínimos razonables de las mismas, y de los niveles de variación.

Para las variables tiempo y coste del viaje en autobús, se estableció un rango de variación de un $\pm 20 \%$ de los valores actuales. Por otra parte, para el número de servicios, los extremos fueron el valor actual y éste mayorado en un $50 \%$. Por último, las características del autobús se dividieron en cuatro niveles (antiguo, seminuevos, nuevo, gran clase), de los cuales a los entrevistados únicamente se presentaría los niveles actual y ligeramente mejorado. En los experimentos de PD se decidió mantener constantes, e iguales a los valores actuales, las características del viaje en vehículo privado $\mathrm{y}$ en tren, a fin de que sirvieran como punto fijo de apoyo para los entrevistados. Los niveles iniciales de las variables quedan expuestos en la Tabla 4-3: 
Tabla 4-3. Selección inicial de variables para los experimentos $P D$

\begin{tabular}{cccc}
\hline ALTERNATIVA & \multicolumn{1}{c}{ VARIABLE } & \multicolumn{2}{c}{ RANGOS DE VARIACIÓN } \\
\hline \multirow{4}{*}{ Autobús } & Tiempo de viaje & Actual $-20 \%$ & Actual $+20 \%$ \\
\cline { 2 - 4 } & Coste del billete & Actual $-20 \%$ & Actual $+20 \%$ \\
\cline { 2 - 3 } & Número de servicios al día & Actual & Actual $+50 \%$ \\
\cline { 2 - 3 } Vehículo privado & Características del vehículo & Actual & Mejorado un nivel \\
\cline { 2 - 3 } & Ruta & Actual \\
\cline { 2 - 3 } & Tiempo de viaje & Actual \\
\hline \multirow{3}{*}{ Ferrocarril } & Coste de viaje & Actual \\
\cline { 2 - 3 } & Tiempo de viaje & Actual \\
\cline { 2 - 3 } & Cónte de viaje & Actual \\
\cline { 2 - 3 } & Número de servicios al día & Actual \\
\cline { 2 - 3 } & Existencia de transbordo & Actual \\
\hline
\end{tabular}

Diseño preliminar de experimentos PD.

En primer lugar, se decidió simplificar al máximo la metodología, separando los experimentos de vehículo privado y ferrocarril. Así, en un primer lugar se presentaría al encuestado, únicamente si tenía disponible un vehículo privado para realizar el viaje, los escenarios de elección entre éste y el autobús y, a continuación, si el trayecto era posible en tren, sus escenarios correspondientes.

Como ya se ha comentado, se recurrió a la base de diseño experimentales ortogonales y equilibrados [90] y, empleando un experimento donde cada variable tenía únicamente dos niveles, se llegó al diseño experimental presentado en la Tabla 4-4, para la comparación entre autobús y vehículo privado, y en la Tabla 4-5, para la comparación del autobús con el ferrocarril:

Tabla 4-4. Diseño preliminar del experimento PD autobús - vehículo privado

\begin{tabular}{|c|c|c|c|c|c|c|}
\hline & \multicolumn{5}{|c|}{ AUTOBÚS } & \multirow{2}{*}{$\begin{array}{l}\text { VEHÍCULO } \\
\text { PRIVADO }\end{array}$} \\
\hline $\begin{array}{c}\mathrm{N}^{\circ} \\
\text { BLOQUE }\end{array}$ & TIEMPO & COSTE & No SERVICIOS & VEHÍCULO & RUTA & \\
\hline \multirow{4}{*}{1} & Actual $+20 \%$ & Actual $+20 \%$ & Actual & Actual & Actual & \multirow{4}{*}{$\begin{array}{c}\text { Tiempo, coste } \\
\text { y ruta con } \\
\text { valores } \\
\text { actuales }\end{array}$} \\
\hline & Actual - $20 \%$ & Actual $+20 \%$ & Actual & Mejorado un nivel & Actual & \\
\hline & Actual - 20\% & Actual - 20\% & Actual $+50 \%$ & Mejorado un nivel & Actual & \\
\hline & Actual $+20 \%$ & Actual - $20 \%$ & Actual $+50 \%$ & Actual & Actual & \\
\hline \multirow{4}{*}{2} & Actual $+20 \%$ & Actual - 20\% & Actual & Mejorado un nivel & Actual & \multirow{4}{*}{$\begin{array}{c}\text { Tiempo, coste } \\
\text { y ruta con } \\
\text { valores } \\
\text { actuales }\end{array}$} \\
\hline & Actual $+20 \%$ & Actual $+20 \%$ & Actual $+50 \%$ & Mejorado un nivel & Actual & \\
\hline & Actual - $20 \%$ & Actual - 20\% & Actual & Actual & Actual & \\
\hline & Actual - $20 \%$ & Actual $+20 \%$ & Actual $+50 \%$ & Actual & Actual & \\
\hline
\end{tabular}


Tabla 4-5. Diseño preliminar del experimento PD autobús - ferrocarril

\begin{tabular}{|c|c|c|c|c|c|c|}
\hline \multicolumn{6}{|c|}{ AUTOBÚS } & \multirow[b]{2}{*}{ FERROCARRIL } \\
\hline $\begin{array}{c}\mathrm{N}^{0} \\
\text { BLOQUE }\end{array}$ & TIEMPO & COSTE & No SERVICIOS & VEHÍCULO & RUTA & \\
\hline \multirow{4}{*}{1} & Actual $+20 \%$ & Actual $+20 \%$ & Actual & Actual & Actual & \multirow{4}{*}{$\begin{array}{c}\text { Tiempo, coste, } \\
\mathrm{n}^{0} \text { servicios y } \\
\text { transbordo con } \\
\text { valores actuales }\end{array}$} \\
\hline & Actual - $20 \%$ & Actual $+20 \%$ & Actual & Mejorado un nivel & Actual & \\
\hline & Actual - $20 \%$ & Actual - $20 \%$ & Actual $+50 \%$ & Mejorado un nivel & Actual & \\
\hline & Actual $+20 \%$ & Actual - $20 \%$ & Actual $+50 \%$ & Actual & Actual & \\
\hline \multirow{4}{*}{2} & Actual $+20 \%$ & Actual - $20 \%$ & Actual & Mejorado un nivel & Actual & \multirow{4}{*}{$\begin{array}{c}\text { Tiempo, coste, } \\
\mathrm{n}^{0} \text { servicios y } \\
\text { transbordo con } \\
\text { valores actuales }\end{array}$} \\
\hline & Actual $+20 \%$ & Actual $+20 \%$ & Actual $+50 \%$ & Mejorado un nivel & Actual & \\
\hline & Actual - $20 \%$ & Actual - $20 \%$ & Actual & Actual & Actual & \\
\hline & Actual - $20 \%$ & Actual $+20 \%$ & Actual $+50 \%$ & Actual & Actual & \\
\hline
\end{tabular}

Como se puede apreciar, dado que el tiempo de realización de la encuesta debía ser lo más breve posible, al detener a los usuarios que proceden a subir o acaban de bajar del autobús, se dividió inicialmente el experimento completo en 2 bloques, que se realizaban de forma correlativa, uno a cada usuario. El hecho de hacer al un único usuario el mismo bloque en ambos experimentos permitiría posteriormente agregar los datos, para elaborar un modelo único con las tres alternativas disponibles.

Prueba piloto del diseño preliminar.

El siguiente paso consistió en la prueba piloto del diseño expuesto en las tablas anteriores, a una muestra reducida de entrevistados. En concreto, se realizaron 140 encuestas en esta fase, a partir de las cuales se elaboraron unos modelos previos, con el fin de determinar si el rango de variación de las variables era adecuado. La calibración y análisis de dichos modelos premilitares se incluye capítulos posteriores.

Modificación del diseño preliminar, para obtener el diseño definitivo.

Tras el análisis de los resultados de la aplicación de esta encuesta a la muestra reducida, se concluyó que los rangos máximo y mínimo de cada variable considerada eran adecuados, observándose suficiente variabilidad en las respuestas de los entrevistados. Sin embargo, sí se detectó la posibilidad de aumentar el número de niveles en las variables de política (tiempo de viaje, coste del billete y número de servicios del autobús) hasta tres, manteniendo el resto constantes. Además, se determinó que, a los usuarios a los que se hacía ambos experimentos, les resultaba demasiado larga la parte de preferencias declaradas, de modo que se decidió abreviarla ligeramente. 
Así, los niveles de variación empleados en la encuesta definitiva fueron los que se presentan en la Tabla 4-6:

Tabla 4-6. Selección definitiva de variables para los experimentos $P D$

\begin{tabular}{|c|c|c|c|c|}
\hline ALTERNATIVA & VARIABLE & \multicolumn{3}{|c|}{ RANGOS DE VARIACIÓN } \\
\hline \multirow{5}{*}{ Autobús } & Tiempo de viaje & Actual - $20 \%$ & Actual & Actual $+20 \%$ \\
\hline & Coste del billete & Actual - $20 \%$ & Actual & Actual $+20 \%$ \\
\hline & Número de servicios al día & Actual & Actual $+20 \%$ & Actual $+50 \%$ \\
\hline & Características del vehículo & \multicolumn{3}{|c|}{ Mejorado un nivel } \\
\hline & Ruta & \multicolumn{3}{|c|}{ Actual } \\
\hline \multirow{3}{*}{ Vehículo privado } & Tiempo de viaje & \multicolumn{3}{|c|}{ Actual } \\
\hline & Coste de viaje & \multicolumn{3}{|c|}{ Actual } \\
\hline & Ruta & \multicolumn{3}{|c|}{ Actual } \\
\hline \multirow{4}{*}{ Ferrocarril } & Tiempo de viaje & \multicolumn{3}{|c|}{ Actual } \\
\hline & Coste de viaje & \multicolumn{3}{|c|}{ Actual } \\
\hline & Número de servicios al día & \multicolumn{3}{|c|}{ Actual } \\
\hline & Existencia de transbordo & \multicolumn{3}{|c|}{ Actual } \\
\hline
\end{tabular}

Una vez recalculados los mejores diseños, se optó por un experimento de 9 escenarios diferentes, que se dividieron en 3 bloques, a realizar correlativamente uno a cada entrevistado, con el mismo objetivo de disminuir el tiempo total de la encuesta. Mediante esta metodología, nos aseguramos de que cada bloque se ha empleado el mismo número de veces que los demás, y que la asignación a cada usuario ha sido aleatoria.

Los diseños experimentales finales resultaron, por tanto, como aparecen en la Tabla 4-7 para el experimento de elección entre autobús y vehículo privado y en la Tabla 4-8 para la comparación del autobús y el ferrocarril:

Tabla 4-7. Diseño definitivo del experimento PD autobús - vehículo privado

\begin{tabular}{|c|c|c|c|c|c|c|}
\hline & \multicolumn{5}{|c|}{ AUTOBÚS } & \multirow{2}{*}{$\begin{array}{l}\text { VEHÍCULO } \\
\text { PRIVADO }\end{array}$} \\
\hline $\begin{array}{c}\mathbf{N}^{\circ} \\
\text { BLOQUE }\end{array}$ & TIEMPO & COSTE & No SERVICIOS & VEHÍCULO & RUTA & \\
\hline \multirow{3}{*}{1} & Actual - 20\% & Actual & Actual $+20 \%$ & Actual & Actual & \multirow{3}{*}{$\begin{array}{c}\text { Tiempo, coste y } \\
\text { ruta con valores } \\
\text { actuales }\end{array}$} \\
\hline & Actual $+20 \%$ & Actual $+20 \%$ & Actual $+20 \%$ & Actual & Actual & \\
\hline & Actual - $20 \%$ & Actual $+20 \%$ & Actual $+50 \%$ & Mejorado un nivel & Actual & \\
\hline \multirow{3}{*}{2} & Actual - $20 \%$ & Actual - $20 \%$ & Actual & Actual & Actual & \multirow{3}{*}{$\begin{array}{c}\text { Tiempo, coste y } \\
\text { ruta con valores } \\
\text { actuales }\end{array}$} \\
\hline & Actual & Actual & Actual $+50 \%$ & Actual & Actual & \\
\hline & Actual & Actual - $20 \%$ & Actual $+20 \%$ & Mejorado un nivel & Actual & \\
\hline \multirow{3}{*}{3} & Actual $+20 \%$ & Actual - $20 \%$ & Actual $+50 \%$ & Actual & Actual & \multirow{3}{*}{$\begin{array}{c}\text { Tiempo, coste y } \\
\text { ruta con valores } \\
\text { actuales }\end{array}$} \\
\hline & Actual $+20 \%$ & Actual & Actual & Mejorado un nivel & Actual & \\
\hline & Actual & Actual $+20 \%$ & Actual & Actual & Actual & \\
\hline
\end{tabular}


Tabla 4-8. Diseño definitivo del experimento PD autobús - ferrocarril

\begin{tabular}{|c|c|c|c|c|c|c|}
\hline \multicolumn{6}{|c|}{ AUTOBÚS } & \multirow[b]{2}{*}{ FERROCARRIL } \\
\hline $\begin{array}{c}\mathrm{N}^{0} \\
\text { BLOQUE }\end{array}$ & TIEMPO & COSTE & $\mathrm{N}^{\circ}$ SERVICIOS & VEHÍCULO & RUTA & \\
\hline \multirow{3}{*}{1} & Actual - $20 \%$ & Actual & Actual $+20 \%$ & Actual & Actual & \multirow{3}{*}{$\begin{array}{l}\text { Tiempo, coste, } \\
\mathrm{n}^{0} \text { servicios y } \\
\text { transbordo con } \\
\text { valores actuales }\end{array}$} \\
\hline & Actual $+20 \%$ & Actual $+20 \%$ & Actual $+20 \%$ & Actual & Actual & \\
\hline & Actual - $20 \%$ & Actual $+20 \%$ & Actual $+50 \%$ & Mejorado un nivel & Actual & \\
\hline \multirow{3}{*}{2} & Actual - $20 \%$ & Actual - $20 \%$ & Actual & Actual & Actual & \multirow{3}{*}{$\begin{array}{c}\text { Tiempo, coste, } \\
\mathrm{n}^{0} \text { servicios y } \\
\text { transbordo con } \\
\text { valores actuales }\end{array}$} \\
\hline & Actual & Actual & Actual $+50 \%$ & Actual & Actual & \\
\hline & Actual & Actual - $20 \%$ & Actual $+20 \%$ & Mejorado un nivel & Actual & \\
\hline \multirow{3}{*}{3} & Actual $+20 \%$ & Actual - $20 \%$ & Actual $+50 \%$ & Actual & Actual & \multirow{3}{*}{$\begin{array}{c}\text { Tiempo, coste, } \\
\mathrm{n}^{0} \text { servicios y } \\
\text { transbordo con } \\
\text { valores actuales }\end{array}$} \\
\hline & Actual $+20 \%$ & Actual & Actual & Mejorado un nivel & Actual & \\
\hline & Actual & Actual $+20 \%$ & Actual & Actual & Actual & \\
\hline
\end{tabular}

Puesta en práctica del diseño definitivo, previa a la realización de la encuesta.

Tras la prueba del nuevo diseño experimental, se determinó que resultaba más agradable a los entrevistados, al incluir valores actuales para las variables de política, haciendo más realistas los escenarios, además de disminuir ligeramente la duración de la encuesta. Por tanto, este fue el diseño definitivo que se empleó en la fase de recopilación de datos.

\subsubsection{Realización de la Encuesta}

Por último, en cuanto a los aspectos prácticos de realización de la encuesta, se planteó la posibilidad de emplear soporte informático, dadas sus ventajas, enumeradas por Polak [117]:

- Facilitar la realización de diferentes formularios de encuesta para cada entrevistado, sin necesitar de emplear tarjetas o cuestionarios distintos, o incluso de calcular en gabinete los escenarios a plantear, provocando la necesidad de contactar posteriormente con el mismo usuario.

- Los entrevistados oyen y ven las preguntas, lo que homogeneiza los resultados, haciéndolos más independientes del encuestador que corresponda, además de mejorar su comprensión. 
- El hecho de disponer de respuestas tipo puede simplificar la elección de los usuarios. Por ejemplo, se puede disponer de una base de datos con las direcciones o, en nuestro caso, los posibles orígenes y destinos.

- Se pueden detectar durante la propia encuesta inconsistencias o incoherencias en las respuestas del entrevistado. Incluso, considerando las respuestas ya contabilizadas en cada momento, se pueden eliminar preguntas que fueran irrelevantes o cuya respuesta se pueda deducir a partir de otras.

- En experimentos de Preferencias Declaradas, se puede colocar las preguntas y alternativas en un orden aleatorio, o incluso adaptar los escenarios in situ según las respuestas previas del entrevistado.

- Por último, una interesante ventaja es la relativa a la percepción de los entrevistados. En este sentido, Polak [117] indica que esta reacción es, en general, extremadamente favorable, lo cual ha sido constatado in situ durante la realización de las encuestas. De hecho, parece suceder que los entrevistados perciben una mayor "seriedad" en las encuestas realizadas con medios informáticos, dedicando un mayor interés y aportando respuestas más elaboradas. Además, el porcentaje de respuesta aumenta en general, con respecto a las encuestas realizadas en papel, al asumir en cierto modo los entrevistados que los datos aportados se tratarán de forma más anónima.

Por el contrario, como también indica Polak [117], las principales limitaciones son las relativas a la potencia del hardware empleado, que suele ser inversamente proporcional a su posibilidad de transporte, y al tamaño de la pantalla de visualización, que puede hacer que ciertos datos no puedan ser presentados de forma simultánea.

Así pues, a la vista de las numerosas ventajas, y conocidos los posibles inconvenientes, se decidió finalmente la realización de las encuestas mediante PDA's, en las cuales se instaló una hoja de cálculo de distribución libre que, mediante el empleo de macros, elaboraba los cuestionarios personalizados de cada usuario.

El formulario completo de la encuesta se adjunta en el Anexo 2, aunque en la Figura 4-2 se presentan algunas de las pantallas de la misma: 
Figura 4-2. Formulario de encuesta (versión reducida)
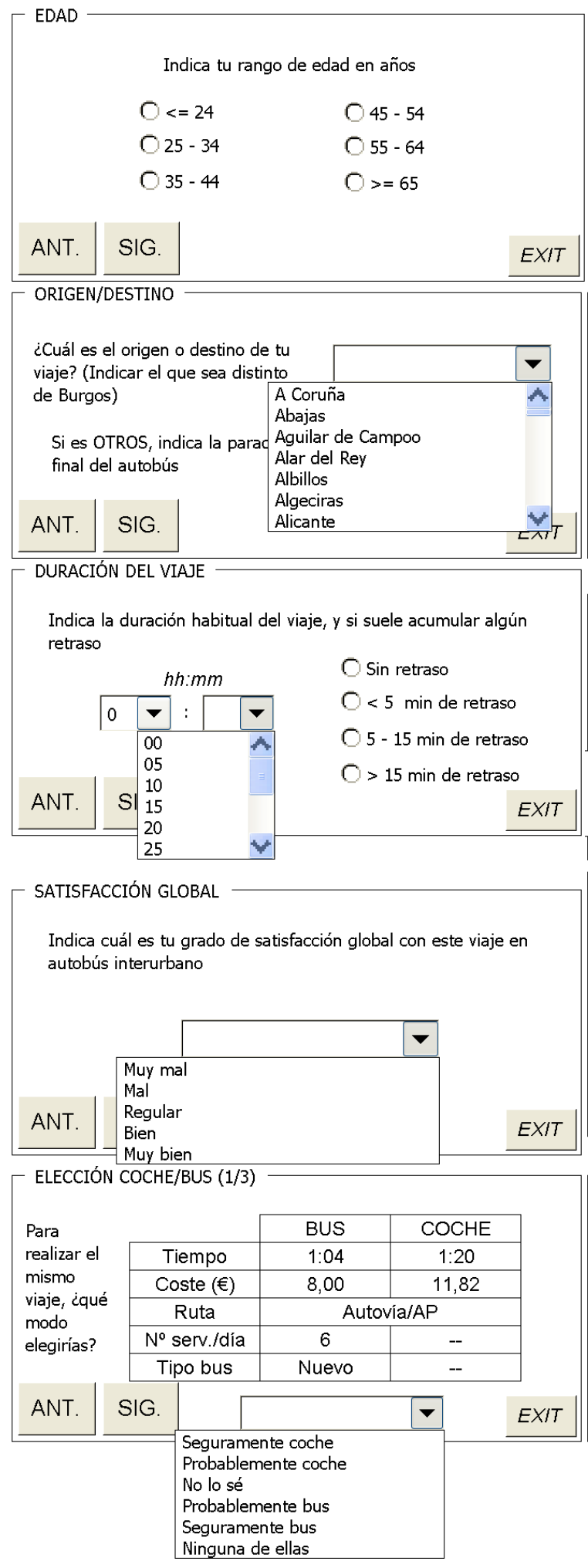

DISPONES DE...

Indica si tienes carnet de conducir, $y$ si podrías emplear un vehículo privado para realizar este viaje

\section{$\Gamma$ Carnet de conducir \\ Г Coche/moto}

\begin{tabular}{|c|c|c|c|}
\hline ANT. & SIG. & & EXIT \\
\hline \multicolumn{4}{|c|}{ MOTIVO DEL VIAJE } \\
\hline \multicolumn{4}{|c|}{ Indica la razón por la que realizas el viaje } \\
\hline & Trabajo & Ocio & \\
\hline & Estudio & Sanidad & \\
\hline & Compras & Asuntos personales & \\
\hline & & Otros & \\
\hline ANT. & SIG. & & EXIT \\
\hline
\end{tabular}

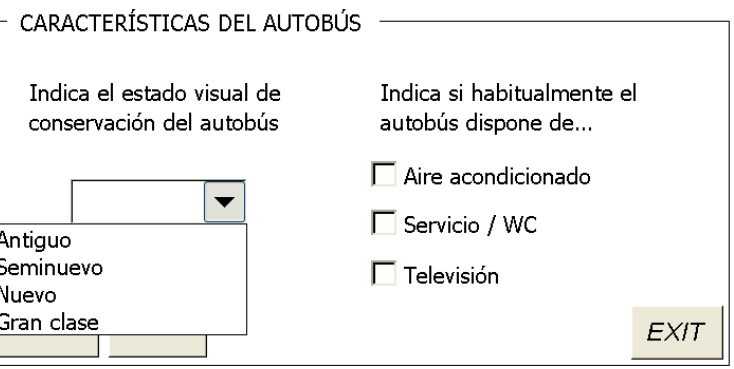

FIDELIDAD COMO VIAJERO

En las mismas condiciones del viaje actual...

¿Si tuvieras disponible otro medio de ¿Recomendarías a familiares o transporte, segurías viajando en amigos realizar este viaje en autobús? autobús?

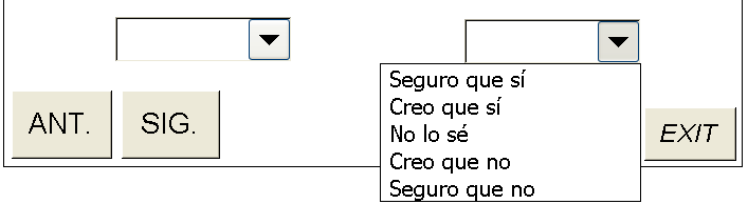

ELECCIÓN TREN/BUS (1/3)

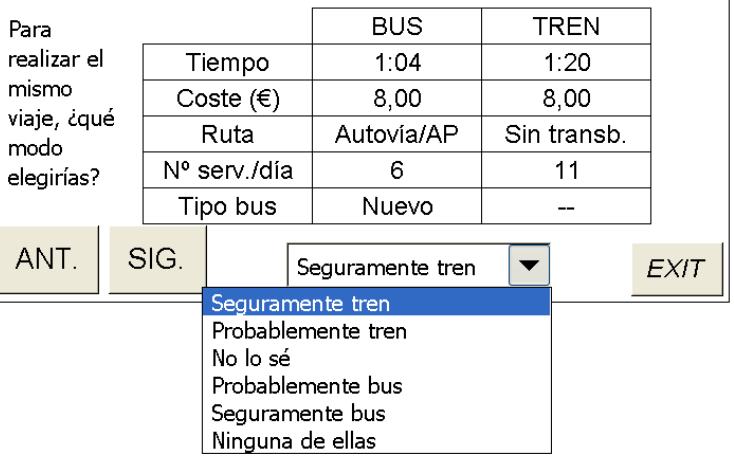


En cualquier momento se permitía la finalización de la encuesta por parte del entrevistado $\mathrm{y}$, además, al final se incluía una pantalla para que indicaran los comentarios $\mathrm{u}$ observaciones que consideraran convenientes.

Para no entorpecer el funcionamiento normal del lugar emplazamiento de las encuestas, que, como ya se ha indicado, fue la estación de autobuses de la ciudad de Burgos, únicamente se ubicó simultáneamente, como máximo, a dos encuestadoras, las cuales disponían de la suficiente experiencia y eran conocedoras del tema de estudio. Otro beneficio implícito obtenido así fue la máxima coherencia entre todas las encuestas, habiendo establecido previamente con las encuestadoras el significado de cada pregunta y cómo debían exponérsela a los entrevistados.

Además, conociendo que el proceso de realización de encuestas precisa un estado positivo por parte del encuestador, se decidió que éstos no trabajaran en la toma de datos durante más de 3 horas seguidas. Así, la encuesta se realizó en bloques de tres horas, durante días laborables, en los meses de Febrero y Marzo del año 2009.

En total, se entrevistó a 849 personas, aunque no todas contestaran la encuesta de forma completa. Los análisis y descripciones estadísticas completas de la muestra figuran en apartados posteriores. 


\subsection{Modelización de la Satisfacción Global del Usuario y su Relación con la Demanda}

En primer lugar, trataremos los principios metodológicos a aplicar correspondientes a la modelización de la satisfacción del usuario y su relación con la demanda de un determinado modo de transporte.

Así, se expondrá básicamente la metodología empleada en los modelos de elección discreta, para, a continuación, indicar los principios que rigen la determinación de la disponibilidad al pago. Además, dado que los modelos más adecuados para datos de encuestas de satisfacción de tipo escalamiento son los de tipo ordinal, se presentará también una breve aproximación a sus fundamentos teóricos.

Por último, dado que el objetivo de la investigación es determinar no sólo las mejores modelizaciones tanto de la satisfacción global del usuario como de su elección modal, sino también la relación existente entre ambas, se presentará una metodología de detección de variables relevantes en uno, otro o ambos criterios. Así, se dedicará un punto exclusivo al análisis de la interacción entre satisfacción de los usuarios con la mayor o menor probabilidad de que vuelvan a emplear el servicio de autobuses interurbanos.

\subsubsection{Modelización mediante Técnicas de Elección Discreta}

Aunque encontramos interesantes experiencias de modelización de la demanda de transporte público no basadas en modelos de elección discreta, como la guía de Balcombe et al [16], los modelos basados en la teoría de la utilidad aleatoria son los más habitualmente empleados para analizar el reparto modal.

Los modelos de elección discreta son modelos de tipo desagregado, que tienen su base fundamental en la Teoría de la Utilidad Aleatoria, basados en técnicas probabilísticas, frente a los de tipo determinista, que tratan de indicar de forma exacta cuál es la alternativa a elegir. Dicha Teoría se apoya en cuatro hipótesis básicas [36]:

1. Los individuos son considerados "homo economicus", es decir, pertenecientes a una población homogénea $Q$, que actúan siempre de forma racional, maximizando la utilidad en sus elecciones. Se supone además que tienen información perfecta, y que elegirán la alternativa más útil de entre aquéllas que tienen disponibles, sujetos a sus restricciones. 
2. Cada individuo $q$ tiene un determinado conjunto de alternativas disponibles $A_{q}$, entre las que realizará su elección.

3. Cada alternativa $A_{i q}$ tiene una utilidad determinada, que representa la bondad de la elección $i$ para el usuario $q$. Dicha utilidad $U_{i q}$ se compone de dos partes principales: una representativa o sistemática y otra aleatoria, que comprende los errores probabilísticos.

$$
U_{i q}=V_{i q}+\varepsilon_{i q}
$$

Donde, $\mathrm{U}_{\mathrm{iq}}$ : utilidad de la alternativa i para el usuario $\mathrm{q}$

$\mathrm{V}_{\mathrm{iq}}$ : utilidad representativa de la alternativa i para el usuario $\mathrm{q}$

$\varepsilon_{\mathrm{iq}}$ : término de error para la alternativa i y el usuario $\mathrm{q}$

La parte representativa es función de los atributos (variables independientes), relativos tanto al usuario como a la alternativa en evaluación. Habitualmente, se expresa de forma lineal, a través de la incorporación de una serie de parámetros (coeficientes), que representan el peso de cada una de las variables consideradas. Así, la expresión general de la misma resulta similar a la que sigue:

$$
V_{i q}=\sum_{k}\left(\theta_{i k q} \cdot x_{i k q}\right)
$$

Donde, $\mathrm{V}_{\mathrm{iq}}$ : utilidad representativa de la alternativa i para el usuario $\mathrm{q}$

$\mathrm{x}_{\mathrm{ikq}}$ : atributo $\mathrm{k}$ de la alternativa i para el usuario $\mathrm{q}$

$\theta_{\mathrm{ikq}}$ : parámetro asociado al atributo $\mathrm{k}$ de la alternativa i para el usuario $\mathrm{q}$

Por otro lado, la parte aleatoria refleja otros factores que pueden inducir errores en la modelación, como por ejemplo: la idiosincrasia y gustos particulares de los individuos, los datos desconocidos o con medición incorrecta...

4. Los usuarios elegirán siempre la alternativa de máxima utilidad de entre las disponibles. Entonces, dado que el término de error es, en principio, desconocido para el modelador, no es posible precisar con certeza cuál será la alternativa elegida por los usuarios, de modo que únicamente podremos establecer la probabilidad de elección de la misma. Dicha probabilidad será igual a la probabilidad de que la alternativa $i$ tenga una utilidad superior al resto.

$$
\begin{gathered}
\operatorname{Pr} o b_{i q}=\operatorname{Pr} o b\left(U_{i q} \geq U_{j q}\right) \forall A_{j} \\
\operatorname{Pr} o b_{i q}=\operatorname{Pr} o b\left(V_{i q}+\varepsilon_{i q} \geq V_{j q}+\varepsilon_{j q}\right)=\operatorname{Pr} o b\left(V_{i q}-V_{j q} \geq \varepsilon_{j q}-\varepsilon_{i q}\right) \quad \forall A_{j}
\end{gathered}
$$


Donde, $\mathrm{U}_{\mathrm{iq}}$ : utilidad de la alternativa i para el usuario $\mathrm{q}$

$\mathrm{V}_{\mathrm{iq}}$ : utilidad representativa de la alternativa i para el usuario $\mathrm{q}$

$\varepsilon_{\mathrm{iq}}$ : término de error para la alternativa i y el usuario q

De aquí se deduce que la probabilidad de elección de una alternativa depende de los valores de las utilidades medibles o sistemáticas de todas las alternativas disponibles y de la función de distribución de los residuos aleatorios $\varepsilon_{\mathrm{ij}}$.

\section{Principales Tipologías de Modelos}

De acuerdo con la formulación anterior, para poder predecir si una alternativa es elegida, debemos comparar el valor de su utilidad con el del resto de opciones. Finalmente, para expresar dicha comparación en términos de probabilidad, que debe estar comprendida entre 0 y 1, existe una gran variedad de transformaciones matemáticas, cuyas gráficas tienen en general forma de S. Los dos modelos más habitualmente empleados han sido los modelos logit multinomial (MNL) y jerárquico (HL), de los cuales se presentarán a continuación sus principales formulaciones. También serán presentados brevemente otros modelos de elección discreta, como los modelos probit multinomial (MNP) y logit mixto (ML).

\section{1) Modelo logit multinomial (MNL) [111].}

El modelo logit multinomial es el modelo de elección discreta más sencillo, y también el más habitualmente empleado para la simulación de la elección modal de los usuarios. La principal hipótesis del mismo es que los residuos aleatorios se distribuyen Gumbel IID (independientes e idénticamente distribuidos) con media nula y matriz de varianza-covarianza diagonal [36]. Introduciendo la función de distribución logística en la ecuación (4-5), las probabilidades de elección de cada alternativa resultan:

$$
P_{i q}=\frac{e^{\lambda V_{i q}}}{\sum_{A_{j} \in A_{q}} e^{\lambda V_{j q}}} \Rightarrow P_{i q}=\frac{e^{V_{i q}}}{\sum_{A_{j} \in A_{q}} e^{V_{j q}}}
$$

Donde, $\mathrm{V}_{\mathrm{iq}}$ : utilidad representativa de la alternativa i para el usuario $\mathrm{q}$

$\mathrm{A}_{\mathrm{q}}$ : conjunto de alternativas disponibles para el usuario $\mathrm{q}$

$\lambda$ : parámetro relacionado con la varianza de los errores, que, al ser inestimable por separado de los coeficientes $\theta_{\mathrm{ikq}}$ de las funciones de utilidad, que se suele normalizar, asumiéndolo igual a 1 
Una característica del modelo MNL es que, a partir del mismo, se pueden derivar de forma bastante sencilla las ecuaciones de las elasticidades directas y cruzadas de la demanda de un determinado modo de transporte respecto de una variable independiente concreta.

Así, la elasticidad directa puntual, que es la variación de la probabilidad de elegir la alternativa $A_{i}$ respecto a una variación marginal en su atributo $x_{i k q}$, teniendo en cuenta la formulación habitualmente lineal de las funciones de utilidad, viene dada por:

$$
E_{P_{i q}, x_{i k q}}=\frac{\partial P_{i q} / P_{i q}}{\partial x_{i k q} / x_{i k q}}=\frac{\partial P_{i q}}{\partial x_{i k q}} \cdot \frac{x_{i k q}}{P_{i q}} \Rightarrow E_{P_{i q}, x_{i k q}}=\theta_{i k q} \cdot x_{i k q} \cdot\left(1-P_{i q}\right)
$$

Donde, $\mathrm{P}_{\mathrm{iq}}$ : probabilidad de que el usuario q elija la alternativa $\mathrm{i}$

$\mathrm{x}_{\mathrm{ikq}}$ : atributo $\mathrm{k}$ de la alternativa i para el usuario $\mathrm{q}$

$\theta_{\mathrm{ikq}}$ : parámetro asociado al atributo $\mathrm{k}$ de la alternativa i para el usuario $\mathrm{q}$

Mientras que las elasticidades cruzadas puntuales, o variación de la probabilidad de elegir la alternativa $A_{i}$ respecto a una variación marginal en un atributo de otra opción $x_{j k q}$, vienen dadas por:

$$
E_{P_{i q}, x_{j k q}}=\frac{\partial P_{i q} / P_{i q}}{\partial x_{j k q} / x_{j k q}}=\frac{\partial P_{i q}}{\partial x_{j k q}} \cdot \frac{x_{j k q}}{P_{i q}} \Rightarrow E_{P_{i q}, x_{j k q}}=-\theta_{j k q} \cdot x_{j k q} \cdot P_{j q}
$$

Donde, $\mathrm{P}_{\mathrm{iq}}$ : probabilidad de que el usuario q elija la alternativa $\mathrm{i}$

$\mathrm{x}_{\mathrm{jkq}}$ : atributo $\mathrm{k}$ de la alternativa $\mathrm{j}$ para el usuario $\mathrm{q}$

$\theta_{\mathrm{jkq}}$ : parámetro asociado al atributo $\mathrm{k}$ de la alternativa j para el usuario q

Una conclusión destacable es que las elasticidades puntuales cruzadas cuando se modifica un atributo de la alternativa $A_{j}$, según el modelo logit multinomial, son independientes de la alternativa $A_{i}$ elegida $\mathrm{y}$, por tanto, iguales para todas. Este resultado, aparentemente ilógico, se debe a la necesidad de suponer funciones IID en la generación del modelo. 
2) Modelo logit jerárquico (HL) [111].

El modelo logit jerárquico presenta ventajas sobre el multinomial en cuanto a que permite considerar, al menos de forma simplificada, la dependencia entre alternativas, a la vez que conserva una expresión analítica similar.

La principal característica que lo define es el hecho de que los subconjuntos de alternativas relacionadas entre sí se agrupan en jerarquías, o nidos. Cada nido se puede considerar como una alternativa compuesta, y comparar su utilidad con la de los nidos o alternativas independientes restantes.

Otra característica, ya citada en cierto modo, es que se puede calibrar de forma similar a la del logit multinomial, pero de forma secuencial. Así, en primer lugar se estima un MNL para modelizar la elección entre las alternativas internas al nido y, a continuación, se calcula la utilidad compuesta del nido, que se comparará con el resto de alternativas o nidos para determinar las probabilidades de elección. Finalmente, la probabilidad de elección de una alternativa dentro del nido seguirá un formulación similar al MNL, pero condicionada a la elección del nido.

En el modelo logit multinomial interno al nido, se excluyen aquéllos atributos que tengan el mismo valor para todas las alternativas del mismo, ya que no aportan variaciones en la utilidades de éstas. Por el contrario, estos atributos se considerarán en la utilidad compuesta del nido, que tiene la formulación que sigue:

$$
\begin{gathered}
V_{\text {nido }}=\phi \cdot E M U+\sum_{k} \alpha_{k} \cdot w_{k} \\
E M U=\ln \sum_{A_{j} \in A_{q}} \exp \left(V_{j}\right)
\end{gathered}
$$

Donde, $\mathrm{V}_{\text {nido: }}$ utilidad compuesta del nido $\mathrm{i}$

EMU: máxima utilidad esperada entre las alternativas del nido

$\mathrm{w}_{\mathrm{k}}$ : atributos de igual valor para todas las alternativas del nido

$\Phi$ y $\alpha_{\mathrm{k}}$ : parámetros a determinar en la calibración

$\mathrm{V}_{\mathrm{j}}$ : utilidad representativa de la alternativa $\mathrm{j}$, suprimiendo los atributos $\mathrm{w}_{\mathrm{k}}$

Una característica que debe cumplir el parámetro $\Phi$ es que esté comprendido entre 0 y 1 (sin valer 0 en ningún caso). En otras circunstancias, si fuera 0 o nulo, resultaría que el mejorar una alternativa interna al nido no aumenta la probabilidad de elección del nido, lo cual es ilógico, y, si fuera mayor a 1, no sólo aumentaría la probabilidad de 
elección de la opción mejorada, sino también la de las del resto del nido. En el caso particular de que sea muy próximo a la unidad, el modelo jerárquico se comporta de modo similar a un MNL, por lo que se puede ir directamente a esta segunda formulación, más sencilla y con una menor cantidad de parámetros a estimar.

Finalmente, las probabilidades de elección del nido frente al resto de nidos o alternativas se calculan de modo similar al MNL:

$$
P_{\text {nido }}=\frac{e^{V_{\text {nido }}}}{\sum e^{V}}
$$

Donde, $\mathrm{P}_{\text {nido: }}$ : probabilidad de elección del nido

$\mathrm{V}_{\text {nido }}$ : utilidad compuesta del nido

V: utilidades de las alternativas independientes y nidos restantes

Por otra parte, las probabilidad de elección de las alternativas internas al nido son condicionadas a la de haber escogido el nido. Así:

$$
P_{i}=P(i / \text { nido }) \cdot P(\text { nido })=\frac{e^{V_{i}}}{\sum_{\text {nido }} e^{V_{i}}} \cdot \frac{e^{V_{\text {nido }}}}{\sum e^{V}}
$$

Donde, $\mathrm{P}_{\mathrm{i}}$ : probabilidad de elección de la alternativa i, interna al nido

$\mathrm{P}_{\mathrm{i} / \text { nido: }}$ : probabilidad de elección de la alternativa $\mathrm{i}$, una vez que se ha escogido el nido

$\mathrm{P}_{\text {nido: }}$ probabilidad de elección del nido

$\mathrm{V}_{\mathrm{i}}$ : utilidad de la alternativa $\mathrm{i}$, interna al nido

$\mathrm{V}_{\text {nido: }}$ utilidad compuesta del nido

V: utilidades de las alternativas independientes y nidos restantes

Con esta estructura, se pueden ir formando estructuras jerárquicas todo lo complejas que se desee, con la condición de que los parámetros $\Phi$ de los nidos sean mayores a medida que alcanzamos niveles superiores, y siempre comprendidos entre 0 y 1 . La desventaja del modelo es que el analista debe ir generando esas estructuras, hasta lograr encontrar la óptima. 
3) Modelo probit multinomial (MNP) [111].

El modelo probit se diferencia del resto en que, en éste, los errores siguen una distribución normal, con media cero y una matriz de varianza-covarianza cualquiera. Debido a esta característica, las alternativas pueden estar correlacionadas entre sí, lo que era imposible en el logit multinomial. Incluso, se pueden incluir funciones de utilidad flexibles, permitiendo modelizar variaciones aleatorias en los gustos de los individuos, frente al comportamiento homogéneo supuesto en el MNL.

Teniendo, entonces, en cuenta la distribución de los errores -y de los parámetros, si existe-, e introduciéndola en la ecuación (4-5), se pueden obtener las probabilidades de elección, a partir de la distribución normal estándar. Así, para el caso binario, donde sólo haya dos alternativas de elección disponibles, resulta:

$$
\left.\begin{array}{l}
U_{1}(\theta, Z)=V_{1}(\theta, Z)+\varepsilon_{1}(\theta, Z) \\
U_{2}(\theta, Z)=V_{2}(\theta, Z)+\varepsilon_{2}(\theta, Z)
\end{array}\right\} \Rightarrow P_{1}(\theta, Z)=\phi\left(\frac{V_{1}-V_{2}}{\sigma_{\varepsilon}}\right)
$$

Donde, $\mathrm{U}_{1}(\theta, \mathrm{Z})$ y $\mathrm{U}_{2}(\theta, \mathrm{Z})$ : utilidades de las alternativas 1 y 2

$\mathrm{V}_{1}(\theta, \mathrm{Z})$ y $\mathrm{V}_{2}(\theta, \mathrm{Z})$ : utilidades representativas de las alternativas 1 y 2

$\varepsilon_{1}(\theta, Z)$ y $\varepsilon_{2}(\theta, Z)$ : términos de error de las alternativas 1 y 2 , que distribuyen según una normal con media nula y varianzas $\sigma_{1}^{2}$ y $\sigma_{2}^{2}$

$\mathrm{P}_{1}(\theta, Z)$ y $\mathrm{P}_{2}(\theta, Z)$ : probabilidades de elección de las alternativas 1 y 2

$\sigma_{\varepsilon}=\sigma_{1}^{2}+\sigma_{2}^{2}-2 \rho \sigma_{1} \sigma_{2}$ ( $\rho$ es el coeficiente de correlación entre alternativas)

$\Phi$ : función de distribución normal acumulada estándar

De forma análoga a como ocurría en el MNL, los parámetros $\theta$ de las funciones de utilidad no pueden ser estimados de forma separada a las desviaciones estándar, por lo que se suelen normalizar una de ellas, asumiéndola igual a la unidad.

Una característica especial de los modelos de tipo probit es que se pueden incluir variaciones en los gustos de los usuarios, haciendo que los parámetros $\theta$ no sean constantes para todos los individuos, sino que sigan una distribución normal multivariada. En ese caso, los residuos $\varepsilon$ pueden ser omitidos de la fórmula de la utilidad, al ser considerados como parámetros específicos de cada alternativa [32]. 
4) Modelo logit mix to (ML) [111].

El modelo logit mixto es la variante más compleja y avanzada de los modelos de elección discreta.

La formulación de la función de utilidad puede ser similar a la extraída de las ecuaciones (4-2) y (4-3). Sin embargo, su principal característica es que el vector de parámetros $\theta$ varía de forma aleatoria, en función de las preferencias de cada individuo, lo cual hace que pueda existir correlación entre alternativas. Además, el error $\varepsilon$ también tiene una distribución aleatoria, independiente de los anteriores.

Si se modifica la formulación, representando los parámetros $\theta$ como la suma de la media poblacional $\theta^{*}$ y la desviación individual $\eta$, que representa las preferencias de cada entrevistado, se puede obtener una formulación alternativa como la que sigue:

$$
U_{i q t}=\theta_{k}^{*} x_{i q k t}+\eta_{q k} x_{i q k t}+\varepsilon_{i q t}
$$

Donde, $\mathrm{U}_{\text {iqt }}$ : utilidad de la alternativa i para el usuario $\mathrm{q}$ en el instante $\mathrm{t}$

$\mathrm{x}_{\mathrm{ikq}}$ : valor del atributo $\mathrm{k}$ de la alternativa i para el usuario $\mathrm{q}$ en el instante $\mathrm{t}$ $\theta^{*}$ : media poblacional del valor del parámetro asociado al atributo $\mathrm{k}$ $\eta_{\text {iqkt: }}$ variación respecto de la media del valor del parámetro asociado al atributo $\mathrm{k}$ para la alternativa i y el usuario $\mathrm{q}$ en el instante $\mathrm{t}$ $\varepsilon_{\text {iqt }}$ : término de error para la alternativa i y el usuario q en el instante $t$

La parte no observada de la utilidad (suma de los términos de error y las variaciones individuales) puede generar correlaciones entre alternativas, variaciones en los gustos...

La expresión de la formulación de cálculo de las probabilidades de elección de las diferentes alternativas será función de la distribución que sigan las variaciones de los parámetros, así que en cada caso tendrá una expresión distinta. 


\section{Estimación y Especificación de Modelos de Elección Discreta}

Para conseguir una especificación correcta de un modelo de elección discreta, se deben considerar una serie de decisiones: la tipología de modelo óptima, las variables independientes a incluir en él, la estructura de la función de utilidad y las alternativas disponibles [111].

El objetivo básico es buscar un modelo con el grado de complejidad adecuado, es decir, lo suficientemente complejo como para representar de forma correcta la realidad, pero no de forma indefinida. De hecho, puede ser útil tratar de encontrar una formulación relativamente sencilla, que permita una rápida estimación y resolución del mismo [111].

En general, a pesar de que la función de utilidad tuviera una formulación de tipo lineal, los parámetros $\theta$ no pueden ser estimados mediante técnicas de mínimos cuadrados, al no conocer las probabilidades de elección de las alternativas, sino la efectivamente seleccionada. Por ello, habitualmente se emplea el método de máxima verosimilitud, que trata de determinar, de entre todos los posibles valores de los mismos, aquéllos que maximizan el grado de "acierto" del modelo.

En dicha metodología, se construye una función de verosimilitud $L(\theta)$ como el producto de las probabilidades de que cada individuo escoja la alternativa que efectivamente eligió [111]. Entonces, maximizando el valor de esta función, se obtienen los valores de los parámetros que hacen que el modelo reproduzca lo mejor posible la realidad observada.

Así, si se tiene una muestra de $Q$ individuos, de los cuales se conoce su elección observada, y utilidades que son dependientes de los parámetos $\theta$, la función de verosimilitud, asumiendo que las observaciones son independientes, resulta:

$$
L(\theta)=\prod_{q} \prod_{i} P_{i q}^{g_{i q}}
$$

Donde, $\mathrm{L}(\theta)$ : verosimilitud de la muestra $\mathrm{Q}$, en función de los parámetros $\theta$

$\mathrm{P}_{\mathrm{iq}}$ : probabilidad, estimada según el modelo, de que el usuario q escoja la alternativa i

$\mathrm{g}_{\mathrm{iq}}$ : variable dummy que vale 1 si usuario q escogió la alternativa i y 0 en otros casos

La maximización de esta función se realiza mediante los procedimientos habituales, aunque suele ser usual emplear su logaritmo neperiano, a menudo denotado como $l(\theta)$, que 
tiene una expresión más sencilla y se maximiza para los mismos valores de $\theta$ [111]. Dicha expresión resulta, teniendo en cuenta la ecuación anterior:

$$
l(\theta)=\ln [L(\theta)]=\ln \left[\prod_{q} \prod_{i} P_{i q}^{g_{i q}}\right]=\sum_{q} \sum_{i}\left(g_{i q} \cdot \ln P_{i q}\right)
$$

Donde, $1(\theta)$ : log-verosimilitud de la muestra Q, en función de los parámetros $\theta$

$\mathrm{L}(\theta)$ : verosimilitud de la muestra $\mathrm{Q}$, en función de los parámetros $\theta$

$\mathrm{P}_{\mathrm{iq}}$ : probabilidad, estimada según el modelo, de que el usuario q escoja la alternativa $\mathrm{i}$

$\mathrm{g}_{\mathrm{iq}}$ : variable dummy que vale 1 si usuario q escogió la alternativa i y 0 en otros casos

Se puede demostrar que los parámetros estimados según el método de máxima verosimilitud siguen una distribución asintóticamente normal y que la función $L R=-2 l(\theta)$ distribuye asintóticamente $\chi^{2}$ con $Q$ grados de libertad [20].

Una propiedad del modelo logit multinomial es que, aplicando el método de máxima verosimilitud, si todas las alternativas disponibles -excepto una- tienen constantes específicas, los porcentajes agregados de reparto modal obtenidos mediante enumeración muestral (promedio de las probabilidades de elección en las distintas observaciones) reproducen de forma exacta las proporciones de mercado observadas [111]. De hecho, estas constantes son específicamente calibradas para que se dé esta circunstancia.

De este modo, el ajuste agregado con el reparto modal observado no es un buen indicador de la calidad de un modelo, ya que, si se da la circunstancia anterior, sucede siempre. Por ello, se suelen emplear otros indicadores distintos, cuyas principales características se indican a continuación:

\section{1) El test-t de significatividad de los parámetros [111].}

Como se ha indicado anteriormente, se puede demostrar que los parámetros $\theta$ estimados por máxima verosimilitud distribuyen asintóticamente normales, con media 0 y varianza $\sigma$. Por tanto, se puede hacen un test de significatividad para cada uno de ellos.

Tomando como hipótesis nula que un parámetro no sea significativamente distinto de cero (es decir, que la media de un determinado parámetro sea nula), podemos generar 
un estadístico t como el siguiente, que se distribuye asintóticamente según una normal $\mathrm{N}(0,1) \cdot[111]$

$$
t_{k}=\frac{\theta_{k}^{*}-\theta_{k}}{\sigma_{k}}=\frac{\theta_{k}^{*}}{\sigma_{k}}
$$

Donde, $\mathrm{t}_{\mathrm{k}}$ : estadístico $\mathrm{t}$ del parámetro k-ésimo

$\theta^{*}$ : estimador de máxima verosimilitud del parámetro k-ésimo

$\theta_{\mathrm{k}}$ : valor promedio del parámetro k-ésimo

$\sigma_{\mathrm{k}}$ : desviación estándar $\mathrm{t}$ del parámetro k-ésimo

Por tanto, valores suficientemente grandes de este valor $t$ darán como resultado, para un determinado nivel de confianza, el rechazo de la hipótesis nula, siendo el parámetro estadísticamente distinto de cero. Así, si este valor es superior a 1,65, el parámetro asociado será estadísticamente significativo para un nivel de confianza del $90 \%$ y, si es mayor a 1,96 , para un nivel de confianza de $95 \%$.

En general, es interesante reducir al máximo el número de variables no significativas en un modelo, de acuerdo con el principio de parsimonia. Sin embargo, puede ser necesario, en determinadas circunstancias, mantener variables no significativas, si sus parámetros tienen el signo adecuado y son relevantes para la prognosis. Un breve resumen esquemático de lo expuesto se encuentra en la Tabla 4-9:

Tabla 4-9. Reglas de buena práctica de inclusión de variables en los modelos de elección discreta Fuente: Ortúzar y Willumsen [111]

\begin{tabular}{|c|c|c|c|}
\hline & & VARIABLES RELEVANTES & OTRAS VARIABLES \\
\hline \multirow{2}{*}{$\begin{array}{l}\text { Signo } \\
\text { correcto }\end{array}$} & Significativa & Inclusión & Inclusión \\
\hline & No significativa & Inclusión habitual & Posible eliminación \\
\hline \multirow{2}{*}{$\begin{array}{c}\text { Signo } \\
\text { incorrecto }\end{array}$} & Significativa & Grave problema - Revisar causas & Eliminación \\
\hline & No significativa & Problema - Revisar causas & Eliminación \\
\hline
\end{tabular}

En cuanto a las variables relativas a las características socioeconómicas del individuo, éstas se pueden incluir como constantes adicionales específicas de una o varias alternativas, como máximo en todas excepto una ya que, en caso contrario, sus parámetros resultan inestimables. Sin embargo, puede ser más interesante emplearlas para simular variaciones sistemáticas en los gustos, parametrizando los coeficientes del modelo, generalmente a través de variables dummy, de modo similar al que sigue:

$$
V_{i q}=\sum_{k}\left[\left(\theta_{i k q}+\sum_{s}\left(\theta_{i k q s} \cdot s_{i q s}\right)\right) \cdot x_{i k q}\right]
$$


Donde, $\mathrm{V}_{\mathrm{iq}}$ : utilidad representativa de la alternativa i para el usuario $\mathrm{q}$ $\mathrm{x}_{\mathrm{ikq}}$ : atributo $\mathrm{k}$ de la alternativa i para el usuario $\mathrm{q}$ $\theta_{\text {ikq }}$ : parámetro asociado al atributo $\mathrm{k}$ de la alternativa i para el usuario $\mathrm{q}$ $\theta_{\text {ikqs }}$ : parámetro asociado a la característica socioeconómica s y al atributo $\mathrm{k}$ de la alternativa i para el usuario $\mathrm{q}$

$\mathrm{s}_{\mathrm{iqs}}$ : variable dummy relativa a la característica socioeconómica s, incluida en la utilidad de la alternativa i para el usuario q

Este modo de inclusión de variaciones sistemáticas en los gustos permite, manteniendo una estructura sencilla en el modelo, obtener funciones de utilidad diferentes para cada individuo. Sin embargo, no se trata de variaciones aleatorias, sino deterministas, ya que individuos para los que todas las variables socioeconómicas consideradas sean iguales tendrán los mismos valores de los coeficientes de su función de utilidad y, por tanto, comportamientos idénticos.

2) El test de razón de verosimilitud [111].

Es un test útil cuando se desea comparar un modelo con otro obtenido como una versión restringida del primero, mediante transformaciones lineales. En ese caso, si los valores de log-verosimilitud para los modelos general y restringido son, respectivamente $l^{*}(\theta)$ y $l^{*}\left(\theta_{r}\right)$, el estadístico $L R=-2\left[l^{*}\left(\theta_{r}\right)-l^{*}(\theta)\right]$ distribuye asintóticamente $\chi^{2}$ con $r$ grados de libertad, siendo $r$ el número de restricciones lineales aplicadas [111].

A partir de esta propiedad, se pueden establecer los tests correspondientes para comprobar si ambos modelos son estadísticamente distintos.

3) El test de ajuste general [111].

Es un caso particular del test de razón verosimilitud cuando se toma como modelo restringido el modelo equiprobable, en el que las utilidades de todas las alternativas son nulas, o bien el modelo de sólo constantes, que reproduce a la perfección las proporciones de mercado observadas en la muestra.

Entonces, denominando respectivamente $l^{*}(0)$ y $l^{*}(C)$ a los valores de log-verosimilitud para estos modelos equiprobable y de sólo constantes, los estadísticos a comprobar serán -2 $\left[l^{*}(0)-l^{*}(\theta)\right]$ y $-2\left[l^{*}(C)-l^{*}(\theta)\right]$. En este caso, ambos distribuirán asintóticamente $\chi^{2}$ con $k$ y $k-c$ grados de libertad, respectivamente, siendo $k$ el número de atributos del modelo completo y $c$ el número de constantes específicas [111]. 
Comparando estos valores con la distribución $\chi^{2}$ para un determinado nivel de confianza, se obtiene como resultado si el modelo completo es estadísticamente diferente de los reducidos.

4) El índice $\rho^{2}[111]$.

El índice $\rho^{2}$ es un indicador que tratar de simular al coeficiente $\mathrm{R}^{2}$ de una regresión. Es decir, es un valor que oscila entre 0 y 1 , para indicar el grado de ajuste del modelo: desde ajuste nulo hasta ajuste perfecto.

Existen dos variantes para la formulación de este índice, considerando los modelos equiprobable y de sólo constantes. Las expresiones de obtención de dichos índices son las que siguen:

$$
\begin{aligned}
& \rho^{2}=1-\frac{l^{*}(\theta)}{l^{*}(0)} \\
& \hat{\rho}^{2}=1-\frac{l^{*}(\theta)}{l^{*}(C)}
\end{aligned}
$$

Donde, $\rho^{2}$ y $\hat{\rho}^{2}$ : índices de ajuste normal y corregido $1^{*}(\theta), 1^{*}(0)$ y $1^{*}(\mathrm{C})$ : valores de log-verosimilitud de los modelos a testear, equiprobable y de sólo constantes, respectivamente

Aunque ambos índices oscilan entre 0 y 1 , y su significado es idéntico en los valores extremos, los valores intermedios no tienen un sentido intuitivo directo. Sin embargo, el índice $\hat{\rho}^{2}$ obtenido con el modelo de sólo constantes, sí tiene relación con la distribución $\chi^{2}$, de modo que puede ser empleado en tests de hipótesis.

\section{5) El porcentaje correctamente predicho ó FPR (first preference recovery) [111].}

El porcentaje correctamente predicho es una medida que representa la proporción de observaciones respecto del total en que la alternativa de máxima utilidad -y, por tanto, de máxima probabilidad de elección- es la efectivamente seleccionada por el entrevistado.

Es un concepto intuitivo y sencillo, pero de interpretación engañosa en cierto sentido. Para evaluar la bondad de un modelo según este índice, es necesario comparar la probabilidad de éxito (chance recovery) de otro modelo sencillo, como el equiprobable, 
con la esperanza de acierto y la proporción de respuestas correctamente predichas de nuestro modelo. Dichos valores se obtienen de la formulación que sigue:

$$
\begin{aligned}
& C R=\frac{1}{Q} \cdot \sum_{q} \frac{1}{N_{q}} \\
& E R=\frac{1}{Q} \cdot \sum_{q} P_{q, \text { máx }}
\end{aligned}
$$

Donde, CR: probabilidad de éxito del modelo equiprobable

ER: esperanza de éxito del modelo a testar

$\mathrm{N}_{\mathrm{q}}$ : número de alternativas disponibles para el usuario $\mathrm{q}$

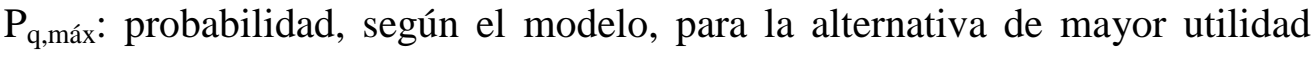
para el usuario $\mathrm{q}$

Así, a medida que el test FPR se acerque a su esperanza de éxito y supere a la probabilidad de acierto del modelo equiprobable, considerando además los valores de sus varianzas, el modelo calibrado tendrá un mejor ajuste [59].

\section{6) El índice de éxito predictivo [109].}

Para la obtención de este índice, el primer paso es la construcción de una tabla de éxito predictivo, como una matriz de $\mathrm{N}^{*} \mathrm{~N}$ celdas, donde $\mathrm{N}$ es el número de alternativas de elección del modelo diseñado. En las columnas de la tabla se colocan las elecciones predichas por el modelo y, en las filas, las elecciones observadas en la muestra.

El sumatorio por filas coincidirá con el número de entrevistados que eligieron una determinada alternativa y, la suma por columnas, la misma cantidad pero predicha por el modelo. Por otro lado, los elementos de la diagonal son las observaciones en las que la elección predicha coincide con la observada y, por tanto, la proporción que constituyen respecto al total resulta el test FPR anterior.

A partir de dicha tabla se puede obtener el índice de éxito predictivo, habitualmente denotado como $\sigma$, que es una medida de bondad de ajuste con significado similar al test FPR, pero válido para comparar modelos diferentes.

La expresión con la que se obtiene el citado índice oscila entre 0 y un valor $\sigma_{\text {máx }}$ que es función de la distribución de las elecciones entre modos. De este modo, es una mejor expresión del índice su versión normalizada $\sigma_{\text {norm }}$, cuya expresión se obtiene mediante la formulación siguiente [109]: 


$$
\left.\begin{array}{l}
\sigma=\sum_{j=1}^{N}\left(\frac{\sum_{i} N_{i j}}{\sum_{i j} N_{i j}} \cdot \sigma_{j}\right)=\sum_{j=1}^{N}\left(\frac{N_{i j}}{\sum_{i j} N_{i j}}-\left(\frac{\sum_{i} N_{i j}}{\sum_{i j} N_{i j}}\right)^{2}\right) \\
\sigma_{\max }=1-\sum_{j=1}^{N}\left(\frac{\sum_{i} N_{i j}}{\sum_{i j} N_{i j}}\right)^{2}
\end{array}\right\} \Rightarrow \sigma_{\text {norm }}=\sigma / \sigma_{\max }
$$

Donde, $\sigma, \sigma_{\text {máx }}$ y $\sigma_{\text {norm: }}$ índice de éxito predictivo, su máximo alcanzable y su valor normalizado

$\mathrm{N}_{\mathrm{ij}}$ : número de observaciones en que el usuario elige la alternativa $\mathrm{i}$, pero la predicha por el modelo es la $\mathrm{j}$

$\sigma_{\mathrm{j}}$ : índice de éxito predictivo parcial de la variable $\mathrm{j}$

Esta expresión normalizada oscila entre 0 y 1 y, a mayor valor del mismo, mejor reproduce el modelo la situación real. Sin embargo, es importante destacar que, de forma similar al test FPR, no tiene relación proporcional con el ajuste del modelo a las observaciones de la muestra, aunque sí es válido para comparar diferentes modelos entre sí.

Existen otros métodos de estimación de modelos de elección discreta, más adecuados cuando la toma de datos tiene una serie de características específicas. Así, por ejemplo, para muestras basadas en la elección conviene asignar unos pesos a las observaciones que sean función de la proporción de individuos que escogen cada alternativa.

Por último, para el caso de los modelos de tipo logit mixto, la expresión de cálculo de las probabilidades conduce a una formulación para la función de verosimilitud, cuyo máximo no puede obtenerse analíticamente. Entonces, es necesario trabajar con aproximaciones, siguiendo un método iterativo, hasta obtener los mejores estimadores de la distribución de los parámetros. En estos casos, a efectos prácticos resulta casi imposible no recurrir a software específico, como ALOGIT ó LIMDEP, por ejemplo.

Cuando se emplean datos de preferencias declaradas (PD), los sesgos que aparecen en la encuesta pueden hacer que la utilidad que se modelice no sea la verdadera estimación de la misma, sino más bien una pseudo-utilidad, que puede generar algún error en la prognosis. De hecho, si utilizamos datos mixtos de preferencias reveladas y declaradas, éstos tendrán un diferente factor de "escala" en los parámetros, debido al efecto del parámetro $\lambda$ en la ecuación (4-6). Entonces, es necesario ajustar los datos PD al comportamiento real antes de 
estimar un modelo empleando los datos conjuntamente, también denominado estimación mixta.

En dicho caso, los datos de preferencias reveladas serían los que reflejan el comportamiento real de los individuos, mientras que, a partir de los de preferencias declaradas, podemos obtener otra información adicional. Según el desarrollo de Ben-Akiva y Morikawa [21], podemos representar las diferencias entre datos PD y PR como una función de las varianzas de cada tipo de error, como sigue:

$$
\sigma_{\varepsilon}^{2}=\mu^{2} \sigma_{\eta}^{2}
$$

Donde, $\sigma_{\varepsilon}$ y $\sigma_{\eta}$ : desviaciones estándar de los errores $\varepsilon$ y $\eta$, correspondientes a los datos de PR y PD, respectivamente

$\mu$ : coeficiente de escala a determinar

A partir de esta consideración, se pueden expresar las funciones de utilidad, para una determinada alternativa, como:

$$
\begin{aligned}
& U_{i}^{P R}=\theta \cdot X_{i}^{P R}+\alpha \cdot Y_{i}^{P R}+\varepsilon_{i} \\
& \mu \cdot U_{i}^{P D}=\mu \cdot\left(\theta \cdot X_{i}^{P D}+\phi \cdot Z_{i}^{P D}+\eta_{i}\right)
\end{aligned}
$$

Donde, $\mathrm{U}_{\mathrm{i}}^{\mathrm{PR}}$ y $\mathrm{U}_{\mathrm{i}}^{\mathrm{PD}}$ : utilidades de la alternativa i para datos de PR y PD

$\mathrm{X}_{\mathrm{i}}^{\mathrm{PR}}$ y $\mathrm{X}_{\mathrm{i}}^{\mathrm{PD}}$ : atributos a considerar de la alternativa i para datos de PR y PD

$\mathrm{Y}_{\mathrm{i}}^{\mathrm{PR}}$ y $\mathrm{Z}_{\mathrm{i}}^{\mathrm{PD}}$ : atributos a considerar de la alternativa $\mathrm{i}$ sólo para un conjunto de datos

$\mu$ : coeficiente de escala a determinar

$\theta, \alpha$ y $\Phi$ : parámetros del modelo a estimar

$\varepsilon$ y $\eta$ : errores correspondientes a los datos de PR y PD, respectivamente

Con la expresión anterior, quedan homogeneizados los términos de error, al igualarse las varianzas entre las observaciones de preferencias reveladas y declaradas. Dado que es esperable que los datos PD tengan más sesgo que los de PR, a la vista de la ecuación (4-24), $\mu$ debería tomar valores entre 0 y 1 (en caso contrario, conviene transformar las ecuaciones, tratando como datos secundarios a los de PR).

Por último, suponiendo que ambos errores siguen distribuciones IID Gumbel, resultarían sendos modelos logit multinomiales, de modo que las probabilidades de elección serían [104]: 


$$
P_{i}^{P R}=\frac{e^{\theta \cdot X_{i}^{P R}+\alpha \cdot Y_{i}^{P R}}}{\sum_{j} e^{\theta \cdot X_{j}^{P R}+\alpha \cdot Y_{j}^{P R}}} \quad ; \quad P_{i}^{P D}=\frac{e^{\mu \cdot\left(\theta \cdot X_{i}^{P D}+\phi \cdot Z_{i}^{P D}\right)}}{\sum_{j} e^{\mu \cdot\left(\theta \cdot X_{j}^{P D}+\phi \cdot Z_{j}^{P D}\right)}}
$$

Donde, $\mathrm{P}_{\mathrm{i}}^{\mathrm{PR}}$ y $\mathrm{P}_{\mathrm{i}}^{\mathrm{PD}}$ : probabilidades de elección de la alternativa i para datos de PR y PD $\mathrm{X}_{\mathrm{i}}^{\mathrm{PR}}$ y $\mathrm{X}_{\mathrm{i}}^{\mathrm{PD}}$ : atributos a considerar de la alternativa i para datos de PR y PD $\mathrm{Y}_{\mathrm{i}}^{\mathrm{PR}}$ y $\mathrm{Z}_{\mathrm{i}}^{\mathrm{PD}}$ : atributos a considerar de la alternativa $\mathrm{i}$ sólo para un conjunto de datos

$\mu$ : coeficiente de escala a determinar

$\theta, \alpha$ y $\Phi$ : parámetros del modelo a estimar

Entonces, es posible construir la siguiente función de verosimilitud conjunta:

$$
L(\theta, \alpha, \phi, \mu)=\left(\prod_{q=1}^{N^{P R}} \prod_{i} P_{i q}^{P R^{g_{i q}^{P R}}}\right) \cdot\left(\prod_{q=1}^{N^{P D}} \prod_{i} P_{i q}^{P D^{g_{i q}^{P D}}}\right)
$$

Donde, $\mathrm{P}_{\mathrm{i}}{ }^{\mathrm{PR}}$ y $\mathrm{P}_{\mathrm{i}}^{\mathrm{PD}}$ : probabilidades de elección de la alternativa i para datos de $\mathrm{PR}$ y $\mathrm{PD}$ $\mathrm{X}_{\mathrm{i}}^{\mathrm{PR}}$ y $\mathrm{X}_{\mathrm{i}}^{\mathrm{PD}}$ : atributos a considerar de la alternativa i para datos de PR y PD $\mathrm{Y}_{\mathrm{i}}^{\mathrm{PR}}$ y $\mathrm{Z}_{\mathrm{i}}^{\mathrm{PD}}$ : atributos a considerar de la alternativa i sólo para un conjunto de datos

$\mu$ : coeficiente de escala a determinar

$\theta, \alpha$ y $\Phi$ : parámetros del modelo a estimar

$\mathrm{g}_{\mathrm{iq}}{ }^{\mathrm{PR}} \mathrm{y} \mathrm{g}_{\mathrm{iq}}{ }^{\mathrm{PD}}$ : variables dummy que valen 1 si usuario q escogió la alternativa i y 0 en otros casos

Maximizando esta función, según el método descrito anteriormente, se pueden obtener los parámetros estimados del modelo. Para su resolución, se puede optar al empleo de software especializado, o bien utilizar dos metodologías simplificadas: la estimación secuencial [21] y la estimación simultánea [25].

El método de estimación secuencial [21] estima por una parte el modelo PD y, a continuación, mediante transformación de variables, el modelo PR, para obtener el factor de escala $\mu$. Finalmente, éste es aplicado a los datos de PD, y se pueden unificar los datos para estimar un modelo conjunto.

Por su parte, el de estimación simultánea [25] se basa en la construcción de una estructura arbórea ficticia, de modo que cada una de las alternativas PD se sitúa dentro de un nido diferente, con una única opción en el mismo. Para las observaciones PR, las alternativas de PD se consideran no disponibles, y el modelo es un logit multinomial, mientras que, para 
las de PD, se desprecian las de PR, y se trata de un logit jerárquico, en el que el parámetro del nido coincide con el factor de escala $\mu$.

Para terminar, es interesante considerar aquí que Ben-Akiva y Morikawa [22] demostraron la existencia de correlaciones entre los datos de PR y PD correspondientes al mismo individuo, que pueden inducir errores en el modelo. Para evitarlos, se pueden introducir, en el modelo PD, variables dummy relativas a la elección real del entrevistado, o bien considerar dicha correlación en ambos modelos PR y PD. Además, destacaron también la correlación existente entre varias respuestas de un mismo individuo para experimentos de preferencias declaradas [22].

\section{Otras Consideraciones}

Como se ha indicado en apartados anteriores, la elección modal se consultaba en la encuesta realizada a los usuarios como una pregunta de preferencias declaradas mediante elección generalizada, donde los usuarios debían escoger entre: "seguramente autobús", "probablemente bus"... Con esta metodología de toma de datos, se puede emplear, entre otras, alguna de las siguientes técnicas para estimar los modelos de la forma más adecuada:

\section{Métodos intuitivos [111].}

Se puede realizar un primer análisis, teniendo en cuenta que sólo servirá para una aproximación inicial al comportamiento de los usuarios, simplemente contabilizando, para cada atributo, el número de veces que cada alternativa es seleccionada, en función del valor del mismo. Además, estos valores se pueden representar de forma gráfica, obteniéndose así una indicación no cuantitativa sobre la importancia de cada atributo, aunque sin interpretación estadística directa.

\section{Modelización con datos de elección [111].}

A partir de un experimento de tipo elección generalizada, como el realizado en la encuesta descrita, es posible colapsar la escala, y transformarlo en otro diferente de elección simple, es decir, donde el usuario elegiría, en cada situación, el modo de transporte. 
Pero, conocidos los sesgos que aparecen cuando se emplean exclusivamente datos de preferencias declaradas, es recomendable, en la medida de lo posible, utilizar datos mixtos de PR y PD [25].

\section{Modelización con datos de elección generalizada [111].}

Cuando se trata de encuestas de elección generalizada, similar al escalamiento, la técnica clásica ha sido asignar un valor numérico a cada grado de la escala, y tratar de ajustar un modelo de regresión lineal o no lineal con los mismos. Sin embargo, el mayor problema de esta metodología radica precisamente en la elección de la escala numérica más correcta, ya que, de hecho, Garrido [50] demostró se pueden obtener resultados completamente diferentes en función de la escala empleada.

Entonces, la búsqueda de la escala adecuada será un problema específico de cada caso particular, aunque ha sido una práctica estándar en estudios de transporte emplear las probabilidades de elección $0,1,0,3,0,5,0,7$ y 0,9 , o bien su transformación de Berkson-Theil, de la que resulta: $R_{1}=2,197, R_{2}=0,847, R_{3}=0,000, R_{4}=-0,847$, $\mathrm{R}_{5}=-2,197[19]$.

Una segunda consideración relevante es la relativa a la decisión de incluir o no efectos no principales en la modelización. A pesar de que los datos de preferencias declaradas ofrecen, en determinadas circunstancias, esta posibilidad, no se suelen considerar habitualmente interacciones de segundo o mayor orden, debido, entre otras causas, a la mayor dificultad en su tratamiento. De hecho, según Louviere [95], el 80\% o más de la varianza de los datos se puede explicar únicamente empleando efectos principales, mientras que los efectos de segundo orden sólo explicarían el 2 ó el 3\%, y con valores aún menores para interacciones de mayor orden.

Por otra parte, puede ser necesario considerar su inclusión, ya que, en caso contrario, sus efectos pueden quedar ocultos tras los efectos principales [90]. Además, los diseños en bloques permiten obtener encuestas PD a partir de las que se puedan incluir dichas interacciones en el modelo. En concreto, Kocur et al [90] afirman que son suficientes unas 30 encuestas relativas a cada bloque, aunque la práctica habitual suele ser escoger un número bastante mayor. 


\section{Introducción a los Modelos de Tipo Ordinal}

Cuando los datos de la encuesta siguen una escala ordenada (como en el caso de encuestas de satisfacción, donde la opción "muy bien" es mejor que "bien", que a su vez es mejor que "regular"...), el modo correcto de introducirlos en un modelo de elección discreta es a través de formulaciones de tipo ordinal. En este caso, las alternativas de elección no son independientes entre sí, por lo que un modelo de tipo logit multinomial no es una elección apropiada. Incluso, Train [131] considera que los modelos de tipo ordinal son también mejores para este tipo de datos que los de tipo probit, ya que éstos últimos no representan la decisión natural de los entrevistados.

En los modelos de tipo ordinal, se parte de la hipótesis de que cada entrevistado tiene una función de utilidad inobservable, que representa su satisfacción general con el servicio recibido. Esta función, que denotaremos como $\mathrm{Y}_{\mathrm{j}}$, donde $\mathrm{j}$ varía entre 1 y $\mathrm{n}$, se corresponde con la calidad percibida, de modo que, a mayor utilidad, mayor satisfacción de los usuarios.

Esta función inobservable tiene la clásica formulación de utilidad, de modo que la podemos expresar como la suma de una parte representativa y otra aleatoria o de error. La parte representativa de la función de utilidad se suele expresar mediante una formulación lineal, así que podemos expresar $\mathrm{Y}_{\mathrm{j}}$ como sigue [110]:

$$
Y_{j}=X_{j} \cdot \theta+\varepsilon_{j}
$$

Donde, $\mathrm{X}_{\mathrm{j}}$ : vector K-dimensional de atributos (variables independientes)

$\theta$ : vector K-dimensional de parámetros (coeficientes) del modelo

$\varepsilon_{\mathrm{j}}$ : término de error (su distribución determinará la probabilidad de elección de las

5 posibles respuestas, y el tipo de modelo ordinal)

j: número de observaciones

En las encuestas de calidad, la valoración de la satisfacción general de los usuarios se debe ajustar a una de las cinco categorías posibles (muy mal, mal, regular, bien o muy bien), que denotaremos como $Z_{j}$. De este modo, la variable $Z_{j}$ es de tipo discreto, y ordinal, ya que las posibles opciones siguen una escala semántica, como se ha indicado anteriormente.

Dicha función $Z_{j}$, que es la respuesta observable del entrevistado, no satisface ninguna fórmula lineal, pero está relacionada con la función de utilidad inobservable $Y_{j}$. Así, si la encuesta incluye $M$ posibles respuestas $R_{1}, R_{2}, \ldots, R_{M}, y \mu_{0}, \mu_{1}, \ldots, \mu_{M}$ son $M+1$ números reales, donde $\mu_{0}=-\infty$ y $\mu_{\mathrm{M}}=+\infty$, comenzaremos asumiendo la hipótesis de que dichos 
números satisfacen la siguiente condición: $\mu_{0} \leq \mu_{1} \leq \ldots \leq \mu_{\mathrm{M}-1} \leq \mu_{\mathrm{M}}$. De este modo, el entrevistado elegirá una u otra opción discreta $\mathrm{R}_{\mathrm{m}}$ en función del rango de valores en el que se encuentre la variable inobservable $\mathrm{Y}_{\mathrm{j}}$.

$$
Z_{j}=R_{m} \Leftrightarrow \mu_{m-1} \leq Y_{j} \leq \mu_{m} \quad \text { para } 1 \leq j \leq n, \quad 1 \leq m \leq M
$$

Donde, $\mathrm{Z}_{\mathrm{j}}$ : variable discreta observable

$\mathrm{R}_{\mathrm{m}}$ : posibles respuestas de la encuesta $\mathrm{R}_{1}, \mathrm{R}_{2}, \ldots, \mathrm{R}_{\mathrm{M}}$

$\mathrm{Y}_{\mathrm{j}}$ : función de utilidad lineal inobservable

$\mu_{\mathrm{m}}$ : valores umbral de la función de utilidad $\mu_{0}, \mu_{1}, \ldots, \mu_{\mathrm{M}}$

j: número de observaciones

Dado que $\mathrm{Z}_{\mathrm{j}}$ es una función de tipo ordinal, la podemos representar a través de una serie de variables tipo dummy (con valores binarios 0 ó 1), como figura a continuación:

$$
Z_{j m}\left\{\begin{array}{l}
1 \text { si } Z_{j} \in R_{m} \\
0 \text { en otro caso }
\end{array} \quad \text { para } 1 \leq j \leq n, \quad 1 \leq m \leq M\right.
$$

Donde, $\mathrm{Z}_{\mathrm{j}}$ : variable discreta observable

$\mathrm{Z}_{\mathrm{jm}}$ : variable dummy correspondiente a un determinado escalón de valores discretos observables

$R_{m}$ : posibles respuestas de la encuesta $R_{1}, R_{2}, \ldots, R_{M}$

j: número de observaciones

Por otra parte, podemos establecer una relación entre las probabilidades de que la función de utilidad inobservable esté en un determinado rango de valores umbral y que el entrevistado elija un valor concreto de las posibles respuestas. Dicha relación figura a continuación: 


$$
\begin{aligned}
& \text { para } 1 \leq j \leq n, \quad 1 \leq m \leq M \Rightarrow \operatorname{Pr} o b\left(Z_{j m}=1\right)=\operatorname{Pr} o b\left(Z_{j} \in R_{m}\right)= \\
& =\operatorname{Pr} o b\left(\mu_{m-1} \leq Y_{j} \leq \mu_{m}\right)=\operatorname{Pr} o b\left(\mu_{m-1} \leq \sum_{k=1}^{K} \theta_{k} X_{k j}+\varepsilon_{j} \leq \mu_{m}\right)= \\
& =\operatorname{Pr} o b\left(\frac{\mu_{m-1}-\sum_{k=1}^{K} \theta_{k} X_{k j}}{\sigma} \leq \frac{\varepsilon_{j}}{\sigma} \leq \frac{\left.\mu_{m}-\sum_{k=1}^{K} \theta_{k} X_{k j}\right)}{\sigma}\right)= \\
& =\operatorname{Pr} o b\left(\frac{\varepsilon_{j}}{\sigma} \leq \frac{\mu_{m}-\sum_{k=1}^{K} \theta_{k} X_{k j}}{\sigma}\right)-\operatorname{Pr} o b\left(\frac{\varepsilon_{j}}{\sigma} \leq \frac{\mu_{m-1}-\sum_{k=1}^{K} \theta_{k} X_{k j}}{\sigma}\right)
\end{aligned}
$$

Donde, $Z_{j}$ : variable discreta observable

$\mathrm{Z}_{\mathrm{jm}}$ : variable dummy correspondiente a un determinado escalón de valores discretos observables

$R_{m}$ : posibles respuestas de la encuesta $R_{1}, R_{2}, \ldots, R_{M}$

$\mathrm{Y}_{\mathrm{j}}$ : función de utilidad lineal inobservable

$\mu_{\mathrm{m}}$ : valores umbral de la función de utilidad $\mu_{0}, \mu_{1}, \ldots, \mu_{\mathrm{M}}$

j: número de observaciones

$\mathrm{X}_{\mathrm{kj}}$ : variables independientes (atributos) de la función de utilidad

$\theta_{\mathrm{k}}$ : coeficientes (parámetros) de la función de utilidad

$\varepsilon_{\mathrm{j}}$ : término de error

$\sigma:$ varianza del término de error

Finalmente, dado que las transformaciones de tipo lineal en la función de utilidad $Y_{j}$ no alteran el resultado, podemos normalizar los parámetros umbral y la varianza del modelo, suponiendo que $\mu_{1}=0$ y $\sigma=1$, para poder estimar los coeficientes finales del modelo [110]. Entonces, únicamente nos resta la estimación de los $\mathrm{K}+\mathrm{M}-2$ coeficientes $\theta_{1}, \ldots, \theta_{\mathrm{K}}$, $\mu_{2}, \ldots, \mu_{\mathrm{M}-1}$ a través de la maximización de la función de verosimilitud, para calibrar el modelo.

Dicha función de verosimilitud, y su logaritmo neperiano, habitualmente empleado para su maximización, seguirán la formulación general presentada en las expresiones (4-15) y (4-16). Sin embargo, en el caso de los modelos de tipo ordinal, las probabilidades a considerar en ésta son las correspondientes a que cada individuo escoja una determinada alternativa, que, como se ha expuesto, coinciden con las de que el valor de la función inobservable $Y_{\mathrm{j}}$ esté dentro de un determinado rango de los parámetros umbral $\mu$. Así pues, dicha función de verosimilitud resultará finalmente, en este caso: 


$$
\left.L(\theta)=\prod_{j, m} P_{m j}^{g_{m j}}=\prod_{j, m}\left[\operatorname{Pr} o b\left(Z_{j m}=1\right)\right]^{g_{m j}}=\prod_{j, m}\left[\operatorname{Pr} o b\left(\mu_{m-1} \leq Y_{j} \leq \mu_{m}\right)\right]\right]^{g_{m j}}
$$

Donde, $\mathrm{L}(\theta)$ : función de verosimilitud de la muestra

$P_{m j}$ : probabilidad, estimada según el modelo, de que el usuario j escoja la opción discreta $\mathrm{m}$

$\mathrm{g}_{\mathrm{mj}}$ : variable dummy que vale 1 si usuario j escogió la opción discreta m y 0 en otros casos

$\mathrm{Z}_{\mathrm{jm}}$ : variable dummy correspondiente a un determinado escalón de valores discretos observables

$Y_{\mathrm{j}}$ : función de utilidad lineal inobservable

$\mu_{\mathrm{m}}$ : valores umbral de la función de utilidad $\mu_{0}, \mu_{1}, \ldots, \mu_{\mathrm{M}}$

j: número de observaciones

m: número de posibles valores discretos de la función observable $\mathrm{Z}_{\mathrm{j}}$

Y la función de log-verosimilitud se obtendrá a partir de su logaritmo neperiano. Como se ha indicado, maximizando dicha función, se pueden estimar los parámetros del modelo $\theta_{1}, \ldots, \theta_{\mathrm{K}}$ y los parámetros umbral $\mu_{2}, \ldots, \mu_{\mathrm{M}-1}$, para calibrar el modelo.

Únicamente basta determinar la distribución más adecuada del término de error, con lo que también queda establecido el tipo de modelo ordinal, para obtener las probabilidades de forma cuantitativa.

Así, por ejemplo, si asumimos que el término de error sigue una distribución de tipo logístico, con media nula y matriz de covarianza $\sigma^{2} \mathrm{I}$ (donde I es la matriz identidad), el modelo que resulta es denominado "logit ordinal". Entonces, la resolución del problema es simple:

$$
\operatorname{Pr} o b\left(Z_{j m}=1\right)=\operatorname{Pr} o b\left(Z_{j} \in R_{m}\right)=\frac{e^{\mu_{m}-\sum_{k=1}^{K} \theta_{k} X_{k j}}}{1+e^{\mu_{m}-\sum_{k=1}^{K} \theta_{k} X_{k j}}}-\frac{e^{\mu_{m-1}-\sum_{k=1}^{K} \theta_{k} X_{k j}}}{1+e^{\mu_{m-1}-\sum_{k=1}^{K} \theta_{k} X_{k j}}}
$$

Donde, $Z_{j}$ : variable discreta observable

$\mathrm{Z}_{\mathrm{jm}}$ : variable dummy correspondiente a un determinado escalón de valores discretos observables

$R_{m}$ : posibles respuestas de la encuesta $R_{1}, R_{2}, \ldots, R_{M}$

$\mathrm{Y}_{\mathrm{j}}$ : función de utilidad lineal inobservable

$\mu_{\mathrm{m}}$ : valores umbral de la función de utilidad $\mu_{0}, \mu_{1}, \ldots, \mu_{\mathrm{M}}$

$\mathrm{j}$ : número de observaciones 
$\mathrm{X}_{\mathrm{kj}}$ : variables independientes (atributos) de la función de utilidad

$\theta_{\mathrm{k}}$ : coeficientes (parámetros) de la función de utilidad

$\varepsilon_{\mathrm{j}}$ : término de error

Es interesante destacar que la expresión de la probabilidad de elección de un determinado rango en los modelos de tipo logit ordinal sigue una formulación semejante a la de los modelos logit binarios. Sin embargo, según indica Train [131], esta circunstancia es sólo accidental, ya que los modelos de tipo binario tienen dos alternativas con funciones de utilidad diferentes, mientras que los ordinales tienen una única función de utilidad, que puede adquirir distintas respuestas en función de su valor.

Por otra parte, si se adopta la hipótesis de que el término de error sigue una distribución normal, tenemos un modelo de tipo probit ordinal, desarrollado inicialmente por Zavoina y McElvey [152]. En este caso, las probabilidades de elección resultan como sigue:

$$
\operatorname{Pr} o b\left(Z_{j m}=1\right)=\operatorname{Pr} o b\left(Z_{j} \in R_{m}\right)=\phi\left(\mu_{m}-\sum_{k=1}^{K} \theta_{k} X_{k j}\right)-\phi\left(\mu_{m-1}-\sum_{k=1}^{K} \theta_{k} X_{k j}\right)
$$

Donde, $\mathrm{Z}_{\mathrm{j}}$ : variable discreta observable

$\mathrm{Z}_{\mathrm{jm}}$ : variable dummy correspondiente a un determinado escalón de valores discretos observables

$R_{m}$ : posibles respuestas de la encuesta $R_{1}, R_{2}, \ldots, R_{M}$

$\mu_{\mathrm{m}}$ : valores umbral de la función de utilidad $\mu_{0}, \mu_{1}, \ldots, \mu_{\mathrm{M}}$

$\mathrm{X}_{\mathrm{kj}}$ : variables independientes (atributos) de la función de utilidad

$\theta_{\mathrm{k}}$ : coeficientes (parámetros) de la función de utilidad

$\varepsilon_{\mathrm{j}}$ : término de error

j: número de observaciones

$\Phi(\cdot)$ : función Normal acumulada estándar

Una mayor información sobre la formulación, especificación y calibración de estos modelos está contemplada con detalle por Train [131], Ortúzar y Garrido [110], Zavoina y McElvey [152], Terza [128] y Johnson [85]. 


\subsubsection{Disponibilidad al Pago}

La disposición al pago es un concepto íntimamente relacionado con el valor subjetivo del tiempo (VST), y cuya determinación resulta muy importante tanto para la optimización de las redes de transporte, como para la modelización de la elección modal, ya que los usuarios tratarán de encontrar la ruta menos "cara", incluyendo en términos monetarios su valoración del tiempo y de las comodidades.

Son numerosas las variables que influyen en la valoración del tiempo que cada usuario considera, aunque suelen ser importantes: las relacionadas con las características socioeconómicas del individuo (ingresos y tiempo disponible, son aspectos fundamentales) y las relacionadas con el viaje (motivo del viaje, modo de transporte, incomodidades asociadas...).

Las teorías que analizan la valoración subjetiva del tiempo de viaje suelen emplear algunas premisas básicas [132]:

a) Se parte de la hipótesis de que considerar a los individuos como "homo economicus": tienen información perfecta, y actúan con el fin de maximizar su satisfacción personal o utilidad directa. Sin embargo, estarán sujetos a tres importantes restricciones: presupuesto y tiempo máximos, así como el tiempo mínimo necesario para realizar cada actividad.

b) El tiempo se interpreta como un recurso más, con dos características especiales diferenciadoras. La primera es que se trata de un recurso limitado, del que todos estamos dotados en la misma cantidad ( 24 horas diarias). Además, un segundo aspecto importante es que no se puede almacenar, sino sólo repartir entre diferentes actividades.

c) En función de cómo asigne este recurso tiempo a las distintas actividades posibles, se obtiene un determinado valor de utilidad, que puede ser medido en términos monetarios. Por ejemplo, los usuarios están dispuestos a reducir horas de ocio para aumentar las de trabajo, a cambio de un sueldo. Del mismo modo, aplicándolo al transporte, pueden estar dispuestos a emplear un modo o ruta más lentos si ello supone un ahorro de dinero, o a la inversa.

El valor subjetivo del tiempo representa, en cierto modo, la capacidad que tiene un individuo de pagar una cierta cantidad por un determinado ahorro de tiempo. Éste puede ser inferido directamente de modelos de elección discreta [81], aunque es importante tener 
en cuenta que la especificación de los mismos influirá fuertemente los resultados obtenidos [53]. Existen numerosas determinaciones del valor del tiempo a través de modelos de elección modal [79, 80], cuyos resultados arrojaron interesantes conclusiones, como que los individuos tratan de maximizar su utilidad diaria, con tres restricciones fundamentales: presupuesto, tiempo disponible y relación entre ellos.

Por último, también hay que considerar que no tiene por qué coincidir la valoración individual del tiempo con la evaluación del mismo que se debe tener en cuenta a efectos de planificación, la cual sería una valoración social, y no subjetiva, del tiempo. Así, estudios como el de Gálvez y Jara-Díaz [49] tratan de determinar este valor considerando no sólo las valoraciones individuales, sino también el "peso" que éstas constituyen en la sociedad, a través de las contribuciones -impuestos- de los diferentes grupos sociales.

En cuanto a la obtención analítica del valor del tiempo, si se dispone de una función de utilidad $V$ previamente calibrada, principalmente mediante técnicas de elección discreta, se puede obtener una valoración cuantitativa de la disponibilidad al pago de los usuarios por determinados cambios sobre las variables de entrada del modelo.

Así, con una formulación de tipo lineal, los valores de los coeficientes (pesos) que afectan a cada variable o atributo se corresponden con las utilidades marginales de cada una de ellas. En este caso, el VST corresponde a la tasa marginal de sustitución entre el tiempo percibido $t$ y el coste $c$, con utilidad constante [53], con una formulación analítica expresada como sigue:

$$
V S T_{i}=\frac{\partial C_{i}}{\partial t_{i}}=\frac{\frac{\partial V_{i}}{\partial t_{i}}}{\frac{\partial V_{i}}{\partial c_{i}}}
$$

Donde, V: utilidad indirecta condicional

t: tiempo (de espera, a pie, en el vehículo...) invertido en la realización del viaje

c: coste del viaje

Simplificando la expresión, y suponiendo, como ya se ha indicado, una función de utilidad lineal, resulta finalmente:

$$
V S T=\theta_{t} / \theta_{c}
$$

Donde, $\theta$ : utilidades marginales (pesos del modelo) de cada variable 
En muchos casos, la variable coste del viaje se presenta dividida entre los ingresos de cada usuario, para considerar el hecho evidente de que un mismo precio no supone igual impacto sobre usuarios de distintos ingresos [130]. En este caso, será necesario aplicar las necesarias transformaciones para que las unidades sean adecuadas.

Así mismo, si se transforman las funciones de utilidad, incorporando variaciones sistemáticas en los gustos, el resultado que se obtiene es que el VST no sólo depende del coste y del tiempo, sino que también influyen las características socioeconómicas y las condiciones del viaje. En este caso, la ecuación (4-35) sigue siendo válida, aunque con valores adaptados a las características de cada individuo.

Evidentemente, dado que los parámetros $\theta$ empleados aquí son estimadores de sus valores reales, será necesaria la inclusión de test y comprobaciones de nivel de confianza para el valor subjetivo del tiempo hallado con ellos [14].

Aunque el modo de variación del VST con el paso del tiempo no está demasiado estudiado, sí hay evidencias de la existencia de una relación no lineal entre éste y el ingreso, lo cual se puede utilizar para inferir ajustes del VST en función del tiempo, a partir de los cambios estimados en el ingreso.

Revisando la experiencia internacional, se puede observar que en Inglaterra, se estimaba que el valor subjetivo del tiempo era directamente proporcional al ingreso, por lo que la prognosis de uno estaba íntimamente ligada a la del otro. Sin embargo, estudios más recientes realizados en Reino Unido sugieren que esta relación no es proporcional, sino que sigue una formulación exponencial, con una elasticidad VST-ingreso del orden de 0,5 [96]. Dando por válida dicha corrección, se podría obtener una proyección de valores subjetivos del tiempo futuros como sigue:

$$
V S T_{t}=\sqrt{I_{t} / I_{t-1}} \cdot V S T_{t-1}
$$

Donde, VST: valor subjetivo del tiempo

\section{I: ingreso}

t, t-1: períodos de tiempo considerados

A partir de la formulación de las ecuaciones (4-35) y (4-36), y dado que los parámetros del tiempo y coste son estimadores de sus valores reales, que siguen una determinada distribución estadística, su relación, coincidente con el VST, también será una variable aleatoria. Por tanto, para tratar de encontrar una indicación de su grado de error, se puede 
buscar una aproximación al estadístico $t$, ya visto en apartados anteriores, o bien determinar su intervalo de confianza.

Sin embargo, se sabe que los estimadores de máxima verosimilitud distribuyen asintóticamente normales, por lo que, su cociente, en principio, sigue una distribución desconocida. Para poder obtener inferencias estadísticas sin recurrir al uso directo de dicha distribución desconocida, aparecen diferentes métodos en la literatura:

* Ettema et al [42] proponen un método de construcción del intervalo de confianza del valor subjetivo del tiempo, válido para los casos en que otras variables de segmentación de muestra interactúen con el tiempo y el coste. Así, sin más que generar valores del VST un número suficiente de veces (alrededor de 1.000), se puede determinar su valor medio y varianza. Además, a partir de los datos de los percentiles 0,025 y 0,975, se obtienen los límites del intervalo de confianza a un 95\% de nivel de confianza. Con la misma metodología se pueden obtener también intervalos de confianza para los tiempos de espera, de acceso...

Armstrong et al [14] consideran dos metodologías diferentes:

Test asintótico del estadístico t. Basándose en la hipótesis nula de que el parámetro relativo al tiempo es igual al del coste multiplicado por el VST, resultado de la ecuación (4-36), se construye un estimador $t$ que distribuye asintóticamente normal si las utilidades son de tipo logit multinomial [20]. La expresión de dicho estadístico fue determinada por Garrido y Ortúzar [51]:

$$
t=\frac{\theta_{t}-V S T \cdot \theta_{c}}{\sqrt{\operatorname{Var}\left(\theta_{t}-V S T \cdot \theta_{c}\right)}}
$$

Donde, VST: valor subjetivo del tiempo

$\theta$ : utilidades marginales (pesos del modelo) de cada variable

Además de la formulación anterior, Garrido y Ortúzar [51] determinaron también los límites superior e inferior del intervalo de confianza del valor subjetivo del tiempo:

$$
V S T_{S, I}=\frac{\theta_{t}}{\theta_{c}} \cdot \frac{t_{c}}{t_{t}} \cdot \frac{t_{t} t_{c}-\rho t^{2}}{t_{c}{ }^{2}-t^{2}} \pm \frac{\theta_{t}}{\theta_{c}} \cdot \frac{t_{c}}{t_{t}} \cdot \frac{\sqrt{\left(\rho t^{2}-t_{t} t_{c}\right)^{2}-\left(t_{t}{ }^{2}-t^{2}\right) \cdot\left(t_{c}{ }^{2}-t^{2}\right)}}{t_{c}{ }^{2}-t^{2}}
$$


Donde, VST $_{\mathrm{S}, \mathrm{I}}$ : valores superior e inferior del valor subjetivo del tiempo $\theta_{\mathrm{t}}$ y $\theta_{\mathrm{c}}$ : utilidades marginales (pesos del modelo) del tiempo y coste $\mathrm{t}_{\mathrm{t}}$ y $\mathrm{t}_{\mathrm{c}}$ : estadísticos $\mathrm{t}$ de los parámetros del tiempo y coste t: estadístico t del valor subjetivo del tiempo, según la ecuación anterior $\rho$ : coeficiente de correlación entre los estimadores de los parámetros $\theta_{\mathrm{t}} \mathrm{y}$ $\theta_{\mathrm{c}}$

Una propiedad interesante de la expresión anterior es que su límite, cuando el número de observaciones y los test-t de tiempo y coste tienden a infinito, los límites del intervalo tienden al valor propuesto en la ecuación (4-38). Es decir, a medida que aumenta el tamaño de la muestra, menor es la amplitud del intervalo de confianza.

Test de razón de verosimilitud. En este caso, se aplica la ecuación (4-36) como una restricción lineal al modelo, y se aplica un test de razón de verosimilitud entre el modelo general y éste restringido.

* Por último, Jara-Díaz et al [78] proponen una formulación más simplificada, a través de un pseudo-ensayo de especificación del test t, con el que éste resultaría:

$$
t_{t c}=\frac{1}{\sqrt{\frac{\sigma_{t}^{2}}{\theta_{t}^{2}}+\frac{\sigma_{c}^{2}}{\theta_{c}^{2}}-\frac{2 \cdot \operatorname{Cov}\left(\theta_{t}, \theta_{c}\right)}{\theta_{t} \cdot \theta_{c}}}}
$$

Donde, $\mathrm{t}_{\mathrm{tc}}$ : pseudo-estadístico $\mathrm{t}$ del valor subjetivo del tiempo

$\theta_{\mathrm{t}}$ y $\theta_{\mathrm{c}}$ : utilidades marginales (pesos del modelo) del tiempo y coste

$\sigma_{\mathrm{t}}$ y $\sigma_{\mathrm{c}}$ : desviaciones estándar de los estimadores de los parámetros del tiempo y coste

Por último, simplemente se desea destacar que se pueden aplicar metodologías similares para la valoración de otros inconvenientes del transporte, como las externalidades del mismo: accidentes, contaminación, ruido... De hecho, en el capítulo siguiente se tratará de determinar el impacto social de las mejoras en el servicio de transporte público interurbano, a través del estudio de los costes externos relativos al mismo. 


\subsubsection{Interrelación entre Calidad y Demanda del Servicio}

Para terminar este punto, relativo a las metodologías existentes para modelizar la satisfacción global del usuario de un determinado servicio, en este caso, el de transporte público interurbano en autobús, con la probabilidad de que vuelva a emplearlo en viajes posteriores, se presentará a continuación una nueva propuesta de confrontación de variables relevantes en uno, otro o ambos aspectos.

Así, desde el punto de vista general, una vez calibrados los submodelos de satisfacción y de demanda, habitualmente mediante técnicas de elección discreta, podemos distribuir las variables como sigue:

Variables tipo 1: estadísticamente significativas tanto en el submodelo de satisfacción como en el de demanda. Las características del servicio aquí incluidas son relevantes tanto para configurar la percepción global del usuario como para fomentar su uso posterior. Así, son variables cuya mejora (o mantenimiento de una buena calidad) resulta especialmente interesante.

* Variables tipo 2: estadísticamente significativas en el submodelo de demanda, pero no así en el de satisfacción. Se incluirían aquí otras características del servicio que, a pesar de no mejorar la visión global del usuario del mismo, sí afectan a su elección modal, con lo que resultan también importantes si se desean potenciar el empleo del autobús interurbano.

* Variables tipo 3: no estadísticamente significativas en el submodelo de demanda, pero sí en el de satisfacción. Estas variables mejoran la visión de la calidad recibida por parte del cliente, con lo que en cierto modo fidelizan al usuario. Sin embargo, no captan nuevos usuarios potenciales, con lo que no son útiles para el aumento de la demanda del servicio.

* Variables tipo 4: no estadísticamente significativas en ninguno de los modelos. Aquí estarían el resto de características, que serían las menos relevantes del servicio.

Se puede, por tanto, representar un sencillo gráfico resumen que, de un golpe de vista, nos permita identificar el grado de relevancia de una variable cualquiera de entre las introducidas en los modelos. Dicha representación se indica en la Figura 4-3. 
Figura 4-3. Metodología de interrelación calidad-demanda para las variables de servicio

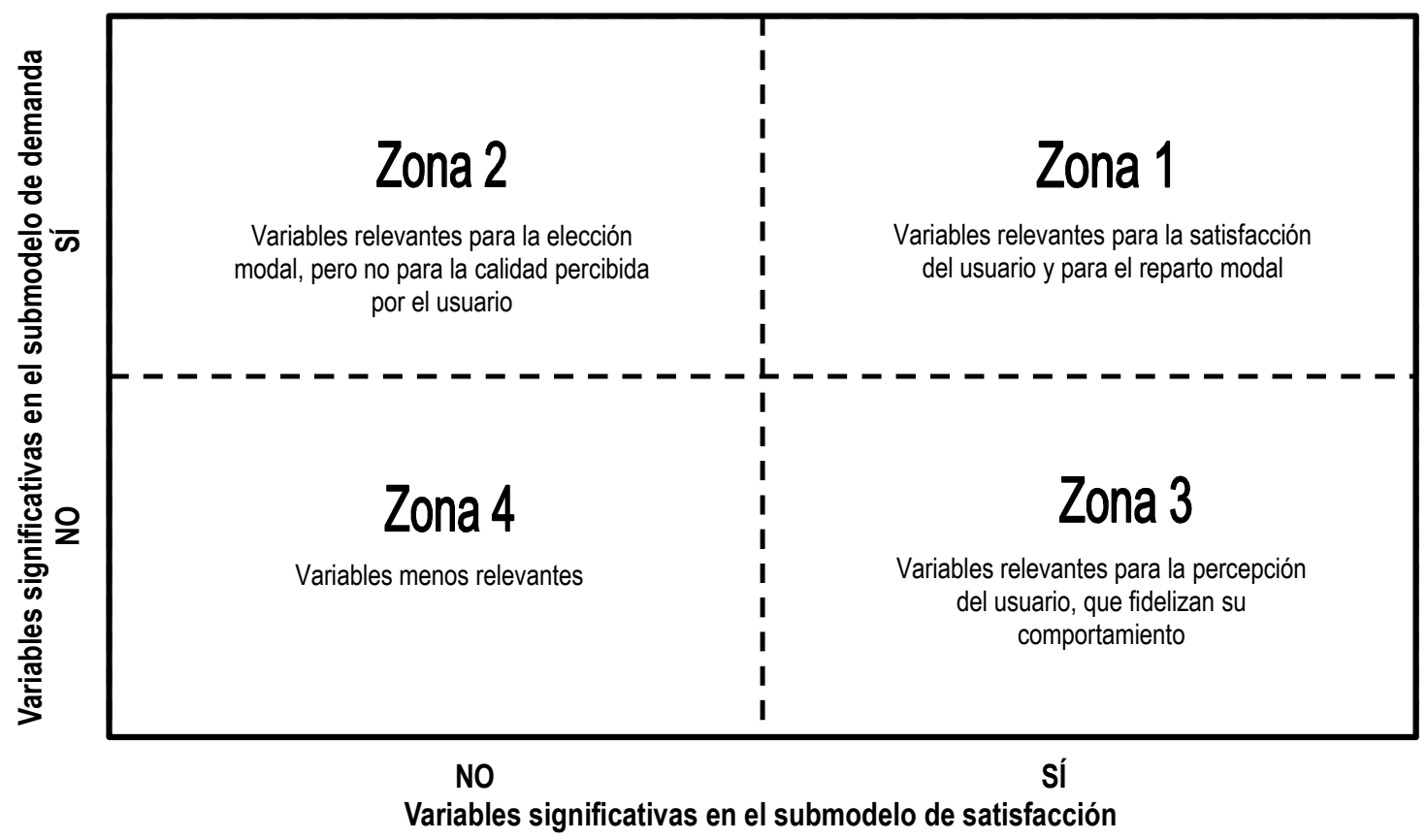

A partir de esta distinción de variables, en el capítulo siguiente, aplicando esta metodología para el caso de estudio, se tratará de detectar qué variables de servicio encajan en cada una de las zonas descritas. El ámbito de estudio, como ya se ha indicado son los trayectos de tipo interurbano en autobús con origen o destino en la estación de autobuses de Burgos. 


\subsection{Aplicaciones a los Contratos de Transporte}

En el presente punto se presentará, por último, la metodología propuesta para la inclusión de estos criterios de calidad en los contratos de transporte público interurbano en autobús. Así, en primer lugar, se analizarán con detalle las propuestas descritas en la bibliografía consultada, indicando la formulación que éstas recomiendan. A continuación, se planteará la propuesta de la presente investigación, que tiene como principales características la inclusión de la disposición de los usuarios a pagar por determinadas mejoras del servicio, así como la valoración de diferentes costes externos considerados. Así, la visión global del sistema permitirá una mejor redistribución de las subvenciones necesarias para los distintos operadores de los sistemas de transporte público interurbano.

\subsubsection{Estudios Internacionales}

Como ya se ha indicado en apartados anteriores, el Instituto de Estudios de Transporte y Logística de Sydney (Australia) es uno de los organismos más especializados en técnicas de estudio de calidad del transporte público y de su relación con los contratos de concesión. De hecho, han elaborado una metodología para incluir parámetros de calidad en los contratos de transporte $[68,70]$. Dicha propuesta fue, en principio, enfocada como una transición posible entre el sistema de contratos inicial y otro distinto basado en la calidad, y está diseñada para ser implementada en un área predefinida, y por un único operador.

La metodología desarrollada está pensada para tener previamente los datos necesarios en cuanto a costes y demanda actuales, para calcular los niveles mínimos de servicio y las tarifas, con la posibilidad de medir, posteriormente, la mejora estimada, que resulta ser un parámetro esencial a la hora de asegurar de que los incentivos se distribuyan de manera correcta. Además, se debe conocer inicialmente la estructura de costes del mercado, para definir la subvención óptima, basada en términos de niveles de coste y eficiencia. Por último, otra condición esencial para poder aplicar esta formulación es la existencia de un sistema de pago que permita evaluar la demanda captada. [68, 70]

A continuación, se presentan los pasos necesarios para poder aplicar la formulación propuesta: 
1) Definir la demanda anual de pasajeros $[68,70]$.

Definieron la demanda de viajes en autobús se define como el número total de viajes (sólo ida) realizados durante el período de contrato, y tomaron como hipótesis de partida que ésta se ve afectada por las tarifas y el nivel de servicio (representado en función de los vehículos-kilómetro en servicio).

Dado que los distintos tipos de usuario tenían diferentes formas de comportamiento ante los mismos rangos de tarifas y nivel de servicio, asignaron a cada segmento del mercado un modelo específico. Además, dentro de cada contexto geográfico, establecieron modelos diferentes para los períodos de horas punta y valle, y para dos tipos de usuarios distintos: autobuses escolares (servicio gratuito) frente al resto. Para la obtención de dichos valores, parten de la demanda en un escenario base conocido, aplicándole a continuación sus elasticidades respecto a la tarifa (sólo para los viajes no gratuitos) y al nivel de servicio, medido en vehículos-kilómetro. Dichas elasticidades deben ser ponderadas en función de los tipos de usuarios que emplean el servicio, diferenciando adultos, niños y usuarios parcial o totalmente subvencionados.

En un primer análisis, se supone una distribución estática, considerando el total de demanda servida durante un período de contrato. Las elasticidades medias calculadas de la demanda respecto a la tarifa rondaron entre $-0,20$ y $-0,45$ para los períodos punta y valle, respectivamente; y, respecto a los vehículos-kilómetro en servicio, entre 0,33 y 0,63 , respectivamente.

El sistema de contratos de calidad requiere una predicción base de la demanda asociada con cada nivel de servicio mínimo exigido. Para obtener esta demanda estimada, se empleó la misma formulación basada en las elasticidades, aunque suponiendo en este caso la misma tarifa que en el escenario base.

Finalmente, la demanda total resultó ser la suma de la de los dos tipos de usuarios considerados.

$$
\begin{gathered}
Y_{A C C}^{A}=Y_{A C C}^{B} \cdot \exp \left[\frac{\varepsilon_{Y(A C C)}^{q}}{q^{B}} \cdot\left(q^{A}-q^{B}\right)+\frac{\varepsilon_{Y(A C C)}^{X}}{X^{B}} \cdot\left(X^{A}-X^{B}\right)\right] \\
Y_{S}^{A}=Y_{S}^{B} \cdot \exp \left[\frac{\varepsilon_{Y(S)}^{X}}{X^{B}} \cdot\left(X^{A}-X^{B}\right)\right]
\end{gathered}
$$




$$
Y_{A C C}^{M S L}=Y_{A C C}^{B} \cdot \exp \left[\frac{\varepsilon_{Y(A C C)}^{X}}{X^{B}} \cdot\left(X^{M S L}-X^{B}\right)\right]
$$

Donde, $\mathrm{Y}_{\mathrm{ACC}}$ : demanda anual de viajeros no escolares

$\mathrm{Y}_{\mathrm{S}}$ : demanda anual de viajeros escolares (autobús gratuito)

Situación A: futuro (aplicación)

Situación B: actual (base)

Situación MSL: imponiendo un nivel de servicio mínimo

q: tarifa

$\mathrm{X}$ : nivel de servicio (vehículos-kilómetro en servicio)

$\varepsilon$ : elasticidad de la demanda respecto a la tarifa o al nivel de servicio

2) Definir el coste total anual $[68,70]$.

El coste de eficiencia del mercado se calculó a partir de una serie de costes totales anuales, para cada período (punta o valle) y región. Dichos costes totales predichos fueron función del coste base del mercado (calculado como el coste por kilómetro óptimo), aplicándole las elasticidades del coste respecto de los cambios previstos en los vehículos-kilómetro (incluyendo los viajes no en servicio, ya que generan costes igualmente) la demanda y el número de autobuses en servicio.

El término suma de los vehículos-kilómetro en servicio y en vacío se puede determinar de forma aproximada mediante correlaciones empíricas entre éste y el nivel de servicio (vehículos-kilómetro en servicio). En la formulación australiana, se supone que el número total de viajes en vacío es, aproximadamente, el 12,5\% de los viajes totales, válido tanto para períodos punta como valle.

Los valores aproximados de la elasticidad del coste con respecto a la demanda rondaron entre $-0,32$ y $-0,20$ para los períodos punta y valle, respectivamente. Las elasticidades con respecto al nivel de servicio fueron de 0,76 y 1,20 , respectivamente, mientras que, respecto a la flota de autobuses (aplicable sólo a períodos punta), de 0,19.

$$
\begin{aligned}
& C^{A}=C^{B} \cdot \exp \left[\frac{\varepsilon_{C}^{X}}{V K M^{B}} \cdot\left(V K M^{A}-V K M^{B}\right)+\frac{\varepsilon_{C}^{Y(A C C)}}{Y_{A C C}^{B}} \cdot\left(Y_{A C C}^{A}-Y_{A C C}^{B}\right)+\right. \\
& \left.+\frac{\varepsilon_{C}^{Y(S)}}{Y_{S}^{B}} \cdot\left(Y_{S}^{A}-Y_{S}^{B}\right)+\frac{\varepsilon_{C}^{\# b u s}}{\# b u s^{B}} \cdot\left(\# b u s^{A}-\# b u s^{B}\right)\right]
\end{aligned}
$$

Donde, C: coste total anual

VKM: vehículos-kilómetro totales (incluyendo viajes en vacío) 
$\mathrm{Y}_{\mathrm{ACC}}$ : demanda anual de viajeros no escolares

$\mathrm{Y}_{\mathrm{S}}$ : demanda anual de viajeros escolares (autobús gratuito)

\#bus: número de autobuses

Situación A: futuro (aplicación)

Situación B: actual (base)

$\mathrm{X}$ : nivel de servicio (vehículos-kilómetro en servicio)

$\varepsilon$ : elasticidad del coste total respecto a cada variable

3) Definir las restricciones $[68,70]$.

Existen una serie de restricciones que nos permiten representar el entorno real en el que el servicio cumple todas las condiciones exigibles. Dichas restricciones clave se presentan a continuación.

3.a) Tarifa $[68,70]$.

En muchas regiones existe un rango de tarifa establecido por contrato (o por concesión), para cada período punta o valle, y en Australia (que es donde se previó la primera aplicación), las tarifas no deben subir anualmente más del incremento del precio del dinero.

Cuando se imponen los sistemas de contratos de calidad, se debe cumplir, por tanto, esta condición, que, suponiendo un incremento máximo del 5\% anual, se representa matemáticamente como sigue:

$$
q^{A}-1,05 \cdot q^{B} \leq 0
$$

Donde, q: tarifa

Situación A: futuro (aplicación)

Situación B: actual (base)

3.b) Vehículos-kilómetro $[68,70]$.

Una de las condiciones habitualmente incorporadas en las concesiones de servicios de transporte público es la obligatoriedad de disponer un número mínimo de servicios, de acuerdo con las condiciones de servicio público. Estos servicios mínimos se determinan por la Administración a través de una serie de criterios externos, y se resumen habitualmente en el requisito de disponer un número mínimo de vehículos-kilómetro en función de las condiciones socioeconómicas y demográficas de la región a servir. 
El valor mínimo de vehículos-kilómetro en servicio puede ser determinado como un valor absoluto, aunque en la formulación australiana lo definen como el 67\% de los vehículos-kilómetro totales actuales, quedando como sigue:

$$
\begin{aligned}
& X^{M S L}=0,67 \cdot V K M \cdot(1-R) \\
& X^{A} \geq X^{M S L}
\end{aligned}
$$

Donde, X: nivel de servicio (vehículos-kilómetro en servicio)

VKM: vehículos-kilómetro actuales

$\mathrm{R}$ : proporción del presupuesto total de subvenciones destinado a los contratos de calidad

Situación A: futuro (aplicación)

Situación MSL: mínimo nivel de servicio admisible

El término $\mathrm{R}$ representa la proporción del presupuesto total disponible que se asigna a los contratos de calidad, y permite introducir variaciones en la estructura de subvenciones en función de si se trabaja en los niveles de servicio mínimos, o por encima de ellos. Su estructura en la ecuación proviene del hecho de que, si R $=0$, resulta que todos los contratos se rigen por los servicios mínimos, por lo que no habrá incentivos especiales; sin embargo, a medida que R aumenta, hay más operadores que trabajan por encima del nivel de servicio mínimo, con lo que es necesario destinar más dinero a incentivarlos.

\section{3.c) Tráfico y capacidad $[68,70]$.}

La diferencia entre el tráfico con el que deben circular los autobuses en períodos punta y valle es muy importante y, para conseguir un determinado valor de nivel de servicio cuando el tráfico es muy denso, se requiere un mayor número de autobuses que cuando el tráfico es fluido.

Una medida directa de la intensidad de utilización de los autobuses en la situación inicial (base) puede venir dada por la siguiente expresión:

$$
Z^{B}=\frac{\text { pers } \# \text { bus }}{X^{B}}
$$

Donde, Z: capacidad requerida por cada vehículo-kilómetro en servicio

$\mathrm{X}$ : nivel de servicio (vehículos-kilómetro en servicio)

pers: ocupación media de los autobuses

\#bus: número de autobuses 
De este modo, imponiendo condiciones de tráfico similares entre la situación actual y la futura (considerando por separado los períodos punta y valle), se puede realizar la siguiente transformación:

$$
\begin{aligned}
& Z^{A}=Z^{B} \\
& X^{A}=\frac{(\text { pers } \# \text { bus })^{A}}{Z^{B}}
\end{aligned}
$$

Donde, Z: capacidad requerida por cada vehículo-kilómetro en servicio

$\mathrm{X}$ : nivel de servicio (vehículos-kilómetro en servicio)

pers: ocupación media de los autobuses

\#bus: número de autobuses

Situación A: futuro (aplicación)

Situación B: actual (base)

El número de autobuses refleja los niveles de demanda del período base, y puede ser aumentado o disminuido, pero siempre se debe conseguir un nivel de servicio real superior al mínimo exigido $\mathrm{X}^{\mathrm{A}}$, de modo que finalmente resulta la restricción siguiente:

$$
X^{A} \leq \frac{(\text { pers } \# \text { bus })^{A}}{Z^{B}}
$$

Donde, Z: capacidad requerida por cada vehículo-kilómetro en servicio

$\mathrm{X}$ : nivel de servicio (vehículos-kilómetro en servicio)

pers: ocupación media de los autobuses

\#bus: número de autobuses

Situación A: futuro (aplicación)

Situación B: actual (base)

\section{3.d) Calidad del servicio $[68,70]$.}

Definieron la calidad del servicio a través de la relación entre la demanda y el nivel de servicio, de tal manera que, cuando se aplican una serie de medidas de mejora del servicio, se debe cumplir la formulación siguiente:

$$
\frac{Y^{A}}{X^{A}} \leq \frac{Y^{B}}{X^{B}}
$$


Donde, $\mathrm{Y}$ : demanda de pasajeros

$\mathrm{X}$ : nivel de servicio (vehículos-kilómetro en servicio)

Situación A: futuro (aplicación)

Situación B: actual (base)

\section{3.e) Restricciones intrínsecas del sistema $[68,70]$.}

Hay dos restricciones intrínsecas del sistema de subvenciones al transporte público, comunes a toda la formulación: el presupuesto máximo disponible para subvenciones y las condiciones comerciales del mercado.

i. Presupuesto máximo disponible para subvenciones $[68,70]$.

Además de las restricciones de tarifa y de nivel de servicio mínimo, la Administración suele disponer de un presupuesto limitado para distribuir entre las subvenciones a los operadores de transporte. Este presupuesto límite se suele considerar como una restricción intrínseca del sistema de transporte, aplicable a todos los operadores y a todos los rangos de estudio.

Este presupuesto límite se determina de forma exógena, pero es a su vez ajustable por las autoridades, y debe ser suficiente para las subvenciones, además de los pagos directos a modo de incentivos por aumentar la demanda captada. El sistema de incentivos propuesto en Sidney se inicia en las ideas de beneficio máximo social y reducción de externalidades, principalmente debidas a la disminución de la congestión del tráfico, por un menor empleo del vehículo privado.

Por cada pasajero adicional ganado respecto de la demanda prevista inicialmente (basada en los vehículos-kilómetro correspondientes al mínimo nivel de servicio permitido y a las tarifas asociadas), el operador tiene la oportunidad de obtener un ingreso, que puede provenir de tres fuentes distintas: los ingresos de taquilla, el aumento de beneficios de los usuarios del sistema de transporte, y la reducción de externalidades por un menor uso del vehículo privado. Las dos últimas fuentes están directamente relacionadas con el sistema de incentivos, y son parte directa del presupuesto total de que gozan las autoridades.

Una vez liquidados los pagos debidos a las condiciones de servicio público establecidas, el balance restante del presupuesto total destinado a 
subvenciones es factible de ser empleado para este tipo de incentivos, lo cual supone una restricción a su valor máximo.

En cuanto a la formulación matemática, la restricción básica de la que se parte es que la suma disponible para el sistema de incentivos descrito sea menor o igual que presupuesto global menos las subvenciones correspondientes a las obligaciones de servicio público. La restricción se concreta matemáticamente en la formulación siguiente:

$\sum_{\text {región, perído }} P \cdot(C S+E B) \leq T B-\sum_{\text {región,período }} C S O \cdot(1-R), \quad$ para $(C S+E B)>0$

Donde, P: proporción de beneficios generados que revierte al operador

CS: beneficio de la totalidad de los usuarios

EB: beneficios por reducción de externalidades

TB: presupuesto total

CSO: subvenciones por las imposiciones de servicio público

R: proporción del presupuesto total de subvenciones destinado a los contratos de calidad

Aunque la suma de los beneficios por reducción de externalidades y por mejora del sistema de transporte representa el beneficio global de la comunidad, la autoridad puede decidir la opción de pagar todo este beneficio al operador, o sólo parcialmente. De este modo, se puede aplicar un ratio de pago, definido como la proporción de beneficios producidos por la mejora del servicio que revierte sobre el operador. Es una constante importante, ya que el enfoque de incentivos no implica que el $100 \%$ de los beneficios obtenidos vuelva al operador, ya que esta situación puede no ser equitativa, o no factible económicamente.

ii. Requisitos comerciales $[68,70]$.

El coste total del sistema de transportes de todos los operadores debe ser cubierto por todas las fuentes de ingresos de cada uno. Por ello, la restricción comercial, que supone la condición de que los costes de cada operador no superen los ingresos, puede ser implementada cuando sólo son consideradas las soluciones viables económicamente, resultando la formulación siguiente:

$\left.\sum_{\text {región, periodo }} \mid C^{A}-\left(q \cdot Y_{A C C}^{A}+P \cdot(C S+E B)\right)\right] \leq \sum_{\text {región,periodo }} C S O \cdot(1-R), \quad$ para $(C S+E B)>0(4-52)$ 
Donde, C: coste total anual

q: tarifa unitaria

$\mathrm{Y}_{\mathrm{ACC}}$ : demanda de pasajeros (que pagan la tarifa)

P: proporción de beneficios generados que revierte al operador

CS: beneficio de la totalidad de los usuarios

EB: beneficios por reducción de externalidades

CSO: subvenciones por las imposiciones de servicio público

$\mathrm{R}$ : proporción del presupuesto total de subvenciones destinado a los contratos de calidad

4) Definir la función objetivo [68, 70].

Los modelos de demanda y de costes, unidos a las restricciones indicadas, condicionan el máximo valor de la función objetivo, que coincide con el beneficio social obtenido, que se formula como sigue:

$$
\begin{aligned}
& \text { Max: } \sum_{\text {region,periodo }}\left[(1+P) \cdot(C S+E B)+q \cdot Y_{A C C}^{A}-C^{A}+C S O \cdot(1-R)-\right. \\
& -(C S O \cdot(1-R)+P \cdot(C S+E B))], \quad \operatorname{para}(C S+E B)>0
\end{aligned}
$$

Donde, C: coste total anual

q: tarifa unitaria

$\mathrm{Y}_{\mathrm{ACC}}$ : demanda de pasajeros (que pagan la tarifa)

$\mathrm{P}$ : proporción de beneficios generados que revierte al operador

CS: beneficio de la totalidad de los usuarios

EB: beneficios por reducción de externalidades

CSO: subvenciones por las imposiciones de servicio público

$\mathrm{R}$ : proporción del presupuesto total de subvenciones destinado a los contratos de calidad

Los beneficios de los usuarios y los debidos a la reducción de externalidades están calculados respecto de la situación de mínimo nivel de servicio exigido. La medida de los beneficios obtenidos por los usuarios es relativamente compleja de modelizar, y puede ser influenciada por cambios en la demanda. 
5) Definir los beneficios [70].

Como ya se ha indicado anteriormente, los principales beneficios obtenidos a partir de la mejora de la calidad del servicio resultante de este sistema de incentivos se dividen en dos grupos principales: los obtenidos directamente por los actuales usuarios, que ven mejorada la calidad del mismo, y los derivados de la reducción de las externalidades debidas a la utilización masiva del vehículo privado, por el incremento esperado de utilización del transporte público que estas medidas suponen. A continuación, se presentan las metodologías incluidas en la propuesta australiana para la cuantificación de ambos grupos.

\section{5.a) Beneficios de los usuarios [70].}

Los beneficios de los usuarios incorporan los beneficios por mejora del servicio respecto del nivel de servicio mínimo exigible y de la máxima tarifa admisible.

En la metodología australiana, se definen a través de una variable compuesta, similar a un "beneficio generalizado" (en contraposición al coste generalizado) para cada usuario, que será función del nivel de tarifas y del nivel de servicio (vehículos-kilómetro en servicio). De este modo, la variable compuesta G, que tiene unidades económicas, en función de estos atributos del viaje, se puede representar como sigue:

$$
\left.\begin{array}{l}
G^{M S L}=k \cdot q^{M S L}+\lambda \cdot X^{M S L} \\
G^{A}=k \cdot q^{A}+\lambda \cdot X^{A}
\end{array}\right\} \Rightarrow G^{M S L}-G^{A}=k \cdot\left(q^{M S L}-q^{A}\right)+\lambda \cdot\left(X^{M S L}-X^{A}\right)
$$

Donde, G: función compuesta de los atributos del viaje

q: tarifa unitaria

X: nivel de servicio (vehículos-kilómetro en servicio)

Situación A: futuro (aplicación)

Situación MSL: mínimo nivel de servicio exigible

$\mathrm{k}$ : parámetro igual a -1,0 (la tarifa es directamente un gasto)

$\lambda$ : disposición al pago para un incremento en 1 vehículo-kilómetro

La obtención de dicha función es complicada, aunque se puede estimar de forma indirecta a través de las disposiciones al pago respecto de dichos factores.

En documentos del citado Instituto [67, 70], se indican valores de disposición al pago respecto de la frecuencia del servicio de 2,66 dólares por viaje y por hora 
(para cada pasajero), y respecto del nivel de servicio de 0,11 dólares/veh-km en horas punta y de 0,0886 dólares/veh-km en horas valle.

Para obtener el beneficio social total, es interesante representar gráficamente la relación entre la demanda y el beneficio generalizado, comparando la situación de mínimo nivel de servicio con la situación futura o de aplicación, pudiendo resultar dos variantes principales: pendiente positiva o negativa. Dicha representación se adjunta en la Figura 4-4.

Figura 4-4. Pendiente de la variable compuesta en función de la demanda Fuente: Hensher y Houghton [70]
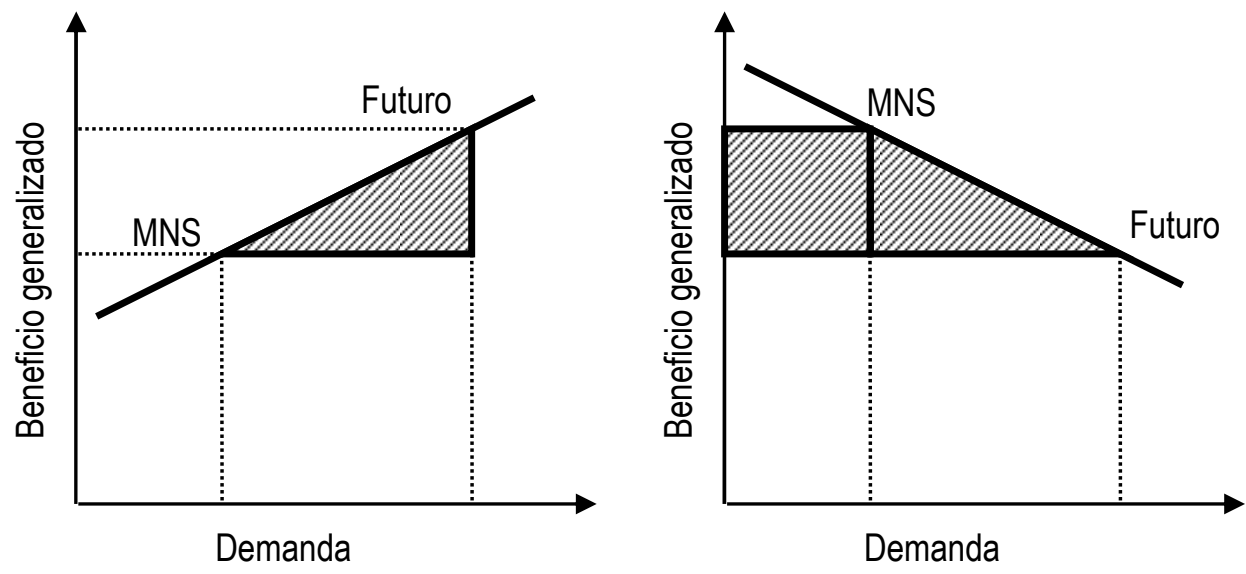

En ambos casos, los beneficios sociales se corresponden con el área del triángulo rallado. De este modo, se puede formular la expresión matemática de los beneficios de los usuarios, como se indica a continuación:

$$
C S= \begin{cases}0,5 \cdot\left(Y_{A C C}^{A}+Y_{S}^{A}-Y_{A C C}^{M S L}-Y_{S}^{M S L}\right) \cdot\left(G^{A}-G^{M S L}\right) & \text { si } G^{A}>G^{M S L} \\ 0,5 \cdot\left(Y_{A C C}^{A}+Y_{S}^{A}+Y_{A C C}^{M S L}+Y_{S}^{M S L}\right) \cdot\left(G^{M S L}-G^{A}\right) & \text { si } G^{A}<G^{M S L}\end{cases}
$$

Donde, CS: beneficios obtenidos por los usuarios

G: función compuesta de los atributos del viaje

Y: demanda anual

Situación A: futuro (aplicación)

Situación MSL: mínimo nivel de servicio exigible

Usuarios ACC: pagan tarifa

Usuarios S: viajes escolares gratuitos 


\section{5.b) Reducción de externalidades [70].}

Los beneficios obtenidos por reducción de las externalidades debidas al uso del coche, en la formulación australiana, se obtienen a través de la incorporación de una serie de hipótesis, que son las siguientes:

- Cada viaje captado por el autobús (que antes se realizaba en coche) supone 10 kilómetros menos de uso del coche.

- De los viajes captados por el autobús, provienen del coche el $40 \%$ de los de usuarios con tarifa y el $20 \%$ de los usuarios de autobús escolar gratuito.

A continuación se presenta la formulación para obtener estos beneficios por reducción de externalidades, considerando las citadas hipótesis:

$E B=(\downarrow \cos$ te usuarios coche $) \cdot(\uparrow$ pasajeros en bus $) \ldots$ para cada región y período $=$ $=\left(\$ / V K M^{\text {coche }}\right) \cdot$ media $\left(V K M^{\text {coche }}\right) \cdot(\uparrow$ pasajeros en bus $)=$

$=\left(\$ / V K M^{\text {coche }}\right) \cdot 10 \mathrm{~km} \cdot\left(Y_{A C C}^{A}+Y_{S}^{A}-Y_{A C C}^{M S L}-Y_{S}^{M S L}\right) \cdot(\%$ int ercambio coche - autobús $)=$

$=\left(\$ / V K M^{\text {coche }}\right) \cdot 10 \mathrm{~km} \cdot\left(Y_{A C C}^{A}+Y_{S}^{A}-Y_{A C C}^{M S L}-Y_{S}^{M S L}\right) \cdot 0,4$

Donde, EB: beneficios obtenidos por reducción de externalidades

VKM: vehículos-kilómetro en servicio

Y: demanda anual

Situación A: futuro (aplicación)

Situación MSL: mínimo nivel de servicio exigible

Usuarios ACC: pagan tarifa

Usuarios $\mathrm{S}$ : viajes escolares gratuitos

El beneficio unitario por reducción de externalidades por cada veh-km (para los usuarios con tarifa) es debido a la suma de 6 externalidades distintas, cuyos valores varían en función de si estamos en horas punta o valle y si el contexto de estudio es metropolitano o exterior. Dichas externalidades son: daño a la infraestructura, congestión, polución aérea, cambio climático, ruido y accidentes. De cada una de ellas, la formulación australiana da unos valores de coste/veh-km en coche, distinguiendo períodos punta-valle y área metropolitana o no, para poder incluir en la ecuación anterior. 
Como orden de magnitud, simplemente citar que la externalidad más "costosa" (con gran diferencia respecto al resto) es la congestión, y que, en todos los casos, los costes en horas punta son muy superiores a los de las horas valle, y en áreas metropolitanas algo mayores que en zonas interurbanas.

\section{5.c) Incentivos totales [70].}

Finalmente, el incentivo por captación de demanda debe ser igual a la suma de los beneficios de los usuarios más los debidos a la reducción de externalidades.

\section{6) Aplicación [70].}

La metodología propuesta fue testeada con algunos operadores de las áreas suburbanas de Sydney.

Los resultados iniciales obtenidos en cuanto a servicios mínimos y distribución de presupuesto arrojaron que casi el 13\% del presupuesto total podría ser dirigido a un sistema de contratos de calidad.

Además, resolviendo el problema de optimización, la óptima proporción de beneficios sociales por externalidad y por mejora del servicio que revierte al operador sería de un $14,5 \%$. Es decir, en términos de costes de los usuarios y de externalidades, por cada unidad monetaria que se asigna al operador, 6,88 unidades son obtenidas por la sociedad en general, con lo que quedaría demostrada la efectividad de este sistema de incentivos.

En una segunda parte de la simulación, los parámetros a determinar fueron las condiciones óptimas de la flota del operador, así como su nivel de servicio óptimo y la tarifa.

Por tanto, a continuación se trató de buscar el valor óptimo de vehículos adicionales que sería necesario introducir para maximizar el beneficio total del sistema. La hipótesis supuesta es que estos autobuses adicionales debían estar disponibles tanto para períodos punta como valle. El resultado final fue que la solución óptima requiere disponer dos autobuses más.

Aunque, en términos globales, el nivel de servicio diario disminuye ligeramente, todavía se cumplen las condiciones mínimas exigidas. Además, es interesante destacar 
que los beneficios por reducción de externalidades se mantienen constantes, mientras que los debidos a los beneficios de los usuarios aumentan, y también los del operador.

Mediante la representación gráfica de la variación de los beneficios totales sociales y del operador en función del número extra de autobuses, se puede comprobar que, en el escenario base (distribución de subvenciones convencional), a mayor número de autobuses introducidos, el beneficio obtenido por los usuarios es cada vez mayor, mientras que el del operador disminuye. Por tanto, los intereses comerciales del operador y sociales de la comunidad siempre están "en desacuerdo", con lo que no es posible obtener una solución óptima para ambos simultáneamente.

Sin embargo, en el escenario con incentivos, las líneas correspondientes a los beneficios sociales y del operador siguen tendencias similares, experimentando un valor máximo cuando hay 2 autobuses más. Esta circunstancia se debe a que, al ir aumentando el número de autobuses adicionales introducidos, aumentan los costes del operador, pero también aumentan los incentivos que recibe por parte de la Administración, que figuran a su vez como un coste económico para toda la sociedad.

Así, una de las principales conclusiones que se pueden extraer de esta aplicación es que la introducción de un sistema de incentivos permite alcanzar un nivel de "armonía" entre los intereses del operador y de la sociedad que, en principio, estaban contrapuestos. Además, con el sistema de incentivos, es factible mejorar la calidad del sistema de transporte público, ya que interesa económicamente a los operadores, y que, adicionalmente, supone para la sociedad en general un volumen de beneficios claramente mayor a los gastos económicos que genera el hecho de aumentar los pagos a los operadores.

Otra característica importante es que este tipo de contratos tiene sentido especialmente cuando se analiza todo el sistema de transporte desde un punto de vista global, considerando los beneficios de toda la sociedad, de tal modo que se aplique a todos los operadores que exploten el servicio, y no realizando estudios parciales para uno o varios operadores aislados. En cualquier caso, como todas las nuevas metodologías, se debe ir incorporando poco a poco, de modo que, en las primeras fases, resulta totalmente compatible con un sistema convencional de subvenciones, aumentando progresivamente el porcentaje de incentivos, hasta llegar al valor óptimo de la formulación.

Para finalizar, basta indicar que este tipo de metodologías, actualmente en fase de diseño, o comenzando a implantarse parcialmente en determinadas áreas, deben afianzarse dentro de los sistemas de contratación o de concesión del transporte público, pues suponen un vuelco 
en la filosofía actual, ya que permiten que sean los propios operadores quienes estén más interesados en la mejora del transporte y en la captación de demanda. Si se consiguen ambos resultados, se obtendrá, por una parte, un servicio de mejor calidad, y, por otra, un mayor empleo del transporte público frente al privado, con los consabidos efectos de mejora medioambiental y reducción de costes externos por congestión, ruido, accidentes, etc.

\subsubsection{Propuesta Metodológica}

La presente investigación parte de la metodología anterior, para incorporar parámetros de valor subjetivo del tiempo y disponibilidad al pago por mejoras en la calidad del servicio, con el fin de determinar la fórmula óptima de subvención. En el capítulo siguiente se aplican estos parámetros a la muestra resultante de la encuesta realizada en la estación de autobuses de la ciudad de Burgos, para resolver un caso particular.

En nuestro caso, el desarrollo de la metodología propuesta precisa conocer la demanda actual de las líneas de transporte público interurbano en autobús a estudiar, así como la estructura de costes de la explotación de las mismas. Por otra parte, a partir de un estudio de satisfacción y demanda del servicio, se deberá conocer las disponibilidades al pago por diferentes mejoras en el mismo, así como las elasticidades de la demanda respecto a las principales variables. También será necesario disponer de un mecanismo de control de la demanda efectivamente captada tras las posibles mejoras, y determinados parámetros económicos a imponer, como: la proporción máxima de las subvenciones destinada a la mejora de la calidad, los niveles mínimos exigidos a los concesionarios, etc.

El ámbito temporal de cálculo será anual, ya que permite conocer con mayor detalle y precisión los datos de demanda y de costes y beneficios de la explotación del servicio. Al igual que se ha presentado en el punto anterior, la metodología seguirá una serie de pasos, hasta completar la formulación:

\section{1) Definir la demanda anual de pasajeros.}

En nuestro caso, se considera que la demanda del servicio será función, entre otras variables, de la duración del viaje, el coste del billete, el número de expediciones diarias, la ruta seguida y las características del vehículo. Así, la coherencia con las preguntas incluidas en la encuesta descrita es total. Además, evidentemente, influyen 
más variables intrínsecas del servicio, así como otras ajenas al mismo: relativas a los entrevistados o al resto de modos de transporte.

Sin embargo, para simplificar el análisis, se estimarán valores promedio de las elasticidades de la demanda con respecto a las 5 características antes indicadas, y suponiendo que el efecto en ambos sentidos es idéntico, y sensiblemente constante independientemente de la magnitud de las variaciones. No obstante, puede ser también interesante calcular diferentes valores de elasticidad en función del tipo de trayecto (metropolitano, regional o nacional), o del día u hora de realización del viaje (laborables frente a festivos, y horas punta frente a horas valle).

Obteniendo las elasticidades mediante el enfoque de enumeración muestral, siempre que dicha muestra se considere representativa del global de la población, no sería necesario aplicar ningún factor corrector ni de ponderación relativo a la tipología de usuario. No obstante, se pueden obtener valores estimados de la elasticidad a partir de las experiencias ya existentes, aunque será obviamente necesario comprobar su idoneidad y aplicabilidad al caso de estudio.

Así, las variaciones estimadas de la demanda se pueden calcular de forma directa a partir de la propia definición de su elasticidad:

$$
E_{P_{i q}, x_{i k q}}=\frac{\partial P_{i q} / P_{i q}}{\partial x_{i k q} / x_{i k q}}=\frac{\partial P_{i q}}{\partial x_{i k q}} \cdot \frac{x_{i k q}}{P_{i q}} \quad ; \quad E_{P_{i q}, x_{j k q}}=\frac{\partial P_{i q} / P_{i q}}{\partial x_{j k q} / x_{j k q}}=\frac{\partial P_{i q}}{\partial x_{j k q}} \cdot \frac{x_{j k q}}{P_{i q}}
$$

Donde, E Eiq,xikq: elasticidad directa de la demanda del modo i respecto de su atributo k-ésimo para el usuario q

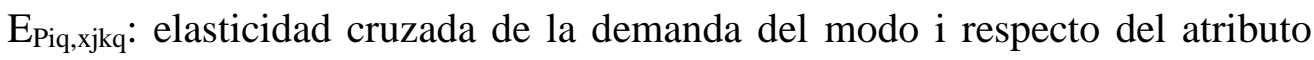
k-ésimo de otro modo j para el usuario q

$\mathrm{P}_{\mathrm{iq}}$ : probabilidad de que el usuario q elija la alternativa $\mathrm{i}$

$\mathrm{x}_{\mathrm{ikq}}$ : atributo k-ésimo (continuo) de la alternativa i para el usuario $\mathrm{q}$

Sin embargo, esta formulación no es válida para variables discretas, de tipo dummy, ya que, en éstas, no se pueden establecer incrementos relativos. Por tanto, cuando los atributos sean de este tipo, como por ejemplo habitualmente las características del vehículo, se emplearán incrementos absolutos tanto para el cálculo de la elasticidad como en la posterior determinación de la variación de la demanda. 
Dado que nuestro objetivo es la mejora de la calidad y la demanda del servicio de autobuses interurbanos, las variables relativas al resto de modos no están en nuestro abanico de posibles acciones. Por tanto, las elasticidades cruzadas no serán en general relevantes para nuestro fin. Con esta consideración, si, en lugar de tomar elasticidades individuales, obtenemos los valores promedio para la población, los incrementos de demanda final serán:

$$
E_{P, x_{k}}=\frac{\partial P / P}{\partial x_{k} / x_{k}}=\frac{\partial P}{\partial x_{k}} \cdot \frac{x_{k}}{P} \approx \frac{\Delta P}{\Delta x_{k}} \cdot \frac{x_{k}}{P} \Rightarrow \Delta P=E_{P, x_{k}} \cdot P \cdot \frac{\Delta x_{k}}{x_{k}}
$$

Donde, $\mathrm{E}_{\mathrm{P}, \mathrm{xk}}$ : elasticidad directa de la demanda del transporte público interurbano en autobús respecto de su atributo k-ésimo

P: probabilidad de empleo del servicio de transporte interurbano en autobús $\mathrm{x}_{\mathrm{k}}$ : atributo k-ésimo (continuo) del servicio

Y, por tanto, la demanda futura estimada, considerando las 5 variables antes citadas como las únicas relevantes, resulta:

$V=V_{o} \cdot\left(1+E_{t} \cdot \frac{\Delta t}{t}\right) \cdot\left(1+E_{c} \cdot \frac{\Delta c}{c}\right) \cdot\left(1+E_{N S} \cdot \frac{\Delta N S}{N S}\right) \cdot\left(1+E_{\text {ruta }} \cdot \frac{\Delta r u t a}{\text { ruta }}\right) \cdot\left(1+E_{\text {bus }} \cdot \Delta b u s\right)($

Donde, V: demanda futura anual del servicio de transporte interurbano en autobús

$\mathrm{V}_{\mathrm{o}}$ : demanda anual actual del servicio

$\mathrm{E}_{\mathrm{x}}$ : elasticidad de la demanda respecto de la variable $\mathrm{x}$

t: duración del viaje

c: coste del billete

NS: número diario de expediciones (salidas)

ruta: proporción del trayecto realizado por vías de alta capacidad

bus: variable dummy relativa a las características del vehículo

2) Definir el coste total anual.

En España, el cálculo de costes para empresas del sector de transporte público interurbano se basa habitualmente en el cálculo de los costes relativos a los siguientes conceptos: amortización, financiación, personal, seguros, impuestos e intereses, combustible y lubricante, neumáticos, reparaciones y conservación, peajes y otros, y costes indirectos. Así, el Ministerio de Fomento [103] publica periódicamente sus observatorios sobre los costes del sector, en los que propone unos valores tipo para cada uno de estos componentes, en función de la tipología del autobús y de la zona de 
estudio. Además, indica también los valores medios del coste por vehículo-kilómetro, por hora de funcionamiento y considerando ambos factores. A falta de datos más exactos, estos valores pueden ser empleados como un primer estimador de la estructura de costes relativa a la explotación del servicio de transporte en autobús interurbano. La Tabla 4-10 presenta un resumen de los datos recogidos en dicha publicación.

Tabla 4-10. Costes anuales de explotación tipo del servicio de autobuses interurbanos Fuente: Ministerio de Fomento [103]

\begin{tabular}{|c|c|c|c|c|c|c|}
\hline \multirow{2}{*}{$\begin{array}{l}\text { TIPO } \\
\text { AUTO } \\
\text {-BÚS }\end{array}$} & \multirow[b]{2}{*}{ ZONA } & \multicolumn{5}{|c|}{ COSTES ANUALES (€) } \\
\hline & & TOTAL & POR VEH-KM & POR HORA & $\begin{array}{r}\text { POR VEH } \\
(\mathrm{S}\end{array}$ & $\begin{array}{l}\text { KM Y HORA } \\
\text { MA) }\end{array}$ \\
\hline \multirow{3}{*}{ 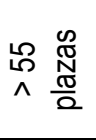 } & Media nacional & 104.496 & 1,433 & 59,720 & 0,512 & 38,372 \\
\hline & Bajo coste personal & 99.751 & 1,330 & 55,417 & 0,512 & 34,069 \\
\hline & Alto coste personal & 115.241 & 1,537 & 62,023 & 0,512 & 42,674 \\
\hline \multirow{3}{*}{ 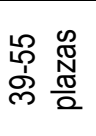 } & Media nacional & 97.370 & 1,298 & 54,094 & 0,435 & 35,984 \\
\hline & Bajo coste personal & 89.625 & 1,195 & 46,791 & 0,435 & 31,681 \\
\hline & Alto coste personal & 105.115 & 1,402 & 58,397 & 0,435 & 40,287 \\
\hline \multirow{3}{*}{$\begin{array}{ll}\infty & \mathbb{N} \\
& \mathbb{N} \\
\grave{N} & \mathbb{0} \\
\end{array}$} & Media nacional & 81.394 & 1,163 & 45,219 & 0,352 & 31,540 \\
\hline & Bajo coste personal & 73.649 & 1,052 & 40,916 & 0,352 & 27,237 \\
\hline & Alto coste personal & 89.139 & 1,273 & 49,522 & 0,352 & 35,843 \\
\hline \multirow{3}{*}{ 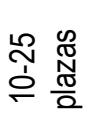 } & Media nacional & 72.747 & 1,039 & 40,415 & 0,310 & 28,346 \\
\hline & Bajo coste personal & 65.002 & 0,929 & 36,112 & 0,310 & 24,043 \\
\hline & Alto coste personal & 80.492 & 1,150 & 44,718 & 0,310 & 32,649 \\
\hline
\end{tabular}

Así, en ausencia total de datos se pueden emplear los valores tipo establecidos en la Tabla 4-10, o por el contrario, si se conocen los valores actuales de los costes de explotación, se puede emplear dicha tabla para calcular las variaciones respecto de la situación inicial en caso de que se apliquen ciertas modificaciones en el servicio. El caso óptimo sería aquél en el que fueran datos conocidos todas las componentes del coste, de modo que se pudieran determinar dichas proporciones para cada situación concreta.

Sea como sea, en función del tipo de parámetro que se emplee para el cálculo del crecimiento de los costes, la formulación será diferente. Así, si únicamente se considera la variación de los costes por vehículo-kilómetro, el coste final del servicio será el que sigue:

$$
C=C_{o}+(\Delta C)_{V K M}=C_{o}+C_{V K M} \cdot \Delta V K M
$$

Donde, C: costes anuales futuros de explotación del servicio de transporte interurbano en autobús

$\mathrm{C}_{\mathrm{o}}$ : costes anuales actuales del servicio 


\section{$\mathrm{C}_{\mathrm{VKM}}$ : coste por vehículo-kilómetro}

VKM: número de vehículos-kilómetro recorridos anualmente

Sin embargo, si se decide emplear la variación de los costes por hora de funcionamiento de cada vehículo, el coste final del servicio quedaría:

$$
C=C_{o}+(\Delta C)_{H E}=C_{o}+C_{H E} \cdot \Delta H E
$$

Donde, C: costes anuales futuros de explotación del servicio de transporte interurbano en autobús

$\mathrm{C}_{\mathrm{o}}$ : costes anuales actuales del servicio

$\mathrm{C}_{\mathrm{HE}}$ : coste por hora de explotación

HE: número de horas totales de funcionamiento requeridas anualmente

Por último, empleando conjuntamente las variaciones de los costes por vehículokilómetro y horas de funcionamiento, el coste final del servicio sería en este caso:

$$
C=C_{o}+(\Delta C)_{V K M}+(\Delta C)_{H E}=C_{o}+C_{V K M} \cdot \Delta V K M+C_{H E} \cdot \Delta H E
$$

Donde, C: costes anuales futuros de explotación del servicio de transporte interurbano en autobús

$\mathrm{C}_{\mathrm{o}}$ : costes anuales actuales del servicio

$\mathrm{C}_{\mathrm{VKM}}$ : coste por vehículo-kilómetro

VKM: número de vehículos-kilómetro recorridos anualmente

$\mathrm{C}_{\mathrm{HE}}$ : coste por hora de explotación

HE: número de horas totales de funcionamiento requeridas anualmente

3) Definir los beneficios.

Como ya indicaban Hensher \& Houghton [70], los beneficios sociales resultantes de una mejora de la calidad del servicio se dividen en dos grandes categorías. Por un lado, los actuales usuarios quedan más satisfechos con el servicio, simplemente a raíz de la mayor calidad percibida por éstos. Pero, por otro lado, también la sociedad consigue beneficios, ya que, si se incrementa el empleo del servicio, disminuyen los costes externos debidos al empleo del vehículo privado.

Parte de estos beneficios sociales podría ser reintegrado al operador, fomentado así sus inversiones para mejorar la calidad del servicio. Sin embargo, si de dicha mejora de calidad se deriva una mayor utilización del servicio, también existirán beneficios 
puramente comerciales para el operador, que serán función de la tarifa y de la demanda adicional captada.

Será necesario, por tanto, cuantificar estas tres cuestiones para obtener el beneficio total.

\section{3.a) Beneficios de los usuarios.}

Una de las principales aportaciones de la presente investigación es la incorporación a este apartado de las disponibilidades al pago no sólo por el número de expediciones y la posible reducción de tarifas (como proponían Hensher \& Houghton [70]), sino también por otras variables de calidad valoradas por los usuarios. Así, se puede conjugar los resultados de estudios de calidad puramente dichos como los de demanda, para determinar de forma más detallada los beneficios de los usuarios actuales del servicio (los usuarios potenciales que se captan a raíz de las posibles mejoras, no perciben dichas mejoras).

Estos beneficios se obtienen considerando por una parte los aspectos puramente económicos (precio del billete) y por otra las disponibilidades al pago por otras cuestiones de calidad. Así, considerando de nuevo como variables relevantes el coste, el tiempo de viaje, el número de expediciones, la ruta seguida y las características de vehículo, serían:

$$
\begin{aligned}
& \Delta B U_{q}=\left(\Delta B U_{q}\right)_{c}+\left(\Delta B U_{q}\right)_{t}+\left(\Delta B U_{q}\right)_{N S}+\left(\Delta B U_{q}\right)_{\text {ruta }}+\left(\Delta B U_{q}\right)_{\text {bus }}= \\
& =-\Delta c_{q}-W T P_{t, q} \cdot \Delta t_{q}+W T P_{N S, q} \cdot \Delta N S_{q}+W T P_{\text {ruta }, q} \cdot \Delta r u t a_{q}+W T P_{b u s, q} \cdot \Delta b u s_{q}
\end{aligned}
$$

Donde, $\Delta \mathrm{BU}_{\mathrm{q}}$ : beneficios del servicio de transporte interurbano en autobús para el usuario q

$\mathrm{WTP}_{\mathrm{x}, \mathrm{q}}$ : disponibilidad al pago (valor absoluto) del usuario q por cambios unitarios en la variable $\mathrm{x}$

c: coste del billete

t: duración del viaje

NS: número diario de expediciones (salidas)

ruta: proporción del trayecto realizado por vías de alta capacidad bus: variable dummy relativa a las características del vehículo

Finalmente, el beneficio total social de una posible mejora en la calidad del servicio sería igual a la diferencia entre los beneficios totales de los usuarios correspondientes a la situación mejorada con los de la actual. Se ha decidido no 
considerar aquí la nueva demanda adicional captada, ya que estos usuarios comienzan a emplear el autobús interurbano cuando éste mejora su calidad, por lo que no experimentan en realidad ningún cambio en el mismo. Así, los beneficios de los usuarios resultan:

$$
\Delta B U=\sum_{q=1}^{V_{o}} \Delta B U_{q}
$$

Donde, $\triangle \mathrm{BU}$ : beneficios sociales de los usuarios del servicio de transporte interurbano en autobús debidos a la mejora de su calidad

$\triangle \mathrm{BU}_{\mathrm{q}}$ : beneficios para el usuario $\mathrm{q}$

$\mathrm{V}_{\mathrm{o}}$ : demanda anual inicial del servicio

3.b) Reducción de externalidades.

La valoración de los beneficios generados por reducción de externalidades es, posiblemente, el elemento más complejo y desconocido de la metodología propuesta. De hecho, el conocimiento del coste estimado que supone el empleo masivo del vehículo privado ha sido objeto de numerosos estudios, obteniéndose por lo general datos muy dispares entre ellos, únicamente válidos para el caso concreto de estudio [24, 27, 33, 93].

En nuestro estudio únicamente se consideran los siguientes modos, todos ellos en ámbito interurbano (metropolitano, provincial, regional o nacional): autobús, vehículo privado y tren. Únicamente se tendrán en cuenta aquí los beneficios obtenidos al disminuir el empleo del vehículo privado, que es el que genera mayores externalidades, por lo que no consideraremos los transvases ferrocarrilautobús. Así mismo, el tráfico de motos se estimará despreciable frente al de coches, por lo que todos los viajes en vehículo privado se considerarán realizados en coche (o similar).

Por ello, se ha tratado de simplificar al máximo la metodología, y se ha optado por aceptar los valores propuestos por Jordá et al [86] para la Comunidad de Madrid en el año 2004. En su estudio, diferencian el transporte de ámbito urbano, metropolitano y rural, y proponen diversos valores de los costes externos por cada vehículo-kilómetro circulado en los diversos modos. Así, los costes externos socioambientales que consideraremos serán los siguientes: accidentes, ruido, contaminación y cambio climático. Además, es necesario considerar los costes que genera el tráfico sobre la propia infraestructura, así como la valoración 
económica, positiva o negativa, de la diferencia de tiempos de viaje entre el vehículo privado y el autobús interurbano. La Tabla 4-11 muestra un resumen de dichos valores, actualizados al año 2010.

Tabla 4-11. Costes del transporte en la Comunidad de Madrid Fuente: Jordá et al [86]

\begin{tabular}{|c|c|c|c|}
\hline \multirow[b]{2}{*}{ TIPOLOGÍA Y DESCRIPCIÓN } & \multirow[b]{2}{*}{ MODO } & \multicolumn{2}{|c|}{ COSTE (€/100 viaj-Km) } \\
\hline & & $\begin{array}{c}\text { ÁMB. } \\
\text { METROPOLITANO }\end{array}$ & $\begin{array}{c}\text { ÁMB. } \\
\text { REGIONAL }\end{array}$ \\
\hline \multirow{2}{*}{$\begin{array}{l}\text { Infraestructuras (Inversiones, } \\
\text { mantenimiento y conservación) }\end{array}$} & Autobús & 0,08 & 0,26 \\
\hline & Coche & 0,42 & 1,41 \\
\hline \multirow{2}{*}{$\begin{array}{c}\text { Operación (personal, vehículos, consumo } \\
\text { energético...) }\end{array}$} & Autobús & 6,51 & 5,65 \\
\hline & Coche & 13,68 & 12,58 \\
\hline \multirow{2}{*}{$\begin{array}{c}\text { Tiempo del viaje (valor promedio del } \\
\text { tiempo de viaje) }\end{array}$} & Autobús & 26,23 & 20,11 \\
\hline & Coche & 26,10 & 18,39 \\
\hline \multirow{2}{*}{$\begin{array}{l}\text { Accidentes (pérdida capital humano, daños } \\
\text { víctima y familiares, costes médicos...) }\end{array}$} & Autobús & 0,16 & 0,10 \\
\hline & Coche & 1,19 & 10,60 \\
\hline \multirow{2}{*}{ Ruido (daños salud y entorno) } & Autobús & 0,09 & 0,01 \\
\hline & Coche & 0,35 & 0,32 \\
\hline \multirow{2}{*}{$\begin{array}{l}\text { Contaminación atmosférica (daños salud y } \\
\text { entorno) }\end{array}$} & Autobús & 0,34 & 0,02 \\
\hline & Coche & 0,75 & 0,08 \\
\hline \multirow{2}{*}{$\begin{array}{c}\text { Cambio climático (riesgos futuros, daños } \\
\text { entorno...) }\end{array}$} & Autobús & 0,06 & 0,06 \\
\hline & Coche & 0,59 & 0,26 \\
\hline \multirow{2}{*}{$\begin{array}{l}\text { Ocupación del suelo (valor promedio del } \\
\text { suelo ocupado) }\end{array}$} & Autobús & 0,05 & 0,05 \\
\hline & Coche & 0,27 & 0,27 \\
\hline
\end{tabular}

Así, en función del ámbito en el que se desarrolle cada línea a estudiar, se podrán tomar unos u otros valores de la misma. Finalmente, si se dispone de unos valores específicos calculados para el problema en cuestión, siempre será más recomendable tomar éstos que los genéricos propuestos en la tabla.

Sea como sea, el beneficio final social que genera la captación de cada usuario que pasa de emplear su vehículo privado al autobús interurbano se puede presentar como sigue:

$$
\begin{aligned}
& \Delta B S_{q}=\left(\Delta B S_{q}\right)_{\text {inf } r}+\left(\Delta B S_{q}\right)_{\text {oper }}+\left(\Delta B S_{q}\right)_{t}+\left(\Delta B S_{q}\right)_{\text {accid }}+\left(\Delta B S_{q}\right)_{\text {ruido }}+\left(\Delta B S_{q}\right)_{\text {contam }}+ \\
& +\left(\Delta B S_{q}\right)_{\text {camb } \lim }+\left(\Delta B S_{q}\right)_{\text {suelo }}=\operatorname{dist}_{q} \cdot \sum_{k}\left(C S_{V I K M, q, k, \text { coche }}-C S_{V I K M, q, k, \text { bus }}\right)
\end{aligned}
$$

Donde, $\triangle \mathrm{BS}_{\mathrm{q}}$ : beneficios sociales del servicio de transporte interurbano en autobús por la captación del usuario q dist $_{\mathrm{q}}$ : distancia de viaje del usuario q, en kilómetros 
$\mathrm{CS}_{\mathrm{VIKM}, \mathrm{q}, \mathrm{x}, \mathrm{coche}}$ : costes sociales del modo coche por la externalidad $\mathrm{x}$ para el usuario q, en €/viajero-kilómetro

$\mathrm{CS}_{\mathrm{VIKM}, \mathrm{q}, \mathrm{x}, \mathrm{coch}}$ : costes sociales del modo autobús por la externalidad $\mathrm{x}$ para el usuario q, en €/viajero-kilómetro

infr: infraestructuras

oper: operación

t: duración del viaje

accid: accidentalidad vial

ruido: ruido provocado por el transporte

contam: contaminación atmosférica

camb clim: cambio climático

suelo: ocupación del suelo

Finalmente, el beneficio total social debido a la captación de demanda será igual a la suma de los beneficios unitarios por cada usuario que deja de emplear su vehículo privado y comienza a usar el autobús interurbano.

$$
\Delta B S=\sum_{q=1}^{V-V_{o}} \Delta B S_{q}
$$

Donde, $\triangle \mathrm{BS}$ : beneficios sociales del servicio de transporte interurbano en autobús por reducción de externalidades

$\triangle \mathrm{BS}_{\mathrm{q}}$ : beneficios sociales por la captación del usuario $\mathrm{q}$

$\mathrm{V}_{\mathrm{o}}$ : demanda anual inicial del servicio

$\mathrm{V}$ : demanda anual final del servicio

3.c) Beneficios del operador.

Por último, y como ya se ha indicado anteriormente, la demanda adicional captada a raíz de las mejoras en la calidad del servicio, también aporta beneficios extra al operador, que se pueden cuantificar como los ingresos totales por venta de billetes anteriores y posteriores a las mejoras implementadas, como sigue:

$$
\Delta B O_{\Delta V, \Delta c}=\sum_{q=1}^{V} c_{q}-\sum_{q=1}^{V_{o}} c_{o, q}
$$

Donde, $\Delta \mathrm{BO}_{\Delta \mathrm{V}, \Delta \mathrm{c}}$ : beneficios del operador debidos a la captación de mayor demanda y/o a la modificación de tarifas 
$\mathrm{V}$ : demanda futura anual del servicio de transporte interurbano en autobús

$\mathrm{V}_{\mathrm{o}}$ : demanda anual actual del servicio

$\mathrm{c}_{\mathrm{o}, \mathrm{q}}$ : coste inicial del billete para el usuario $\mathrm{q}$

$\mathrm{c}_{\mathrm{q}}$ : coste final del billete para el usuario $\mathrm{q}$

$\mathrm{Si}$, adicionalmente, se "devolviera" al operador parte de los beneficios sociales que las mejoras implementadas en el servicio proporcionan, sería necesario añadir un término a esta expresión. Así, finamente, el beneficio total del operador sería el siguiente:

$$
\Delta B O=\Delta B O_{\Delta V, \Delta c}+P \cdot(\Delta B U+\Delta B S)
$$

Donde, $\triangle \mathrm{BO}$ : beneficios totales del operador por su mejora en las condiciones de calidad del servicio

$\Delta \mathrm{BO}_{\Delta \mathrm{V}, \Delta \mathrm{c}}$ : beneficios del operador debidos a la captación de mayor demanda y/o a la modificación de tarifas

$\triangle \mathrm{BU}$ : beneficios de los usuarios por mejora de la calidad

$\triangle \mathrm{BS}$ : beneficios de la sociedad por reducción de externalidades

P: proporción de los beneficios sociales y de los usuarios que revierte al operador

4) Definir las restricciones.

De nuevo, resulta evidente que existen ciertas restricciones, que condicionan la solución del problema. Las exponemos a continuación.

\section{4.a) Condiciones de calidad del servicio.}

Con este sistema, es posible incorporar unos niveles mínimos admisibles para las diferentes variables que configuran la calidad del servicio y, consecuentemente, su demanda.

Una de las condiciones habitualmente incorporadas en las concesiones de servicios de transporte público es la obligatoriedad de disponer un número mínimo de servicios, de acuerdo con las condiciones de servicio público. Así, de forma similar a la restricción para la tarifa, resultaría lo siguiente:

$$
N S_{x} \geq N S_{x, \min }
$$


Donde, $\mathrm{NS}_{\mathrm{x}}$ : número de expediciones (salidas) diarias de la línea $\mathrm{x}$

$\mathrm{NS}_{\mathrm{x}, \mathrm{mín}}$ : mínimo número admisible de expediciones diarias (salidas) de la línea $\mathrm{x}$

Además, puede que se imponga una condición de que la tarifa no puede superar un determinado valor, o que el tiempo de viaje esté comprendido en unos límites, o incluso exigir unas condiciones concretas al vehículo (autobús) que realizará la ruta. En este caso, dichas restricciones quedarían como sigue:

$$
\begin{aligned}
& 0 \leq c_{x} \leq c_{x, \text { máx }} \\
& 0 \leq t_{x} \leq t_{x, \text { máx }} \\
& \text { ruta }_{x} \geq \text { ruta }_{x, \text { min }} \\
& \text { bus }_{x} \geq \text { bus }_{x, \text { min }}
\end{aligned}
$$

Donde, $Z_{\mathrm{x}}$ : variable $\mathrm{Z}$ del servicio para la línea $\mathrm{x}$

$\mathrm{Z}_{\mathrm{x}, \text { máx }} / \mathrm{Z}_{\mathrm{x}, \text { mín: }}$ máximo/mínimo valor admisible de la variable $\mathrm{Z}$ del servicio para la línea $x$

c: coste del billete

t: duración del viaje

ruta: proporción del trayecto realizado por vías de alta capacidad

bus: variable dummy relativa a las características del vehículo

\section{4.b) Tráfico y capacidad.}

Es evidente que, otra condición que se debe cumplir, es que la posible demanda adicional captada pueda ser absorbida por el servicio. Así, la demanda del servicio debe ser menor o igual a la oferta, que se calcula mediante el número de expediciones, el número de autobuses dispuestos en cada uno (considerando, por tanto, la posibilidad de refuerzos) y la capacidad de los mismos.

$$
V_{x} \leq \sum_{\text {anual }}\left(N S_{x} \cdot Q_{x} \cdot N b u S_{x}\right)
$$

Donde, $\mathrm{V}_{\mathrm{x}}$ : demanda futura anual de la línea $\mathrm{x}$ del servicio de transporte interurbano en autobús

$\mathrm{NS}_{\mathrm{x}}$ : número de expediciones diarias (salidas) de la línea $\mathrm{x}$

$\mathrm{Q}_{\mathrm{x}}$ : capacidad (personas) media de los autobuses que operan la línea $\mathrm{X}$

Nbus: número medio de autobuses dispuestos en cada salida de la línea 


\section{4.c) Presupuesto máximo disponible.}

El problema de escasez de presupuesto es un recurrente en el servicio de autobús interurbano, que de hecho es uno de los causantes del "círculo vicioso" expuesto en el punto 1.1. Así, si se decide "devolver" al operador una fracción de los beneficios sociales y de los usuarios que genera su inversión en mejorar la calidad, ésta cantidad debe ser sustraída de la cantidad correspondiente a sufragar las condiciones de servicio público. Por tanto, la determinación del valor óptimo de dicha fracción no es una cuestión trivial.

Una vez liquidados los pagos debidos a las condiciones de servicio público establecidas, el balance restante del presupuesto total es factible de ser empleado para incentivar la mejora de la calidad, lo cual supone una restricción a su valor máximo.

Según se describe en la expresión (4-68), por la demanda adicional ganada respecto de la prevista inicialmente (función de las condiciones mínimas de calidad del servicio impuestas en el pliego de condiciones), el operador percibe un ingreso, que puede provenir de tres fuentes distintas: lo recaudado en taquilla, el aumento de beneficios de los usuarios del sistema de transporte, y la reducción de externalidades por un menor uso del vehículo privado. Las dos últimas son parte del presupuesto total del sistema de transporte público en autobús interurbano.

Así, la suma disponible para el sistema de incentivos será menor o igual que el presupuesto global menos las subvenciones correspondientes a las obligaciones de servicio público, y se expresa matemáticamente como sigue:

$$
\sum_{x} P \cdot\left(\Delta B U_{x}+\Delta B S_{x}\right)+\sum_{x} S S P_{x} \leq P T, \quad \text { para }\left(\Delta B U_{x}+\Delta B S_{x}\right) \geq 0
$$

Donde, P: proporción de los beneficios sociales y de los usuarios que revierte al operador

$\triangle \mathrm{BU}_{\mathrm{x}}$ : beneficios de los usuarios de la línea $\mathrm{x}$ por mejora de la calidad $\triangle \mathrm{BS}_{\mathrm{x}}$ : beneficios de la sociedad por reducción de externalidades en la línea $\mathrm{x}$

PT: presupuesto total disponible

$\mathrm{SSP}_{\mathrm{x}}$ : subvenciones por las imposiciones de servicio público para la línea $\mathrm{x}$ 
Así, pues, en función del valor que resulte para $P$, las cantidades destinadas a fomentar las mejoras en el servicio y a mantener las obligaciones de servicio público variarán, aunque su suma deba ser constante. Si se anula este valor, el esquema vuelve a ser el actual, donde el presupuesto disponible se reparte únicamente en función de las subvenciones por mantenimiento de servicio público. Sin embargo, a medida que aumenta dicho valor, las subvenciones "fijas" pueden llegar, incluso, a anularse, dejando el mercado en total libertad. Por tanto, la determinación de dicha fracción es una cuestión sumamente relevante para la detección del punto óptimo de funcionamiento del servicio.

\section{4.d) Requisitos comerciales.}

Evidentemente, se debe incluir un único requisito: la viabilidad económica del sistema para los operadores. Así, los costes en que incurra por las mejoras introducidas en el servicio no deben superar los beneficios que reciba, tanto por venta de billetes como a través de incentivos y/o subvenciones de la Administración. Expresada en forma de ecuación, esta restricción resulta, para cada operador:

$$
\left.\begin{array}{l}
(1+B I) \cdot \sum_{x \in \text { operador }} C_{x}=\sum_{x \in \text { operador }}\left(B O_{x}+S S P_{x}\right)= \\
=\sum_{x \in \text { operador }}\left(V_{x} \cdot c_{x}+P \cdot\left(\Delta B U_{x}+\Delta B S_{x}\right)+S S P_{x}\right)
\end{array}\right\} \quad \text { para } B I>0
$$

Donde, $\mathrm{C}_{\mathrm{x}}$ : coste total anual de la línea x para el operador

BI: beneficio industrial (tanto por uno) del operador

$\mathrm{BO}_{\mathrm{x}}$ : beneficios del operador de la línea $\mathrm{x}$

$\mathrm{SSP}_{\mathrm{x}}$ : subvenciones por las imposiciones de servicio público para la línea $\mathrm{x}$

$\mathrm{V}_{\mathrm{x}}$ : demanda final anual de la línea $\mathrm{x}$

$c_{\mathrm{X}}$ : precio del billete final de la línea $\mathrm{x}$

P: proporción de los beneficios sociales y de los usuarios que revierte al operador

$\triangle \mathrm{BU}_{\mathrm{x}}$ : beneficios de los usuarios de la línea $\mathrm{x}$ por mejora de la calidad $\Delta \mathrm{BS}_{\mathrm{x}}$ : beneficios de la sociedad por reducción de externalidades en la línea $\mathrm{x}$ 
5) Definir la función objetivo.

Por tanto, únicamente resta ya plantear la función objetivo a maximizar, que se corresponde con el beneficio total de la sociedad en conjunto. Así, debemos sumar los beneficios de los actuales usuarios y los beneficios sociales por reducción de externalidades, pero también considerando los ingresos del operador por venta de billetes y los costes de explotación que soporta para mantener el servicio.

$$
\operatorname{Max}: \sum_{x}\left(\Delta B U_{x}+\Delta B S_{x}+\Delta B O_{x}-\Delta C_{x}\right), \quad \operatorname{para}\left(\Delta B U_{x}+\Delta B S_{x}\right)>0
$$

Donde, $\Delta \mathrm{BU}_{\mathrm{x}}$ : beneficios de los usuarios de la línea $\mathrm{x}$ por mejora de la calidad $\triangle \mathrm{BS}_{\mathrm{x}}$ : beneficios de la sociedad por reducción de externalidades en la línea $\mathrm{x}$ $\mathrm{V}_{\mathrm{x}}$ : demanda final anual de la línea $\mathrm{x}$

$c_{x}$ : precio del billete final de la línea $\mathrm{x}$

$\mathrm{C}_{\mathrm{x}}$ : coste total anual de la línea $\mathrm{x}$ para el operador

Sin embargo, otra segunda opción sería no considerar los beneficios del operador, con lo que la función objetivo quedaría, en este caso:

$$
\operatorname{Max}: \sum_{x}\left(\Delta B U_{x}+\Delta B S_{x}\right), \quad \operatorname{para}\left(\Delta B U_{x}+\Delta B S_{x}\right)>0
$$

Donde, $\Delta \mathrm{BU}_{\mathrm{x}}$ : beneficios de los usuarios de la línea $\mathrm{x}$ por mejora de la calidad $\triangle \mathrm{BS}_{\mathrm{x}}$ : beneficios de la sociedad por reducción de externalidades en la línea $\mathrm{x}$ P: proporción de los beneficios sociales y de los usuarios que revierte al operador

De la elección entre una u otra dependerá la solución al problema.

Sea como sea, una vez definida la función objetivo a maximizar, junto con las restricciones pertinentes, el problema radica en encontrar la proporción del presupuesto total que podría ser dirigido a la mejora de la calidad de los contratos. Además, es necesario determinar las condiciones óptimas del servicio, en cuanto a las variables que se han considerado relevantes: precio del billete, duración del viaje, número diario de servicios, ruta a seguir y características del vehículo. La proporción de beneficios sociales y de los usuarios que revierte al operador se considerará única para todas las concesiones, mientras que el punto óptimo de explotación será calculado específicamente para cada línea. Por tanto, el número de variables independientes a considerar en la función objetivo puede alcanzar valores extremadamente altos a medida que la escala del estudio crece. 
Con esta metodología, parece posible "poner de acuerdo" los criterios económicos de los operadores con los objetivos de calidad de la sociedad, pues una inversión que reporte mejoras en la satisfacción de los usuarios también tendrá recompensa a través del incentivo recibido de la Administración. Así, el círculo vicioso que describíamos en el punto 1.1 puede ser roto, obteniendo beneficios sociales (y también económicos) para todos.

En el capítulo que sigue que introducirá dicha formulación a los datos recogidos para el caso de estudio, y se probará su aplicación en diversas experiencias piloto. 



\section{CASO DE ESTUDIO}

A continuación se presentarán los resultados numéricos cuantitativos del estudio realizado. Así, en un primer apartado, se mostrará un resumen de la caracterización del usuario del servicio de transporte público en autobús, y del viaje analizado. En segundo lugar, se indicarán los modelos calibrados tanto para calidad como para demanda, así como los valores de disponibilidad al pago resultantes de los mismos. Por último, se planteará una propuesta de aplicación a la Comunidad Autónoma de Castilla y León, incluyendo variables representativas de la calidad del servicio percibida por los usuarios en los contratos de transporte. 


\subsection{Análisis Estadístico}

En este apartado, presentaremos en primer lugar un breve análisis de las características de los encuestados, a fin de determinar de forma inicial el colectivo potencial de usuarios del transporte público en autobús interurbano. Además, también se indicarán los principales datos relativos a los viajes realizados por dichos entrevistados, ya que su conocimiento puede resultar fundamental para su posterior mejora.

\subsubsection{Caracterización del Usuario}

En primer lugar, se han estudiado las proporciones de los usuarios en función de su género, edad, disponibilidad de carnet de conducir y vehículo privado, y actividad y status económico y zona de residencia. Con dichos datos, se pretende tener una idea global de cuáles son los actuales usuarios del autobús interurbano, a fin de identificar el mayor grupo potencial que lo emplearía, al mismo tiempo que podamos conocer cómo son los no usuarios, para tratar de captarlos hacia el transporte público.

Tal y como sucede habitualmente en la mayoría de estudios de transporte público, es especialmente destacable la distribución de los entrevistados en función de su género. Así, la muestra se compone de un $59 \%$ de mujeres y un $41 \%$ de hombres, como presenta la Figura 5-1. Dado que la muestra se puede considerar representativa de la población, podemos estimar que el ratio sería similar si se tuviera en cuenta el total de usuarios. De este modo, aparece un hecho constante en la mayoría de las encuestas, según el cual las mujeres son un estrato más orientado al empleo del transporte público que los hombres, ya que, según el padrón del año 2008 [41], las proporciones de mujeres y hombres en el total de la provincia son prácticamente iguales.

Figura 5-1. Distribución de los entrevistados en función de su sexo

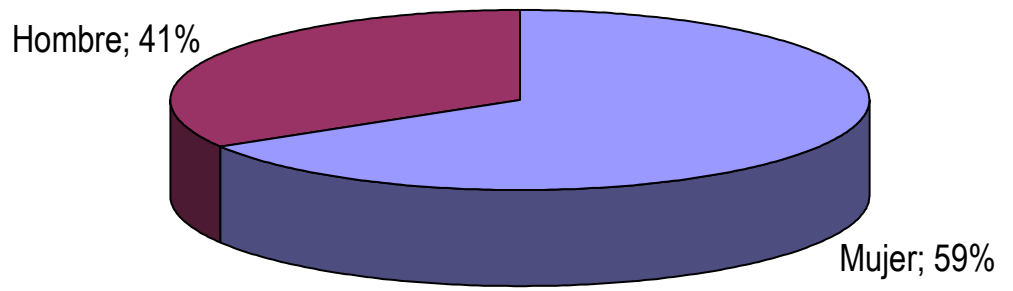

Por otra parte, si nos fijamos en la distribución de edad de los entrevistados, vemos que la proporción de los usuarios disminuye a medida que aumenta su edad. En la Figura 5-2 se 
muestra la representación de la edad de los encuestados, tal y como se consultó en las entrevistas (descrito en la Tabla 4-1). De la misma se extrae, en primer lugar, la clara conclusión de que el empleo del transporte público disminuye con la edad de los entrevistados, excepto para el último grupo de edad -mayores de 65 años-, que, por sus características económicas o personales, experimentan un repunte. Además, de los datos obtenidos resulta que la edad promedio de los usuarios es unos 37 años de edad. Comparando los valores de nuestra muestra con la pirámide de población de la provincia [41], ambas siguen una forma similar a una campana invertida, aunque con extremos menos apuntados en los datos del padrón.

Figura 5-2. Distribución de los entrevistados por rangos de edad

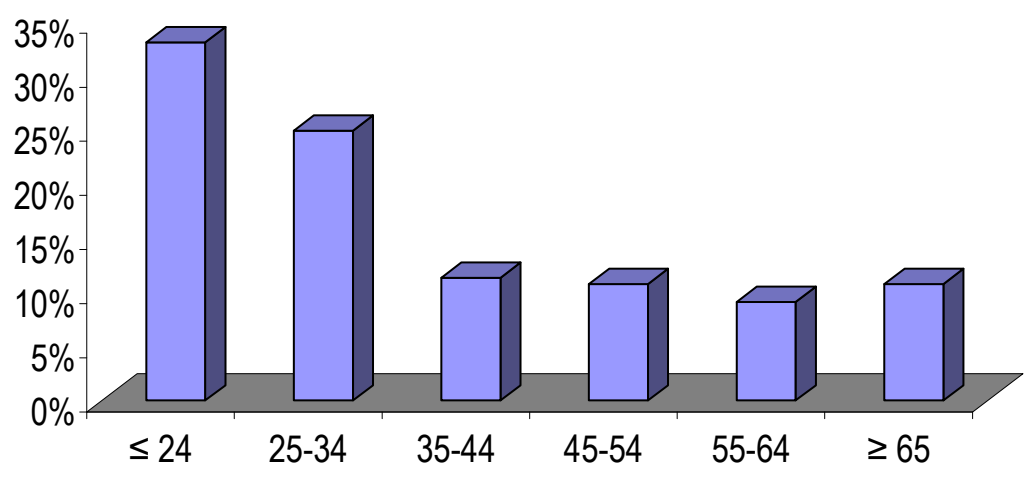

En cuanto a la consideración del lugar de residencia de los encuestados nos indica que sólo el 38\% de los usuarios son residentes en la ciudad de Burgos o en su Alfoz, siendo el 25\% de los encuestados del resto de la provincia. Si comparamos estos valores con el hecho de que, según el padrón de 2008 [41], casi el 50\% de los habitantes de la provincia residen en la capital, resulta la conclusión de que, proporcionalmente, es más habitual el uso del transporte público interurbano entre los no residentes en la capital. Además, podemos comprobar que la mayoría de población reside en un lugar situado entre 10 y 30 minutos a pie a la estación de autobuses más cercana. Dichos datos se reflejan en la Figura 5-3. 
Figura 5-3. Residencia de los encuestados

Zona de residencia

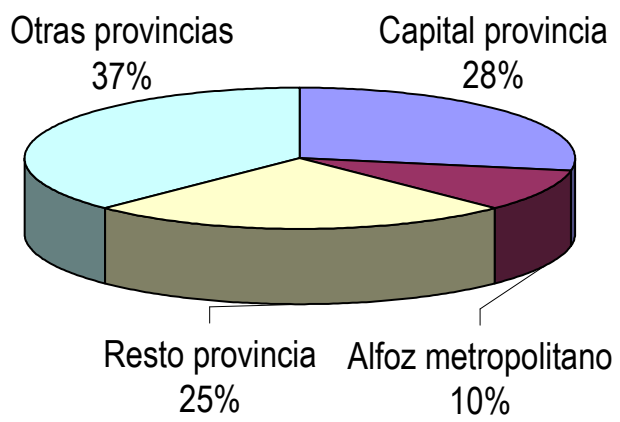

Tiempo de acceso hasta la estación (min)

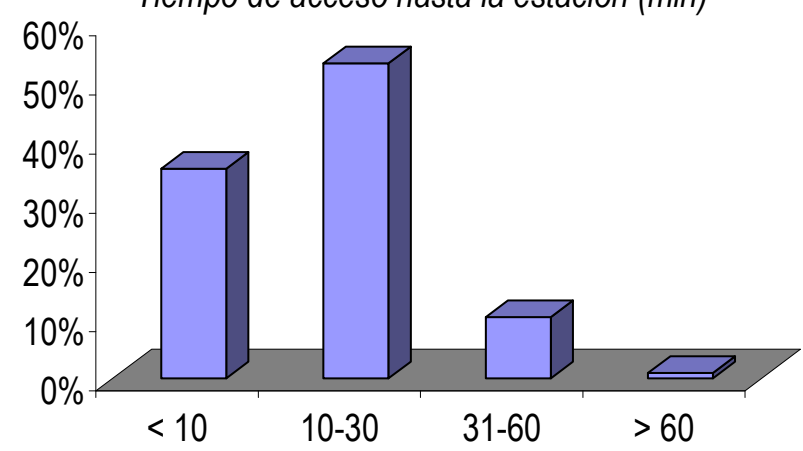

Un dato especialmente interesante para determinar el tipo de usuario es su disponibilidad de carnet de conducir o de un vehículo privado con el que pudieran haber realizado el viaje. Así, aunque el 58\% de los encuestados sí disponía de carnet de conducir, sólo el $40 \%$ habría podido emplear un vehículo privado para realizar el viaje analizado, como se observa en la Figura 5-4. Por tanto, para aquellos trayectos no realizables vía tren, tenemos un alto porcentaje de usuarios cautivos del autobús.

Figura 5-4. Disponibilidad de carnet de conducir y vehículo privado de los encuestados
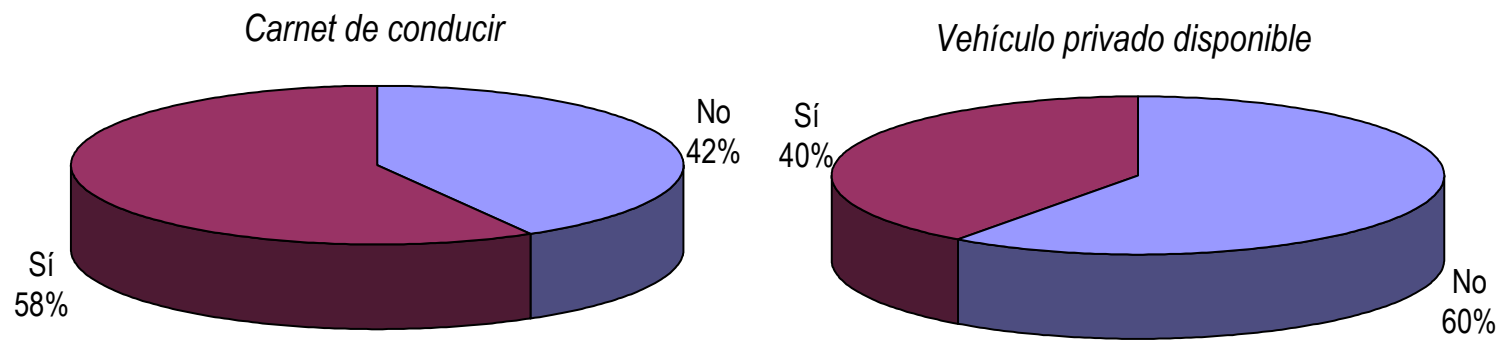

En cuanto a la actividad económica de los encuestados, en la Figura 5-5 observamos que en la muestra hay un $33 \%$ de trabajadores activos, junto con un $25 \%$ de estudiantes. Así pues, comparando estos valores con los promedios poblacionales, donde la tasa de personas activas es de algo más del 40\% [41], concluimos que, en general, los trabajadores son el grupo de menor potencial de empleo del transporte público, como sucede a menudo en esta tipología de estudios. 
Figura 5-5. Distribución de los entrevistados según su actividad

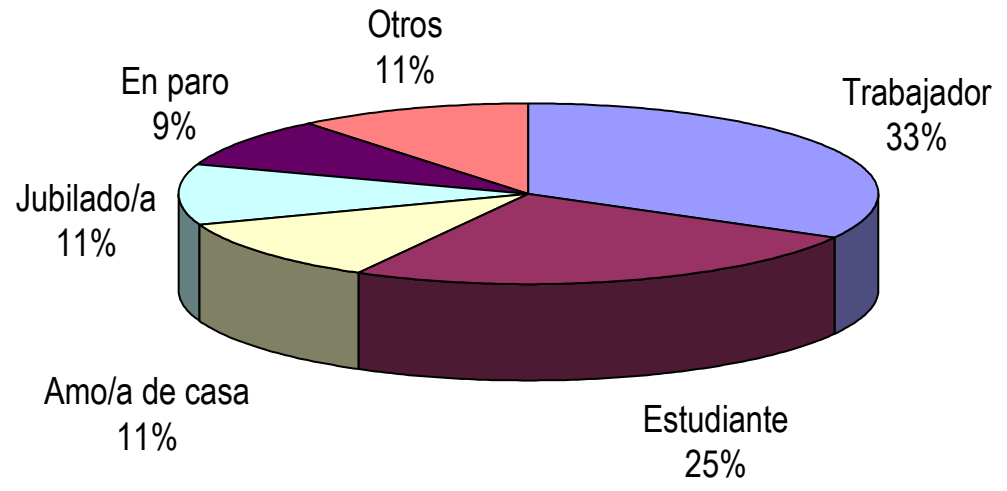

Por último, analizando el status económico de las familias de los usuarios, se puede observar que la distribución de los mismos en función de sus ingresos netos mensuales per cápita es bastante uniforme entre unos $200 €$ y $1.200 €$, restando únicamente un $10 \%$ con rentas superiores a este último valor. Además, el valor de ingresos netos mensuales correspondiente a la mediana de la muestra está en unos $650 € /$ persona. Por otra parte, también se consultó a los entrevistados sobre el nivel de motorización familiar, resultando un $20 \%$ de encuestados en cuyas familias no hay ningún vehículo a motor, una mediana en la muestra de 0,5 vehículos/persona y un valor máximo de 1 vehículo/persona, principalmente en familias de un solo miembro y con un vehículo privado. Además, la tasa media provincial es de 0,65 vehículos a motor por habitante [41], con lo que podemos concluir que, evidentemente, el empleo del transporte público es mayor en familias con menor índice de motorización. La distribución de percentiles correspondiente a los ingresos netos mensuales y el índice de motorización se presenta en la Figura 5-6.

Figura 5-6. Status económico familiar de los encuestados

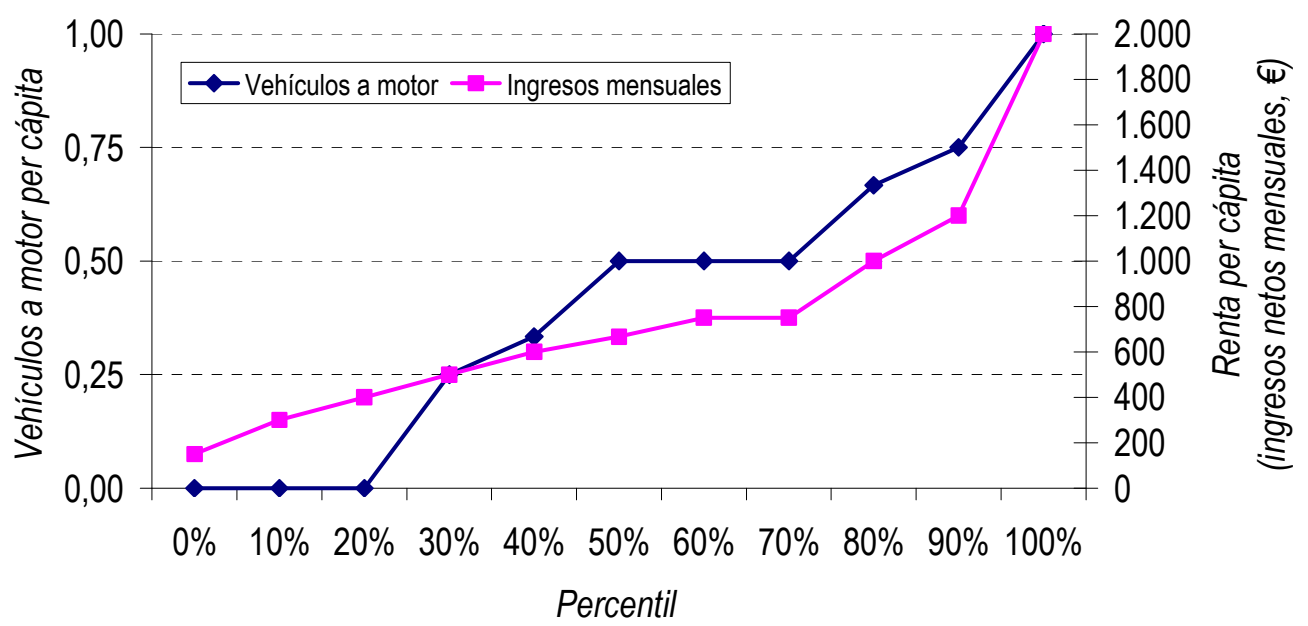


De este modo, podemos concluir que el usuario tipo del autobús interurbano sería una mujer joven trabajadora, con carnet de conducir pero sin un vehículo privado disponible para ella. En su familia dispondrían de un vehículo para cada dos personas, y su vivienda estaría localizada en la provincia de Burgos, a unos 20 minutos de la estación de autobuses más próxima. Así pues, los usuarios cuyas características personales difieran en gran medida respecto de éstas, son el grupo que precisa un mayor cambio de mentalidad, si el objetivo fuera conseguir su transvase modal hacia el transporte público interurbano.

\subsubsection{Principales Características de los Viajes}

Una vez determinado el tipo de usuario más habitual del transporte interurbano en autobús, a continuación se presentará un resumen estadístico de las principales características sobre sus viajes.

Así, en primer lugar, se consultó a los entrevistados sobre la frecuencia con la que empleaban el servicio. Los resultados se presentan en la Figura 5-7. En ella se aprecia que el 69\% de los usuarios sólo emplean el autobús interurbano de forma ocasional, o incluso menor aún. Este hecho pone de manifiesto una característica claramente indeseable del servicio: su incapacidad de conseguir "fidelizar" a los usuarios que hacen viajes interurbanos de forma habitual. De hecho, como se ha indicado anteriormente, gran parte de los usuarios del servicio son cautivos del mismo, al no disponer en muchos casos de otro modo de transporte disponible. Aplicando valores numéricos a la escala semántica de la encuesta, se obtendría un promedio de 3,5 veces/mes de empleo del servicio por cada entrevistado, lo cual quedó reflejado en la siguiente pregunta de la encuesta, ya que el $90 \%$ de los encuestados indicó que ya habían realizado el mismo viaje con anterioridad.

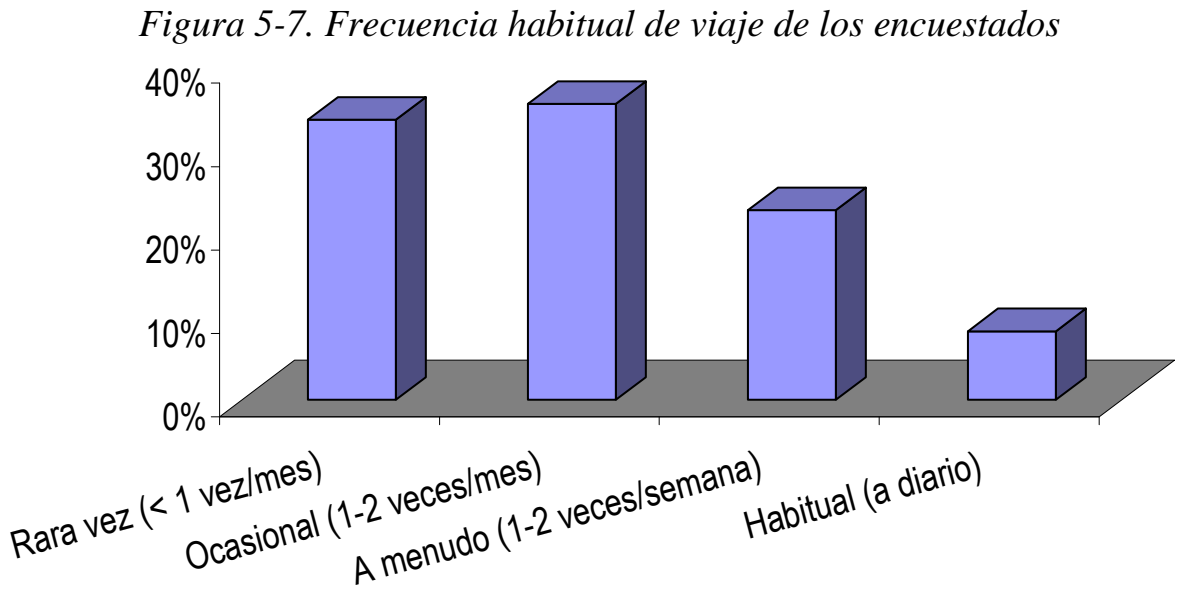


De forma similar, se ha obtenido una distribución de las longitudes de viaje de los entrevistados, dado que se les consultaba su origen y destino. Así, podemos obtener la Figura 5-8, de la que se observa que las mayores proporciones de viajes se corresponden con longitudes entre 120 y 300 km, es decir, en distancias medias-largas. De hecho, la distancia promedio de viaje es de unos $170 \mathrm{~km}$, lo cual coincide con la apreciación anterior. Además, los viajes de tipo metropolitano, de acceso a las localidades del alfoz, representan únicamente algo más del $6 \%$ del total.

Figura 5-8. Distribución de longitudes de viaje

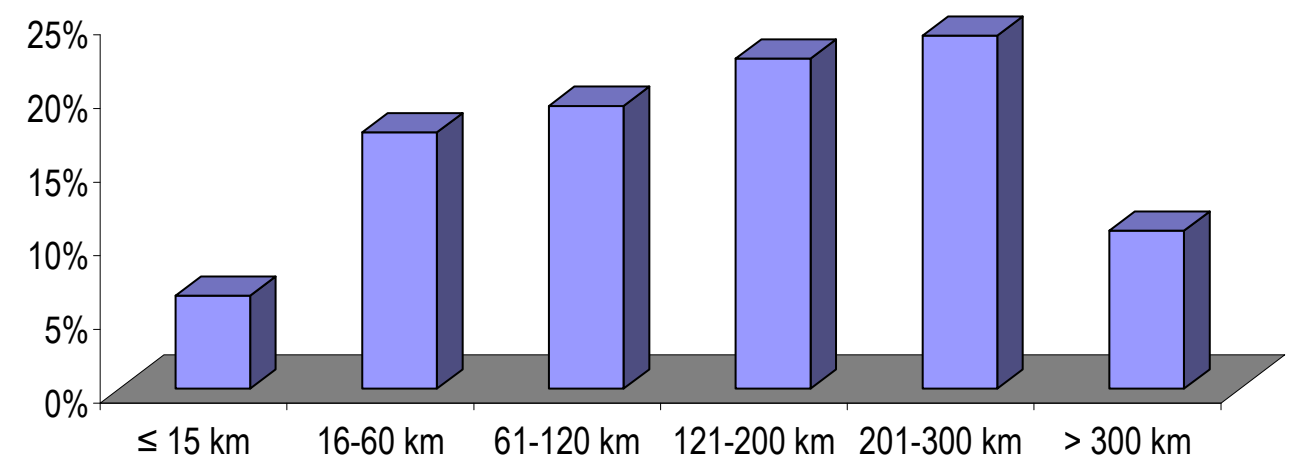

En cuanto a los motivos de viaje, podemos comprobar que la mayor parte de los mismos se realiza por motivos personales, como se presenta en la Figura 5-9. De hecho, la movilidad obligada con motivo trabajo/estudio únicamente representa un $33 \%$ del total de los viajes, lo que concuerda con las apreciaciones anteriores sobre la ocasionalidad de los viajes registrados.

Figura 5-9. Motivos de viaje de los entrevistados

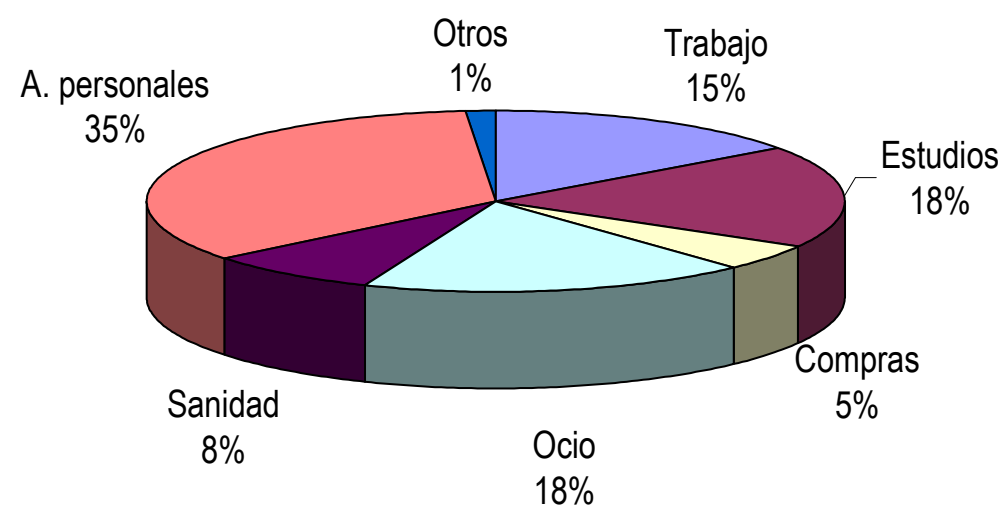

Por otra parte, conjugando los datos de la distancia, tiempo de viaje y coste del billete aportados por los entrevistados, y una vez filtrados los outliers, correspondientes en gran 
medida a errores de observación y a viajes no demasiado representativos, se obtiene la Figura 5-10, que presenta las velocidades de recorrido y costes del billete. Los valores promedio de los datos se corresponden con una velocidad de unos $71 \mathrm{~km} / \mathrm{h}$ y un billete que cuesta alrededor de $10 €$. Si se representaran los valores relativos al coste por kilómetro, se obtendrían valores cercanos a $0,066 € / \mathrm{km}$, el cual constituye la mediana de la muestra.

Figura 5-10. Velocidad y coste de los viajes

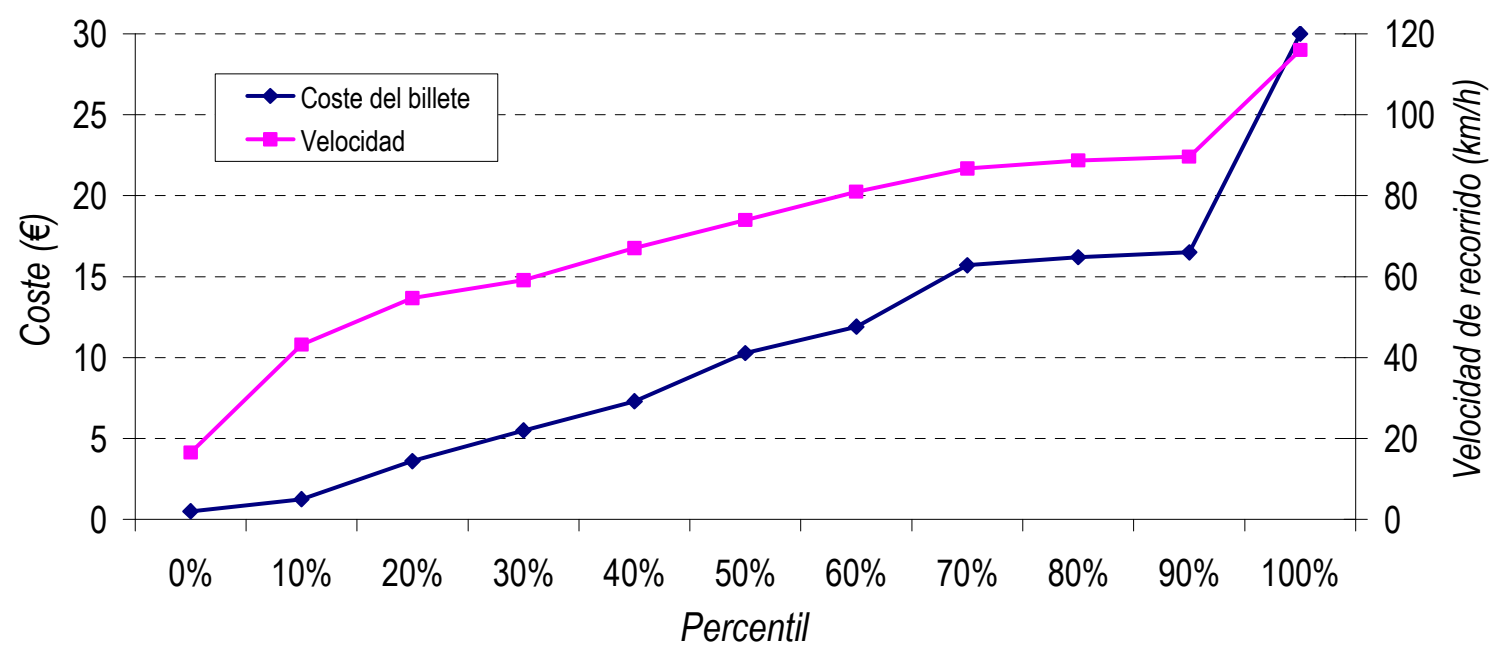

Además, se consultó también a los entrevistados sobre el retraso sufrido en su viaje, así como el número de paradas del mismo. De este modo, se obtuvieron los datos relativos a la Figura 5-11, en la que se observa que más del 70\% de los viajes no tuvieron retraso, lo cual supone una importante característica positiva. Cuando aparecen retrasos, los valores más habituales están entre 5 y 15 minutos, siendo prácticamente nula la proporción de viajes con demora superior a 15 minutos. Por otra parte, aproximadamente el $40 \%$ de los viajes era de tipo directo, siendo el número medio de paradas de 2,3. De hecho, más del 95\% de los viajeros en trayectos con paradas afirman que preferirían un viaje más directo.

Figura 5-11. Retrasos y número de paradas de los viajes
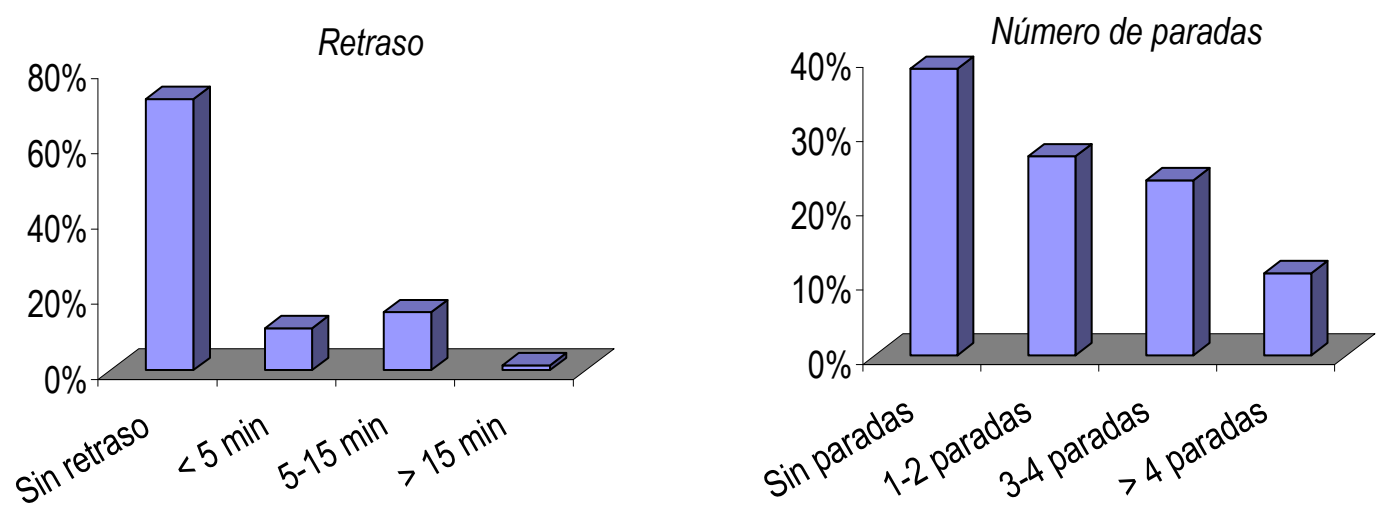
Las siguientes preguntas fueron relativas al equipamiento del autobús y de la estación. Así, la Figura 5-12 muestra los porcentajes de usuarios que consideraron adecuadas determinadas características de la estación de autobuses y de la compra del billete, mientras que, en la Figura 5-13, se indica el equipamiento observado en el autobús y la antigüedad percibida por los entrevistados.

\section{Figura 5-12. Características de la estación}

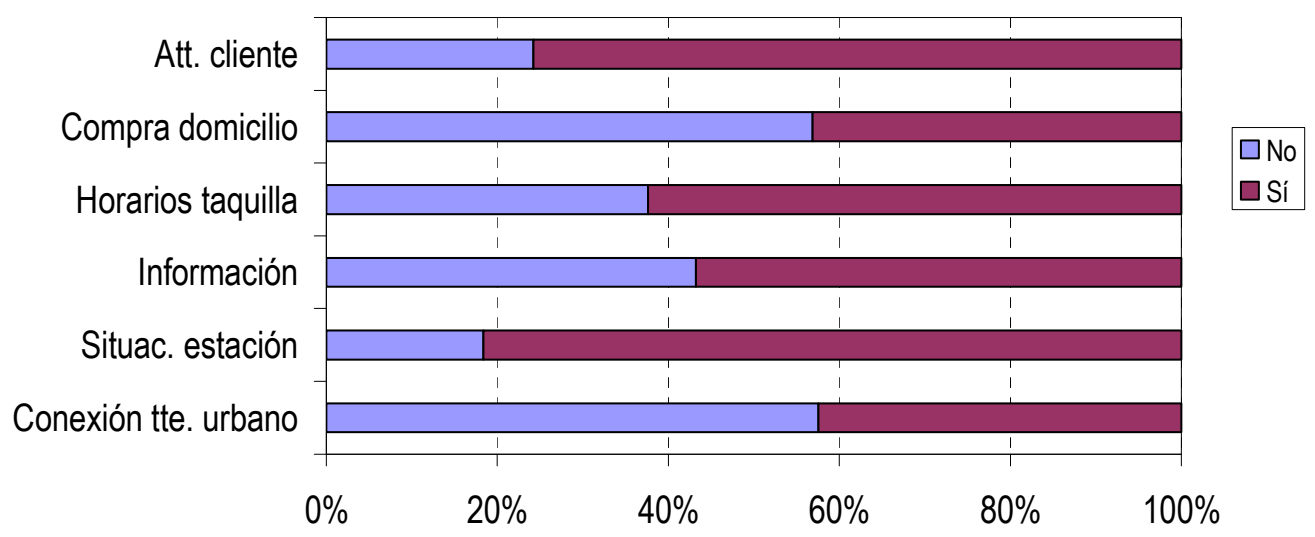

Figura 5-13. Equipamiento y antigüedad del autobús

Antigüedad del autobús

Gran clase; $1 \%$

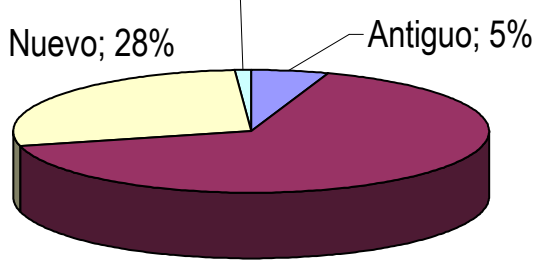

Seminuevo; $66 \%$
Equipamiento del autobús

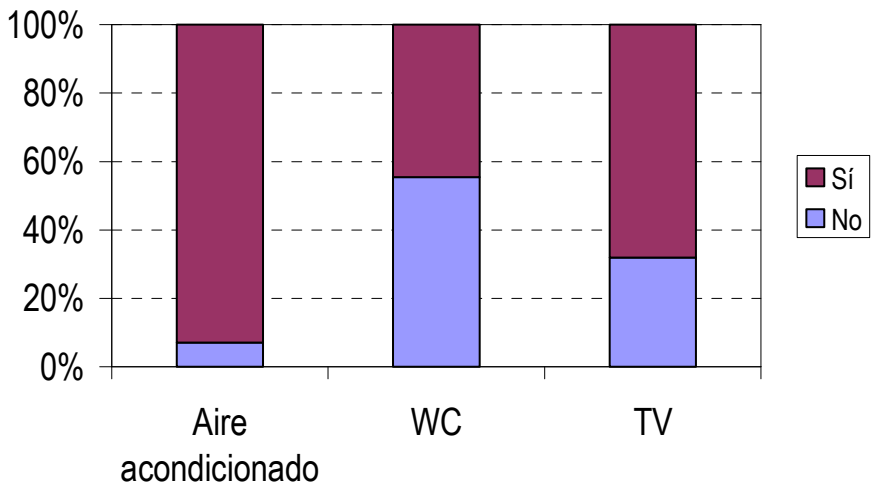

Vemos que, respecto a la estación, las características más valoradas son la atención al cliente y si situación en el centro urbano; por el contrario, los encuestados estiman insuficiente las conexiones con el transporte urbano y las posibilidades de compra del billete desde el domicilio. Por otro lado, el 66\% de los autobuses eran "seminuevos", y la mayor parte de ellos contaban con aire acondicionado y televisión.

Por último, las últimas consultas que se realizaron a los entrevistados fueron su satisfacción global con el viaje realizado, así como las relativas a su fidelidad como usuario [44]: probabilidad de que volvieran a emplearlo y si lo recomendarían a sus 
conocidos. La Figura 5-14 muestra los resultados de ambas cuestiones. Destaca especialmente la apreciación global de la calidad por parte de los encuestados, ya que más del 70\% la considera "buena" o "muy buena". Sin embargo, cuando se les pregunta sobre la probabilidad de que volvieran a emplear el servicio si tuvieran disponible otro modo de transporte, sólo un $40 \%$ cree -o asegura- que lo haría. Esto nos hace de nuevo concluir que gran parte de los usuarios del servicio de autobús interurbano lo son en realidad porque no tienen otra alternativa, circunstancia a cambiar en el futuro.

Figura 5-14. Satisfacción global y fidelidad de los usuarios

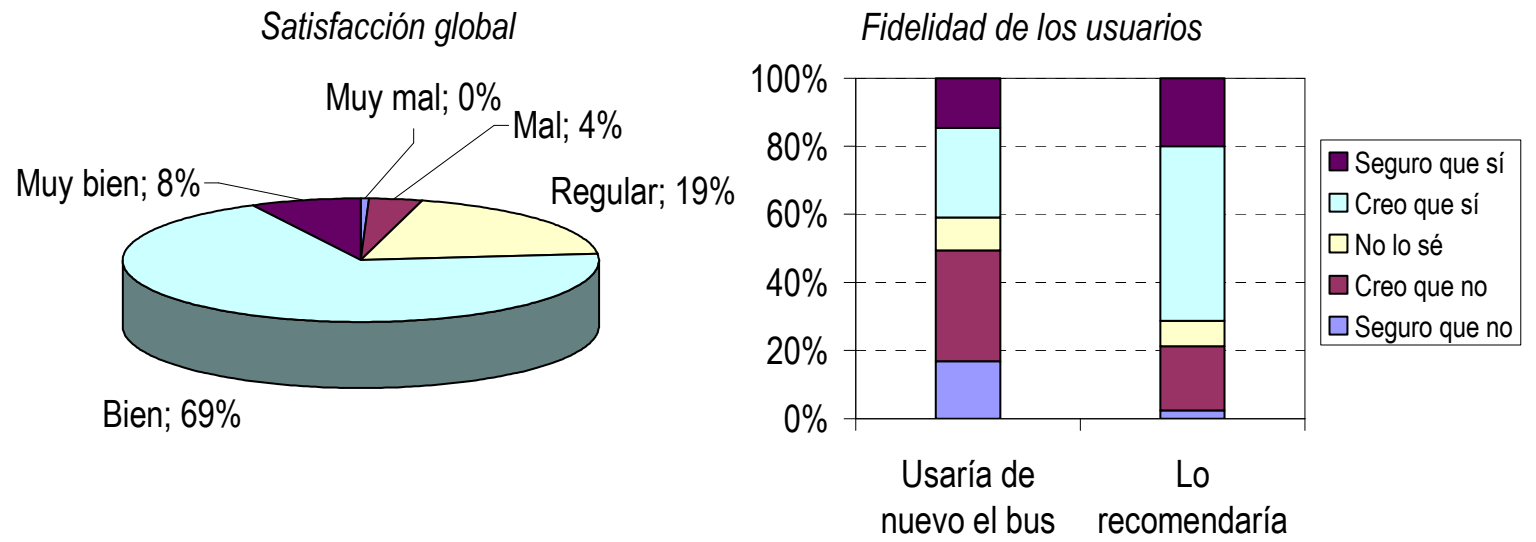

Para comprobar esta teoría, en la Figura 5-15 se muestra un gráfico de dispersión, comparando los valores que cada entrevistado asignó a su satisfacción global con las variables de fidelidad anteriores. En ésta se observa, sin embargo, que aunque sí existe relación entre ambas variables, los coeficientes de correlación de las rectas obtenidas por regresión lineal son muy bajos $(0,10$ para la recta satisfacción-volverían a viajar y 0,06 para la recta satisfacción-recomendarían). Ello implica que, mejorando la satisfacción del usuario, la demanda del servicio podría aumentar en cierta medida, aunque no de forma tan directa como cabría esperar.

Para concluir este apartado, observamos que la mayor parte de los viajes son de tipo ocasional, en distancias medias-largas, y por motivos de movilidad no obligada, sobre todo de tipo directo y con escaso retraso. En cuanto a las características de la estación, sus puntos fuertes son su céntrica situación y la correcta atención al cliente, mientras que se debe presta atención en la mejora de las conexiones con el transporte público urbano y facilitar la posibilidad de compra del billete a domicilio. La mayoría de los viajes se realizan en autobuses seminuevos, los cuales suelen disponer de aire acondicionado y, en muchos casos, televisión. 
Figura 5-15. Comparación satisfacción-fidelidad

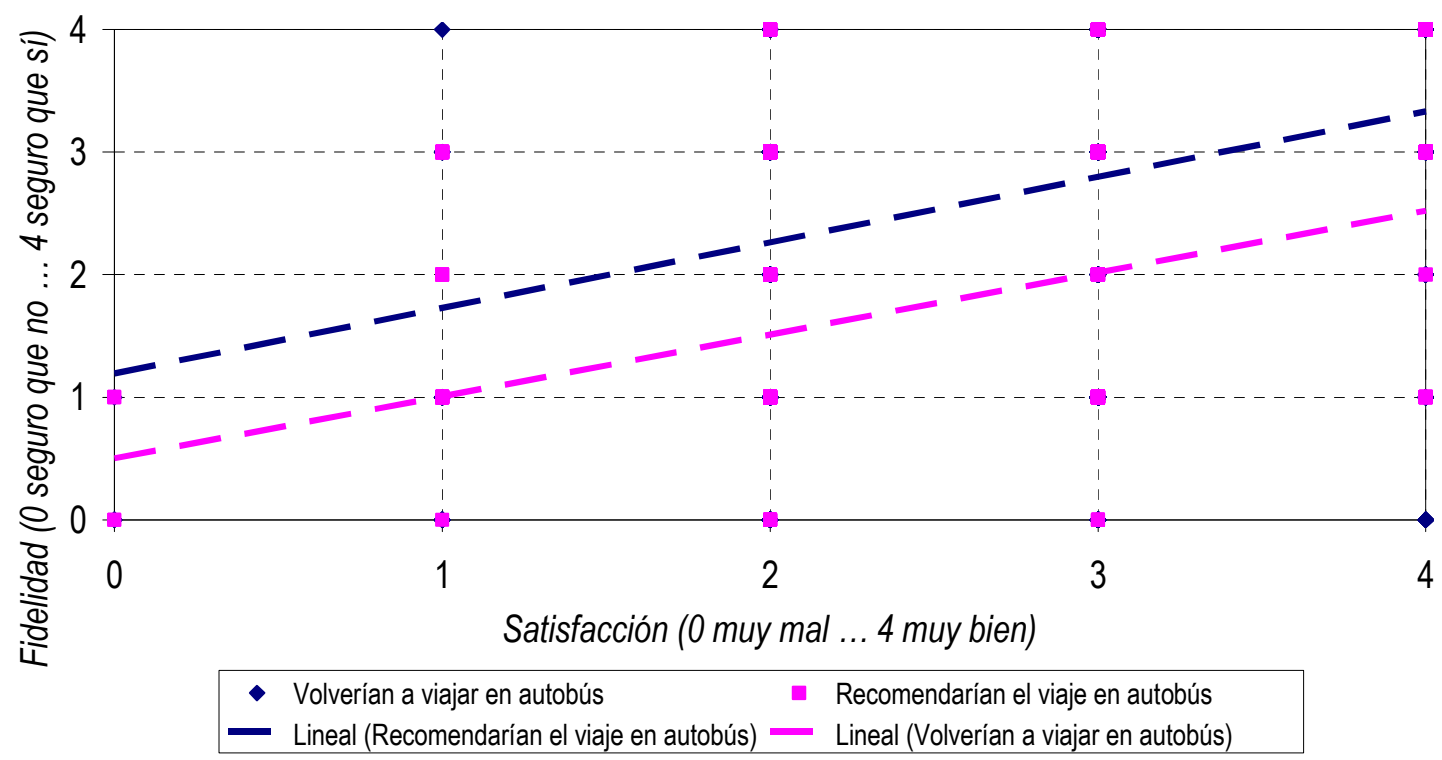

Por último, se observa que, a pesar de la buena satisfacción por parte de los usuarios, prácticamente la mitad de ellos afirma que, si tuvieran otro modo de transporte disponible, no volverían a realizar el viaje en autobús. Aquí aparece uno de los puntos de inflexión de la presente investigación, relacionado con la necesidad de mejorar no sólo la calidad percibida por los usuarios, sino también la demanda del servicio de transporte público, frente al vehículo privado.

Para ello, el único "arma" con que cuenta la Administración son las condiciones de los contratos de transporte establecido con las empresas operadoras. Por tanto, la inclusión de unos baremos mínimos o deseables de calidad entre las cláusulas de éstos, siempre que se haga de forma correcta, podría tener una influencia importante sobre su utilización. Es esta cuestión la que se tratará de resolver en los apartados que siguen, buscando, en primer lugar, la relación entre demanda y calidad del transporte público interurbano en autobús y, a continuación, la metodología apropiada para incorporarla a los contratos, de modo que las habituales subvenciones al servicio se realicen de forma racional y óptima. 


\subsection{Modelización del Comportamiento del Usuario}

A partir de los resultados del apartado anterior, deducimos que no es suficiente con conseguir una buena calidad del servicio de transporte público interurbano, sino que resulta fundamental conocer las variables que potencian su empleo.

Por tanto, en los puntos que siguen se presentarán los resultados de los modelos de satisfacción del usuario y demanda del servicio, así como la relación existente entre ambas cuestiones. La calibración de los diversos modelos planteados se ha efectuado empleando el software NLOGIT, de amplia distribución.

\subsubsection{Submodelo de Calidad y Satisfacción}

Como ya se ha indicado en apartados anteriores, la modelización de un experimento de escalamiento, como el realizado en el presente estudio, presenta diversas complejidades. Así, en nuestro caso, se solicitó a los encuestados que evaluaran su satisfacción global con el servicio como "muy mal", "mal", "regular", "bien” o "muy bien”. En este caso, las posibilidades de elección para el usuario son claramente dependientes entre sí, ya que una valoración "regular" es mejor que "mala" (y mejor aún que "muy mala"), pero peor que "buena" y "muy buena".

Por tanto, al ser las alternativas de elección dependientes entre sí, no es adecuado el empleo de modelos de elección discreta tales como el logit multinomial, ni tampoco el probit [131]. Así, el modo clásico de abordar esta tipología de datos ha sido mediante técnicas de regresión lineal, aunque éstas tienen el inconveniente de precisar una variable dependiente continua, caso que tampoco se da. Por tanto, el problema ha radicado principalmente en decidir cómo se transforman las respuestas de los usuarios, que siguen una escala semántica, en datos numéricos. El asunto no es sencillo, y en función de la decisión que se tome los resultados del modelo pueden variar [19, 50].

Así, para modelizar la satisfacción del usuario se ha optado finalmente por emplear modelos de tipo ordinal, más adecuados para los datos de entrada de que se dispone en el presente estudio. Las principales características e hipótesis de su formulación aparecen reflejadas en el capítulo anterior.

Para calibrar los modelos en software específico, la variable dependiente -en este caso, la satisfacción global- debe ser transformada a una escala numérica, que habitualmente oscila 
entre 0 y n, siendo $\mathrm{n}+1$ el número de posibles elecciones. Así, con los datos obtenidos, la variable satisfacción podría valer: 0 ("muy mal"), 1 (“mal"), 2 ("regular"), 3 ("bien") ó 4 ("muy bien"). Sin embargo, a la vista de los resultados del punto anterior, vemos que el número de entrevistados que eligieron las opciones "muy mal" o "mal" son muy bajos en comparación con el resto de grupos; por tanto, se procedió a reorganizar los datos en sólo 4 grupos: 0 ("muy mal” o "mal"), 1 ("regular"), 2 ("bien") ó 3 ("muy bien"). Se han probado ambas configuraciones, obteniendo sendos modelos que, con características globales bastante similares, tienen sensibles diferencias en cuanto a los valores de los parámetros resultantes.

Es importante destacar que, una de las principales ventajas de los modelos de tipo ordinal es que la escala numérica por la que se opte no influye en absoluto en los resultados del modelo, ya que la elección discreta del usuario será función del valor de una variable inobservable, denominada $Y_{j}$ en el punto 4.2, y de los parámetros umbral $\mu$. Es esta función de utilidad inobservable $\mathrm{Y}_{\mathrm{j}}$ la que se calibra para obtener el modelo de satisfacción, a partir de formulaciones de tipo lineal, como la presentada en la ecuación (4-28).

El primer paso ha sido verificar la no existencia de variables exógenas correlacionadas entre sí de forma significativa. Para ello, se ha calculado la matriz de correlación entre variables, que se adjunta completa en el Anexo 3, a partir de la cual la Tabla 5-1 muestra las que tienen alguna correlación superior al $40 \%$ con otra (ver descripción de variables exógenas incluida en la Tabla 5-2).

Como se puede apreciar, en cuanto a las características personales del entrevistado, la edad está relacionada con el motivo del viaje y el tipo de actividad a la que se dedica, como resulta lógico. Además, las variables relacionadas con el tamaño familiar (número de miembros, vehículos o nivel de ingresos) tienen entre sí cierto grado de dependencia. Por último, la disponibilidad de carnet de conducir y de vehículo privado del entrevistado están relacionadas entre sí y con el número de vehículos de la unidad familiar, y también se aprecia correlación entre el motivo y la frecuencia habitual de viaje, siendo más comunes los debidos a trabajo o estudios (movilidad obligada) que los de otro tipo. 
Tabla 5-1. Matriz (resumen) de correlación entre variables exógenas (satisfacción)

\begin{tabular}{|c|c|c|c|c|c|c|c|c|c|c|c|c|c|c|c|c|c|c|c|c|}
\hline & 号 & 总 & 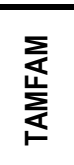 & $\begin{array}{l}\text { 䒺 } \\
\text { 닢ㅆ }\end{array}$ & 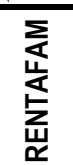 & $\begin{array}{l}\frac{0}{\overleftarrow{L}} \\
\text { 夏 }\end{array}$ & 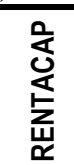 & 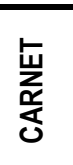 & 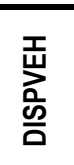 & 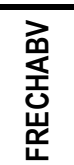 & $\stackrel{\text { P }}{\stackrel{0}{0}}$ & $\begin{array}{l}\stackrel{\omega}{\mathrm{P}} \\
\stackrel{\mathrm{U}}{\zeta}\end{array}$ & $\begin{array}{l}\text { 㤩 } \\
\text { 岂 }\end{array}$ & $\stackrel{\text { 总 }}{\mathrm{g}}$ & 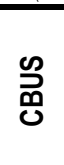 & 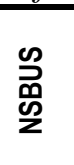 & 总 & 知 & $\stackrel{\text { s. }}{\mathrm{m}}$ & os \\
\hline EDAD & : & 深 & $\begin{array}{l}\text { 茴 } \\
\text { i. }\end{array}$ & 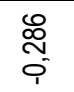 & ì & 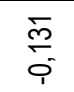 & $\begin{array}{l}\bar{o} \\
\text { og } \\
0\end{array}$ & $\begin{array}{l}\text { o. } \\
\text { o. }\end{array}$ & $\begin{array}{l}\text { on } \\
\text { o. } \\
\end{array}$ & 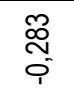 & $\begin{array}{l}\text { z్ } \\
\text { co }\end{array}$ & $\begin{array}{l}\text { o. } \\
\text { co }\end{array}$ & $\begin{array}{l}\bar{s} \\
\\
\end{array}$ & $\begin{array}{l}\overline{5} \\
\text { o. }\end{array}$ & & 号 & $\begin{array}{l}\text { sos } \\
0\end{array}$ & $\begin{array}{l}\text { סे } \\
\text { Oे. }\end{array}$ & $\begin{array}{l}\text { : } \\
0 \\
0\end{array}$ & 웅 \\
\hline ACTIVECO & 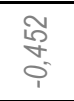 & ; & $\begin{array}{l}\frac{8}{6} \\
\stackrel{0}{0}\end{array}$ & $\begin{array}{l}\text { \&্: } \\
\stackrel{0}{0}\end{array}$ & 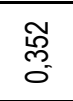 & 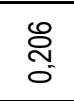 & $\frac{\text { 营 }}{0}$ & 商 & $\frac{\text { og }}{\circ}$ & 菍 & 疍 & 总 & $\begin{array}{l}\text { o } \\
\stackrel{0}{\circ}\end{array}$ & 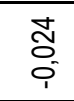 & 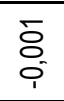 & 誉 & $\begin{array}{l}\tilde{\delta} \\
\tilde{i} \\
\\
\end{array}$ & 䓂 & 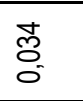 & 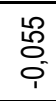 \\
\hline TAMFAM & 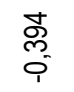 & $\begin{array}{l}\stackrel{2}{2} \\
\stackrel{2}{0}\end{array}$ & : & 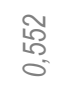 & ז. & $\frac{8}{0}$ & 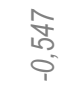 & స్. & 矛 & 芯 & $\underset{\substack{\text { N } \\
0}}{ }$ & $\begin{array}{l}\text { o. } \\
\text { o. } \\
\end{array}$ & $\begin{array}{l}\circ \\
\text { 음 } \\
\text { i. }\end{array}$ & 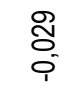 & $\begin{array}{l}\bar{\delta} \\
\text { o. }\end{array}$ & $\frac{\substack{0 \\
c}}{0}$ & $\begin{array}{l}\hat{o} \\
\text { ì } \\
\end{array}$ & $\begin{array}{l}\text { o } \\
\stackrel{0}{0} \\
0 \\
i\end{array}$ & $\begin{array}{l}\text { o. } \\
\text { io } \\
\\
\end{array}$ & ઠ్. \\
\hline VEHFAM & 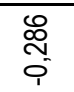 & 总 & 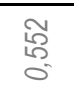 & : & $\begin{array}{l} \\
\text { ơ } \\
0 \\
0\end{array}$ & 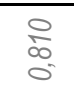 & $\begin{array}{l}\text { \% } \\
\text { : } \\
\\
\end{array}$ & 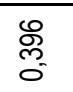 & $\begin{array}{l}8 \\
8 \\
0 \\
0\end{array}$ & $\frac{\widetilde{\sigma}}{0}$ & $\begin{array}{l}\text { : } \\
\text { O্ }\end{array}$ & 范 & 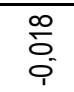 & $\begin{array}{l}\text { o. } \\
\text { o. } \\
\end{array}$ & $\begin{array}{l}\overline{0} \\
\bar{o} \\
0\end{array}$ & $\begin{array}{l}\text { mo } \\
\stackrel{m}{0} \\
\end{array}$ & 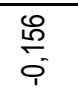 & $\begin{array}{l}\text { o } \\
\text { o } \\
1\end{array}$ & 它 & 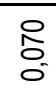 \\
\hline RENTAFAM & 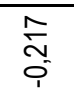 & 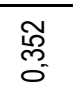 & 㢂 & 产 & : & 令 & 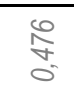 & \begin{tabular}{l}
\multirow{N}{N}{} \\
$\overline{0}$
\end{tabular} & 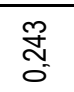 & $\begin{array}{l}\tilde{y} \\
\tilde{0}\end{array}$ & 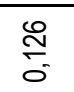 & 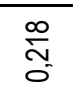 & $\begin{array}{l}\text { to } \\
\text { o. }\end{array}$ & 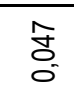 & $\begin{array}{l}\text { : } \\
\vdots \\
0\end{array}$ & 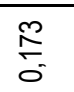 & 容 & 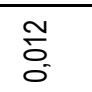 & 豙 & $\stackrel{\Sigma}{E}$ \\
\hline VEHCAP & $\frac{\bar{m}}{c}$ & 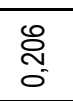 & $\frac{8}{0}$ & 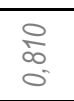 & 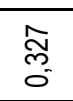 & ' & $\frac{\mathscr{\infty}}{0}$ & 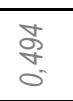 & 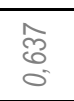 & 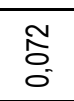 & $\frac{9}{0}$ & $\begin{array}{l} \\
\\
\\
0\end{array}$ & 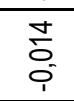 & 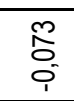 & 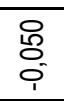 & $\bar{\delta}$ & $\frac{\mathscr{6}}{0}$ & 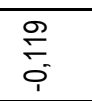 & $\begin{array}{l}\text { o. } \\
\text { o } \\
\\
\end{array}$ & $\stackrel{\circ}{\check{5}}$ \\
\hline RENTACAP & 鸽 & $\underset{0}{\frac{J}{0}}$ & 势 & $\begin{array}{l}\text { \% } \\
: \\
\end{array}$ & 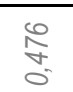 & $\stackrel{\mathscr{0}}{\square}$ & ' & $\begin{array}{l}\infty \\
\stackrel{\circ}{0} \\
\end{array}$ & $\frac{10}{0}$ & 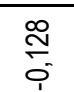 & $\begin{array}{l}\text { Po } \\
\text { P. } \\
\end{array}$ & $\frac{0}{0}$ & 孞 & 奥 & $\begin{array}{l}8 \\
:\end{array}$ & סू & 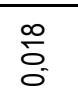 & $\begin{array}{l}\text { go } \\
\\
0\end{array}$ & $\begin{array}{l}\text { go } \\
\text { ci } \\
\end{array}$ & $\begin{array}{l}\text { S } \\
0\end{array}$ \\
\hline CARNET & 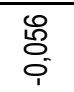 & 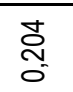 & $\begin{array}{l}\bar{\delta} \\
\bar{\delta}\end{array}$ & 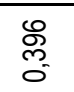 & $\begin{array}{l}\bar{N} \\
\bar{N} \\
\tilde{N}\end{array}$ & \begin{tabular}{l}
\multirow{3}{*}{} \\
总
\end{tabular} & $\begin{array}{l}\stackrel{\circ}{\circ} \\
\\
\end{array}$ & 1 & 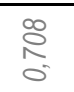 & 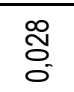 & 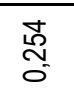 & $\begin{array}{l}\text { 兽 } \\
\end{array}$ & $\begin{array}{l}\infty \\
0 \\
0 \\
0\end{array}$ & 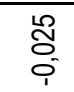 & ๙̃ & 嘈 & $\begin{array}{l}\text { \&o } \\
0 \\
0\end{array}$ & 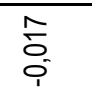 & 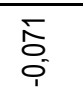 & $\begin{array}{l}\infty \\
0 \\
o \\
0 \\
0\end{array}$ \\
\hline DISPVEH & $\begin{array}{l}\text { o } \\
0 \% \\
0 \\
0\end{array}$ & $\stackrel{\text { 응 }}{\circ}$ & 容 & $\begin{array}{l}8 \\
8 \\
0 \\
0\end{array}$ & $\begin{array}{l}\text { d } \\
\text { d. }\end{array}$ & $\begin{array}{l}\hat{y} \\
\hat{\delta} \\
0\end{array}$ & $\frac{8}{\circ}$ & $\begin{array}{l}\text { 里 } \\
\text { : } \\
0 \\
0\end{array}$ & : & 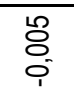 & $\begin{array}{l}\infty \\
0 \\
\vdots \\
0\end{array}$ & $\frac{d}{0}$ & 寊 & 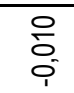 & \% & 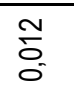 & $\begin{array}{l}\text { o. } \\
\text { o. } \\
\text { o. }\end{array}$ & $\begin{array}{l}0 \\
0 \\
0 \\
\end{array}$ & $\begin{array}{l}\text { 品 } \\
\text { o. }\end{array}$ & $\bar{\Phi}$ \\
\hline FRECHABV & 怘 & 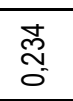 & 兽 & $\frac{\widetilde{\alpha}}{\sigma}$ & 商 & $\tilde{\Sigma}$ & 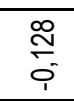 & 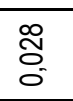 & $\begin{array}{l}\text { Lo } \\
0 \\
1\end{array}$ & : & $\begin{array}{l}\text { 品 } \\
\vdots \\
\vdots\end{array}$ & 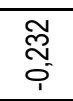 & 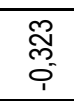 & 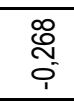 & 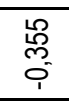 & 高 & $\begin{array}{l}\bar{p} \\
\bar{m} \\
\dot{p}\end{array}$ & $\begin{array}{l}\text { 总 } \\
\text { ô }\end{array}$ & 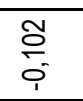 & 응 \\
\hline MOTIVO & 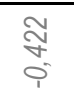 & $\begin{array}{l}\text { me } \\
0 \\
0\end{array}$ & $\underset{\substack{\bar{N} \\
0}}{\bar{N}}$ & 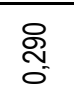 & 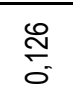 & $\frac{O}{\frac{O}{0}}$ & $\begin{array}{l}\text { ?: } \\
\text { o. } \\
\text { in }\end{array}$ & 芯 & $\begin{array}{l}\infty \\
0 \\
0 \\
0\end{array}$ & 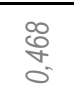 & : & $\begin{array}{l}\text { o. } \\
0 \\
\end{array}$ & $\frac{\circ}{\circ}$ & 알 & 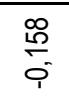 & 密 & $\begin{array}{l}\text { \% } \\
\text { : } \\
\end{array}$ & $\stackrel{\infty}{\infty}$ & 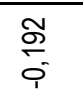 & t \\
\hline WCBUS & $\begin{array}{l}\mathscr{0} \\
: \\
\\
\end{array}$ & $\begin{array}{l}\text { 总 } \\
\text { o. } \\
\end{array}$ & 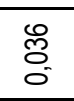 & $\begin{array}{l}\qquad 8 \\
0 \\
0 \\
0\end{array}$ & $\begin{array}{l}\infty \\
\stackrel{\infty}{N} \\
\substack{0\\
}\end{array}$ & $\begin{array}{l}\text { o } \\
\text { o } \\
0\end{array}$ & 兑 & $\begin{array}{l}\text { 莒 } \\
\text { - }\end{array}$ & $\frac{⿱ 乛}{\frac{8}{0}}$ & $\begin{array}{l}\widetilde{\tilde{N}} \\
\text { o. } \\
\end{array}$ & 음 & : & 搃 & $\begin{array}{l}\text { 索 } \\
0\end{array}$ & 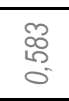 & $\frac{0}{0}$ & $\frac{\circ}{\circ}$ & $\begin{array}{l}8 \\
8 \\
0 \\
0\end{array}$ & 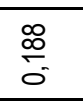 & 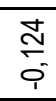 \\
\hline TELEBUS & $\begin{array}{l}\overline{\bar{g}} \\
\bar{i} \\
\end{array}$ & $\begin{array}{l}\text { o } \\
\text { : } \\
0\end{array}$ & $\begin{array}{l}\text { 음 } \\
\text { co } \\
\end{array}$ & 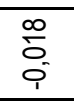 & 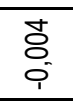 & 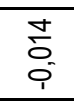 & mo & $\begin{array}{l}0 \\
\text { o } \\
0 \\
\end{array}$ & $\begin{array}{l}8 \\
8 \\
\end{array}$ & 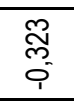 & $\frac{8}{\circ}$ & $\begin{array}{l}\text { 总 } \\
\text { o. }\end{array}$ & : & $\begin{array}{l} \\
0 \\
0 \\
0\end{array}$ & $\begin{array}{l}\text { 惫 } \\
\text { o. }\end{array}$ & $\begin{array}{l}\frac{8}{5} \\
\\
\end{array}$ & $\begin{array}{l}8 \\
8 \\
0\end{array}$ & $\begin{array}{l}\text { 令 } \\
\text { O. }\end{array}$ & $\begin{array}{l}8 \\
\\
\end{array}$ & $\begin{array}{l}\text { to } \\
\text { o. } \\
0\end{array}$ \\
\hline TBUS & $\begin{array}{l}\overline{5} \\
\bar{i} \\
\end{array}$ & 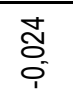 & 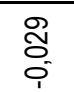 & 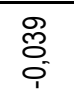 & 容 & 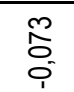 & 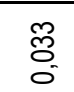 & 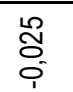 & $\begin{array}{l} \\
0 \\
\\
\\
\end{array}$ & 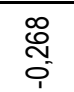 & 을 & $\begin{array}{l}\text { 亭 } \\
\text { o }\end{array}$ & 总 & ; & 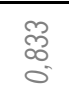 & 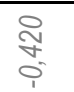 & $\frac{\mathscr{\infty}}{0}$ & 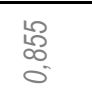 & 炅 & స్ \\
\hline CBUS & $\begin{array}{l}\text { 웅 } \\
\text { in }\end{array}$ & $\overline{\mathrm{o}}$ & $\begin{array}{l}\bar{\delta} \\
\bar{i}\end{array}$ & $\begin{array}{l}\hat{0} \\
\text { o. }\end{array}$ & $\begin{array}{l}\mathscr{0} \\
0 \\
0\end{array}$ & 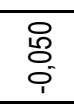 & $\begin{array}{l} \\
\end{array}$ & $\begin{array}{l}\text { Iू } \\
\text { o. }\end{array}$ & $\begin{array}{l} \\
\text { ơ } \\
0 \\
0\end{array}$ & 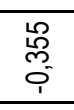 & 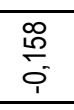 & 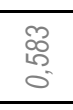 & 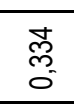 & $\begin{array}{l}\infty \\
\infty \\
\infty \\
\infty \\
\end{array}$ & 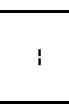 & 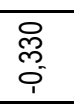 & 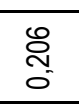 & 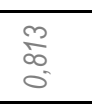 & 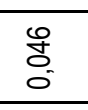 & $\begin{array}{l}\text { to } \\
\text { : }\end{array}$ \\
\hline NSBUS & 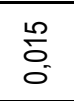 & $\begin{array}{l}\text { o. } \\
\text { o. }\end{array}$ & $\begin{array}{l}\frac{\infty}{0} \\
\frac{9}{0}\end{array}$ & $\frac{\infty}{0}$ & $\stackrel{\frac{N}{5}}{0}$ & סे & $\begin{array}{l}\bar{\delta} \\
\bar{\delta}\end{array}$ & 总 & $\begin{array}{l}N \\
\text { D. } \\
0\end{array}$ & 客 & $\begin{array}{l}\text { g. } \\
\\
0 \\
0\end{array}$ & 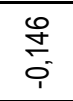 & $\begin{array}{l}\frac{8}{5} \\
\\
\end{array}$ & 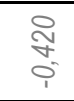 & 怘 & $:$ & 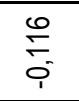 & $\begin{array}{l}\text { 亲 } \\
\text { व. }\end{array}$ & 壱 & 0 \\
\hline BUSS & 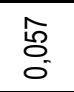 & $\begin{array}{l}\tilde{\delta} \\
\bar{i} \\
\end{array}$ & $\begin{array}{l}\hat{\hat{o}} \\
\text { î } \\
\text { in }\end{array}$ & 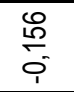 & 客 & 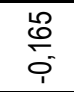 & $\stackrel{\infty}{0}_{0}^{\infty}$ & $\begin{array}{l}\text { 里 } \\
0 \\
0 \\
0\end{array}$ & $\begin{array}{l}\text { o. } \\
\text { o. } \\
\text { i. }\end{array}$ & $\begin{array}{l}\overline{\bar{m}} \\
\bar{o} \\
\bar{i}\end{array}$ & $\begin{array}{l}\text { \% } \\
\stackrel{8}{\circ} \\
\end{array}$ & $\frac{8}{0}$ & $\begin{array}{l}8 \\
8 \\
0 \\
0\end{array}$ & $\stackrel{\mathscr{\infty}}{0}$ & 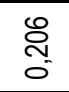 & & : & $\begin{array}{l}\text { ờ } \\
\text { o }\end{array}$ & $\begin{array}{l}\infty \\
: \\
0 \\
0\end{array}$ & $\begin{array}{l}\text { git } \\
\text { in } \\
\end{array}$ \\
\hline DIST & 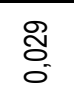 & $\hat{D}_{0}$ & $\begin{array}{l}\text { o } \\
\vdots 0 \\
0 \\
0\end{array}$ & $\begin{array}{l}\text { o } \\
08 \\
0 . \\
1.0\end{array}$ & 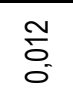 & & $\begin{array}{l}\text { o } \\
\text { o } \\
0\end{array}$ & 蒿 & $\begin{array}{l}\text { o } \\
0 \\
0 . \\
1\end{array}$ & $\begin{array}{l}\text { 总 } \\
\text { o. }\end{array}$ & $\frac{\mathscr{\infty}}{\stackrel{\infty}{c}}$ & $\begin{array}{l}8 \\
8 \\
0 \\
0 \\
0\end{array}$ & 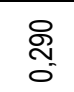 & $\begin{array}{l}\mathscr{L}_{0} \\
\infty \\
0 \\
0\end{array}$ & $\begin{array}{c}\frac{m}{\infty} \\
c_{0}^{\infty}\end{array}$ & 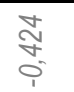 & ¿্ণি & 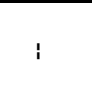 & 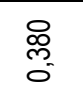 & 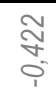 \\
\hline VBUS & 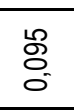 & $\begin{array}{l}\text { 总 } \\
\text { o. }\end{array}$ & $\begin{array}{l}\text { o. } \\
: \\
0 \\
\end{array}$ & $\begin{array}{l}\bar{f} \\
i \\
\end{array}$ & î & 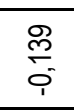 & $\begin{array}{l} \\
\end{array}$ & \begin{tabular}{l} 
\\
\multirow{2}{5}{} \\
0 \\
\end{tabular} & 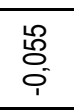 & $\frac{\mathrm{o}}{\mathrm{o}}$ & 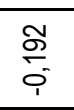 & $\begin{array}{l}\frac{\infty}{\infty} \\
\stackrel{\infty}{0}\end{array}$ & : & & 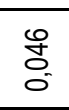 & 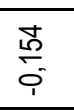 & $\begin{array}{l}\infty \\
: \\
0 \\
\end{array}$ & $\begin{array}{l}\text { o. } \\
\text { o. } \\
0\end{array}$ & & 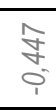 \\
\hline TUBUS & $\begin{array}{l}\infty \\
\stackrel{0}{0} \\
0\end{array}$ & 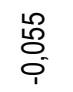 & 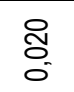 & 怘 & $\underset{0}{E}$ & 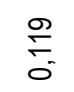 & : & $\begin{array}{l}\infty \\
\stackrel{\infty}{8} \\
0 \\
\end{array}$ & 兽 & $\begin{array}{l}\text { o. } \\
\text { cin }\end{array}$ & $\begin{array}{l}\text { षे } \\
\text { o. }\end{array}$ & 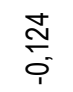 & $\begin{array}{l}\text { 总 } \\
\text { o. }\end{array}$ & 9 & 0 & 惢 & $\begin{array}{l}\text { o } \\
\text { of } \\
\\
i\end{array}$ & 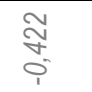 & $\begin{array}{l}\text { 菓 } \\
\text { i }\end{array}$ & \\
\hline
\end{tabular}


Tabla 5-2. Relación de variables incluidas en los modelos de satisfacción

\begin{tabular}{|c|c|c|c|}
\hline VARIABLE & DESCRIPCIÓN & UNIDAD & VALORES \\
\hline SEXO & Género del entrevistado & -- & 0 - mujer; 1 - hombre \\
\hline EDAD & Edad & años & suceso aleatorio dentro del rango escogido \\
\hline ACTIVECO & Actividad económica del entrevistado & -- & 1 - trabajador/estudiante; 0 - otros casos \\
\hline TAMFAM & Tamaño familiar & ud. & $\mathrm{n}^{0}$ de personas que integran el núcleo familiar \\
\hline VEHFAM & $\begin{array}{l}\text { Nivel de motorización familiar } \\
\text { (transformada en } 2 \text { var. dummy) }\end{array}$ & -- & $\begin{array}{c}0-0 \text { veh./fam.; } 1-1 \text { ó más veh./fam. } \\
0-0 \text { ó } 1 \text { veh./fam.; } 1-2 \text { ó más veh./fam. }\end{array}$ \\
\hline RENTAFAM & $\begin{array}{l}\text { Nivel de ingresos neto mensual } \\
\text { familiar }\end{array}$ & $€$ & suceso aleatorio dentro del rango escogido \\
\hline VEHCAP & Îndice de motorización medio familiar & veh./persona & $\mathrm{n}^{0}$ vehículos / $\mathrm{n}^{0}$ miembros familia \\
\hline RENTACAP & Renta per cápita media familiar & $€ /$ persona & ingresos netos mensuales $/ \mathrm{n}^{0}$ miembros familia \\
\hline CARNET & $\begin{array}{l}\text { Disponibilidad de carnet de conducir } \\
\text { por parte del entrevistado }\end{array}$ & -- & 0 - no; 1 - sí \\
\hline DISPVEH & $\begin{array}{c}\text { Disponibilidad de vehículo propio por } \\
\text { parte del entrevistado }\end{array}$ & -- & 0 - no; 1 - sí \\
\hline TIEMPOES & $\begin{array}{c}\text { Tiempo de acceso hasta/desde la } \\
\text { estación }\end{array}$ & minutos & suceso aleatorio dentro del rango escogido \\
\hline FRECHABV & Frecuencia habitual de viaje & veces/mes & suceso aleatorio dentro del rango escogido \\
\hline MOTIVO & Motivo del viaje realizado/a realizar & -- & 1 - trabajo/estudios; 0 - otros casos \\
\hline RETRASO & Retraso acumulado del autobús & minutos & suceso aleatorio dentro del rango escogido \\
\hline NUMPARAD & $\begin{array}{c}\text { Número de paradas intermedias en el } \\
\text { trayecto }\end{array}$ & ud. & suceso aleatorio dentro del rango escogido \\
\hline AABUS & $\begin{array}{c}\text { Existencia de aire acondicionado en el } \\
\text { autobús }\end{array}$ & -- & 0 - no; 1 - sí \\
\hline WCBUS & $\begin{array}{c}\text { Existencia de servicio/WC en el } \\
\text { autobús }\end{array}$ & -- & 0 - no; 1 - sí \\
\hline TELEBUS & Existencia de televisión en el autobús & -- & 0 - no; 1 - sí \\
\hline CONEXTTE & $\begin{array}{l}\text { Adecuada conexión con el transporte } \\
\text { público para ir a la estación }\end{array}$ & -- & 0 - no; 1 - sí \\
\hline SITUACES & Buena ubicación de la estación & -- & 0 - no; 1 - sí \\
\hline INFORMES & $\begin{array}{c}\text { Información sobre horarios claramente } \\
\text { disponible en la estación }\end{array}$ & -- & 0 - no; 1 - sí \\
\hline HORTAQ & $\begin{array}{c}\text { Horarios de apertura de taquillas } \\
\text { correctos }\end{array}$ & -- & 0 - no; 1 - sí \\
\hline COMPRACA & $\begin{array}{l}\text { Posibilidad de compra del billete a } \\
\text { domicilio (internet, teléfono...) }\end{array}$ & -- & 0 - no; 1 - sí \\
\hline ATTCLIEN & Adecuada atención al cliente & -- & 0 - no; 1 - sí \\
\hline TBUS & Tiempo de viaje & horas & indicado por el usuario \\
\hline CBUS & Coste del viaje & $€$ & indicado por el usuario \\
\hline NSBUS & Número de serv. diarios del trayecto & buses/día & $\mathrm{n}^{0}$ salidas/día \\
\hline BUSS & Autobús seminuevo (frente a antiguo) & -- & 0 - antiguo; 1 - resto de casos \\
\hline BUSN & Autobús nuevo & -- & 0 - antiguo/seminuevo; 1 - nuevo/gran clase \\
\hline BUSGC & Autobús gran clase & -- & 1 - gran clase; 1 - resto de casos \\
\hline RUTA & $\begin{array}{l}\text { Trayecto realizado por } \\
\text { autopista/autovía }\end{array}$ & -- & 0 - no; 1 - sí \\
\hline DIST & Distancia de viaje & $\mathrm{km}$ & obtenido a partir de origen y destino \\
\hline VBUS & Velocidad media de recorrido de viaje & $\mathrm{km} / \mathrm{h}$ & obtenido de datos anteriores \\
\hline TUBUS & Tarifa usuario del viaje & $€ / \mathrm{km}$ & obtenido de datos anteriores \\
\hline SATISFGL & Satisfacción global del usuario & -- & $\begin{array}{l}0 \text { - muy mal; } 1 \text { - mal; } 2 \text { - regular; } 3 \text { - bien; } 4 \text { - muy bier } \\
0 \text { - muy mal - mal; } 1 \text { - regular; } 2 \text { - bien; } 3 \text { - muy bien }\end{array}$ \\
\hline
\end{tabular}


Por otra parte, centrándonos más en las propias características del servicio, el hecho de disponer de servicios y televisión en el autobús se dan más a menudo en los viajes de mayor longitud, y cuando el autobús es seminuevo (o mejor). Evidentemente, el tiempo, el coste y la distancia de viaje tienen una fuerte correlación entre ellos, e inversa con la tarifa usuario y la velocidad media de recorrido, como resulta lógico a priori. Por último, otras correlaciones no tan evidentes serían, por ejemplo, la que se da, con signo negativo, entre el número diario de servicios con el tiempo y distancia de viaje, que también resulta lógica al considerar que, habitualmente, los trayectos más largos tienen menor frecuencia que los de tipo cercanías.

\section{Modelos Genéricos para Todos los Usuarios}

En primer lugar, se han probado diversas modelizaciones sin variaciones por tipo de usuario, es decir, incluyendo únicamente las características del servicio más relevantes para todos los usuarios en general. Aunque se puede asumir que, incluyendo variaciones en los gustos, las predicciones del modelo se pueden ajustar con más exactitud a la realidad observada, el interés de estas modelizaciones radica en poder conseguir unos valores de los parámetros comunes para todos los usuarios, que luego se emplearán en consideraciones posteriores.

En general, se ha verificado que introducir la variable "coste del viaje" en los modelos provocaba la aparición de un parámetro positivo asociado a la misma. Una posible causa para esta circunstancia radica en que, habitualmente, un billete con mayor coste se asocia a trayectos más largos y con mejores vehículos. Por ello, se ha considerado conveniente no introducir directamente esta variable, sino sustituirla por la "tarifa usuario", o coste del billete por kilómetro de distancia recorrida. Aun así, como se podrá apreciar en los modelos, esta variable resulta en general no significativa, lo que indica que no es una de las cuestiones principales por las que los usuarios rigen su evaluación del servicio.

Teniendo en cuenta estas consideraciones, en la Tabla 5-3 se muestran los resultados de algunos de los principales modelos calibrados con 5 rangos de elección en la variable dependiente, que básicamente han sido de dos tipos: probit ordinal (OP) y logit ordinal (OL). Las variables incluidas en ella están codificadas de acuerdo con la Tabla 5-2, expuesta anteriormente. Únicamente se expondrán en ellas las variables que han resultado significativas para los modelos presentados. 
Como se puede apreciar en ella, en todos los modelos se ha optado por mantener la variable "tiempo de viaje", a pesar de su escasa significatividad, de acuerdo con los criterios descritos en la Tabla 4-9, sobre reglas de buena práctica. El resto de variables, también de acuerdo con la citada Tabla, al no ser consideradas de igual relevancia que éstas, sólo se han incluido cuando resultaban estadísticamente significativas a un nivel de confianza superior a un 85-90\%. Una excepción a destacar ha sido el coste del viaje, tanto tomado directamente como a través de la "tarifa usuario": en ambos casos ha resultado una variable no significativa, incluso para valores muy bajos del nivel de confianza, en todos los modelos, por lo que no figura en las tablas siguientes.

Además, se puede comprobar que ninguna de las variables simultáneamente incluidas en un modelo tiene correlación importante con el resto. Se desea hacer notar la inexistencia de correlación relevante entre las variables dummies que discretizan las características del autobús, por lo que pueden ser incluidas simultáneamente en los modelos sin introducir errores inadmisibles en éstos. De hecho, el sistema de división de esta variable ha sido tal que el resultado sería similar a introducir interacciones entre ellas, de modo que, por ejemplo, para un autobús "gran clase", el parámetro final sería la suma de los tres.

Tabla 5-3. Modelos de satisfacción genéricos para todos los usuarios (5 rangos de elección)

Modelos con 5 rangos de variación en la variable independiente

\begin{tabular}{|c|c|c|c|c|c|c|c|c|}
\hline \multirow{3}{*}{ VARIABLE } & \multicolumn{8}{|c|}{$\begin{array}{l}\text { Modelos con } 5 \text { rangos de variación en la variable independiente } \\
(0 \text { - muy mal; } 1 \text { - mal; } 2 \text { - regular; } 3 \text { - bien; } 4 \text { - muy bien })\end{array}$} \\
\hline & \multicolumn{2}{|c|}{ OP-5.1 } & \multicolumn{2}{|c|}{ OP -5.2} & \multicolumn{2}{|c|}{ OL-5.1 } & \multicolumn{2}{|c|}{ OL-5.2 } \\
\hline & Parámetro & Test-t & Parámetro & Test-t & Parámetro & Test-t & Parámetro & Test-t \\
\hline RETRASO & $-0,0251$ & $-2,21$ & $-0,0254$ & $-2,25$ & $-0,0483$ & $-2,39$ & $-0,0449$ & $-2,20$ \\
\hline NUMPARAD & $-0,0419$ & $-2,54$ & $-0,0404$ & $-2,46$ & $-0,0844$ & $-2,85$ & $-0,0799$ & $-2,68$ \\
\hline AABUS & 0,5987 & 2,91 & 0,5956 & 2,90 & 1,1393 & 3,07 & 1,1876 & 3,19 \\
\hline CONEXTTE & 0,3227 & 3,28 & 0,3376 & 3,40 & 0,6863 & 3,67 & 0,6715 & 3,58 \\
\hline SITUACES & 0,3395 & 2,76 & 0,3550 & 2,90 & 0,6642 & 3,01 & 0,6448 & 2,91 \\
\hline HORTAQ & 0,1424 & 1,43 & & & & & & \\
\hline ATTCLIEN & 0,4984 & 4,23 & 0,5195 & 4,45 & 0,9251 & 4,39 & 0,9171 & 4,35 \\
\hline TBUS & $-0,0493$ & $-1,48$ & $-0,0463$ & $-1,39$ & & & $-0,0742$ & $-1,26$ \\
\hline BUSS & 1,1097 & 6,43 & 1,1382 & 6,65 & 1,8521 & 6,17 & 1,9019 & 6,28 \\
\hline BUSN & 0,2950 & 2,61 & 0,2829 & 2,51 & 0,5552 & 2,62 & 0,5660 & 2,66 \\
\hline BUSGC & 0,6491 & 1,55 & 0,6349 & 1,52 & 1,1348 & 1,50 & 1,1755 & 1,57 \\
\hline RUTA & 0,1879 & 1,51 & 0,2079 & 1,69 & 0,3097 & 1,44 & 0,4044 & 1,77 \\
\hline$\mu_{0}$ & $-\infty$ & -- & $-\infty$ & -- & $-\infty$ & -- & $-\infty$ & -- \\
\hline$\mu_{1}$ & 0 & -- & 0 & -- & 0 & -- & 0 & -- \\
\hline$\mu_{2}$ & 0,6512 & 8,28 & 0,6436 & 8,23 & 1,2427 & 8,07 & 1,2425 & 8,06 \\
\hline$\mu_{3}$ & 1,6447 & 22,36 & 1,6335 & 22,27 & 3,0581 & 21,17 & 3,0623 & 21,17 \\
\hline$\mu_{4}$ & 4,0988 & 40,52 & 4,0842 & 40,49 & 7,3662 & 35,44 & 7,3743 & 35,47 \\
\hline$\mu_{5}$ & $+\infty$ & -- & $+\infty$ & -- & $+\infty$ & -- & $+\infty$ & -- \\
\hline$I^{*}(\theta)$ & \multicolumn{2}{|c|}{$-551,9$} & \multicolumn{2}{|c|}{$-552,9$} & \multicolumn{2}{|c|}{$-555,3$} & \multicolumn{2}{|c|}{$-554,5$} \\
\hline$I^{*}(C)$ & \multicolumn{2}{|c|}{$-587,2$} & \multicolumn{2}{|c|}{$-587,2$} & \multicolumn{2}{|c|}{$-587,2$} & \multicolumn{2}{|c|}{$-587,2$} \\
\hline
\end{tabular}


A la vista de los resultados, observamos que hay determinadas variables que han resultado ser significativas en todos los modelos seleccionados. Así, respecto de los horarios del trayecto, destacan el retraso del viaje y el número de paradas intermedias entre el origen y el destino del usuario. Por otra parte, en cuanto al autobús, es especialmente valorado que disponga de aire acondicionado, y también que tenga características de nivel superior (novedoso o incluso "gran clase"). Las características más relevantes de la estación se refieren a su situación idónea, la conexión con el transporte público urbano y la adecuada atención al cliente. Finalmente, el hecho de que la ruta discurra en su mayor parte por autopista o autovía es también un factor a considerar, así como, en menor media, la duración del viaje.

En resumen, parece poderse concluir que, en general, frente a la creencia clásica de que el usuario emplea el transporte público interurbano porque es más barato, resulta que, finalmente, su satisfacción es más función de otras características, como el equipamiento del autobús, su puntualidad y que el trayecto sea realizado por vías de alta capacidad y con pocas paradas. Además, aunque son variables de más difícil actuación, se valora muy positivamente la adecuada ubicación de la estación en el centro de la ciudad, así como una red de transporte público urbano que permita su fácil acceso.

Por su parte, la Tabla 5-4 muestra un resumen de los resultados de la modelización cuando se simplifican las posibilidades de elección, agrupado los resultados de satisfacción "mala" y "muy mala", de acuerdo con la codificación de variables expuesta en la Tabla 5-2.

En ella observamos que, a diferencia de los resultados de la Tabla 5-3 (con 5 rangos de elección para la satisfacción global), se ha conseguido una calibración de parámetros con niveles de confianza relativamente admisibles, empleando como variable la "velocidad media de recorrido" del viaje. De nuevo, las variables correspondientes al coste del viaje han resultado no significativas en los modelos calibrados, incluso para niveles de confianza muy bajos, por lo que han sido eliminados de los mismos, de acuerdo con los criterios establecidos en la Tabla 4-9. También se ha eliminado el resto de variables no significativas a un nivel de confianza superior a un $85-90 \%$. Además, se puede comprobar que ninguna de las variables simultáneamente incluidas en un modelo tiene correlación importante con el resto. 
Tabla 5-4. Modelos de satisfacción genéricos para todos los usuarios (4 rangos de elección)

Modelos con 4 rangos de variación en la variable independiente

\begin{tabular}{|c|c|c|c|c|c|c|c|c|}
\hline \multirow{3}{*}{ VARIABLE } & \multirow{2}{*}{\multicolumn{2}{|c|}{ OP-4.1 }} & \multirow{2}{*}{\multicolumn{2}{|c|}{ OP-4.2 }} & \multirow{2}{*}{\multicolumn{2}{|c|}{ OL-4.1 }} & \multirow{2}{*}{\multicolumn{2}{|c|}{ OL-4.2 }} \\
\hline & & & & & & & & \\
\hline & Parámetro & Test-t & Parámetro & Test-t & Parámetro & Test-t & Parámetro & Test-t \\
\hline RETRASO & $-0,0289$ & $-2,56$ & $-0,0268$ & $-2,36$ & $-0,0498$ & $-2,46$ & $-0,0493$ & $-2,44$ \\
\hline NUMPARAD & $-0,0600$ & $-3,68$ & $-0,0588$ & $-3,61$ & $-0,1118$ & $-3,84$ & $-0,1083$ & $-3,72$ \\
\hline AABUS & 0,2850 & 1,45 & 0,3770 & 1,90 & 0,5943 & 1,66 & 0,6729 & 1,90 \\
\hline CONEXTTE & 0,3394 & 3,41 & 0,3302 & 3,31 & 0,6388 & 3,42 & 0,6567 & 3,53 \\
\hline SITUACES & 0,2589 & 2,10 & 0,2501 & 2,02 & 0,4578 & 2,06 & 0,4933 & 2,23 \\
\hline HORTAQ & & & 0,1398 & 1,41 & & & & \\
\hline ATTCLIEN & 0,5120 & 4,36 & 0,4719 & 3,99 & 0,8968 & 4,25 & 0,8727 & 4,16 \\
\hline TBUS & & & $-0,0403$ & $-1,27$ & & & & \\
\hline BUSS & 0,8958 & 5,21 & 0,9222 & 5,28 & 1,5144 & 4,99 & 1,5624 & 5,19 \\
\hline BUSN & 0,2893 & 2,59 & 0,3244 & 2,90 & 0,5732 & 2,73 & 0,6025 & 2,89 \\
\hline BUSGC & 0,5981 & 1,44 & 0,6529 & 1,56 & 1,1685 & 1,54 & 1,1526 & 1,52 \\
\hline VBUS & 0,0012 & 1,53 & & & 0,0022 & 1,53 & & \\
\hline$\mu_{0}$ & $-\infty$ & -- & $-\infty$ & -- & $-\infty$ & -- & $-\infty$ & -- \\
\hline$\mu_{1}$ & 0 & -- & 0 & -- & 0 & -- & 0 & -- \\
\hline$\mu_{2}$ & 0,9999 & 14,15 & 0,9952 & 14,10 & 1,8677 & 13,67 & 1,8517 & 13,63 \\
\hline$\mu_{3}$ & 3,4388 & 34,23 & 3,4413 & 34,16 & 6,1396 & 29,98 & 6,1223 & 29,96 \\
\hline$\mu_{4}$ & $+\infty$ & -- & $+\infty$ & -- & $+\infty$ & -- & $+\infty$ & -- \\
\hline$I^{*}(\theta)$ & \multicolumn{2}{|c|}{$-533,6$} & \multicolumn{2}{|c|}{$-533,5$} & \multicolumn{2}{|c|}{$-533,3$} & \multicolumn{2}{|c|}{$-534,8$} \\
\hline$I^{*}(C)$ & \multicolumn{2}{|c|}{$-577,7$} & \multicolumn{2}{|c|}{$-578,0$} & \multicolumn{2}{|c|}{$-577,7$} & \multicolumn{2}{|c|}{$-578,0$} \\
\hline
\end{tabular}

De nuevo, podemos ver que hay variables que han resultado significativas en todos los modelos. Por ejemplo, vuelven a aparecer el retraso del viaje y el número de paradas intermedias entre el origen y el destino del usuario en cuanto a los horarios. Además, en cuanto a las características del bus, se considera muy importante el hecho de que sea de nivel superior. Igual que en los modelos anteriores, la conexión con el transporte público urbano y la adecuada atención al cliente son variables muy relevantes para el usuario, aunque poco abordables desde el punto de vista del operador del servicio.

Así pues, los resultados vuelven a arrojar la idea de que los usuarios no valoran excesivamente el precio del billete, sino que su satisfacción es función de otra serie de características no económicas, como el equipamiento del autobús, el cumplimiento de los horarios y que el viaje sea lo más directo posible. También, aunque son variables de más difícil actuación, resultan relevantes para los usuarios la adecuada conexión de la estación con el transporte público urbano, así como su ubicación en el centro de la ciudad.

Por tanto, para concluir este primer análisis, simplemente se desea destacar que, a la vista de los modelos expuestos, las variables clásicas relativas al coste del billete no resultan suficientemente relevantes para los usuarios, y que incluso la duración (o la velocidad) del 
viaje, aun siendo significativa, no es la más importante a la hora de evaluar globalmente el servicio. Por el contrario, resultan más relevantes las características del autobús, la puntualidad en los horarios previstos o que el número de paradas intermedias sea el menor posible. Actuando sobre éstas, sería posible mejorar la percepción general de los usuarios del autobús interurbano.

Para tratar de adaptar los resultados a las características particulares de cada individuo, a continuación se tratará de encontrar modelos que incluyan variables específicas del usuario, que permitan un mejor ajuste a los datos observados.

\section{Modelos con Variaciones en los Gustos de los Usuarios}

Además de los modelos anteriores, incorporando variaciones sistemáticas en los gustos de los usuarios, se han obtenido los modelos que siguen, que adaptan con más realismo las predicciones a los valores observados.

En ellos, incluiremos las variables específicas de los usuarios, tanto de forma aislada como interaccionando con variables del servicio, a fin de determinar cuáles de ellas resultan efectivamente importantes para diferenciar el comportamiento de los usuarios.

En primer lugar, en la Tabla 5-5 se indica el significado de las variables nuevas que aparecen en estos modelos (aunque se han probado todas las interacciones posibles), obtenidas mediante la multiplicación de variables de servicio con otras específicas del entrevistado.

Es importante considerar las correlaciones existentes entre determinadas variables relativas al entrevistado. Así, según figura en la Tabla 5-1, existe correlación entre edad, motivo del viaje y tipo de actividad económica; tamaño familiar, número de vehículos en la familia y nivel de renta; disponibilidad de carnet de conducir y de vehículo privado con número de vehículos de la unidad familiar; y entre el motivo y la frecuencia habitual de viaje.

Así mismo, a la vista de los resultados anteriores, podemos concluir que el modelo con 4 rangos de variación en los gustos aporta al modelo prácticamente la misma información que los calibrados con 5 rangos. Incluso, se puede comprobar que existe una mayor significatividad de determinadas variables "clave", por lo que, a partir de este punto, se trabajará con los datos de las evaluaciones "mala" y "muy mala" agrupados (es necesario 
considerar que únicamente aparecen 4 observaciones en las que la calidad ha sido considerada "muy mala").

Tabla 5-5. Relación de variables incluidas en los modelos de satisfacción con variaciones sistemáticas en los gustos de los usuarios

\begin{tabular}{|c|c|c|}
\hline VARIABLE & DESCRIPCIÓN & VALORES \\
\hline ANC & Entrevistado mayor o igual de 65 años & $0-<65 ; 1-\geq 65$ \\
\hline AC*RETRASO & $\begin{array}{c}\text { Interacción entre actividad económica y } \\
\text { retraso }\end{array}$ & $\begin{array}{c}\text { AC: } 1 \text { - trabajador/estudiante; } 0 \text { - otros casos } \\
\text { RETR: min (suceso aleatorio dentro rango escogido) }\end{array}$ \\
\hline UV*CONEXTTE & $\begin{array}{l}\text { Interacción entre disponibilidad familiar de un } \\
\text { vehículo y adecuada conexión de la estación }\end{array}$ & $\begin{array}{c}\text { UV: } 0 \text { - no vehículos; } 1 \text { - } 1 \text { ó más veh. } \\
\text { CXES: } 0 \text { - no; } 1 \text { - sí }\end{array}$ \\
\hline JO*HORTAQ & $\begin{array}{c}\text { Interacción entre edad joven y adecuados } \\
\text { horarios de taquilla }\end{array}$ & $\begin{array}{l}\text { JO: } 0 \text { - >24; } 1 \text { - } \leq 24 \\
\text { HOES: } 0 \text { - no; } 1 \text { - sí }\end{array}$ \\
\hline AC*TBUS & $\begin{array}{c}\text { Interacción entre actividad económica y } \\
\text { tiempo de viaje }\end{array}$ & $\begin{array}{l}\text { AC: } 1 \text { - trabajador/estudiante; } 0 \text { - otros casos } \\
\text { TBUS: min (indicado por el usuario) }\end{array}$ \\
\hline SE*BUSS & $\begin{array}{c}\text { Interacción entre género y bus seminuevo } \\
\text { (frente a antiguo) }\end{array}$ & $\begin{array}{c}\text { SE: } 0 \text { - mujer; } 1 \text { - hombre } \\
\text { BUSS: } 0 \text { - no; } 1 \text { - sí }\end{array}$ \\
\hline UV*BUSS & $\begin{array}{l}\text { Interacción entre disponibilidad familiar de un } \\
\text { vehículo y bus seminuevo (frente a antiguo) }\end{array}$ & $\begin{array}{c}\text { UV: } 0 \text { - no vehículos; } 1 \text { - } 1 \text { ó más veh. } \\
\text { BUSS: } 0 \text { - no; } 1 \text { - sí }\end{array}$ \\
\hline$A C * B U S N$ & $\begin{array}{c}\text { Interacción entre actividad económica y bus } \\
\text { nuevo }\end{array}$ & $\begin{array}{l}\text { AC: } 1 \text { - trabajador/estudiante; } 0 \text { - otros casos } \\
\text { BUSN: } 0 \text { - no; } 1 \text { - sí }\end{array}$ \\
\hline SE*RUTA & $\begin{array}{c}\text { Interacción entre género y ruta del viaje por } \\
\text { autopista/autovía }\end{array}$ & $\begin{array}{c}\text { SE: } 0 \text { - mujer; } 1 \text { - hombre } \\
\text { RUBU: } 0 \text { - no; } 1 \text { - sí }\end{array}$ \\
\hline ANC*TUBUS & Interacción entre $3^{a}$ edad y tarifa usuario & $\begin{array}{c}\text { ANC: } 0-<65 ; 1-\geq 65 \\
\text { TUBU: } € / \mathrm{km}\end{array}$ \\
\hline
\end{tabular}

La Tabla 5-6 muestra los modelos calibrados con variaciones sistemáticas en los gustos, para un nivel de confianza del 90\%, excepto en las variables relacionadas con el tiempo de viaje y la tarifa usuario que, de acuerdo con los criterios expuestos en la Tabla 4-9, se han admitido con niveles inferiores. Dada la gran cantidad de interacciones consideradas, únicamente figuran en dicha tabla aquéllas que han resultado significativas y con sentido correcto.

Observando los resultados de los modelos expuestos en la Tabla 5-6, la primera conclusión que cabe extraer es la gran similitud existente entre todos los modelos calibrados, cuando imponemos que el nivel de confianza mínimo admisible sea del 90\%, excepto para las variables de tiempo y tarifa de viaje.

Por otra parte, la primera diferencia que encontramos con respecto a los modelos genéricos para todos los usuarios es la aparición de una constante específica sólo para los entrevistados de mayor edad. En concreto, los usuarios mayores de 65 años tienen una predisposición inicial a considerar más positivamente la calidad del viaje en autobús que el resto. 
En cuanto al retraso y al tiempo de viaje, parece que afectan casi exclusivamente a los entrevistados que trabajan o estudian, es decir, con mayores presiones en cuanto al tiempo disponible. El número de paradas, la situación céntrica de la estación y la adecuada atención al cliente parecen ser valoradas de igual modo por todos los entrevistados. Sin embargo, la conexión de la estación con el transporte público urbano es considerada relevante sólo por los usuarios con vehículo privado disponible en la familia, mientras que los amplios horarios de taquilla son importantes para los más jóvenes.

En cuanto a las características del autobús, la diferenciación entre antiguo y seminuevo, así como los servicios de "gran clase", son valorados por todos los usuarios. Cabe destacar, no obstante, que los usuarios de sexo masculino y con vehículo privado disponible en la familia no aportan tanta consideración al hecho de que el autobús no sea antiguo, ya que, podemos intuir, entienden que dicha característica debería ser inherente al servicio. Así mismo, los usuarios que estudian o trabajan consideran también la diferencia entre autobús seminuevo y nuevo.

Tabla 5-6. Modelos de satisfacción incorporando variaciones en los gustos de los usuarios

\begin{tabular}{|c|c|c|c|c|c|c|c|c|}
\hline \multirow[t]{3}{*}{ VARIABLE } & \multicolumn{8}{|c|}{$\begin{array}{l}\text { Modelos con } 4 \text { rangos de variación en la variable independiente } \\
(0 \text { - muy mal ó mal; } 1 \text { - regular; } 2 \text { - bien; } 3 \text { - muy bien) }\end{array}$} \\
\hline & \multicolumn{2}{|c|}{ OP-4.3 } & \multicolumn{2}{|c|}{ OP-4.4 } & \multicolumn{2}{|c|}{ OL-4.3 } & \multicolumn{2}{|c|}{ OL-4.4 } \\
\hline & Parámetro & Test-t & Parámetro & Test-t & Parámetro & Test-t & Parámetro & Test-t \\
\hline ANC & 0,6714 & 3,69 & 0,8909 & 3,22 & 1,2539 & 3,60 & 1,6730 & 3,19 \\
\hline AC*RETRASO & $-0,0321$ & $-2,50$ & $-0,0289$ & $-2,19$ & $-0,0559$ & $-2,40$ & $-0,0500$ & $-2,08$ \\
\hline NUMPARAD & $-0,0720$ & $-4,35$ & $-0,0723$ & $-4,36$ & $-0,1347$ & $-4,55$ & $-0,1353$ & $-4,57$ \\
\hline UV*CONEXTTE & 0,4961 & 4,43 & 0,4716 & 4,17 & 0,9437 & 4,52 & 0,8989 & 4,26 \\
\hline SITUACES & 0,3537 & 3,02 & 0,3613 & 3,08 & 0,6720 & 3,22 & 0,6868 & 3,27 \\
\hline JO*HORTAQ & & & 0,2166 & 1,78 & & & 0,3548 & 1,59 \\
\hline ATTCLIEN & 0,5656 & 4,97 & 0,5517 & 4,83 & 1,0104 & 4,94 & 0,9783 & 4,76 \\
\hline AC*TBUS & & & $-0,0394$ & $-1,20$ & & & $-0,0678$ & $-1,17$ \\
\hline BUSS & 1,3028 & 7,78 & 1,3380 & 7,71 & 2,2919 & 7,54 & 2,3477 & 7,48 \\
\hline SE*BUSS & $-0,5871$ & $-3,06$ & $-0,6007$ & $-3,10$ & $-1,1616$ & $-3,28$ & $-1,1826$ & $-3,30$ \\
\hline UV*BUSS & $-0,2388$ & $-1,83$ & $-0,2483$ & $-1,89$ & $-0,4493$ & $-1,86$ & $-0,4511$ & $-1,85$ \\
\hline$A C * B U S N$ & 0,3311 & 2,65 & 0,3591 & 2,82 & 0,6024 & 2,57 & 0,6426 & 2,69 \\
\hline BUSGC & 0,7297 & 1,74 & 0,7574 & 1,80 & 1,4108 & 1,84 & 1,4668 & 1,91 \\
\hline SE*RUTA & 0,7680 & 3,79 & 0,7870 & 3,82 & 1,5425 & 4,13 & 1,5758 & 4,14 \\
\hline ANC*TUBUS & & & $-3,4466$ & $-1,16$ & & & $-6,3625$ & $-1,19$ \\
\hline$\mu_{0}$ & $-\infty$ & -- & $-\infty$ & -- & $-\infty$ & -- & $-\infty$ & -- \\
\hline$\mu_{1}$ & 0 & -- & 0 & -- & 0 & -- & 0 & -- \\
\hline$\mu_{2}$ & 1,0103 & 13,94 & 1,0147 & 13,90 & 1,8721 & 13,49 & 1,8771 & 13,44 \\
\hline$\mu_{3}$ & 3,5366 & 33,17 & 3,5588 & 32,96 & 6,3361 & 28,85 & 6,3701 & 28,70 \\
\hline$\mu_{4}$ & $+\infty$ & -- & $+\infty$ & -- & $+\infty$ & -- & $+\infty$ & -- \\
\hline$I^{*}(\theta)$ & $-518,5$ & & -515 & & -517 & & -51 & \\
\hline$I^{*}(\mathbf{C})$ & $-575,9$ & & -575 & & -575 & & -575 & \\
\hline
\end{tabular}


Por último, en cuanto a la relevancia del coste del billete, vemos que tanto el valor absoluto como su tarifa usuario equivalente resultan no significativas en ningún caso, para el general de los usuarios. Sin embargo, si analizamos los distintos grupos considerados por separado, sí aparecen significatividades para las interacciones de dicha tarifa usuario con la variable dummy relativa al mayor grupo de edad. Es decir, únicamente los usuarios que superan los 65 años de edad consideran el precio como una característica relevante del servicio, lógico a priori si tenemos en cuenta su, a menudo, inferior capacidad económica respecto del promedio de entrevistados.

Para finalizar este apartado, simplemente resta indicar que, a pesar de que los modelos con variaciones sistemáticas en los gustos aportan una mayor información, ya que enriquecen la visión obtenida con los modelos generales, no son válidos de forma directa para evaluar la óptima calidad del servicio. Así, a no ser que se obtengan unos parámetros genéricos, no es posible emplear el procedimiento que se presentará en apartados posteriores para integrar las valoraciones tanto de calidad como de demanda en una única metodología.

\section{Evaluación y Selección de Modelos}

En el presente apartado, se tratará de determinar, de entre todos los modelos presentados, cuáles son los que reflejan de manera más correcta el comportamiento de los usuarios. El objetivo final será, por tanto, la elección del modelo más representativo para su empleo en apartados posteriores.

Así, teniendo en cuenta lo expresado en el capítulo anterior, al haber estimado los parámetros de los modelos expuestos mediante el método de máxima verosimilitud, éstos seguirán una distribución asintóticamente normal, y la función $L R=-2 l(\theta)$ distribuirá asintóticamente $\chi^{2}$ con $Q$ grados de libertad [20].

Sin embargo, como también se ha expuesto en dicho capítulo, una adecuada reproducción de las proporciones de mercado observadas por nuestro modelo no indica necesariamente la corrección del mismo, sino que existen indicadores más idóneos para identificar cuál es el mejor de entre los distintos modelos calibrados. De hecho, los modelos de tipo ordinal, que son los que mejor se adaptan a nuestra tipología de datos de entrada, raramente aportan un gran éxito en la predicción, aunque sus parámetros sean altamente significativos [58].

Así, la bondad de este tipo de modelos se estudia habitualmente mediante otro tipo de indicadores, como pueden ser los siguientes: 
1) Test-t de significatividad de los parámetros.

Como se ha indicado anteriormente, los estadísticos $t$, calculados según la expresión (4-17), representan de forma cuantitativa la significatividad de los parámetros. Así, si este valor es superior a 1,65, el parámetro asociado será estadísticamente significativo para un nivel de confianza del $90 \%$ y, si es mayor a 1,96, para un nivel de confianza del $95 \%$.

En general, se puede comprobar que, en los modelos calibrados, todas las variables son estadísticamente significativas para niveles de confianza superiores a un $85-90 \%$, excepto determinadas variables de política consideradas especialmente necesarias -como el tiempo y el coste del viaje-, que se han incluido aun siendo no significativas, de acuerdo con los criterios expuestos en la Tabla 4-9, sobre reglas de buena práctica.

2) Test de razón de verosimilitud y test de ajuste general.

El test de razón de verosimilitud es útil cuando se desea comparar un modelo con otro obtenido como una versión restringida del primero, mediante transformaciones lineales. El test de ajuste general es un caso particular del mismo cuando se toma como modelo restringido el equiprobable, en el que las utilidades de todas las alternativas son nulas, o bien el de sólo constantes, que reproduce a la perfección las proporciones de mercado observadas en la muestra. Sin embargo, dada la escasa representatividad del test cuando se emplea como modelo restringido el equiprobable (ya que sólo en muy raras ocasiones no se cumple), es más empleado el modelo de sólo constantes para verificar la bondad de nuestro modelo [111].

Como se ha indicado en capítulos anteriores, denominando respectivamente $l^{*}(0)$ y $l^{*}(C)$ a los valores de log-verosimilitud para estos modelos equiprobable y de sólo constantes, los estadísticos a comprobar serán $-2\left[l^{*}(0)-l^{*}(\theta)\right]$ y $-2\left[l^{*}(C)-l^{*}(\theta)\right]$. Ambos distribuirán asintóticamente $\chi^{2}$ con $k$ y $k-c$ grados de libertad, respectivamente, siendo $k$ el número de atributos del modelo completo y $c$ el número de constantes específicas [111]. Comparando estos valores con la distribución $\chi^{2}$ para un determinado nivel de confianza, se obtiene como resultado si el modelo completo es estadísticamente diferente de los reducidos.

En la Tabla 5-7 se presentan los valores correspondientes a dicho test, únicamente tomando como modelo restringido es de sólo constantes, según las consideraciones expuestas anteriormente. 
A la vista de los resultados, observamos que todos los modelos verifican este test, lo que indica que se adaptan mejor a los datos disponibles que el modelo de sólo constantes. Sin embargo, este dato no nos permite aún inferir cuál modelo es mejor de entre los calibrados.

Tabla 5-7. Modelos de satisfacción - test de ajuste general

\begin{tabular}{cccccccc}
\hline MODELO & $\mathbf{I}^{*}(\boldsymbol{\theta})$ & $\mathbf{I}^{*}(\mathbf{C})$ & $\mathbf{k}$ & $\mathbf{c}$ & $\mathbf{- 2}\left[\mathbf{I}^{*}(\mathbf{C})-\mathbf{I}^{*}(\boldsymbol{\theta})\right]$ & $\mathbf{X} \mathbf{2}(\mathbf{k}-\mathbf{c}, 95 \%)$ & TEST OK \\
\hline OP-4.1 & $-533,6$ & $-577,7$ & 12 & 3 & 88,1 & 16,9 & $\checkmark$ \\
\hline OP-4.2 & $-533,5$ & $-578,0$ & 13 & 3 & 89,1 & 18,3 & $\checkmark$ \\
\hline OP-4.3 & $-518,5$ & $-575,9$ & 14 & 3 & 114,8 & 19,7 & $\checkmark$ \\
\hline OP-4.4 & $-515,8$ & $-575,9$ & 17 & 3 & 120,2 & 23,7 & $\checkmark$ \\
\hline OL-4.1 & $-533,3$ & $-577,7$ & 12 & 3 & 88,8 & 16,9 & $\checkmark$ \\
\hline OL-4.2 & $-534,8$ & $-578,0$ & 11 & 3 & 86,6 & 15,5 & $\checkmark$ \\
\hline OL-4.3 & $-517,9$ & $-575,9$ & 14 & 3 & 116,1 & 19,7 & $\checkmark$ \\
\hline OL-4.4 & $-515,4$ & $-575,9$ & 17 & 3 & 120,9 & 23,7 & $\checkmark$ \\
\hline OP-5.1 & $-551,9$ & $-587,2$ & 15 & 4 & 70,6 & 19,7 & $\checkmark$ \\
\hline OP-5.2 & $-552,9$ & $-587,2$ & 14 & 4 & 68,6 & 18,3 & $\checkmark$ \\
\hline OL-5.1 & $-555,3$ & $-587,2$ & 13 & 4 & 63,9 & 16,9 & $\checkmark$ \\
\hline OL-5.2 & $-554,5$ & $-587,2$ & 14 & 4 & 65,5 & 18,3 & $\checkmark$ \\
\hline
\end{tabular}

3) Índice $\rho^{2}$.

El índice $\rho^{2}$ es un indicador que tratar de simular al coeficiente $\mathrm{R}^{2}$ de una regresión, oscilando entre 0 , para indicar un ajuste nulo, hasta 1 , para indicar un ajuste perfecto. Las expresiones (4-19) y (4-20) nos permiten calcular su valor, teniendo como referencia el modelo equiprobable o el de sólo constantes.

Como ya se ha indicado en el capítulo anterior, el significado del índice es directo en sus extremos, pero no así en el rango de valores intermedios. Sin embargo, el índice $\hat{\rho}^{2}$ obtenido con el modelo de sólo constantes, sí tiene relación con la distribución $\chi^{2}$, de modo que puede ser empleado en tests de hipótesis. Además, tiene la ventaja de que es comparable entre distintas muestras, por lo que resulta más útil a la hora de establecer rankings entre modelos.

En la Tabla 5-8 se presentan los valores correspondientes a dicho test. A la vista de los resultados expuestos en la misma, observamos en primer lugar que los modelos que incluyen variaciones sistemáticas en los gustos de los entrevistados son los que entregan un mejor índice. Por el contrario, vemos que los modelos con cinco rangos de elección son los que peor ajuste ofrecen, como ya habíamos intuido en apartados 
anteriores. En cuanto a la elección entre tipología de modelo logit o probit ordinales, no queda claro aún cuál es el óptimo entre ellos.

Tabla 5-8. Modelos de satisfacción - índice $\rho^{2}$

\begin{tabular}{ccccc}
\hline MODELO & $I^{*}(\theta)$ & $I^{*}(C)$ & $\hat{\rho}^{2}$ & RANKING \\
\hline OP-4.1 & $-533,6$ & $-577,7$ & 0,076 & $7^{0}$ \\
\hline OP-4.2 & $-533,5$ & $-578,0$ & 0,077 & $5^{\circ}$ \\
\hline OP-4.3 & $-518,5$ & $-575,9$ & 0,100 & $4^{0}$ \\
\hline OP-4.4 & $-515,8$ & $-575,9$ & 0,104 & $2^{\circ}$ \\
\hline OL-4.1 & $-533,3$ & $-577,7$ & 0,077 & $6^{\circ}$ \\
\hline OL-4.2 & $-534,8$ & $-578,0$ & 0,075 & $8^{\circ}$ \\
\hline OL-4.3 & $-517,9$ & $-575,9$ & 0,101 & $3^{\circ}$ \\
\hline OL-4.4 & $-515,4$ & $-575,9$ & 0,105 & $1^{0}$ \\
\hline OP-5.1 & $-551,9$ & $-587,2$ & 0,060 & $9^{\circ}$ \\
\hline OP-5.2 & $-552,9$ & $-587,2$ & 0,058 & $10^{\circ}$ \\
\hline OL-5.1 & $-555,3$ & $-587,2$ & 0,054 & $12^{\circ}$ \\
\hline OL-5.2 & $-554,5$ & $-587,2$ & 0,056 & $11^{\circ}$ \\
\hline
\end{tabular}

\section{4) Test FPR (first preference recovery).}

El porcentaje correctamente predicho representa la proporción de observaciones en que la alternativa de máxima utilidad -y, por tanto, de máxima probabilidad de elección- es la efectivamente seleccionada por el entrevistado.

Sin embargo, como ya se ha indicado en el capítulo anterior, es un concepto intuitivo y sencillo, pero de interpretación engañosa. Así, para evaluar la bondad de un modelo según este índice, es necesario comparar su proporción de respuestas correctamente predichas con su esperanza de acierto y con la probabilidad de éxito de otro modelo sencillo, como el equiprobable. Así, a medida que el test FPR se acerque a su esperanza de éxito y supere a la probabilidad de acierto del modelo equiprobable, considerando además los valores de sus varianzas, el modelo calibrado tendrá un mejor ajuste [59]. Dichos valores se obtienen de la formulación expuesta en las expresiones (4-21) y $(4-22)$.

En la Tabla 5-9 se presentan los valores correspondientes a dicho test (los resultados predictivos del modelo, necesarios para su cálculo, se presentan en el Anexo 4). Considerando los resultados expuestos en ella, observamos que todos los modelos son correctos según esta comprobación, ya que en todos ellos el valor del test FPR es del orden de magnitud de ER, y bastante superior a CR, considerando sus varianzas [59]. Además, observamos que los valores de porcentaje correctamente predicho son 
bastante elevados, rondando en todos los casos el 70\%. En general, observamos que los modelos con 5 rangos de variación en la variable dependiente obtienen un éxito algo menor, obvio en principio ya que hay más alternativas de elección en ellos, y que en general los modelos con variaciones sistemáticas en los gustos arrojan mejores resultados, como también cabría esperar.

Tabla 5-9. Modelos de satisfacción - test FPR

\begin{tabular}{ccccccc}
\hline MODELO & CR & $\operatorname{Var}(\mathrm{CR})$ & ER & $\operatorname{Var}($ ER) & FPR & TEST OK \\
\hline OP-4.1 & 0,25 & 0,188 & 0,705 & 0,199 & 0,715 & $\checkmark$ \\
\hline OP-4.2 & 0,25 & 0,188 & 0,706 & 0,198 & 0,707 & $\checkmark$ \\
\hline OP-4.3 & 0,25 & 0,188 & 0,706 & 0,196 & 0,715 & $\checkmark$ \\
\hline OP-4.4 & 0,25 & 0,188 & 0,707 & 0,195 & 0,710 & $\checkmark$ \\
\hline OL-4.1 & 0,25 & 0,188 & 0,708 & 0,196 & 0,706 & $\checkmark$ \\
\hline OL-4.2 & 0,25 & 0,188 & 0,708 & 0,196 & 0,702 & $\checkmark$ \\
\hline OL-4.3 & 0,25 & 0,188 & 0,711 & 0,193 & 0,713 & $\checkmark$ \\
\hline OL-4.4 & 0,25 & 0,188 & 0,712 & 0,192 & 0,713 & $\checkmark$ \\
\hline OP-5.1 & 0,2 & 0,16 & 0,703 & 0,197 & 0,705 & $\checkmark$ \\
\hline OP-5.2 & 0,2 & 0,16 & 0,703 & 0,197 & 0,706 & $\checkmark$ \\
\hline OL-5.1 & 0,2 & 0,16 & 0,706 & 0,195 & 0,699 & $\checkmark$ \\
\hline OL-5.2 & 0,2 & 0,16 & 0,707 & 0,195 & 0,699 & $\checkmark$ \\
\hline
\end{tabular}

5) Índice de éxito predictivo.

La tabla de éxito predictivo del modelo, con $\mathrm{N}^{*} \mathrm{~N}$ celdas, donde $\mathrm{N}$ es el número de alternativas de elección del modelo diseñado, contiene en sus columnas las predicciones del modelo $\mathrm{y}$, en las filas, las elecciones observadas en la muestra. El sumatorio por filas coincidirá con el número de entrevistados que eligieron una determinada alternativa $\mathrm{y}$, por columnas, la misma cantidad pero predicha por el modelo. Los elementos de la diagonal son las observaciones en las que la elección predicha coincide con la observada, deduciéndose de su proporción con respecto al total el test FPR.

A partir de dicha tabla se puede obtener el índice de éxito predictivo, habitualmente denotado como $\sigma$, así como sus valores máximo $\sigma_{\text {máx }}$ y normalizado $\sigma_{\text {norm }}$, que nos dan una medida de bondad de ajuste con significado similar al test FPR, pero válida para comparar modelos diferentes. Dichos valores se obtienen a partir de la expresión (4-23).

Se desea hacer notar aquí otra vez que, a pesar de que los modelos empleados han sido de tipo ordinal, por ser los que mejor se adaptan a nuestra tipología de datos de entrada, 
raramente aportan un gran índice de éxito predictivo, aunque sean perfectamente válidos, tal y como indica Greene [58].

De hecho, ninguno de los modelos calibrados se ajusta correctamente a las observaciones situadas en los rangos extremos, centrando todas las predicciones en los valores intermedios. Como ya hemos indicado, esta es una circunstancia que habitualmente se produce en los modelos de tipo ordinal, lo que no implica la necesidad de desechar el modelo. Por tanto, concluimos aquí el cálculo de este índice, al no ser correctamente compatible con la tipología de modelos empleada.

Una vez calculados los índices correspondientes a cada uno de los test probados, únicamente resta la elección de un mejor modelo de cada tipo, que se empleará en fases posteriores del estudio. En primer lugar, en la Tabla 5-10 se presenta un resumen de las clasificaciones entre modelos obtenidas según los distintos índices verificados. En ella se muestra la clasificación cualitativa estimada a partir de los distintos criterios considerados, y el ranking global, obtenido a partir de la media ponderada de las anteriores, asignando peso unitario al test de ajuste general, doble al test FPR y triple al índice $\hat{\rho}^{2}$.

\begin{tabular}{|c|c|c|c|c|c|}
\hline \multirow[b]{2}{*}{ MODELO } & \multicolumn{3}{|c|}{ RANKING PARCIALES } & \multirow{2}{*}{$\begin{array}{c}\text { MEDIA } \\
\text { PONDERADA }\end{array}$} & \multirow{2}{*}{$\begin{array}{c}\text { RAKING } \\
\text { FINAL }\end{array}$} \\
\hline & $\begin{array}{c}\text { Ajuste } \\
\text { Gral. }\end{array}$ & Índice $\rho^{2}$ & FPR & & \\
\hline OP-4.1 & $6^{0}$ & $7^{0}$ & $1^{0}$ & 4.8 & $5^{0}$ \\
\hline OP-4.2 & $8^{\circ}$ & $5^{\circ}$ & $6^{0}$ & 5.8 & $6^{0}$ \\
\hline OP-4.3 & $4^{0}$ & $4^{\circ}$ & $2^{0}$ & 3.3 & $4^{0}$ \\
\hline OP-4.4 & $2^{0}$ & $2^{\circ}$ & $5^{0}$ & 3.0 & $2^{\circ} / 3^{\circ}$ \\
\hline OL-4.1 & $5^{0}$ & $6^{0}$ & $8^{\circ}$ & 6.5 & $7^{0}$ \\
\hline OL-4.2 & $7^{\circ}$ & $8^{\circ}$ & $10^{\circ}$ & 8.5 & $8^{\circ}$ \\
\hline OL-4.3 & $3^{\circ}$ & $3^{\circ}$ & $3^{\circ}$ & 3.0 & $2^{\circ} / 3^{\circ}$ \\
\hline OL-4.4 & $1^{0}$ & $1^{0}$ & $4^{0}$ & 2.0 & $1^{0}$ \\
\hline OP-5.1 & $9^{\circ}$ & $9^{\circ}$ & $9^{\circ}$ & 9.0 & $9 \% / 10^{\circ}$ \\
\hline OP-5.2 & $10^{\circ}$ & $10^{\circ}$ & $7^{0}$ & 9.0 & $9 \% / 10^{\circ}$ \\
\hline OL-5.1 & $12^{\circ}$ & $12^{\circ}$ & $11^{\circ} / 12^{\circ}$ & 11.8 & $12^{\circ}$ \\
\hline OL-5.2 & $11^{\circ}$ & $11^{\circ}$ & $11 \% / 12^{\circ}$ & 11.2 & $11^{\circ}$ \\
\hline
\end{tabular}

A la vista de los resultados, observamos que los modelos mejor situados en el ranking son los que incluyen variaciones sistemáticas en los gustos de los usuarios, entre los que se podría escoger como definitivo el denominado OL-4.4. A continuación, de entre los genéricos para todos los entrevistados, se aprecia que los que tienen sólo 4 rangos de variación para la variable dependiente arrojan mejores resultados que los de 5 rangos. En concreto, de entre los 8 modelos calibrados de este tipo, el que mejor ajusta los datos, 
manteniendo además una gran regularidad en los distintos índices testados ha sido el denominado OP-4.1. Además, el hecho de que aparezcan en el mismo variables de política consideradas relevantes (como la velocidad de recorrido del viaje, por ejemplo), favorece su empleo a los efectos de priorización de actuaciones de mejora del servicio.

\subsubsection{Submodelo de Demanda y Disponibilidad al Pago}

En el presente apartado, se tratará de modelizar no tanto las variables que influyen en la satisfacción final de un determinado usuario del servicio de transporte público interurbano en autobús, sino cuáles son las que afectan a la probabilidad de que dicho usuario emplee uno u otro modo de transporte para el viaje a realizar. Para ello, dado que la mayoría de las encuestas fueron realizadas en la estación de autobuses de la ciudad de Burgos, es necesario acudir a los datos recogidos en los experimentos de preferencias declaradas (PD) en la citada encuesta.

En el capítulo anterior se ha descrito la metodología seguida para la elección y el diseño de los experimentos PD, destacando de nuevo el hecho de que, gracias al empleo de PDA's programadas para tal efecto, los experimentos fueron diseñados específicamente para cada usuario, a partir de los datos recopilados previamente sobre su viaje y sus características personales. Así, se emplearon diseños experimentales ortogonales y equilibrados, de modo que se minimizara la correlación entre los atributos presentados a los entrevistados.

Tal y como se explicado en apartados anteriores, la construcción de los experimentos PD constó de varias etapas, que en resumen son las que siguen:

Preselección de las variables a incluir, a partir de experiencias y encuestas previas. Se incluyó 4 variables representativas del funcionamiento de cada modo (autobús, tren y vehículo privado): tiempo de viaje, coste del billete, número diario de servicios y características del vehículo.

Determinación inicial de los valores máximos y mínimos razonables de las mismas, y de los niveles de variación. En la Tabla 4-3 se exponen los parámetros inicialmente escogidos para la encuesta, donde todas las variables tenían como máximo 2 rangos de variación.

Diseño preliminar de experimentos PD. Para simplificar al máximo las preguntas presentadas a los entrevistados, se realizaron sendos experimentos de comparación 
entre autobús y vehículo privado (según el diseño expuesto en la Tabla 4-4) y entre autobús y tren (según el diseño expuesto en la Tabla 4-5). Ambos experimentos fueron diseñados cumpliendo las condiciones de ortogonalidad y equilibrio entre variables, optando por un diseño en 2 bloques, que se realizaban de forma correlativa, uno a cada usuario. Al preguntar al mismo usuario con el mismo bloque en ambos experimentos permitiría posteriormente agregar los datos, para elaborar un modelo único con las tres alternativas disponibles.

Prueba piloto del diseño preliminar. Se realizaron 140 encuestas en la fase de prueba, a partir de las cuales se elaboraron unos modelos previos, con el fin de determinar si el rango de variación de las variables era adecuado.

Modificación del diseño preliminar, para obtener el diseño definitivo. Tras el análisis de los resultados de la encuesta piloto, se decidió aumentar el número de niveles en las variables de política (tiempo de viaje, coste del billete y número de servicios del autobús) hasta tres, manteniendo el resto constantes, según lo expuesto en la Tabla 4-6. Además, se dividió el experimento en 3 bloques, a realizar correlativamente uno a cada entrevistado, con el objetivo de disminuir el tiempo total de la encuesta. Finalmente, los diseños elegidos son los que aparecen en la Tabla 4-7 para la comparación entre autobús y vehículo privado y en la Tabla 4-8 para la elección entre autobús y ferrocarril.

Puesta en práctica del diseño definitivo. Se observó que, con las modificaciones descrita, el nuevo diseño resultaba más agradable a los entrevistados, por lo que el escogido para la recopilación de datos.

En cuanto a la tipología de modelos empleada, se ha optado por el uso de modelos de tipo logit multinomial y jerárquico, dada su mayor sencillez, ya que uno de los objetivos de la presente investigación es que sea factible su aplicación posterior en los contratos de transporte. Es por esto que determinadas metodologías más avanzadas, como los modelos de tipo logit mixto u otras variaciones con parámetros no fijos, a pesar de que a priori podrían resultar más potentes, no han sido empleados. Las principales características e hipótesis de formulación de dichos modelos aparecen reflejadas en el capítulo anterior. 
Tabla 5-11. Matriz (resumen) de correlación entre variables exógenas (demanda)

\begin{tabular}{|c|c|c|c|c|c|c|c|c|c|c|c|c|c|c|c|c|c|}
\hline & 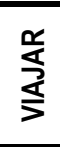 & $\begin{array}{l}\Sigma_{\mathcal{U}} \\
\text { } \\
\end{array}$ & $\stackrel{\text { On }}{-}$ & 苞 & $\begin{array}{l}\text { 号 } \\
\text { 罢 }\end{array}$ & $\underset{\mathbf{c}}{\mathbb{5}}$ & $\begin{array}{l}\text { 똥 } \\
\text { 인 }\end{array}$ & $\begin{array}{l}\text { 똥 } \\
\text { 엉 }\end{array}$ & $\begin{array}{c}\underset{\mathfrak{u}}{\mathfrak{u}} \\
\text { E }\end{array}$ & 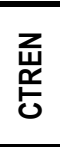 & 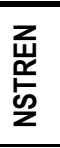 & 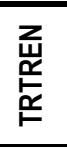 & $\frac{5}{5}$ & $\begin{array}{l}\text { 山्⿱士 } \\
\text { О } \\
\text { ㅇ }\end{array}$ & $\begin{array}{l}\text { zu } \\
\text { 営 }\end{array}$ & 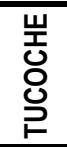 & $\begin{array}{l}\text { z } \\
\text { 范 } \\
\text { ㄱ }\end{array}$ \\
\hline VIAJAR & : & 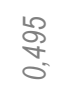 & $\stackrel{\infty}{ָ}$ & $\frac{\mathscr{R}}{\frac{1}{0}}$ & $\begin{array}{l}\text { O্ } \\
\text { O. }\end{array}$ & \begin{tabular}{l}
\multirow{心}{0}{} \\
o
\end{tabular} & 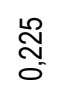 & 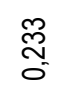 & $\begin{array}{l}\text { 잉 } \\
\text { i }\end{array}$ & $\begin{array}{l}\text { R } \\
\text { O } \\
0\end{array}$ & $\begin{array}{l}\forall \\
\stackrel{8}{\circ}\end{array}$ & $\begin{array}{l}\text { J } \\
\text { : } \\
\text { i }\end{array}$ & 莕 & 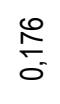 & $\frac{8}{5}$ & గ్రి & $\begin{array}{l}\text { o } \\
\stackrel{\circ}{0} \\
\end{array}$ \\
\hline RECOM & 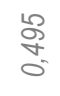 & : & $\begin{array}{l}\infty \\
\stackrel{\circ}{\circ}\end{array}$ & $\begin{array}{l}\frac{m}{\sigma} \\
0 \\
i\end{array}$ & 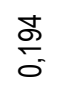 & 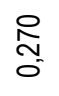 & đั & 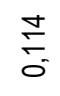 & $\begin{array}{l}0 \\
\frac{m}{i} \\
\end{array}$ & $\begin{array}{l}\widetilde{8} \\
\stackrel{-}{1}\end{array}$ & 응 & ণ్రి & $\begin{array}{l}\bar{o} \\
\text { o. }\end{array}$ & $\begin{array}{l}\infty \\
\vdots \\
0 \\
0\end{array}$ & $\stackrel{8}{\circ}$ & 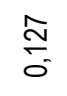 & $\begin{array}{l}\hat{N} \\
\text { ò }\end{array}$ \\
\hline TBUS & 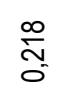 & 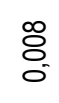 & 1 & $\begin{array}{l}\stackrel{\infty}{\circ} \\
\stackrel{0}{0}\end{array}$ & $\begin{array}{c}\text { ָ̃ } \\
\text { ì }\end{array}$ & $\begin{array}{l}\mathscr{2} \\
0 \\
0\end{array}$ & $\begin{array}{l}\text { 옹 } \\
\text { - }\end{array}$ & $\begin{array}{l}0 \\
\text { o } \\
0 \\
0\end{array}$ & $\begin{array}{l}\hat{\tilde{b}} \\
0 \\
0\end{array}$ & $\begin{array}{l}\infty \\
\stackrel{0}{0} \\
0\end{array}$ & $\begin{array}{l}\text { I } \\
\text { i }\end{array}$ & $\frac{8}{\circ}$ & $\begin{array}{l}\text { : } \\
0 \\
0 \\
0\end{array}$ & $\begin{array}{l}\text { : } \\
\text { O. }\end{array}$ & $\frac{\bar{\sigma}}{i}$ & $\frac{\hat{m}}{i}$ & $\frac{\mathscr{P}}{\frac{f}{i}}$ \\
\hline CBUS & $\stackrel{\circ}{\circ}$ & $\stackrel{m}{0}$ & \begin{tabular}{l}
$\stackrel{8}{\circ}$ \\
\hdashline
\end{tabular} & : & $\begin{array}{l}0 \\
\stackrel{0}{0} \\
0 \\
1\end{array}$ & $\frac{\widehat{m}}{\sigma}$ & $\begin{array}{l}\mathscr{0} \\
\infty \\
\infty \\
0\end{array}$ & 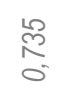 & $\stackrel{\infty}{\underset{\sigma}{\sigma}}$ & $\begin{array}{l}\bar{g} \\
\text { g }\end{array}$ & $\frac{\infty}{0}$ & $\check{c}_{0}^{m}$ & $\begin{array}{l}\text { 怘 } \\
0 \\
0\end{array}$ & d & $\begin{array}{l}\sqrt{0} \\
0 \\
0\end{array}$ & $\begin{array}{l}\text { ô } \\
\text { o } \\
1\end{array}$ & $\begin{array}{l}\text { స్ } \\
\text { i }\end{array}$ \\
\hline NSBUS & $\begin{array}{l}\text { o. } \\
\text { : }\end{array}$ & $\frac{5}{\circ}$ & $\begin{array}{l}\text { ల్స } \\
\text { i. }\end{array}$ & 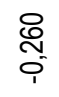 & : & $\begin{array}{l}\text { \& } \\
\text { o. }\end{array}$ & $\begin{array}{l}\text { స్స } \\
\text { ò }\end{array}$ & $\frac{\text { so }}{i=-1}$ & 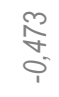 & $\begin{array}{l}\text { 융 } \\
0\end{array}$ & $\stackrel{0}{\circ}$ & 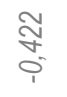 & $\frac{⿱}{+}$ & 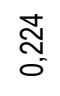 & $\begin{array}{l}\text { ஜ్రి } \\
0\end{array}$ & $\frac{\stackrel{2}{0}}{-}$ & $\frac{\infty}{\frac{1}{0}}$ \\
\hline RUTA & $\begin{array}{l}\text { đo } \\
\text { ON }\end{array}$ & $\underset{\substack{\mathfrak{d} \\
0}}{ }$ & 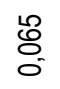 & $\frac{\widehat{m}}{0}$ & 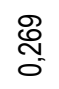 & : & $\begin{array}{l}0 \\
\vdots \\
\\
i\end{array}$ & $\frac{\hat{\sigma}}{0}$ & $\begin{array}{l}0 \\
\hat{i} \\
i \\
i\end{array}$ & \begin{tabular}{l} 
J \\
\multirow{2}{*}{} \\
$i$
\end{tabular} & 吕 & $\begin{array}{l}\text { 心 } \\
\text { i. }\end{array}$ & $\stackrel{\infty}{\circ}$ & 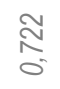 & $\begin{array}{l}\text { 鹿 } \\
0\end{array}$ & $\underset{\widetilde{N}}{\bar{N}}$ & $\begin{array}{l}\bar{\sigma} \\
\text { o } \\
\text { i. }\end{array}$ \\
\hline TCOCHE & 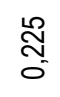 & ॄั & $\begin{array}{l}\text { gे } \\
\text { cे }\end{array}$ & $\begin{array}{l}0 \\
\infty \\
0 \\
0\end{array}$ & 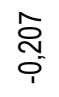 & $\begin{array}{l}0 \\
\vdots \\
\\
i\end{array}$ & : & $\begin{array}{l}\text { D } \\
\infty \\
0 \\
0\end{array}$ & $\begin{array}{l}\stackrel{2}{0} \\
\text { ర. }\end{array}$ & $\begin{array}{l}\stackrel{\aleph}{0} \\
\stackrel{0}{0}\end{array}$ & $\begin{array}{l}\text { ণ్ల్ } \\
\text { ì }\end{array}$ & $\frac{\hat{\sigma}}{0}$ & $\begin{array}{l}\hat{\infty} \\
\text { o } \\
0 \\
0\end{array}$ & 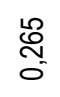 & $\frac{8}{\circ}$ & $\underset{i}{\stackrel{E}{c}}$ & $\begin{array}{l}\text { oे } \\
\text { o }\end{array}$ \\
\hline CCOCHE & 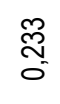 & $\underset{\sigma}{\stackrel{\Xi}{E}}$ & $\begin{array}{l}0 \\
\text { o } \\
0 \\
0\end{array}$ & $\begin{array}{l}\stackrel{\sim}{\tilde{N}} \\
\stackrel{\sigma}{\sigma}\end{array}$ & $\frac{\frac{8}{9}}{i=0}$ & $\frac{\hat{y}}{0}$ & $\begin{array}{l}\mathscr{2} \\
\infty \\
0 \\
0\end{array}$ & i & $\begin{array}{c}\hat{\hat{m}} \\
0 \\
0\end{array}$ & $\frac{\hat{\sigma}}{\delta}$ & $\begin{array}{l}0 \\
8 \\
0 \\
\end{array}$ & $\begin{array}{l}\text { ৪ } \\
\text { - }\end{array}$ & $\begin{array}{l}\text { ৪ } \\
\stackrel{8}{\circ}\end{array}$ & $\underset{\widetilde{m}}{\stackrel{\tilde{m}}{0}}$ & $\begin{array}{l}\hat{o} \\
\text { O. }\end{array}$ & 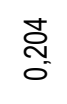 & $\begin{array}{l}\text { 芯 } \\
\text { i }\end{array}$ \\
\hline TTREN & $\begin{array}{l}\text { 号 } \\
\text { - }\end{array}$ & $\frac{\mathscr{m}}{i}$ & 存 & $\frac{\infty}{\hbar}$ & 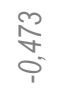 & $\begin{array}{c}\frac{2}{N} \\
0 \\
i\end{array}$ & $\begin{array}{l}\mathscr{W} \\
\text { ○ }\end{array}$ & $\begin{array}{c}\hat{N} \\
\text { s. } \\
0\end{array}$ & : & 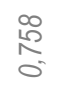 & $\begin{array}{l}\bar{\delta} \\
\text { ల్ } \\
\text { i. }\end{array}$ & 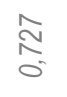 & $\begin{array}{l}\bar{N} \\
\text { ర } \\
0\end{array}$ & $\begin{array}{l}\text { 芯 } \\
\text { i } \\
\end{array}$ & $\begin{array}{l}R \\
i \\
i\end{array}$ & $\begin{array}{l}\text { 岕 } \\
\text { o. }\end{array}$ & 용 \\
\hline CTREN & $\begin{array}{l}\text { 员 } \\
\text { O }\end{array}$ & đֶ. & $\begin{array}{l}\stackrel{\infty}{c} \\
0\end{array}$ & 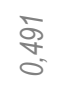 & 융 & $\begin{array}{l}\frac{8}{7} \\
i \\
i\end{array}$ & $\begin{array}{c}\text { న్ల } \\
\text { o }\end{array}$ & 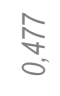 & $\begin{array}{l}\infty \\
\stackrel{R}{R} \\
\sigma^{\prime \prime}\end{array}$ & 1 & $\begin{array}{l}\text { o } \\
\& \\
i \\
i\end{array}$ & స్ల్ల్ & $\begin{array}{l}\bar{\alpha} \\
\stackrel{0}{o}\end{array}$ & $\stackrel{\nabla}{\circ}$ & 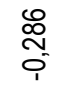 & 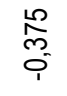 & $\begin{array}{l}+ \\
0 \\
0 \\
0\end{array}$ \\
\hline NSTREN & $\begin{array}{l}\text { Z } \\
\text { O }\end{array}$ & 응 & $\begin{array}{l}\text { P } \\
\text { ․ }\end{array}$ & $\frac{\infty}{\stackrel{\circ}{i}}$ & $\frac{0}{0}$ & $\begin{array}{l}\text { O্ } \\
\text { 心్ }\end{array}$ & $\begin{array}{l}\text { ণ్స్ } \\
\text { î }\end{array}$ & $\begin{array}{l}\text { : } \\
\text { i. }\end{array}$ & $\begin{array}{l}\bar{\delta} \\
\overline{0} \\
0\end{array}$ & 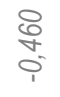 & i & ¿o & $\begin{array}{l}\mathbb{N} \\
\text { O }\end{array}$ & \begin{tabular}{l}
\multirow{N}{0}{} \\
$\vdots$ \\
\end{tabular} & 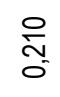 & \begin{tabular}{l} 
J \\
\multirow{\sigma}{*}{}
\end{tabular} & 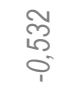 \\
\hline TRTREN & $\begin{array}{l}\text { S } \\
\text { i }\end{array}$ & 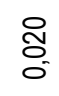 & $\frac{8}{\circ}$ & $\check{c}_{0}^{m}$ & 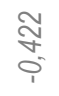 & $\begin{array}{l}\text { స } \\
\text { o } \\
\text { i }\end{array}$ & $\frac{\hat{\sigma}}{0}$ & $\begin{array}{l}\text { 8. } \\
\text { i. }\end{array}$ & 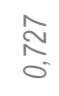 & ঙ্লি & $\stackrel{\infty}{0}_{i}^{\infty}$ & : & $\begin{array}{l}\text { \&̊ } \\
\stackrel{0}{0}\end{array}$ & $\begin{array}{l}\hat{2} \\
0 \\
i\end{array}$ & $\begin{array}{l}\mathbb{N} \\
\infty \\
0 \\
0\end{array}$ & $\begin{array}{l}\text { o } \\
\text { m } \\
\text { o. }\end{array}$ & 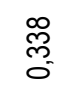 \\
\hline DIST & 只 & $\begin{array}{l}\bar{\alpha} \\
\stackrel{0}{0}\end{array}$ & $\begin{array}{l}\text { \&े } \\
0 \\
0\end{array}$ & $\begin{array}{l}\text { I } \\
0 \\
0 \\
0\end{array}$ & 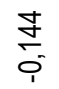 & $\frac{\infty}{0}$ & $\begin{array}{l}\hat{o} \\
\stackrel{0}{0}\end{array}$ & $\begin{array}{l}8 \\
8 \\
0\end{array}$ & $\begin{array}{l}\bar{్} \\
0 \\
0\end{array}$ & $\begin{array}{l}\bar{n} \\
0 \\
0\end{array}$ & 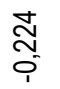 & $\begin{array}{l}\text { L } \\
0 \\
0\end{array}$ & i & o্ & $\begin{array}{l}\text { o̊ } \\
\text { i. }\end{array}$ & $\frac{8}{\circ}$ & $\frac{2}{\stackrel{\infty}{i}}$ \\
\hline VCOCHE & $\stackrel{0}{\stackrel{2}{\circ}}$ & $\begin{array}{l}\infty \\
\vdots \\
0 \\
0\end{array}$ & $\begin{array}{l}\stackrel{8}{0} \\
\text { d. } \\
0\end{array}$ & $\begin{array}{l}8 \\
\stackrel{+}{0} \\
0\end{array}$ & 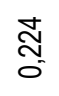 & $\begin{array}{l}\mathbb{N} \\
0\end{array}$ & $\begin{array}{l}\text { 芯 } \\
0 \\
0\end{array}$ & $\begin{array}{c}\widehat{N} \\
0 \\
0\end{array}$ & $\begin{array}{l}\text { 落 } \\
\text { i }\end{array}$ & $\stackrel{\nabla}{\Delta}$ & \begin{tabular}{l}
\multirow{N}{0}{} \\
$\vdots$ \\
\end{tabular} & $\begin{array}{l}\hat{2} \\
0 \\
i\end{array}$ & 昰 & : & $\begin{array}{l}\stackrel{\infty}{R} \\
0\end{array}$ & $\begin{array}{l}\overline{0} \\
\text { o. }\end{array}$ & $\begin{array}{l}\frac{N}{5} \\
\text { i. }\end{array}$ \\
\hline VTREN & $\frac{8}{5}$ & $\begin{array}{l}\stackrel{2}{0} \\
0 \\
0\end{array}$ & $\frac{\delta}{i}$ & $\begin{array}{l}\hat{2} \\
0 \\
0 \\
i\end{array}$ & $\begin{array}{l}\text { ஜ্ర } \\
0\end{array}$ & 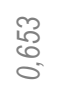 & $\frac{8}{0}$ & $\begin{array}{l}\hat{0} \\
0 \\
0\end{array}$ & $\begin{array}{l}R \\
\stackrel{R}{0} \\
i\end{array}$ & $\begin{array}{l}\stackrel{0}{0} \\
\stackrel{\square}{i} \\
i\end{array}$ & 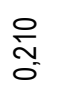 & 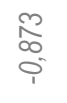 & 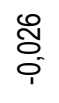 & $\begin{array}{l}\infty \\
\stackrel{2}{0} \\
0\end{array}$ & : & $\begin{array}{l}\stackrel{\$}{~} \\
\text { O }\end{array}$ & 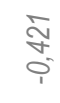 \\
\hline TUCOCHE & 尽 & $\stackrel{\Xi}{\underline{0}}$ & $\frac{\hat{m}}{i}$ & $\begin{array}{l}\text { ô } \\
\stackrel{N}{i} \\
i=1\end{array}$ & $\frac{\stackrel{2}{0}}{-}$ & $\underset{\text { స్ }}{\bar{N}}$ & $\frac{\hat{N}}{i}$ & 忍 & 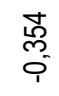 & $\begin{array}{l}\frac{2}{2} \\
\tilde{n} \\
0 \\
1\end{array}$ & 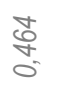 & 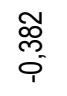 & $\frac{8}{\frac{8}{0}}$ & $\begin{array}{l}\overline{0} \\
\text { o. } \\
1\end{array}$ & $\begin{array}{l}\text { O } \\
\text { N } \\
0\end{array}$ & : & $\begin{array}{c}\hat{m} \\
\text { m } \\
\end{array}$ \\
\hline TUTREN & $\begin{array}{l}\text { هo } \\
\stackrel{1}{1}\end{array}$ & 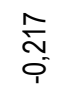 & $\frac{\text { fo }}{\frac{1}{i}}$ & $\begin{array}{l}\stackrel{N}{N} \\
\text { ì }\end{array}$ & $\stackrel{\infty}{\stackrel{\infty}{c}}$ & $\begin{array}{l}\bar{\ddagger} \\
0 \\
0 \\
\end{array}$ & $\begin{array}{l}\text { og } \\
\text { o. }\end{array}$ & 芯 & $\begin{array}{c}\stackrel{8}{d} \\
0\end{array}$ & $\begin{array}{l}\square \\
\text { D. } \\
0 \\
0\end{array}$ & $\begin{array}{l}\text { ్ָ } \\
\text { in }\end{array}$ & 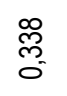 & $\stackrel{\text { }}{\stackrel{0}{i}}$ & $\begin{array}{l}\text { N } \\
\text { i } \\
\text { s. }\end{array}$ & $\begin{array}{l}\bar{z} \\
\text { s. }\end{array}$ & $\begin{array}{l}\widehat{\hat{m}} \\
0 \\
0 \\
0\end{array}$ & i \\
\hline
\end{tabular}


Tabla 5-12. Relación de variables adicionales incluidas en los modelos de demanda

\begin{tabular}{|c|c|c|c|}
\hline VARIABLE & DESCRIPCIÓN & UNIDAD & VALORES \\
\hline $\begin{array}{c}\text { VIAJAR } \\
\text { RECOMEN }\end{array}$ & $\begin{array}{l}\text { En las mismas condiciones del viaje actual } \\
\text { ¿viajaría otra vez/recomendaría en bus? }\end{array}$ & -- & $\begin{array}{l}0 \text { - seg. no; } 1 \text { - creo que no; } 2 \text { - no lo sé; } \\
3 \text { - creo que sí; } 4 \text { - seg. sí }\end{array}$ \\
\hline $\begin{array}{c}\text { TBUS } \\
\text { TCOCHE } \\
\text { TTREN }\end{array}$ & $\begin{array}{l}\text { Tiempo de viaje en autobús, vehículo } \\
\text { privado y ferrocarril }\end{array}$ & horas & $\begin{array}{l}\text { indicado por el usuario (autobús) y } \\
\text { obtenido a partir de datos O/D (coche/tren) }\end{array}$ \\
\hline $\begin{array}{c}\text { CBUS } \\
\text { CCOCHE } \\
\text { CTREN }\end{array}$ & $\begin{array}{l}\text { Coste de viaje en autobús, vehículo } \\
\text { privado y ferrocarril }\end{array}$ & $€$ & $\begin{array}{l}\text { indicado por el usuario (autobús) y } \\
\text { obtenido a partir de datos O/D (coche/tren) }\end{array}$ \\
\hline $\begin{array}{c}\text { NSBUS } \\
\text { NSTREN }\end{array}$ & $\begin{array}{l}\text { Número de servicios diarios en autobús y } \\
\text { ferrocarril }\end{array}$ & ud. & $\begin{array}{l}\text { indicado por el usuario (autobús) y } \\
\text { obtenido a partir de datos O/D (tren) }\end{array}$ \\
\hline BUSS & Autobús seminuevo (frente a antiguo) & -- & 0 - no; 1 - sí \\
\hline BUSN & Autobús nuevo & -- & 0 - no; 1 - sí \\
\hline BUSGC & Autobús gran clase & -- & $0-$ no; 1 - sí \\
\hline DBUSGC & $\begin{array}{l}\text { Interacción entre distancia de viaje y } \\
\text { autobús gran clase }\end{array}$ & $\mathrm{km}$ & $\begin{array}{l}\text { distancia de viaje * variable dummy } \\
\text { autobús gran clase }\end{array}$ \\
\hline $\begin{array}{l}\text { RUTABU } \\
\text { RUTACO }\end{array}$ & Trayecto realizado por autopista/autovía & -- & 0 - no; 1 - sí \\
\hline $\begin{array}{l}\text { RUTANUBU } \\
\text { RUTANUCO }\end{array}$ & $\begin{array}{l}\text { Proporción (en longitud) del trayecto } \\
\text { realizado por autopista/autovía }\end{array}$ & Tanto por uno & obtenido a partir de datos O/D \\
\hline DIST & Distancia de viaje & $\mathrm{km}$ & obtenido a partir de datos O/D \\
\hline $\begin{array}{c}\text { VBUS } \\
\text { VCOCHE } \\
\text { VTREN }\end{array}$ & $\begin{array}{l}\text { Velocidad media de recorrido de viaje en } \\
\text { autobús, vehículo privado y ferrocarril }\end{array}$ & $\mathrm{km} / \mathrm{h}$ & obtenido de datos anteriores \\
\hline $\begin{array}{c}\text { TUBUS } \\
\text { TUCOCHE } \\
\text { TUTREN } \\
\end{array}$ & $\begin{array}{l}\text { Tarifa usuario de viaje en autobús, } \\
\text { vehículo privado y ferrocarril }\end{array}$ & $€ / \mathrm{km}$ & obtenido de datos anteriores \\
\hline $\begin{array}{c}\text { CTEBUS } \\
\text { CTECOCHE } \\
\text { CTETREN }\end{array}$ & $\begin{array}{l}\text { Constantes específicas de las variables } \\
\text { autobús, vehículo privado y ferrocarril }\end{array}$ & -- & unidades \\
\hline
\end{tabular}

Además, para que un único modelo reflejara toda la casuística a considerar, se ha optado en este caso por unir ambos experimentos (ya que los fueron realizados al mismo usuario), sin más que considerar diferentes choice sets en función del escenario al que cada observación se refiera: comparación coche-autobús y tren-autobús. Así tendremos tres funciones de utilidad, que serán por lo general de forma lineal, como se ha explicado en el capítulo anterior.

Sin embargo, al igual que se hizo para los modelos calibrados a partir de datos de preferencias reveladas (PR), el primer paso es verificar la no existencia de variables exógenas correlacionadas entre sí de forma significativa. Para ello, en el Anexo 3 se adjunta la matriz completa de correlación entre variables, de la que la Tabla 5-1 nos mostraba aquéllas entre las que se apreciaba correlación para los modelos PR y la Tabla 
5-11 hace lo mismo para las variables nuevas que aparecen en los modelos PD (ver descripción de variables exógenas incluida en la Tabla 5-2 para modelos PR y en la Tabla 5-12 para $\mathrm{PD})$.

Como se puede apreciar, existen bastantes correlaciones, todas ellas bastante evidentes, como las que se dan entre distancias, tiempos y costes de viaje (o sus variaciones). Pero además aparece correlación, también bastante predecible a priori, entre la probabilidad de que el usuario vuelva a viajar en autobús y que recomiende dicho viaje a familiares o amigos. En cualquier caso, se ha verificado que estas correlaciones no afectan al correcto funcionamiento de los modelos a calibrar.

\section{Modelos Genéricos para Todos los Usuarios}

En primer lugar, al igual que se procedió para los submodelos de satisfacción, se han probado diversas modelizaciones sin variaciones por tipo de usuario, es decir, incluyendo únicamente las características del servicio, de modo que los modelos resultantes sean válidos para cualquier usuario. Así, se obtendrán unos modelos preliminares, más simplificados que los que se expondrán en puntos posteriores, incluyendo variaciones sistemáticas en los gustos.

En primer lugar, para evaluar el correcto funcionamiento de los datos recogidos en la encuesta, se calibraron unos modelos sencillos para la encuesta piloto, todos ellos de tipo logit multinomial (MNL), dada la necesidad de obtención de resultados sencillos. A la vista de los resultados, concluimos que, en general, los resultados obtenidos son relativamente correctos, a pesar del escaso número de observaciones recogidas en la experiencia piloto. Así pues, se dio por válido el diseño, únicamente con las correcciones citadas en el capítulo anterior.

A continuación, presentamos un resumen de los resultados de la modelización realizada a partir de los datos recogidos en la encuesta definitiva, de acuerdo con la codificación de variables expuesta en la Tabla 5-2 para los datos de PR y en la Tabla 5-12 para los de PD. Se han calibrado diversos modelos tanto de tipo logit multinomial (MNL) como logit jerárquico (HL), a fin de determinar qué tipología se adaptaba mejor a nuestros datos.

Los resultados de algunos de los mejores modelos de tipo logit multinomial calibrados se presentan en la Tabla 5-13. Al igual que en apartados anteriores, únicamente se expondrán en ellas las variables que han resultado significativas para los modelos presentados. El 
primero de ellos, denominado MNL-1, considera todas las variables genéricas para los tres modos de transporte disponibles, a excepción de la constante específica y ciertas características únicas de determinados modos (como el tipo de autobús, por ejemplo). El resto van diferenciando los parámetros por modo de transporte, aportando mayor riqueza, aunque también más complejidad, al modelo.

Tabla 5-13. Modelos de demanda (logit multinomial) genéricos para todos los usuarios

\begin{tabular}{|c|c|c|c|c|c|c|c|c|}
\hline \multirow{2}{*}{ VARIABLE } & \multicolumn{2}{|c|}{ MNL-1 } & \multicolumn{2}{|c|}{ MNL-2 } & \multicolumn{2}{|c|}{ MNL-3 } & \multicolumn{2}{|c|}{ MNL-4 } \\
\hline & Parámetro & Test-t & Parámetro & Test-t & Parámetro & Test-t & Parámetro & Test-t \\
\hline CTEBUS & $-0,5353$ & $-4,49$ & & & & & & \\
\hline CTECOCHE & & & 0,4217 & 1,99 & 0,4808 & 2,09 & 0,5267 & 2,29 \\
\hline TBUS & $-1,5339$ & $-14,45$ & $-1,5286$ & $-14,13$ & $-1,5348$ & $-14,11$ & $-1,4505$ & $-12,81$ \\
\hline TCOCHE & $-1,5339$ & $-14,45$ & $-1,5286$ & $-14,13$ & $-1,6537$ & $-7,50$ & $-1,6313$ & $-7,42$ \\
\hline TTREN & $-1,5339$ & $-14,45$ & $-1,5286$ & $-14,13$ & $-1,5348$ & $-14,11$ & $-1,7350$ & $-12,76$ \\
\hline CBUS & $-0,1108$ & $-13,26$ & $-0,1498$ & $-10,72$ & $-0,1552$ & $-9,53$ & $-0,1737$ & $-9,76$ \\
\hline CCOCHE & $-0,1108$ & $-13,26$ & $-0,1235$ & $-10,25$ & $-0,1168$ & $-7,48$ & $-0,1193$ & $-7,63$ \\
\hline CTREN & $-0,1108$ & $-13,26$ & $-0,1103$ & $-11,52$ & $-0,1131$ & $-10,76$ & $-0,0957$ & $-8,04$ \\
\hline NSBUS & 0,0907 & 7,76 & 0,0974 & 7,70 & 0,0947 & 7,10 & 0,1076 & 7,61 \\
\hline NSTREN & 0,0907 & 7,76 & 0,0974 & 7,70 & 0,0947 & 7,10 & 0,1076 & 7,61 \\
\hline DBUSGC & 0,0010 & 1,11 & 0,0018 & 1,96 & 0,0017 & 1,93 & 0,0017 & 1,89 \\
\hline RUTANUBU & 0,9305 & 6,23 & 0,8359 & 4,44 & 0,8554 & 4,48 & 0,7805 & 4,05 \\
\hline RUTANUCO & 0,9305 & 6,23 & 0,8227 & 2,17 & 0,7709 & 2,00 & 0,7261 & 1,87 \\
\hline$I^{*}(\theta)$ & \multicolumn{2}{|c|}{$-918,6$} & \multicolumn{2}{|c|}{$-910,2$} & \multicolumn{2}{|c|}{$-910,0$} & \multicolumn{2}{|c|}{$-905,9$} \\
\hline$I^{*}(\mathrm{C})$ & \multicolumn{2}{|c|}{$-1.269,4$} & \multicolumn{2}{|c|}{$-1.269,4$} & \multicolumn{2}{|c|}{$-1.269,4$} & \multicolumn{2}{|c|}{$-1.269,4$} \\
\hline
\end{tabular}

Como se puede apreciar en ella, en todos los modelos se ha optado por mantener la variable relativa a la tipología de autobús, a pesar de su, en ocasiones, escasa significatividad, de acuerdo con los criterios descritos en la Tabla 4-9, sobre reglas de buena práctica. El resto de variables, también de acuerdo con la citada Tabla, al no ser consideradas de igual relevancia que éstas, sólo se han incluido en función de su nivel de significatividad.

Lo primero que se observa en ellas es que, a diferencia de los calibrados con datos de PR para la simulación de la satisfacción global del usuario, el coste del viaje sí es aquí un parámetro relevante. Así pues, parece suceder que, a pesar de que un individuo cualquiera no aprecia demasiado el precio del billete a la hora de evaluar la calidad del viaje, sí considera dicha circunstancia a la hora de decidir si emplea uno u otro modo de transporte.

Por el contrario, podemos comprobar que, mientras en los modelos de satisfacción el tipo de autobús era una variable muy importante, aquí ya no lo es tanto. De hecho, únicamente resulta significativa cuando se la combina (multiplica) con la distancia de viaje, de modo 
que, sólo en viajes largos resulta relevante una variable correspondiente a si el viaje se realiza en "gran clase" o no.

Respecto a los modelos de tipo logit jerárquico (HL), en todos ellos se ha creado una estructura arbórea con un único nido agrupando las alternativas de transporte público -autobús y ferrocarril- y otra rama directa para el vehículo privado. Sin embargo, se ha verificado que los parámetros $\Phi$, definidos según la formulación descrita en el punto 4.2, no resultaban estadísticamente distintos de la unidad, por lo que los modelos colapsarían a otros más simplificados, de tipo logit multinomial (MNL), volviendo a resultados similares a los expuestos en la Tabla 5-13. Por tanto, se ha optado por desechar esta tipología de modelos, al concluirse que las alternativas de transporte público -autobús y tren- son efectivamente independientes entre sí, y no es conveniente agruparlas en un único nido.

Así pues, concluimos este apartado destacando que las variables que resultaban más relevantes para configurar la satisfacción general del usuario respecto del viaje realizado no tienen una relación directa con aquéllas que le harían volver a realizarlo en autobús. Por tanto, ésta será una circunstancia a tener muy en cuenta a la hora de determinar las variables más importantes sobre las que actuar.

Para tratar de adaptar los resultados a las características particulares de cada individuo, a continuación se tratará de encontrar modelos que incluyan variables específicas del usuario, que permitan un mejor ajuste a los datos observados.

\section{Modelos con Variaciones en los Gustos de los Usuarios}

Además de los modelos anteriores, al igual que se hizo con la modelización de la satisfacción global percibida por el usuario, se han calibrado también modelos incorporando variaciones sistemáticas en los gustos de los usuarios, que se adaptan con más realismo a los valores observados. Ellos, se incluirán no sólo variables relativas al funcionamiento de cada modo de transporte considerado -vehículo privado, autobús y ferrocarril-, sino también al entrevistado, aisladas o interaccionando con otras, a fin de determinar cuáles inciden en mayor medida en la elección modal.

Para ello, en primer lugar, en la Tabla 5-14 se indica el significado de las nuevas variables que aparecen en estos modelos. Se desea hacer notar, sin embargo, que todas las posibles interacciones han sido probadas, seleccionando únicamente aquéllas que aportan información a los modelos y cumplen las condiciones expuestas en el punto 4.2. 
Tabla 5-14. Relación de variables incluidas en los modelos de demanda con variaciones sistemáticas en los gustos de los usuarios

\begin{tabular}{|c|c|c|}
\hline VARIABLE & DESCRIPCIÓN & VALORES \\
\hline JO*CTEBUS & $\begin{array}{l}\text { Interacción entre edad joven y constante } \\
\text { específica del modo autobús }\end{array}$ & $\begin{array}{c}\text { JO: } 0 \text { - >24; } 1 \text { - } \leq 24 \\
\text { CTEBUS: } 0 \text { - coche ó ferrocarril; } 1 \text { - autobús }\end{array}$ \\
\hline UV*CTECOCHE & $\begin{array}{l}\text { Interacción entre disponibilidad familiar de un } \\
\text { vehículo y constante específica del modo coche }\end{array}$ & $\begin{array}{l}\text { UV: } 0 \text { - no vehículos; } 1 \text { - } 1 \text { ó más veh. } \\
\text { CTECOCHE: } 0 \text { - autobús ó ferrocarril; } 1 \text { - coche }\end{array}$ \\
\hline SE*CTETREN & $\begin{array}{c}\text { Interacción entre género y constante específica } \\
\text { del modo tren }\end{array}$ & $\begin{array}{c}\text { SE: } 0 \text { - mujer; } 1 \text { - hombre } \\
\text { CTETREN: } 0 \text { - autobús ó coche; } 1 \text { - ferrocarril }\end{array}$ \\
\hline DV*CTETREN & $\begin{array}{l}\text { Interacción entre alta motorización familiar y } \\
\text { constante específica del modo tren }\end{array}$ & $\begin{array}{c}\text { DV: } 0 \text { - } 0 \text { ó } 1 \text { veh.; } 1 \text { - } 2 \text { ó más veh } \\
\text { CTETREN: } 0 \text { - autobús ó coche; } 1 \text { - ferrocarril }\end{array}$ \\
\hline SE*TBUS & Interacción entre género y tiempo de viaje & $\begin{array}{c}\text { SE: } 0 \text { - mujer; } 1 \text { - hombre } \\
\text { TBUS: } h\end{array}$ \\
\hline $\begin{array}{c}\text { AC*TBUS } \\
\text { AC*TCOCHE } \\
\text { AC*TTREN }\end{array}$ & $\begin{array}{c}\text { Interacción entre actividad económica y tiempo de } \\
\text { viaje }\end{array}$ & $\begin{array}{c}\text { AC: } 1 \text { - trabajador/estudiante; } 0 \text { - otros casos } \\
\text { TBUS, TCOCHE, TTREN: } h\end{array}$ \\
\hline $\begin{array}{c}U^{*}{ }^{*} \text { TBUS } \\
\text { UV*TCOCHE } \\
\text { UV*TTREN }\end{array}$ & $\begin{array}{l}\text { Interacción entre disponibilidad familiar de un } \\
\text { vehículo y tiempo de viaje }\end{array}$ & $\begin{array}{l}\text { UV: } 0 \text { - no vehículos; } 1 \text { - } 1 \text { ó más veh. } \\
\text { TBUS, TCOCHE, TTREN: } h\end{array}$ \\
\hline $\begin{array}{c}\text { ANC*TBUS } \\
\text { ANC*TCOCHE } \\
\text { ANC*TTREN }\end{array}$ & Interacción entre $3^{a}$ edad y tiempo de viaje & $\begin{array}{l}\text { ANC: } 0-<65 ; 1-\geq 65 \\
\text { TBUS, TCOCHE, TTREN: } h\end{array}$ \\
\hline $\begin{array}{c}\text { JO*CBUS } \\
\text { JO*CCOCHE } \\
\text { JO*CTREN }\end{array}$ & Interacción entre edad joven y coste del viaje & $\begin{array}{c}\text { JO: } 0 \text { - >24; } 1 \text { - } \leq 24 \\
\text { CBUS, CCOCHE, CTREN: } €\end{array}$ \\
\hline $\begin{array}{l}\text { SE*NSBUS } \\
\text { SE*NSTREN }\end{array}$ & $\begin{array}{l}\text { Interacción entre género y número diario de } \\
\text { expediciones }\end{array}$ & $\begin{array}{l}\text { SE: } 0 \text { - mujer; } 1 \text { - hombre } \\
\text { NSBUS, NSTREN: ud. }\end{array}$ \\
\hline $\begin{array}{l}\text { ANC*NSBUS } \\
\text { ANC*NSTREN }\end{array}$ & $\begin{array}{c}\text { Interacción entre } 3^{\mathrm{a}} \text { edad y número diario de } \\
\text { expediciones }\end{array}$ & $\begin{array}{l}\text { ANC: } 0 \text { - <65; } 1 \text { - } \geq 65 \\
\text { NSBUS, NSTREN: ud. }\end{array}$ \\
\hline ANC*BUSS & $\begin{array}{c}\text { Interacción entre } 3^{\mathrm{a}} \text { edad y bus seminuevo (frente } \\
\text { a antiguo }\end{array}$ & $\begin{array}{l}\text { ANC: } 0 \text { - <65; } 1 \text { - } \geq 65 \\
\text { BUSS: } 0 \text { - no; } 1 \text { - sí }\end{array}$ \\
\hline $\begin{array}{l}\text { DV*RUTANUBU } \\
\text { DV*RUTANUCO }\end{array}$ & $\begin{array}{l}\text { Interacción entre alta motorización familiar y } \\
\text { proporc. de la ruta realizada en autopista/autovía }\end{array}$ & $\begin{array}{l}\text { DV: } 0 \text { - } 0 \text { ó } 1 \text { veh.; } 1 \text { - } 2 \text { ó más veh } \\
\text { RUTANUBU, RUTANUCO: tanto por uno }\end{array}$ \\
\hline $\begin{array}{l}\text { JO*RUTANUBU } \\
\text { JO*RUTANUCO }\end{array}$ & $\begin{array}{l}\text { Interacción entre edad joven y proporción de la } \\
\text { ruta realizada en autopista/autovía }\end{array}$ & $\begin{array}{c}\text { JO: } 0 \text { - >24; } 1 \text { - } \leq 24 \\
\text { RUTANUBU, RUTANUCO: tanto por uno }\end{array}$ \\
\hline
\end{tabular}

De nuevo, se han tenido en cuenta las posibles correlaciones entre variables, expuestas Es importante considerar las correlaciones existentes entre variables. Éstas han sido expuestas en la Tabla 5-1 para los modelos de satisfacción y en la Tabla 5-11 para los de demanda. A pesar de que, efectivamente, hay correlaciones importantes, se ha comprobado la no existencia simultánea en un mismo modelo de correlaciones importantes, lo que invalidaría las hipótesis de los modelos de tipo logit multinomial y logit jerárquico.

En primer lugar, la Tabla 5-15 muestra los modelos de tipo logit multinomial calibrados con variaciones sistemáticas en los gustos. 
Modelización de la Interrelación entre las Variables de Servicio y la Demanda de Viajeros de Autobuses de Tipo Interurbano

Tabla 5-15. Modelos de demanda (logit multinomial) con variaciones en los gustos de los usuarios

\begin{tabular}{|c|c|c|c|c|c|c|c|c|}
\hline \multirow{2}{*}{ VARIABLE } & \multicolumn{2}{|c|}{ MNL-5 } & \multicolumn{2}{|c|}{ MNL-6 } & \multicolumn{2}{|c|}{ MNL-7 } & \multicolumn{2}{|c|}{ MNL-8 } \\
\hline & Parámetro & Test-t & Parámetro & Test-t & Parámetro & Test-t & Parámetro & Test-t \\
\hline CTEBUS & & & & & $-0,4539$ & $-3,46$ & $-0,4195$ & $-1,82$ \\
\hline CTECOCHE & & & 0,5687 & 4,72 & & & & \\
\hline JO*CTEBUS & & & & & $-0,4553$ & $-2,52$ & & \\
\hline DV*CTETREN & & & & & $-0,3666$ & $-2,04$ & & \\
\hline TBUS & $-0,5651$ & $-2,61$ & $-0,6226$ & $-2,84$ & $-0,6289$ & $-2,87$ & $-0,7450$ & $-3,19$ \\
\hline TCOCHE & $-0,5651$ & $-2,61$ & $-0,6226$ & $-2,84$ & $-0,6289$ & $-2,87$ & $-0,9854$ & $-3,36$ \\
\hline TTREN & $-0,5651$ & $-2,61$ & $-0,6226$ & $-2,84$ & $-0,6289$ & $-2,87$ & $-0,9125$ & $-3,55$ \\
\hline SE*TBUS & & & & & & & 0,1384 & 1,65 \\
\hline AC*TBUS & $-0,4556$ & $-2,18$ & $-0,4430$ & $-2,13$ & $-0,4253$ & $-2,04$ & $-0,4955$ & $-2,31$ \\
\hline AC*TCOCHE & $-0,4556$ & $-2,18$ & $-0,4430$ & $-2,13$ & $-0,4253$ & $-2,04$ & $-0,4955$ & $-2,31$ \\
\hline AC*TTREN & $-0,4556$ & $-2,18$ & $-0,4430$ & $-2,13$ & $-0,4253$ & $-2,04$ & $-0,4955$ & $-2,31$ \\
\hline UV*TBUS & $-0,8047$ & $-3,56$ & $-0,6373$ & $-2,77$ & $-0,6500$ & $-2,83$ & $-0,4995$ & $-2,00$ \\
\hline UV*TCOCHE & $-0,8047$ & $-3,56$ & $-0,6373$ & $-2,77$ & $-0,6500$ & $-2,83$ & $-0,4995$ & $-2,00$ \\
\hline UV*TTREN & $-0,8047$ & $-3,56$ & $-0,6373$ & $-2,77$ & $-0,6500$ & $-2,83$ & $-0,4995$ & $-2,00$ \\
\hline ANC*TBUS & $-2,4593$ & $-2,55$ & $-2,7622$ & $-2,70$ & $-2,2749$ & $-2,63$ & $-3,1436$ & $-2,92$ \\
\hline ANC*TCOCHE & $-2,4593$ & $-2,55$ & $-2,7622$ & $-2,70$ & $-2,2749$ & $-2,63$ & $-3,1436$ & $-2,92$ \\
\hline ANC*TTREN & $-2,4593$ & $-2,55$ & $-2,7622$ & $-2,70$ & $-2,2749$ & $-2,63$ & $-3,1436$ & $-2,92$ \\
\hline CBUS & $-0,1160$ & $-14,78$ & $-0,1141$ & $-14,51$ & $-0,1152$ & $-14,60$ & $-0,1850$ & $-10,00$ \\
\hline CCOCHE & $-0,1160$ & $-14,78$ & $-0,1141$ & $-14,51$ & $-0,1152$ & $-14,60$ & $-0,1285$ & $-7,38$ \\
\hline CTREN & $-0,1160$ & $-14,78$ & $-0,1141$ & $-14,51$ & $-0,1152$ & $-14,60$ & $-0,1159$ & $-8,63$ \\
\hline SE*CTREN & & & & & & & 0,0308 & 2,94 \\
\hline JO*CCOCHE & & & & & & & 0,0274 & 2,90 \\
\hline NSBUS & 0,0703 & 6,11 & 0,1024 & 7,54 & 0,0931 & 7,87 & 0,0926 & 5,23 \\
\hline NSTREN & 0,0703 & 6,11 & 0,1024 & 7,54 & 0,0931 & 7,87 & 0,1666 & 5,78 \\
\hline SE*NSBUS & $-0,0299$ & $-1,97$ & $-0,0280$ & $-1,81$ & & & $-0,0347$ & $-1,76$ \\
\hline SE*NSTREN & $-0,0299$ & $-1,97$ & $-0,0280$ & $-1,81$ & & & $-0,0347$ & $-1,76$ \\
\hline ANC*NSBUS & 0,1061 & 1,70 & 0,0943 & 1,48 & & & 0,2160 & 2,71 \\
\hline ANC*NSTREN & 0,1061 & 1,70 & 0,0943 & 1,48 & & & & \\
\hline ANC*BUSS & 1,0802 & 1,93 & 1,2971 & 2,24 & 1,3568 & 2,59 & & \\
\hline DBUSGC & & & 0,0013 & 1,47 & 0,0011 & 1,24 & 0,0020 & 2,22 \\
\hline RUTANUBU & & & & & & & 1,8647 & 4,50 \\
\hline RUTANUCO & & & & & & & 1,6976 & 4,22 \\
\hline DV*RUTANUBU & 0,4289 & 2,27 & 0,3570 & 1,83 & & & & \\
\hline DV*RUTANUCO & 0,4289 & 2,27 & 0,3570 & 1,83 & & & & \\
\hline JO*RUTANUBU & 0,4227 & 2,36 & 0,3719 & 2,03 & 0,8494 & 3,19 & & \\
\hline JO*RUTANUCO & 0,4227 & 2,36 & 0,3719 & 2,03 & 0,8494 & 3,19 & & \\
\hline$I^{*}(\theta)$ & -911 & & -90 & & -899 & & -88 & \\
\hline$I^{*}(C)$ & -1269 & & -126 & & -126 & & -126 & \\
\hline
\end{tabular}

Por otra parte, la Tabla 5-16 muestra los de tipo logit jerárquico, que en este caso, sí han resultado factibles, al obtenerse parámetros $\Phi$, definidos según la formulación descrita en el punto 4.2, estadísticamente distintos de la unidad. La estructura arbórea definida ha sido 
la conformada por un solo nido, agrupando las alternativas de transporte público -autobús y ferrocarril-, y una rama directa para el vehículo privado.

Tabla 5-16. Modelos de demanda (logit jerárquico) con variaciones en los gustos de los usuarios

\begin{tabular}{|c|c|c|c|c|c|c|c|c|}
\hline \multirow{2}{*}{ VARIABLE } & \multicolumn{2}{|c|}{ HL-1 } & \multicolumn{2}{|c|}{ HL-2 } & \multicolumn{2}{|c|}{ HL-3 } & \multicolumn{2}{|c|}{ HL-4 } \\
\hline & Parámetro & Test-t & Parámetro & Test-t & Parámetro & Test-t & Parámetro & Test-t \\
\hline CTEBUS & & & & & 0,7729 & 4,38 & $-0,3647$ & $-1,42$ \\
\hline CTECOCHE & 0,4303 & 1,90 & 0,4559 & 2,72 & & & & \\
\hline $\mathrm{UV}^{*} \mathrm{CTECOCHE}$ & & & & & 1,1083 & 4,71 & & \\
\hline TBUS & $-0,6926$ & $-2,98$ & $-0,5880$ & $-2,60$ & $-0,5250$ & $-2,29$ & $-0,6886$ & $-2,96$ \\
\hline TCOCHE & $-0,5950$ & $-1,56$ & $-0,5880$ & $-2,60$ & $-1,0917$ & $-3,02$ & $-0,5727$ & $-1,44$ \\
\hline TTREN & $-0,6926$ & $-2,98$ & $-0,5880$ & $-2,60$ & $-0,5250$ & $-2,29$ & $-0,6886$ & $-2,96$ \\
\hline SE*TBUS & & & & & & & 0,1812 & 2,11 \\
\hline$A C * T B U S$ & $-0,5566$ & $-2,31$ & $-0,5471$ & $-2,36$ & $-0,6240$ & $-2,48$ & $-0,5910$ & $-2,44$ \\
\hline $\mathrm{AC} \star \mathrm{TCOCHE}$ & $-0,5566$ & $-2,31$ & $-0,5471$ & $-2,36$ & $-0,6240$ & $-2,48$ & $-0,5910$ & $-2,44$ \\
\hline AC*TTREN & $-0,5566$ & $-2,31$ & $-0,5471$ & $-2,36$ & $-0,6240$ & $-2,48$ & $-0,5910$ & $-2,44$ \\
\hline UV*TBUS & $-0,6103$ & $-2,41$ & $-0,7237$ & $-2,95$ & $-0,7512$ & $-3,00$ & $-0,6370$ & $-2,55$ \\
\hline UV*TCOCHE & $-0,6103$ & $-2,41$ & $-0,7237$ & $-2,95$ & & & $-0,6370$ & $-2,55$ \\
\hline UV*TTREN & $-0,6103$ & $-2,41$ & $-0,7237$ & $-2,95$ & $-0,7512$ & $-3,00$ & $-0,6370$ & $-2,55$ \\
\hline ANC*TBUS & $-3,3291$ & $-2,92$ & $-1,8898$ & $-2,39$ & $-1,9528$ & $-2,42$ & $-3,4238$ & $-3,06$ \\
\hline ANC ${ }^{*} \mathrm{TCOCHE}$ & $-3,3291$ & $-2,92$ & $-2,2151$ & $-2,36$ & $-2,2079$ & $-2,45$ & $-3,4238$ & $-3,06$ \\
\hline ANC*TTREN & $-3,3291$ & $-2,92$ & $-1,5665$ & $-1,88$ & $-1,6350$ & $-1,93$ & $-3,4238$ & $-3,06$ \\
\hline CBUS & $-0,1731$ & $-10,49$ & $-0,1588$ & $-10,10$ & $-0,1607$ & $-10,00$ & $-0,1810$ & $-9,69$ \\
\hline$\overline{\mathrm{CCOCHE}}$ & $-0,1249$ & $-12,81$ & $-0,1191$ & $-12,74$ & $-0,1189$ & $-12,60$ & $-0,1246$ & $-7,25$ \\
\hline CTREN & $-0,1249$ & $-12,81$ & $-0,1191$ & $-12,74$ & $-0,1189$ & $-12,60$ & $-0,1296$ & $-10,38$ \\
\hline SE*CTREN & 0,0225 & 3,01 & 0,0208 & 2,76 & 0,0204 & 2,71 & 0,0362 & 3,35 \\
\hline JO*CBUS & & & $-0,0510$ & $-3,92$ & $-0,0530$ & $-3,86$ & & \\
\hline JO*CCOCHE & 0,0269 & 2,98 & & & & & 0,0262 & 2,80 \\
\hline JO*CTREN & & & $-0,0510$ & $-3,92$ & $-0,0530$ & $-3,86$ & & \\
\hline NSBUS & 0,0738 & 4,62 & 0,0977 & 7,62 & 0,0995 & 7,01 & 0,0912 & 4,84 \\
\hline NSTREN & 0,1594 & 5,73 & 0,0977 & 7,62 & 0,0995 & 7,01 & 0,1702 & 5,82 \\
\hline ANC*NSBUS & 0,1952 & 2,56 & 1,3259 & 2,29 & & & 0,2021 & 2,66 \\
\hline SE*NSBUS & & & & & & & $-0,0404$ & $-1,96$ \\
\hline SE*NSTREN & & & & & & & $-0,0404$ & $-1,96$ \\
\hline ANC*BUSS & & & & & 1,3187 & 2,23 & & \\
\hline DBUSGC & 0,0021 & 2,16 & 0,0021 & 2,23 & 0,0022 & 2,24 & 0,0022 & 2,23 \\
\hline RUTANUBU & 1,6133 & 4,86 & 0,8012 & 4,17 & & & 1,9281 & 4,42 \\
\hline RUTANUCO & 1,1696 & 3,26 & 0,8012 & 4,17 & & & 1,5846 & 4,06 \\
\hline$\Phi_{\text {tte. público }}$ & 0,8756 & 10,24 & 0,9000 & 22,61 & 0,8439 & 9,08 & 0,8776 & 10,25 \\
\hline$I^{*}(\theta)$ & -883, & & -882 & & -881 & & -88 & \\
\hline$I^{*}(C)$ & -1269 & & -126 & & -126 & & -126 & \\
\hline
\end{tabular}

El nivel de confianza seleccionado en ambas ha sido de un 85-90\%, excepto en determinadas variables consideradas especialmente relevantes, que, de acuerdo con los criterios expuestos en la Tabla 4-9, se han admitido con niveles ligeramente inferiores. 
Dada la gran cantidad de interacciones consideradas, únicamente figuran en dichas tablas aquéllas que han resultado significativas y con sentido correcto.

Observando los resultados expuestos en ellas, la primera conclusión que cabe extraer es la gran similitud existente entre todos los modelos calibrados. Así, además de las variables de servicio de cada modo, aparecen de forma recurrente ciertas interacciones con características del entrevistado. Por ejemplo, los individuos que trabajan o estudian valoran de forma más especial su tiempo, al igual que aquéllos cuya familia dispone de, al menos, un vehículo privado y el grupo de mayor edad.

Respecto al coste del viaje, que resulta posiblemente la variable más relevante para la elección modal, podemos concluir que los jóvenes la perciben de modo diferente al resto de entrevistados. Así, penalizan el precio del billete del autobús y del ferrocarril, mientras que favorecen al vehículo privado en el mismo criterio. También los usuarios de sexo masculino consideran no tan grave el coste del viaje en su coche.

En cuanto al número de servicios diarios de los modos de transporte público -autobús y ferrocarril-, parece que los entrevistados de mayor edad lo consideran más relevante que el resto. Por el contrario, los hombres lo valoran menos que las mujeres. Por otro lado, el hecho de que el trayecto discurra por autopista o autovía es considerado más importante por los jóvenes y por los miembros de familias con alta tasa de motorización (mayor o igual a 2 vehículos).

Por último, en cuanto a la antigüedad y equipamiento del autobús, sólo aparece de forma aislada en los modelos cuando está interaccionando con la distancia del viaje, lo que indica de nuevo que únicamente es relevante en viajes largos. Sólo los usuarios de mayor edad consideran positivo que el autobús sea seminuevo (o mejor) en cualquier trayecto.

Para finalizar, analizando las variables relativas al individuo que aparecen de forma aislada, vemos que, obviamente, los entrevistados con vehículo privado disponible otorgan mayor utilidad a dicho modo. De nuevo, los jóvenes penalizan en especial al autobús, en cualquiera de las condiciones de uso, mientras que los individuos procedentes de familias con mayor tasa de motorización consideran peor el viaje en tren.

Vemos, de nuevo, los modelos con variaciones sistemáticas en los gustos aportan una mayor información, al enriquecer la visión obtenida con los modelos genéricos. Aunque aquéllos siguen siendo especialmente útiles cuando se trata de buscar conclusiones generales, válidas para todos los usuarios. Por ello, los genéricos serán los empleados para analizar la relación entre satisfacción de los usuarios y demanda del servicio. 


\section{Evaluación y Selección de Modelos}

Al igual que se hizo en los modelos de satisfacción, en el presente apartado se tratará de determinar, qué modelos reflejan de manera más correcta el comportamiento de los usuarios. El objetivo final será, de nuevo, la elección del modelo más representativo para su empleo en apartados posteriores.

Como ya se ha indicado en puntos anteriores, la bondad de los modelos de elección discreta se estudia habitualmente ciertos indicadores, como pueden ser los siguientes:

\section{1) Test-t de significatividad de los parámetros.}

Los estadísticos $t$, calculados según la expresión (4-17), representan de forma cuantitativa la significatividad de los parámetros. Así, si este valor es superior a 1,65, el parámetro asociado será estadísticamente significativo para un nivel de confianza del $90 \%$ y, si es mayor a 1,96, para un nivel de confianza del 95\%. En general, se puede comprobar que, en los modelos calibrados, todas las variables son estadísticamente significativas para niveles de confianza superiores a un $85-90 \%$, excepto determinadas variables de política consideradas especialmente necesarias, que se han incluido aun siendo no significativas, de acuerdo con los criterios expuestos en la Tabla 4-9, sobre reglas de buena práctica.

2) Test de razón de verosimilitud y test de ajuste general.

El test de razón de verosimilitud es útil cuando se desea comparar un modelo con otro obtenido como una versión restringida del primero, mediante transformaciones lineales. El test de ajuste general es un caso particular del mismo cuando se toma como modelo restringido el equiprobable, en el que las utilidades de todas las alternativas son nulas, o bien el de sólo constantes, que reproduce a la perfección las proporciones de mercado observadas en la muestra. Sin embargo, dada la escasa representatividad del test cuando se emplea como modelo restringido el equiprobable (ya que sólo en muy raras ocasiones no se cumple), es más empleado el modelo de sólo constantes para verificar la bondad de nuestro modelo [111].

Como se ha indicado en capítulos anteriores, denominando respectivamente $l^{*}(0)$ y $l^{*}(C)$ a los valores de log-verosimilitud para estos modelos equiprobable y de sólo constantes, los estadísticos a comprobar serán $-2\left[l^{*}(0)-l^{*}(\theta)\right]$ y $-2\left[l^{*}(C)-l^{*}(\theta)\right]$. Ambos distribuirán asintóticamente $\chi^{2}$ con $k$ y $k-c$ grados de libertad, 
respectivamente, siendo $k$ el número de atributos del modelo completo y $c$ el número de constantes específicas [111]. Comparando estos valores con la distribución $\chi^{2}$ para un determinado nivel de confianza, se obtiene como resultado si el modelo completo es estadísticamente diferente de los reducidos.

En la Tabla 5-17 se presentan los valores correspondientes a dicho test, tomando como modelo restringido es de sólo constantes. En ella observamos que todos los modelos verifican este test. Sin embargo, esto únicamente que indica que se adaptan mejor a los datos disponibles que el modelo de sólo constantes, por lo que es un datos que no nos permite aún inferir cuál modelo es mejor de entre los calibrados.

Tabla 5-17. Modelos de demanda - test de ajuste general

\begin{tabular}{cccccccc}
\hline MODELO & $\mathbf{I}^{*}(\boldsymbol{\theta})$ & $\mathbf{I}^{*}(\mathbf{C})$ & $\mathbf{k}$ & $\mathbf{c}$ & $\mathbf{- 2}\left[\mathbf{I}^{*}(\mathbf{C})-I^{*}(\boldsymbol{\theta})\right]$ & $\mathbf{X} \mathbf{2}(\mathbf{k}-\mathbf{c}, 95 \%)$ & TEST OK \\
\hline MNL-1 & $-918,6$ & $-1269,4$ & 6 & 2 & 701,6 & 9,5 & $\checkmark$ \\
\hline MNL-2 & $-910,2$ & $-1269,4$ & 9 & 2 & 718,4 & 14,1 & $\checkmark$ \\
\hline MNL-3 & $-910,0$ & $-1269,4$ & 10 & 2 & 718,8 & 15,5 & $\checkmark$ \\
\hline MNL-4 & $-905,9$ & $-1269,4$ & 11 & 2 & 726,9 & 16,9 & $\checkmark$ \\
\hline MNL-5 & $-911,6$ & $-1269,4$ & 11 & 2 & 715,6 & 16,9 & $\checkmark$ \\
\hline MNL-6 & $-900,0$ & $-1269,4$ & 13 & 2 & 738,7 & 19,7 & $\checkmark$ \\
\hline MNL-7 & $-899,2$ & $-1269,4$ & 12 & 2 & 740,4 & 18,3 & $\checkmark$ \\
\hline MNL-8 & $-881,3$ & $-1269,4$ & 20 & 2 & 776,2 & 28,9 & $\checkmark$ \\
\hline HL-1 & $-883,4$ & $-1269,4$ & 17 & 2 & 771,9 & 25,0 & $\checkmark$ \\
\hline HL-2 & $-882,5$ & $-1269,4$ & 16 & 2 & 773,7 & 23,7 & $\checkmark$ \\
\hline HL-3 & $-881,1$ & $-1269,4$ & 17 & 2 & 776,5 & 25,0 & $\checkmark$ \\
\hline HL-4 & $-881,7$ & $-1269,4$ & 20 & 2 & 775,3 & 28,9 & $\checkmark$ \\
\hline
\end{tabular}

3) Índice $\rho^{2}$.

El índice $\rho^{2}$ es un indicador que tratar de simular al coeficiente $\mathrm{R}^{2}$ de una regresión, oscilando entre 0 , para indicar un ajuste nulo, hasta 1 , para indicar un ajuste perfecto. Las expresiones (4-19) y (4-20) nos permiten calcular su valor, teniendo como referencia el modelo equiprobable o el de sólo constantes.

Como ya se ha indicado en el capítulo anterior, el índice $\hat{\rho}^{2}$ obtenido con el modelo de sólo constantes, tiene relación con la distribución $\chi^{2}$, de modo que puede ser empleado en tests de hipótesis. Además, tiene la ventaja de que es comparable entre distintas muestras, por lo que resulta más útil a la hora de establecer rankings entre modelos.

En la Tabla 5-18 se presentan los valores correspondientes a dicho test. A la vista de los resultados expuestos en la misma, observamos en primer lugar que los modelos que 
incluyen variaciones sistemáticas en los gustos de los entrevistados son los que entregan un mejor índice y, en general, los de tipo logit jerárquico.

Tabla 5-18. Modelos de demanda - índice $\rho^{2}$

\begin{tabular}{ccccc}
\hline MODELO & $I^{*}(\theta)$ & $I^{*}(\mathbf{C})$ & $\hat{\rho}^{2}$ & RANKING \\
\hline MNL-1 & $-918,6$ & $-1269,4$ & 0,276 & $12^{\circ}$ \\
\hline MNL-2 & $-910,2$ & $-1269,4$ & 0,283 & $10^{\circ}$ \\
\hline MNL-3 & $-910,0$ & $-1269,4$ & 0,283 & $9^{\circ}$ \\
\hline MNL-4 & $-905,9$ & $-1269,4$ & 0,286 & $8^{\circ}$ \\
\hline MNL-5 & $-911,6$ & $-1269,4$ & 0,282 & $11^{\circ}$ \\
\hline MNL-6 & $-900,0$ & $-1269,4$ & 0,291 & $7^{0}$ \\
\hline MNL-7 & $-899,2$ & $-1269,4$ & 0,292 & $6^{\circ}$ \\
\hline MNL-8 & $-881,3$ & $-1269,4$ & 0,306 & $2^{\circ}$ \\
\hline HL-1 & $-883,4$ & $-1269,4$ & 0,304 & $5^{\circ}$ \\
\hline HL-2 & $-882,5$ & $-1269,4$ & 0,305 & $4^{0}$ \\
\hline HL-3 & $-881,1$ & $-1269,4$ & 0,306 & $1^{\circ}$ \\
\hline HL-4 & $-881,7$ & $-1269,4$ & 0,305 & $3^{\circ}$ \\
\hline
\end{tabular}

\section{4) Test FPR (first preference recovery).}

El porcentaje correctamente predicho representa la proporción de observaciones en que la alternativa de máxima utilidad -y, por tanto, de máxima probabilidad de elección- es la efectivamente seleccionada por el entrevistado.

Sin embargo, como ya se ha indicado en puntos anteriores, es un concepto intuitivo y sencillo, pero de interpretación engañosa. Por lo tanto, es necesario comparar la proporción de respuestas correctamente predichas de nuestro modelo con su esperanza de acierto y con la probabilidad de éxito de otro modelo sencillo, como el equiprobable. A medida que el test FPR se acerque a su esperanza de éxito y supere a la probabilidad de acierto del modelo equiprobable, considerando además los valores de sus varianzas, el modelo calibrado tendrá un mejor ajuste [59]. Dichos valores se obtienen de la formulación expuesta en las expresiones (4-21) y (4-22).

En la Tabla 5-19 se presentan los valores correspondientes a dicho test (los resultados predictivos del modelo, necesarios para su cálculo, se presentan en el Anexo 4). Considerando los resultados expuestos en ella, observamos que todos los modelos son correctos según esta comprobación, ya que en todos ellos el valor del test FPR es del orden de magnitud de ER, y bastante superior a CR, considerando sus varianzas [59]. Además, observamos que los valores de porcentaje correctamente predicho son muy elevados, rondando en todos los casos el $75 \%$. En general, observamos que los modelos 
de tipo logit jerárquico aportan mayor éxito predictivo que los de tipo multinomial. Dentro de éstos últimos, no queda clara la mejora obtenida con la inclusión de variaciones sistemáticas en los gustos de los usuarios -sí en los modelos con estructura anidada-.

Tabla 5-19. Modelos de demanda - test FPR

\begin{tabular}{ccccccc}
\hline MODELO & CR & $\operatorname{Var}$ (CR) & ER & $\operatorname{Var}($ ER) & FPR & TEST OK \\
\hline MNL-1 & 0,5 & 0,250 & 0,807 & 0,132 & 0,740 & $\checkmark$ \\
\hline MNL-2 & 0,5 & 0,250 & 0,812 & 0,130 & 0,743 & $\checkmark$ \\
\hline MNL-3 & 0,5 & 0,250 & 0,812 & 0,130 & 0,743 & $\checkmark$ \\
\hline MNL-4 & 0,5 & 0,250 & 0,814 & 0,129 & 0,745 & $\checkmark$ \\
\hline MNL-5 & 0,5 & 0,250 & 0,807 & 0,131 & 0,739 & $\checkmark$ \\
\hline MNL-6 & 0,5 & 0,250 & 0,812 & 0,129 & 0,744 & $\checkmark$ \\
\hline MNL-7 & 0,5 & 0,250 & 0,812 & 0,129 & 0,745 & $\checkmark$ \\
\hline MNL-8 & 0,5 & 0,250 & 0,818 & 0,126 & 0,750 & $\checkmark$ \\
\hline HL-1 & 0,5 & 0,250 & 0,816 & 0,127 & 0,750 & $\checkmark$ \\
\hline HL-2 & 0,5 & 0,250 & 0,816 & 0,127 & 0,750 & $\checkmark$ \\
\hline HL-3 & 0,5 & 0,250 & 0,816 & 0,127 & 0,750 & $\checkmark$ \\
\hline HL-4 & 0,5 & 0,250 & 0,816 & 0,127 & 0,750 & $\checkmark$ \\
\hline
\end{tabular}

5) Índice de éxito predictivo.

La tabla de éxito predictivo del modelo, con $\mathrm{N}^{*} \mathrm{~N}$ celdas, donde $\mathrm{N}$ es el número de alternativas de elección del modelo diseñado, contiene en sus columnas las predicciones del modelo y, en las filas, las elecciones observadas en la muestra. El sumatorio por filas coincidirá con el número de entrevistados que eligieron una determinada alternativa $\mathrm{y}$, por columnas, la misma cantidad pero predicha por el modelo. Los elementos de la diagonal son las observaciones en las que la elección predicha coincide con la observada, deduciéndose de su proporción con respecto al total el test FPR.

A partir de dicha tabla se puede obtener el índice de éxito predictivo, habitualmente denotado como $\sigma$, así como sus valores máximo $\sigma_{\text {máx }}$ y normalizado $\sigma_{\text {norm }}$, que nos dan una medida de bondad de ajuste con significado similar al test FPR, pero válida para comparar modelos diferentes. Dichos valores se obtienen a partir de la expresión $(4-23)$.

La Tabla 5-20 muestra los resultados de dicho índice (las tablas completas de éxito predictivo de cada modelo se incluyen en el Anexo 4), tanto en su valor nominal como normalizado de 0 a 1 , que permite comparar los distintos modelos calibrados. 
Modelización de la Interrelación entre las Variables de Servicio y la Demanda de Viajeros de Autobuses de Tipo Interurbano

Tabla 5-20. Modelos de demanda - indice de éxito predictivo

\begin{tabular}{ccccc}
\hline MODELO & $\boldsymbol{\sigma}$ & $\sigma_{\text {máx }}$ & $\sigma_{\text {norm }}$ & RANKING \\
\hline MNL-1 & 0,180 & 0,440 & 0,409 & $11^{\circ}$ \\
\hline MNL-2 & 0,184 & 0,441 & 0,417 & $10^{\circ}$ \\
\hline MNL-3 & 0,184 & 0,441 & 0,417 & $9^{\circ}$ \\
\hline MNL-4 & 0,186 & 0,441 & 0,421 & $6^{\circ}$ \\
\hline MNL-5 & 0,166 & 0,426 & 0,389 & $12^{\circ}$ \\
\hline MNL-6 & 0,186 & 0,442 & 0,420 & $8^{\circ}$ \\
\hline MNL-7 & 0,186 & 0,441 & 0,421 & $7^{0}$ \\
\hline MNL-8 & 0,191 & 0,440 & 0,433 & $2^{\circ}$ \\
\hline HL-1 & 0,192 & 0,442 & 0,434 & $1^{\circ}$ \\
\hline HL-2 & 0,191 & 0,441 & 0,433 & $4^{\circ}$ \\
\hline HL-3 & 0,191 & 0,441 & 0,433 & $3^{\circ}$ \\
\hline HL-4 & 0,190 & 0,440 & 0,431 & $5^{\circ}$ \\
\hline
\end{tabular}

En ella volvemos a detectar que, en general, los modelos con variaciones sistemáticas en los gustos dan mejor resultado que los genéricos. También de nuevo vemos que los de tipo logit jerárquico predicen con mayor realidad las observaciones de la muestra que los multinomiales.

Una vez calculados los índices correspondientes a cada uno de los test probados, únicamente resta la elección de un mejor modelo de cada tipo, que se empleará en fases posteriores del estudio. En primer lugar, en la Tabla 5-21 se presenta un resumen de las clasificaciones entre modelos obtenidas según los distintos índices verificados.

Tabla 5-21. Modelos de demanda - resumen de test de bondad

\begin{tabular}{|c|c|c|c|c|c|c|}
\hline \multirow[b]{2}{*}{ MODELO } & \multicolumn{4}{|c|}{ RANKING PARCIALES } & \multirow{2}{*}{$\begin{array}{c}\text { MEDIA } \\
\text { PONDERADA }\end{array}$} & \multirow{2}{*}{$\begin{array}{c}\text { RAKING } \\
\text { FINAL }\end{array}$} \\
\hline & $\begin{array}{l}\text { Ajuste } \\
\text { General }\end{array}$ & Índice $\rho^{2}$ & FPR & $\begin{array}{c}\text { Índice } \\
\text { éxito pred. }\end{array}$ & & \\
\hline MNL-1 & $12^{\circ}$ & $12^{\circ}$ & $11^{\circ}$ & $11^{\circ}$ & 11,3 & $11^{\circ}$ \\
\hline MNL-2 & $9^{\circ}$ & $10^{\circ}$ & $10^{\circ}$ & $10^{\circ}$ & 9,6 & $10^{\circ}$ \\
\hline MNL-3 & $10^{\circ}$ & $9^{\circ}$ & $9^{\circ}$ & $9^{0}$ & 8,9 & $9^{\circ}$ \\
\hline MNL-4 & $8^{\circ}$ & $8^{\circ}$ & $6^{0}$ & $6^{0}$ & 6,0 & $6^{0}$ \\
\hline MNL-5 & $11^{\circ}$ & $11^{\circ}$ & $12^{\circ}$ & $12^{\circ}$ & 11,5 & $12^{\circ}$ \\
\hline MNL-6 & $7^{\circ}$ & $7^{\circ}$ & $8^{\circ}$ & $8^{\circ}$ & 8,3 & $8^{\circ}$ \\
\hline MNL-7 & $6^{\circ}$ & $6^{0}$ & $7^{0}$ & $7^{0}$ & 6,5 & $7^{0}$ \\
\hline MNL-8 & $3^{\circ}$ & $2^{0}$ & 10 & $2^{0}$ & 3,1 & $2^{\circ}$ \\
\hline $\mathrm{HL}-1$ & $4^{\circ}$ & $5^{\circ}$ & $3^{\circ}$ & 10 & 3,5 & $3^{0}$ \\
\hline HL-2 & $2^{\circ}$ & $4^{0}$ & $4^{\circ} / 5^{\circ}$ & $4^{0}$ & 4,0 & $5^{\circ}$ \\
\hline HL-3 & 10 & $1^{0}$ & $2^{\circ}$ & $3^{\circ}$ & 1,5 & $1^{0}$ \\
\hline $\mathrm{HL}-4$ & $5^{\circ}$ & $3^{0}$ & $4^{\circ} / 5^{\circ}$ & $5^{\circ}$ & 3,9 & $4^{0}$ \\
\hline
\end{tabular}

En ella se muestra la clasificación cualitativa estimada a partir de los distintos criterios considerados, y el ranking global, obtenido a partir de la media ponderada de las 
anteriores, asignando peso unitario al test de ajuste general, doble al test FPR y al índice de éxito predictivo y triple al índice $\hat{\rho}^{2}$.

A la vista de los resultados, observamos que los modelos mejor situados en el ranking son los que incluyen variaciones sistemáticas en los gustos de los usuarios, entre los que se podría escoger como definitivo el denominado HL-3. Sin embargo, a efectos de la obtención de la disponibilidad al pago, el empleo de un modelo jerárquico dificulta sumamente la evaluación de los modos internos al nido, ya que sus utilidades serían condicionadas a haber escogido el transporte público. Por ello, resulta más conveniente emplear, para este fin, un modelo de tipo multinomial. Así, de entre los distintos calibrados, el mejor modelo sería el denominado MNL-8, que únicamente obtiene una puntuación algo inferior que el anterior en el test FPR. Por último, de entre los genéricos para todos los entrevistados, el modelo seleccionado para su uso en puntos posteriores será el denominado MNL-4, al ser el mejor de los cuatro en todos los criterios considerados.

\section{Disponibilidad al Pago}

Como última conclusión a los modelos de demanda, podemos calcular la disponibilidad al pago, que, como se ha indicado en capítulos anteriores, es un concepto íntimamente relacionado con el valor subjetivo del tiempo, y cuya determinación resulta muy importante para la elección modal, ya que los usuarios tratarán de encontrar la alternativa menos "cara", incluyendo en términos monetarios su valoración del tiempo y de las comodidades.

El valor subjetivo del tiempo representa, en cierto modo, la capacidad que tiene un individuo de pagar una cierta cantidad por un determinado ahorro de tiempo. Éste puede ser inferido directamente de modelos de elección discreta [81], aunque es importante tener en cuenta que la especificación de los mismos influirá fuertemente los resultados obtenidos [53]. Las variables que influyen en el mismo son muy numerosas, aunque suelen aparecer de forma recurrente: las relacionadas con las características socioeconómicas del individuo (ingresos y tiempo disponible, son aspectos fundamentales) y las relacionadas con el viaje (motivo del viaje, modo de transporte, incomodidades asociadas...).

En cuanto a la obtención analítica del valor del tiempo, como ya se ha indicado en el capítulo anterior, si se dispone de una función de utilidad $V$ previamente calibrada, se puede obtener una valoración cuantitativa del mismo. Así, dado que nuestra formulación 
ha sido de tipo lineal, podemos obtener el precio que el usuario medio estaría dispuesto a pagar por determinados cambios sobre las variables de entrada del modelo sin más que aplicar las ecuaciones (4-35) y (4-36). Es decir, la disponibilidad al pago de cada variable sería la relación (en las unidades que corresponda) entre el estimador de su parámetro y el del coste del viaje, para cada modo considerado.

Además, dado que los parámetros $\theta$ empleados aquí son estimadores de sus valores reales, será necesaria la inclusión de test y comprobaciones de nivel de confianza para el valor subjetivo del tiempo hallado con ellos. Así, Jara-Díaz et al [78] proponen una formulación sencilla para obtener un pseudo-estadístico $t$ de los valores de disponibilidad al pago obtenidos a partir de las ecuaciones (4-35) y (4-36). La expresión relativa al valor subjetivo del tiemplo es la presenta en la ecuación (4-40).

Por tanto, considerando como modelo óptimo de entre los genéricos para todos los usuarios, el denominado MNL-4, según lo descrito en puntos anteriores, podemos calcular los valores de disponibilidades al pago de las diferentes variables que aparecen en el mismo y sus pseudo-estadísticos $t$. Los resultados de dicho proceso se muestran en la Tabla 5-22, donde se indica, para cada modo de transporte considerado, el precio que el usuario estaría dispuesto a pagar por mejorar cada variable.

Tabla 5-22. Disponibilidad al pago (usuario medio) por mejoras en las variables de servicio

\begin{tabular}{|c|c|c|c|c|}
\hline MODO & VARIABLE & $\begin{array}{l}\text { DISPONIBILIDAD } \\
\text { AL PAGO }\end{array}$ & UNIDAD & DESCRIPCIÓN \\
\hline \multirow{4}{*}{ AUTOBÚS } & TBUS & $\begin{array}{l}8,35 \\
(7,77)\end{array}$ & $€ / h$ & $\begin{array}{c}\text { Valor }(€) \text { que el usuario está dispuesto a pagar } \\
\text { por disminuir una hora el tiempo del viaje en } \\
\text { autobús }\end{array}$ \\
\hline & NSBUS & $\begin{array}{c}0,62 \\
(5,99)\end{array}$ & $€ /$ exped. & $\begin{array}{l}\text { Valor }(€) \text { que el usuario está dispuesto a pagar } \\
\text { por aumentar en una unidad el número diario de } \\
\text { servicios del autobús }\end{array}$ \\
\hline & RUTANUBU & $\begin{array}{l}0,045 \\
(3,75)\end{array}$ & $€ / \%$ & $\begin{array}{l}\text { Valor }(€) \text { que el usuario está dispuesto a pagar } \\
\text { por aumentar en un punto el porcentaje de ruta } \\
\text { del autobús que se realiza por vías rápidas }\end{array}$ \\
\hline & DBUSGC & $\begin{array}{l}0,010 \\
(1,86) \\
\end{array}$ & $€ / \mathrm{km}$ & $\begin{array}{l}\text { Valor (€/km) que el usuario está dispuesto a } \\
\text { pagar por mejorar el autobús a "gran clase" }\end{array}$ \\
\hline \multirow{2}{*}{ COCHE } & TCOCHE & $\begin{array}{l}13,68 \\
(5,30)\end{array}$ & $€ / h$ & $\begin{array}{c}\text { Valor }(€) \text { que el usuario está dispuesto a pagar } \\
\text { por disminuir una hora el tiempo del viaje en } \\
\text { coche }\end{array}$ \\
\hline & RUTANUCO & $\begin{array}{l}0,042 \\
(1,82)\end{array}$ & $€ / \%$ & $\begin{array}{l}\text { Valor }(€) \text { que el usuario está dispuesto a pagar } \\
\text { por aumentar en un punto el porcentaje de ruta } \\
\text { del coche que se realiza por vías rápidas }\end{array}$ \\
\hline \multirow[b]{2}{*}{ TREN } & TTREN & $\begin{array}{l}18,14 \\
(6,80) \\
\end{array}$ & $€ / h$ & $\begin{array}{l}\text { Valor (€) que el usuario está dispuesto a pagar } \\
\text { por disminuir una hora el tiempo del viaje en tren }\end{array}$ \\
\hline & NSTREN & $\begin{array}{c}1,12 \\
(5,51)\end{array}$ & $€ /$ exped. & $\begin{array}{l}\text { Valor }(€) \text { que el usuario está dispuesto a pagar } \\
\text { por aumentar en una unidad el número diario de } \\
\text { servicios del tren }\end{array}$ \\
\hline
\end{tabular}


Por tanto, vemos que la disponibilidad al pago por disminución del tiempo de viaje oscila entre $8,3 € / \mathrm{h}$ para el autobús, $13,7 € / \mathrm{h}$ para el vehículo privado y $18,1 € / \mathrm{h}$ para el ferrocarril. Es decir, los usuarios del autobús valoran menos su tiempo de viaje que los del resto de modos, a pesar de resultan una variable sumamente relevante en los modelos de reparto modal.

En cuanto al número diario de expediciones, los usuarios del autobús estarían dispuestos a pagar $0,61 €$ por cada servicio añadido, frente a los 1,12 € por servicio del ferrocarril. Por otra parte, el valor subjetivo del tipo de ruta por carretera resulta muy similar para el autobús y el vehículo privado, siendo respectivamente de 0,045 y $0,042 €$ por cada punto porcentual de la misma realizado por vías rápidas.

Por último, en lo referente a las características del autobús interurbano empleado en el servicio de transporte público, los usuarios estarían dispuestos a pagar 0,010 € por cada kilómetro de distancia, si el vehículo se mejorara a otro de tipo "gran clase". Así por ejemplo, en un trayecto de unos $200 \mathrm{~km}$, dicha disponibilidad al pago sería de 1,98€.

Además, considerando los valores de los pseudo-estadísticos $t$, vemos que, en general, resultan bastante fiables, para niveles de confianza superiores al $90 \%$.

Por otra parte, si empleamos los modelos con variaciones sistemáticas en los gustos, dado que la formulación de las funciones de utilidad sigue siendo lineal, las disponibilidades al pago se pueden obtener igualmente a partir de la expresión (4-35), aunque empleando los parámetros relativos a cada clase de usuario. Así, basándonos en el modelo denominado MNL-8, la Tabla 5-23 muestra los resultados de las disponibilidades a pagar por ciertas mejoras en los servicios, para diferentes categorías de usuario (la descripción de cada variable aparece indicada en la Tabla 5-22). No se indica en este caso los valores de los pseudo-estadísticos $t$, ya que su determinación no es posible con la formulación indicada en la ecuación (4-40), al ser los valores finales función de varios estimadores adicionales de los parámetros relativos a la tipología de usuario.

Como vemos en ella, hay determinadas variables en las que no se ha apreciado variación en función del tipo de usuario, como la proporción de la ruta que discurre por vías de alta capacidad (con valores de 0,10 € para el autobús y $0,17 €$ para el coche por cada punto porcentual) y la realización del trayecto en autobús "gran clase" (igual valor que en los modelos genéricos, es decir, $0,010 €$ por cada kilómetro de distancia). 
Tabla 5-23. Disponibilidad al pago (variaciones en los gustos) por mejoras en las variables de servicio

\begin{tabular}{|c|c|c|c|c|c|}
\hline $\begin{array}{c}\text { MODO Y } \\
\text { VARIABLE }\end{array}$ & & & TIPO DE USUARIO & & $\begin{array}{l}\text { DISPONIBILIDAD } \\
\text { AL PAGO }\end{array}$ \\
\hline \multirow{16}{*}{ TBUS } & \multirow{8}{*}{ Hombre } & \multirow{4}{*}{$<=64$ años } & \multirow{2}{*}{ trabaja/estudia } & con vehículo & $8,66 € / \mathrm{h}$ \\
\hline & & & & sin vehículo & $5,96 € / h$ \\
\hline & & & \multirow{2}{*}{ no trabaja/estudia } & con vehículo & $5,98 € / h$ \\
\hline & & & & sin vehículo & $3,28 € / h$ \\
\hline & & \multirow{4}{*}{$>=65$ años } & \multirow{2}{*}{ trabaja/estudia } & con vehículo & $25,65 € / h$ \\
\hline & & & & sin vehículo & $22,95 € / h$ \\
\hline & & & \multirow{2}{*}{ no trabaja/estudia } & con vehículo & $22,97 € / h$ \\
\hline & & & & sin vehículo & $20,27 € / h$ \\
\hline & \multirow{8}{*}{ Mujer } & \multirow{4}{*}{$<=64$ años } & \multirow{2}{*}{ trabaja/estudia } & con vehículo & $9,41 € / h$ \\
\hline & & & & sin vehículo & $6,71 € / \mathrm{h}$ \\
\hline & & & \multirow{2}{*}{ no trabaja/estudia } & con vehículo & $6,73 € / h$ \\
\hline & & & & sin vehículo & $4,03 € / h$ \\
\hline & & \multirow{4}{*}{$>=65$ años } & \multirow{2}{*}{ trabaja/estudia } & con vehículo & $26,40 € / h$ \\
\hline & & & & sin vehículo & $23,70 € / h$ \\
\hline & & & \multirow{2}{*}{ no trabaja/estudia } & con vehículo & $23,72 € / h$ \\
\hline & & & & sin vehículo & $21,02 € / \mathrm{h}$ \\
\hline \multirow{8}{*}{ TCOCHE } & & \multirow{4}{*}{$<=64$ años } & \multirow{2}{*}{ trabaja/estudia } & con vehículo & $19,60 € / h$ \\
\hline & & & & sin vehículo & $14,66 € / h$ \\
\hline & & & \multirow{2}{*}{ no trabaja/estudia } & con vehículo & $14,70 € / h$ \\
\hline & & & & sin vehículo & $9,75 € / h$ \\
\hline & & \multirow{4}{*}{$>=65$ años } & \multirow{2}{*}{ trabaja/estudia } & con vehículo & $39,88 € / \mathrm{h}$ \\
\hline & & & & sin vehículo & $35,99 € / h$ \\
\hline & & & \multirow{2}{*}{ no trabaja/estudia } & con vehículo & $36,02 € / h$ \\
\hline & & & & sin vehículo & $32,14 € / \mathrm{h}$ \\
\hline \multirow{8}{*}{ TTREN } & & \multirow{4}{*}{$<=64$ años } & \multirow{2}{*}{ trabaja/estudia } & con vehículo & $22,43 € / h$ \\
\hline & & & & sin vehículo & $16,55 € / \mathrm{h}$ \\
\hline & & & motrongiolnotioli & con vehículo & $16,60 € / \mathrm{h}$ \\
\hline & & & no trabaja/estuala & sin vehículo & $10,73 € / h$ \\
\hline & & & trohaingctudin & con vehículo & $59,39 € / h$ \\
\hline & & -65 กี̃ก & trabaja/estudla & sin vehículo & $53,51 € / h$ \\
\hline & & $--0 s$ allus & no trohoioloctudi & con vehículo & $53,56 € / h$ \\
\hline & & & no trabaja/estuala & sin vehículo & $47,69 € / \mathrm{h}$ \\
\hline & Hombro & $<=64$ años & & & $0,31 € /$ exped. \\
\hline NSRUIS & Homore & $>=65$ años & & & 1,48 €/exped. \\
\hline NOBDUS & Mirg & $<=64$ años & & & $0,50 € /$ exped. \\
\hline & tiver & $>=65$ años & & & 1,67 €/exped. \\
\hline NCTPEN & Hombre & & & & $3,59 € /$ exped. \\
\hline NOIREN & Mujer & & & & 1,44 €/exped. \\
\hline RUTANUBU & & & & & $0,10 € / \%$ \\
\hline RUTANUCO & & & & & $0,17 € / \%$ \\
\hline DBUSGC & & & & & $0,01 € / \mathrm{km}$ \\
\hline
\end{tabular}


Otra variable con no demasiada variación en función de las características del entrevistado es el número diario de expediciones, para los modos de transporte público. Vemos que, en general, la disponibilidad al pago es mayor para el ferrocarril que para el autobús, al igual que en los modelos genéricos, y mayor para los hombres que para las mujeres. Así mismo, únicamente para los usuarios del autobús, también se aprecia diferencia entre la percepción de los entrevistados de mayor edad y el resto, estando los primeros más dispuestos a pagar un precio mayor si hubiera mayor frecuencia del servicio. Este hecho puede tener relación por su mayor dependencia de los servicios de transporte público.

Por último, la variable que más variaciones experimenta es el tiempo de viaje. Así, para los tres modos considerados, la disponibilidad al pago es mayor entre los usuarios de mayor edad, los que trabajan o estudian y los que forman parte de familias que disponen de vehículo privado. Además, únicamente para el autobús, las mujeres están dispuestas a pagar un mayor precio que los hombres por un viaje más rápido.

Teniendo en cuenta lo expresado por Gaudry et al [53], sobre el hecho de que la especificación del modelo influye fuertemente en los resultados de la disponibilidad al pago, se han calculado también los valores resultantes con el resto de modelos, tanto en el caso genérico como incorporando variaciones en los gustos. En términos generales, los valores obtenidos resultan del mismo orden de magnitud que los expuestos aquí, aunque obviamente con sensibles diferencias. Así, los valores indicados pueden ser útiles como aproximación media al pensamiento de los entrevistados, aunque no se pueden tomar como datos inequívocos.

En cualquier caso, se desea hacer notar que, en general, los valores obtenidos para la disponibilidad al pago en los modelos con variaciones sistemáticas en los gustos de los entrevistados, expuestos en la Tabla 5-23, son a grandes rasgos similares (o del mismo orden de magnitud) que los genéricos, presentados en la Tabla 5-22. Por tanto, a efectos de aplicación a los contratos de transporte, se considerarán válidos los valores genéricos, que facilitan su incorporación a la formulación propuesta. Además, la obtención de una metodología sencilla es un factor clave para la posterior aplicabilidad de la misma a casos reales.

A pesar de las interesantes conclusiones de Gálvez y Jara-Díaz [49], quienes afirman que no tiene por qué coincidir la valoración individual del tiempo con la evaluación del mismo que se debe tener en cuenta a efectos de planificación, y consideran el "peso" que éstas constituyen en la sociedad, a través de las contribuciones -impuestos- de los diferentes grupos sociales, se ha optado en este caso por considerar un peso igual para todos los 
ciudadanos, según el principio democrático de: "una persona - un voto" [96]. Además, dado que el ingreso no ha sido una variable relevante en nuestros modelos, finalmente podemos suponer que los valores obtenidos en las tablas anteriores sí son representativos del pensamiento general de la población, y calcular a partir de ellos los beneficios sociales que se darían bajo ciertas mejoras del servicio.

\section{Elasticidad de la Demanda del Servicio de Autobuses Interurbanos}

Como se ha indicado en el punto 4.2, los modelos de tipo logit multinomial tienen una característica especial que permite obtener de forma sencilla las elasticidades directa y cruzada de la demanda de un determinado modo de transporte respecto de cada variable independiente concreta.

Así, la elasticidad directa puntual, que es la variación de la probabilidad de elegir la alternativa $A_{i}$ respecto a una variación marginal en su atributo $x_{i k q}$, teniendo en cuenta la formulación habitualmente lineal de las funciones de utilidad, viene dada por la expresión (4-7), mientras que las elasticidades cruzadas puntuales, o variación de la probabilidad de elegir la alternativa $A_{i}$ respecto a una variación marginal en un atributo de otra opción $x_{j k q}$, se obtienen de la expresión (4-8). Una conclusión destacable de ésta última es que las elasticidades puntuales cruzadas cuando se modifica un atributo de la alternativa $A_{j}$, según el modelo logit multinomial, son independientes de la alternativa $A_{i}$ elegida y, por tanto, iguales para todas. Este resultado, aparentemente ilógico, se debe a la necesidad de suponer funciones IID en la generación del modelo [111].

Sin embargo, los cálculos relativos a este punto se han realizado mediante el enfoque de enumeración muestral, al disponer de una base de datos con todas las observaciones de la muestra, y considerarse ésta representativa del sentir general de los usuarios. Para ello, en primer lugar, se han estimado las proporciones de mercado actuales de la muestra a partir de los modelos seleccionados. Así, se han calculado las utilidades de cada modo para cada usuario, y promediando los valores de las probabilidades obtenidas, el resultado es la proporción de mercado estimada para cada modo (un resumen de los cálculos efectuados se adjunta en el Anexo 5). Los resultados resumidos se presentan en la Tabla 5-24.

Tabla 5-24. Proporciones estimadas de elección modal
\begin{tabular}{cccc}
\hline MODELO & $\mathbf{P}_{\text {bus }}$ & $\mathbf{P}_{\text {coche }}$ & $\mathbf{P}_{\text {tren }}$ \\
\hline MNL-4 & 0,652 & 0,198 & 0,150 \\
\hline MNL-8 & 0,662 & 0,190 & 0,149 \\
\hline HL-3 & 0,589 & 0,272 & 0,139 \\
\hline
\end{tabular}


Vemos que los tres modelos seleccionados arrojan valores similares, de modo que en torno a un $60-65 \%$ de los entrevistados escogerían el autobús, un 20-25\% el coche y un $14-15 \%$ el tren. Como se ha indicado, estos valores han sido calculados mediante enumeración muestral.

A partir de ellos, el cálculo de la elasticidad se realizará introduciendo en los datos de entrada pequeñas modificaciones en las variables independientes, y recalculando estas proporciones de mercado mediante el mismo enfoque de enumeración muestral. Así, las elasticidades directas y cruzadas puntuales, se calculan a partir de la expresión (4-57). Sin embargo, las globales para toda la muestra resultarán:

$$
E_{P_{i}, x_{i k}}=\frac{\partial P_{i} / P_{i}}{\partial x_{i k} / x_{i k}} \approx \frac{\Delta P_{i} / P_{i}}{\Delta x_{i k} / x_{i k}} \quad ; \quad E_{P_{i}, x_{j k}}=\frac{\partial P_{i} / P_{i}}{\partial x_{j k} / x_{j k}} \approx \frac{\Delta P_{i} / P_{i}}{\Delta x_{j k} / x_{j k}}
$$

Donde, $\mathrm{E}_{\mathrm{Pi} \text {,xik: }}$ elasticidad directa de la demanda del modo i respecto de su atributo k-ésimo

$\mathrm{E}_{\mathrm{Pi}, \mathrm{xjk}}$ : elasticidad cruzada de la demanda del modo i respecto del atributo k-ésimo de otro modo $\mathrm{j}$

$\mathrm{P}_{\mathrm{i}}$ : probabilidad de empleo de la alternativa $\mathrm{i}$

$\mathrm{x}_{\mathrm{ik}}$ : atributo k-ésimo de la alternativa $\mathrm{i}$

A partir de dicha formulación, la Tabla 5-25 muestra los resultados obtenidos para las diferentes variables independientes consideradas. Las variables con elasticidad positiva son aquéllas tales que, al aumentar su valor, crece la demanda del servicio de autobuses.

Tabla 5-25. Elasticidades de la demanda del servicio de autobuses interurbanos

\begin{tabular}{|c|c|c|c|c|c|c|c|c|c|c|}
\hline \multirow[b]{2}{*}{ MODO } & \multirow[b]{2}{*}{ VARIABLE } & \multicolumn{3}{|c|}{ ELAST. DIRECTA } & \multicolumn{3}{|c|}{$\begin{array}{c}\text { ELAST. CRUZADA } \\
\text { (COCHE) }\end{array}$} & \multicolumn{3}{|c|}{$\begin{array}{c}\text { ELAST. CRUZADA } \\
\text { (TREN) }\end{array}$} \\
\hline & & MNL-4 & MNL-8 & HL-3 & MNL-4 & MNL-8 & HL-3 & MNL-4 & MNL-8 & HL-3 \\
\hline \multirow{5}{*}{ 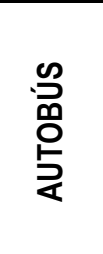 } & TBUS & $-0,71$ & $-0,73$ & $-0,74$ & & & & & & \\
\hline & CBUS & $-0,44$ & $-0,44$ & $-0,40$ & & & & & & \\
\hline & NSBUS & 0,15 & 0,13 & 0,11 & & & & & & \\
\hline & RUTANUBU & 0,042 & 0,093 & & & & & & & \\
\hline & BUS (dummy) & 0,023 & 0,025 & 0,028 & & & & & & \\
\hline \multirow{3}{*}{$\begin{array}{l}\text { 퐁 } \\
\text { O }\end{array}$} & TCOCHE & & & & 0,20 & 0,23 & 0,074 & & & \\
\hline & CCOCHE & & & & 0,14 & 0,13 & 0,17 & & & \\
\hline & RUTANUCO & & & & 0,042 & 0,093 & & & & \\
\hline \multirow{3}{*}{ 茎 } & TTREN & & & & & & & 0,39 & 0,36 & 0,31 \\
\hline & CTREN & & & & & & & 0,19 & 0,19 & 0,22 \\
\hline & NSTREN & & & & & & & $-0,063$ & $-0,085$ & $-0,056$ \\
\hline
\end{tabular}


Así, en la tabla observamos que por cada $1 \%$ que disminuyera el tiempo de viaje en autobús, la demanda del servicio aumentaría entre un $0,71 \%$ y un $0,74 \%$. Respecto a los otros modos, si su tiempo de viaje en coche y en ferrocarril aumentaran en un $1 \%$, la demanda del autobús interurbano aumentaría alrededor de un $0,20 \%$ y un $0,35 \%$ respectivamente.

En cuanto a los costes, un incremento del $1 \%$ en el precio del billete del autobús disminuiría su empleo alrededor de un 0,40-0,45\%. Por el contrario, si aumentara el coste del viaje en un $1 \%$ para el coche y el ferrocarril, la demanda del autobús crecería un $0,15 \%$ y un $0,20 \%$, en respectivas circunstancias.

Si tenemos en cuenta el número de expediciones diarias para los modos de transporte público, un incremento de un $1 \%$ en el número de servicios de autobús aumentaría su demanda entre un $0,13 \%$ y un $0,15 \%$, mientras que si lo que aumentara fueran las expediciones del ferrocarril, el empleo del autobús disminuiría un $0,07 \%$. Y considerando la proporción del trayecto realizada por vías de alta capacidad, un incremento de un $1 \%$ (relativo) generaría un aumento de uso del autobús interurbano de entre un 0,04\% y un $0,09 \%$.

Por último, atendiendo a las características del autobús empleado para el servicio, es una variable de tipo dummy en todas las formulaciones empleadas, por lo que el procedimiento cambia ligeramente. Así, se mejorara todos los autobuses un nivel (pasando los antiguos a seminuevos, los seminuevos a nuevos y los nuevos a "gran clase"), la demanda del servicio aumentaría alrededor de un $2,5 \%$.

Concluimos este apartado eligiendo uno de los modelos como representativo del comportamiento de los usuarios. Para ser coherentes con lo considerado en puntos anteriores, seleccionaremos como modelo óptimo el denominado MNL-8, cuyas elasticidades suelen estar en los rangos medios de las resultantes con los tres modelos. Con ellas se tratará de inferir los efectos de posibles acciones de mejora del servicio, para determinar el beneficio social resultante.

\subsubsection{Relación entre Satisfacción del Usuario y Elección Modal}

Para finalizar este punto, a continuación se compararán los resultados obtenidos en los submodelos de calidad y de demanda, a fin de identificar cuáles son las variables más relevantes en uno, otro o ambos simultáneamente. 
En primer lugar, se desean destacar los resultados expuestos en el punto 5.1, en el que se resumían los principales resultados del análisis estadístico de la muestra obtenida. En concreto, en la Figura 5-14 se mostraban los valores de la satisfacción global percibida por los usuarios, así como otras cuestiones relativas a su fidelidad al servicio [44]: probabilidad de que volvieran a emplearlo y si lo recomendarían a sus conocidos. Destacó entonces la gran apreciación global de la calidad por parte de los encuestados, al considerarla "buena" o "muy buena" más del 70\%. Sin embargo, respecto a la probabilidad de que volvieran a emplear el servicio si tuvieran disponible otro modo de transporte, sólo un $40 \%$ indica que lo haría.

Además, en la Figura 5-15 se mostraba un gráfico de dispersión, comparando los valores que cada entrevistado asignó a su satisfacción global con las variables de fidelidad anteriores. En ella que se observó que, a pesar de que sí existe relación positiva entre ellas, las rectas de regresión alcanzaban coeficientes $\mathrm{R}^{2}$ muy bajos, lo que indica una gran incertidumbre respecto a esta relación, en principio positiva.

Por tanto, teniendo en cuenta ambas cuestiones, pudimos concluir entonces que gran parte de los usuarios del servicio de autobús interurbano lo son en realidad porque no tienen otra alternativa y que, mejorando la satisfacción del usuario, la demanda del servicio podría aumentar en cierta medida, aunque no de forma tan directa como cabría esperar.

Por ello, recurriendo a la metodología expuesta en el punto 4.2 sobre evaluación de la interrelación entre calidad y demanda para las variables de servicio del transporte público en autobús interurbano, y tras la calibración de ambos submodelos, podemos diferenciar las variables como sigue, también recogida en la Figura 4-3:

Variables tipo 1: estadísticamente significativas tanto en el submodelo de satisfacción como en el de demanda. Las características del servicio aquí incluidas son relevantes tanto para configurar la percepción global del usuario como para fomentar su uso posterior. Así, son variables cuya mejora (o mantenimiento de una buena calidad) resulta especialmente interesante.

* Variables tipo 2: estadísticamente significativas en el submodelo de demanda, pero no así en el de satisfacción. Se incluirían aquí otras características del servicio que, a pesar de no mejorar la visión global del usuario del mismo, sí afectan a su elección modal, con lo que resultan también importantes si se desean potenciar el empleo del autobús interurbano. 
- Variables tipo 3: no estadísticamente significativas en el submodelo de demanda, pero sí en el de satisfacción. Estas variables mejoran la visión del servicio por parte del cliente, con lo que en cierto modo fidelizan al usuario, aunque no captan nuevos clientes potenciales.

Variables tipo 4: no estadísticamente significativas en ninguno de los modelos. Aquí estarían el resto de características, que serían las menos relevantes del servicio.

En nuestro caso de estudio, el modelo escogido como óptimo para la evaluación de la satisfacción global del usuario, de entre los genéricos, válidos para todos los usuarios, fue el denominado OP-4.1, a la vista de su gran regularidad en los test probados, así como por la aparición en él de determinadas variables consideraras "de política". Por otra parte, de entre los modelos de demanda, también considerando únicamente los genéricos para todos los usuarios, a fin de que sean comparables con los de satisfacción, el finalmente seleccionado ha sido el denominado MNL-4, al ser el mejor en todos los test calibrados, incluidos los índices de éxito predictivo y $\rho^{2}$. A modo de resumen, en la Tabla 5-26, se presentan los parámetros de sendos modelos (la descripción de cada variable se incluye en la Tabla 5-2 para el submodelo de satisfacción y en la Tabla 5-12 para el de demanda).

Tabla 5-26. Comparación de modelos de satisfacción y demanda genéricos para todos los usuarios

\begin{tabular}{|c|c|c|c|c|c|}
\hline \multicolumn{3}{|c|}{$\begin{array}{l}\text { Modelo de satisfacción OP-4.1 } \\
\text { (0 - muy mal o mal; } 1 \text { - regular; } 2 \text { - bien; } \\
3 \text { - muy bien) }\end{array}$} & \multicolumn{3}{|c|}{$\begin{array}{l}\text { Modelo de demanda MNL-4 } \\
\text { (0 - alternativa no escogida; } \\
1 \text { - alternativa seleccionada) }\end{array}$} \\
\hline VARIABLE & Parámetro & Test-t & VARIABLE & Parámetro & Test-t \\
\hline RETRASO & $-0,0289$ & $-2,56$ & CTECOCHE & 0,5267 & 2,29 \\
\hline NUMPARAD & $-0,0600$ & $-3,68$ & TBUS & $-1,4505$ & $-12,81$ \\
\hline AABUS & 0,2850 & 1,45 & TCOCHE & $-1,6313$ & $-7,42$ \\
\hline CONEXTTE & 0,3394 & 3,41 & TTREN & $-1,7350$ & $-12,76$ \\
\hline SITUACES & 0,2589 & 2,10 & CBUS & $-0,1737$ & $-9,76$ \\
\hline ATTCLIEN & 0,5120 & 4,36 & CCOCHE & $-0,1193$ & $-7,63$ \\
\hline BUSS & 0,8958 & 5,21 & CTREN & $-0,0957$ & $-8,04$ \\
\hline BUSN & 0,2893 & 2,59 & NSBUS & 0,1076 & 7,61 \\
\hline BUSGC & 0,5981 & 1,44 & NSTREN & 0,1076 & 7,61 \\
\hline VBUS & 0,0012 & 1,53 & DBUSGC & 0,0017 & 1,89 \\
\hline$\mu_{0}$ & $-\infty$ & -- & RUTANUBU & 0,7805 & 4,05 \\
\hline$\mu_{1}$ & 0 & -- & RUTANUCO & 0,7261 & 1,87 \\
\hline$\mu_{2}$ & 0,9999 & 14,15 & -- & -- & -- \\
\hline$\mu_{3}$ & 3,4388 & 34,23 & -- & -- & -- \\
\hline$\mu_{4}$ & $+\infty$ & -- & -- & -- & -- \\
\hline$I^{*}(\theta)$ & & & $I^{*}(\theta)$ & & \\
\hline$I^{*}(C)$ & & & $I^{*}(C)$ & & \\
\hline
\end{tabular}


A la vista de los resultados, y excluyendo las constantes específicas, ya que no aportan al modelo ninguna información (sólo se introducen en él para incorporar explicación a las variables ausentes), vemos que las variables que aparecen en los citados modelos son las siguientes:

* Variables tipo 1: estadísticamente significativas tanto en el submodelo de satisfacción como en el de demanda. Aparecen aquí las variables relativas a: la duración del viaje (directamente en el modelo de demanda y a través de la velocidad media de recorrido en el de satisfacción) y al hecho de que el autobús sea "gran clase" (interaccionando con la distancia de viaje en el modelo de demanda). Como se ha indicado antes, estas variables son las de mayor prioridad en cuanto a su mejora o mantenimiento de buenos estándares.

- Variables tipo 2: estadísticamente significativas en el submodelo de demanda, pero no así en el de satisfacción. Se incluyen aquí: los costes del viaje en cada modo considerado, el número diario de expediciones en los modos de transporte público y la proporción del viaje realizado por vías de alta capacidad en los modos de carretera. Estas variables, a pesar de no mejorar la percepción del usuario del servicio, sí influyen de forma importante en la demanda del mismo, por lo que son también relevantes para potenciar su empleo.

- Variables tipo 3: no estadísticamente significativas en el submodelo de demanda, pero sí en el de satisfacción. Tenemos aquí las siguientes características del viaje en autobús: retraso, número de paradas intermedias entre origen y destino, existencia de aire acondicionado en el vehículo, adecuada situación y conexión con el transporte urbano de la estación de autobuses, correcta atención al cliente y el hecho de que el autobús sea relativamente moderno. Estas variables mejoran la visión del servicio por parte del cliente, con lo que en cierto modo lo fidelizan, aunque no son útiles para captar nuevos usuarios.

* Variables tipo 4: no estadísticamente significativas en ninguno de los modelos. Aquí estarían las características menos relevantes del servicio, que serían el resto de las que aparecen en la Tabla 5-2 para el submodelo de satisfacción y en la Tabla 5-12 para el de demanda.

Por tanto, empleando la representación gráfica propuesta en el punto 4.2, podemos elaborar la Figura 5-16, en la que aparezcan los cuatro tipos de variables expuestos. En ella, en el caso de que las variables sean estadísticamente significativas, se confrontarán los test-t (en 
valor absoluto) obtenidos en ambos submodelos. Por tanto, los límites de zona se pueden establecer, por ejemplo, en los ejes de coordenadas, o en el valor mínimo admisible considerado para dicho test-t (en valor absoluto). Las variables situadas en el cuadrante superior derecho son las de mayor prioridad de mejora (mayor cuanto más próximas estén a la esquina superior derecha). Por el contrario, las variables de la cuarta zona son las menos relevantes.

Figura 5-16. Resultados de interrelación calidad-demanda para las variables de servicio

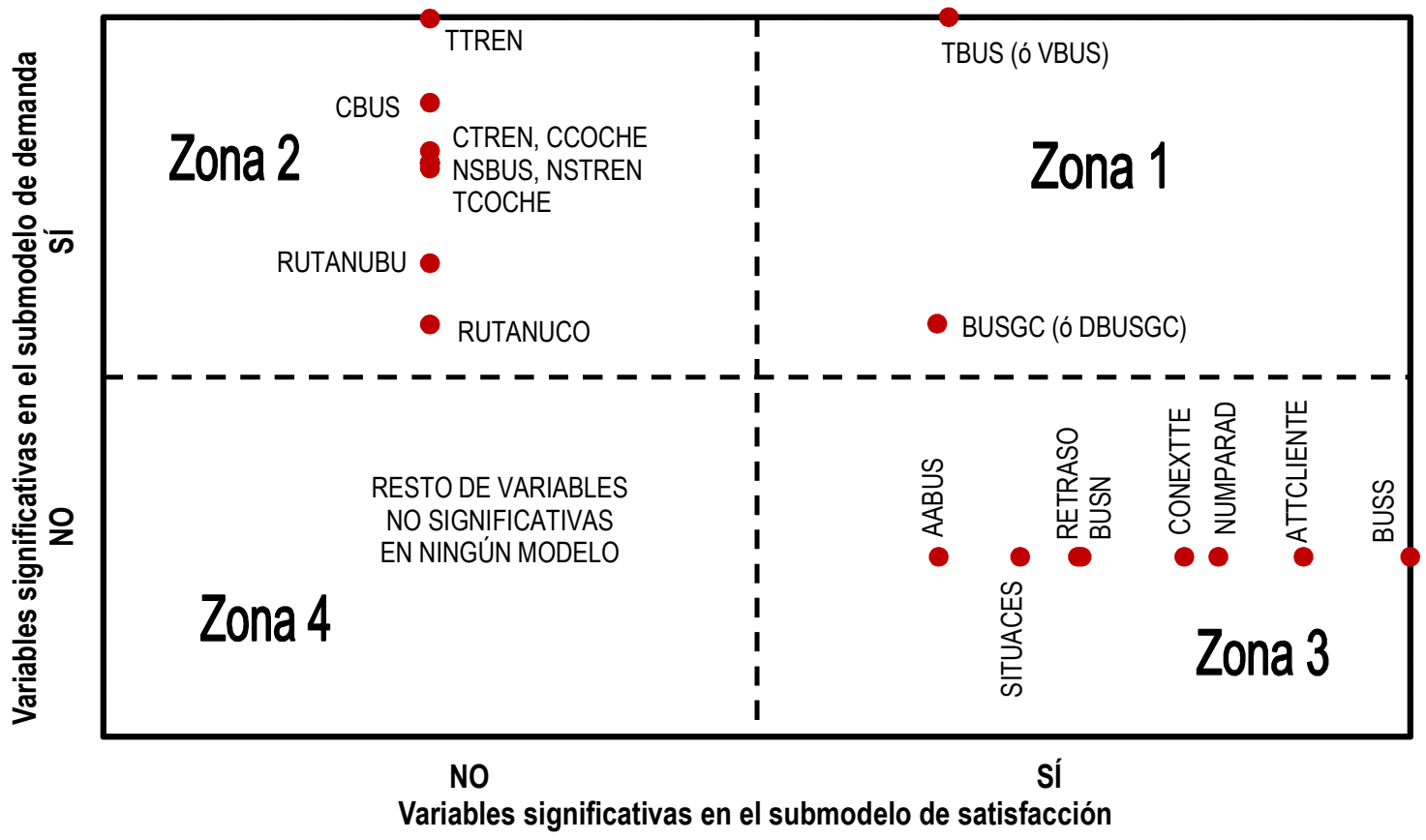

Así pues, finalizamos este punto simplemente remarcando de nuevo el hecho de que la duración el viaje (o su velocidad) y que el autobús sea de "gran clase" (interaccionando con la distancia para la elección modal) son variables relevantes tanto para la satisfacción de los usuarios como para la demanda del servicio. Otra serie de características son sólo relevantes para la demanda o para la satisfacción, mientras que hay también determinadas variables que no han resultado importantes en ninguno de los criterios.

Esta metodología nos permite clasificar fácilmente las variables de servicio en los cuatro tipos indicados anteriormente. Aunque en este caso ha sido empleada para la encuesta realizada en la estación de autobuses de la ciudad de Burgos, en relación al servicio de transporte interurbano en autobús, es extrapolable de forma sencilla a cualquier otro estudio que trate de inferir relaciones entre calidad y empleo de un determinado servicio, lo que la puede constituir como un método rápido y sencillo de detección de las variables más relevantes a la hora de mejorar la percepción del usuario. 


\subsection{Inclusión de Variables de Calidad en los Contratos de Transporte}

A continuación, se aplicará la metodología propuesta en el punto 4.3 al escenario de estudio, es decir, los viajes de tipo interurbano en autobús con origen o destino en la estación de autobuses de Burgos. Para ello, se emplearán los valores de elasticidades y disponibilidades al pago calculados en el punto anterior.

En concreto, se plantearán dos escenarios de estudio: uno primero en el que se analizará únicamente las líneas comprendidas en las rutas de transporte metropolitano del Alfoz, y otro a continuación que añadirá el resto de trayectos de competencia exclusiva de la Comunidad Autónoma de Castilla y León que prestan servicio en los municipios comprendidos en el área metropolitana. Los datos para ello han sido obtenidos, mayoritariamente, del Plan Coordinado de Explotación de Burgos y su Área Metropolitana, elaborado por la Junta de Castilla y León [87]. La relación de líneas contempladas se muestra en la Tabla 5-27, cuyos datos quedan más desglosados en el Anexo 6.

Como peculiaridades en ella, vemos que hay concesiones que incluyen un único trayecto, como la VACL-033, mientras que la mayoría están compuestas por varios. También es especialmente notable el caso de la línea metropolitana M3, cuya explotación es compartida entre las concesiones VACL-075 y VACL-079, que, además, son operadas por empresas diferentes.

A partir de estos datos de partida, se indicará a continuación, siguiendo los puntos expuestos en la propuesta metodológica, los valores a considerar para nuestro caso de estudio. Como ya se ha expuesto, el ámbito temporal será anual, en este caso con horizonte inicial en el 2009 (ya que son los últimos datos completos de que se dispone) y final en el 2010.

1) Demanda anual de pasajeros.

La demanda anual estimada en una situación hipotética de mejora de la calidad se puede obtener a partir de su valor inicial, y sus elasticidades con respecto a determinadas variables "clave" del servicio. Así, si dichas variables son la duración del viaje, el coste del billete, el número de expediciones diarias, la ruta seguida y las características del vehículo, la demanda futura se puede calcular a partir de la expresión (4-59), sin más que conocer las elasticidades. 
Tabla 5-27. Líneas incluidas en la aplicación de modificación de concesiones Fuente: Junta de Castilla y León [87]

\begin{tabular}{|c|c|c|}
\hline \multirow{2}{*}{ CONC. } & \multicolumn{2}{|r|}{ LÍNEA } \\
\hline & ID & RUTA \\
\hline \multirow{7}{*}{ VACL-001 } & 1 & Ibeas de Juarros - Urb. Tomillares - San Medel (M7) \\
\hline & 2 & Burgos - Pradoluengo \\
\hline & 3 & Burgos - Fresneda de la Sierra Tirón \\
\hline & 4 & Burgos - Arija \\
\hline & 5 & Burgos - Santander \\
\hline & 6 & Ubierna - Quintanaortuño - Sotopalacios - Vivar del Cid - Quintanilla Vivar (M5) \\
\hline & 7 & Burgos - Bilbao \\
\hline \multirow{2}{*}{ VACL-027 } & 8 & Burgos - Aranda de Duero \\
\hline & 9 & Burgos - Roa \\
\hline \multirow{7}{*}{ VACL-004 } & 10 & Arenillas de Río Pisuerga - Burgos \\
\hline & 11 & Villariezo - Arcos - Villagonzalo-Pedernales (M1) \\
\hline & 12 & Los Balbases - Burgos \\
\hline & 13 & Peral de Arlanza - Burgos \\
\hline & 14 & Santa María del Campo - Burgos \\
\hline & 15 & Tórtoles de Esgueva - Burgos \\
\hline & 16 & $\begin{array}{c}\text { Villamiel de Muñó - Albillos - Cayuela - Cavia - Buniel - Quintanilla de las } \\
\text { Carretas - San Mamés de Burgos - Villacienzo - Renuncio (M2) }\end{array}$ \\
\hline \multirow{2}{*}{ VACL-015 } & 17 & Burgos - Salas de Bureba \\
\hline & 18 & Riocerezo - Hurones - Villayerno Morquillas (M6) \\
\hline \multirow{3}{*}{ VACL-007 } & 19 & Caleruega - Burgos \\
\hline & 20 & Santillán del Agua - Burgos \\
\hline & 21 & $\begin{array}{c}\text { Sarracín - Ventas de Saldaña - Saldaña de Burgos - Cojóbar - Modúbar de la } \\
\text { Emparedada - Humienta - Olmosalbos - Revillarruz (M9) }\end{array}$ \\
\hline \multirow[t]{2}{*}{ VACL-010 } & 22 & $\begin{array}{c}\text { Castrillo del Val - Cardeñajimeno - Urb. Fuentes Blancas - Carcedo de Burgos - } \\
\text { Cardeñadijo (M8) }\end{array}$ \\
\hline & 23 & Jaramillo de la Fuente - Burgos \\
\hline \multirow{3}{*}{ VACL-019 } & 24 & Cervera de Pisuerga - Burgos \\
\hline & 25 & Santibáñez-Zarzaguda - Burgos \\
\hline & 26 & Villarmero - Sotragero - Arroyal - Quintanadueñas (M4) \\
\hline VACL-033 & 27 & Cuzcurrita de Juarros - Burgos \\
\hline \multirow{3}{*}{ VACL-075 } & 28 & Osorno - Burgos \\
\hline & 29 & Melgar de Fernamental - Burgos \\
\hline & 30 & Villalbilla de Burgos - Pol. Ind. Los Brezos (M3) \\
\hline \multirow{6}{*}{ VACL-079 } & 31 & Alar del Rey - Burgos \\
\hline & 32 & Frómista - Burgos \\
\hline & 33 & Grijalba - Burgos \\
\hline & 34 & Herrera de Pisuerga - Burgos \\
\hline & 35 & Sasamón - Burgos \\
\hline & 36 & Villadiego - Burgos \\
\hline VACL-116 & 37 & Burgos - Palencia \\
\hline
\end{tabular}


Simplificando al máximo el proceso, ya que el objetivo último es su fácil aplicación a las rutas interurbanas con origen o destino en Burgos, se tomarán como valores únicos de las elasticidades los correspondientes al modelo denominado MNL-8 en la Tabla 5-25. Así, finalmente la demanda estimada en los años futuros para una determinada línea será:

$$
\begin{aligned}
& V_{x}=V_{o x} \cdot\left(1-0,73 \cdot \frac{\Delta t_{x}}{t_{x}}\right) \cdot\left(1-0,44 \cdot \frac{\Delta c_{x}}{c_{x}}\right) . \\
& \cdot\left(1+0,13 \cdot \frac{\Delta N S_{x}}{N S_{x}}\right) \cdot\left(1+0,093 \cdot \frac{\Delta r u t a_{x}}{\text { ruta }_{x}}\right) \cdot\left(1+0,025 \cdot \Delta b u s_{x}\right)
\end{aligned}
$$

Donde, $\mathrm{V}_{\mathrm{x}}$ : demanda futura anual de la línea $\mathrm{x}$ del servicio de transporte interurbano en autobús

$\mathrm{V}_{\mathrm{ox}}$ : demanda anual actual de la línea $\mathrm{x}$ del servicio

$t_{x}$ : duración del viaje en la línea $x$

$\mathrm{c}_{\mathrm{x}}$ : coste del billete de la línea $\mathrm{x}$

$\mathrm{NS}_{\mathrm{x}}$ : número diario de expediciones (salidas) de la línea $\mathrm{x}$

ruta $_{\mathrm{x}}$ : proporción del trayecto realizado por vías de alta capacidad en la ruta $\mathrm{x}$ bus $_{\mathrm{x}}$ : variable dummy relativa a las características del vehículo de la línea $\mathrm{x}$

Por tanto, ya sólo restaría determinar los valores iniciales de la demanda de cada línea para poder estimar su variación y, por tanto, su resultado final tras posibles cambios en las 5 variables consideradas en los modelos. Dichos valores han sido obtenidos a partir de los datos publicados por la Junta de Castilla y León [87], estando explícitamente indicado el número de viajeros en el año 2009 para las líneas metropolitanas; el resto han sido inferidos a partir de sus valores anteriores y las estimaciones para dicho año. La demanda inicial de las líneas contempladas, junto con los parámetros actuales de la explotación, se muestran en la Tabla 5-28 (los valores actuales de las variables de servicio han sido determinados a partir de los observados en la encuesta, a fin de que la coherencia entre las partes del estudio sea máxima).

Además, se desea hacer notar que, a pesar de que hay operadores que explotan más de una concesión, este dato no es relevante para el estudio, ya que, como se verá más adelante, una condición que se impone es que cada concesión sea rentable económicamente por sí misma (o con ayuda de subvenciones por parte de la Administración). También se desea hacer constar que la demanda indicada son viajeros contabilizados en los tramos incluidos en el área metropolitana (de aquí que sus valores sean tan pequeños). 
Tabla 5-28. Demanda y situación inicial de las líneas metropolitanas y provinciales Fuente: Junta de Castilla y León [87]; elaboración propia

\begin{tabular}{|c|c|c|c|c|c|c|c|}
\hline \multirow[b]{2}{*}{ CONC. } & \multirow[b]{2}{*}{$\begin{array}{c}\text { ID } \\
\text { LÍNEA }\end{array}$} & \multicolumn{6}{|c|}{ EXPLOTACIÓN ACTUAL } \\
\hline & & $\begin{array}{c}\mathrm{V}_{\mathrm{o}} \\
\text { (viajeros/año) }\end{array}$ & $t(h)$ & $c(€)$ & $\begin{array}{c}\text { NS } \\
\text { (salidas/lab.) }\end{array}$ & $\begin{array}{l}\text { Prop. ruta } \\
\text { vías } \\
\text { rápidas }\end{array}$ & Tipo bus \\
\hline \multirow{7}{*}{ VACL-001 } & 1 & 23.670 & 0,50 & 0,52 & 4,4 & 0,24 & Seminuevo \\
\hline & 2 & 3.118 & 1,03 & 3,8 & 0,8 & 0,08 & Seminuevo \\
\hline & 3 & 6.805 & 1,08 & 3,25 & 1,2 & 0,08 & Seminuevo \\
\hline & 4 & 1.144 & 1,43 & 10 & 0,6 & 0,08 & Seminuevo \\
\hline & 5 & 7.454 & 2,17 & 11,1 & 2 & 0,59 & Nuevo \\
\hline & 6 & 13.430 & 0,75 & 0,52 & 3 & 0,00 & Seminuevo \\
\hline & 7 & 7.483 & 1,68 & 11,5 & 4 & 0,94 & Nuevo \\
\hline \multirow{2}{*}{ VACL-027 } & 8 & 11.807 & 0,90 & 7,5 & 4 & 0,93 & Nuevo \\
\hline & 9 & 1.074 & 1,10 & 7,05 & 1 & 0,64 & Seminuevo \\
\hline \multirow{7}{*}{ VACL-004 } & 10 & 336 & 0,72 & 10 & 1,1 & 0,82 & Seminuevo \\
\hline & 11 & 13.302 & 0,67 & 0,52 & 4 & 0,39 & Seminuevo \\
\hline & 12 & 336 & 0,52 & 8 & 1 & 0,87 & Seminuevo \\
\hline & 13 & 336 & 0,68 & 10 & 1 & 0,80 & Seminuevo \\
\hline & 14 & 1.208 & 0,60 & 3,8 & 2 & 0,69 & Seminuevo \\
\hline & 15 & 252 & 1,23 & 7,95 & 0,65 & 0,58 & Nuevo \\
\hline & 16 & 6.900 & 0,95 & 0,52 & 4 & 0,17 & Seminuevo \\
\hline \multirow{2}{*}{ VACL-015 } & 17 & 167 & 1,02 & 4,6 & 0,2 & 0,12 & Seminuevo \\
\hline & 18 & 2.078 & 0,42 & 0,52 & 4 & 0,01 & Seminuevo \\
\hline \multirow{3}{*}{ VACL-007 } & 19 & 302 & 1,12 & 10 & 1 & 0,75 & Seminuevo \\
\hline & 20 & 637 & 0,47 & 4 & 2 & 0,85 & Seminuevo \\
\hline & 21 & 3.950 & 0,83 & 0,51 & 4 & 0,41 & Seminuevo \\
\hline \multirow{2}{*}{ VACL-010 } & 22 & 4.250 & 0,31 & 0,51 & 4 & 0,00 & Seminuevo \\
\hline & 23 & 184 & 1,07 & 8 & 0,3 & 0,13 & Seminuevo \\
\hline \multirow{3}{*}{ VACL-019 } & 24 & 686 & 1,53 & 7 & 1,2 & 0,07 & Nuevo \\
\hline & 25 & 746 & 0,48 & 3 & 0,4 & 0,06 & Seminuevo \\
\hline & 26 & 11.260 & 0,42 & 0,51 & 3,5 & 0,08 & Seminuevo \\
\hline VACL-033 & 27 & 370 & 0,42 & 3 & 2 & 0,22 & Seminuevo \\
\hline \multirow{3}{*}{ VACL-075 } & 28 & 1.182 & 0,70 & 6 & 1 & 0,94 & Seminuevo \\
\hline & 29 & 3.472 & 0,60 & 1,95 & 2,1 & 0,89 & Nuevo \\
\hline & 30 & 1.020 & 0,25 & 0,54 & 2,5 & 0,75 & Seminuevo \\
\hline \multirow{6}{*}{ VACL-079 } & 31 & 584 & 1,07 & 5,15 & 1 & 0,93 & Antiguo \\
\hline & 32 & 794 & 0,88 & 10 & 1 & 0,93 & Seminuevo \\
\hline & 33 & 389 & 0,58 & 4,2 & 1 & 0,74 & Nuevo \\
\hline & 34 & 860 & 1,02 & 3,8 & 1 & 0,93 & Seminuevo \\
\hline & 35 & 97 & 0,45 & 5 & 0,5 & 0,87 & Seminuevo \\
\hline & 36 & 415 & 0,65 & 3 & 1,4 & 0,52 & Seminuevo \\
\hline VACL-116 & 37 & 2.473 & 0,98 & 7 & 1,3 & 0,94 & Seminuevo \\
\hline TOTAL & & 134.568 & & & & & \\
\hline
\end{tabular}


Es de destacar el que número de servicios puede ser no entero si su valor no es constante de lunes a viernes, ya que se calcula como la semisuma de las entradas y salidas de los días laborables.

2) Coste total anual.

Tal y como se ha expuesto en el punto 4.3, el Ministerio de Fomento [103] publica periódicamente sus observatorios sobre los costes del sector del transporte interurbano de viajeros, en los que propone unos valores tipo, en función de la tipología del autobús y de la zona de estudio, junto con los valores medios del coste por vehículo-kilómetro, por hora de funcionamiento y considerando ambos factores. En la Tabla 4-10 se ha presentado un resumen de dichos datos, tanto en valor global como en función de los vehículos-kilómetro anuales, de las horas de explotación o ambos conjuntamente.

Esta metodología puede ser útil en el caso de desconocer los valores de partida. Sin embargo, a través de los datos de la Junta de Castilla y León [87], ha sido posible estimar tanto los costes de explotación iniciales (al ser conocidos los ingresos por venta de billetes y la subvención de la Administración) como los vehículos-kilómetro y las horas de explotación. Por tanto, determinando los valores unitarios de coste por vehículo kilómetro y por hora de explotación, el incremento de costes se determina mediante la expresión (4-62). Los valores de los costes de explotación iniciales, así como sus valores unitarios, quedan recogidos en la Tabla 5-29.

Sin embargo, es evidente que, si se realizan mejoras en la calidad del autobús, aumentarán los valores iniciales de coste por vehículo-kilómetro y por hora de explotación, lo que debe ser recogido en la formulación. Para incluir este efecto de forma aproximada, añadiremos, cuando el autobús ascienda a "gran clase", la diferencia recogida en la Tabla 4-10 entre las dos últimas categorías de autobús (medias nacionales), mientras que, si mejora a "nuevo", la semidiferencia.

\section{3) Beneficios.}

Como ya se ha indicado en el punto 4.3 , los beneficios radicarán de la mejora de calidad percibida por los usuarios, la reducción de externalidades por captación de nuevos usuarios y el aumento de ingresos del operador. 
Tabla 5-29. Costes de explotación iniciales de las líneas metropolitanas y provinciales

Fuente: Junta de Castilla y León [87]

\begin{tabular}{|c|c|c|c|c|c|c|c|}
\hline \multirow[b]{2}{*}{ CONC. } & \multirow{2}{*}{$\begin{array}{c}\text { ID } \\
\text { LíNEA }\end{array}$} & \multicolumn{6}{|c|}{ EXPLOTACIÓN ACTUAL } \\
\hline & & $\begin{array}{c}C_{0} \\
\text { (€/año) }\end{array}$ & $\begin{array}{c}\text { VKM。 } \\
\text { (veh-km/año) }\end{array}$ & $\begin{array}{c}\mathrm{HE}_{0} \\
\text { (h/año) }\end{array}$ & $\begin{array}{c}\text { C/VKM } \\
\text { (€/veh-km) }\end{array}$ & $\begin{array}{l}\mathrm{C} / \mathrm{HE} \\
(\in / \mathrm{h}) \\
\end{array}$ & $\begin{array}{c}\text { Subvenc. } \\
(€)\end{array}$ \\
\hline \multirow{7}{*}{ VACL-001 } & 1 & 32.333 & 47.376 & 1.128 & 0,682 & 28,7 & 20.000 \\
\hline & 2 & 12.460 & 24.400 & 413 & 0,511 & 30,1 & 612 \\
\hline & 3 & 23.241 & 44.928 & 761 & 0,517 & 30,6 & 1.126 \\
\hline & 4 & 12.100 & 27.900 & 430 & 0,434 & 28,1 & 663 \\
\hline & 5 & 88.472 & 275.844 & 3.302 & 0,321 & 26,8 & 5.732 \\
\hline & 6 & 60.037 & 34.040 & 1.277 & 1,764 & 47,0 & 53.040 \\
\hline & 7 & 94.587 & 435.660 & 4.612 & 0,217 & 20,5 & 8.533 \\
\hline \multirow{2}{*}{ VACL-027 } & 8 & 88.552 & 254.040 & 2.628 & 0,349 & 33,7 & -- \\
\hline & 9 & 7.570 & 51.170 & 662 & 0,148 & 11,4 & -- \\
\hline \multirow{7}{*}{ VACL-004 } & 10 & 13.189 & 15.000 & 179 & 0,879 & 73,6 & 9.834 \\
\hline & 11 & 67.583 & 55.776 & 1.328 & 1,212 & 50,9 & 60.665 \\
\hline & 12 & 8.471 & 9.000 & 103 & 0,941 & 82,0 & 5.787 \\
\hline & 13 & 11.041 & 12.000 & 137 & 0,920 & 80,8 & 7.685 \\
\hline & 14 & 35.671 & 44.820 & 598 & 0,796 & 59,7 & 31.081 \\
\hline & 15 & 29.529 & 39.804 & 528 & 0,742 & 55,9 & 27.525 \\
\hline & 16 & 78.489 & 95.616 & 1.892 & 0,821 & 41,5 & 74.900 \\
\hline \multirow{2}{*}{ VACL-015 } & 17 & 25.945 & 6.300 & 102 & 4,118 & 255,2 & 25.177 \\
\hline & 18 & 63.182 & 41.832 & 830 & 1,510 & 76,1 & 62.101 \\
\hline \multirow{3}{*}{ VACL-007 } & 19 & 7.729 & 54.873 & 673 & 0,141 & 11,48 & 4.714 \\
\hline & 20 & 6.502 & 47.765 & 544 & 0,136 & 12,0 & 3.954 \\
\hline & 21 & 56.871 & 90.835 & 1.660 & 0,626 & 34,3 & 54.839 \\
\hline \multirow{2}{*}{ VACL-010 } & 22 & 62.852 & 41.832 & 1.228 & 1,502 & 51,2 & 60.665 \\
\hline & 23 & 7.467 & 13.534 & 215 & 0,552 & 34,7 & 5.991 \\
\hline \multirow{3}{*}{ VACL-019 } & 24 & 34.913 & 98.070 & 1.432 & 0,356 & 24,4 & 30.113 \\
\hline & 25 & 4.019 & 4.800 & 97 & 0,837 & 41,6 & 1.780 \\
\hline & 26 & 62.989 & 33.246 & 770 & 1,895 & 81,8 & 57.243 \\
\hline VACL-033 & 27 & 1.110 & 9.200 & 167 & 0,121 & 6,7 & -- \\
\hline \multirow{3}{*}{ VACL-075 } & 28 & 20.330 & 39.732 & 421 & 0,512 & 48,2 & 13.239 \\
\hline & 29 & 30.559 & 69.410 & 757 & 0,440 & 40,4 & 23.788 \\
\hline & 30 & 13.771 & 19.920 & 311 & 0,691 & 44,2 & 13.225 \\
\hline \multirow{6}{*}{ VACL-079 } & 31 & 29.068 & 60.802 & 642 & 0,478 & 45,3 & 26.061 \\
\hline & 32 & 29.523 & 51.170 & 532 & 0,577 & 55,5 & 21.581 \\
\hline & 33 & 13.425 & 22.908 & 291 & 0,586 & 46,2 & 11.790 \\
\hline & 34 & 28.106 & 56.588 & 612 & 0,497 & 45,9 & 24.839 \\
\hline & 35 & 5.033 & 9.711 & 112 & 0,518 & 44,9 & 4.547 \\
\hline & 36 & 19.683 & 32.154 & 454 & 0,612 & 43,3 & 18.440 \\
\hline VACL-116 & 37 & 53.287 & 65.286 & 690 & 0,816 & 77,2 & 35.976 \\
\hline TOTAL & & 1.239 .688 & 2.337.342 & 32.518 & 0,530 & 38,1 & 807.244 \\
\hline
\end{tabular}




\section{3.a) Beneficios de los usuarios.}

Estos beneficios se obtienen considerando por una parte los aspectos puramente económicos (precio del billete) y por otra las disponibilidades al pago por otras cuestiones de calidad. Así, considerando como variables relevantes el coste, el tiempo de viaje, el número de expediciones, la ruta seguida y las características de vehículo, los beneficios obtenidos por cada usuario o globales se calcularían mediante las expresiones (4-63) y (4-64).

Los valores medios de disponibilidad al pago se han expuesto en la Tabla 5-22, de acuerdo con la modelización presentada en el punto 5.2. Añadiendo estos datos numéricos a las expresiones indicadas, y considerando que los cambios en las variables de calidad son los mismos para todos los usuarios (simplificación no exacta en el caso de rutas con paradas intermedias), finalmente el beneficio correspondiente a cada línea se obtiene como sigue:

$$
\Delta B U_{x}=V_{o x} \cdot\left(-\Delta c_{x}-8,35 \cdot \Delta t_{x}+0,62 \cdot \Delta N S_{x}+0,045 \cdot \Delta r u t a_{x}+0,010 \cdot \text { dist }_{x} \cdot \text { busG }_{x}\right)(
$$

Donde, $\Delta \mathrm{BU}_{\mathrm{x}}$ : beneficios de la línea $\mathrm{x}$ del servicio de transporte interurbano en autobús para los usuarios, en $€$

$\mathrm{V}_{\text {ox }}$ : demanda anual inicial de la línea $\mathrm{x}$

$\mathrm{c}_{\mathrm{x}}$ : coste del billete de la línea $\mathrm{x}$, en $€$

$t_{x}$ : duración del viaje en la línea $x$, en $h$

$\mathrm{NS}_{\mathrm{x}}$ : número diario de expediciones (salidas) de la línea $\mathrm{x}$, en servicios/día laborable

ruta : proporción del trayecto realizado por vías de alta capacidad en la ruta $\mathrm{x}$, en tanto por uno

dist $_{\mathrm{x}}$ : distancia recorrida en la ruta $\mathrm{x}$, en $\mathrm{km}$

busGC $\mathrm{C}_{\mathrm{x}}$ : variable dummy, con valor 1 si el autobús de la ruta $\mathrm{x}$ es de "gran clase" y 0 en caso contrario

\section{3.b) Reducción de externalidades.}

Como ya se ha indicado en el punto 4.3, Jordá et al [86] propusieron unos valores tipo para el transporte de ámbito urbano, metropolitano y rural para la Comunidad de Madrid en el año 2004, considerando diferentes costes externos. La Tabla 4-11 muestra un resumen de dichos valores, actualizados al año 2010, para los ámbitos metropolitano y provincial/regional. 
Considerando únicamente la reducción de externalidades por el traspaso de viajeros del vehículo privado al autobús, el beneficio social que genera la captación de cada usuario que pasa de emplear su vehículo privado al autobús interurbano y su valor global se obtiene de las expresiones (4-65) y (4-66). Por tanto, agrupando dichas expresiones, y considerando los valores expuestos en la Tabla 4-11, finalmente los beneficios sociales generados por la captación de demanda de una determinada línea de autobús interurbano se calcula como sigue:

$$
\left.\begin{array}{l}
\Delta B S_{x}=\left(V-V_{o}\right)_{x} \cdot d i s t_{x} \cdot \frac{43,36-33,50}{100} \cdot \operatorname{Pr} o_{\text {coche a bus }, x}= \\
=0,10 \cdot\left(V-V_{o}\right)_{x} \cdot d i s t_{x} \cdot \operatorname{Pr} o p_{\text {coche a bus }, x} \\
\left.\Delta B S_{x}=\left(V-V_{o}\right)_{x} \cdot d i s t_{x} \cdot \frac{43,90-26,26}{100} \cdot \operatorname{Pr} o p_{\text {coche a bus }, x}=\right\} \text { provincial / regional } \\
=0,18 \cdot\left(V-V_{o}\right)_{x} \cdot \text { dist }_{x} \cdot \operatorname{Pr} o p_{\text {coche a bus }, x}
\end{array}\right\}
$$

Donde, $\triangle \mathrm{BS}_{\mathrm{x}}$ : beneficios sociales de la línea $\mathrm{x}$ del servicio de transporte interurbano en autobús por la captación de demanda

$\mathrm{V}_{\mathrm{x}}$ : demanda anual final de la línea $\mathrm{x}$

$\mathrm{V}_{\mathrm{ox}}$ : demanda anual inicial de la línea $\mathrm{x}$ dist $_{\mathrm{x}}$ : distancia de viaje de la línea $\mathrm{x}$, en kilómetros

Prop $_{\text {coche a bus, } \mathrm{x}}$ : proporción de nueva demanda generada por la línea $\mathrm{x}$ que proviene del coche, en tanto por uno

El único valor que aún nos restaría por conocer sería la proporción, de entre los nuevos usuarios captados por el autobús interurbano, que procede del coche. Para ello, se emplean los datos procedentes de los cálculos de enumeración muestral realizado en el punto 5.2, y se determina, en función de la variable independiente que se modifique, qué proporción de los nuevos usuarios procede del coche y cuál del ferrocarril. La Tabla 5-30 muestra dichos valores.

\begin{tabular}{ccc}
\multicolumn{3}{c}{ Tabla 5-30. Procedencia de la nueva demanda captada por el autobús interurbano } \\
\hline PROCEDENCIA DE NUEVOS USUARIOS DE BUS & VEH. PRIVADO & FERROCARRIL \\
\hline Disminución del tiempo de viaje & $52,9 \%$ & $47,1 \%$ \\
\hline Reducción de tarifa & $52,2 \%$ & $47,8 \%$ \\
\hline Aumento del número de expediciones & $53,8 \%$ & $46,2 \%$ \\
\hline Mayor proporción de la ruta por vías de alta capacidad & -- & $100 \%$ \\
\hline Mejora del vehículo & $50,3 \%$ & $49,7 \%$ \\
\hline
\end{tabular}


Por lo tanto, en el caso de que cambien varias variables simultáneamente, la proporción de nueva demanda procedente del coche se puede estimar, de forma simplificada, a partir de una media ponderada, en función del efecto aislado de cada una de ellas. Así, finalmente se puede obtener dicho valor como se indica a continuación:

$\operatorname{Pr}$ op $_{\text {coche a bus }, x}=\frac{0,529 \cdot\left(\Delta V_{x}\right)_{t}+0,522 \cdot\left(\Delta V_{x}\right)_{c}+0,538 \cdot\left(\Delta V_{x}\right)_{N S}+0,503 \cdot\left(\Delta V_{x}\right)_{\text {bus }}}{\Delta V_{x}}(5-5)$

Donde, Prop ${ }_{\text {coche a bus, } x}$ : proporción de nueva demanda generada por la línea $\mathrm{x}$ que proviene del coche, en tanto por uno

$\mathrm{V}_{\mathrm{x}}$ : demanda anual final de la línea $\mathrm{x}$

t: duración del viaje

c: coste del billete

NS: número diario de expediciones (salidas)

ruta: proporción del trayecto realizado por vías de alta capacidad

bus: variable dummy relativa a las características del vehículo

\section{3.c) Beneficios del operador.}

Por último, los beneficios que recibe el operador provienen, por una parte, del aumento de ingresos en taquilla por la demanda adicional captada y, por otra, del incentivo que le aporta la Administración, en función de los beneficios sociales y a los usuarios que generan sus inversiones en mejora de la calidad. Considerando que todos los usuarios de la misma línea soportan la misma tarifa (lo cual, como ya se ha indicado, es una simplificación asumible en distancias relativamente cortas), dichos beneficios se calculan a partir de las expresiones (4-67) y (4-68), que se conjugan como sigue para una determinada línea:

$$
\Delta B O_{x}=\Delta(V \cdot c)_{x}+P \cdot\left(\Delta B U_{x}+\Delta B S_{x}\right)
$$

Donde, $\Delta \mathrm{BO}_{\mathrm{x}}$ : beneficios del operador de la línea $\mathrm{x}$

$\mathrm{V}_{\mathrm{x}}$ : demanda anual de la línea $\mathrm{x}$

$\mathrm{c}_{\mathrm{x}}$ : coste del billete para la línea $\mathrm{x}$

$\Delta \mathrm{BU}_{\mathrm{x}}$ : beneficios de los usuarios por mejora de la calidad en la línea $\mathrm{x}$ $\Delta \mathrm{BS}_{\mathrm{x}}$ : beneficios de la sociedad por reducción de externalidades producida por la línea $\mathrm{x}$

P: proporción de los beneficios sociales y de los usuarios que revierte al operador 
4) Función objetivo.

Por tanto, únicamente resta ya plantear la función objetivo a maximizar, que se corresponde con el beneficio total final. Así, si consideramos los beneficio de la sociedad en su conjunto más los del operador, la función a maximizar será la expuesta en la expresión (4-74), mientras que, si descartamos el beneficio del operador (aunque imponiendo siempre un margen mínimo de beneficios), sería la (4-75). En nuestro caso, probaremos ambas opciones, a fin de comparar si los resultados son similares en ambos casos o sí, por el contrario, difieren sustancialmente.

En el caso aquí presentado, se trata un problema de optimización no lineal, en el que todas las restricciones, así como la función objetivo, son, sin embargo, "suavizadas" (smooth). Dada la complejidad de su resolución, se han implementado los diversos problemas en la herramienta SOLVER, de la hoja de cálculo Microsoft Excel. Así, empleando el método GRG (Generalized Reduced Gradient) no lineal, se han obtenido los diferentes resultados, partiendo de diversas soluciones iniciales, automáticamente generadas por el programa en función de las restricciones que debían cumplir las variables.

Sin embargo, dadas las condiciones de integralidad de la variable relativa a la calidad del autobús, cada problema ha sido dividido en una serie de subproblemas, mediante la metodología Branch \& Bound. En ésta, en primer lugar se resuelve el problema sin tener en cuenta las restricciones de integralidad, es decir, "relajando" la solución para dichas variables. A continuación, para cada una de éstas que resultó no entera, se plantean dos subproblemas, forzando a que adquiera los dos valores enteros inmediatamente superior e inferior, para finalmente escoger una de las dos opciones. Repitiendo este proceso para cada variable que deba cumplir la condición de integralidad, finalmente se llega a la solución última del problema.

\section{5) Restricciones.}

Sin embargo, la maximización de dicha función objetivo debe estar sujeta a una serie de restricciones a cumplir. Éstas son las que siguen. 


\section{5.a) Condiciones de calidad del servicio.}

En nuestro caso, impondremos que los cambios sobre la situación actual sólo pueden mejorarla. Por tanto, cada variable deberá estar comprendida entre su valor actual y un valor máximo/mínimo a determinar.

Dicho valor máximo/mínimo se ha estimado en función del actual y de las características habituales de los servicios de transporte interurbano en autobús. Así, para cada variable, resultan los siguientes:

- Tiempo de viaje: reducción máxima del $10 \%$ respecto del valor actual

- Coste de viaje: reducción máxima del 50\% respecto del valor actual

- Número diario de servicios (salidas) en día laborable: máximo final diario de 12 expediciones (ida y vuelta cada hora en 12 horas)

- Ruta: valor actual, ya que es complicado, manteniendo los trayectos, modificar la proporción que se realiza por vías de alta capacidad

- Bus: máximo alcanzable bus "gran clase"

Así pues, las primeras restricciones a imponer a la solución son las que siguen:

$$
\begin{aligned}
& 0,9 \cdot t_{o x} \leq t_{x} \leq t_{o x} \quad ; \quad 0,5 \cdot c_{o x} \leq c_{x} \leq c_{o x} \\
& N S_{o x} \leq N S_{x} \leq 12 \quad ; \quad \text { ruta }_{x}=\text { ruta }_{o x} \\
& \text { bus }_{o x} \leq \text { bus }_{x} \leq \text { gran clase }
\end{aligned}
$$

Donde, $\mathrm{Z}_{\mathrm{x}}$ : variable $\mathrm{Z}$ del servicio para la línea $\mathrm{x}$

$\mathrm{Z}_{\mathrm{ox}}$ : valor inicial de la variable $\mathrm{Z}$ del servicio para la línea $\mathrm{x}$

t: duración del viaje

c: coste del billete

NS: mínimo de expediciones diarias (salidas) en laborable ruta: proporción del trayecto realizado por vías de alta capacidad bus: variable dummy relativa a las características del vehículo

\section{5.b) Tráfico y capacidad.}

Como se ha expresado en el punto 4.3, es evidente que la nueva demanda captada debe poder ser satisfecha por la oferta del servicio. Esta restricción queda reflejada en la expresión (4-71). 


\section{5.c) Requisitos comerciales.}

Otra condición a cumplir es que, para que los operadores estén de acuerdo en realizar las mejoras de calidad, se les debe asegurar la viabilidad económica de su concesión, incluso con un determinado margen de beneficios. A pesar de que hay operadores que explotan más de una concesión, a fin de simplificar el proceso, y permitir su aplicación en cualquier situación posible, se ha impuesto la condición de que cada concesión sea viable económicamente, bien por sí misma o bien a través de la subvención recibida de la Administración.

Así, basándonos en la expresión (4-73), y considerando un beneficio industrial tipo del 10\%, esta restricción queda finalmente como sigue, para cada concesión:

$1,10 \cdot \sum_{x}^{\text {concesión }} C_{x} \leq \sum_{x}^{\text {concesión }} B O_{x}+S S P_{\text {concesión }}=\sum_{x}^{\text {concesión }}\left(V_{x} \cdot c_{x}+P \cdot\left(\Delta B U_{x}+\Delta B S_{x}\right)\right)+S S P_{\text {concesión }}$

Donde, $\mathrm{C}_{\mathrm{X}}$ : coste de operación total anual de la línea $\mathrm{x}$

$\mathrm{BO}_{\mathrm{x}}$ : beneficios del operador de la línea $\mathrm{x}$

$\mathrm{SSP}_{\text {concesión: }}$ subvención recibida para la concesión que opera la línea $\mathrm{x}$

$\mathrm{V}_{\mathrm{x}}$ : demanda final anual de la línea $\mathrm{x}$

$\mathrm{c}_{\mathrm{x}}$ : precio del billete final de la línea $\mathrm{x}$

P: proporción de los beneficios sociales y de los usuarios que revierte al operador

$\triangle \mathrm{BU}_{\mathrm{x}}$ : beneficios de los usuarios de la línea $\mathrm{x}$ por mejora de la calidad $\triangle \mathrm{BS}_{\mathrm{x}}$ : beneficios de la sociedad por reducción de externalidades generada por la línea $\mathrm{x}$

\section{5.d) Presupuesto máximo disponible.}

Por último, otra restricción a cumplir es que el presupuesto total que la Administración debe asignar al mantenimiento y mejora del servicio de autobús interurbano no supere el máximo disponible para ello. Dicha restricción se expone en la ecuación (4-72), aunque expresando las subvenciones en términos de concesiones, y no de líneas aisladas, resulta finalmente como sigue:

$\sum_{x} P \cdot\left(\Delta B U_{x}+\Delta B S_{x}\right)+\sum_{\text {concesiones }} S S P_{\text {concesión }} \leq P T, \quad$ para $\left(\Delta B U_{x}+\Delta B S_{x}\right) \geq 0$

Donde, P: proporción de los beneficios sociales y de los usuarios que revierte al operador 
$\triangle \mathrm{BU}_{\mathrm{x}}$ : beneficios de los usuarios de la línea $\mathrm{x}$ por mejora de la calidad $\triangle \mathrm{BS}_{\mathrm{x}}$ : beneficios de la sociedad por reducción de externalidades generada por la línea $\mathrm{x}$

PT: presupuesto total disponible

$\mathrm{SSP}_{\text {concesión }}$ : subvención recibida para la concesión que opera la línea $\mathrm{x}$

En función del valor que resulte para $P$, las cantidades destinadas a fomentar las mejoras en el servicio y a mantener las obligaciones de servicio público variarán, aunque su suma deba ser constante. Si se anula este valor, el esquema retorna al actual, donde el presupuesto disponible se reparte únicamente en función de los déficits de explotación de cada concesión.

Así, el problema radica en encontrar la proporción del presupuesto total que podría ser dirigido a la mejora de la calidad de los contratos, así como el punto óptimo de calidad del servicio, es decir, para cada línea: precio del billete, duración del viaje, número diario de servicios, ruta a seguir y características del vehículo. A continuación, se mostrarán los resultados obtenidos en las pruebas piloto realizadas.

\subsubsection{Prueba Piloto 1. Alfoz Metropolitano}

En primer lugar, se mostrarán los resultados obtenidos considerando únicamente las 8 rutas (una de ellas con dos sub-trayectos) incluidas dentro del Transporte Metropolitano de Burgos. Todas ellas tienen distancias de viaje reducidas, y un número relativamente amplio de servicios diarios, en laborable.

Se ha probado dos configuraciones diferentes, tanto maximizando el beneficio total de los usuarios más las reducciones por externalidades más los beneficios del operador, en cuyo caso la función objetivo se indica en la expresión (4-74), como no considerando los beneficios del operador (aunque imponiendo siempre un margen mínimo de beneficios), en cuyo caso emplearemos la (4-75). En cuanto al presupuesto máximo disponible, será igual al total empleado en la misma anualidad para compensar el déficit de explotación de las concesiones, de modo que nuestra metodología no añade ningún coste adicional a la Administración.

Los resultados de la optimización aplicada, cuando el objetivo es maximizar tanto los beneficios sociales y de los usuarios como para el operador, se presentan en la Tabla 5-31, en la que se presenta el punto óptimo de explotación y en la Tabla 5-32, en la que se 
exponen los aspectos económicos. La nomenclatura empleada en ellas coincide con la expuesta anteriormente.

El beneficio industrial tipo considerado ha sido, como ya se ha indicado, del $10 \%$ como mínimo. De este modo, la metodología asegura que, sin exceder el presupuesto máximo disponible (que en años anteriores se dedicaba únicamente a subvencionar los déficit de explotación), éste sea repartido de forma diferente, fomentando las mejoras de calidad de los operadores, a la vez que se les asegura un resultado económico positivo para cada concesión.

Tabla 5-31. Prueba 1: Alfoz metropolitano. Maximización beneficio social + operador.

Punto óptimo de explotación

\begin{tabular}{|c|c|c|c|c|c|c|c|}
\hline \multirow[b]{2}{*}{ CONC. } & \multirow{2}{*}{$\begin{array}{l}\text { ID } \\
\text { LíNEA }\end{array}$} & \multicolumn{6}{|c|}{ EXPLOTACIÓN ÓPTIMA (VALORES FINALES) } \\
\hline & & $\begin{array}{c}\mathbf{V} \\
\text { (viaj./año) }\end{array}$ & $t(h)$ & $c(€)$ & $\begin{array}{c}\text { NS } \\
\text { (salidas/lab.) }\end{array}$ & $\begin{array}{c}\text { Prop. ruta } \\
\text { vías rápidas }\end{array}$ & Tipo bus \\
\hline \multirow{2}{*}{ VACL-001 } & 1 & 29.103 & 0,45 & 0,41 & 4,4 & 0,24 & Gran clase \\
\hline & 6 & 16.376 & 0,68 & 0,42 & 3 & -- & Gran clase \\
\hline \multirow{2}{*}{ VACL-004 } & 11 & 17.303 & 0,60 & 0,34 & 4 & 0,39 & Gran clase \\
\hline & 16 & 9.468 & 0,86 & 0,26 & 4 & 0,17 & Gran clase \\
\hline VACL-015 & 18 & 2.556 & 0,38 & 0,41 & 4 & 0,01 & Gran clase \\
\hline VACL-007 & 21 & 5.420 & 0,75 & 0,26 & 4 & 0,41 & Gran clase \\
\hline VACL-010 & 22 & 4.786 & 0,28 & 0,51 & 4 & -- & Gran clase \\
\hline VACL-019 & 26 & 13.547 & 0,38 & 0,43 & 3,5 & 0,08 & Gran clase \\
\hline $\begin{array}{l}\text { VACL-075 } \\
\text { VACL-079 } \\
\end{array}$ & 30 & 1.198 & 0,23 & 0,48 & 2,5 & 0,75 & Gran clase \\
\hline TOTAL & & 99.757 & & & & & \\
\hline \multirow[b]{2}{*}{ CONC. } & \multirow[b]{2}{*}{$\begin{array}{l}\text { ID } \\
\text { LÍNEA }\end{array}$} & \multicolumn{6}{|c|}{ EXPLOTACIÓN ÓPTIMA (INCREMENTOS RELATIVOS) } \\
\hline & & $\Delta \mathbf{V}(\%)$ & $\Delta t(\%)$ & $\begin{array}{l}\Delta c \\
(\%) \\
\end{array}$ & $\Delta \mathrm{NS}(\%)$ & $\begin{array}{l}\Delta \text { Prop. ruta vías } \\
\text { rápidas (\%) }\end{array}$ & $\begin{array}{c}\Delta \text { Tipo } \\
\text { bus }\end{array}$ \\
\hline \multirow{2}{*}{ VACL-001 } & 1 & $23,0 \%$ & $-10 \%$ & $-21 \%$ & -- & -- & 2 niveles \\
\hline & 6 & $21,9 \%$ & $-10 \%$ & $-19 \%$ & -- & -- & 2 niveles \\
\hline \multirow{2}{*}{ VACL-004 } & 11 & $30,1 \%$ & $-10 \%$ & $-35 \%$ & -- & -- & 2 niveles \\
\hline & 16 & $37,2 \%$ & $-10 \%$ & $-50 \%$ & -- & -- & 2 niveles \\
\hline VACL-015 & 18 & $23,0 \%$ & $-10 \%$ & $-21 \%$ & -- & -- & 2 niveles \\
\hline VACL-007 & 21 & $37,2 \%$ & $-10 \%$ & $-50 \%$ & -- & -- & 2 niveles \\
\hline VACL-010 & 22 & $12,6 \%$ & $-10 \%$ & -- & -- & -- & 2 niveles \\
\hline VACL-019 & 26 & $20,3 \%$ & $-10 \%$ & $-16 \%$ & -- & -- & 2 niveles \\
\hline $\begin{array}{l}\text { VACL-075 } \\
\text { VACL-079 }\end{array}$ & 30 & $17,5 \%$ & $-10 \%$ & $-10 \%$ & -- & -- & 2 niveles \\
\hline TOTAL & & $24,9 \%$ & & & & & \\
\hline
\end{tabular}

En primer lugar, observamos en ellas que la óptima proporción de beneficios sociales y de los usuarios que debería ser revertida al operador es de un $100 \%$, lo que indicaría que la apuesta de la Administración por la mejora de calidad debe ser muy fuerte. Además, es de destacar el que número de servicios puede ser no entero si su valor no es constante de lunes 
a viernes, tanto para la situación actual como para la óptima, ya que se calcula como un promedio entre los datos de cada día laborable.

Por otra parte, analizando los puntos óptimos operación de cada línea, observamos que los tiempos y costes deberían, en general, reducirse ostensiblemente, mientras que el número diario de servicios podría mantenerse relativamente constante. En cuanto a las características del autobús, la mejora del mismo es también muy positiva. Y respecto a la capacidad de los mismos, es más que suficiente con autobuses de unas 45 plazas para asegurar que la demanda captada puede ser satisfecha.

Tabla 5-32. Prueba 1: Alfoz metropolitano. Maximización beneficio social + operador. Resultados económicos

\begin{tabular}{|c|c|c|c|c|c|c|c|}
\hline \multirow[b]{2}{*}{ CONC. } & \multirow[b]{2}{*}{$\begin{array}{l}\text { ID } \\
\text { LíNEA }\end{array}$} & \multicolumn{6}{|c|}{ RESULTADOS ECONÓMICOS (VALORES FINALES) } \\
\hline & & $\begin{array}{c}\text { C explot. } \\
\text { (€/año) }\end{array}$ & $\begin{array}{l}\text { Subvenc. } \\
\text { (€/año) }\end{array}$ & $\mathrm{BI}(\%)$ & $\begin{array}{c}\text { C Admón. } \\
\text { (€/año) }\end{array}$ & $\begin{array}{c}\mathrm{PT} \\
\text { (€/año) }\end{array}$ & $\mathbf{P}$ \\
\hline \multirow{2}{*}{ VACL-001 } & 1 & 28.917 & \multirow{2}{*}{34.181} & \multirow{2}{*}{$10 \%$} & \multirow{2}{*}{72.841} & \multirow{2}{*}{456.677} & \multirow{2}{*}{1,000} \\
\hline & 6 & 54.477 & & & & & \\
\hline \multirow{2}{*}{ VACL-004 } & 11 & 60.480 & \multirow{2}{*}{99.261} & \multirow{2}{*}{$10 \%$} & \multirow{2}{*}{135.428} & \multirow{2}{*}{456.677} & \multirow{2}{*}{1,000} \\
\hline & 16 & 70.154 & & & & & \\
\hline VACL-015 & 18 & 56.639 & 59.356 & $10 \%$ & 61.254 & 456.677 & 1,000 \\
\hline VACL-007 & 21 & 50.763 & 45.456 & $10 \%$ & 54.445 & 456.677 & 1,000 \\
\hline VACL-010 & 22 & 59.550 & 61.218 & $10 \%$ & 63.042 & 456.677 & 1,000 \\
\hline VACL-019 & 26 & 56.847 & 47.767 & $10 \%$ & 56.700 & 456.677 & 1,000 \\
\hline $\begin{array}{l}\text { VACL-075 } \\
\text { VACL-079 }\end{array}$ & 30 & 12.314 & 12.393 & $10 \%$ & 12.967 & 456.677 & 1,000 \\
\hline \multirow[t]{2}{*}{ TOTAL } & & 450.151 & 359.631 & & 456.677 & & 1,000 \\
\hline & & \multicolumn{6}{|c|}{ RESULTADOS ECONÓMICOS (INCREMENTOS) } \\
\hline CONC. & $\begin{array}{l}\text { ID } \\
\text { LíNEA }\end{array}$ & $\begin{array}{c}\Delta C \\
\text { (€/año) }\end{array}$ & $\begin{array}{c}\Delta \mathrm{BU} \\
\text { (€/año) }\end{array}$ & $\begin{array}{c}\Delta \mathrm{BS} \\
\text { (€/año) }\end{array}$ & $\begin{array}{c}\Delta \mathrm{BO} \\
(€ / \text { año) }\end{array}$ & \multicolumn{2}{|c|}{$\begin{array}{c}\text { Función objetivo } \\
\Delta \mathrm{BU}+\Delta \mathrm{BS}+\Delta \mathrm{BO}-\Delta \mathrm{C} \\
\text { (€/año) }\end{array}$} \\
\hline \multirow{2}{*}{ VACL-001 } & 1 & -3.416 & 17.400 & 5.843 & 22.888 & \multicolumn{2}{|c|}{49.547} \\
\hline & 6 & -5.560 & 12.399 & 3.018 & 15.334 & \multicolumn{2}{|c|}{36.311} \\
\hline \multirow{2}{*}{ VACL-004 } & 11 & -7.104 & 13.551 & 5.742 & 18.182 & \multicolumn{2}{|c|}{44.579} \\
\hline & 16 & -8.334 & 10.550 & 6.324 & 15.748 & \multicolumn{2}{|c|}{40.957} \\
\hline VACL-015 & 18 & -6.543 & 1.384 & 514 & 1.866 & \multicolumn{2}{|c|}{10.306} \\
\hline VACL-007 & 21 & -6.108 & 5.550 & 3.439 & 8.351 & \multicolumn{2}{|c|}{23.448} \\
\hline VACL-010 & 22 & -3.302 & 1.537 & 287 & 2.100 & \multicolumn{2}{|c|}{7.226} \\
\hline VACL-019 & 26 & -6.142 & 6.826 & 2.107 & 9.018 & \multicolumn{2}{|c|}{24.094} \\
\hline $\begin{array}{l}\text { VACL-075 } \\
\text { VACL-079 }\end{array}$ & 30 & -1.457 & 429 & 146 & 607 & \multicolumn{2}{|c|}{2.638} \\
\hline TOTAL & & -47.966 & 69.625 & 27.421 & 94.094 & & \\
\hline
\end{tabular}

Además, es relevante el hecho de que, aun con la demanda adicional captada, que adquiere valores superiores entre el $20 \%$ y el $30 \%$ en casi todas las líneas, no hay ninguna concesión que tenga un resultado económico de explotación superior al 10\% (sin contabilizar la 
subvención de la Administración), considerado como mínimo admisible. Por tanto, queda de nuevo patente que el problema económico de los operadores no es un tema de fácil solución, y que probablemente habría que aumentar las partidas económicas en este sentido para favorecer las mejoras de calidad.

Por último, aunque el gasto total de la Administración se mantiene igual al de la situación inicial, de forma que no generamos un mayor esfuerzo económico para ésta, su distribución sí observa importantes variaciones. Así, de los aproximadamente $457.000 €$ gastados en total, casi $360.000 €$ se invierten en subvencionar el déficit de explotación de las líneas (para un beneficio industrial del 10\%), mientras que únicamente los $97.000 €$ restantes se asignan como incentivos a los operadores que generen beneficios sociales y de los usuarios. Es decir, algo más del $21 \%$ del presupuesto total disponible para el servicio de transporte público interurbano en autobús podría ser "devuelto" a los operadores. Además, el conjunto de la sociedad, los usuarios del servicio y el operador tendría unos beneficios de más de $239.000 €$, respecto de la situación actual, de los cuales serían casi $70.000 €$ para los actuales usuarios por mejoras en la calidad y más de $27.000 €$ para la sociedad en general por reducción de externalidades.

Sin embargo, los resultados anteriores han sido obtenidos suponiendo constantes el presupuesto total que la Administración asigna al transporte público interurbano en autobús y el porcentaje de beneficio industrial mínimo del operador. Por tanto, actuando sobre dichos valores, resultarían situaciones finales diferentes, sin más que variar los datos de partida de las optimizaciones correspondientes.

Representando gráficamente los resultados totales de las posibles situaciones, la Figura 5-17 muestra cómo variarían éstos en caso de que el presupuesto total disponible fuera sensiblemente diferente del inicialmente considerado (actual, $+10 \%,+20 \%$ y $-1,5 \%$, mínimo que se puede conseguir sin variar el beneficio industrial), mientras que la Figura 5-18 presenta lo mismo, pero variando el beneficio industrial mínimo (nulo, 5\%, 10\% y $11,8 \%$, máximo alcanzable sin aumentar el presupuesto).

Observando los resultados expuestos en ellas, vemos que los mayores valores de beneficios sociales y de los usuarios se consiguen cuando el beneficio industrial es nulo, es decir, en el equilibrio estricto de las concesiones. Sin embargo, esta situación es claramente inestable, ya que los operadores serán reacios a aceptarla. En cualquier caso, es destacable que, independientemente del beneficio industrial que se establezca, la proporción de beneficios sociales y de los usuarios que revierte al operador debería ser la máxima posible. 
Figura 5-17. Prueba 1: Alfoz metropolitano. Maximización beneficio social + operador. Variaciones en el presupuesto

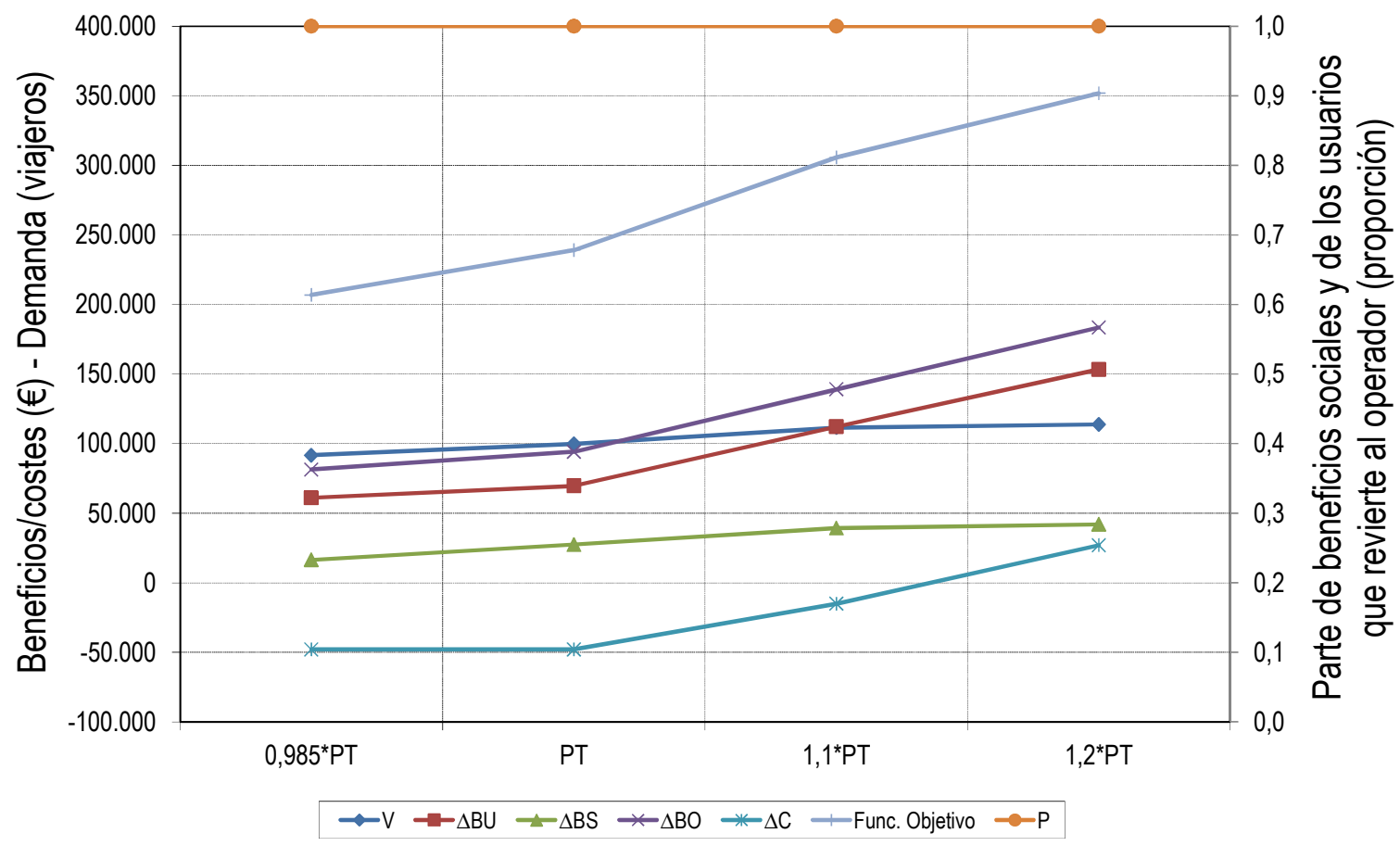

Figura 5-18. Prueba 1: Alfoz metropolitano. Maximización beneficio social + operador. Variaciones en el beneficio industrial

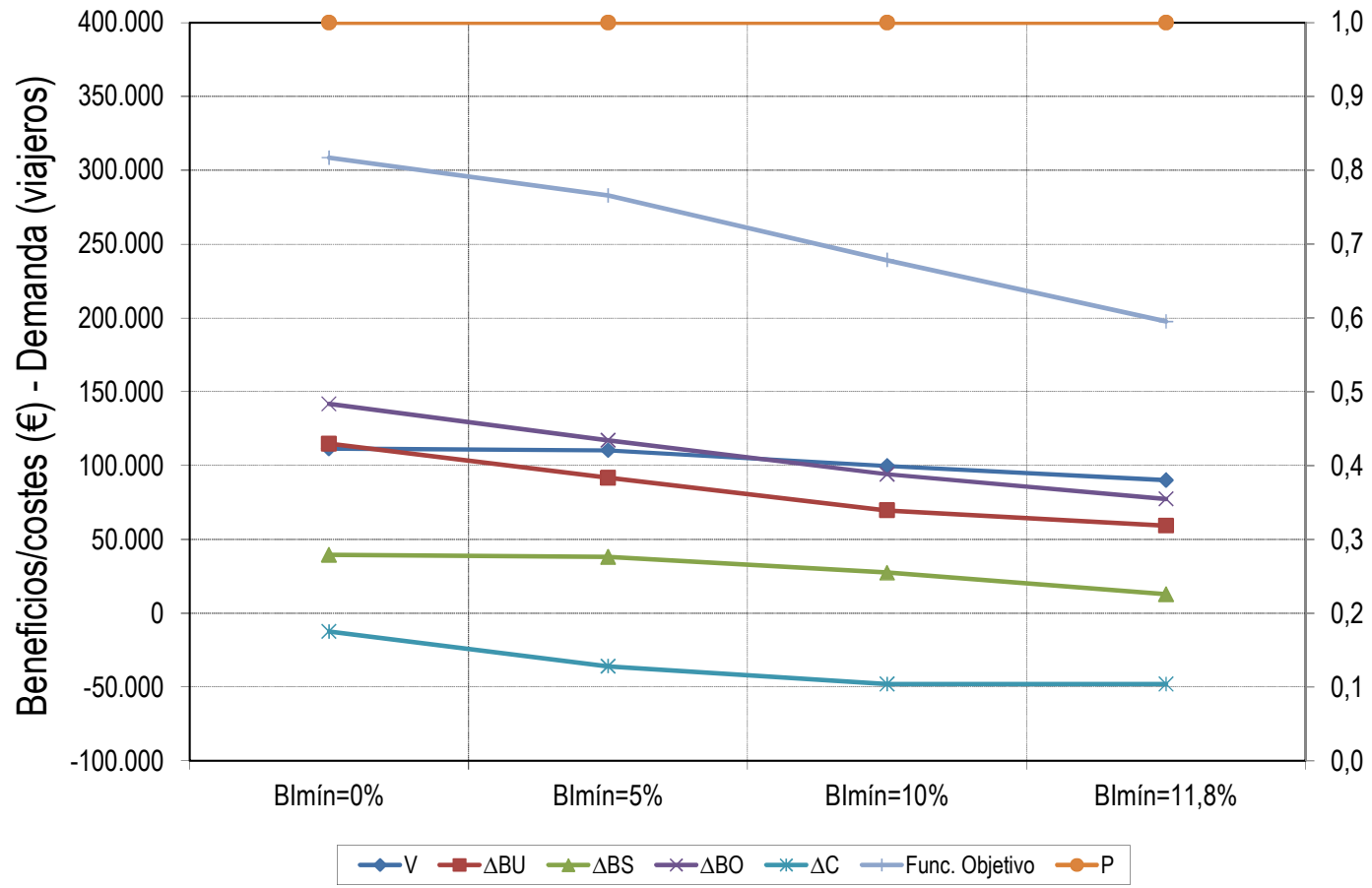


Por otra parte, en cuanto a los cambios en el presupuesto total disponible, vemos que la situación actual del sistema es crítica, ya que la máxima disminución viable en el mismo para seguir consiguiendo una solución factible es de tan sólo el 1,5\%. Así pues, cualquier disminución del presupuesto supondría también menores beneficios para los operadores, lo que podría hacer peligrar la viabilidad de la propuesta. De hecho, analizando los resultados obtenidos para valores de presupuesto superiores al actual, observamos que, a medida que éste aumenta, los resultados son mejores para todos, como cabría esperar.

Cambiando el punto de vista, si el objetivo es maximizar únicamente los beneficios sociales y de los usuarios, aunque manteniendo un margen mínimo de beneficios para el operador, los resultados varían ligeramente. En la Tabla 5-33 se muestran los valores del punto óptimo de explotación, mientras que la Tabla 5-34 resume los resultados económicos.

Tabla 5-33. Prueba 1: Alfoz metropolitano. Maximización beneficio social. Punto óptimo de explotación

\begin{tabular}{|c|c|c|c|c|c|c|c|}
\hline \multirow[b]{2}{*}{ CONC. } & \multirow{2}{*}{$\begin{array}{l}\text { ID } \\
\text { LÍNEA }\end{array}$} & \multicolumn{6}{|c|}{ EXPLOTACIÓN ÓPTIMA (VALORES FINALES) } \\
\hline & & $\begin{array}{c}V \\
\text { (viaj./año) }\end{array}$ & $t(h)$ & $c(€)$ & $\begin{array}{c}\text { NS } \\
\text { (salidas/lab.) }\end{array}$ & $\begin{array}{c}\text { Prop. ruta } \\
\text { vías rápidas }\end{array}$ & Tipo bus \\
\hline \multirow{2}{*}{ VACL-001 } & 1 & 29.101 & 0,45 & 0,41 & 4,4 & 0,24 & Gran clase \\
\hline & 6 & 16.376 & 0,68 & 0,42 & 3 & -- & Gran clase \\
\hline \multirow{2}{*}{ VACL-004 } & 11 & 17.302 & 0,60 & 0,34 & 4 & 0,39 & Gran clase \\
\hline & 16 & 9.468 & 0,86 & 0,26 & 4 & 0,17 & Gran clase \\
\hline VACL-015 & 18 & 2.561 & 0,38 & 0,41 & 4 & 0,01 & Gran clase \\
\hline VACL-007 & 21 & 5.420 & 0,75 & 0,26 & 4 & 0,41 & Gran clase \\
\hline VACL-010 & 22 & 4.786 & 0,28 & 0,51 & 4 & -- & Gran clase \\
\hline VACL-019 & 26 & 13.545 & 0,38 & 0,43 & 3,5 & 0,08 & Gran clase \\
\hline $\begin{array}{l}\text { VACL-075 } \\
\text { VACL-079 }\end{array}$ & 30 & 1.198 & 0,23 & 0,48 & 2,5 & 0,75 & Gran clase \\
\hline TOTAL & & 99.757 & & & & & \\
\hline \multirow[b]{2}{*}{ CONC. } & \multirow[b]{2}{*}{$\begin{array}{l}\text { ID } \\
\text { LÍNEA }\end{array}$} & \multicolumn{6}{|c|}{ EXPLOTACIÓN ÓPTIMA (INCREMENTOS RELATIVOS) } \\
\hline & & $\Delta \mathbf{V}(\%)$ & $\Delta t(\%)$ & $\begin{array}{c}\Delta \mathrm{C} \\
(\%) \\
\end{array}$ & $\Delta \mathrm{NS}(\%)$ & $\begin{array}{l}\Delta \text { Prop. ruta vías } \\
\text { rápidas }(\%)\end{array}$ & $\begin{array}{c}\Delta \text { Tipo } \\
\text { bus }\end{array}$ \\
\hline \multirow{2}{*}{ VACL-001 } & 1 & $22,9 \%$ & $-10 \%$ & $-21 \%$ & -- & -- & 2 niveles \\
\hline & 6 & $21,9 \%$ & $-10 \%$ & $-19 \%$ & -- & -- & 2 niveles \\
\hline \multirow{2}{*}{ VACL-004 } & 11 & $30,1 \%$ & $-10 \%$ & $-35 \%$ & -- & - & 2 niveles \\
\hline & 16 & $37,2 \%$ & $-10 \%$ & $-50 \%$ & -- & -- & 2 niveles \\
\hline VACL-015 & 18 & $23,2 \%$ & $-10 \%$ & $-22 \%$ & -- & -- & 2 niveles \\
\hline VACL-007 & 21 & $37,2 \%$ & $-10 \%$ & $-50 \%$ & -- & -- & 2 niveles \\
\hline VACL-010 & 22 & $12,6 \%$ & $-10 \%$ & -- & -- & -- & 2 niveles \\
\hline VACL-019 & 26 & $20,3 \%$ & $-10 \%$ & $-16 \%$ & -- & -- & 2 niveles \\
\hline $\begin{array}{l}\text { VACL-075 } \\
\text { VACL-079 }\end{array}$ & 30 & $17,5 \%$ & $-10 \%$ & $-10 \%$ & -- & -- & 2 niveles \\
\hline TOTAL & & $24,9 \%$ & & & & & \\
\hline
\end{tabular}


La primera conclusión que podemos extraer, analizando el punto óptimo de explotación, es que la variación con respecto a la primera hipótesis es muy pequeña. De hecho, prácticamente todos los valores son los mismos, excepto el precio del billete en la línea denominada 18 (correspondiente a la metropolitana M6), que se ve reducido en una pequeño cantidad. Por tanto, podemos observar que la situación óptima del servicio de autobuses interurbano, desde el punto de vista de la calidad, es prácticamente independiente de que se incluyan o no los beneficios y costes del operador en la formulación de la función objetivo, siempre que se le aseguren ciertos rendimientos económicos, ya que, en caso contrario, no sería muy proclive a invertir en mejorarla.

Tabla 5-34. Prueba 1: Alfoz metropolitano. Maximización beneficio social. Resultados económicos

\begin{tabular}{|c|c|c|c|c|c|c|c|}
\hline \multirow[b]{2}{*}{ CONC. } & \multirow[b]{2}{*}{$\begin{array}{c}\text { ID } \\
\text { LIINEA }\end{array}$} & \multicolumn{6}{|c|}{ RESULTADOS ECONÓMICOS (VALORES FINALES) } \\
\hline & & $\begin{array}{l}\text { C explot. } \\
\text { (€/año) }\end{array}$ & $\begin{array}{l}\text { Subvenc. } \\
\text { (€/año) }\end{array}$ & $\mathrm{BI}(\%)$ & $\begin{array}{l}\text { C Admón. } \\
\text { (€/año) }\end{array}$ & $\begin{array}{c}\mathrm{PT} \\
\text { (€/año) }\end{array}$ & $\mathbf{P}$ \\
\hline \multirow{2}{*}{ VACL-001 } & 1 & 28.917 & \multirow{2}{*}{72.839} & \multirow{2}{*}{$10 \%$} & \multirow{2}{*}{72.839} & \multirow{2}{*}{456.677} & \multirow{2}{*}{0,000} \\
\hline & 6 & 54.477 & & & & & \\
\hline \multirow{2}{*}{ VACL-004 } & 11 & 60.480 & \multirow{2}{*}{135.428} & \multirow{2}{*}{$10 \%$} & \multirow{2}{*}{135.428} & \multirow{2}{*}{456.677} & \multirow{2}{*}{0,000} \\
\hline & 16 & 70.154 & & & & & \\
\hline VACL-015 & 18 & 56.639 & 61.258 & $10 \%$ & 61.258 & 456.677 & 0,000 \\
\hline VACL-007 & 21 & 50.763 & 54.445 & $10 \%$ & 54.445 & 456.677 & 0,000 \\
\hline VACL-010 & 22 & 59.550 & 63.042 & $10 \%$ & 63.042 & 456.677 & 0,000 \\
\hline VACL-019 & 26 & 56.847 & 56.698 & $10 \%$ & 56.698 & 456.677 & 0,000 \\
\hline $\begin{array}{l}\text { VACL-075 } \\
\text { VACL-079 }\end{array}$ & 30 & 12.314 & 12.967 & $10 \%$ & 12.967 & 456.677 & 0,000 \\
\hline TOTAL & & 450.141 & 456.677 & & 456.677 & & 0,000 \\
\hline \multirow[b]{2}{*}{ CONC. } & \multirow[b]{2}{*}{$\begin{array}{c}\text { ID } \\
\text { LIINEA }\end{array}$} & \multicolumn{6}{|c|}{ RESULTADOS ECONÓMICOS (INCREMENTOS) } \\
\hline & & $\begin{array}{c}\Delta C \\
\text { (€/año) }\end{array}$ & $\begin{array}{c}\Delta \mathrm{BU} \\
\text { (€/año) }\end{array}$ & & & & $\begin{array}{c}\text { Función objetivo } \\
\Delta \mathrm{BU}+\Delta \mathrm{BS} \\
\text { (€/año) }\end{array}$ \\
\hline \multirow{2}{*}{ VACL-001 } & 1 & -3.416 & 17.399 & & & & 23.241 \\
\hline & 6 & -5.560 & 12.398 & & & & 15.415 \\
\hline \multirow{2}{*}{ VACL-004 } & 11 & -7.104 & 13.550 & & & & 19.291 \\
\hline & 16 & -8.334 & 10.550 & & & & 16.874 \\
\hline VACL-015 & 18 & -6.543 & 1.389 & & & & 1.907 \\
\hline VACL-007 & 21 & -6.108 & 5.550 & & & & 8.989 \\
\hline VACL-010 & 22 & -3.302 & 1.537 & & & & 1.824 \\
\hline VACL-019 & 26 & -6.142 & 6.824 & & & & 8.929 \\
\hline $\begin{array}{l}\text { VACL-075 } \\
\text { VACL-079 }\end{array}$ & 30 & -1.457 & 429 & & & & 574 \\
\hline TOTAL & & -47.966 & 69.625 & & & & 97.046 \\
\hline
\end{tabular}

Sin embargo, a pesar de mantenerse constante el gasto total que la Administración debe asumir, sí varía ostensiblemente la proporción de beneficios sociales y de los usuarios que ésta revierte al operador, que de hecho se anula en este caso, volviendo a la situación 
actual. Por otra parte, observamos de nuevo que no existe ninguna concesión que, por sí misma, es decir, sin tener en cuenta la subvención de la Administración, consiga un beneficio igual al 10\%. Este hecho radica precisamente en la proporción de beneficios sociales y de los usuarios que revierte al operador, que se ha visto anulada, lo cual provoca el desequilibrio económico de las líneas.

Además, en este caso, los aproximadamente $457.000 €$ gastados en total se destinan íntegramente a subvencionar el déficit de explotación de las líneas (para un beneficio industrial del 10\%), de modo que no existen incentivos por mejoras de calidad de los operadores y, por tanto, su captación de demanda. Es decir, con esta segunda hipótesis, ninguna proporción de los beneficios que generan los operadores les es "devuelta". Además, el conjunto de la sociedad y los usuarios del servicio tendrían unos beneficios de más de $97.000 €$, respecto de la situación actual, siendo serían casi $70.000 €$ para los actuales usuarios por mejoras en la calidad y más de $27.000 €$ para la sociedad en general por reducción de externalidades.

Para finalizar, concluimos resaltando de nuevo la gran similitud existente en líneas generales entre las optimizaciones de los beneficios sociales y de los usuarios añadiendo/sin añadir los del operador. En cuanto al funcionamiento de las diferentes rutas, los resultados son, de hecho, prácticamente iguales, aunque no tanto si hablamos desde el punto de vista económico. En este aspecto, el escenario cambia bastante, ya que la proporción de beneficios sociales y de los usuarios que se revierte al operador es máxima si consideramos también sus beneficios y costes, mientras que se anula si no lo hacemos, conllevando la circunstancia asociada de que ninguna línea consiga un beneficio industrial igual al mínimo admisible, considerado en este caso del $10 \%$.

De, nuevo, considerando posibles variaciones en el presupuesto total disponible y el beneficio industrial mínimo del operador, podemos obtener diferentes escenarios. Así, la Figura 5-19 muestra los resultados de la optimización cuando variamos el presupuesto total disponible (actual, $+10 \%,+20 \%$ y $-1,5 \%$, mínimo que se puede conseguir sin variar el beneficio industrial), mientras que la Figura 5-20 presenta lo mismo, pero variando el valor mínimo de beneficio industrial (nulo, 5\%, $10 \%$ y 11,8\%, máximo alcanzable sin aumentar el presupuesto). 
Figura 5-19. Prueba 1: Alfoz metropolitano. Maximización beneficio social. Variaciones en el presupuesto

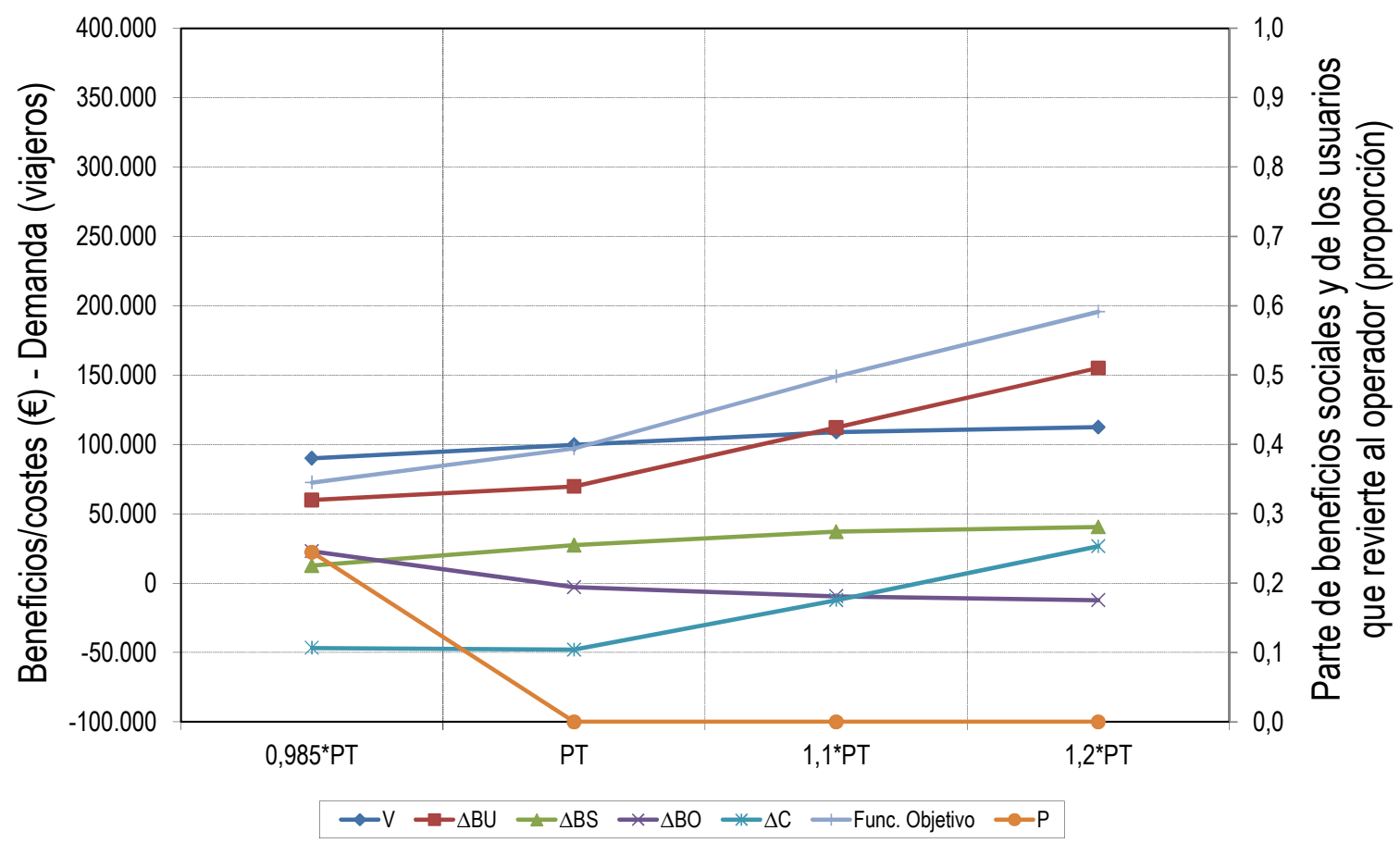

Figura 5-20. Prueba 1: Alfoz metropolitano. Maximización beneficio social. Variaciones en el beneficio industrial

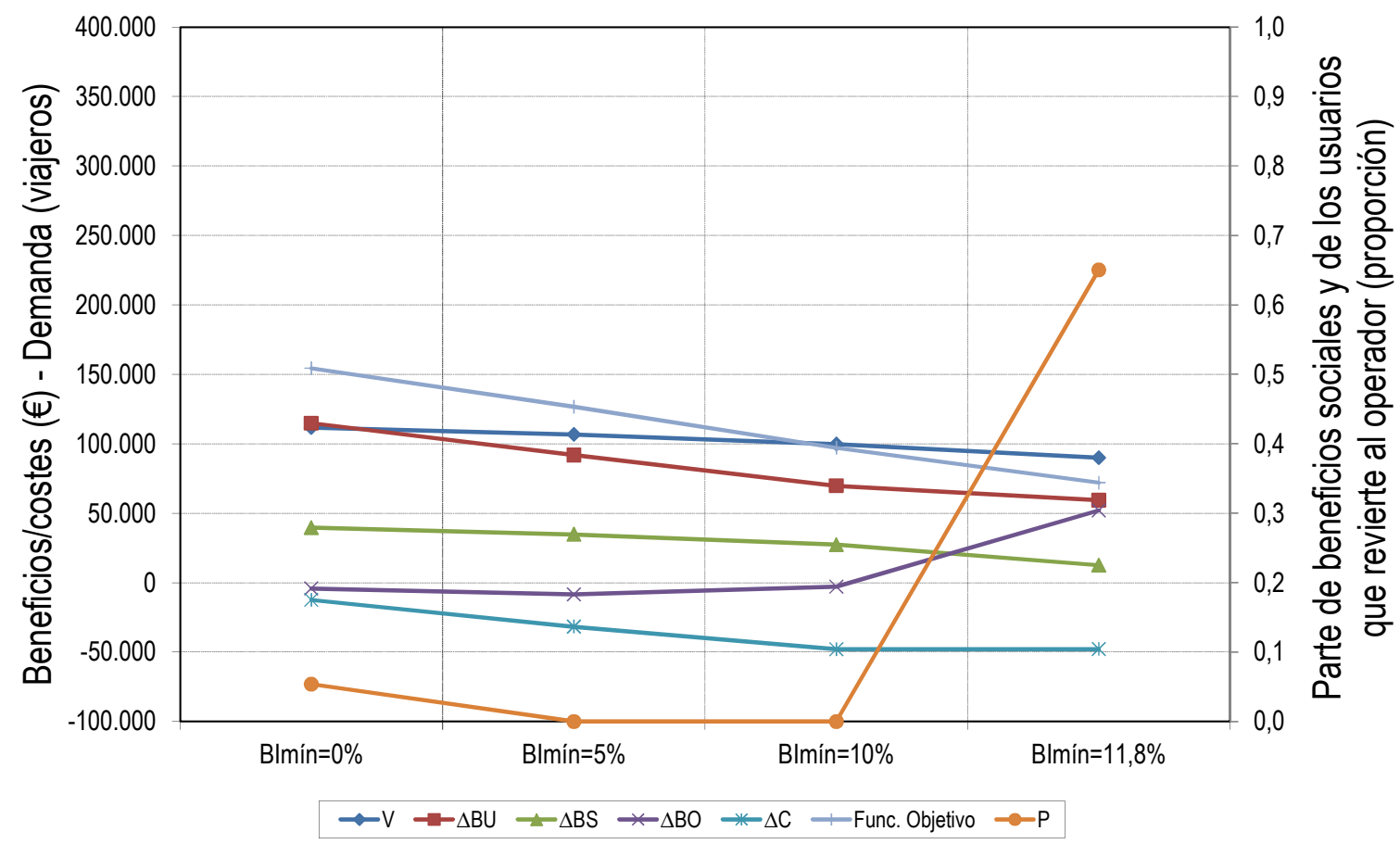


En ellas observamos, de nuevo, que el presupuesto actualmente asignado al servicio es prácticamente el mínimo admisible, sólo pudiendo ser disminuido en un 1,5\%. Descensos mayores conllevarían menores beneficios industriales para los operadores. Sin embargo, se da una circunstancia peculiar con respecto a la consideración anterior, que hace que, cuando el presupuesto disminuye, deba aumentar la proporción de beneficios sociales y de los usuarios devuelta al operador, lo que hace que aumenten relativamente sus beneficios, aunque no así la demanda del servicio.

Por otra parte, vemos otra vez que los mayores valores de beneficios sociales y de los usuarios se consiguen cuando el beneficio industrial es nulo, es decir, en el equilibrio estricto de las concesiones, aunque ya hemos indicado que esta situación sería claramente inestable. Además, observamos aquí la diferencia de que, para el beneficio industrial máximo, la proporción de beneficios que revierte al operador debe ser bastante elevada.

Para finalizar este punto, simplemente se desea recordar que la simulación aquí presentada parte de los valores de elasticidad de la demanda y disponibilidad al pago obtenidos en la modelización expuesta en puntos anteriores. Por tanto, no deben ser tomados en ningún caso como valores absolutos, sino posibles aproximaciones a la situación real. Además, como ya ha sido indicado en el punto 4.3, la metodología correcta consiste en optimizar simultáneamente todas las líneas que son competencia de una misma Administración. Para ello, en el punto siguiente, se introducirán el resto de líneas consideradas, y se presentarán los resultados globales para el conjunto.

\subsubsection{Prueba Piloto 2. Trayectos Provinciales/Regionales}

En el presente apartado, se mostrarán los resultados obtenidos considerando el global de líneas de competencia exclusiva de la Comunidad Autónoma de Castilla y León que prestan servicio en los municipios comprendidos en el área metropolitana, recogidas en la Tabla 5-27, elaborada a partir de los datos de la Junta de Castilla y León [87].

De nuevo, se ha probado dos configuraciones diferentes, tanto maximizando el beneficio total de los usuarios más las reducciones por externalidades más los beneficios del operador, en cuyo caso la función objetivo se indica en la expresión (4-74), como no considerando los beneficios del operador (aunque imponiendo siempre un margen mínimo de beneficios), en cuyo caso emplearemos la (4-75). En cuanto al presupuesto máximo disponible, será también igual al total empleado en la misma anualidad para compensar el 
déficit de explotación de las concesiones (ahora mayor, al aumentar el número de líneas consideradas).

Los resultados de la optimización aplicada, cuando el objetivo es maximizar tanto los beneficios sociales y de los usuarios como para el operador, se presentan de la Tabla 5-35 a la Tabla 5-38, en las que se presenta el punto óptimo de explotación y los aspectos económicos. La nomenclatura empleada en todas ellas coincide con la expuesta anteriormente.

El beneficio industrial tipo considerado ha sido, como ya se ha indicado, del $10 \%$ como mínimo. De este modo, la metodología asegura que, sin exceder el presupuesto máximo disponible (que en años anteriores se dedicaba únicamente a subvencionar los déficit de explotación), éste sea repartido de forma diferente, fomentando las mejoras de calidad de los operadores, a la vez que se les asegura un resultado económico positivo para cada concesión.

Al igual que en el caso de optimizar únicamente las 8 líneas incluidas en los trayectos metropolitanos, observamos que la óptima proporción de beneficios sociales y de los usuarios que debería ser revertida al operador es de un $100 \%$, lo que incide de nuevo en la necesidad de una fuerte apuesta de la Administración por la mejora de calidad del servicio.

Por otra parte, analizando los puntos óptimos operación de cada línea, observamos que, a diferencia de los casos expuestos en el punto anterior, el número de servicios no precisa ser aumentado en ningún caso, y las características del vehículo sólo deberían ser mejoradas en unas pocas líneas. Además, sería conveniente disminuir los tiempos de viaje, mientras que los costes sólo deben bajar en unas rutas determinadas. Y respecto a la capacidad de los autobuses, es suficiente con vehículos de unas 45 plazas para asegurar que la demanda captada puede ser satisfecha.

Además, es de destacar que, aunque la demanda del servicio aumenta menos (relativamente) que en el caso anterior, experimentando la mayor parte de las líneas crecimientos entre un $7 \%$ y un $15 \%$, existen algunas concesiones con beneficio industrial igual o superior al $10 \%$ sin necesidad de subvención por parte de la Administración (aunque sí reciben los incentivos por beneficios sociales y de los usuarios). Éstas son las concesiones VACL-027 y VACL-033. Sin embargo, vemos que la gran mayoría sí precisa el apoyo económico de la Administración para la consecución del citado margen de beneficios. 
Tabla 5-35. Prueba 2: Tray. Provinciales/Regionales. Maximización beneficio social + operador. Punto óptimo de explotación (valores finales)

\begin{tabular}{|c|c|c|c|c|c|c|c|}
\hline \multirow[b]{2}{*}{ CONC. } & \multirow{2}{*}{$\begin{array}{l}\text { ID } \\
\text { LíNEA }\end{array}$} & \multicolumn{6}{|c|}{ EXPLOTACIÓN ÓPTIMA (VALORES FINALES) } \\
\hline & & $\begin{array}{c}\mathrm{V} \\
\text { (viaj./año) }\end{array}$ & $t(h)$ & $c(€)$ & $\begin{array}{c}\text { NS } \\
\text { (salidas/lab.) }\end{array}$ & $\begin{array}{l}\text { Prop. ruta } \\
\text { vías rápidas }\end{array}$ & Tipo bus \\
\hline \multirow{7}{*}{ VACL-001 } & 1 & 25.390 & 0,45 & 0,52 & 4,4 & 0,24 & Seminuevo \\
\hline & 2 & 3.512 & 0,93 & 3,80 & 0,8 & 0,08 & Gran clase \\
\hline & 3 & 7.209 & 1,03 & 3,25 & 1,2 & 0,08 & Nuevo \\
\hline & 4 & 1.227 & 1,29 & 10,00 & 0,6 & 0,08 & Seminuevo \\
\hline & 5 & 7.998 & 1,95 & 11,09 & 2 & 0,59 & Nuevo \\
\hline & 6 & 14.407 & 0,68 & 0,52 & 3 & -- & Seminuevo \\
\hline & 7 & 8.041 & 1,52 & 11,45 & 4 & 0,94 & Nuevo \\
\hline \multirow{2}{*}{ VACL-027 } & 8 & 12.305 & 0,88 & 7,50 & 4 & 0,93 & Gran clase \\
\hline & 9 & 1.165 & 1,01 & 7,05 & 1 & 0,64 & Nuevo \\
\hline \multirow{7}{*}{ VACL-004 } & 10 & 363 & 0,65 & 9,80 & 1,1 & 0,82 & Seminuevo \\
\hline & 11 & 14.268 & 0,60 & 0,52 & 4 & 0,39 & Seminuevo \\
\hline & 12 & 360 & 0,47 & 8,00 & 1 & 0,87 & Seminuevo \\
\hline & 13 & 360 & 0,62 & 10,00 & 1 & 0,8 & Seminuevo \\
\hline & 14 & 1.296 & 0,54 & 3,80 & 2 & 0,69 & Seminuevo \\
\hline & 15 & 270 & 1,11 & 7,95 & 0,65 & 0,58 & Nuevo \\
\hline & 16 & 8.240 & 0,86 & 0,42 & 4 & 0,17 & Nuevo \\
\hline \multirow{2}{*}{ VACL-015 } & 17 & 182 & 0,92 & 4,46 & 0,2 & 0,12 & Seminuevo \\
\hline & 18 & 2.250 & 0,38 & 0,51 & 4 & 0,01 & Seminuevo \\
\hline \multirow{3}{*}{ VACL-007 } & 19 & 337 & 1,01 & 9,02 & 1 & 0,75 & Seminuevo \\
\hline & 20 & 683 & 0,42 & 4,00 & 2 & 0,85 & Seminuevo \\
\hline & 21 & 4.578 & 0,75 & 0,42 & 4 & 0,41 & Seminuevo \\
\hline \multirow{2}{*}{ VACL-010 } & 22 & 4.596 & 0,28 & 0,50 & 4 & -- & Seminuevo \\
\hline & 23 & 208 & 0,96 & 8,00 & 0,3 & 0,13 & Gran clase \\
\hline \multirow{3}{*}{ VACL-019 } & 24 & 697 & 1,50 & 7,00 & 1,2 & 0,07 & Nuevo \\
\hline & 25 & 771 & 0,46 & 3,00 & 0,4 & 0,06 & Seminuevo \\
\hline & 26 & 12.080 & 0,38 & 0,51 & 3,5 & 0,08 & Seminuevo \\
\hline VACL-033 & 27 & 389 & 0,40 & 2,85 & 2 & 0,22 & Seminuevo \\
\hline \multirow{3}{*}{ VACL-075 } & 28 & 1.268 & 0,63 & 6,00 & 1 & 0,94 & Seminuevo \\
\hline & 29 & 3.733 & 0,54 & 1,94 & 2,1 & 0,89 & Nuevo \\
\hline & 30 & 1.100 & 0,25 & 0,48 & 2,5 & 0,75 & Nuevo \\
\hline \multirow{6}{*}{ VACL-079 } & 31 & 638 & 0,96 & 4,93 & 1 & 0,93 & Antiguo \\
\hline & 32 & 852 & 0,80 & 9,99 & 1 & 0,93 & Seminuevo \\
\hline & 33 & 403 & 0,56 & 4,20 & 1 & 0,74 & Nuevo \\
\hline & 34 & 941 & 0,92 & 3,62 & 1 & 0,93 & Seminuevo \\
\hline & 35 & 104 & 0,44 & 4,44 & 0,5 & 0,87 & Seminuevo \\
\hline & 36 & 461 & 0,59 & 2,75 & 1,4 & 0,52 & Seminuevo \\
\hline VACL-116 & 37 & 2.653 & 0,89 & 7,00 & 1,3 & 0,13 & Seminuevo \\
\hline TOTAL & & 145.334 & & & & & \\
\hline
\end{tabular}


Tabla 5-36. Prueba 2: Tray. Provinciales/Regionales. Maximización beneficio social + operador.

Punto óptimo de explotación (incrementos relativos)

\begin{tabular}{|c|c|c|c|c|c|c|c|}
\hline \multirow[b]{2}{*}{ CONC. } & \multirow[b]{2}{*}{$\begin{array}{c}\text { ID } \\
\text { LÍNEA }\end{array}$} & \multicolumn{6}{|c|}{ EXPLOTACIÓN ÓPTIMA (INCREMENTOS RELATIVOS) } \\
\hline & & $\Delta \mathbf{V}(\%)$ & $\Delta t(\%)$ & $\Delta c(\%)$ & $\Delta \mathrm{NS}(\%)$ & $\begin{array}{c}\Delta \text { Prop. ruta } \\
\text { vías rápidas } \\
(\%)\end{array}$ & $\Delta$ Tipo bus \\
\hline \multirow{7}{*}{ VACL-001 } & 1 & $7,3 \%$ & $-10 \%$ & -- & -- & -- & -- \\
\hline & 2 & $12,6 \%$ & $-10 \%$ & -- & -- & -- & 2 niveles \\
\hline & 3 & $5,9 \%$ & $-5 \%$ & -- & -- & -- & 1 nivel \\
\hline & 4 & $7,3 \%$ & $-10 \%$ & -- & -- & -- & -- \\
\hline & 5 & $7,3 \%$ & $-10 \%$ & -- & -- & -- & -- \\
\hline & 6 & $7,3 \%$ & $-10 \%$ & -- & -- & -- & -- \\
\hline & 7 & $7,5 \%$ & $-10 \%$ & -- & -- & -- & -- \\
\hline \multirow{2}{*}{ VACL-027 } & 8 & $4,2 \%$ & $-2 \%$ & -- & -- & -- & 1 nivel \\
\hline & 9 & $8,5 \%$ & $-8 \%$ & -- & -- & -- & 1 nivel \\
\hline \multirow{7}{*}{ VACL-004 } & 10 & $8,2 \%$ & $-10 \%$ & $-2 \%$ & -- & -- & -- \\
\hline & 11 & $7,3 \%$ & $-10 \%$ & -- & -- & -- & -- \\
\hline & 12 & $7,3 \%$ & $-10 \%$ & -- & -- & -- & -- \\
\hline & 13 & $7,3 \%$ & $-10 \%$ & -- & -- & -- & -- \\
\hline & 14 & $7,3 \%$ & $-10 \%$ & -- & -- & -- & -- \\
\hline & 15 & $7,3 \%$ & $-10 \%$ & -- & -- & -- & -- \\
\hline & 16 & $19,4 \%$ & $-10 \%$ & $-20 \%$ & -- & -- & 1 nivel \\
\hline \multirow{2}{*}{ VACL-015 } & 17 & $8,7 \%$ & $-10 \%$ & $-3 \%$ & -- & -- & -- \\
\hline & 18 & $8,3 \%$ & $-10 \%$ & $-2 \%$ & -- & -- & -- \\
\hline \multirow{3}{*}{ VACL-007 } & 19 & $11,9 \%$ & $-10 \%$ & $-10 \%$ & -- & -- & -- \\
\hline & 20 & $7,3 \%$ & $-10 \%$ & -- & -- & -- & -- \\
\hline & 21 & $15,9 \%$ & $-10 \%$ & $-18 \%$ & -- & -- & -- \\
\hline \multirow{2}{*}{ VACL-010 } & 22 & $8,1 \%$ & $-10 \%$ & $-2 \%$ & -- & -- & -- \\
\hline & 23 & $12,6 \%$ & $-10 \%$ & -- & -- & -- & 2 niveles \\
\hline \multirow{3}{*}{ VACL-019 } & 24 & $1,7 \%$ & $-2 \%$ & -- & -- & -- & -- \\
\hline & 25 & $3,3 \%$ & $-5 \%$ & -- & -- & -- & -- \\
\hline & 26 & $7,3 \%$ & $-10 \%$ & -- & -- & -- & -- \\
\hline VACL-033 & 27 & $5,2 \%$ & $-4 \%$ & $-5 \%$ & -- & -- & -- \\
\hline \multirow{3}{*}{ VACL-075 } & 28 & $7,3 \%$ & $-10 \%$ & -- & -- & -- & -- \\
\hline & 29 & $7,5 \%$ & $-10 \%$ & $-1 \%$ & -- & -- & -- \\
\hline & 30 & $7,9 \%$ & $-1 \%$ & $-11 \%$ & -- & -- & 1 nivel \\
\hline \multirow{6}{*}{ VACL-079 } & 31 & $9,2 \%$ & $-10 \%$ & $-4 \%$ & -- & -- & -- \\
\hline & 32 & $7,3 \%$ & $-10 \%$ & -- & -- & -- & -- \\
\hline & 33 & $3,5 \%$ & $-5 \%$ & -- & -- & -- & -- \\
\hline & 34 & $9,4 \%$ & $-10 \%$ & $-5 \%$ & -- & -- & -- \\
\hline & 35 & $6,9 \%$ & $-3 \%$ & $-11 \%$ & -- & -- & -- \\
\hline & 36 & $11,2 \%$ & $-10 \%$ & $-8 \%$ & -- & -- & -- \\
\hline VACL-116 & 37 & $7,3 \%$ & $-10 \%$ & -- & -- & -- & -- \\
\hline TOTAL & & $8,0 \%$ & & & & & \\
\hline
\end{tabular}


Tabla 5-37. Prueba 2: Tray. Provinciales/Regionales. Maximización beneficio social + operador. Resultados económicos (valores finales)

\begin{tabular}{|c|c|c|c|c|c|c|c|}
\hline \multirow[b]{2}{*}{ CONC. } & \multirow{2}{*}{$\begin{array}{c}\text { ID } \\
\text { LíNEA }\end{array}$} & \multicolumn{6}{|c|}{ RESULTADOS ECONÓMICOS (VALORES FINALES) } \\
\hline & & $\begin{array}{c}\text { C explot. } \\
\text { (€/año) }\end{array}$ & $\begin{array}{c}\text { Subvenc. } \\
\text { (€/año) }\end{array}$ & BI (\%) & $\begin{array}{c}\text { C Admón. } \\
\text { (€/año) }\end{array}$ & $\begin{array}{c}\text { PT } \\
\text { (€/año) }\end{array}$ & $\mathbf{P}$ \\
\hline \multirow{7}{*}{ VACL-001 } & 1 & 29.193 & \multirow{7}{*}{14} & \multirow{7}{*}{$10 \%$} & \multirow{7}{*}{77.183} & \multirow{7}{*}{807.244} & \multirow{7}{*}{1,000} \\
\hline & 2 & 11.115 & & & & & \\
\hline & 3 & 22.289 & & & & & \\
\hline & 4 & 10.890 & & & & & \\
\hline & 5 & 82.408 & & & & & \\
\hline & 6 & 54.746 & & & & & \\
\hline & 7 & 87.281 & & & & & \\
\hline \multirow{2}{*}{ VACL-027 } & 8 & 87.050 & \multirow{2}{*}{--} & \multirow{2}{*}{$26 \%$} & \multirow{2}{*}{17.668} & \multirow{2}{*}{807.244} & \multirow{2}{*}{1,000} \\
\hline & 9 & 7.008 & & & & & \\
\hline \multirow{7}{*}{ VACL-004 } & 10 & 10.288 & \multirow{7}{*}{188.311} & \multirow{7}{*}{$10 \%$} & \multirow{7}{*}{209.005} & \multirow{7}{*}{807.244} & \multirow{7}{*}{1,000} \\
\hline & 11 & 60.798 & & & & & \\
\hline & 12 & 6.353 & & & & & \\
\hline & 13 & 8.280 & & & & & \\
\hline & 14 & 32.089 & & & & & \\
\hline & 15 & 27.239 & & & & & \\
\hline & 16 & 70.381 & & & & & \\
\hline \multirow{2}{*}{ VACL-015 } & 17 & 23.350 & \multirow{2}{*}{85.068} & \multirow{2}{*}{$10 \%$} & \multirow{2}{*}{86.253} & & 1000 \\
\hline & 18 & 56.838 & & & & $80 / .244$ & 1,000 \\
\hline & 19 & 7.088 & & & & & \\
\hline VACL-007 & 20 & 5.943 & 57.006 & $10 \%$ & 62.918 & 807.244 & 1,000 \\
\hline & 21 & 51.161 & & & & & \\
\hline VACI -010 & 22 & 59.697 & 67492 & $10 \%$ & 69246 & 807244 & 1000 \\
\hline VACLETIO & 23 & 6.874 & 01.492 & $10 \%$ & $09 . \angle 40$ & $80 / .244$ & 1,000 \\
\hline & 24 & 34.380 & & & & & \\
\hline VACL-019 & 25 & 3.837 & 86.220 & $10 \%$ & 91.410 & 807.244 & 1,000 \\
\hline & 26 & 57.021 & & & & & \\
\hline VACL-033 & 27 & 995 & -- & $27 \%$ & 149 & 807.244 & 1,000 \\
\hline & 28 & 18.642 & & & & & \\
\hline VACL-075 & 29 & 27.942 & 39.244 & $10 \%$ & 43.649 & 807.244 & 1,000 \\
\hline & 30 & 13.664 & & & & & \\
\hline & 31 & 26.654 & & & & & \\
\hline & 32 & 27.071 & & & & & \\
\hline VACL-079 & 33 & 12.773 & 110.507 & $10 \%$ & 115.140 & 807.244 & 1,000 \\
\hline & 34 & 25.772 & & & & & \\
\hline & 35 & 4.903 & & & & & \\
\hline & 36 & 17.712 & & & & & \\
\hline VACL-116 & 37 & 48.353 & 31.032 & $10 \%$ & 34.623 & 807.244 & 1,000 \\
\hline TOTAL & & 1.138 .077 & 664.894 & & 807.244 & & 1,000 \\
\hline
\end{tabular}


Tabla 5-38. Prueba 2: Tray. Provinciales/Regionales. Maximización beneficio social + operador.

Resultados económicos (incrementos)

\begin{tabular}{|c|c|c|c|c|c|c|}
\hline \multirow[b]{2}{*}{ CONC. } & \multirow[b]{2}{*}{$\begin{array}{c}\text { ID } \\
\text { LÍNEA }\end{array}$} & \multicolumn{5}{|c|}{ RESULTADOS ECONÓMICOS (INCREMENTOS) } \\
\hline & & $\begin{array}{c}\Delta C \\
\text { (€/año) }\end{array}$ & $\begin{array}{c}\Delta \mathrm{BU} \\
\text { (€/año) }\end{array}$ & $\begin{array}{c}\Delta \mathrm{BS} \\
\text { (€/año) }\end{array}$ & $\begin{array}{c}\Delta \mathrm{BO} \\
(€ / \text { /año) }\end{array}$ & $\begin{array}{c}\text { Función objetivo } \\
\Delta \mathrm{BU}+\Delta \mathrm{BS}+\Delta \mathrm{BO}-\Delta \mathrm{C} \\
(€ / \text { año })\end{array}$ \\
\hline \multirow{7}{*}{ VACL-001 } & 1 & -3.140 & 9.898 & 1.882 & 12.673 & 27.593 \\
\hline & 2 & -1.345 & 4.581 & 2.195 & 8.266 & 16.386 \\
\hline & 3 & -952 & 2.850 & 2.365 & 6.519 & 12.687 \\
\hline & 4 & -1.210 & 1.372 & 721 & 2.921 & 6.223 \\
\hline & 5 & -6.064 & 13.547 & 9.172 & 28.684 & 57.468 \\
\hline & 6 & -5.291 & 8.413 & 1.018 & 9.937 & 24.659 \\
\hline & 7 & -7.306 & 10.886 & 8.270 & 25.175 & 51.637 \\
\hline \multirow{2}{*}{ VACL-027 } & 8 & -1.503 & 12.237 & 3.919 & 19.888 & 37.547 \\
\hline & 9 & -562 & 798 & 714 & 2.157 & 4.231 \\
\hline \multirow{7}{*}{ VACL-004 } & 10 & -2.902 & 268 & 154 & 624 & 3.947 \\
\hline & 11 & -6.785 & 7.405 & 1.410 & 9.316 & 24.917 \\
\hline & 12 & -2.118 & 145 & 102 & 442 & 2.806 \\
\hline & 13 & -2.760 & 191 & 136 & 571 & 3.659 \\
\hline & 14 & -3.581 & 605 & 368 & 1.306 & 5.861 \\
\hline & 15 & -2.290 & 260 & 159 & 564 & 3.272 \\
\hline & 16 & -8.107 & 6.181 & 3.309 & 9.341 & 26.939 \\
\hline \multirow{2}{*}{ VACL-015 } & 17 & -2.594 & 166 & 85 & 292 & 3.138 \\
\hline & 18 & -6.344 & 746 & 188 & 998 & 8.275 \\
\hline \multirow{3}{*}{ VACL-007 } & 19 & -641 & 578 & 302 & 906 & 2.428 \\
\hline & 20 & -558 & 249 & 177 & 610 & 1.594 \\
\hline & 21 & -5.710 & 3.123 & 1.483 & 4.495 & 14.811 \\
\hline \multirow{2}{*}{ VACL-010 } & 22 & -3.155 & 1.136 & 189 & 1.458 & 5.938 \\
\hline & 23 & -593 & 287 & 142 & 615 & 1.637 \\
\hline \multirow{3}{*}{ VACL-019 } & 24 & -533 & 200 & 111 & 389 & 1.233 \\
\hline & 25 & $\begin{array}{l}-182 \\
\end{array}$ & 136 & 55 & 264 & 637 \\
\hline & 26 & -5.968 & 3.920 & 769 & 5.104 & 15.761 \\
\hline VACL-033 & 27 & -115 & 108 & 41 & 150 & 414 \\
\hline \multirow{3}{*}{ VACL-075 } & 28 & -1.689 & 692 & 528 & 1.734 & 4.642 \\
\hline & 29 & -2.618 & 1.778 & 1.338 & 3.584 & 9.318 \\
\hline & 30 & -107 & 74 & 65 & 120 & 366 \\
\hline \multirow{6}{*}{ VACL-079 } & 31 & -2.414 & 646 & 506 & 1.292 & 4.858 \\
\hline & 32 & -2.452 & 597 & 461 & 1.627 & 5.138 \\
\hline & 33 & -652 & 91 & 58 & 204 & 1.004 \\
\hline & 34 & -2.334 & 881 & 708 & 1.732 & 5.655 \\
\hline & 35 & -130 & 64 & 24 & 63 & 281 \\
\hline & 36 & -1.971 & 329 & 198 & 551 & 3.049 \\
\hline VACL-116 & 37 & -4.934 & 2.033 & 1.557 & 4.845 & 13.369 \\
\hline TOTAL & & -101.611 & 97.470 & 44.881 & 169.415 & 413.377 \\
\hline
\end{tabular}


Por último, al igual que en el caso anterior, aunque el gasto total de la Administración se mantiene igual al de la situación inicial, de forma que no generamos un mayor esfuerzo económico para ésta, su distribución sí observa interesantes variaciones. Así, de los algo más de $807.000 €$ gastados en total, casi $665.000 €$ se invierten en subvencionar el déficit de explotación de las líneas (para un beneficio industrial del 10\%), mientras que los $142.000 €$ restantes se asignan como incentivos a los operadores que generen beneficios sociales y de los usuarios. Es decir, alrededor del 18\% del presupuesto total disponible para el servicio podría ser "devuelto" a los operadores, cifra en absoluto desdeñable teniendo en cuenta su valor numérico, y se conseguirían unos beneficios totales de más de $413.000 €$ (97.000 € para los usuarios por mejoras en la calidad, $45.000 €$ para la sociedad por reducción de externalidades, y el resto para el operador).

Por otra parte, si el objetivo es maximizar únicamente los beneficios sociales y de los usuarios, aunque manteniendo un margen mínimo de beneficios para el operador, los resultados cambian ligeramente. De la Tabla 5-39 a la Tabla 5-42 se muestran los valores del punto óptimo de explotación, y los resultados económicos asociados al mismo.

La primera conclusión que podemos extraer, analizando el punto óptimo de explotación, es que la variación con respecto a la primera hipótesis es relativamente pequeña (aunque superior a la experimentada en el caso de modificar únicamente las 8 líneas metropolitanas). Así, se ven mejoradas en mayor medida las características del autobús, que suben de nivel en más líneas que en el caso anterior, y los costes se reducen algo más. Sin embargo, el número de servicios se mantiene, de nuevo, constante. Por tanto, deducimos que la situación óptima del servicio de autobuses interurbano, desde el punto de vista de la calidad, requiere un mejor servicio cuando no se consideran los beneficios y costes del operador que cuando sí lo hacemos, como cabría en cierto modo esperar.

Sin embargo, a pesar de mantenerse constante el gasto total que la Administración debe asumir, sí varía ostensiblemente la proporción de beneficios sociales y de los usuarios que ésta revierte al operador, descendiendo en este caso hasta un $8,8 \%$. No obstante, el hecho de que siga teniendo valores positivos indica que, incluso aunque los beneficios y costes del operador no sean tenidos en cuenta, las mejoras en calidad deben conllevar un cierto incentivo económico, pues en caso contrario revertimos a la situación actual. 
Tabla 5-39. Prueba 2: Tray. Provinciales/Regionales. Maximización beneficio social.

Punto óptimo de explotación (valores finales)

\begin{tabular}{|c|c|c|c|c|c|c|c|}
\hline \multirow[b]{2}{*}{ CONC. } & \multirow[b]{2}{*}{$\begin{array}{c}\text { ID } \\
\text { LíNEA }\end{array}$} & \multicolumn{6}{|c|}{ EXPLOTACIÓN ÓPTIMA (VALORES FINALES) } \\
\hline & & $\begin{array}{c}\mathrm{V} \\
\text { (viaj./laño) }\end{array}$ & $t(h)$ & $c(€)$ & $\begin{array}{c}\text { NS } \\
\text { (salidas/lab.) }\end{array}$ & $\begin{array}{l}\text { Prop. ruta } \\
\text { vías rápidas }\end{array}$ & Tipo bus \\
\hline \multirow{7}{*}{ VACL-001 } & 1 & 25.701 & 0,50 & 0,48 & 4,4 & 0,24 & Gran clase \\
\hline & 2 & 3.258 & 0,97 & 3,79 & 0,8 & 0,08 & Seminuevo \\
\hline & 3 & 6.913 & 1,06 & 3,25 & 1,2 & 0,08 & Seminuevo \\
\hline & 4 & 1.227 & 1,29 & 10,00 & 0,6 & 0,08 & Seminuevo \\
\hline & 5 & 8.194 & 1,95 & 11,10 & 2 & 0,59 & Gran clase \\
\hline & 6 & 14.806 & 0,69 & 0,47 & 3 & -- & Seminuevo \\
\hline & 7 & 8.026 & 1,52 & 11,50 & 4 & 0,94 & Nuevo \\
\hline \multirow{2}{*}{ VACL-027 } & 8 & 12.592 & 0,83 & 7,29 & 4 & 0,93 & Nuevo \\
\hline & 9 & 1.312 & 0,99 & 4,75 & 1 & 0,64 & Seminuevo \\
\hline \multirow{7}{*}{ VACL-004 } & 10 & 392 & 0,65 & 7,97 & 1,1 & 0,82 & Seminuevo \\
\hline & 11 & 14.267 & 0,60 & 0,52 & 4 & 0,39 & Seminuevo \\
\hline & 12 & 399 & 0,47 & 6,81 & 1 & 0,87 & Gran clase \\
\hline & 13 & 373 & 0,63 & 9,43 & 1 & 0,80 & Nuevo \\
\hline & 14 & 1.306 & 0,54 & 3,73 & 2 & 0,69 & Seminuevo \\
\hline & 15 & 280 & 1,11 & 7,78 & 0,65 & 0,58 & Gran clase \\
\hline & 16 & 7.529 & 0,86 & 0,50 & 4 & 0,17 & Seminuevo \\
\hline \multirow{2}{*}{ VACL-015 } & 17 & 210 & 0,92 & 2,81 & 0,2 & 0,12 & Seminuevo \\
\hline & 18 & 2.661 & 0,38 & 0,32 & 4 & 0,01 & Nuevo \\
\hline \multirow{3}{*}{ VACL-007 } & 19 & 318 & 1,07 & 10,00 & 1 & 0,75 & Nuevo \\
\hline & 20 & 730 & 0,46 & 2,95 & 2 & 0,85 & Nuevo \\
\hline & 21 & 4.543 & 0,75 & 0,49 & 4 & 0,41 & Gran clase \\
\hline \multirow{2}{*}{ VACL-010 } & 22 & 5.245 & 0,28 & 0,37 & 4 & -- & Nuevo \\
\hline & 23 & 203 & 0,99 & 7,11 & 0,3 & 0,13 & Seminuevo \\
\hline \multirow{3}{*}{ VACL-019 } & 24 & 777 & 1,38 & 6,09 & 1,2 & 0,07 & Nuevo \\
\hline & 25 & 896 & 0,44 & 2,18 & 0,4 & 0,06 & Seminuevo \\
\hline & 26 & 12.786 & 0,38 & 0,44 & 3,5 & 0,08 & Seminuevo \\
\hline VACL-033 & 27 & 444 & 0,38 & 2,16 & 2 & 0,22 & Seminuevo \\
\hline \multirow{3}{*}{ VACL-075 } & 28 & 1.253 & 0,69 & 5,28 & 1 & 0,94 & Seminuevo \\
\hline & 29 & 3.787 & 0,54 & 1,87 & 2,1 & 0,89 & Nuevo \\
\hline & 30 & 1.165 & 0,23 & 0,48 & 2,5 & 0,75 & Nuevo \\
\hline \multirow{6}{*}{ VACL-079 } & 31 & 661 & 0,96 & 4,49 & 1 & 0,93 & Antiguo \\
\hline & 32 & 830 & 0,88 & 9,06 & 1 & 0,93 & Seminuevo \\
\hline & 33 & 457 & 0,56 & 2,85 & 1 & 0,74 & Nuevo \\
\hline & 34 & 932 & 1,00 & 3,18 & 1 & 0,93 & Seminuevo \\
\hline & 35 & 111 & 0,42 & 3,89 & 0,5 & 0,87 & Seminuevo \\
\hline & 36 & 436 & 0,61 & 2,98 & 1,4 & 0,52 & Seminuevo \\
\hline VACL-116 & 37 & 2.785 & 0,89 & 7,00 & 1,3 & 0,13 & Gran clase \\
\hline TOTAL & & 147.804 & & & & & \\
\hline
\end{tabular}


Tabla 5-40. Prueba 2: Tray. Provinciales/Regionales. Maximización beneficio social.

Punto óptimo de explotación (incrementos relativos)

\begin{tabular}{|c|c|c|c|c|c|c|c|}
\hline \multirow[b]{2}{*}{ CONC. } & \multirow[b]{2}{*}{$\begin{array}{c}\text { ID } \\
\text { LÍNEA }\end{array}$} & \multicolumn{6}{|c|}{ EXPLOTACIÓN ÓPTIMA (INCREMENTOS RELATIVOS) } \\
\hline & & $\Delta \mathbf{V}(\%)$ & $\Delta t(\%)$ & $\Delta \mathrm{c}(\%)$ & $\Delta \mathrm{NS}(\%)$ & $\begin{array}{c}\Delta \text { Prop. ruta } \\
\text { vías rápidas } \\
(\%)\end{array}$ & $\Delta$ Tipo bus \\
\hline \multirow{7}{*}{ VACL-001 } & 1 & $8,6 \%$ & $-1 \%$ & $-7 \%$ & -- & -- & 2 niveles \\
\hline & 2 & $4,5 \%$ & $-6 \%$ & -- & -- & -- & -- \\
\hline & 3 & $1,6 \%$ & $-2 \%$ & -- & -- & -- & -- \\
\hline & 4 & $7,3 \%$ & $-10 \%$ & -- & -- & -- & -- \\
\hline & 5 & $9,9 \%$ & $-10 \%$ & -- & -- & -- & 1 nivel \\
\hline & 6 & $10,2 \%$ & $-8 \%$ & $-9 \%$ & -- & -- & -- \\
\hline & 7 & $7,3 \%$ & $-10 \%$ & -- & -- & -- & -- \\
\hline \multirow{2}{*}{ VACL-027 } & 8 & $6,7 \%$ & $-7 \%$ & $-3 \%$ & -- & -- & -- \\
\hline & 9 & $22,2 \%$ & $-10 \%$ & $-33 \%$ & -- & -- & -- \\
\hline \multirow{7}{*}{ VACL-004 } & 10 & $16,8 \%$ & $-10 \%$ & $-20 \%$ & -- & -- & -- \\
\hline & 11 & $7,3 \%$ & $-10 \%$ & -- & -- & -- & -- \\
\hline & 12 & $18,9 \%$ & $-9 \%$ & $-15 \%$ & -- & -- & 2 niveles \\
\hline & 13 & $11,2 \%$ & $-8 \%$ & $-6 \%$ & -- & -- & 1 nivel \\
\hline & 14 & $8,1 \%$ & $-10 \%$ & $-2 \%$ & -- & -- & -- \\
\hline & 15 & $11,0 \%$ & $-10 \%$ & $-2 \%$ & -- & -- & 1 nivel \\
\hline & 16 & $9,1 \%$ & $-10 \%$ & $-4 \%$ & -- & -- & -- \\
\hline \multirow{2}{*}{ VACL-015 } & 17 & $25,5 \%$ & $-10 \%$ & $-39 \%$ & -- & -- & -- \\
\hline & 18 & $28,0 \%$ & $-10 \%$ & $-38 \%$ & -- & -- & 1 nivel \\
\hline \multirow{3}{*}{ VACL-007 } & 19 & $5,4 \%$ & $-4 \%$ & -- & -- & -- & 1 nivel \\
\hline & 20 & $14,6 \%$ & -- & $-26 \%$ & -- & -- & 1 nivel \\
\hline & 21 & $15,0 \%$ & $-10 \%$ & $-5 \%$ & -- & -- & 2 niveles \\
\hline \multirow{2}{*}{ VACL-010 } & 22 & $23,4 \%$ & $-10 \%$ & $-28 \%$ & -- & -- & 1 nivel \\
\hline & 23 & $10,3 \%$ & $-7 \%$ & $-11 \%$ & -- & -- & -- \\
\hline \multirow{3}{*}{ VACL-019 } & 24 & $13,3 \%$ & $-10 \%$ & $-13 \%$ & -- & -- & -- \\
\hline & 25 & $20,1 \%$ & $-10 \%$ & $-27 \%$ & -- & -- & -- \\
\hline & 26 & $13,6 \%$ & $-10 \%$ & $-13 \%$ & -- & -- & -- \\
\hline VACL-033 & 27 & $20,1 \%$ & $-10 \%$ & $-28 \%$ & -- & -- & -- \\
\hline \multirow{3}{*}{ VACL-075 } & 28 & $6,0 \%$ & $-1 \%$ & $-12 \%$ & -- & -- & -- \\
\hline & 29 & $9,1 \%$ & $-10 \%$ & $-4 \%$ & -- & -- & -- \\
\hline & 30 & $14,2 \%$ & $-9 \%$ & $-11 \%$ & -- & -- & 1 nivel \\
\hline \multirow{6}{*}{ VACL-079 } & 31 & $13,2 \%$ & $-10 \%$ & $-13 \%$ & -- & -- & -- \\
\hline & 32 & $4,5 \%$ & $-1 \%$ & $-9 \%$ & -- & -- & -- \\
\hline & 33 & $17,3 \%$ & $-4 \%$ & $-32 \%$ & -- & -- & -- \\
\hline & 34 & $8,4 \%$ & $-2 \%$ & $-16 \%$ & -- & -- & -- \\
\hline & 35 & $14,2 \%$ & $-6 \%$ & $-22 \%$ & -- & -- & -- \\
\hline & 36 & $5,1 \%$ & $-6 \%$ & $-1 \%$ & -- & -- & -- \\
\hline VACL-116 & 37 & $12,6 \%$ & $-10 \%$ & -- & -- & -- & 2 niveles \\
\hline TOTAL & & $9,8 \%$ & & & & & \\
\hline
\end{tabular}


Tabla 5-41. Prueba 2: Tray. Provinciales/Regionales. Maximización beneficio social. Resultados económicos (valores finales)

\begin{tabular}{|c|c|c|c|c|c|c|c|}
\hline \multirow[b]{2}{*}{ CONC. } & \multirow{2}{*}{$\begin{array}{c}\text { ID } \\
\text { LÍNEA }\end{array}$} & \multicolumn{6}{|c|}{ RESULTADOS ECONÓMICOS (VALORES FINALES) } \\
\hline & & $\begin{array}{l}\text { C explot. } \\
\text { (€/año) }\end{array}$ & $\begin{array}{l}\text { Subvenc. } \\
\text { (€/año) }\end{array}$ & BI (\%) & $\begin{array}{l}\text { C Admón. } \\
\text { (€/año) }\end{array}$ & $\begin{array}{c}\text { PT } \\
\text { (€/año) }\end{array}$ & $\mathbf{P}$ \\
\hline \multirow{7}{*}{ VACL-001 } & 1 & 32.157 & \multirow{7}{*}{75.935} & \multirow{7}{*}{$10 \%$} & \multirow{7}{*}{83.127} & \multirow{7}{*}{807.244} & \multirow{7}{*}{0,088} \\
\hline & 2 & 11.728 & & & & & \\
\hline & 3 & 22.811 & & & & & \\
\hline & 4 & 10.891 & & & & & \\
\hline & 5 & 82.161 & & & & & \\
\hline & 6 & 55.631 & & & & & \\
\hline & 7 & 87.283 & & & & & \\
\hline \multirow{2}{*}{ VACL-027 } & 8 & 83.930 & \multirow{2}{*}{177} & \multirow{2}{*}{$10 \%$} & \multirow{2}{*}{1.996} & \multirow{2}{*}{807.244} & \multirow{2}{*}{0,088} \\
\hline & 9 & 6.968 & & & & & \\
\hline \multirow{7}{*}{ VACL-004 } & 10 & 10.288 & \multirow{7}{*}{208.557} & \multirow{7}{*}{$10 \%$} & \multirow{7}{*}{210.364} & \multirow{7}{*}{807.244} & \multirow{7}{*}{0,088} \\
\hline & 11 & 60.801 & & & & & \\
\hline & 12 & 6.587 & & & & & \\
\hline & 13 & 8.754 & & & & & \\
\hline & 14 & 32.089 & & & & & \\
\hline & 15 & 27.191 & & & & & \\
\hline & 16 & 70.609 & & & & & \\
\hline \multirow{2}{*}{ VACL-015 } & 17 & 23.355 & \multirow{2}{*}{86.437} & \multirow{2}{*}{$10 \%$} & \multirow{2}{*}{86.652} & 807241 & 0088 \\
\hline & 18 & 56.739 & & & & 001.244 & 0,000 \\
\hline & 19 & 7.452 & & & & & \\
\hline VACL-007 & 20 & 6.480 & 62.970 & $10 \%$ & 63.611 & 807.244 & 0,088 \\
\hline & 21 & 50.763 & & & & & \\
\hline$V A C I 010$ & 22 & 59.625 & 69777 & $10 \%$ & 60070 & 807244 & 0088 \\
\hline VACLOUTO & 23 & 7.073 & $09.14 !$ & $10 \%$ & 09.919 & 001.244 & 0,000 \\
\hline & 24 & 32.562 & & & & & \\
\hline VACL-019 & 25 & 3.617 & 89.325 & $10 \%$ & 90.182 & 807.244 & 0,088 \\
\hline & 26 & 57.021 & & & & & \\
\hline VACL-033 & 27 & 842 & -- & $20 \%$ & 52 & 807.244 & 0,088 \\
\hline & 28 & 20.165 & & & & & \\
\hline VACL-075 & 29 & 27.943 & 45.380 & $10 \%$ & 45.832 & 807.244 & 0,088 \\
\hline & 30 & 12.550 & & & & & \\
\hline & 31 & 26.654 & & & & & \\
\hline & 32 & 29.386 & & & & & \\
\hline VACL-079 & 33 & 12.881 & 121.440 & $10 \%$ & 121.921 & 807.244 & 0,088 \\
\hline & 34 & 27.723 & & & & & \\
\hline & 35 & 4.744 & & & & & \\
\hline & 36 & 18.408 & & & & & \\
\hline VACL-116 & 37 & 48.202 & 32.917 & $10 \%$ & 33.529 & 807.244 & 0,088 \\
\hline TOTAL & & 1.144 .063 & 792.884 & & 807.244 & & 0,088 \\
\hline
\end{tabular}


Tabla 5-42. Prueba 2: Tray. Provinciales/Regionales. Maximización beneficio social. Resultados económicos (incrementos)

\begin{tabular}{|c|c|c|c|c|c|c|}
\hline \multirow[b]{2}{*}{ CONC. } & \multirow[b]{2}{*}{$\begin{array}{c}\text { ID } \\
\text { LíNEA }\end{array}$} & \multicolumn{5}{|c|}{ RESULTADOS ECONÓMICOS (INCREMENTOS) } \\
\hline & & $\begin{array}{c}\Delta C \\
\text { (€/año) }\end{array}$ & $\begin{array}{c}\Delta \mathrm{BU} \\
\text { (€/año) }\end{array}$ & $\begin{array}{c}\Delta \mathrm{BS} \\
\text { (€/año) }\end{array}$ & $\begin{array}{c}\Delta \mathrm{BO} \\
\text { (€/año) }\end{array}$ & $\begin{array}{c}\text { Función objetivo } \\
\Delta \mathrm{BU}+\Delta \mathrm{BS} \\
(€ / \text { /año) }\end{array}$ \\
\hline \multirow{7}{*}{ VACL-001 } & 1 & -176 & 6.304 & 2.147 & 874 & 8.452 \\
\hline & 2 & -732 & 1.640 & 794 & 696 & 2.435 \\
\hline & 3 & -430 & 1.354 & 648 & 529 & 2.002 \\
\hline & 4 & -1.209 & 1.369 & 720 & 1.013 & 2.088 \\
\hline & 5 & -6.312 & 26.862 & 12.339 & 11.663 & 39.201 \\
\hline & 6 & -4.406 & 7.648 & 1.426 & 817 & 9.074 \\
\hline & 7 & -7.303 & 10.517 & 8.050 & 7.876 & 18.567 \\
\hline \multirow{2}{*}{ VACL-027 } & 8 & -4.622 & 9.049 & 6.355 & 4.560 & 15.403 \\
\hline & 9 & -602 & 3.414 & 1.873 & -872 & 5.287 \\
\hline \multirow{7}{*}{ VACL-004 } & 10 & -2.901 & 882 & 313 & -127 & 1.195 \\
\hline & 11 & -6.782 & 7.405 & 1.408 & 1.277 & 8.813 \\
\hline & 12 & -1.884 & 675 & 261 & 112 & 936 \\
\hline & 13 & -2.287 & 346 & 208 & 215 & 554 \\
\hline & 14 & -3.581 & 689 & 410 & 378 & 1.099 \\
\hline & 15 & -2.338 & 535 & 237 & 240 & 772 \\
\hline & 16 & -7.879 & 5.615 & 1.569 & 803 & 7.184 \\
\hline \multirow{2}{*}{ VACL-015 } & 17 & -2.590 & 441 & 248 & -119 & 689 \\
\hline & 18 & -6.443 & 1.130 & 629 & -63 & 1.759 \\
\hline \multirow{3}{*}{ VACL-007 } & 19 & -277 & 110 & 135 & 184 & 245 \\
\hline & 20 & -22 & 678 & 348 & -305 & 1.025 \\
\hline & 21 & -6.108 & 4.633 & 1.382 & 720 & 6.015 \\
\hline \multirow{2}{*}{ VACL-010 } & 22 & -3.228 & 1.707 & 537 & -47 & 2.245 \\
\hline & 23 & -394 & 281 & 118 & 5 & 398 \\
\hline \multirow{3}{*}{ VACL-019 } & 24 & -2.351 & 1.500 & 890 & 145 & 2.390 \\
\hline & 25 & -401 & 913 & 332 & -175 & 1.245 \\
\hline & 26 & -5.968 & 4.689 & 1.423 & 440 & 6.111 \\
\hline VACL-033 & 27 & -268 & 436 & 158 & -98 & 594 \\
\hline \multirow{3}{*}{ VACL-075 } & 28 & -165 & 922 & 433 & -360 & 1.355 \\
\hline & 29 & -2.617 & 2.002 & 1.612 & 646 & 3.614 \\
\hline & 30 & -1.221 & 244 & 119 & 40 & 363 \\
\hline \multirow{6}{*}{ VACL-079 } & 31 & -2.413 & 904 & 724 & 106 & 1.629 \\
\hline & 32 & -137 & 781 & 283 & -328 & 1.064 \\
\hline & 33 & -543 & 601 & 286 & -256 & 888 \\
\hline & 34 & -383 & 655 & 629 & -192 & 1.285 \\
\hline & 35 & -289 & 128 & 50 & -38 & 178 \\
\hline & 36 & -1.276 & 155 & 90 & 74 & 245 \\
\hline VACL-116 & 37 & -5.085 & 4.311 & 2.650 & 2.794 & 6.960 \\
\hline TOTAL & & -95.624 & 111.524 & 51.835 & 33.227 & 163.359 \\
\hline
\end{tabular}


Por otra parte, respecto al beneficio industrial real de las concesiones, de las dos concesiones que, en el caso anterior, tenían un margen igual o superior al 10\% sin precisar de subvención por parte de la Administración, sólo una lo mantiene al suprimir de la optimización los beneficios y costes del operador. Este hecho radica precisamente en la proporción de beneficios sociales y de los usuarios que revierte al operador, que se ha visto reducida considerablemente, lo cual provoca el desequilibrio económico de las líneas.

Además, en este caso, de los $807.244 €$ gastados en total, casi $793.000 €$ se invierten en subvencionar el déficit de explotación de las líneas (para un beneficio industrial del 10\%), de modo que sólo restan algo más de 14.000 € para incentivar las mejoras de calidad de los operadores y, por tanto, su captación de demanda. Es decir, con esta segunda hipótesis, sólo el $2 \%$ del presupuesto total disponible para el del servicio podría ser "devuelto" a los operadores, y se conseguirían unos beneficios totales de más de $163.000 €$ (112.000 € para los actuales usuarios por mejoras en la calidad y $52.000 €$ para la sociedad en general por reducción de externalidades). Ambos valores resultan superiores a los resultantes en el caso de considerar también la economía de los operadores en la función objetivo.

Para finalizar, concluimos resaltando la necesidad de una importante mejora en la calidad del servicio de transporte público interurbano en autobús, resultante de las optimizaciones de los beneficios sociales y de los usuarios, tanto si añadimos como si no los del operador. En cuanto a los aspectos económicos, el escenario cambia bastante, ya que la proporción de beneficios sociales y de los usuarios que se revierte al operador es máxima si consideramos también sus beneficios y costes, mientras que se reduce en más de un $90 \%$ si no lo hacemos, conllevando la circunstancia asociada de sólo una concesión consiga un beneficio industrial igual al mínimo admisible, considerado en este caso del 10\%. El resto deberán solicitar una subvención a la Administración para alcanzarlo.

Por último, si representáramos al igual que en el caso de las 8 líneas del Alfoz Metropolitano, los resultados que se obtienen al variar los valores iniciales del presupuesto total disponible y del beneficio industrial mínimo de los operadores, se obtendrían similares conclusiones.

Concluimos este punto, remarcando de nuevo que, a pesar de que la metodología empleada es fácilmente extrapolable a cualquier otra situación similar, los valores de elasticidad y disponibilidad al pago son únicamente válidos para nuestro caso de estudio. Por lo tanto, si deseara aplicar la metodología propuesta en otro ámbito, únicamente sería necesario rehacer la labor de toma de datos y la calibración de los modelos, de forma similar a la expuesta aquí. 



\section{CONCLUSIONES Y FUTURAS LÍNEAS DE INVESTIGACIÓN}

En la presente Tesis Doctoral se ha tratado de forma global el problema de calidad del transporte público interurbano en autobús, con el objetivo final de comprobar cómo fomentar la demanda del mismo frente al vehículo privado y su posibilidad de aplicación en los sistemas de concesiones actuales.

De este modo, tras una breve introducción al problema de estudio, se han adjuntado las principales cifras globales del sector a nivel nacional, con especial incidencia en las correspondientes a las concesiones de transporte público regular de tipo permanente. A continuación, se ha presentado una exhaustiva recopilación bibliográfica, tanto incluyendo estudios orientados al análisis de la calidad del transporte público como otros enfocados a la estimación de su demanda, o incluso a la posible incorporación de dichos criterios a los contratos de transporte.

Tras el análisis de los estudios existentes, se plantea la metodología a seguir. En primer lugar, tiene lugar la fase de recolección de datos, proponiendo un modelo de encuesta relativamente sencillo, que fue efectuada con soporte informático para poder establecer escenarios de preferencias declaradas específicos para cada entrevistado, y diseñados en tiempo real, sin necesidad de contactar con los usuarios para segundas consultas.

En cuanto a la modelización planteada, la metodología se ha basado fundamentalmente en las técnicas de elección discreta. Sin embargo, los modelos correspondientes a la percepción de calidad por parte de los usuarios han sido de tipo ordinal, que funcionan mejor cuando las alternativas de elección son dependientes entre sí y siguen una determinada jerarquía, como en las encuestas de escalamiento. Por su parte, los correspondientes al análisis de la demanda interurbana, han sido de tipo logit multinomial y jerárquico, buscando así opciones sencillas, fácilmente utilizables en situaciones reales.

Por último, se ha planteado una nueva metodología para incorporar estas cuestiones a las concesiones de transporte, con las principales novedades de incorporar variables de calidad (a través de las elasticidades de la demanda respecto de éstas y las disponibilidades al pago por mejoras en las mismas). Aplicando dicha metodología al caso de estudio de los viajes con origen o destino en la estación de autobuses de la ciudad de Burgos, los resultados han arrojado interesantes conclusiones, tanto considerando los beneficios del operador dentro de la optimización del sistema como teniendo en cuenta únicamente los beneficios sociales, por reducción de externalidades, y de los actuales usuarios, por mejoras en la calidad percibida por éstos. 
De todo ello se pueden extraer, por tanto, las siguientes conclusiones:

1. Los modelos de elección discreta de tipo ordinal se adaptan perfectamente a los estudios de calidad del transporte público, especialmente cuando los datos de partida siguen una jerarquía -semántica o numérica-, como la habitualmente presentada en encuestas de satisfacción. En dichas circunstancias, el habitual empleo de técnicas de regresión múltiple no es adecuado, ya que la variable de elección es de tipo discreto, al sólo existir un determinado número de opciones disponibles. Tampoco las técnicas clásicas de elección discreta, como los modelos de tipo logit multinomial o jerárquico, son correctas, ya que las alternativas de decisión son claramente dependientes entre sí. De aquí surge la necesidad de nuevas metodologías de modelización para esta tipología de encuestas, como los modelos de tipo ordinal aquí empleados.

2. Al contrario, el análisis de la demanda del transporte público interurbano en autobús puede ser llevado a cabo mediante modelizaciones relativamente sencillas, que permiten a su vez la obtención de valores sumamente interesantes, como su elasticidad con respecto a las variables de calidad consideradas, o las disponibilidades al pago de los usuarios por mejoras en las mismas.

3. Introduciendo incentivos a los operadores de las diferentes concesiones por las mejoras que éstos lleven a cabo en el servicio, y por la reducción de externalidades que se infiera de las mismas, es posible variar el sistema actual de concesiones del transporte público interurbano en autobús. En el caso de estudio analizado, para viajes de distancias cortas/medias, los resultados han indicado que, sin un mayor coste para la Administración competente, las mejoras en calidad pueden resultar también beneficiosas para los propios operadores del servicio, cuando éstas son acompañadas de un esfuerzo económico por parte de las autoridades.

4. Las soluciones obtenidas varían en función del ámbito de aplicación se escoja. Por tanto, a pesar de que las metodologías propuestas son válidas para cualquier caso de estudio, las variables de calidad del servicio a considerar y los valores concretos de elasticidades de la demanda y disponibilidades al pago de los usuarios deberán ser determinados en cada situación. En cualquier caso, para un determinado ámbito de estudio, la metodología a seguir deberá abarcar el total de líneas que son competencia de cada Administración, ya que la solución óptima considera la globalidad de trayectos disponibles. 
Así, las metodologías propuestas, junto con su aplicación al caso de estudio, podrían permitir una mejora en la calidad del servicio de transporte público interurbano en autobús y un mayor empleo del mismo, a la vez que se mantiene el equilibrio económico de los operadores (incluso con un determinado margen de beneficios asegurado), y sin aumentar el coste soportado por la Administración. Sería, por tanto, una situación en la que todos ganamos, ya que, al reducirse la proporción de viajes en vehículo privado, no sólo bajan los costes internos del transporte, sino que también disminuyen las externalidades negativas asociadas al mismo: accidentalidad vial (que en ámbito interurbano supone un importante punto a considerar), congestión y contaminación atmosférica, entre otras.

Para finalizar, simplemente se desea indicar las posibles líneas futuras de investigación que la presente Tesis Doctoral deja abiertas, algunas de las cuales podrían ser las siguientes:

- Emplear diseños eficientes en la encuesta, como los de tipo D-error, para lo que sería necesaria la utilización de soporte informático de gran potencia, a la vez que altamente portátil -ya que la obtención de los experimentos de preferencias declaradas (PD) en este caso precisa de unos cálculos iterativos que raramente se pueden efectuar en un tiempo aceptable con las actuales prestaciones del hardware habitual tipo PDA-.

- Encontrar un índice cuantitativo de calidad del servicio de transporte interurbano en autobús, representativo de la percepción global de los usuarios del mismo, y válido para el global de la población de estudio, que interrelacione de forma más compacta los resultados de los submodelos de calidad y de demanda. Para su obtención se pueden emplear herramientas de análisis factorial o cluster, a partir de las variables de calidad más relevantes, detectadas en los citados modelos. La determinación de dicho índice puede ser útil en la metodología de aplicación a los contratos, pudiendo considerarlo como la única variable relevante de la calidad del servicio. Así, la metodología se vería bastante simplificada, al tener un único parámetro a optimizar para cada línea, junto con la proporción de beneficios sociales y de los usuarios que revierte al operador.

- Incluir parámetros aleatorios en los submodelos de calidad y de demanda, para mejorar su adaptabilidad a los datos reales. Sin embargo, los parámetros finales a introducir en la metodología de modificación de las concesiones de transporte deberán ser válidos para el global de la población, lo que conllevará la necesidad de aplicar un procedimiento de obtención de valores "medios". En caso de que se 
empleen valores diferentes para cada entrevistado, el grueso de la metodología también sería válido, aunque con las correcciones pertinentes.

- Extender a ámbito nacional el procedimiento de aplicación a las líneas de transporte público interurbano en autobús. Así, podríamos aplicar la misma metodología al total de líneas del país, pero diferenciándolas en cuanto a la Administración competente, de modo que se estableciera un nuevo marco concesional estatal, con beneficios mucho mayores que los aquí expuestos.

- Emplear metodologías de optimización más eficientes, especialmente si se extiende el ámbito de estudio. De hecho, uno de los principales problemas detectados en la aplicación práctica a las concesiones de ámbito provincial y regional ha sido el excesivo tiempo de resolución del hardware empleado. Así, si el caso de estudio se ampliara a escala nacional, la utilización de algoritmos más rápidos resulta prácticamente imprescindible.

Con estas modificaciones, la metodología propuesta puede ser aplicada para diferentes casos de estudio de mayor escala territorial, como a la red de concesiones de transporte público regular interurbano de competencia estatal. Así, podría suponer un nuevo punto de partida para el sistema de transporte interurbano en autobús, haciéndolo no sólo más "apetecible" para los usuarios potenciales, sino también más rentable económicamente. De este modo, todos nos vemos beneficiados: los actuales usuarios ven mejorada la calidad, la sociedad sostiene menores costes externos, y los operadores mantienen un margen de beneficios aceptable. 


\section{REFERENCIAS BIBLIOGRÁFICAS}

[1] AENOR, 1994. Norma ISO 9002 (Sistemas de la calidad. Modelo para el aseguramiento de la calidad en la producción, la instalación y el servicio posventa).

[2] AENOR, 1999. Norma EN 12798:1999 (Sistema de la calidad en el transporte. Transporte por carretera, ferrocarril y vía fluvial. Requisitos del sistema de la calidad complementarios a la Norma EN ISO 9002 con respecto a la seguridad en el transporte de mercancías peligrosas).

[3] AENOR, 2000. Norma ISO 9001:2000 (Sistemas de gestión de la calidad. Requisitos).

[4] AENOR, 2000. Norma ISO 9004:2000 (Sistemas de gestión de la calidad. Directrices para la mejora del desempeño).

[5] AENOR, 2001. Norma EN 12507:2001 (Servicios de transporte. Guía para la aplicación de la Norma EN ISO 9002 a las empresas de transporte por carretera, almacenamiento y distribución).

[6] AENOR, 2003. Norma UNE-EN 13186 (Transporte. Logística y servicios. Transporte público de pasajeros. Definición de la calidad del servicio, objetivos y mediciones).

[7] AENOR, 2006. Norma UNE-EN 15140 (Transporte público de pasajeros. Requisitos básicos y recomendaciones para los sistemas de medición de la calidad del servicio producida).

[8] AENOR, 2007. Norma UNE 152001:2007 (Transporte público de pasajeros. Guía para establecer una calidad de servicio de referencia en la aplicación de la Norma UNE-EN 13816).

[9] AENOR, 2008. Norma UNE-EN ISO 9001:2008 (Sistemas de gestión de la calidad. Requisitos).

[10] AENOR, 2009. Norma UNE-EN ISO 9004:2009 (Gestión para el éxito sostenido de una organización. Enfoque de gestión de la calidad).

[11] AJZEN, I., 1991. The Theory of Planned Behavior. Organizational behavior and human decision processes, 50, pp. 179-211.

[12] AMADOR, F.J., GONZÁLEZ, R.M. \& ORTÚZAR, J.D., 2005. Preference heterogeneity and willingness to pay for travel time savings. Transportation, 32 (6), pp. 627-647.

[13] ANDREU, M., 2002. Conocer para Mejorar: el Proyecto BEST. Barcelona Metrópolis, Monográfico núm. 2 "Presente y Futuro del Transporte Metropolitano".

[14] ARMSTRONG, P., GARRIDO, R. \& ORTÚZAR, J.D., 2001. Confidence intervals to bound the value of time. Transportation Research Part E, 37 (2-3), pp. 143-161. 
[15] AYUNTAMIENTO DE BURGOS, 2009. Horario de Invierno. Estación de Autobuses de Burgos. http://www.aytoburgos.es.

[16] BALCOMBE, R., MACKETT, R., PAUllEY, N., PRESTON, J., SHIRES, J., TITHERIDGE, H., WARDMAN, M. \& WHITE, P., 2004. The demand for public transport: a practical guide. Transport Research Laboratory, UK.

[17] BAMBERG, S., RÖLLE, D. \& WEBER, C., 2003. Does habitual car use not lead to more resistance to change of travel mode? Transportation, 30, pp. 97-108.

[18] BARRIOS, M.C. \& MARTÍNEZ, M.A., 1999. El valor del tiempo en los desplazamientos al trabajo: una estimación en el caso de Cádiz. Estudios de economía aplicada, 12, pp. 5-16.

[19] BATES, J.J. AND ROBERTS, M., 1983. Recent experience with models fitted to stated preference data. In Proceedings 11th PTRC Summer Annual Meeting, University of Sussex, England.

[20] BEN-AKIVA, M.E. \& LERMAN, S.R., 1985. Discrete choice analysis: theory and application to travel demand. The MIT Press, Cambridge, MA.

[21] BEN-AKIVA, M.E. \& MORIKAWA, T., 1990. Estimation of travel demand models from multiple data sources. In Transportation and Traffic Theory, M. KOSHI, Ed. Elsevier, New York, pp. 461-478.

[22] BEN-AKIVA, M.E. AND MORIKAWA, T., 1997. Methods to estimate discrete choice models with stated and revealed preferences. In NSF Symposium on Eliciting Preferences, Berkeley, California.

[23] BILBAO, J. \& FERNÁNDEZ, A., 2004. The influence of quality and price on the demand for urban transport: the case of university students. Transportation Research Part A, 38 (8), pp. 607-614.

[24] BLACK, W.R., 2010. Sustainable Transportation. Problems and Solutions. The Guilford Press, New York (USA).

[25] BRADLEY, M.A. \& DALY, A.J., 1997. Estimation of logit choice models using mixed stated preference and revealed preference information. In Understanding Travel Behaviour in an Era of Change, P. STOPHER \& M. LEE-GOSSELIN, Eds. Pergamon, Oxford, pp. 209-231.

[26] BUTCHER, K., SPARKS, B. \& O'CALLAGHAN, F., 2001. Evaluative and relational influences on service loyalty. International Journal of Service Industry Management, 12 (4), pp. 310-327. 
[27] CALTHROP, E. \& PROOST, S., 2003. Environmental Pricing in Transport. In Handbook of Transport and the Environment, D.A. HENSHER \& K.J. BUTTON, Eds. Elsevier, Hungary, pp. 529-545.

[28] CASCETTA, E. \& RUSSO, F., 1997. Calibrating aggregate travel demand models with traffic counts: Estimators and statistical performance. Transportation, 24 (3), pp. 271-293.

[29] CHERCHI, E. \& ORTÚZAR, J.D., 2002. Mixed RP/SP models incorporating interaction effects. Transportation, 29 (4), pp. 371-395.

[30] CHERNIACK, N., 1981. Transit Subsidies Can be Reduced... Quality Bus Transit Could be Profitable. ITE Journal, 51 (8).

[31] CONSORCIO REGIONAL DE TRANSPORTES DE MADRID, 2009. Plan de Modernización y condiciones de convalidación de las concesiones de transporte público regular permanente de viajeros de uso general por carretera.

[32] DAGANZO, C.F., 1979. Multinomial probit: The theory and its application to demand forecasting. Academic Press, New York.

[33] DHINGRA, S.L., RAO, K.V.K. \& TOM, V.M., 2003. Environmental Impact Assessment for Sustainable Transport. In Handbook of Transport and the Environment, D.A. HENSHER \& K.J. BUTTON, Eds. Elsevier, Hungary, pp. 309-329.

[34] DIRECCIÓN GENERAL DE TRÁFICO, 2009. http://www.dgt.es.

[35] DODGSON, J.S. \& TOPHAM, N., 1987. Benefit-Cost Rules for Urban Transit Subsidies: An Integration of Allocational, Distributional and Public Finance Issues. Journal of Transport Economics and Policy, XXI (1), pp. 57-71.

[36] DOMENCICH, T.A. \& MCFADDEN, D., 1975. Urban travel demand: a behavioral analysis: a Charles River Associates research study. North-Holland, Amsterdam.

[37] EBOLI, L. \& MAZZULLA, G., 2008. A Stated Preference Experiment for Measuring Service Quality in Public Transport. Transportation Planning and Technology, 31 (5), pp. 509-523.

[38] ESPINO, R., ORTÚZAR, J.D. \& ROMÁN, C., 2004. Diseño de preferencias declaradas para analizar la demanda de viajes. Estudios de Economía Aplicada, 22 (3), pp. 759-793.

[39] ESPINO, R., ROMÁN, C. \& ORTÚZAR, J.D., 2006. Analysing demand for suburban trips: a mixed RP/SP model with latent variables and interaction effects. Transportation, 33 (3), pp. 241-261.

[40] ESPINO, R., ORTÚZAR, J.D. \& ROMÁN, C., 2007. Understanding suburban travel demand: Flexible modelling with revealed and stated choice data. Transportation Research Part A, 41 (10), pp. 899-912. 
[41] ESTUDIOS CAJA ESPAÑA, 2010. Datos Económicos y Sociales de los Municipios de España. http://www.cajaespana.es/.

[42] ETTEMA, D., GUNN, H., DE JONG, G. AND LINDVELD, K., 1997. A simulation method for determining the confidence interval of a weighted group average value of time. In Proceedings of the 25th European Transport Forum, Brunel University, England.

[43] FOOTE, P.J. \& STUART, D.G., 1998. Customer Satisfaction Contrasts. Express Versus Local Bus Service in Chicago's North Corridor. Transportation Research Record: Journal of the Transportation Research Board, 1618, pp. 143-152.

[44] FOOTE, P.J., STUART, D.G. \& ELMORE-YALCH, R., 2001. Exploring Customer Loyalty as a Transit Performance Measure. Transportation Research Record: Journal of the Transportation Research Board, 1753, pp. 93-101.

[45] FUJII, S. \& KITAMURA, R., 2003. What does a one-month free bus ticket do to habitual drivers? An experimental analysis of habit and attitude change. Transportation, 30 (1), pp. 81-95.

[46] FUNDACIÓN FETMO \& MINISTERIO DE FOMENTO, 2006. Buenas prácticas y recomendaciones para la mejora de la satisfacción del cliente de transporte público de viajeros por carretera. Dirección General de Transportes por Carretera, Ministerio de Fomento, Madrid.

[47] FUNDACIÓN FETMO \& MINISTERIO DE FOMENTO, 2006. Manual de apoyo para la implantación de la gestión de la calidad según norma UNE-EN 13816 en empresas de transporte de viajeros por carretera. Dirección General de Transportes por Carretera, Ministerio de Fomento, Madrid.

[48] FUNDACIÓN FETMO \& MINISTERIO DE FOMENTO, 2008. Calidad y corresponsabilidad en el transporte público de viajeros por carretera. Dirección General de Transportes por Carretera, Ministerio de Fomento, Madrid.

[49] GÁLVEZ, T.E. \& JARA-DÍAZ, S.R., 1998. On the social valuation of travel time savings. International Journal of Transport Economics, 25 (2), pp. 205-219.

[50] GARRIDO, R.A., 1992. The influence of the semantic scale on the estimation of values of time from linear regression models fitted to stated preference data. Working Paper 62, Department of Transport Engineering, Pontificia Universidad Católica de Chile.

[51] GARRIDO, R.A. AND ORTÚZAR, J.D., 1993. The Chilean value of time study: methodological developments. In Proceedings of the 21st PTRC Summer Annual Meeting, University of Manchester, Institute of Science and Technology, England. 
[52] GARRIDO, R.A. \& ORTÚZAR, J.D., 1994. Deriving Public Transport Level of Service Weights from a Multiple Comparison of Latent and Observable Variables. The Journal of the Operational Research Society, 45 (10), pp. 1099-1107.

[53] GAUDRY, M.J.I., JARA-DIAZ, S.R. \& ORTÚZAR, J.D., 1989. Value of time sensitivity to model specification. Transportation Research, 23 (2), pp. 151-158.

[54] GLAISTER, S., 1984. The allocation of urban public transport subsidy. In Privatisation and the Welfare State, J. LEGRAND \& R. ROBINSON, Eds. George Allen and Unwin, Londres.

[55] GLASCOCK, J., 1997. Research on Customer Requirements for Transit Service Design and Delivery. Transportation Research Record: Journal of the Transportation Research Board, 1604, pp. 121-127.

[56] GONZÁLEZ, R.M., AMADOR, F.J. \& ALONSO, B. La sensibilidad del valor del tiempo de viaje a la especificación econométrica del modelo.

[57] GONZÁLEZ, R.M., 1995. La demanda de transporte de pasajeros en el trayecto Gran Canaria-Tenerife.

[58] GREENE, W.H. Limdep. Econometric Modeling Guide. Econometric Software, Inc.

[59] GUNN, H.F. \& BATES, J.J., 1982. Statistical aspects of travel demand modelling. Transportation Research Part A, 16, pp. 371-382.

[60] GWILLIAM, K., 2008. A review of issues in transit economics. Research in Transportation Economics, 23 (1), pp. 4-22.

[61] GWILLIAM, K., 2008. Bus transport: Is there a regulatory cycle? Transportation Research Part A, 42 (9), pp. 1183-1194.

[62] HAGUE CONSULTING GROUP, 1990. The Netherlands' value of time study: final report.

[63] HAGUE CONSULTING GROUP, ACCENT MARKETING \& RESEARCH \& DEPARTMENT OF THE ENVIRONMENT, TRANSPORT AND THE REGIONS, 1999. The value of time on UK roads.

[64] HALDENBILEN, S. \& CEYLAN, H., 2005. The development of a policy for road tax in Turkey, using a genetic algorithm approach for demand estimation. Transportation Research Part A, 39 (10), pp. 861-877.

[65] Hensher, D., GWilliam, K., BURTON, M., SMiTH, N., VAN DE VELDE, D. \& FRIDSTROM, L., 2008. The ideal contract roundtable. Research in Transportation Economics, 22 (1), pp. 188-194. 
[66] HENSHER, D.A. \& REYES, A.J., 2000. Trip chaining as a barrier to the propensity to use public transport. Transportation, 27 (4), pp. 341-361.

[67] HENSHER, D.A., 2002. A Systematic Assessment of the Environmental Impacts of Transport Policy. Environmental and Resource Economics, 22 (1), pp. 185-217.

[68] HENSHER, D.A. \& STANLEY, J., 2003. Performance-based quality contracts in bus service provision. Transportation Research Part A, 37 (6), pp. 519-538.

[69] HENSHER, D.A., STOPHER, P. \& BULLOCK, P., 2003. Service quality-developing a service quality index in the provision of commercial bus contracts. Transportation Research Part A, 37, pp. 499-517.

[70] HENSHER, D.A. \& HOUGHTON, E., 2004. Performance-based quality contracts for the bus sector: delivering social and commercial value for money. Transportation Research Part B, 38 (2), pp. 123-146.

[71] HENSHER, D.A., ROSE, J. \& GREENE, W.H., 2005. The implications on willingness to pay of respondents ignoring specific attributes. Transportation, 32 (3), pp. 203-222.

[72] HENSHER, D.A., YVRANDE-BILLON, A., MACÁRIO, R., PRESTON, J., WHITE, P., TYSON, B., VAN DE VELDE, D.M., VAN WEE, B., DE ARAGÃO, J.J.G., SANTOS, E.M., FILHO, R.D.O. \& HENSHER, D., 2007. Delivering value for money to government through efficient and effective public transit service continuity: some thoughts. Transport Reviews, 27 (4), pp. 411-448.

[73] HENSHER, D.A. \& STANLEY, J., 2008. Transacting under a performance-based contract: The role of negotiation and competitive tendering. Transportation Research Part A, 42 (9), pp. 1143-1151.

[74] HOOPER, L., 2008. Paying for performance: Uncertainty, asymmetric information and the payment model. Research in Transportation Economics, 22 (1), pp. 157-163.

[75] HU, K. \& JEN, W., 2006. Passengers' Perceived Service Quality of City Buses in Taipei: Scale Development and Measurement. Transport Reviews, 26 (5), pp. 645-662.

[76] IAKOVOU, E.T. \& PACHON, J.E., 2001. Optimization of the Transportation System at a University Campus: a Continuous Improvemente Quality Management Methodology. Quality Engineering, 13 (3), pp. 427-435.

[77] INSTITUTO NACIONAL DE ESTADÍSTICA (INE), 2010. Base de Datos del Instituto Nacional de Estadística. http://www.ine.es/inebase/.

[78] JARA-DIAZ, S.R., ORTÚZAR, J.D. AND PARRA, R., 1988. Valor subjetivo del tiempo considerando efecto ingreso en la partición modal. In Actas del V Congreso Panamericano de Ingeniería de Tránsito y Transporte, Universidad de Puerto Rico en Mayagüez, Julio de 1988. 
[79] JARA-DÍAZ, S.R. \& FARAH, M., 1987. Transport demand and users' benefits with fixed income: The goods/leisure trade off revisited. Transportation Research Part B, 21 (2), pp. 165-170.

[80] JARA-DÍAZ, S.R. \& ORTÚZAR, J.D., 1989. Introducing the expenditure rate in the estimation of mode choice models. Journal of Transport Economics and Policy, 23, pp. 293-308.

[81] JARA-DÍAZ, S.R., 2000. Allocation and valuation of travel-time savings. In Handbook of Transport Modelling, D.A. HENSHER \& K.J. BUTTON, Eds. Pergamon, pp. 304-319.

[82] JEN, W. \& HU, K., 2003. Application of perceived value model to identify factors affecting passengers' repurchase intentions on city bus: A case of the Taipei metropolitan area. Transportation, 30, pp. 307-327.

[83] JOEWONO, T.B. \& KUBOTA, H., 2008. Paratransit Service in Indonesia: User Satisfaction and Future Choice. Transportation Planning and Technology, 31 (3), pp. 325-345.

[84] JOHANSEN, K.W., LARSEN, O.I. \& NORHEIM, B., 2001. Towards achievement of both allocative efficiency and X-efficiency in public transport. Journal of Transport Economics and Policy, pp. 491-511.

[85] JOHNSON, L.W., 1990. Discrete choice analysis with ordered alternatives. In Spatial Choices and Processes, M.M. FISCHER, P. NIJKAMP \& Y.Y. PAPAGEORIOU, Eds. North Holland, Amsterdam, pp. 279-289.

[86] JORDÁ, P., MONZÓN, A. AND FERNÁNDEZ, A., 2008. Cuenta Socioambiental del transporte terrestre de viajeros en la Comunidad de Madrid, año 2004. In Actas del VIII Congreso de Ingeniería del Transporte, A Coruña, Julio 2008, Demarcación de Galicia del Colegio de Ingenieros de Caminos, Canales y Puertos.

[87] JUNTA DE CASTILLA Y LEÓN, 2010. Plan Coordinado de Explotación de Burgos y su Área Metropolitana (Borrador).

[88] KIM, Y., KIM, T. \& HEO, E., 2003. Bayesian estimation of multinomial probit models of work trip choice. Transportation, 30 (3), pp. 351-365.

[89] KITAMURA, R., CHEN, C., PENDYALA, R.M. \& NARAYANAN, R., 2000. Microsimulation of daily activity-travel patterns for travel demand forecasting. Transportation, 27 (1), pp. 25-51.

[90] KOCUR, G., ADLER, T., HYMAN, W. \& AUNET, B., 1982. Guide to Forecasting Travel Demand with Direct Utility Assessment. U.S. Department of Transportation - Urban Mass Transportation Administration, Washington, D.C. 
[91] KUMAR, C.V.P., BASU, D. \& MAITRA, B., 2004. Modeling generalized cost of travel for rural bus users: a case study. Journal of Public Transportation, 7 (2), pp. 59-72.

[92] LARSEN, O.I., 2001. Designing incentive schemes for public transport operators in Hordaland County, Norway. In Proceedings of the 7th International Conference on Competition and Ownership of Land Passenger Transport, Molde, Norway.

[93] LITMAN, T.A., 2011. Socially Optimal Transport Prices and Markets. Principles, Strategies and Impacts. Victoria Transport Policy Institute.

[94] LÓPEZ, E., 2002. Los Contratos-Programa. Barcelona Metrópolis Monográfico núm. 2, "Presente y Futuro del Transporte Metropolitano".

[95] LOUVIERE, J.J., 1988. Analysing Decision Making: Metric Conjoint Analysis. Sage Publications, Newbury Park, California.

[96] MACKIE, P.J., JARA-DÍAZ, S.R. \& FOWKES, A.S., 2001. The value of travel time savings in evaluation. Transportation research part E, 37 (2-3), pp. 91-106.

[97] MARTÍNEZ, P., 2002. Un Proceso Dinámico, Repleto de Retos y Oportunidades de Futuro. Barcelona Metrópolis, Monográfico núm. 2 "Presente y Futuro del Transporte Metropolitano".

[98] MATAS, A. \& RAYMOND, J.L., 1998. Technical characteristics and efficiency of urban bus companies: The case of Spain. Transportation, 25 (3), pp. 243-263.

[99] MINISTERIO DE FOMENTO, 2003. Plan de Líneas de Actuación del Transporte en Autobús (PLATA). Documento de Base.

[100] MINISTERIO DE FOMENTO, 2005. Observatorio del Transporte de Viajeros por Carretera.

[101] MINISTERIO DE FOMENTO, 2005. Modelos para implantar la mejora continua en la gestión de empresas de transporte por carretera. Ministerio de Fomento, Madrid.

[102] MINISTERIO DE FOMENTO, 2010. Observatorio del Transporte de Viajeros por Carretera.

[103] MINISTERIO DE FOMENTO, 2010. Observatorio de Costes del Transporte de Viajeros en Autocar.

[104] MORIKAWA, T., BEN-AKIVA, M. AND YAMADA, K., 1992. Estimation of mode choice models with serially correlated RP and SP data. In Proceedings 6th World Conference on Transport Research, Lyon, Francia, Junio 1992.

[105] NATHANAIL, E., 2008. Measuring the quality of service for passengers on the Hellenic railways. Transportation Research Part A, 42, pp. 48-66. 
[106] NIIRO, K., 1989. Demand for buses in Japanese medium sized cities. Transportation, 16 (4), pp. 279-295.

[107] ORTÚZAR, J.D., 1983. Nested logit models for mixed-mode travel in urban corridors. Transportation Research Part A, 17 (4), pp. 283-299.

[108] ORTÚZAR, J.D., IVELIC, A.M. \& CANDIA, A., 1997. User perception of public transport level-of-service. In Understanding Travel Behaviour in an Era of Change, P. STOPHER \& M. LEE-GOSSELIN, Eds. Pergamon, Oxford, pp. 123-142.

[109] ORTÚZAR, J.D., 2000. Modelos econométricos de elección discreta. Ediciones Universidad Católica de Chile, Chile.

[110] ORTÚZAR, J.D. \& GARRIDO, R.A., 2000. An application of ordinal probit to SP rating data. In Stated Preference Modelling Techniques, J.D. ORTÚZAR, Ed. PTRC Education and Research Services, UK, pp. 103-120.

[111] ORTÚZAR, J.D. \& WILLUMSEN, L.G., 2008. Modelos de Transporte. PUbliCan Ediciones de la Universidad de Cantabria, Santander.

[112] PARASURAMAN, A., ZEITHAML, V.A. \& BERRY, L.L., 1985. A Conceptual Model of Service Quality and its Implications for Future Research. Journal of Marketing, 49, pp. 41-50.

[113] PARASURAMAN, A., ZEITHAML, V.A. \& BERRY, L.L., 1988. SERVQUAL: A Multiple-Item Scale for Measuring Consumer Perceptions of Service Quality. Journal of Retailing, 64 (1), pp. 12-40.

[114] PAUllEy, N., BALCOMBE, R., MACKETT, R., TITHERIDGE, H., PRESTON, J., WARDMAN, M., SHIRES, J. \& WHITE, P., 2006. The demand for public transport: The effects of fares, quality of service, income and car ownership. Transport Policy, 13 (4), pp. 295-306.

[115] PÉREZ, R. Gestión de los autobuses metropolitanos en Madrid.

[116] PETIT, C. La mejora de la calidad en los sistemas de transporte público como pilar de una movilidad más sostenible.

[117] POLAK, J., 2000. The use of computer-based methods in stated preference research. In Stated preference modelling techniques, J.D. ORTÚZAR, Ed. PTRC Education and Research Services Ltd, UK, pp. 73-90.

[118] PRESTON, J., 2001. Regulation policy in land passenger transportation in Europe. In Proceedings of the 7th International Conference on Competition and Ownership of Land Passenger Transport, Molde, Norway, 25-28. 
[119] PRIONI, P. \& HENSHER, D.A., 2000. Measuring service quality in scheduled bus services. Journal of Public Transportation, 3 (2), pp. 51-74.

[120] PROCHASKA, J.O., DICLEMENTE, C. \& NORCROSS, J.C., 1992. In Search of How People Change. Applications to Addictive Behaviors. American Psychologist, pp. 1102-1114.

[121] RENFE, 2009. Horarios y Precios. http://www.renfe.com.

[122] RIETVELD, P. \& ROSON, R., 2002. Direction dependent prices in public transport: A good idea? The back haul pricing problem for a monopolistic public transport firm. Transportation, 29 (4), pp. 397-417.

[123] ROJO, M., DELL'OLIO, L., MOURA, J.L. AND GONZALO, H., 2008. User Satisfaction in Interurban Bus Transit: Modelling Relevant Variables and Their Influence. In Proceeding of the 10th International Conference on Applications of Advanced Technologies in Transportation, Atenas, 28-30 Mayo 2008.

[124] ROJO, M., GONZALO, H., DELL'OLIO, L. \& IBEAS, A., 2011. Modelling gender perception of quality in interurban bus services. Proceedings of the Institution of Civil Engineers, Transport, 164 (1), pp. 43-53.

[125] SILLANO, M. \& ORTÚZAR, J.D., 2005. Willingness-to-pay estimation with mixed logit models: some new evidence. Environment and Planning A, 37 (3), pp. 525-550.

[126] SPEAR, B.D., 1977. Applications of new travel demand forecasting techniques to transportation planning. A study of individual choice models. U.S. Department of Transportation, Washington, D.C.

[127] STANLEY, J. \& VAN DE VELDE, D., 2008. Risk and reward in public transport contracting. Research in Transportation Economics, 22 (1), pp. 20-25.

[128] TERZA, J.V., 1985. Ordinal probit: a generalization. Communications in Statistics-Theory and Methods, 14 (1), pp. 1-11.

[129] TIS, NTUA, NEA, ERASMUS, ISIS, TSU, HGL, TOI, LT CONSULTANTS, HUR, TRANSTEC, HVV, FGM-AMOR, INFRAS, ENPC \& TRANSMAN, 2003. MARETOPE Handbook. Managing and Assessing Regulatory Evolution in Local Public Transport Operations in Europe.

[130] TRAIN, K. \& MCFADDEN, D., 1978. The goods/leisure trade-off and disaggregate work trip mode choice models. Transportation Research, 12 (5), pp. 349-353.

[131] TRAIN, K, 2003. Discrete choice methods with simulation. Cambridge University Press, Cambridge, UK. 
[132] TRANSCONSUlT, SCT \& STEER DAVIES GLEAVE, 2006. Modelación de Demanda para Carreteras de Cuota. Documento preparado para la Secretaría de Comunicaciones y Transportes de México.

[133] TRANSPORTATION RESEARCH BOARD, 1999. Transit Capacity and Quality of Service Manual. Transportation Research Board, Washington, D.C.

[134] TRANSPORTATION RESEARCH BOARD, 2003. Transit Capacity and Quality of Service Manual: 2nd Edition. Transportation Research Board, Washington, D.C.

[135] UPALA, P., 2007. Measuring the Service Quality of Urban Transit in the Future. In Proceedings of the $7^{\text {th }}$ International Conference on Urban Planning and Environment (UPE), Bangkok.

[136] VAN DE VELDE, D., 2008. A new regulation for the European public transport. Research in Transportation Economics, 22 (1), pp. 78-84.

[137] VAN DE VELDE, D., VEENEMAN, W. \& SCHIPHOLT, L.L., 2008. Competitive tendering in The Netherlands: Central planning vs. functional specifications. Transportation Research Part A, 42 (9), pp. 1152-1162.

[138] VAN DE VELDE, D., 2009. Long-distance bus services in Europe: concessions or free market? In 18th International Transport Research Symposium, Madrid, 2009.

[139] VÍA MICHELÍN, 2009. Cálculo de Itinerarios. http://www.viamichelin.es.

[140] VITON, P.A., 1998. Changes in multi-mode bus transit efficiency, 1988-1992. Transportation, 25, pp. 1-21.

[141] WALLIS, I. AND GALE, J., 2001. Economic Incentives to Increase Public Transport Patronage - The Theory and the Practice. In Proceedings of the 7th International Conference on Competition and Ownership of Land Passenger Transport, Molde, Norway.

[142] WALTERS, J. \& JANSSON, J.O., 2008. Risk and reward in public transportation contracting. Research in Transportation Economics, 22 (1), pp. 26-30.

[143] WARDMAN, M., 1997. A review of evidence on the value of travel time in Great Britain. Working paper 495.

[144] WARDMAN, M., 2001. A review of British evidence on time and service quality valuations. Transportation Research Part E, 37 (2-3), pp. 107-128.

[145] WEBSTER, F.V. \& BLY, P.H., 1980. The Demand for Public Transport: Report of the international Collaborative study of The factors affecting Public Transport. Transport and Road Research Lab. 
[146] WEISBROD, G., VARY, D. \& TREYZ, G., 2003. Measuring economic costs of urban traffic congestion to business. Transportation Research Record: Journal of the Transportation Research Board, 1839 (1), pp. 98-106.

[147] WEN, C., LAN, L.W. \& CHENG, H., 2005. Structural Equation Modeling to Determine Passenger Loyalty Toward Intercity Bus Services. Transportation Research Record: Journal of the Transportation Research Board, 1927, pp. 249-255.

[148] WILliAMS, B.T., 1999. The Wisconsin Multi-Modal Intercity Passenger Demand Forecasts. In Statewide Travel Demand Forecasting. Conference Proceedings, Irvine, California, 1998, TRANSPORTATION RESEARCH BOARD, Ed. Transportation Research Board, 166-169.

[149] WIRASINGHE, S.C. \& KUMARAGE, A.S., 1998. An aggregate demand model for intercity passenger travel in Sri Lanka. Transportation, 25 (1), pp. 77-98.

[150] YEH, C., DENG, H. \& CHANG, Y., 2000. Fuzzy multicriteria analysis for performance evaluation of bus companies. European Journal of Operational Research, 126, pp. 459-473.

[151] ZADEH, L.A., 1965. Fuzzy sets. Information and Control, 8, pp. 338-353.

[152] ZAVOINA, R. \& MCELVEY, W., 1975. A statistical model for the analysis of ordinal level dependent variables. Journal of Mathematical Sociology, 4 (1), pp. 103-120.

[153] ZELENY, M., 1982. Multiple criteria decision making. McGraw-Hill Companies, New York. 


\section{Anexos}

Anexo 1. Líneas y Destinos desde la Estación de Autobuses de Burgos ......................... 277

Anexo 2. Encuesta Completa (Vista de Pantalla)........................................................... 287

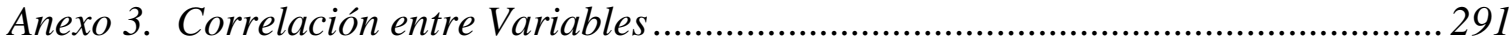

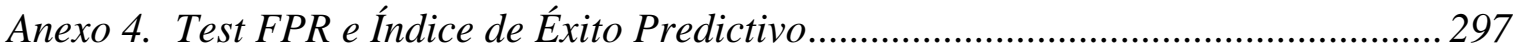

Anexo 5. Elasticidades de la Demanda. Enumeración Muestral .................................... 305

Anexo 6. Aplicación a las Concesiones. Datos de Entrada ............................................. 307 



\section{Anexo 1. Líneas y Destinos desde la Estación de Autobuses de Burgos}

Tabla A1-1. Relación de líneas entrantes y salientes (de lunes a viernes laborables)

Fuente: Ayuntamiento de Burgos [15]

\begin{tabular}{|c|c|c|c|c|}
\hline LÍNEA & $\begin{array}{c}\text { DÍAS DE } \\
\text { SERVICIO }\end{array}$ & ENTRADAS & SALIDAS & OPERADOR \\
\hline $\begin{array}{l}\text { M1 Arcos - Villariezo } \\
\text { - Villagonzalo }\end{array}$ & L-V & $8,3012,3015,3021,00$ & $\begin{array}{c}8,0012,0013,15 \text { (temp. } \\
\text { escolar) } 15,0020,30\end{array}$ & $\begin{array}{l}\text { Autobuses de } \\
\text { Castilla, S.L. }\end{array}$ \\
\hline $\begin{array}{c}\text { M2 Albillos - } \\
\text { Cayuela - Buniel }\end{array}$ & $L-V$ & $7,5714,57$ 16,57 21,12 & $7,0014,0016,0020,15$ & Soto y Alonso, S.L. \\
\hline M3 Villalbilla & L-V & $8,1512,1517,15$ & $7,3020,30$ & El Noroeste - Amaya \\
\hline $\begin{array}{l}\text { M4 Quintanadueñas } \\
\text { - Sotragero }\end{array}$ & L-V & $7,4010,1015,55$ & $12,3014,3019,3020,15$ & $\begin{array}{l}\text { Autobuses del } \\
\text { Pisuerga }\end{array}$ \\
\hline $\begin{array}{c}\text { M5 Sotopalacios - } \\
\text { Ubierna }\end{array}$ & L-V & $8,3016,1522,00$ & $7,0014,4520,30$ & Alsa - Enatcar \\
\hline $\begin{array}{c}\text { M6 Riocerezo - } \\
\text { Hurones }\end{array}$ & L-V & $7,459,1015,4020,10$ & $8,0014,3019,00$ & Soto y Alonso, S.L. \\
\hline $\begin{array}{c}\text { M7 S. Medel - } \\
\text { Tomillares - Ibeas }\end{array}$ & L-V & $8,1512,3015,4518,30$ & $\begin{array}{c}7,1511,3014,4517,30 \\
21,00(L-J) \\
\end{array}$ & Alsa - Enatcar \\
\hline $\begin{array}{l}\text { M8 Cardeñajimeno - } \\
\text { Castrillo }\end{array}$ & L-V & $7,5012,3015,3020,40$ & $7,1512,0015,0020,10$ & $\begin{array}{c}\text { Autobuses } \\
\text { Arceredillo, S.L. }\end{array}$ \\
\hline $\begin{array}{l}\text { M8 Cardeñadijo - } \\
\text { Carcedo }\end{array}$ & L-V & $8,1512,5515,5521,05$ & $7,5012,3015,3020,40$ & $\begin{array}{c}\text { Autobuses } \\
\text { Arceredillo, S.L. }\end{array}$ \\
\hline $\begin{array}{c}\text { M9 Sarracín - } \\
\text { Saldaña - Modúbar }\end{array}$ & L-V & $8,5012,5015,5020,50$ & $8,0012,0015,0020,00$ & $\begin{array}{c}\text { Autobuses } \\
\text { Arceredillo, S.L. }\end{array}$ \\
\hline $\begin{array}{l}\text { Aguilar de Campoo - } \\
\text { Cervera de Pisuerga }\end{array}$ & L-V & $9,1517,30(\mathrm{~J})$ & 9,30 (J) 17,30 & $\begin{array}{l}\text { Autobuses del } \\
\text { Pisuerga, S.L. }\end{array}$ \\
\hline Alar del Rey & L-V & 9,30 & 17,30 & $\begin{array}{c}\text { Autobuses Amaya, } \\
\text { S.L. }\end{array}$ \\
\hline $\begin{array}{l}\text { Aranda de Duero - } \\
\text { Lerma }\end{array}$ & L-V & $\begin{array}{c}9,1511,4513,3015,30 \\
16,3018,3021,15\end{array}$ & $\begin{array}{c}6,458,3010,4512,30 \\
14,0015,3017,3020,00\end{array}$ & Alsa - Enatcar \\
\hline Arija & $L, X, V$ & 9,15 & 16,00 & Alsa - Enatcar \\
\hline Badajoz - Béjar & L-V & 18,30 & 11,30 & Alsa - Enatcar \\
\hline Barcelona & L-V & $\begin{array}{c}16,3017,103,506,15 \\
6,302,20(\mathrm{~V})\end{array}$ & $12,1513,5023,4523,50$ & Alsa - Enatcar \\
\hline Belorado & L-V & $\begin{array}{c}8,1510,1513,0015,00 \\
19,0021,15\end{array}$ & $\begin{array}{c}8,3010,3012,4515,00 \\
16,3019,45\end{array}$ & $\begin{array}{l}\text { Autobuses Logroza, } \\
\text { S.L. }\end{array}$ \\
\hline Bilbao (directo) & L-V & $\begin{array}{c}10,2012,5017,0520,50 \\
22,20(\mathrm{~V}) \\
\end{array}$ & $\begin{array}{c}8,3010,1516,0019,00 \\
21,00(\mathrm{~V}) \\
\end{array}$ & Alsa - Enatcar \\
\hline $\begin{array}{l}\text { Bilbao (por } \\
\text { Villarcayo) } \\
\end{array}$ & L-V & $9,4512,1517,0020,45$ & $7,1512,0014,0017,30$ & Alsa - Enatcar \\
\hline $\begin{array}{l}\text { Bilbao - Sestao - } \\
\text { Baracaldo - } \\
\text { Portugalete - } \\
\text { Santurce } \\
\end{array}$ & L-V & 10,20 & 19,00 & Alsa - Enatcar \\
\hline $\begin{array}{c}\text { Bilbao - Espinosa de } \\
\text { los Monteros }\end{array}$ & L-V & $9,4512,15$ & $14,0017,30$ & Alsa - Enatcar \\
\hline Briviesca & L-V & $\begin{array}{c}7,458,459,4011,10 \\
15,4516,4518,30 \text { (temp. } \\
\text { Escolar) } 20,00 \text { (L,V) } 22,40 \\
23,30\end{array}$ & $\begin{array}{c}6,157,4510,30 \text { (L,V) } \\
12,00 \text { (temp. Escolar) } \\
13,1515,0017,30 \text { (temp. } \\
\text { Escolar) } 18,3020,00 \\
20,30 \\
\end{array}$ & Soto y Alonso, S.L. \\
\hline
\end{tabular}




\begin{tabular}{|c|c|c|c|c|}
\hline LÍNEA & $\begin{array}{c}\text { DÍAS DE } \\
\text { SERVICIO }\end{array}$ & ENTRADAS & SALIDAS & OPERADOR \\
\hline $\begin{array}{c}\text { Cáceres - Plasencia } \\
\text { - Mérida } \\
\end{array}$ & L-V & 7,45 (L) 18,30 & $11,3021,00(L, V)$ & Alsa - Enatcar \\
\hline $\begin{array}{l}\text { Castrojeriz - } \\
\text { Arenillas de } \\
\text { Riopisuerga } \\
\end{array}$ & L-V & 9,30 & $14,4518,30(\mathrm{M}-\mathrm{V})$ & $\begin{array}{l}\text { Autobuses de } \\
\text { Castilla, S.L. }\end{array}$ \\
\hline $\begin{array}{c}\text { Córdoba - Sevilla - } \\
\text { Cádiz - S. Fernando } \\
\text { - Algeciras } \\
\end{array}$ & L-V & 7,15 & 23,15 & UNIONBUS, S.A.U. \\
\hline $\begin{array}{l}\text { Coruña - Lugo - } \\
\text { Santiago de } \\
\text { Compostela }\end{array}$ & L-V & $23,006,15$ & 13,15 & $\begin{array}{l}\text { Alsa - Intercar - } \\
\quad \text { Enatcar }\end{array}$ \\
\hline $\begin{array}{c}\text { Eibar - Vergara - } \\
\text { Mondragón }\end{array}$ & L-V & 11,30 & $16,0019,15$ & Alsa - Enatcar \\
\hline Fresneda & L-V & 9,15 & $13,30(\mathrm{~V}) 19,30$ & Alsa - Enatcar \\
\hline Frías & $L, V$ & 8,50 & 18,30 & Soto y Alonso, S.L. \\
\hline $\begin{array}{c}\text { Frómista - Astudillo } \\
\text { - Castrojeriz }\end{array}$ & L-V & 9,30 & 17,30 & $\begin{array}{c}\text { Autobuses Amaya, } \\
\text { S.L. }\end{array}$ \\
\hline Haro & L-V & 15,45 & 7,45 (M-J) 10,30 (L,V) & Soto y Alonso, S.L. \\
\hline Ibeas de Juarros & L-V & & $\begin{array}{c}7,1513,3014,4517,30 \\
19,30 \\
\end{array}$ & Alsa - Continental \\
\hline Irún & $L-V$ & $12,3019,3022,003,45$ & $10,3014,1518,303,15$ & Alsa - Enatcar \\
\hline Laredo & L-V & 20,30 (Julio-Septiembre) & $\begin{array}{c}\text { 12,00 (Julio-Septiembre) } \\
19,00 \text { (V de Octubre- } \\
\text { Junio) }\end{array}$ & Alsa - Enatcar \\
\hline León & L-V & $12,1513,2018,0023,15$ & $\begin{array}{c}6,3511,3016,3017,25 \\
18,15(\mathrm{~V}) \\
\end{array}$ & Alsa - Enatcar \\
\hline $\begin{array}{l}\text { Covarrubias - Sta. } \\
\text { Inés }\end{array}$ & $L-V$ & $10,0017,15$ & $13,0018,30$ & $\begin{array}{c}\text { Autobuses } \\
\text { Arceredillo, S.L. }\end{array}$ \\
\hline $\begin{array}{c}\text { Logroño (por } \\
\text { Briviesca) }\end{array}$ & L-V & $15,4520,00(L, V)$ & $7,4510,30(L, V)$ & Soto y Alonso, S.L. \\
\hline $\begin{array}{l}\text { Logroño (por } \\
\text { Belorado) }\end{array}$ & $L-V$ & $\begin{array}{c}10,1513,0015,0019,00 \\
21,15\end{array}$ & $\begin{array}{c}7,008,3010,3012,45 \\
13,00(V) 15,0016,30 \\
19,45\end{array}$ & $\begin{array}{c}\text { Autobuses Logroza, } \\
\text { S.L. }\end{array}$ \\
\hline Los Balbases & $L, V$ & 9,45 & 19,00 & $\begin{array}{c}\text { Autobuses de } \\
\text { Castilla, S.L. }\end{array}$ \\
\hline Madrid & L-V & $\begin{array}{c}9,4510,2011,4513,45 \\
15,4518,2019,4521,45 \\
0,453,15\end{array}$ & $\begin{array}{c}7,309,3011,0012,45 \\
13,1514,3015,30(\mathrm{~V}) \\
16,1516,30(\mathrm{~V}) 17,30 \\
18,30(\mathrm{~V}) 20,0022,303,45\end{array}$ & Alsa - Enatcar \\
\hline Madrid (gran clase) & L-V & 18,45 & $8,153,15$ & Alsa - Enatcar \\
\hline $\begin{array}{c}\text { Mahamud - } \\
\text { Presencio - Arcos }\end{array}$ & $L, V$ & 9,45 & 19,00 & $\begin{array}{l}\text { Autobuses de } \\
\text { Castilla, S.L. }\end{array}$ \\
\hline Málaga & & & & UNIONBUS, S.A.U. \\
\hline $\begin{array}{c}\text { Melgar de } \\
\text { Fernamental }\end{array}$ & L-V & $9,1510,3016,00$ & $13,3019,30$ & $\begin{array}{c}\text { El Noroeste de } \\
\text { Burgos, S.L. }\end{array}$ \\
\hline $\begin{array}{c}\text { Melgar de } \\
\text { Fernamental - } \\
\text { Osorno } \\
\end{array}$ & L-V & 10,30 & 17,15 & $\begin{array}{l}\text { El Noroeste de } \\
\text { Burgos, S.L. }\end{array}$ \\
\hline $\begin{array}{c}\text { Murcia - Valencia - } \\
\text { Alicante - Benidorm } \\
\text { - Teruel }\end{array}$ & $L-V$ & 19,15 & $10,3015,00$ & $\begin{array}{c}\text { Autobuses Logroza, } \\
\text { S.L. }\end{array}$ \\
\hline
\end{tabular}




\begin{tabular}{|c|c|c|c|c|}
\hline LÍNEA & $\begin{array}{c}\text { DÍAS DE } \\
\text { SERVICIO }\end{array}$ & ENTRADAS & SALIDAS & OPERADOR \\
\hline Miranda de Ebro & L-V & $\begin{array}{c}\text { 7,30 (temp. escolar) 9,45 } \\
16,3018,30 \text { (temp. } \\
\text { escolar) 23,20 } \\
\end{array}$ & $\begin{array}{c}6,4513,1515,00 \text { (temp. } \\
\text { escolar) 20,30 }\end{array}$ & Soto y Alonso, S.L. \\
\hline Oviedo - Gijón & L-V & $12,1523,15$ & $6,3517,25$ & Alsa - Enatcar \\
\hline Palencia & L-V & $10,3016,0019,45(V)$ & $6,4513,1517,15(\mathrm{~V})$ & $\begin{array}{c}\text { Moreno-Vicente y } \\
\text { Cía. } \\
\end{array}$ \\
\hline Pamplona & & & & Vibasa Información \\
\hline $\begin{array}{c}\text { Peral de Arlanza - } \\
\text { Villahoz }\end{array}$ & $L, V$ & 9,45 & 19,00 & $\begin{array}{l}\text { Autobuses de } \\
\text { Castilla, S.L. }\end{array}$ \\
\hline $\begin{array}{l}\text { Poza de la Sal - } \\
\text { Salas de Bureba - } \\
\text { Padrones- } \\
\text { Caderechas } \\
\end{array}$ & V & 8,45 & 18,30 & Soto y Alonso, S.L. \\
\hline $\begin{array}{l}\text { Poza de la Sal - } \\
\text { Salas de Bureba - } \\
\text { La Parte - Salas }\end{array}$ & $L, V$ & 8,45 & 18,30 & Soto y Alonso, S.L. \\
\hline $\begin{array}{c}\text { Poza de la Sal - } \\
\text { Salas de Bureba - } \\
\text { Rojas - Rublacedo - } \\
\text { Lences }\end{array}$ & $\mathrm{M}, \mathrm{J}$ & 8,45 & 18,30 & Soto y Alonso, S.L. \\
\hline $\begin{array}{l}\text { Poza de la Sal - } \\
\text { Salas de Bureba - } \\
\text { Rojas - Llano } \\
\end{array}$ & $x$ & 8,45 & 18,30 & Soto y Alonso, S.L. \\
\hline Pradoluengo & L-V & $9,1516,15$ & $13,3019,30$ & Alsa - Enatcar \\
\hline $\begin{array}{l}\text { Quintanilla Cabrera - } \\
\text { Jaramillo de la } \\
\text { Fuente }\end{array}$ & V & 10,00 & 18,00 & $\begin{array}{c}\text { Autobuses } \\
\text { Arceredillo, S.L. }\end{array}$ \\
\hline $\begin{array}{c}\text { Rabé de las } \\
\text { Calzadas } \\
\end{array}$ & V & 10,00 & 13,30 & $\begin{array}{l}\text { El Noroeste de } \\
\text { Burgos, S.L. }\end{array}$ \\
\hline Roa (por Cilleruelo) & $L, X, V$ & 9,15 & 17,30 & Alsa - Enatcar \\
\hline Roa (por Quintana) & $\mathrm{M}, \mathrm{J}$ & 9,15 & 17,30 & Alsa - Enatcar \\
\hline Salamanca & L-V & $\begin{array}{l}7,15(\mathrm{~L}) 12,3015,5017,00 \\
\text { (V) } 18,1519,15(\mathrm{~V})\end{array}$ & $11,3017,4521,00(\mathrm{~L}, \mathrm{~V})$ & Alsa - Enatcar \\
\hline San Sebastián & L-V & $\begin{array}{c}12,3014,0016,0019,30 \\
22,0024,003,45\end{array}$ & $\begin{array}{c}7,0010,3014,1516,00 \\
17,00 \text { (V) 18,30 22,00 } \\
24,00(\mathrm{~V}) 3,15\end{array}$ & Alsa - Enatcar \\
\hline Sasamón & L-V & 9,30 & 13,30 & $\begin{array}{c}\text { Autobuses Amaya, } \\
\text { S.L. }\end{array}$ \\
\hline $\begin{array}{c}\text { Sasamón - Grijalba } \\
\text { - Herrera de } \\
\text { Pisuerga }\end{array}$ & L-V & 9,30 & 17,30 & $\begin{array}{c}\text { Autobuses Amaya, } \\
\text { S.L. }\end{array}$ \\
\hline Santander & $L-V$ & $10,4513,30 \quad 19,3021,45$ & $10,3016,0022,00$ & Alsa - Enatcar \\
\hline $\begin{array}{c}\text { Santander (gran } \\
\text { clase) }\end{array}$ & L-V & 3,15 & 3,15 & Alsa - Enatcar \\
\hline $\begin{array}{c}\text { Santander- } \\
\text { Cabezón - Comillas } \\
\text { - Torrelavega - San } \\
\text { Vicente de la } \\
\text { Barquera }\end{array}$ & & & $\begin{array}{c}\text { 10,30 (Julio-Septiembre) } \\
19,00 \text { (V de Octubre- } \\
\text { Junio) }\end{array}$ & Alsa - Enatcar \\
\hline $\begin{array}{c}\text { Santiago de } \\
\text { Compostela - Lugo }\end{array}$ & L-V & $23,5513,206,15$ & $13,154,4516,50$ & Alsa - Enatcar \\
\hline
\end{tabular}




\begin{tabular}{|c|c|c|c|c|}
\hline LÍNEA & $\begin{array}{l}\text { DÍAS DE } \\
\text { SERVICIO }\end{array}$ & ENTRADAS & SALIDAS & OPERADOR \\
\hline $\begin{array}{l}\text { Santibáñez } \\
\text { Zarzaguda }\end{array}$ & $M, V$ & $10,00(V)$ & 13,15 & $\begin{array}{l}\text { Autobuses del } \\
\text { Pisuerga, S.L. }\end{array}$ \\
\hline $\begin{array}{l}\text { Santo Domingo de la } \\
\text { Calzada }\end{array}$ & L-V & $\begin{array}{c}10,1513,0015,0019,00 \\
21,15 \\
\end{array}$ & $\begin{array}{c}8,3010,3012,4513,00(\mathrm{~V}) \\
15,0016,3019,45 \\
\end{array}$ & $\begin{array}{c}\text { Autobuses Logroza, } \\
\text { S.L. }\end{array}$ \\
\hline $\begin{array}{l}\text { Santo Domingo de } \\
\text { Silos - Caleruega }\end{array}$ & L-V & 10,00 & $17,3018,30(\mathrm{~V})$ & $\begin{array}{c}\text { Autobuses } \\
\text { Arceredillo, S.L. }\end{array}$ \\
\hline Soria (por Covaleda) & L-V & $9,0017,00$ & $7,0014,0018,30$ & $\begin{array}{c}\text { Automóviles La } \\
\text { Serrana, S.A. }\end{array}$ \\
\hline Soria (por Leonardo) & L-V & $9,0016,3020,30$ & $7,0014,0018,30$ & $\begin{array}{c}\text { Automóviles La } \\
\text { Serrana, S.A. }\end{array}$ \\
\hline $\begin{array}{c}\text { Tinieblas de la Sierra } \\
\text { - Cuzcurrita de } \\
\text { Juarros } \\
\end{array}$ & $L, V$ & 10,30 & 19,30 & Arroyo Bus \\
\hline Tobar & V & 11,00 & 19,15 & $\begin{array}{c}\text { Autobuses Amaya, } \\
\text { S.L. }\end{array}$ \\
\hline Tordómar & $L, V$ & 9,45 & 19,00 & $\begin{array}{c}\text { Autobuses de } \\
\text { Castilla, S.L. }\end{array}$ \\
\hline $\begin{array}{l}\text { Tordómar - Arcos - } \\
\text { Santa María - } \\
\text { Presencio } \\
\end{array}$ & L-V & & $\begin{array}{c}13,15 \text { (temp. escolar) } \\
14,45 \text { (M,V de temp. no } \\
\text { escolar) } \\
\end{array}$ & $\begin{array}{l}\text { Autobuses de } \\
\text { Castilla, S.L. }\end{array}$ \\
\hline Torrelavega & L-V & $10,4519,3021,45$ & $10,3022,00$ & Alsa - Enatcar \\
\hline $\begin{array}{l}\text { Torrelavega - } \\
\text { Comillas - San } \\
\text { Vicente }\end{array}$ & L-V & 19,30 (Julio-Septiembre) & 10,30 (Julio-Septiembre) & Alsa - Enatcar \\
\hline $\begin{array}{c}\text { Torrelavega (gran } \\
\text { clase) }\end{array}$ & L-V & 3,15 & 3,15 & Alsa - Enatcar \\
\hline Tórtoles de Esgueva & L-V & 9,30 & $14,45(L, X) 18,30$ & $\begin{array}{l}\text { Autobuses de } \\
\text { Castilla, S.L. }\end{array}$ \\
\hline $\begin{array}{c}\text { Trespaderne - } \\
\text { Briviesca - Oña } \\
\end{array}$ & $L, X, V$ & 15,45 & 13,00 & Soto y Alonso, S.L. \\
\hline Trespaderne & $\mathrm{L}-\mathrm{V}$ & 8,50 & 18,30 & Soto y Alonso, S.L. \\
\hline Valladolid & L-V & $\begin{array}{c}7,45 \text { (L) } 12,3015,5017,00 \\
\text { (V) } 18,4523,50\end{array}$ & $\begin{array}{c}6,3011,00(\mathrm{~L}, \mathrm{~J}) 11,30 \\
16,3017,4521(\mathrm{~L}, \mathrm{~V}) 21,45 \\
(\mathrm{~V})\end{array}$ & Alsa - Enatcar \\
\hline $\begin{array}{c}\text { Vigo - Orense - } \\
\text { Pontevedra }\end{array}$ & & & & Vibasa \\
\hline Villadiego & L-V & $9,3016,30(\mathrm{~L})$ & $\begin{array}{c}9,30(\mathrm{~L}) 13,3017,3019,15 \\
(\mathrm{~L}, \mathrm{~V})\end{array}$ & $\begin{array}{c}\text { Autobuses Amaya, } \\
\text { S.L. } \\
\end{array}$ \\
\hline Villahoz - Mahamud & L-V & 9,30 & $18,3019,00(L, V)$ & $\begin{array}{c}\text { Autobuses de } \\
\text { Castilla, S.L. }\end{array}$ \\
\hline Villodrigo - Vallejera & $x$ & & 17,15 & $\begin{array}{c}\text { Moreno-Vicente y } \\
\text { Cía. }\end{array}$ \\
\hline Vitoria & L-V & $\begin{array}{c}12,3014,0016,0017,30 \\
19,3022,0024,003,45\end{array}$ & $\begin{array}{c}7,0010,3012,0014,15 \\
16,0018,3022,0024,00 \\
\text { (V) } 3,15\end{array}$ & Alsa - Enatcar \\
\hline Vitoria (gran clase) & L-V & 8,15 & 18,45 & Alsa - Enatcar \\
\hline $\begin{array}{l}\text { Valencia - Murcia - } \\
\text { Benidorm - Teruel }\end{array}$ & L-V & 19,15 & $10,3015,00$ & $\begin{array}{c}\text { Autobuses Logroza, } \\
\text { S.L. }\end{array}$ \\
\hline Zamora - Toro & L-V & $13,5015,5023,50$ & $\begin{array}{c}6,3011,15(\mathrm{M}, \mathrm{X}, \mathrm{V}) 11,45 \\
(\mathrm{~L}, \mathrm{~J}) 16,3021,45(\mathrm{~V})\end{array}$ & Alsa - Enatcar \\
\hline Zaragoza & $L-V$ & $13,0015,0019,1521,30$ & $\begin{array}{c}8,3010,3013,00(\mathrm{~V}) 15,00 \\
16,30\end{array}$ & $\begin{array}{c}\text { Autobuses Logroza, } \\
\text { S.L. }\end{array}$ \\
\hline
\end{tabular}


Tabla A1-2. Relación de posibles destinos

Fuente: Vía Michelín [139]; Renfe [121]

\begin{tabular}{|c|c|c|c|c|c|c|c|c|c|c|}
\hline O/D & $\begin{array}{l}\text { Dist } \\
(\mathrm{Km})\end{array}$ & $\begin{array}{l}\text { Dist } \\
\text { VR } \\
(\mathrm{Km})\end{array}$ & $\begin{array}{l}T_{\text {coche }} \\
\text { (h) }\end{array}$ & $\begin{array}{c}C_{\text {coche }} \\
(€)\end{array}$ & $\begin{array}{c}\text { NS }_{\text {bus }} \\
\text { (salidas) }\end{array}$ & TREN & $\begin{array}{l}T_{\text {tren }} \\
\text { (h) }\end{array}$ & $\begin{array}{c}C_{\text {tren }} \\
(€)\end{array}$ & $\begin{array}{l}\mathrm{NS}_{\text {tren }} \\
\text { (salidas) }\end{array}$ & $\begin{array}{c}\text { Trans- } \\
\text { bordo } \\
\text { tren }\end{array}$ \\
\hline A Coruña & 488 & 474 & $4: 50$ & 50,44 & 1 & $\mathrm{SI}$ & $8: 30$ & 44,20 & 3 & \\
\hline Abajas & 38 & 0 & $0: 44$ & 4,02 & 1 & & & & & \\
\hline $\begin{array}{l}\text { Aguilar de } \\
\text { Campoo }\end{array}$ & 79 & 0 & 1:06 & 6,42 & 1 & & & & & \\
\hline Alar del Rey & 101 & 95 & 1:03 & 9,53 & 1 & & & & & \\
\hline Albillos & 14 & 4,5 & $0: 17$ & 1,68 & 4 & & & & & \\
\hline Algeciras & 890 & 878 & $8: 59$ & 91,74 & 1 & SI & 9:00 & 105,40 & 2 & sí \\
\hline Alicante & 653 & 636 & 6:09 & 61,61 & 2 & SI & $8: 30$ & 63,80 & 8 & sí \\
\hline Amorebieta & 168 & 154 & $1: 47$ & 33,97 & 2 & & & & & \\
\hline Arraya de Oca & 38 & 11 & $0: 34$ & 4,70 & 1 & & & & & \\
\hline Aranda de Duero & 87 & 81 & $0: 54$ & 8,03 & 8 & $\mathrm{SI}$ & 1:00 & 17,40 & 1 & \\
\hline Arcos & 14 & 6 & $0: 15$ & 1,57 & 6 & & & & & \\
\hline $\begin{array}{l}\text { Arenillas de } \\
\text { Riopisuerga }\end{array}$ & 60 & 49 & $0: 42$ & 5,66 & 2 & & & & & \\
\hline Arija & 93 & 0 & $1: 28$ & 8,53 & 1 & & & & & \\
\hline Astudillo & 77 & 55 & $0: 55$ & 7,23 & 1 & & & & & \\
\hline $\begin{array}{c}\text { Avellanosa del } \\
\text { Páramo }\end{array}$ & 35 & 17 & $0: 34$ & 3,71 & 1 & & & & & \\
\hline Badajoz & 577 & 566 & $5: 53$ & 56,26 & 1 & $\mathrm{SI}$ & $10: 30$ & 77,50 & 2 & Sí \\
\hline Baracaldo & 166 & 158 & $1: 47$ & 32,74 & 1 & & & & & \\
\hline Barbadillo & 265 & 257 & $2: 29$ & 23,90 & 1 & & & & & \\
\hline Barcelona & 609 & 573 & 6:08 & 101,98 & 4 & $\mathrm{SI}$ & $7: 00$ & 42,00 & 4 & \\
\hline Béjar & 320 & 312 & 3:07 & 29,78 & 1 & & & & & \\
\hline Belorado & 51 & 5,5 & $0: 50$ & 4,75 & 6 & & & & & \\
\hline Benidorm & 696 & 678 & $6: 31$ & 68,34 & 2 & & & & & \\
\hline Bergara & 155 & 143 & $1: 40$ & 24,83 & 2 & & & & & \\
\hline Bilbao & 159 & 150 & $1: 41$ & 31,99 & 3 & $\mathrm{SI}$ & $3: 00$ & 18,10 & 5 & \\
\hline Briviesca & 46 & 39 & $0: 33$ & 8,74 & 10 & $\mathrm{SI}$ & $0: 30$ & 3,85 & 6 & \\
\hline Buniel & 16 & 14 & $0: 13$ & 1,65 & 4 & & & & & \\
\hline Busto de Bureba & 61 & 39 & $0: 44$ & 9,90 & 1 & & & & & \\
\hline Cabezón & 177 & 96 & $2: 05$ & 15,81 & 1 & & & & & \\
\hline Cabia & 21 & 17 & $0: 16$ & 2,05 & 1 & & & & & \\
\hline Cáceres & 456 & 445 & $4: 43$ & 44,71 & 2 & $\mathrm{SI}$ & $8: 30$ & 70,40 & 2 & sí \\
\hline Caderechas & 81 & 39 & $1: 15$ & 12,61 & 1 & & & & & \\
\hline Cádiz & 829 & 812 & $8: 23$ & 85,41 & 1 & $\mathrm{SI}$ & $10: 15$ & 107,10 & 2 & Sí \\
\hline Caleruega & 91 & 68 & $1: 07$ & 8,86 & 1 & & & & & \\
\hline Carcedo & 10 & 0 & $0: 16$ & 1,35 & 4 & & & & & \\
\hline Cardeñadijo & 6,5 & 0 & $0: 11$ & 0,87 & 4 & & & & & \\
\hline Cardeñajimeno & 7 & 0 & $0: 11$ & 0,92 & 4 & & & & & \\
\hline Castrillo del Val & 18 & 5,5 & $0: 19$ & 1,89 & 4 & & & & & \\
\hline Castrojeriz & 55 & 37 & $0: 41$ & 5,22 & 3 & & & & & \\
\hline Cayuela & 23 & 17 & $0: 19$ & 2,35 & 4 & & & & & \\
\hline $\begin{array}{l}\text { Cervera de } \\
\text { Pisuerga }\end{array}$ & 104 & 0 & $1: 33$ & 9,02 & 1 & & & & & \\
\hline
\end{tabular}




\begin{tabular}{|c|c|c|c|c|c|c|c|c|c|c|}
\hline O/D & $\begin{array}{l}\text { Dist } \\
(\mathrm{Km})\end{array}$ & $\begin{array}{c}\text { Dist } \\
\text { VR } \\
(\mathrm{Km})\end{array}$ & $\begin{array}{c}T_{\text {coche }} \\
\text { (h) }\end{array}$ & $\begin{array}{c}C_{\text {coche }} \\
(€)\end{array}$ & $\begin{array}{c}\text { NS }_{\text {bus }} \\
\text { (salidas) }\end{array}$ & TREN & $\begin{array}{l}T_{\text {tren }} \\
\text { (h) }\end{array}$ & $\begin{array}{c}C_{\text {tren }} \\
(€)\end{array}$ & $\begin{array}{c}\text { NS }_{\text {tren }} \\
\text { (salidas) }\end{array}$ & $\begin{array}{c}\text { Trans- } \\
\text { bordo } \\
\text { tren }\end{array}$ \\
\hline $\begin{array}{c}\text { Cerezo de Río } \\
\text { Tirón }\end{array}$ & 65 & 39 & $0: 53$ & 10,84 & 1 & & & & & \\
\hline Cilleruelo & 58 & 50 & $0: 39$ & 5,53 & 1 & & & & & \\
\hline Ciudad Rodrigo & 330 & 326 & $3: 02$ & 29,65 & 1 & SI & $4: 10$ & 29,65 & 1 & \\
\hline Comillas & 184 & 96 & $2: 12$ & 16,58 & 1 & & & & & \\
\hline Corconte & 93 & 0 & $1: 25$ & 8,36 & 1 & & & & & \\
\hline Córdoba & 635 & 619 & $6: 11$ & 60,05 & 1 & SI & $8: 30$ & 45,00 & 1 & \\
\hline Coria & 417 & 375 & $4: 21$ & 39,88 & 1 & & & & & \\
\hline Covaleda & 99 & 9 & $1: 38$ & 9,52 & 3 & & & & & \\
\hline Covarrubias & 42 & 9 & $0: 42$ & 4,27 & 2 & & & & & \\
\hline Cuéllar & 187 & 1,75 & $1: 58$ & 17,90 & 1 & & & & & \\
\hline $\begin{array}{l}\text { Cuzcurrita de } \\
\text { Juarros }\end{array}$ & 22 & 5,5 & $0: 24$ & 2,30 & 1 & & & & & \\
\hline $\begin{array}{c}\text { Duruelo de la } \\
\text { Sierra }\end{array}$ & 94 & 9 & $1: 33$ & 9,04 & 1 & & & & & \\
\hline Eibar & 192 & 178 & 2:03 & 38,20 & 2 & & & & & \\
\hline $\begin{array}{c}\text { Espinosa de los } \\
\text { Monteros }\end{array}$ & 116 & 0 & $1: 55$ & 11,08 & 2 & & & & & \\
\hline Fresneda & 64 & 5,5 & 1:06 & 6,29 & 1 & & & & & \\
\hline Frías & 82 & 39 & 1:07 & 12,33 & 1 & & & & & \\
\hline Frómista & 83 & 70 & $0: 54$ & 7,63 & 1 & & & & & \\
\hline Fuentes de Oñoro & 356 & 350 & $3: 17$ & 32,12 & 1 & SI & $4: 30$ & 32,12 & 1 & \\
\hline Gijón & 317 & 309 & $3: 14$ & 39,95 & 2 & SI & 5:00 & 27,80 & 2 & \\
\hline Girona & 688 & 643 & $6: 49$ & 112,51 & 1 & SI & $8: 30$ & 81,40 & 3 & Sí \\
\hline Granada & 663 & 646 & $6: 23$ & 62,24 & 8 & $\mathrm{SI}$ & $10: 30$ & 104,00 & 2 & Sí \\
\hline Grijalba & 46 & 34 & $0: 34$ & 4,42 & 1 & & & & & \\
\hline Gumiel de Izán & 71 & 68 & $0: 44$ & 6,59 & 1 & & & & & \\
\hline $\begin{array}{c}\text { Gumiel de } \\
\text { Mercado }\end{array}$ & 75 & 54 & $0: 54$ & 7,19 & 1 & & & & & \\
\hline Haro & 92 & 61 & 1:06 & 15,14 & 1 & SI & $1: 30$ & 10,00 & 2 & \\
\hline $\begin{array}{c}\text { Herrera de } \\
\text { Pisuerga }\end{array}$ & 94 & 87 & $1: 00$ & 8,90 & 1 & & & & & \\
\hline Hontomín & 28 & 0 & $0: 33$ & 2,91 & 1 & & & & & \\
\hline Hoyos del Tozo & 57 & 0 & $0: 50$ & 4,84 & 1 & & & & & \\
\hline Hurones & 14 & 1,9 & $0: 17$ & 1,60 & 3 & & & & & \\
\hline Ibeas de Juarros & 19 & 5,5 & $0: 20$ & 1,89 & 7 & & & & & \\
\hline Irún & 245 & 227 & $2: 33$ & 33,98 & 4 & SI & 4:00 & 23,60 & 5 & \\
\hline $\begin{array}{c}\text { Jaramillo de la } \\
\text { Fuente }\end{array}$ & 67 & 9 & $1: 03$ & 6,53 & 1 & & & & & \\
\hline La Parte & 49 & 24 & $0: 42$ & 4,88 & 1 & & & & & \\
\hline Laredo & 212 & 203 & $2: 13$ & 37,15 & 1 & & & & & \\
\hline Lences & 63 & 0 & 1:04 & 6,15 & 1 & & & & & \\
\hline León & 189 & 178 & $1: 59$ & 17,92 & 4 & SI & $2: 00$ & 19,50 & 4 & \\
\hline Lerma & 41 & 38 & $0: 27$ & 3,89 & 8 & & & & & \\
\hline Llano de Bureba & 62 & 39 & $0: 53$ & 10,59 & 1 & & & & & \\
\hline Lleida & 448 & 416 & $4: 33$ & 75,47 & 1 & $\mathrm{SI}$ & $5: 00$ & 46,90 & 4 & \\
\hline Logroño & 134 & 100 & $1: 33$ & 22,10 & 7 & SI & $2: 00$ & 18,20 & 3 & \\
\hline
\end{tabular}




\begin{tabular}{|c|c|c|c|c|c|c|c|c|c|c|}
\hline O/D & $\begin{array}{l}\text { Dist } \\
(\mathrm{Km})\end{array}$ & $\begin{array}{c}\text { Dist } \\
\text { VR } \\
(\mathrm{Km}) \\
\end{array}$ & $\begin{array}{l}T_{\text {coche }} \\
\text { (h) }\end{array}$ & $\begin{array}{c}C_{\text {coche }} \\
(€)\end{array}$ & $\begin{array}{l}\mathrm{NS}_{\text {bus }} \\
\text { (salidas) }\end{array}$ & TREN & $\begin{array}{l}T_{\text {tren }} \\
\text { (h) }\end{array}$ & $\begin{array}{l}C_{\text {tren }} \\
(€)\end{array}$ & $\begin{array}{l}\mathrm{NS} \text { tren } \\
\text { (salidas) }\end{array}$ & $\begin{array}{c}\text { Trans- } \\
\text { bordo } \\
\text { tren }\end{array}$ \\
\hline Los Balbases & 45 & 38 & $0: 31$ & 4,32 & 1 & & & & & \\
\hline Lugo & 394 & 380 & 3:54 & 40,32 & 4 & $\mathrm{SI}$ & $6: 00$ & 50,00 & 2 & \\
\hline Madrid & 244 & 235 & $2: 28$ & 22,40 & 11 & $\mathrm{SI}$ & $2: 30$ & 39,30 & 6 & \\
\hline Mahamud & 47 & 31 & $0: 39$ & 4,77 & 2 & & & & & \\
\hline Medina de Pomar & 87 & 0 & $1: 32$ & 8,91 & 2 & & & & & \\
\hline $\begin{array}{c}\text { Melgar de } \\
\text { Fernamental }\end{array}$ & 55 & 49 & $0: 36$ & 5,09 & 3 & & & & & \\
\hline Mérida & 520 & 511 & $5: 21$ & 51,12 & 2 & $\mathrm{SI}$ & 9:40 & 74,40 & 2 & sí \\
\hline Mieres & 280 & 274 & $2: 49$ & 36,46 & 2 & $\mathrm{SI}$ & $3: 40$ & 29,60 & 1 & \\
\hline Miranda de Ebro & 84 & 77 & $0: 55$ & 16,27 & 4 & $\mathrm{SI}$ & $1: 00$ & 6,10 & 13 & \\
\hline Modúbar & 17 & 9 & $0: 16$ & 1,71 & 4 & & & & & \\
\hline Mondragón & 150 & 121 & $1: 43$ & 23,74 & 2 & & & & & \\
\hline Murcia & 633 & 617 & $5: 56$ & 59,89 & 2 & $\mathrm{SI}$ & $9: 20$ & 82,60 & 2 & Sí \\
\hline Oña & 72 & 39 & 1:01 & 11,34 & 2 & & & & & \\
\hline Orense & 457 & 447 & 4:19 & 41,38 & 1 & $\mathrm{SI}$ & $6: 00$ & 38,80 & 3 & \\
\hline Osorno & 66 & 62 & $0: 41$ & 6,06 & 1 & & & & & \\
\hline Oviedo & 296 & 290 & 3:01 & 38,09 & 2 & SI & $3: 45$ & 28,00 & 2 & \\
\hline Padrones & 78 & 39 & $1: 10$ & 12,25 & 1 & & & & & \\
\hline Palencia & 93 & 87 & $0: 58$ & 8,66 & 2 & $\mathrm{SI}$ & $0: 50$ & 4,60 & 9 & \\
\hline Pamplona & 211 & 201 & $2: 07$ & 30,67 & 1 & $\mathrm{SI}$ & $2: 00$ & 22,80 & 1 & \\
\hline $\begin{array}{c}\text { Pedrosa de Río } \\
\text { Urbel }\end{array}$ & 26 & 17 & $0: 22$ & 2,64 & 1 & & & & & \\
\hline Peral de Arlanza & 61 & 48 & $0: 42$ & 5,78 & 1 & & & & & \\
\hline Pineda Trasmonte & 62 & 54 & $0: 40$ & 5,83 & 1 & & & & & \\
\hline Plasencia & 378 & 368 & $3: 46$ & 35,94 & 2 & & & & & \\
\hline Pontevedra & 572 & 565 & $5: 20$ & 54,84 & 1 & $\mathrm{SI}$ & $10: 15$ & 53,80 & 5 & Sí \\
\hline Portugalete & 170 & 162 & $1: 47$ & 33,04 & 1 & & & & & \\
\hline Poza de la Sal & 58 & 0 & $0: 58$ & 5,59 & 1 & & & & & \\
\hline Pradoluengo & 61 & 5,5 & 1:03 & 5,97 & 2 & & & & & \\
\hline Presencio & 45 & 31 & $0: 36$ & 4,55 & 2 & & & & & \\
\hline Quintana del Pidio & 73 & 63 & $0: 48$ & 6,94 & 1 & & & & & \\
\hline Quintanadueñas & 9 & 1,4 & $0: 12$ & 1,09 & 4 & & & & & \\
\hline $\begin{array}{c}\text { Quintanar de la } \\
\text { Sierra }\end{array}$ & 82 & 9 & 1:20 & 7,78 & 2 & & & & & \\
\hline $\begin{array}{c}\text { Quintanilla } \\
\text { Cabrera }\end{array}$ & 46 & 5,5 & $0: 50$ & 4,95 & 1 & & & & & \\
\hline $\begin{array}{l}\text { Rabé de las } \\
\text { Calzadas }\end{array}$ & 20 & 12 & $0: 18$ & 2,02 & 1 & & & & & \\
\hline Revillarruz & 17 & 9 & $0: 16$ & 1,68 & 4 & & & & & \\
\hline Riocerezo & 19 & 1,9 & $0: 23$ & 2,21 & 3 & & & & & \\
\hline Roa & 85 & 54 & 1:05 & 8,20 & 1 & & & & & \\
\hline Rojas & 60 & 39 & $0: 51$ & 10,33 & 1 & & & & & \\
\hline $\begin{array}{l}\text { Royuela de Río } \\
\text { Franco }\end{array}$ & 64 & 37 & $0: 53$ & 6,36 & 1 & & & & & \\
\hline Rublacedo & 35 & 0 & $0: 41$ & 3,78 & 1 & & & & & \\
\hline Sahagún & 124 & 118 & 1:13 & 11,21 & 1 & $\mathrm{SI}$ & $1: 20$ & 15,90 & 3 & \\
\hline
\end{tabular}




\begin{tabular}{|c|c|c|c|c|c|c|c|c|c|c|}
\hline$O / D$ & $\begin{array}{l}\text { Dist } \\
(\mathrm{Km})\end{array}$ & $\begin{array}{c}\text { Dist } \\
\text { VR } \\
(\mathrm{Km}) \\
\end{array}$ & $\begin{array}{c}T_{\text {coche }} \\
\text { (h) }\end{array}$ & $\begin{array}{c}\text { C coche }_{\text {co }} \\
(€)\end{array}$ & $\begin{array}{c}\text { NS bus } \\
\text { (salidas) }\end{array}$ & TREN & $\begin{array}{l}T_{\text {tren }} \\
\text { (h) }\end{array}$ & $\begin{array}{c}C_{\text {tren }} \\
(€)\end{array}$ & $\begin{array}{c}\text { NS }_{\text {tren }} \\
\text { (salidas) }\end{array}$ & $\begin{array}{c}\text { Trans- } \\
\text { bordo } \\
\text { tren }\end{array}$ \\
\hline Salamanca & 243 & 233 & $2: 21$ & 22,01 & 3 & SI & $3: 30$ & 22,00 & 4 & \\
\hline Salas de Bureba & 71 & 39 & $1: 02$ & 11,40 & 1 & & & & & \\
\hline $\begin{array}{c}\text { Salas de los } \\
\text { Infantes }\end{array}$ & 58 & 9 & $0: 51$ & 5,17 & 1 & & & & & \\
\hline Saldaña (Palencia) & 109 & 84 & $1: 13$ & 10,07 & 1 & & & & & \\
\hline $\begin{array}{c}\text { Saldaña de } \\
\text { Burgos }\end{array}$ & 12 & 9 & $0: 10$ & 1,22 & 4 & & & & & \\
\hline San Fernando & 833 & 821 & $8: 19$ & 85,81 & 1 & SI & $9: 45$ & 105,70 & 2,00 & Sí \\
\hline $\begin{array}{c}\text { San Leonardo de } \\
\text { Yagüe } \\
\end{array}$ & 90 & 9 & $1: 16$ & 7,66 & 3 & & & & & \\
\hline San Mamés & 19 & 12 & $0: 16$ & 1,84 & 2 & & & & & \\
\hline San Medel & 15 & 5,5 & $0: 15$ & 1,49 & 4 & & & & & \\
\hline San Sebastián & 227 & 213 & $2: 23$ & 30,77 & 7 & $\mathrm{SI}$ & $3: 00$ & 26,40 & 5 & \\
\hline $\begin{array}{c}\text { San Vicente de la } \\
\text { Barquera }\end{array}$ & 191 & 110 & $2: 12$ & 17,08 & 1 & & & & & \\
\hline Santa Inés & 40 & 35 & $0: 28$ & 3,87 & 2 & & & & & \\
\hline $\begin{array}{c}\text { Santa María } \\
\text { Ribarredonda }\end{array}$ & 62 & 39 & $0: 44$ & 9,92 & 1 & & & & & \\
\hline $\begin{array}{c}\text { Santa María del } \\
\text { Campo }\end{array}$ & 45 & 31 & $0: 36$ & 4,47 & 1 & & & & & \\
\hline Santander & 181 & 99 & $2: 12$ & 16,42 & 3 & $\mathrm{SI}$ & 5:00 & 16,90 & 8 & sí \\
\hline $\begin{array}{l}\text { Santiago de } \\
\text { Compostela }\end{array}$ & 529 & 512 & $5: 14$ & 57,22 & 3 & SI & $7: 50$ & 38,50 & 1 & \\
\hline $\begin{array}{l}\text { Santibáñez } \\
\text { Zarzaguda } \\
\end{array}$ & 28 & 0 & $0: 34$ & 3,01 & 1 & & & & & \\
\hline $\begin{array}{c}\text { Santo Domingo de } \\
\text { la Calzada }\end{array}$ & 98 & 61 & $1: 15$ & 15,78 & 6 & & & & & \\
\hline $\begin{array}{l}\text { Santo Domingo de } \\
\text { Silos } \\
\end{array}$ & 73 & 9 & $1: 07$ & 6,81 & 1 & & & & & \\
\hline Santurce & 172 & 164 & $1: 50$ & 33,31 & 1 & & & & & \\
\hline Sarracín & 13 & 9 & $0: 12$ & 1,34 & 4 & & & & & \\
\hline Sasamón & 39 & 34 & $0: 27$ & 3,70 & 2 & & & & & \\
\hline Sestao & 169 & 159 & $1: 48$ & 32,98 & 1 & & & & & \\
\hline Sevilla & 710 & 700 & $7: 12$ & 69,19 & 1 & & & & & \\
\hline Soria & 143 & 9 & $2: 08$ & 12,42 & 3 & $\mathrm{SI}$ & $10: 45$ & 53,85 & 1 & sí \\
\hline Sotopalacios & 11 & 0 & $0: 14$ & 1,14 & 3 & & & & & \\
\hline Sotragero & 9 & 0 & $0: 12$ & 1,05 & 4 & & & & & \\
\hline Tamarón & 35 & 29 & $0: 25$ & 3,43 & 1 & & & & & \\
\hline Tardajos & 18 & 12 & $0: 16$ & 1,80 & 2 & & & & & \\
\hline Teruel & 471 & 434 & $4: 48$ & 66,52 & 2 & $\mathrm{SI}$ & $7: 45$ & 44,30 & 4 & Sí \\
\hline $\begin{array}{c}\text { Tinieblas de la } \\
\text { Sierra } \\
\end{array}$ & 45 & 5,5 & $0: 48$ & 4,89 & 1 & & & & & \\
\hline Tobar & 44 & 24 & $0: 36$ & 4,32 & 1 & & & & & \\
\hline Toledo & 335 & 323 & $3: 22$ & 39,60 & 1 & $\mathrm{SI}$ & 5:00 & 48,75 & 1 & sí \\
\hline Tomillares & 17 & 5,5 & $0: 17$ & 1,68 & 4 & & & & & \\
\hline Tordómar & 47 & 37 & $0: 33$ & 4,49 & 1 & & & & & \\
\hline Toro & 191 & 183 & $1: 50$ & 17,32 & 3 & & & & & \\
\hline Torrelavega & 158 & 78 & $1: 53$ & 14,05 & 3 & & & & & \\
\hline
\end{tabular}




\begin{tabular}{|c|c|c|c|c|c|c|c|c|c|c|}
\hline O/D & $\begin{array}{l}\text { Dist } \\
(\mathrm{Km})\end{array}$ & $\begin{array}{c}\text { Dist } \\
\text { VR } \\
(\mathrm{Km}) \\
\end{array}$ & $\begin{array}{l}T_{\text {coche }} \\
\text { (h) }\end{array}$ & $\begin{array}{c}C_{\text {coche }} \\
(€)\end{array}$ & $\begin{array}{l}\text { NS }_{\text {bus }} \\
\text { (salidas) }\end{array}$ & TREN & $\begin{array}{l}T_{\text {tren }} \\
\text { (h) }\end{array}$ & $\begin{array}{c}C_{\text {tren }} \\
(€)\end{array}$ & $\begin{array}{l}\mathrm{NS}_{\text {tren }} \\
\text { (salidas) }\end{array}$ & $\begin{array}{c}\text { Trans- } \\
\text { bordo } \\
\text { tren }\end{array}$ \\
\hline Torrevieja & 691 & 662 & $6: 34$ & 64,89 & 2 & & & & & \\
\hline $\begin{array}{c}\text { Tórtoles de } \\
\text { Esgueva }\end{array}$ & 93 & 54 & 1:14 & 9,14 & 2 & & & & & \\
\hline Trespaderne & 84 & 39 & 1:15 & 12,65 & 2 & & & & & \\
\hline Tubilla del Agua & 47 & 0 & $0: 44$ & 4,14 & 1 & & & & & \\
\hline Ubierna & 18 & 0 & $0: 20$ & 1,68 & 3 & & & & & \\
\hline Valdelateja & 58 & 0 & $0: 55$ & 5,22 & 1 & & & & & \\
\hline Valdorros & 22 & 20 & $0: 16$ & 2,12 & 1 & & & & & \\
\hline Valencia & 589 & 569 & $5: 37$ & 56,04 & 2 & $\mathrm{SI}$ & $6: 00$ & 84,80 & 1 & sí \\
\hline Valladolid & 127 & 120 & $1: 20$ & 11,82 & 7 & $\mathrm{SI}$ & $1: 20$ & 8,00 & 12 & \\
\hline Vallejera & 53 & 43 & $0: 36$ & 5,06 & 1 & & & & & \\
\hline Vigo & 553 & 545 & $5: 12$ & 50,39 & 1 & $\mathrm{SI}$ & $7: 30$ & 45,00 & 3 & \\
\hline Villadiego & 46 & 24 & $0: 38$ & 4,54 & 3 & & & & & \\
\hline Villafruela & 59 & 42 & $0: 44$ & 5,77 & 1 & & & & & \\
\hline Villagonzalo & 10 & 1,4 & $0: 14$ & 1,24 & 5 & & & & & \\
\hline Villahoz & 53 & 37 & $0: 39$ & 5,05 & 2 & & & & & \\
\hline Villalbilla & 16 & 12 & $0: 13$ & 1,60 & 2 & & & & & \\
\hline Villalmanzo & 37 & 35 & $0: 24$ & 3,49 & 1 & & & & & \\
\hline $\begin{array}{l}\text { Villanueva } \\
\text { Matamala }\end{array}$ & 18 & 6 & $0: 20$ & 2,02 & 2 & & & & & \\
\hline Villarcayo & 82 & 0 & $1: 25$ & 8,16 & 4 & & & & & \\
\hline Villariezo & 12 & 6 & $0: 12$ & 1,31 & 5 & & & & & \\
\hline Villodrigo & 46 & 43 & $0: 29$ & 4,29 & 1 & & & & & \\
\hline Vitoria & 115 & 101 & 1:17 & 20,21 & 8 & $\mathrm{SI}$ & 1:15 & 17,90 & 10 & \\
\hline Yudego & 36 & 24 & $0: 31$ & 3,61 & 1 & & & & & \\
\hline $\begin{array}{c}\text { Zalamea de la } \\
\text { Serena }\end{array}$ & 601 & 551 & $6: 14$ & 57,41 & 1 & & & & & \\
\hline Zamora & 224 & 217 & $2: 13$ & 20,55 & 3 & $\mathrm{SI}$ & 4:05 & 16,65 & 4 & Sí \\
\hline Zaragoza & 306 & 276 & $3: 14$ & 51,25 & 4 & SI & 4:00 & 27,40 & 4 & \\
\hline
\end{tabular}





\section{Anexo 2. Encuesta Completa (Vista de Pantalla)}

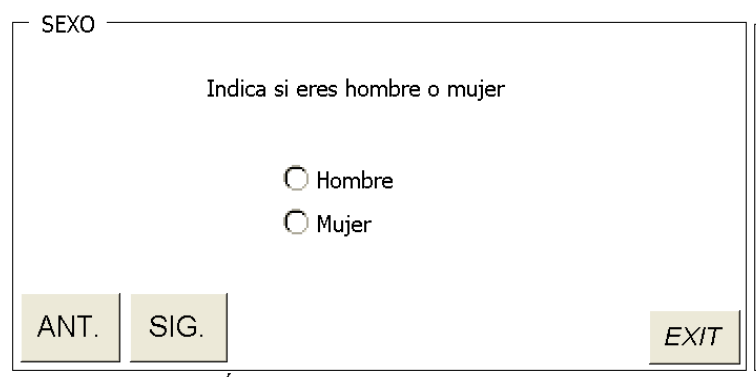

ACTIVIDAD ECONÓMICA

Indica a qué te dedicas

\begin{tabular}{|c|c|}
\hline Trabajador/a & O Jubilado/a \\
\hline$\bigcirc$ Estudiante & $\bigcirc$ En paro \\
\hline Amo/a de casa & Otros \\
\hline
\end{tabular}

ANT.

SIG.

— VEHÍCULOS A MOTOR

Indica el número de coches/motos de que disponéis en casa

○o

O 1

O 2

ANT.

SIG.

$\mathrm{C}>=3$
EDAD

Indica tu rango de edad en años

$\begin{array}{ll}\bigcirc<=24 & \bigcirc 45-54 \\ \bigcirc 25-34 & \bigcirc 55-64 \\ \bigcirc 35-44 & \bigcirc>=65\end{array}$

ANT. SIG.

EXIT

TAMAÑO FAMILIAR

Indica el número de personas que actualmente viven en casa

O 1

O 2

O 3

ANT. SIG.

O $>=4$

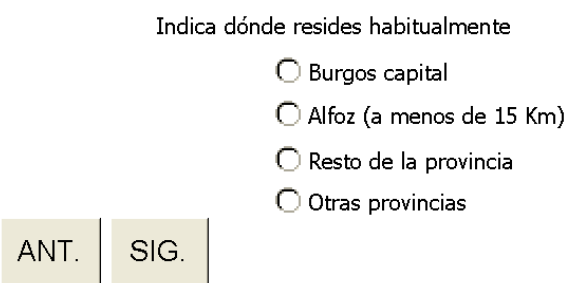

- NIVEL DE RENTA FAMILIAR

Puedes indicar aquí los ingresos netos mensuales totales de tu familia (miembros que viven en casa)

$\begin{aligned} & \bigcirc<900 € \\ & \bigcirc 900-1.500 € \\ & \bigcirc 1.501-2.500 € \\ \text { ANT. SIG. } & \bigcirc>2.500 €\end{aligned}$

DISPONES DE...

Indica si tienes carnet de conducir, y si podrías emplear un vehículo privado para realizar este viaje

\section{ГCarnet de conducir \\ Г Coche/moto}

ANT.

DISTANCIA HASTA LA ESTACIÓN

Indica el tiempo que tardas en llegar hasta la estación de autobuses más cercana a tu domicilio

$$
\begin{aligned}
& O<10 \mathrm{~min} \\
& \bigcirc 10-30 \mathrm{~min} \\
& 031-60 \mathrm{~min} \\
& O>1 \text { hora }
\end{aligned}
$$

FRECUENCIA HABITUAL DE VIAJE

Indica con qué frecuencia realizas viajes en autobús interurbano

Rara vez ( $<1$ vez al mes)

Ocasional (1-2 veces al mes)

A menudo (1-2 veces por semana)

ANT. SIG 


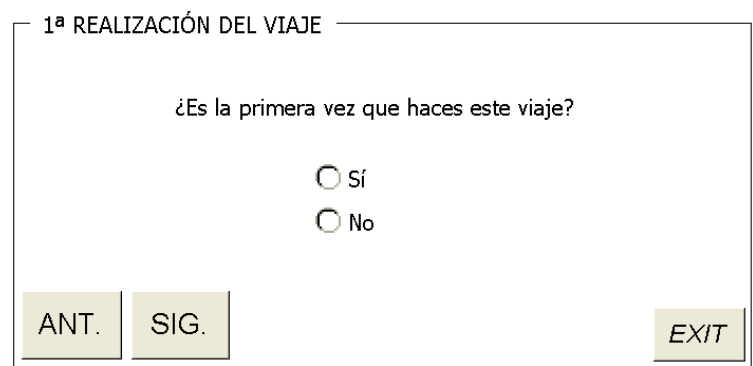

\begin{tabular}{|c|c|c|c|}
\hline \multicolumn{4}{|c|}{ Indica la razón por la que realizas el viaje } \\
\hline & Trabajo & Ocio & \\
\hline & Estudio & Sanidad & \\
\hline & Compras & Asuntos personales & \\
\hline & & Otros & \\
\hline ANI. & SIG. & & EXIT \\
\hline
\end{tabular}
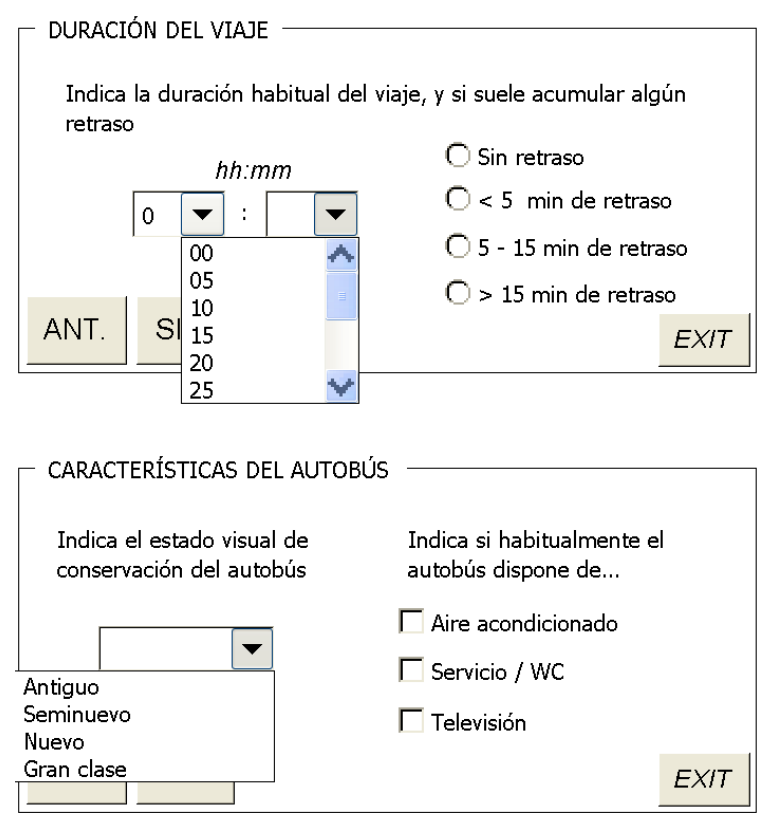

\begin{tabular}{|l||}
\hline CARACTERÍSTICAS DE LAS TAQUILLAS \\
Marca la/s frase/s siguiente/s que consideres cierta/s \\
Г Los horarios de apertura de taquillas son correctos \\
Г Puedo comprar el billete desde casa \\
Г La atención al cliente es adecuada \\
ANT. SIG. EXIT
\end{tabular}
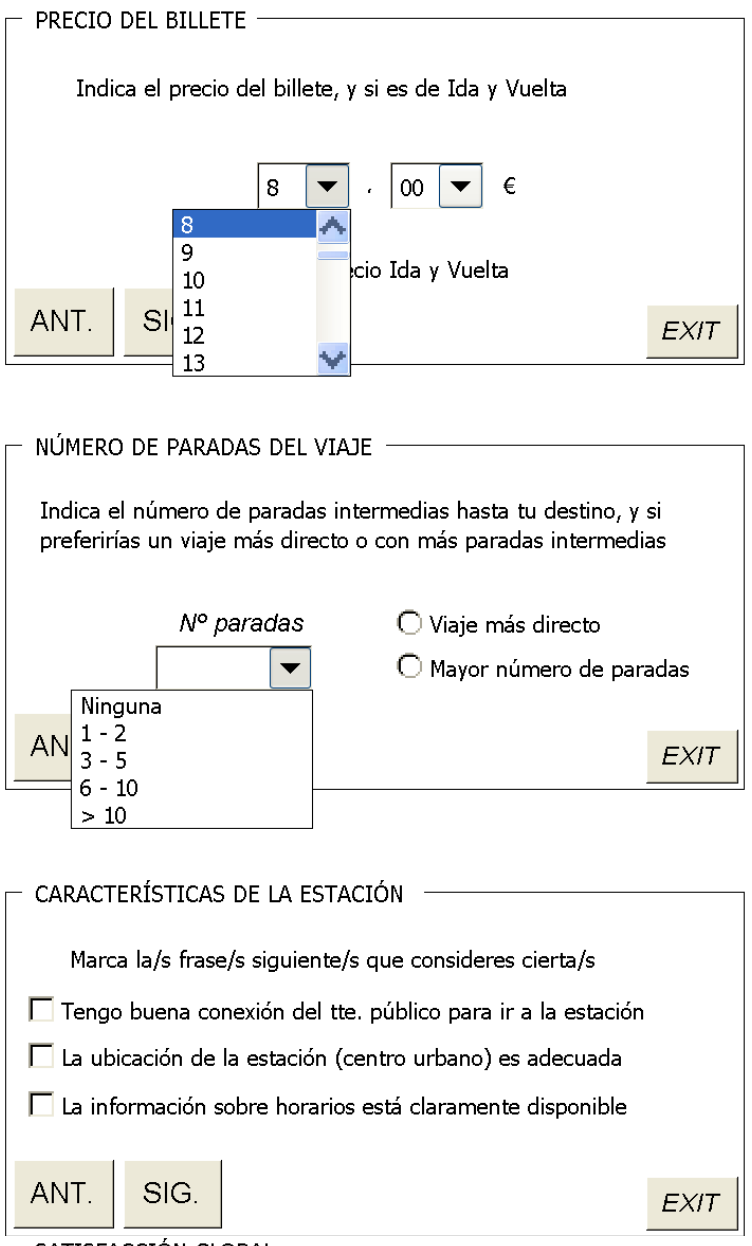

- SATISFACCIÓN GLOBAL

Indica cuál es tu grado de satisfacción global con este viaje en autobús interurbano

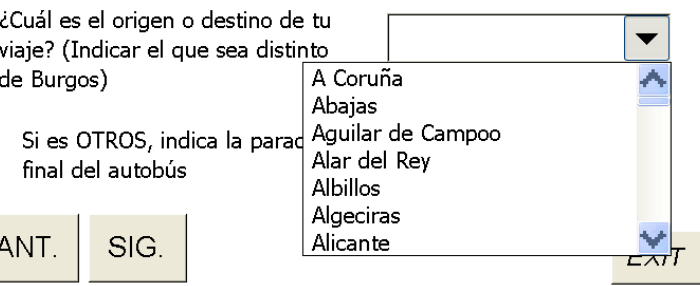

PRECIO DEL BILLETE

Indica el precio del billete, $y$ si es de Ida y Vuelta

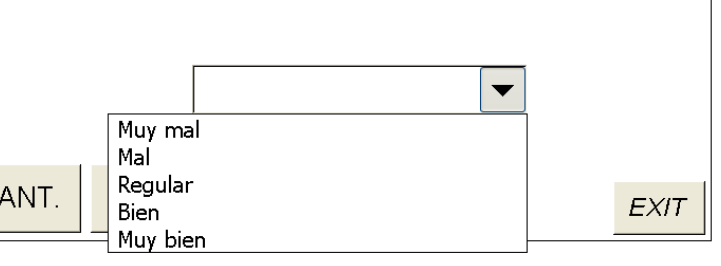



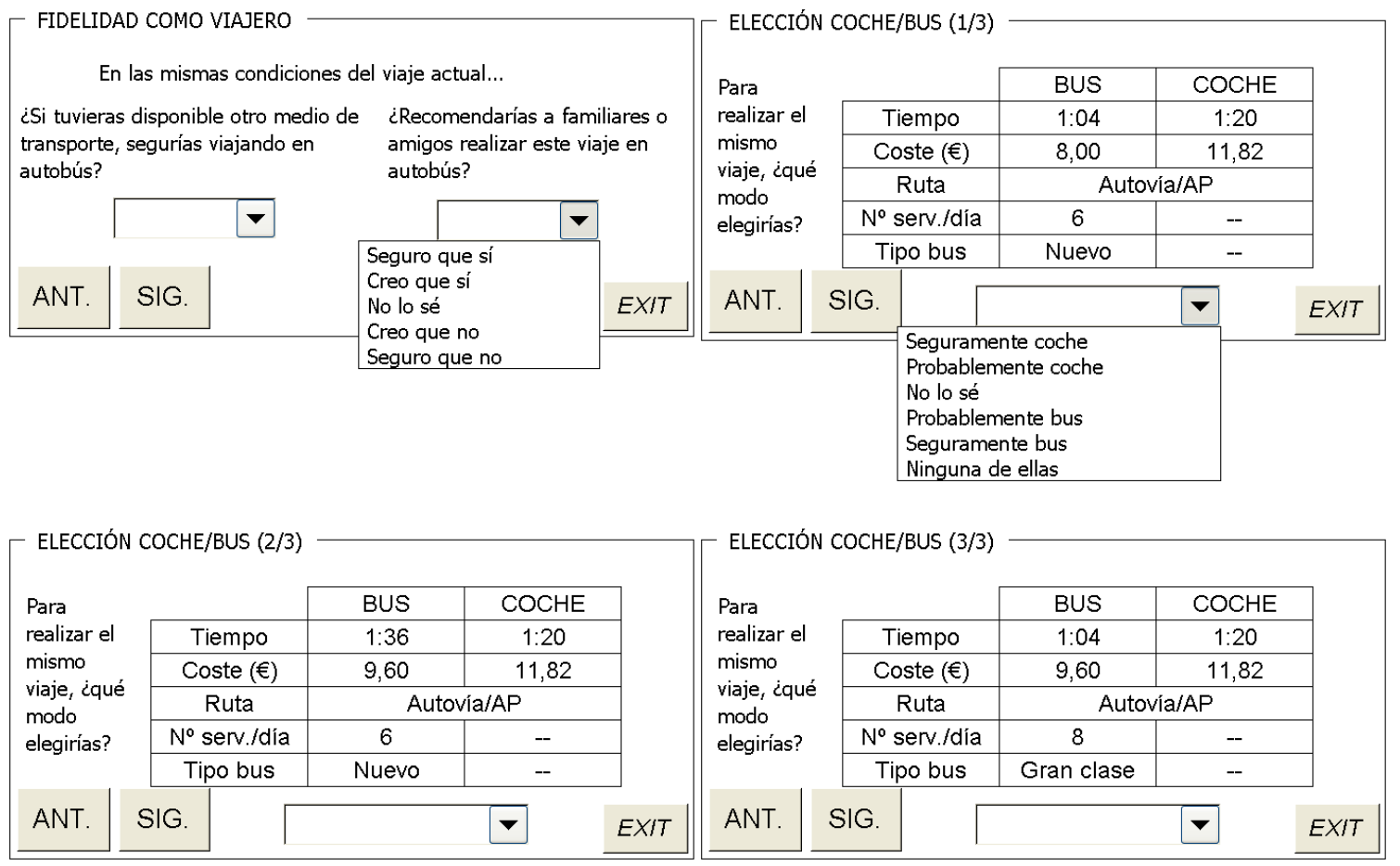

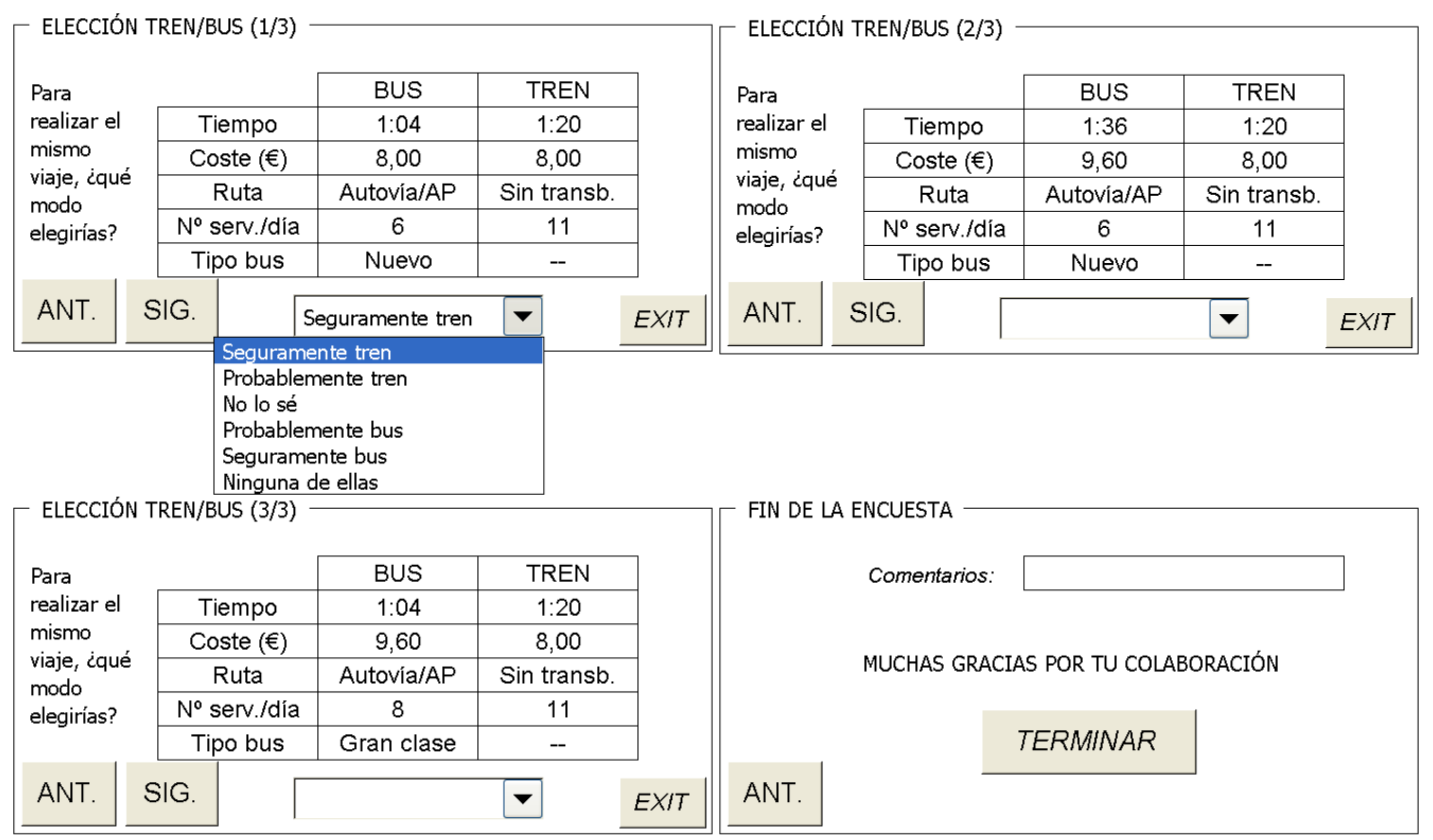





\section{Anexo 3. Correlación entre Variables}

Tabla A3-1. Matriz de correlación entre variables. Submodelo de satisfacción

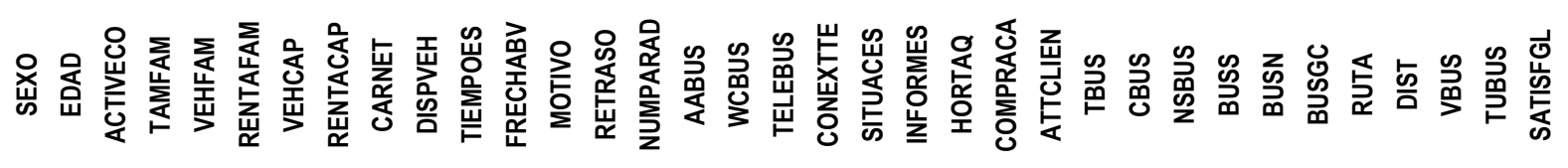

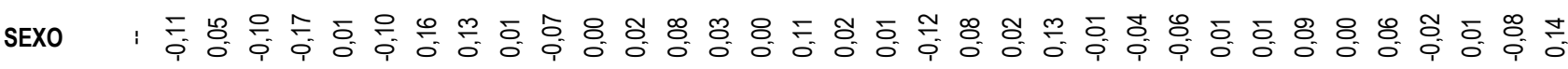

EDAD 둔

ACTIVECO 뉴, 이,

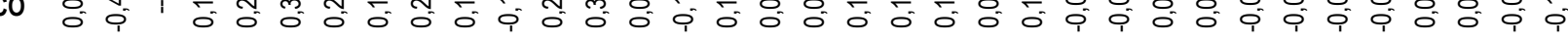

TAMFAM 응 이,

VEHFAM $\approx$ ㅊำ

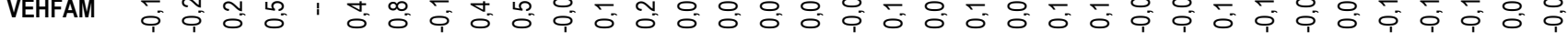

RENTAFAM $\delta$ 층

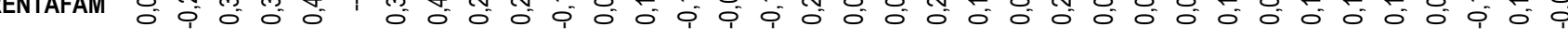

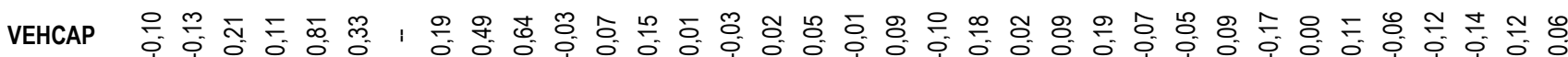

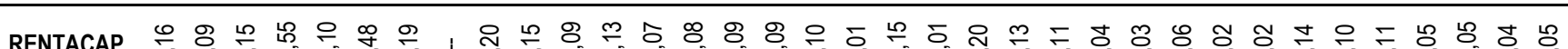

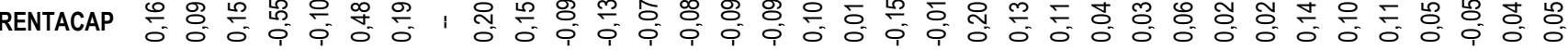

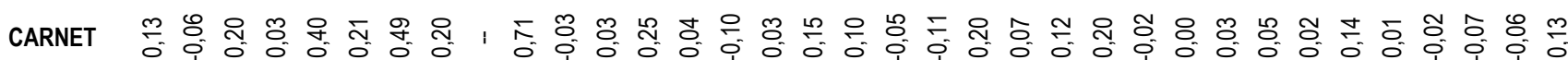

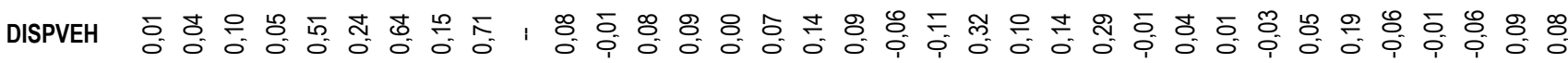
TIEMPOES

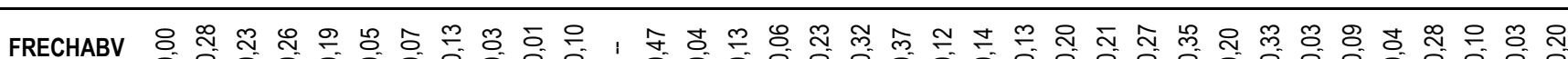

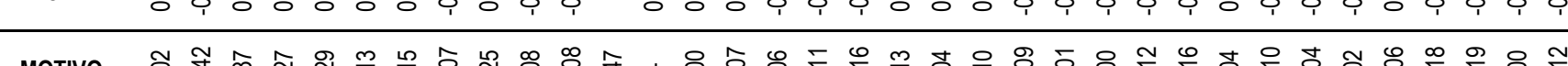
MOTIVO O RETRASO $\%$ \% NUMPARD

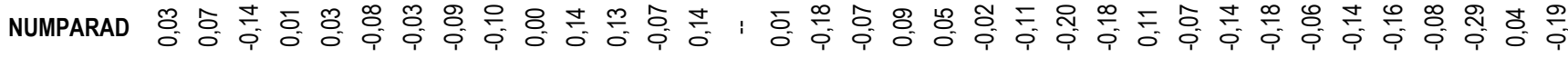

AABUS

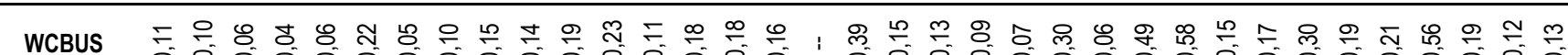

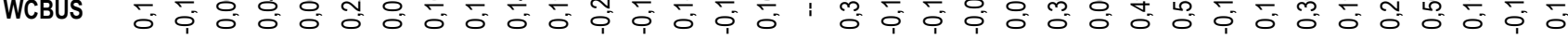

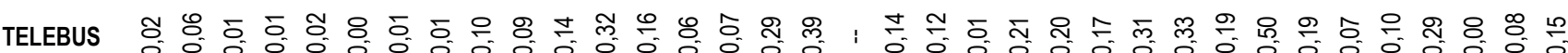

CONEXTTE

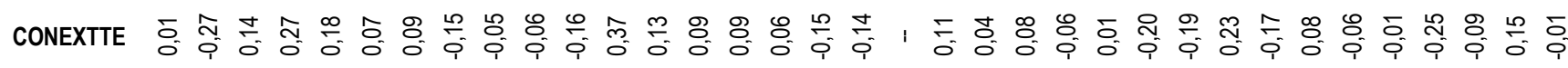

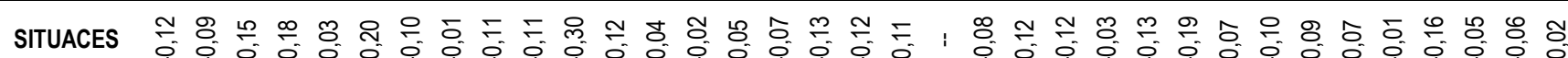
INFORMES 
Tabla A3-2. Matriz de correlación entre variables. Submodelo de demanda

\begin{tabular}{|c|c|c|c|}
\hline & EXPERIMENTO PD 1 & EXPERIMENTO PD 2 & EXPERIMENTO PD3 \\
\hline 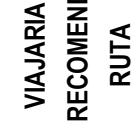 & 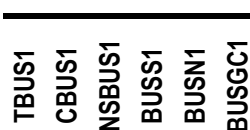 & 惫 兽 & 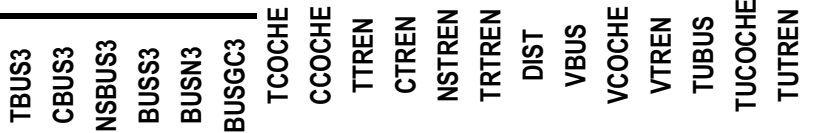 \\
\hline
\end{tabular}

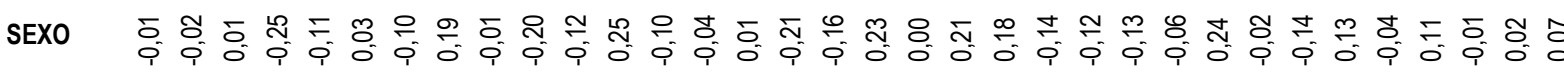

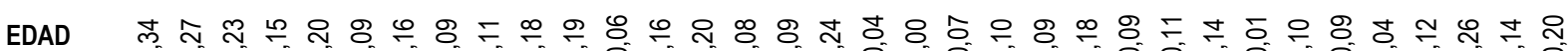

ACTVEC

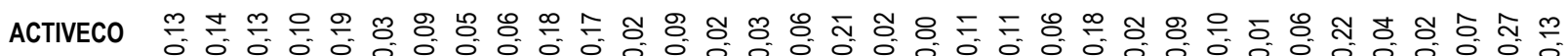

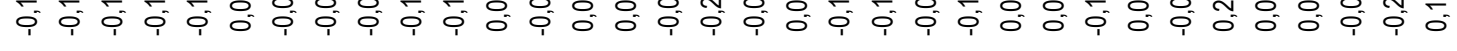

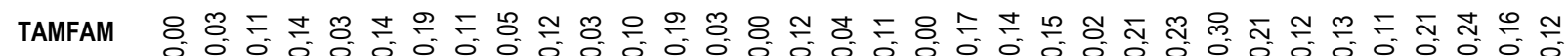

VEHFAM

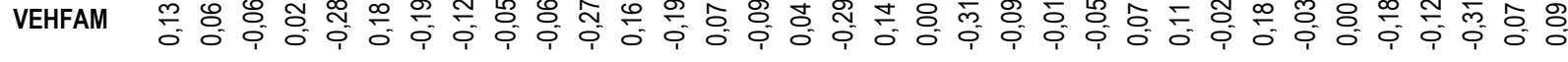

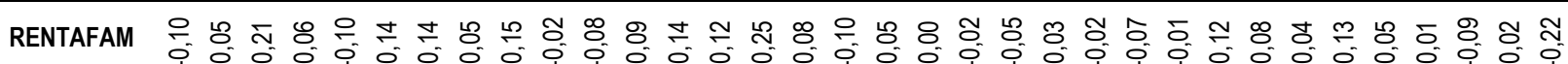

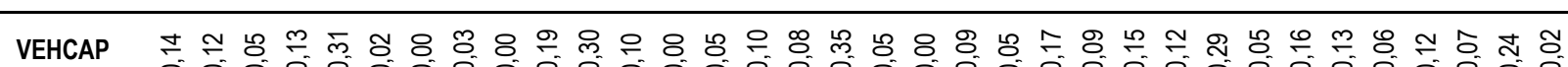

VEHCAP ó ó ó ó

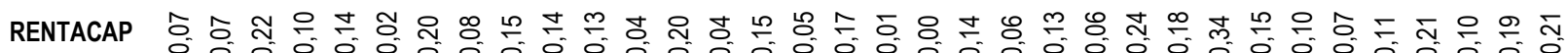

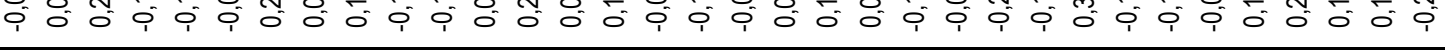

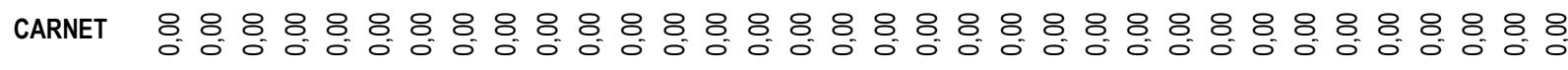

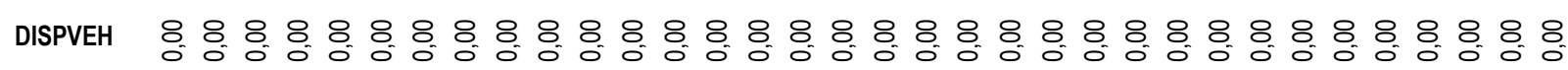

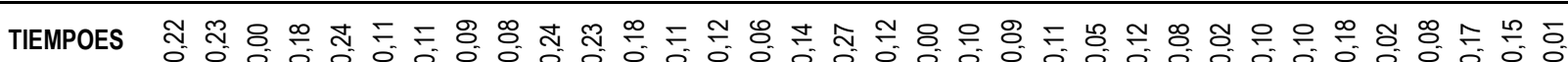

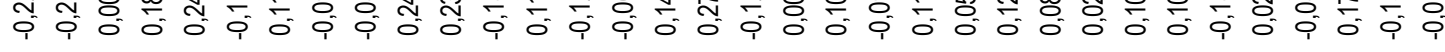

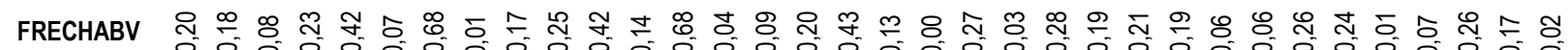

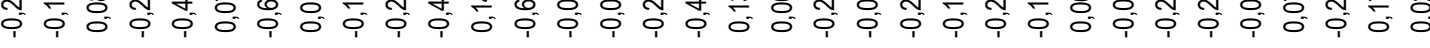

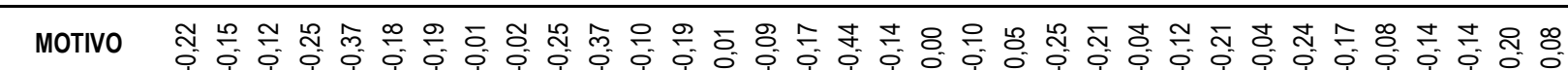

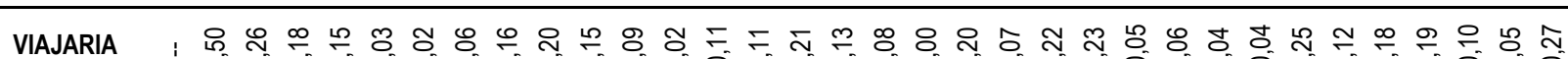

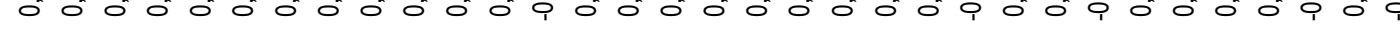

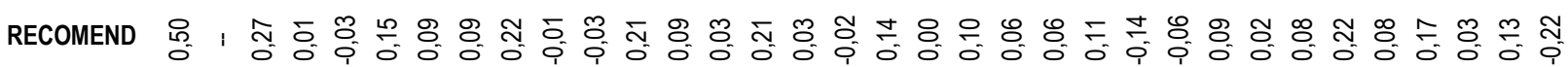

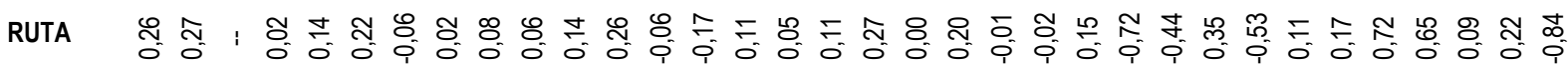

TBUS1

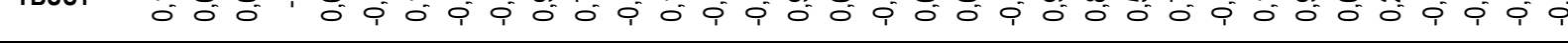

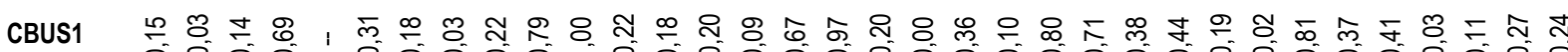
NSBUS1 NSBUS1 0.

Buss1 용 $80 \%$

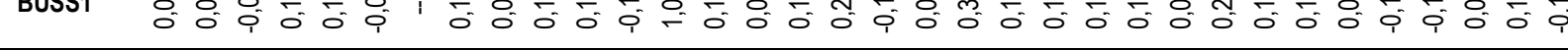

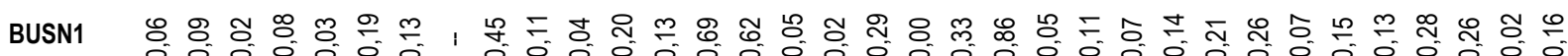

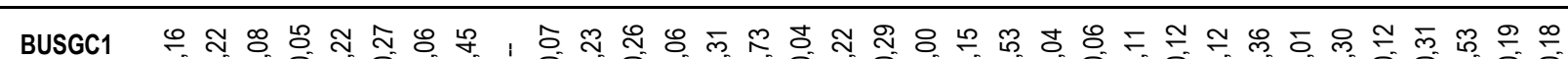

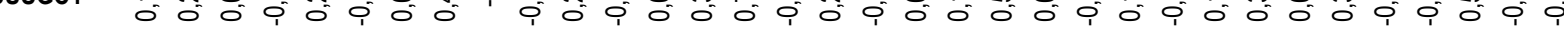

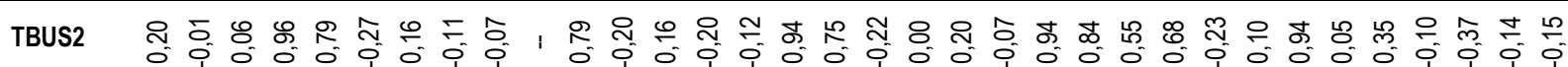




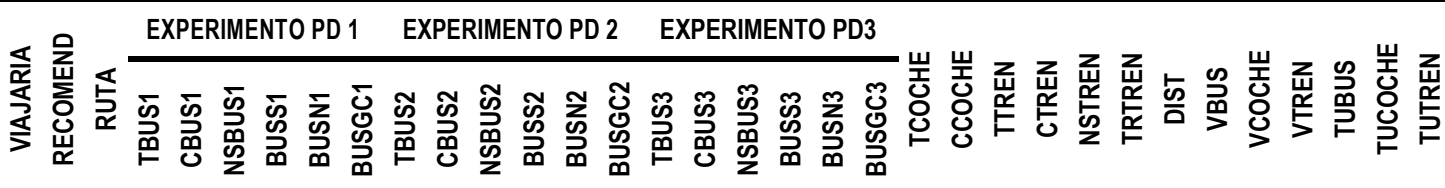

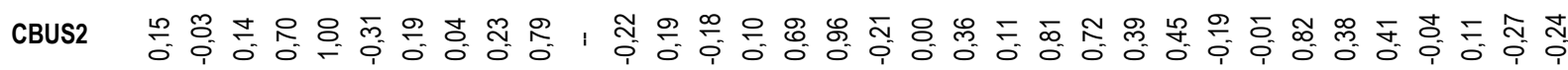

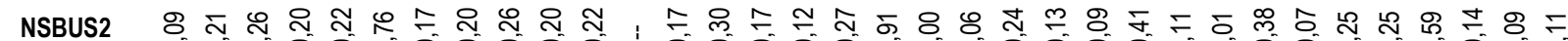

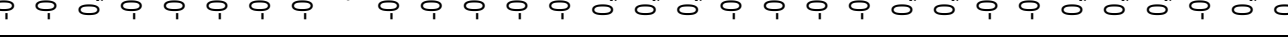

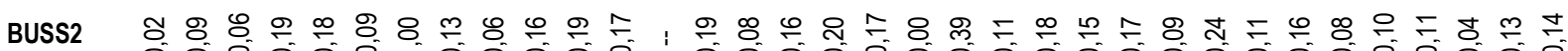

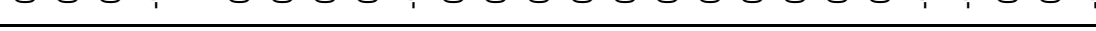

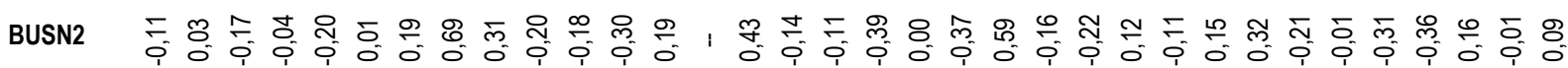

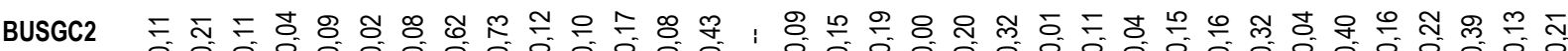

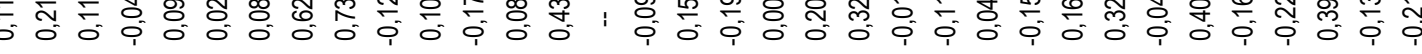

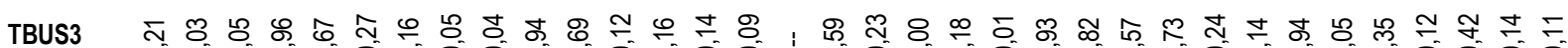

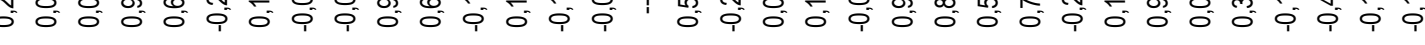

CBUS3

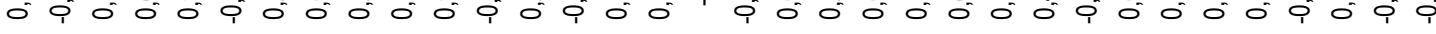

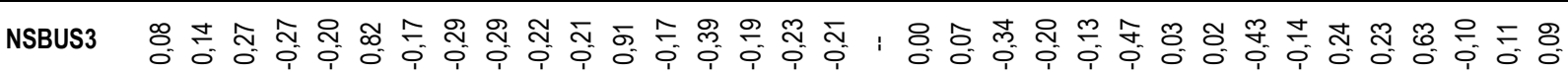

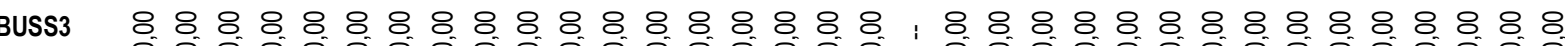

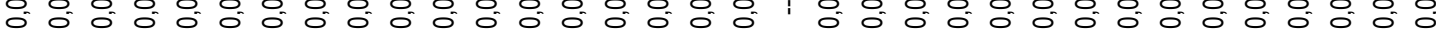

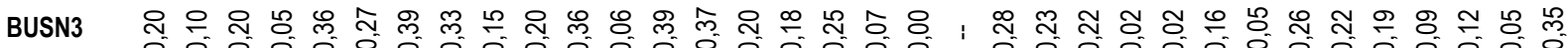

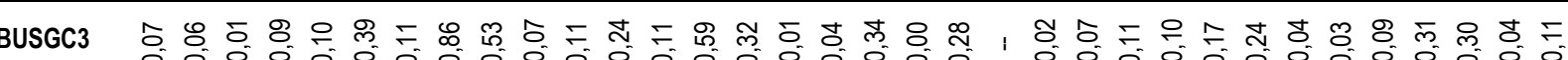

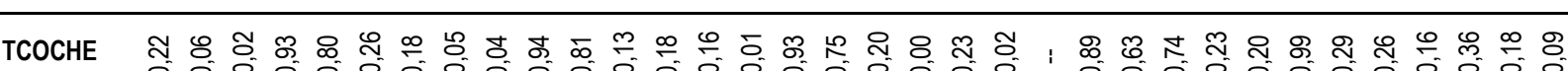

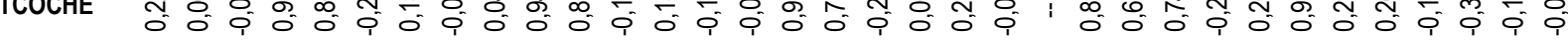

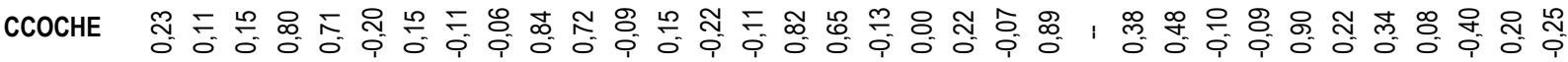

TTREN

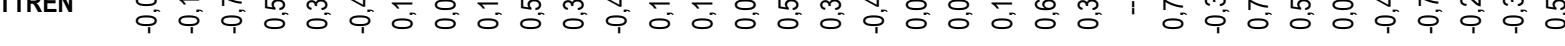

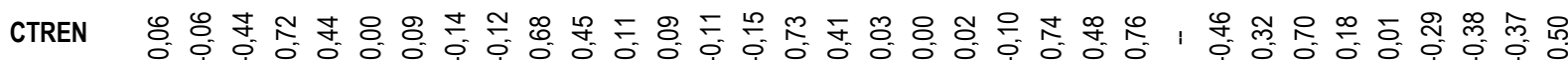

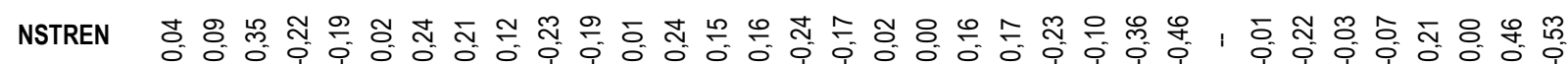

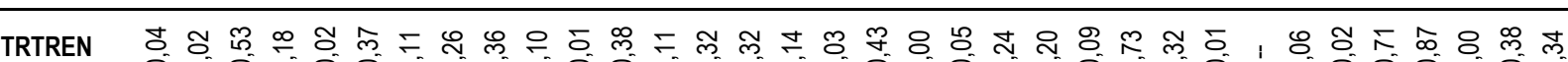

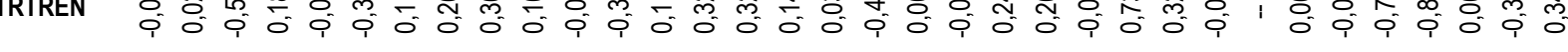

DIST

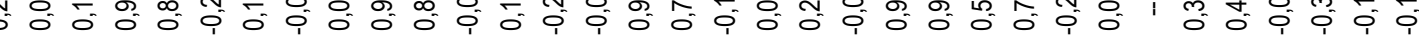

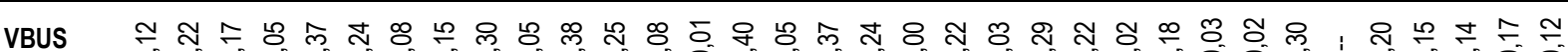

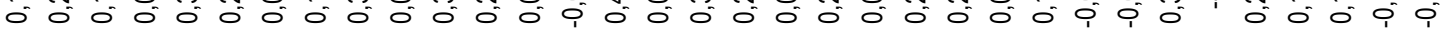

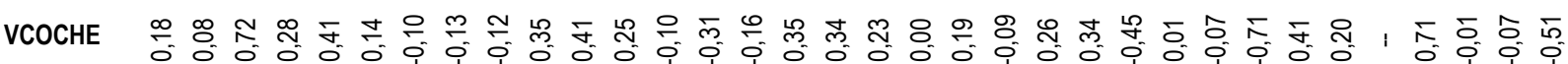

VTREN 두융유유 VTREN ó ó ó ói

IVBUS 隽

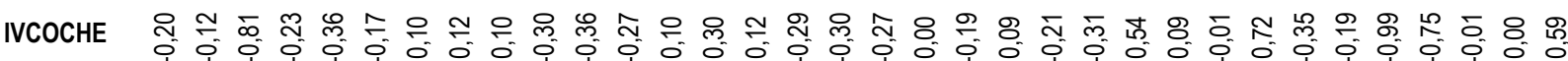




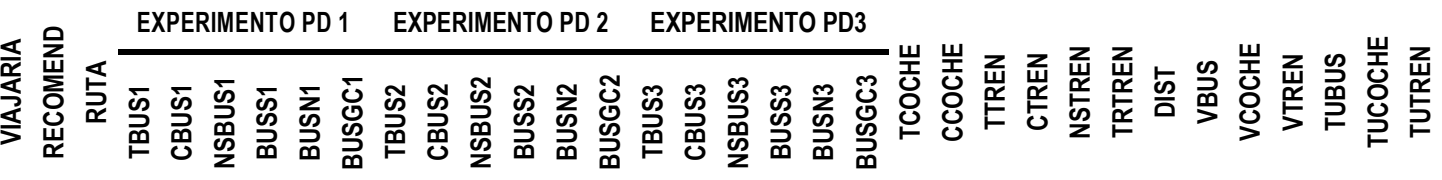

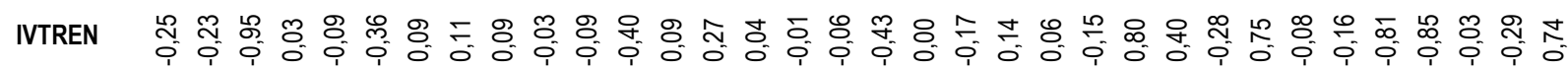

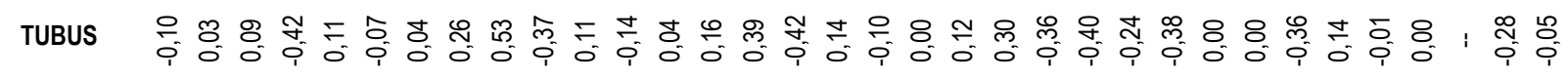

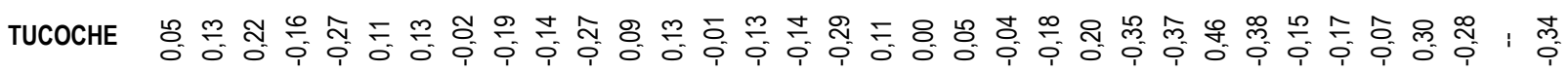

TUTREN N 



\section{Anexo 4. Test FPR e Índice de Éxito Predictivo}

Tabla A4-1. Modelo OP-4.1

\begin{tabular}{cccccccc}
\hline & $\begin{array}{c}\text { Muy mal/ } \\
\text { mal }\end{array}$ & Regular & Bien & $\begin{array}{c}\text { Muy } \\
\text { bien }\end{array}$ & Suma & $\begin{array}{c}\text { Prop. } \\
\text { Observada }\end{array}$ & $\begin{array}{c}\text { Prop. } \\
\text { Obs. Exito }\end{array}$ \\
\hline Muy mal/mal & 2 & 2 & 24 & 0 & 28 & $4,3 \%$ & $7,1 \%$ \\
\hline Regular & 4 & 3 & 104 & 0 & 111 & $16,9 \%$ & $2,7 \%$ \\
\hline Bien & 0 & 1 & 465 & 0 & 466 & $70,9 \%$ & $99,8 \%$ \\
\hline Muy bien & 0 & 0 & 52 & 0 & 52 & $7,9 \%$ & $0,0 \%$ \\
\hline Suma & 6 & 6 & 645 & 0 & 657 & & \\
\hline Prop. Predicha & $0,9 \%$ & $0,9 \%$ & $98,2 \%$ & $0,0 \%$ & $100 \%$ & & \\
\hline Prop. Pred. Éxito (FPR) & $33,3 \%$ & $50,0 \%$ & $72,1 \%$ & -- & $71,5 \%$ & & \\
\hline
\end{tabular}

Tabla A4-2. Modelo OP-4.2

\begin{tabular}{cccccccc}
\hline & $\begin{array}{c}\text { Muy mall } \\
\text { mal }\end{array}$ & Regular & Bien & $\begin{array}{c}\text { Muy } \\
\text { bien }\end{array}$ & Suma & $\begin{array}{c}\text { Prop. } \\
\text { Observada }\end{array}$ & $\begin{array}{c}\text { Prop. } \\
\text { Obs. Exito }\end{array}$ \\
\hline Muy mal/mal & 2 & 3 & 23 & 0 & 28 & $4,3 \%$ & $7,1 \%$ \\
\hline Regular & 4 & 2 & 105 & 0 & 111 & $16,9 \%$ & $1,8 \%$ \\
\hline Bien & 0 & 6 & 461 & 0 & 467 & $71,0 \%$ & $98,7 \%$ \\
\hline Muy bien & 0 & 0 & 52 & 0 & 52 & $7,9 \%$ & $0,0 \%$ \\
\hline Suma & 6 & 11 & 641 & 0 & 658 & & \\
\hline Prop. Predicha & $0,9 \%$ & $1,7 \%$ & $97,4 \%$ & $0,0 \%$ & $100 \%$ & & \\
\hline Prop. Pred. Éxito (FPR) & $33,3 \%$ & $18,2 \%$ & $71,9 \%$ & -- & $70,7 \%$ & & \\
\hline
\end{tabular}

Tabla A4-3. Modelo OP-4.3

\begin{tabular}{cccccccc}
\hline & $\begin{array}{c}\text { Muy mall } \\
\text { mal }\end{array}$ & Regular & Bien & $\begin{array}{c}\text { Muy } \\
\text { bien }\end{array}$ & Suma & $\begin{array}{c}\text { Prop. } \\
\text { Observada }\end{array}$ & $\begin{array}{c}\text { Prop. } \\
\text { Obs. Exito }\end{array}$ \\
\hline Muy mal/mal & 2 & 4 & 22 & 0 & 28 & $4,3 \%$ & $7,1 \%$ \\
\hline Regular & 5 & 6 & 99 & 0 & 110 & $16,8 \%$ & $5,5 \%$ \\
\hline Bien & 0 & 6 & 460 & 0 & 466 & $71,0 \%$ & $98,7 \%$ \\
\hline Muy bien & 0 & 0 & 51 & 1 & 52 & $7,9 \%$ & $1,9 \%$ \\
\hline Suma & 7 & 16 & 632 & 1 & 656 & & \\
\hline Prop. Predicha & $1,1 \%$ & $2,4 \%$ & $96,3 \%$ & $0,2 \%$ & $100 \%$ & & \\
\hline Prop. Pred. Éxito (FPR) & $28,6 \%$ & $37,5 \%$ & $72,8 \%$ & $100,0 \%$ & $71,5 \%$ & & \\
\hline
\end{tabular}

Tabla A4-4. Modelo OP-4.4

\begin{tabular}{cccccccc}
\hline & $\begin{array}{c}\text { Muy mall } \\
\text { mal }\end{array}$ & Regular & Bien & $\begin{array}{c}\text { Muy } \\
\text { bien }\end{array}$ & Suma & $\begin{array}{c}\text { Prop. } \\
\text { Observada }\end{array}$ & $\begin{array}{c}\text { Prop. } \\
\text { Obs. Exito }\end{array}$ \\
\hline Muy mal/mal & 2 & 4 & 22 & 0 & 28 & $4,3 \%$ & $7,1 \%$ \\
\hline Regular & 7 & 5 & 98 & 0 & 110 & $16,8 \%$ & $4,5 \%$ \\
\hline Bien & 0 & 8 & 458 & 0 & 466 & $71,0 \%$ & $98,3 \%$ \\
\hline Muy bien & 0 & 0 & 51 & 1 & 52 & $7,9 \%$ & $1,9 \%$ \\
\hline Suma & 9 & 17 & 629 & 1 & 656 & & \\
\hline Prop. Predicha & $1,4 \%$ & $2,6 \%$ & $95,9 \%$ & $0,2 \%$ & $100 \%$ & & \\
\hline Prop. Pred. Éxito (FPR) & $22,2 \%$ & $29,4 \%$ & $72,8 \%$ & $100,0 \%$ & $71,0 \%$ & & \\
\hline
\end{tabular}


Tabla A4-5. Modelo OL-4.1

\begin{tabular}{cccccccc}
\hline & $\begin{array}{c}\text { Muy mall } \\
\text { mal }\end{array}$ & Regular & Bien & $\begin{array}{c}\text { Muy } \\
\text { bien }\end{array}$ & Suma & $\begin{array}{c}\text { Prop. } \\
\text { Observada }\end{array}$ & $\begin{array}{c}\text { Prop. } \\
\text { Obs. Exito }\end{array}$ \\
\hline Muy mal/mal & 1 & 5 & 22 & 0 & 28 & $4,3 \%$ & $3,6 \%$ \\
\hline Regular & 3 & 6 & 102 & 0 & 111 & $16,9 \%$ & $5,4 \%$ \\
\hline Bien & 0 & 9 & 457 & 0 & 466 & $70,9 \%$ & $98,1 \%$ \\
\hline Muy bien & 0 & 0 & 52 & 0 & 52 & $7,9 \%$ & $0,0 \%$ \\
\hline Suma & 4 & 20 & 633 & 0 & 657 & & \\
\hline Prop. Predicha & $0,6 \%$ & $3,0 \%$ & $96,3 \%$ & $0,0 \%$ & $100 \%$ & & \\
\hline Prop. Pred. Éxito (FPR) & $25,0 \%$ & $30,0 \%$ & $72,2 \%$ & -- & $70,6 \%$ & & \\
\hline
\end{tabular}

Tabla A4-6. Modelo OL-4.2

\begin{tabular}{cccccccc}
\hline & $\begin{array}{c}\text { Muy mall } \\
\text { mal }\end{array}$ & Regular & Bien & $\begin{array}{c}\text { Muy } \\
\text { bien }\end{array}$ & Suma & $\begin{array}{c}\text { Prop. } \\
\text { Observada }\end{array}$ & $\begin{array}{c}\text { Prop. } \\
\text { Obs. Exito }\end{array}$ \\
\hline Muy mal/mal & 1 & 5 & 22 & 0 & 28 & $4,3 \%$ & $3,6 \%$ \\
\hline Regular & 4 & 5 & 102 & 0 & 111 & $16,9 \%$ & $4,5 \%$ \\
\hline Bien & 0 & 11 & 456 & 0 & 467 & $71,0 \%$ & $97,6 \%$ \\
\hline Muy bien & 0 & 0 & 52 & 0 & 52 & $7,9 \%$ & $0,0 \%$ \\
\hline Suma & 5 & 21 & 632 & 0 & 658 & & \\
\hline Prop. Predicha & $0,8 \%$ & $3,2 \%$ & $96,0 \%$ & $0,0 \%$ & $100 \%$ & & \\
\hline Prop. Pred. Éxito (FPR) & $20,0 \%$ & $23,8 \%$ & $72,2 \%$ & -- & $70,2 \%$ & & \\
\hline
\end{tabular}

Tabla A4-7. Modelo OL-4.3

\begin{tabular}{cccccccc}
\hline & $\begin{array}{c}\text { Muy mal/ } \\
\text { mal }\end{array}$ & Regular & Bien & $\begin{array}{c}\text { Muy } \\
\text { bien }\end{array}$ & Suma & $\begin{array}{c}\text { Prop. } \\
\text { Observada }\end{array}$ & $\begin{array}{c}\text { Prop. } \\
\text { Obs. Exito }\end{array}$ \\
\hline Muy mal/mal & 0 & 10 & 18 & 0 & 28 & $4,3 \%$ & $0,0 \%$ \\
\hline Regular & 3 & 14 & 93 & 0 & 110 & $16,8 \%$ & $12,7 \%$ \\
\hline Bien & 0 & 13 & 453 & 0 & 466 & $71,0 \%$ & $97,2 \%$ \\
\hline Muy bien & 0 & 0 & 51 & 1 & 52 & $7,9 \%$ & $1,9 \%$ \\
\hline Suma & 3 & 37 & 615 & 1 & 656 & & \\
\hline Prop. Predicha & $0,5 \%$ & $5,6 \%$ & $93,8 \%$ & $0,2 \%$ & $100 \%$ & & \\
\hline Prop. Pred. Éxito (FPR) & $0,0 \%$ & $37,8 \%$ & $73,7 \%$ & $100,0 \%$ & $\mathbf{7 1 , 3 \%}$ & & \\
\hline
\end{tabular}

Tabla A4-8. Modelo OL-4.4

\begin{tabular}{cccccccc}
\hline & $\begin{array}{c}\text { Muy mal/ } \\
\text { mal }\end{array}$ & Regular & Bien & $\begin{array}{c}\text { Muy } \\
\text { bien }\end{array}$ & Suma & $\begin{array}{c}\text { Prop. } \\
\text { Observada }\end{array}$ & $\begin{array}{c}\text { Prop. } \\
\text { Obs. Éxito }\end{array}$ \\
\hline Muy mal/mal & 1 & 8 & 19 & 0 & 28 & $4,3 \%$ & $3,6 \%$ \\
\hline Regular & 3 & 12 & 95 & 0 & 110 & $16,8 \%$ & $10,9 \%$ \\
\hline Bien & 0 & 12 & 454 & 0 & 466 & $71,0 \%$ & $97,4 \%$ \\
\hline Muy bien & 0 & 1 & 50 & 1 & 52 & $7,9 \%$ & $1,9 \%$ \\
\hline Suma & 4 & 33 & 618 & 1 & 656 & & \\
\hline Prop. Predicha & $0,6 \%$ & $5,0 \%$ & $94,2 \%$ & $0,2 \%$ & $100 \%$ & & \\
\hline Prop. Pred. Éxito (FPR) & $25,0 \%$ & $36,4 \%$ & $73,5 \%$ & $100,0 \%$ & $71,3 \%$ & & \\
\hline
\end{tabular}


Tabla A4-9. Modelo OP-5.1

\begin{tabular}{ccccccccc}
\hline & $\begin{array}{c}\text { Muy } \\
\text { mal }\end{array}$ & Mal & Regular & Bien & $\begin{array}{c}\text { Muy } \\
\text { bien }\end{array}$ & Suma & $\begin{array}{c}\text { Prop. } \\
\text { Observada }\end{array}$ & $\begin{array}{c}\text { Prop. Obs. } \\
\text { Éxito }\end{array}$ \\
\hline Muy mal & 0 & 0 & 1 & 2 & 0 & 3 & $0,5 \%$ & $0,0 \%$ \\
\hline Mal & 0 & 0 & 4 & 21 & 0 & 25 & $3,8 \%$ & $0,0 \%$ \\
\hline Regular & 2 & 0 & 8 & 101 & 0 & 111 & $16,9 \%$ & $7,2 \%$ \\
\hline Bien & 0 & 0 & 11 & 455 & 0 & 466 & $70,9 \%$ & $97,6 \%$ \\
\hline Muy bien & 0 & 0 & 0 & 52 & 0 & 52 & $7,9 \%$ & $0,0 \%$ \\
\hline Suma & 2 & 0 & 24 & 631 & 0 & 657 & & \\
\hline Prop. Predicha & $0,3 \%$ & $0,0 \%$ & $3,7 \%$ & $96,0 \%$ & $0,0 \%$ & $100 \%$ & & \\
\hline Prop. Pred. Éxito (FPR) & $0,0 \%$ & -- & $33,3 \%$ & $72,1 \%$ & -- & $70,5 \%$ & & \\
\hline
\end{tabular}

Tabla A4-10. Modelo OP-5.2

\begin{tabular}{ccccccccc}
\hline & $\begin{array}{c}\text { Muy } \\
\text { mal }\end{array}$ & Mal & Regular & Bien & $\begin{array}{c}\text { Muy } \\
\text { bien }\end{array}$ & Suma & $\begin{array}{c}\text { Prop. } \\
\text { Observada }\end{array}$ & $\begin{array}{c}\text { Prop. Obs. } \\
\text { Exito }\end{array}$ \\
\hline Muy mal & 0 & 0 & 1 & 2 & 0 & 3 & $0,5 \%$ & $0,0 \%$ \\
\hline Mal & 0 & 0 & 3 & 22 & 0 & 25 & $3,8 \%$ & $0,0 \%$ \\
\hline Regular & 3 & 0 & 6 & 102 & 0 & 111 & $16,9 \%$ & $5,4 \%$ \\
\hline Bien & 0 & 0 & 8 & 458 & 0 & 466 & $70,9 \%$ & $98,3 \%$ \\
\hline Muy bien & 0 & 0 & 0 & 52 & 0 & 52 & $7,9 \%$ & $0,0 \%$ \\
\hline Suma & 3 & 0 & 18 & 636 & 0 & 657 & & \\
\hline Prop. Predicha & $0,5 \%$ & $0,0 \%$ & $2,7 \%$ & $96,8 \%$ & $0,0 \%$ & $100 \%$ & & \\
\hline Prop. Pred. Exito (FPR) & $0,0 \%$ & -- & $33,3 \%$ & $72,0 \%$ & -- & $70,6 \%$ & & \\
\hline
\end{tabular}

Tabla A4-11. Modelo OL-5.1

\begin{tabular}{ccccccccc}
\hline & $\begin{array}{c}\text { Muy } \\
\text { mal }\end{array}$ & Mal & Regular & Bien & $\begin{array}{c}\text { Muy } \\
\text { bien }\end{array}$ & Suma & $\begin{array}{c}\text { Prop. } \\
\text { Observada }\end{array}$ & $\begin{array}{c}\text { Prop. Obs. } \\
\text { Éxito }\end{array}$ \\
\hline Muy mal & 0 & 0 & 1 & 2 & 0 & 3 & $0,5 \%$ & $0,0 \%$ \\
\hline Mal & 0 & 0 & 6 & 19 & 0 & 25 & $3,8 \%$ & $0,0 \%$ \\
\hline Regular & 2 & 0 & 8 & 101 & 0 & 111 & $16,9 \%$ & $7,2 \%$ \\
\hline Bien & 0 & 0 & 15 & 451 & 0 & 466 & $70,9 \%$ & $96,8 \%$ \\
\hline Muy bien & 0 & 0 & 0 & 52 & 0 & 52 & $7,9 \%$ & $0,0 \%$ \\
\hline Suma & 2 & 0 & 30 & 625 & 0 & 657 & & \\
\hline Prop. Predicha & $0,3 \%$ & $0,0 \%$ & $4,6 \%$ & $95,1 \%$ & $0,0 \%$ & $100 \%$ & & \\
\hline Prop. Pred. Éxito (FPR) & $0,0 \%$ & -- & $26,7 \%$ & $72,2 \%$ & -- & $69,9 \%$ & & \\
\hline
\end{tabular}

Tabla A4-12. Modelo OL-5.2

\begin{tabular}{ccccccccc}
\hline & $\begin{array}{c}\text { Muy } \\
\text { mal }\end{array}$ & Mal & Regular & Bien & $\begin{array}{c}\text { Muy } \\
\text { bien }\end{array}$ & Suma & $\begin{array}{c}\text { Prop. } \\
\text { Observada }\end{array}$ & $\begin{array}{c}\text { Prop. Obs. } \\
\text { Éxito }\end{array}$ \\
\hline Muy mal & 0 & 0 & 1 & 2 & 0 & 3 & $0,5 \%$ & $0,0 \%$ \\
\hline Mal & 0 & 0 & 6 & 19 & 0 & 25 & $3,8 \%$ & $0,0 \%$ \\
\hline Regular & 2 & 0 & 8 & 101 & 0 & 111 & $16,9 \%$ & $7,2 \%$ \\
\hline Bien & 0 & 0 & 15 & 451 & 0 & 466 & $70,9 \%$ & $96,8 \%$ \\
\hline Muy bien & 0 & 0 & 0 & 52 & 0 & 52 & $7,9 \%$ & $0,0 \%$ \\
\hline Suma & 2 & 0 & 30 & 625 & 0 & 657 & & \\
\hline Prop. Predicha & $0,3 \%$ & $0,0 \%$ & $4,6 \%$ & $95,1 \%$ & $0,0 \%$ & $100 \%$ & & \\
\hline Prop. Pred. Éxito (FPR) & $0,0 \%$ & -- & $26,7 \%$ & $72,2 \%$ & -- & $69,9 \%$ & & \\
\hline
\end{tabular}


Tabla A4-13. Modelo MNL-1

\begin{tabular}{ccccccc}
\hline & BUS & COCHE & TREN & Suma & $\begin{array}{c}\text { Prop. } \\
\text { Observada }\end{array}$ & $\begin{array}{c}\text { Prop. } \\
\text { Obs. Exito }\end{array}$ \\
\hline BUS & 1330 & 153 & 140 & 1623 & $72,2 \%$ & $81,9 \%$ \\
\hline COCHE & 155 & 184 & 0 & 339 & $15,1 \%$ & $54,3 \%$ \\
\hline TREN & 137 & 0 & 149 & 286 & $12,7 \%$ & $52,1 \%$ \\
\hline Suma & 1622 & 337 & 289 & 2248 & & \\
\hline Prop. Predicha & $72,2 \%$ & $15,0 \%$ & $12,9 \%$ & $100 \%$ & & \\
\hline Prop. Pred. Éxito (FPR) & $82,0 \%$ & $54,6 \%$ & $51,6 \%$ & $\mathbf{7 4 , 0 \%}$ & & \\
\hline Índice de Éxito & 0,0984 & 0,39608 & 0,387 & $\mathbf{0 , 1 8 0}$ & & \\
\hline Máximo Índice de Éxito & & & & $\mathbf{0 , 4 4 0}$ & & \\
\hline Índice de Éxito Normalizado & & & & $\mathbf{0 , 4 0 9}$ & & \\
\hline Error en prop. pred. & $0,0 \%$ & $-0,1 \%$ & $0,1 \%$ & & & \\
\hline
\end{tabular}

Tabla A4-14. Modelo MNL-2

\begin{tabular}{ccccccc}
\hline & BUS & COCHE & TREN & Suma & $\begin{array}{c}\text { Prop. } \\
\text { Observada }\end{array}$ & $\begin{array}{c}\text { Prop. } \\
\text { Obs. Exito }\end{array}$ \\
\hline BUS & 1332 & 152 & 138 & 1622 & $72,2 \%$ & $82,1 \%$ \\
\hline COCHE & 152 & 187 & 0 & 339 & $15,1 \%$ & $55,2 \%$ \\
\hline TREN & 136 & 0 & 150 & 286 & $12,7 \%$ & $52,4 \%$ \\
\hline Suma & 1620 & 339 & 288 & 2247 & & \\
\hline Prop. Predicha & $72,1 \%$ & $15,1 \%$ & $12,8 \%$ & $100 \%$ & & \\
\hline Prop. Pred. Éxito (FPR) & $82,2 \%$ & $55,2 \%$ & $52,1 \%$ & $\mathbf{7 4 , 3 \%}$ & & \\
\hline Índice de Éxito & 0,1013 & 0,40075 & 0,3927 & $\mathbf{0 , 1 8 4}$ & & \\
\hline Máximo Índice de Éxito & & & & $\mathbf{0 , 4 4 1}$ & & \\
\hline Índice de Éxito Normalizado & & & & $\mathbf{0 , 4 1 7}$ & & \\
\hline Error en prop. pred. & $-0,1 \%$ & $0,0 \%$ & $0,1 \%$ & & & \\
\hline
\end{tabular}

Tabla A4-15. Modelo MNL-3

\begin{tabular}{ccccccc}
\hline & BUS & COCHE & TREN & Suma & $\begin{array}{c}\text { Prop. } \\
\text { Observada }\end{array}$ & $\begin{array}{c}\text { Prop. } \\
\text { Obs. Exito }\end{array}$ \\
\hline BUS & 1333 & 152 & 138 & 1623 & $72,2 \%$ & $82,1 \%$ \\
\hline COCHE & 152 & 187 & 0 & 339 & $15,1 \%$ & $55,2 \%$ \\
\hline TREN & 136 & 0 & 150 & 286 & $12,7 \%$ & $52,4 \%$ \\
\hline Suma & 1621 & 339 & 288 & 2248 & & \\
\hline Prop. Predicha & $72,1 \%$ & $15,1 \%$ & $12,8 \%$ & $100 \%$ & & \\
\hline Prop. Pred. Éxito (FPR) & $82,2 \%$ & $55,2 \%$ & $52,1 \%$ & $\mathbf{7 4 , 3 \%}$ & & \\
\hline Índice de Éxito & 0,1012 & 0,40082 & 0,3927 & $\mathbf{0 , 1 8 4}$ & & \\
\hline Máximo Índice de Éxito & & & & $\mathbf{0 , 4 4 1}$ & & \\
\hline Índice de Éxito Normalizado & & & & $\mathbf{0 , 4 1 7}$ & & \\
\hline Error en prop. pred. & $-0,1 \%$ & $0,0 \%$ & $0,1 \%$ & & & \\
\hline
\end{tabular}


Tabla A4-16. Modelo MNL-4

\begin{tabular}{ccccccc}
\hline & BUS & COCHE & TREN & Suma & $\begin{array}{c}\text { Prop. } \\
\text { Observada }\end{array}$ & $\begin{array}{c}\text { Prop. } \\
\text { Obs. Éxito }\end{array}$ \\
\hline BUS & 1334 & 151 & 136 & 1621 & $72,2 \%$ & $82,3 \%$ \\
\hline COCHE & 151 & 188 & 0 & 339 & $15,1 \%$ & $55,5 \%$ \\
\hline TREN & 135 & 0 & 151 & 286 & $12,7 \%$ & $52,8 \%$ \\
\hline Suma & 1620 & 339 & 287 & 2246 & & \\
\hline Prop. Predicha & $72,1 \%$ & $15,1 \%$ & $12,8 \%$ & $100 \%$ & & \\
\hline Prop. Pred. Éxito (FPR) & $82,3 \%$ & $55,5 \%$ & $52,6 \%$ & $\mathbf{7 4 , 5 \%}$ & & \\
\hline Índice de Éxito & 0,1022 & 0,40364 & 0,3983 & $\mathbf{0 , 1 8 6}$ & & \\
\hline Máximo Índice de Éxito & & & & $\mathbf{0 , 4 4 1}$ & & \\
\hline Índice de Éxito Normalizado & & & & $\mathbf{0 , 4 2 1}$ & & \\
\hline Error en prop. pred. & $0,0 \%$ & $0,0 \%$ & $0,0 \%$ & & &
\end{tabular}

Tabla A4-17. Modelo MNL-5

\begin{tabular}{ccccccc}
\hline & BUS & COCHE & TREN & Suma & $\begin{array}{c}\text { Prop. } \\
\text { Observada }\end{array}$ & $\begin{array}{c}\text { Prop. } \\
\text { Obs. Éxito }\end{array}$ \\
\hline BUS & 1341 & 132 & 147 & 1620 & $72,2 \%$ & $82,8 \%$ \\
\hline COCHE & 170 & 169 & 0 & 339 & $15,1 \%$ & $49,9 \%$ \\
\hline TREN & 136 & 0 & 150 & 286 & $12,7 \%$ & $52,4 \%$ \\
\hline Suma & 1647 & 301 & 297 & 2245 & & \\
\hline Prop. Predicha & $73,4 \%$ & $13,4 \%$ & $13,2 \%$ & $100 \%$ & & \\
\hline Prop. Pred. Éxito (FPR) & $81,4 \%$ & $56,1 \%$ & $50,5 \%$ & $\mathbf{7 3 , 9 \%}$ & & \\
\hline Índice de Éxito & 0,0806 & 0,42739 & 0,3728 & $\mathbf{0 , 1 6 6}$ & & \\
\hline Máximo Índice de Éxito & & & & $\mathbf{0 , 4 2 6}$ & & \\
\hline Índice de Éxito Normalizado & & & & $\mathbf{0 , 3 8 9}$ & & \\
\hline Error en prop. pred. & $1,2 \%$ & $-1,7 \%$ & $0,5 \%$ & & & \\
\hline
\end{tabular}

Tabla A4-18. Modelo MNL-6

\begin{tabular}{ccccccc}
\hline & BUS & COCHE & TREN & Suma & $\begin{array}{c}\text { Prop. } \\
\text { Observada }\end{array}$ & $\begin{array}{c}\text { Prop. } \\
\text { Obs. Exito }\end{array}$ \\
\hline BUS & 1330 & 152 & 137 & 1619 & $72,1 \%$ & $82,1 \%$ \\
\hline COCHE & 152 & 187 & 0 & 339 & $15,1 \%$ & $55,2 \%$ \\
\hline TREN & 134 & 0 & 152 & 286 & $12,7 \%$ & $53,1 \%$ \\
\hline Suma & 1616 & 339 & 289 & 2244 & & \\
\hline Prop. Predicha & $72,0 \%$ & $15,1 \%$ & $12,9 \%$ & $100 \%$ & & \\
\hline Prop. Pred. Éxito (FPR) & $82,3 \%$ & $55,2 \%$ & $52,6 \%$ & $\mathbf{7 4 , 4 \%}$ & & \\
\hline Índice de Éxito & 0,1029 & 0,40055 & 0,3972 & $\mathbf{0 , 1 8 6}$ & & \\
\hline Máximo Índice de Éxito & & & & $\mathbf{0 , 4 4 2}$ & & \\
\hline Índice de Éxito Normalizado & & & & $\mathbf{0 , 4 2 0}$ & & \\
\hline Error en prop. pred. & $-0,1 \%$ & $0,0 \%$ & $0,1 \%$ & & & \\
\hline
\end{tabular}


Tabla A4-19. Modelo MNL-7

\begin{tabular}{ccccccc}
\hline & BUS & COCHE & TREN & Suma & $\begin{array}{c}\text { Prop. } \\
\text { Observada }\end{array}$ & $\begin{array}{c}\text { Prop. } \\
\text { Obs. Exito }\end{array}$ \\
\hline BUS & 1331 & 151 & 136 & 1618 & $72,1 \%$ & $82,3 \%$ \\
\hline COCHE & 151 & 188 & 0 & 339 & $15,1 \%$ & $55,5 \%$ \\
\hline TREN & 135 & 0 & 151 & 286 & $12,8 \%$ & $52,8 \%$ \\
\hline Suma & 1617 & 339 & 287 & 2243 & & \\
\hline Prop. Predicha & $72,1 \%$ & $15,1 \%$ & $12,8 \%$ & $100 \%$ & & \\
\hline Prop. Pred. Éxito (FPR) & $82,3 \%$ & $55,5 \%$ & $52,6 \%$ & $\mathbf{7 4 , 5 \%}$ & & \\
\hline Índice de Éxito & 0,1022 & 0,40344 & 0,3982 & $\mathbf{0 , 1 8 6}$ & & \\
\hline Máximo Índice de Éxito & & & & $\mathbf{0 , 4 4 1}$ & & \\
\hline Índice de Éxito Normalizado & & & & $\mathbf{0 , 4 2 1}$ & & \\
\hline Error en prop. pred. & $0,0 \%$ & $0,0 \%$ & $0,0 \%$ & & &
\end{tabular}

Tabla A4-20. Modelo MNL-8

\begin{tabular}{ccccccc}
\hline & BUS & COCHE & TREN & Suma & $\begin{array}{c}\text { Prop. } \\
\text { Observada }\end{array}$ & $\begin{array}{c}\text { Prop. } \\
\text { Obs. Exito }\end{array}$ \\
\hline BUS & 1339 & 147 & 133 & 1619 & $72,1 \%$ & $82,7 \%$ \\
\hline COCHE & 149 & 190 & 0 & 339 & $15,1 \%$ & $56,0 \%$ \\
\hline TREN & 131 & 0 & 155 & 286 & $12,7 \%$ & $54,2 \%$ \\
\hline Suma & 1619 & 337 & 288 & 2244 & & \\
\hline Prop. Predicha & $72,1 \%$ & $15,0 \%$ & $12,8 \%$ & $100 \%$ & & \\
\hline Prop. Pred. Éxito (FPR) & $82,7 \%$ & $56,4 \%$ & $53,8 \%$ & $\mathbf{7 5 , 0 \%}$ & & \\
\hline Índice de Éxito & 0,1056 & 0,41362 & 0,4099 & $\mathbf{0 , 1 9 1}$ & & \\
\hline Máximo Índice de Éxito & & & & $\mathbf{0 , 4 4 0}$ & & \\
\hline Índice de Éxito Normalizado & & & & $\mathbf{0 , 4 3 3}$ & & \\
\hline Error en prop. pred. & $0,0 \%$ & $-0,1 \%$ & $0,1 \%$ & & & \\
\hline
\end{tabular}

Tabla A4-21. Modelo HL-1

\begin{tabular}{ccccccc}
\hline & BUS & COCHE & TREN & Suma & $\begin{array}{c}\text { Prop. } \\
\text { Observada }\end{array}$ & $\begin{array}{c}\text { Prop. } \\
\text { Obs. Éxito }\end{array}$ \\
\hline BUS & 1337 & 150 & 132 & 1619 & $72,1 \%$ & $82,6 \%$ \\
\hline COCHE & 150 & 189 & 0 & 339 & $15,1 \%$ & $55,8 \%$ \\
\hline TREN & 129 & 0 & 157 & 286 & $12,7 \%$ & $54,9 \%$ \\
\hline Suma & 1616 & 339 & 289 & 2244 & & \\
\hline Prop. Predicha & $72,0 \%$ & $15,1 \%$ & $12,9 \%$ & $100 \%$ & & \\
\hline Prop. Pred. Éxito (FPR) & $82,7 \%$ & $55,8 \%$ & $54,3 \%$ & $\mathbf{7 5 , 0} \%$ & & \\
\hline Índice de Éxito & 0,1072 & 0,40645 & 0,4145 & $\mathbf{0 , 1 9 2}$ & & \\
\hline Máximo Índice de Éxito & & & & $\mathbf{0 , 4 4 2}$ & & \\
\hline Índice de Éxito Normalizado & & & & $\mathbf{0 , 4 3 4}$ & & \\
\hline Error en prop. pred. & $-0,1 \%$ & $0,0 \%$ & $0,1 \%$ & & & \\
\hline
\end{tabular}


Tabla A4-22. Modelo HL-2

\begin{tabular}{ccccccc}
\hline & BUS & COCHE & TREN & Suma & $\begin{array}{c}\text { Prop. } \\
\text { Observada }\end{array}$ & $\begin{array}{c}\text { Prop. } \\
\text { Obs. Exito }\end{array}$ \\
\hline BUS & 1337 & 150 & 132 & 1619 & $72,1 \%$ & $82,6 \%$ \\
\hline COCHE & 150 & 189 & 0 & 339 & $15,1 \%$ & $55,8 \%$ \\
\hline TREN & 130 & 0 & 156 & 286 & $12,7 \%$ & $54,5 \%$ \\
\hline Suma & 1617 & 339 & 288 & 2244 & & \\
\hline Prop. Predicha & $72,1 \%$ & $15,1 \%$ & $12,8 \%$ & $100 \%$ & & \\
\hline Prop. Pred. Éxito (FPR) & $82,7 \%$ & $55,8 \%$ & $54,2 \%$ & $75,0 \%$ & & \\
\hline Índice de Éxito & 0,1063 & 0,40645 & 0,4133 & $\mathbf{0 , 1 9 1}$ & & \\
\hline Máximo Índice de Éxito & & & & $\mathbf{0 , 4 4 1}$ & & \\
\hline Índice de Éxito Normalizado & & & & $\mathbf{0 , 4 3 3}$ & & \\
\hline Error en prop. pred. & $-0,1 \%$ & $0,0 \%$ & $0,1 \%$ & & & \\
\hline & & & & &
\end{tabular}

Tabla A4-23. Modelo HL-3

\begin{tabular}{ccccccc}
\hline & BUS & COCHE & TREN & Suma & $\begin{array}{c}\text { Prop. } \\
\text { Observada }\end{array}$ & $\begin{array}{c}\text { Prop. } \\
\text { Obs. Exito }\end{array}$ \\
\hline BUS & 1338 & 150 & 130 & 1618 & $72,1 \%$ & $82,7 \%$ \\
\hline COCHE & 150 & 189 & 0 & 339 & $15,1 \%$ & $55,8 \%$ \\
\hline TREN & 130 & 0 & 156 & 286 & $12,8 \%$ & $54,5 \%$ \\
\hline Suma & 1618 & 339 & 286 & 2243 & & \\
\hline Prop. Predicha & $72,1 \%$ & $15,1 \%$ & $12,8 \%$ & $100 \%$ & & \\
\hline Prop. Pred. Éxito (FPR) & $82,7 \%$ & $55,8 \%$ & $54,5 \%$ & $\mathbf{7 5 , 0} \%$ & & \\
\hline Índice de Éxito & 0,1056 & 0,40639 & 0,4179 & $\mathbf{0 , 1 9 1}$ & & \\
\hline Máximo Índice de Éxito & & & & $\mathbf{0 , 4 4 1}$ & & \\
\hline Índice de Éxito Normalizado & & & $\mathbf{0 , 4 3 3}$ & & \\
\hline Error en prop. pred. & $0,0 \%$ & $0,0 \%$ & $0,0 \%$ & & & \\
\hline
\end{tabular}

Tabla A4-24. Modelo HL-4

\begin{tabular}{ccccccc}
\hline & BUS & COCHE & TREN & Suma & $\begin{array}{c}\text { Prop. } \\
\text { Observada }\end{array}$ & $\begin{array}{c}\text { Prop. } \\
\text { Obs. Exito }\end{array}$ \\
\hline BUS & 1338 & 149 & 132 & 1619 & $72,1 \%$ & $82,6 \%$ \\
\hline COCHE & 151 & 188 & 0 & 339 & $15,1 \%$ & $55,5 \%$ \\
\hline TREN & 130 & 0 & 156 & 286 & $12,7 \%$ & $54,5 \%$ \\
\hline Suma & 1619 & 337 & 288 & 2244 & & \\
\hline Prop. Predicha & $72,1 \%$ & $15,0 \%$ & $12,8 \%$ & $100 \%$ & & \\
\hline Prop. Pred. Éxito (FPR) & $82,6 \%$ & $55,8 \%$ & $54,2 \%$ & $75,0 \%$ & & \\
\hline Índice de Éxito & 0,105 & 0,40769 & 0,4133 & $\mathbf{0 , 1 9 0}$ & & \\
\hline Máximo Índice de Éxito & & & & $\mathbf{0 , 4 4 0}$ & & \\
\hline Índice de Éxito Normalizado & & & $\mathbf{0 , 4 3 1}$ & & \\
\hline Error en prop. pred. & $0,0 \%$ & $-0,1 \%$ & $0,1 \%$ & & & \\
\hline
\end{tabular}





\section{Anexo 5. Elasticidades de la Demanda. Enumeración Muestral}

Tabla A5-1. Modelo MNL-4

\begin{tabular}{|c|c|c|c|c|c|c|}
\hline \multirow{2}{*}{ SITUACIÓN } & \multicolumn{3}{|c|}{ PROBABILIDADES DE ELECCIÓN } & \multicolumn{3}{|c|}{ ELASTICIDADES DEMANDA BUS } \\
\hline & Bus & Coche & Tren & Directa & Cruzada coche & Cruzada tren \\
\hline Actual & 0,652 & 0,198 & 0,150 & & & \\
\hline$+1 \%$ TBUS & 0,647 & 0,200 & 0,152 & $-0,71$ & & \\
\hline$+1 \%$ CBUS & 0,649 & 0,199 & 0,151 & $-0,44$ & & \\
\hline$+1 \%$ NSBUS & 0,653 & 0,197 & 0,149 & 0,15 & & \\
\hline$+1 \%$ RUTANUBU & 0,652 & 0,198 & 0,150 & 0,042 & & \\
\hline+1 UD. BUS & 0,667 & 0,190 & 0,143 & 2,31 & & \\
\hline$+1 \%$ TCOCHE & 0,653 & 0,196 & 0,150 & & 0,20 & \\
\hline$+1 \% \mathrm{CCOCHE}$ & 0,653 & 0,197 & 0,150 & & 0,14 & \\
\hline$+1 \%$ RUTANUCO & 0,652 & 0,198 & 0,150 & & 0,042 & \\
\hline$+1 \%$ TTREN & 0,655 & 0,198 & 0,147 & & & 0,39 \\
\hline$+1 \%$ CTREN & 0,653 & 0,198 & 0,148 & & & 0,19 \\
\hline$+1 \%$ NSTREN & 0,652 & 0,198 & 0,150 & & & $-0,063$ \\
\hline
\end{tabular}

Tabla A5-2. Modelo MNL-8

\begin{tabular}{|c|c|c|c|c|c|c|}
\hline \multirow{2}{*}{ SITUACIÓN } & \multicolumn{3}{|c|}{ PROBABILIDADES DE ELECCIÓN } & \multicolumn{3}{|c|}{ ELASTICIDADES DEMANDA BUS } \\
\hline & Bus & Coche & Tren & Directa & Cruzada coche & Cruzada tren \\
\hline Actual & 0,662 & 0,190 & 0,149 & & & \\
\hline$+1 \%$ TBUS & 0,657 & 0,192 & 0,151 & $-0,73$ & & \\
\hline$+1 \%$ CBUS & 0,659 & 0,191 & 0,150 & $-0,44$ & & \\
\hline$+1 \%$ NSBUS & 0,662 & 0,189 & 0,148 & 0,11 & & \\
\hline$+1 \%$ RUTANUBU & 0,662 & 0,190 & 0,148 & 0,093 & & \\
\hline+1 UD. BUS & 0,678 & 0,182 & 0,140 & 2,49 & & \\
\hline$+1 \% \mathrm{TCOCHE}$ & 0,663 & 0,188 & 0,149 & & 0,23 & \\
\hline$+1 \% \mathrm{CCOCHE}$ & 0,662 & 0,189 & 0,149 & & 0,13 & \\
\hline$+1 \%$ RUTANUCO & 0,662 & 0,190 & 0,148 & & 0,093 & \\
\hline$+1 \%$ TTREN & 0,664 & 0,190 & 0,146 & & & 0,36 \\
\hline$+1 \%$ CTREN & 0,663 & 0,190 & 0,147 & & & 0,19 \\
\hline$+1 \%$ NSTREN & 0,661 & 0,190 & 0,149 & & & $-0,085$ \\
\hline
\end{tabular}


Tabla A5-3. Modelo HL-3

\begin{tabular}{ccccccc}
\hline \multirow{2}{*}{ SITUACIÓN } & \multicolumn{2}{c}{ PROBABILIDADES DE ELECCIÓN } & \multicolumn{2}{c}{ ELASTICIDADES DEMANDA BUS } \\
\cline { 2 - 7 } & Bus & Coche & Tren & Directa & Cruzada coche & Cruzada tren \\
\hline Actual & 0,589 & 0,272 & 0,139 & & & \\
\hline$+1 \%$ TBUS & 0,585 & 0,274 & 0,141 & $-0,74$ & & \\
\hline$+1 \%$ CBUS & 0,587 & 0,273 & 0,140 & $-0,40$ & & \\
\hline$+1 \%$ NSBUS & 0,590 & 0,271 & 0,139 & 0,13 & & \\
\hline$+1 \%$ RUTANUBU & 0,589 & 0,272 & 0,139 & 0,00 & & \\
\hline+1 UD. BUS & 0,605 & 0,262 & 0,132 & 2,78 & & 0,074 \\
\hline$+1 \%$ TCOCHE & 0,590 & 0,271 & 0,139 & & & 0,00 \\
\hline$+1 \%$ CCOCHE & 0,590 & 0,270 & 0,140 & & & 0,31 \\
\hline$+1 \%$ RUTANUCO & 0,589 & 0,272 & 0,139 & & & $-0,056$ \\
\hline$+1 \%$ TTREN & 0,591 & 0,272 & 0,137 & & & \\
\hline$+1 \%$ CTREN & 0,590 & 0,272 & 0,138 & & & \\
\hline$+1 \%$ NSTREN & 0,589 & 0,271 & 0,140 & & & \\
\hline
\end{tabular}




\section{Anexo 6. Aplicación a las Concesiones. Datos de Entrada}

Tabla A6-1. Relación de municipios servidos

Fuente: Junta de Castilla y León [87]

\begin{tabular}{|c|c|c|c|c|c|}
\hline \multirow{2}{*}{ MUNICIPIO } & \multirow{2}{*}{$\begin{array}{l}\text { NÚCLEO DE } \\
\text { POBLACIÓN }\end{array}$} & \multirow{2}{*}{$\begin{array}{l}\text { DIST. A } \\
\text { CAPITAL } \\
(\mathrm{Km}) \\
\end{array}$} & \multicolumn{3}{|c|}{ RED DE TRANSPORTE } \\
\hline & & & LÍNEA & CONCESIÓN & CONCESIONARIO \\
\hline \multirow{2}{*}{ Albillos } & \multirow{2}{*}{ Albillos } & \multirow{2}{*}{14} & Los Balbases - Burgos & \multirow{2}{*}{ VACL-004 } & \multirow{2}{*}{$\begin{array}{l}\text { Autobuses de } \\
\text { Castilla, S.L. }\end{array}$} \\
\hline & & & Servicio Parcial M2 & & \\
\hline \multirow{6}{*}{$\begin{array}{c}\text { Alfoz de } \\
\text { Quintanadueñas }\end{array}$} & \multirow[t]{2}{*}{ Quintanadueñas } & \multirow[t]{2}{*}{6} & $\begin{array}{c}\text { Cervera de Pisuerga - } \\
\text { Burgos }\end{array}$ & \multirow{6}{*}{ VACL-019 } & \multirow{6}{*}{$\begin{array}{l}\text { Autobuses del } \\
\text { Pisuerga, S.A. }\end{array}$} \\
\hline & & & Servicio Parcial M4 & & \\
\hline & Arroyal & 9 & $\begin{array}{c}\text { Cervera de Pisuerga - } \\
\text { Burgos }\end{array}$ & & \\
\hline & & & Servicio Parcial M4 & & \\
\hline & \multirow[t]{2}{*}{ Villarmero } & \multirow[t]{2}{*}{3} & $\begin{array}{c}\text { Santibáñez-Zarzaguda - } \\
\text { Burgos } \\
\end{array}$ & & \\
\hline & & & Servicio Parcial M4 & & \\
\hline \multirow{4}{*}{$\begin{array}{l}\text { Arcos de la } \\
\quad \text { Llana }\end{array}$} & \multirow{3}{*}{$\begin{array}{l}\text { Arcos de la } \\
\text { Llana }\end{array}$} & \multirow{3}{*}{10} & Servicio Parcial M1 & \multirow{4}{*}{ VACL-004 } & \multirow{4}{*}{$\begin{array}{l}\text { Autobuses de } \\
\text { Castilla, S.L. }\end{array}$} \\
\hline & & & $\begin{array}{c}\text { Santa María del Campo - } \\
\text { Burgos }\end{array}$ & & \\
\hline & & & Peral de Arlanza - Burgos & & \\
\hline & $\begin{array}{l}\text { Villanueva- } \\
\text { Matamala } \\
\end{array}$ & 11 & $\begin{array}{c}\text { Santa María del Campo - } \\
\text { Burgos }\end{array}$ & & \\
\hline \multirow[t]{3}{*}{ Buniel } & \multirow[t]{3}{*}{ Buniel } & \multirow[t]{3}{*}{12} & $\begin{array}{c}\text { Tórtoles de Esgueva - } \\
\text { Burgos } \\
\text { Arenillas de Río Pisuerga - } \\
\text { Burgos } \\
\end{array}$ & \multirow[t]{2}{*}{ VACL-004 } & \multirow[t]{2}{*}{$\begin{array}{l}\text { Autobuses de } \\
\text { Castilla, S.L. }\end{array}$} \\
\hline & & & Servicio Parcial M2 & & \\
\hline & & & Burgos - Palencia & VACL-116 & $\begin{array}{l}\text { Moreno Vicente y } \\
\text { Compañía, S.L. }\end{array}$ \\
\hline \multirow{2}{*}{ Cavia } & \multirow{2}{*}{ Cavia } & \multirow{2}{*}{15} & Los Balbases - Burgos & \multirow{2}{*}{ VACL-004 } & \multirow{2}{*}{$\begin{array}{l}\text { Autobuses de } \\
\text { Castilla, S.L. }\end{array}$} \\
\hline & & & Servicio Parcial M2 & & \\
\hline \multirow[b]{2}{*}{$\begin{array}{l}\text { Carcedo de } \\
\text { Burgos }\end{array}$} & \multirow[b]{2}{*}{$\begin{array}{l}\text { Carcedo de } \\
\text { Burgos }\end{array}$} & & Servicio Parcial M8 & & \\
\hline & & 9 & $\begin{array}{c}\text { Jaramillo de la Fuente - } \\
\text { Burgos }\end{array}$ & VACL-010 & $\begin{array}{c}\text { Autocares } \\
\text { Arceredillo, S.L. }\end{array}$ \\
\hline & & & Servicio Parcial M8 & & \\
\hline Cardeñadijo & Cardeñadijo & 5 & $\begin{array}{c}\text { Jaramillo de la Fuente - } \\
\text { Burgos }\end{array}$ & VACL-010 & $\begin{array}{c}\text { Autocares } \\
\text { Arceredillo, S.L. }\end{array}$ \\
\hline & & & Servicio Parcial M8 & & \\
\hline Cardeñajimeno & Cardeñajimeno & 8 & $\begin{array}{c}\text { Jaramillo de la Fuente - } \\
\text { Burgos }\end{array}$ & VACL-010 & $\begin{array}{c}\text { Autocares } \\
\text { Arceredillo, S.L. }\end{array}$ \\
\hline & San Medel & 6 & Servicio Parcial M7 & & \\
\hline
\end{tabular}




\begin{tabular}{|c|c|c|c|c|c|}
\hline \multirow{2}{*}{ MUNICIPIO } & \multirow{2}{*}{$\begin{array}{l}\text { NÚCLEO DE } \\
\text { POBLACIÓN }\end{array}$} & \multirow{2}{*}{$\begin{array}{c}\text { DIST. A } \\
\text { CAPITAL } \\
(\mathrm{Km})\end{array}$} & \multicolumn{3}{|c|}{ RED DE TRANSPORTE } \\
\hline & & & LÍNEA & CONCESIÓN & CONCESIONARIO \\
\hline \multirow{10}{*}{ Castrillo del Val } & \multirow[b]{2}{*}{ Castrillo del Val } & \multirow[b]{2}{*}{11} & Servicio Parcial M8 & \multirow[b]{2}{*}{ VACL-010 } & \multirow[b]{2}{*}{$\begin{array}{c}\text { Autocares } \\
\text { Arceredillo, S.L. }\end{array}$} \\
\hline & & & $\begin{array}{c}\text { Jaramillo de la Fuente - } \\
\text { Burgos }\end{array}$ & & \\
\hline & \multirow{4}{*}{ Urb. Tomillares } & \multirow{4}{*}{13} & Servicio Parcial M7 & \multirow{8}{*}{ VACL-001 } & \multirow{8}{*}{$\begin{array}{c}\text { Autocares Castilla y } \\
\text { León, S.A. }\end{array}$} \\
\hline & & & Burgos - Pradoluengo & & \\
\hline & & & $\begin{array}{c}\text { Burgos - Fresneda de la } \\
\text { Sierra Tirón }\end{array}$ & & \\
\hline & & & Burgos - Urb. Tomillares & & \\
\hline & \multirow{4}{*}{ Base Militar } & \multirow{4}{*}{13} & Servicio Parcial M7 & & \\
\hline & & & Burgos - Pradoluengo & & \\
\hline & & & $\begin{array}{c}\text { Burgos - Fresneda de la } \\
\text { Sierra Tirón }\end{array}$ & & \\
\hline & & & Burgos - Urb. Tomillares & & \\
\hline \multirow{3}{*}{ Cayuela } & \multirow{2}{*}{ Cayuela } & \multirow{2}{*}{12} & Los Balbases - Burgos & \multirow{3}{*}{ VACL-004 } & \multirow{3}{*}{$\begin{array}{l}\text { Autobuses de } \\
\text { Castilla, S.L. }\end{array}$} \\
\hline & & & Servicio Parcial M2 & & \\
\hline & $\begin{array}{l}\text { Villamiel de } \\
\text { Muñó }\end{array}$ & 10 & Servicio Parcial M2 & & \\
\hline \multirow{3}{*}{ Cogollos } & \multirow{3}{*}{ Cogollos } & \multirow{3}{*}{16} & Caleruega - Burgos & VACL-007 & $\begin{array}{c}\text { Autocares } \\
\text { Arceredillo, S.L. }\end{array}$ \\
\hline & & & Burgos - Aranda de Duero & \multirow{2}{*}{ VACL-027 } & \multirow{2}{*}{$\begin{array}{c}\text { Autocares Castilla y } \\
\text { León, S.A. }\end{array}$} \\
\hline & & & Burgos - Roa & & \\
\hline Hurnnec & Hurnnec & 11 & Burgos - Salas de Bureba & V/ACI 067 & Automóviles Soto y \\
\hline Tlutultes & rutones & 11 & Servicio Parcial M6 & VACL-UDI & Alonso, S.L. \\
\hline & & & Servicio Parcial M7 & & \\
\hline lbeas de & & & Burgos - Pradoluengo & & \\
\hline Juarros & Juarros & 16 & $\begin{array}{c}\text { Burgos - Fresneda de la } \\
\text { Sierra Tirón }\end{array}$ & VACL-001 & León, S.A. \\
\hline & & & Burgos - Urb. Tomillares & & \\
\hline & & & Burgos - Santander & & \\
\hline & Sotonalacios & 10 & Burgos - Arija & & \\
\hline & & & Burgos - Bilbao & & \\
\hline Merindad de & & & Servicio Parcial M5 & VACL-001 & Autocares castilla y \\
\hline & & & Burgos - Santander & & \\
\hline & Ubierna & 18 & Burgos - Arija & & \\
\hline & & & Servicio Parcial M5 & & \\
\hline Modúbar de la & $\begin{array}{l}\text { Modúbar de la } \\
\text { Emparedada }\end{array}$ & 10 & Servicio Parcial M9 & VACL-007 & Autocares \\
\hline Emparedada & Cojóbar & 14 & Servicio Parcial M9 & & \\
\hline & & & Burgos - Santander & & \\
\hline Quintanaortuño & Quintanaortuño & 13 & Burgos - Arija & VACL-001 & $\begin{array}{c}\text { Autocares Castilla y } \\
\text { Jeón SA }\end{array}$ \\
\hline & & & Servicio Parcial M5 & & \\
\hline & & & Burgos - Santander & & \\
\hline & Quintanilla Vivar & 9 & Burgos - Arija & & \\
\hline Ouintanilla Yivar & & & Servicio Parcial M5 & V/ACI $0 \cap 1$ & Autocares Castilla y \\
\hline Quintanilla vivar & & & Burgos - Santander & VACL-UU1 & León, S.A. \\
\hline & Vivar del Cid & 10 & Burgos - Arija & & \\
\hline & & & Servicio Parcial M5 & & \\
\hline
\end{tabular}




\begin{tabular}{|c|c|c|c|c|c|}
\hline \multirow{2}{*}{ MUNICIPIO } & \multirow{2}{*}{$\begin{array}{l}\text { NÚCLEO DE } \\
\text { POBLACIÓN }\end{array}$} & \multirow{2}{*}{$\begin{array}{c}\text { DIST. A } \\
\text { CAPITAL } \\
(\mathrm{Km})\end{array}$} & \multicolumn{3}{|c|}{ RED DE TRANSPORTE } \\
\hline & & & LÍNEA & CONCESIÓN & CONCESIONARIO \\
\hline \multirow{5}{*}{ Revillarruz } & \multirow{2}{*}{ Revillarruz } & \multirow{2}{*}{14} & Santillán del Agua - Burgos & \multirow{5}{*}{ VACL-007 } & \multirow{5}{*}{$\begin{array}{c}\text { Autocares } \\
\text { Arceredillo, S.L. }\end{array}$} \\
\hline & & & Servicio Parcial M9 & & \\
\hline & Olmogalhec & 16 & Santillán del Agua - Burgos & & \\
\hline & Uimosalidos & 10 & Servicio Parcial M9 & & \\
\hline & Humienta & 16 & Servicio Parcial M9 & & \\
\hline \multirow{5}{*}{$\begin{array}{l}\text { Saldaña de } \\
\text { Burgos }\end{array}$} & $\begin{array}{c}\text { Saldaña de } \\
\text { Brgos }\end{array}$ & 9 & Servicio Parcial M9 & \multirow{5}{*}{ VACL-007 } & \multirow{5}{*}{$\begin{array}{c}\text { Autocares } \\
\text { Arceredillo, S.L. }\end{array}$} \\
\hline & Saldañuela de & 8 & Santillán del Agua - Burgos & & \\
\hline & Burgos & 8 & Servicio Parcial M9 & & \\
\hline & Palacio de & 0 & Santillán del Agua - Burgos & & \\
\hline & Saldañuela & $y$ & Servicio Parcial M9 & & \\
\hline \multirow{5}{*}{$\begin{array}{l}\text { San Mamés de } \\
\text { Burgos }\end{array}$} & \multirow{4}{*}{$\begin{array}{c}\text { San Mamés de } \\
\text { Burgos }\end{array}$} & \multirow{4}{*}{8} & Burgos - Palencia & VACL-116 & $\begin{array}{l}\text { Moreno Vicente y } \\
\text { Compañía, S.L. }\end{array}$ \\
\hline & & & $\begin{array}{c}\text { Tórtoles de Esgueva - } \\
\text { Burgos }\end{array}$ & \multirow{4}{*}{ VACL-004 } & \multirow{4}{*}{$\begin{array}{l}\text { Autobuses de } \\
\text { Castilla, S.L. }\end{array}$} \\
\hline & & & $\begin{array}{c}\text { Arenillas de Río Pisuerga - } \\
\text { Burgos }\end{array}$ & & \\
\hline & & & Servicio Parcial M2 & & \\
\hline & $\begin{array}{l}\text { Quintanilla de } \\
\text { las Carretas }\end{array}$ & 10 & Servicio Parcial M2 & & \\
\hline \multirow{4}{*}{ Sarracín } & \multirow{4}{*}{ Sarracín } & \multirow{4}{*}{9} & Santillán del Agua - Burgos & \multirow{2}{*}{ VACL-007 } & \multirow{2}{*}{$\begin{array}{c}\text { Autocares } \\
\text { Arceredillo, S.L. }\end{array}$} \\
\hline & & & Servicio Parcial M9 & & \\
\hline & & & Burgos - Aranda de Duero & \multirow{2}{*}{ VACL-027 } & \multirow{2}{*}{$\begin{array}{c}\text { Autocares Castilla y } \\
\text { León, S.A. }\end{array}$} \\
\hline & & & Burgos - Roa & & \\
\hline \multirow[t]{2}{*}{ Sotragero } & \multirow[t]{2}{*}{ Sotragero } & \multirow[t]{2}{*}{9} & $\begin{array}{c}\text { Santibáñez-Zarzaguda - } \\
\text { Burgos }\end{array}$ & \multirow[t]{2}{*}{ VACL-019 } & \multirow{2}{*}{$\begin{array}{l}\text { Autobuses del } \\
\text { Pisuerga, S.A. }\end{array}$} \\
\hline & & & Servicio Parcial M4 & & \\
\hline \multirow{3}{*}{ Valdorros } & \multirow{3}{*}{ Valdorros } & & Caleruega - Burgos & VACL-007 & $\begin{array}{c}\text { Autocares } \\
\text { Arceredillo, S.L. }\end{array}$ \\
\hline & & 20 & Burgos - Aranda de Duero & & Autocares Castilla y \\
\hline & & & Burgos - Roa & VACL-027 & León, S.A. \\
\hline Valle de las & & 22 & Burgos - Salas de Bureba & YAC। 067 & Automóviles Soto y \\
\hline Navas & RIocerezo & 23 & Servicio Parcial M6 & VACL-06! & Alonso, S.L. \\
\hline & & & Los Balbases - Burgos & & \\
\hline $\begin{array}{l}\text { Villagonzalo- } \\
\text { Pedernales }\end{array}$ & $\begin{array}{l}\text { Villagonzalo- } \\
\text { Pedernales }\end{array}$ & 5 & $\begin{array}{c}\text { Santa María del Campo - } \\
\text { Burgos }\end{array}$ & VACL-004 & $\begin{array}{l}\text { Autobuses de } \\
\text { Castilla, S.L. }\end{array}$ \\
\hline & & & Servicio Parcial M1 & & \\
\hline
\end{tabular}




\begin{tabular}{|c|c|c|c|c|c|}
\hline \multirow{2}{*}{ MUNICIPIO } & \multirow{2}{*}{$\begin{array}{l}\text { NÚCLEO DE } \\
\text { POBLACIÓN }\end{array}$} & \multirow{2}{*}{$\begin{array}{c}\text { DIST. A } \\
\text { CAPITAL } \\
(\mathrm{Km})\end{array}$} & \multicolumn{3}{|c|}{ RED DE TRANSPORTE } \\
\hline & & & LÍNEA & CONCESIÓN & CONCESIONARIO \\
\hline \multirow{11}{*}{$\begin{array}{l}\text { Villalbilla de } \\
\text { Burgos }\end{array}$} & \multirow{9}{*}{$\begin{array}{l}\text { Villalbilla de } \\
\text { Burgos }\end{array}$} & \multirow{9}{*}{7} & Osorno - Burgos & \multirow{3}{*}{ VACL-075 } & \multirow{3}{*}{$\begin{array}{l}\text { El Noroeste de } \\
\text { Burgos, S.L. }\end{array}$} \\
\hline & & & $\begin{array}{c}\text { Melgar de Fernamental - } \\
\text { Burgos } \\
\end{array}$ & & \\
\hline & & & Servicio Parcial M3 & & \\
\hline & & & Alar del Rey - Burgos & \multirow{6}{*}{ VACL-079 } & \multirow{6}{*}{$\begin{array}{c}\text { Autobuses Amaya, } \\
\text { S.L. }\end{array}$} \\
\hline & & & Frómista - Burgos & & \\
\hline & & & $\begin{array}{c}\text { Herrera de Pisuerga - } \\
\text { Burgos }\end{array}$ & & \\
\hline & & & Grijalba - Burgos & & \\
\hline & & & Sasamón - Burgos & & \\
\hline & & & Villadiego - Burgos & & \\
\hline & Villacienzo & 10 & Servicio Parcial M2 & VACL-004 & $\begin{array}{l}\text { Autobuses de } \\
\text { Castilla, S.L. }\end{array}$ \\
\hline & Renuncio & 11 & Servicio Parcial M2 & VACL-004 & $\begin{array}{l}\text { Autobuses de } \\
\text { Castilla, S.L. }\end{array}$ \\
\hline \multirow{2}{*}{ Villariezo } & \multirow{2}{*}{ Villariezo } & \multirow{2}{*}{9} & Peral de Arlanza - Burgos & \multirow{2}{*}{ VACL-004 } & \multirow{2}{*}{$\begin{array}{l}\text { Autobuses de } \\
\text { Castilla, S.L. }\end{array}$} \\
\hline & & & Servicio Parcial M1 & & \\
\hline \multirow{2}{*}{$\begin{array}{l}\text { Villayerno } \\
\text { Morquillas }\end{array}$} & \multirow{2}{*}{$\begin{array}{l}\text { Villayerno } \\
\text { Morquillas }\end{array}$} & \multirow{2}{*}{8} & Burgos - Salas de Bureba & \multirow{2}{*}{ VACL-067 } & \multirow{2}{*}{$\begin{array}{c}\text { Automóviles Soto y } \\
\text { Alonso, S.L. }\end{array}$} \\
\hline & & & Servicio Parcial M6 & & \\
\hline
\end{tabular}


Tabla A6-2. Datos de explotación

Fuente: Junta de Castilla y León [87]

\begin{tabular}{|c|c|c|c|c|c|c|c|c|c|c|}
\hline \multirow[b]{2}{*}{ LÍNEA } & \multirow{2}{*}{$\begin{array}{l}\text { NÚCLEOS } \\
\text { METROP. CON } \\
\text { SERVICIO }\end{array}$} & \multirow{2}{*}{$\begin{array}{l}\text { NÚM. ANUAL DE } \\
\text { VIAJEROS ÁREA } \\
\text { METROPOLITANA } \\
(2008) \\
\end{array}$} & \multirow[b]{2}{*}{$\begin{array}{l}\text { CONCE- } \\
\text { SIÓN }\end{array}$} & \multicolumn{7}{|c|}{ NS (I+V) DIARIO } \\
\hline & & & & $\mathbf{L}$ & M & $x$ & $J$ & V & $\mathbf{S}$ & D \\
\hline $\begin{array}{l}\text { Ibeas de Juarros - Urb. } \\
\text { Tomillares - San Medel } \\
\text { (M7) }\end{array}$ & $\begin{array}{l}\text { Ibeas de Juarros - } \\
\text { Urbanización }\end{array}$ & 15.272 & VACL-001 & 9 & 9 & 9 & 9 & 8 & & 1 \\
\hline Burgos - Pradoluengo & Tomillares - San & 2.040 & VACL-001 & 2 & 2 & 2 & 2 & & & \\
\hline $\begin{array}{c}\text { Burgos - Fresneda de la } \\
\text { Sierra Tirón }\end{array}$ & & 4.452 & VACL-001 & 2 & 2 & 2 & 2 & 4 & 2 & \\
\hline $\begin{array}{l}\text { Arenillas de Río Pisuerga } \\
\text { - Burgos }\end{array}$ & $\begin{array}{c}\text { Buniel - San Mamés } \\
\text { de Burgos }\end{array}$ & 400 & VACL-004 & 2 & 2 & 2 & 2 & 3 & & \\
\hline $\begin{array}{c}\text { Villariezo - Arcos - } \\
\text { Villagonzalo-Pedernales } \\
\text { (M1) }\end{array}$ & $\begin{array}{l}\text { Villariezo - Arcos de } \\
\text { la Llana - } \\
\text { Villagonzalo- } \\
\text { Pedernales } \\
\end{array}$ & 7.221 & VACL-004 & 8 & 8 & 8 & 8 & 8 & & \\
\hline Los Balbases - Burgos & $\begin{array}{l}\text { Cavia - Cayuela - } \\
\text { Albillos - } \\
\text { Villagonzalo- } \\
\text { Pedernales }\end{array}$ & 400 & VACL-004 & 2 & 2 & 2 & 2 & 2 & & \\
\hline $\begin{array}{l}\text { Peral de Arlanza - } \\
\text { Burgos }\end{array}$ & $\begin{array}{c}\text { Villariezo - Arcos de } \\
\text { la Llana }\end{array}$ & 400 & VACL-004 & 2 & 2 & 2 & 2 & 2 & & \\
\hline $\begin{array}{c}\text { Santa María del Campo - } \\
\text { Burgos }\end{array}$ & $\begin{array}{l}\text { Villanueva-Matamala } \\
\text { - Arcos de la Llana - } \\
\text { Villagonzalo- } \\
\text { Pedernales } \\
\end{array}$ & 1.440 & VACL-004 & 4 & 4 & 4 & 4 & 4 & & \\
\hline $\begin{array}{c}\text { Tórtoles de Esgueva - } \\
\text { Burgos }\end{array}$ & $\begin{array}{c}\text { Buniel - San Mamés } \\
\text { de Burgos }\end{array}$ & 300 & VACL-004 & & 2 & 3 & 2 & & 2 & \\
\hline $\begin{array}{l}\text { Villamiel de Muñó - } \\
\text { Albillos - Cayuela - Cavia } \\
\text { - Buniel - Quintanilla de } \\
\text { las Carretas - San } \\
\text { Mamés de Burgos - } \\
\text { Villacienzo - Renuncio } \\
\text { (M2) }\end{array}$ & $\begin{array}{l}\text { Albillo - Cayuela - } \\
\text { Villamiel de Muñó - } \\
\text { Cavia - Buniel - San } \\
\text { Mamés de Burgos - } \\
\text { Quintanilla de las } \\
\text { Carretas - } \\
\text { Villacienzo - } \\
\text { Renuncio - } \\
\text { Villagonzalo- } \\
\text { Pedernales }\end{array}$ & -- & VACL-004 & 8 & 8 & 8 & 8 & 8 & & \\
\hline Caleruega - Burgos & Valdorros - Cogollos & 0 & VACL-007 & 2 & 2 & 2 & 2 & 2 & 2 & \\
\hline $\begin{array}{l}\text { Santillán del Agua - } \\
\text { Burgos }\end{array}$ & $\begin{array}{c}\text { Revillarruz - } \\
\text { Olmosalbos - } \\
\text { Cojóbar - Sarracín }\end{array}$ & 1.899 & VACL-007 & 4 & 4 & 4 & 4 & 4 & 2 & 1 \\
\hline $\begin{array}{c}\text { Sarracín - Ventas de } \\
\text { Saldaña - Saldaña de } \\
\text { Burgos - Cojóbar - } \\
\text { Modúbar de la } \\
\text { Emparedada - Humienta } \\
\text { - Olmosalbos - } \\
\text { Revillarruz (M9) }\end{array}$ & $\begin{array}{c}\text { Revillarruz - } \\
\text { Olmosalbos - } \\
\text { Cojóbar - Saldaña } \\
\text { de Burgos - Modúbar } \\
\text { de la Emparedada - } \\
\text { Humienta - Sarracín }\end{array}$ & -- & VACL-007 & 8 & 8 & 8 & 8 & 8 & & \\
\hline $\begin{array}{l}\text { Castrillo del Val - } \\
\text { Cardeñajimeno - Urb. } \\
\text { Fuentes Blancas - }\end{array}$ & $\begin{array}{l}\text { Cardeñadijo - } \\
\text { Cardeñajimeno - } \\
\text { Castrillo del Val - }\end{array}$ & 8.466 & VACL-010 & 8 & 8 & 8 & 8 & 8 & & \\
\hline
\end{tabular}




\begin{tabular}{|c|c|c|c|c|c|c|c|c|c|c|}
\hline \multirow[b]{2}{*}{ LÍNEA } & \multirow{2}{*}{$\begin{array}{l}\text { NÚCLEOS } \\
\text { METROP. CON } \\
\text { SERVICIO }\end{array}$} & \multirow{2}{*}{$\begin{array}{c}\text { NÚM. ANUAL DE } \\
\text { VIAJEROS ÁREA } \\
\text { METROPOLITANA } \\
(2008)\end{array}$} & \multirow[b]{2}{*}{$\begin{array}{l}\text { CONCE- } \\
\text { SIÓN }\end{array}$} & \multicolumn{7}{|c|}{ NS (I+V) DIARIO } \\
\hline & & & & L & M & $x$ & J & V & $S$ & D \\
\hline $\begin{array}{l}\text { Carcedo de Burgos - } \\
\text { Cardeñadijo (M8) }\end{array}$ & Carcedo de Burgos & & & & & & & & & \\
\hline $\begin{array}{c}\text { Jaramillo de la Fuente - } \\
\text { Burgos }\end{array}$ & $\begin{array}{l}\text { Cardeñajimeno - } \\
\text { Castrillo del Val - } \\
\text { Carcedo de Burgos }\end{array}$ & 550 & VACL-010 & & & & & 3 & 1 & \\
\hline $\begin{array}{c}\text { Cervera de Pisuerga - } \\
\text { Burgos }\end{array}$ & $\begin{array}{c}\text { Arroyal - } \\
\text { Quintanadueñas }\end{array}$ & 598 & VACL-019 & 2 & 2 & 2 & 4 & 2 & 4 & 2 \\
\hline $\begin{array}{c}\text { Santibáñez-Zarzaguda - } \\
\text { Burgos }\end{array}$ & $\begin{array}{l}\text { Sotragero - } \\
\text { Villarmero }\end{array}$ & 650 & VACL-019 & & 2 & & & 2 & & \\
\hline $\begin{array}{l}\text { Villarmero - Sotragero - } \\
\text { Arroyal - } \\
\text { Quintanadueñas (M4) }\end{array}$ & $\begin{array}{l}\text { Arroyal - Sotragero - } \\
\text { Villarmero - } \\
\text { Quintanadueñas }\end{array}$ & -- & VACL-019 & 7 & 7 & 7 & 7 & 7 & 2 & \\
\hline $\begin{array}{l}\text { Burgos - Aranda de } \\
\text { Duero }\end{array}$ & \multirow{2}{*}{$\begin{array}{l}\text { Valdorros - Cogollos } \\
\text { - Sarracín }\end{array}$} & 7.663 & VACL-027 & 8 & 8 & 8 & 8 & 8 & 8 & 8 \\
\hline Burgos - Roa & & 700 & VACL-027 & 2 & 2 & 2 & 2 & 2 & 2 & \\
\hline $\begin{array}{c}\text { Cuzcurrita de Juarros - } \\
\text { Burgos }\end{array}$ & San Medel (cruce) & 370 & VACL-033 & 4 & 4 & 4 & 4 & 4 & & \\
\hline Osorno - Burgos & \multirow{8}{*}{ Villalbilla de Burgos } & 3.000 & VACL-075 & 2 & 2 & 2 & 2 & 2 & 2 & \\
\hline $\begin{array}{c}\text { Melgar de Fernamental - } \\
\text { Burgos }\end{array}$ & & 8.823 & VACL-075 & 4 & 4 & 4 & 4 & 5 & 4 & 3 \\
\hline Alar del Rey - Burgos & & 1.494 & VACL-079 & 2 & 2 & 2 & 2 & 2 & 2 & \\
\hline Frómista - Burgos & & 2.024 & VACL-079 & 2 & 2 & 2 & 2 & 2 & 2 & \\
\hline Grijalba - Burgos & & 996 & VACL-079 & 2 & 2 & 2 & 2 & 2 & & \\
\hline $\begin{array}{c}\text { Herrera de Pisuerga - } \\
\text { Burgos }\end{array}$ & & 2.200 & VACL-079 & 2 & 2 & 2 & 2 & 2 & 2 & \\
\hline Sasamón - Burgos & & 249 & VACL-079 & 1 & 1 & 1 & 1 & 1 & & \\
\hline Villadiego - Burgos & & 1.058 & VACL-079 & 5 & 2 & 2 & 2 & 3 & & \\
\hline $\begin{array}{c}\text { Villalbilla de Burgos - } \\
\text { Pol. Ind. Los Brezos (M3) }\end{array}$ & $\begin{array}{l}\text { Villalbilla de Burgos - } \\
\text { Pol. Ind. Los Brezos }\end{array}$ & -- & $\begin{array}{l}\text { VACL-075 } \\
\text { VACL-079 } \\
\end{array}$ & 5 & 5 & 5 & 5 & 5 & & \\
\hline Burgos - Palencia & $\begin{array}{c}\text { Buniel - San Mamés } \\
\text { de Burgos }\end{array}$ & 2.466 & VACL-116 & 2 & 2 & 3 & 3 & 3 & 2 & \\
\hline $\begin{array}{c}\text { Burgos - Salas de } \\
\text { Bureba }\end{array}$ & $\begin{array}{l}\text { Villayerno Morquillas } \\
\text { - Hurones - } \\
\text { Riocerezo } \\
\end{array}$ & 200 & VACL-015 & & & & & 2 & & \\
\hline $\begin{array}{l}\text { Riocerezo - Hurones - } \\
\text { Villayerno Morquillas } \\
\text { (M6) }\end{array}$ & $\begin{array}{l}\text { Villayerno Morquillas } \\
\text { - Hurones - } \\
\text { Riocerezo }\end{array}$ & -- & VACL-015 & 8 & 8 & 8 & 8 & 8 & & \\
\hline Burgos - Arija & \multirow{2}{*}{$\begin{array}{c}\text { Ubierna - } \\
\text { Sotopalacios - Vivar } \\
\text { del Cid - Quintanilla } \\
\text { Vivar }\end{array}$} & 750 & VACL-001 & 2 & & 2 & & 2 & & \\
\hline Burgos - Santander & & 4.881 & VACL-001 & 4 & 4 & 4 & 4 & 4 & 4 & 5 \\
\hline $\begin{array}{c}\text { Ubierna - Quintanaortuño } \\
\text { - Sotopalacios - Vivar del } \\
\text { Cid - Quintanilla Vivar } \\
\text { (M5) }\end{array}$ & $\begin{array}{c}\text { Ubierna - } \\
\text { Sotopalacios - Vivar } \\
\text { del Cid - Quintanilla } \\
\text { Vivar }\end{array}$ & -- & VACL-001 & 6 & 6 & 6 & 6 & 6 & 4 & \\
\hline Burgos - Bilbao & $\begin{array}{c}\text { Sotopalacios - Vivar } \\
\text { del Cid }\end{array}$ & 4.915 & VACL-001 & 8 & 8 & 8 & 8 & 8 & 7 & 6 \\
\hline
\end{tabular}


Modelización de la Interrelación entre las Variables de Servicio y la Demanda de Viajeros de Autobuses de Tipo Interurbano

Tabla A6-3. Subvenciones de explotación en 2009

Fuente: Junta de Castilla y León [87]

\begin{tabular}{|c|c|c|c|c|c|c|c|}
\hline \multirow{2}{*}{\multicolumn{2}{|c|}{ CONCESIÓN }} & \multirow[b]{2}{*}{ OPERADOR } & \multirow{2}{*}{\multicolumn{2}{|c|}{ RUTA }} & \multicolumn{3}{|c|}{ SUBVENCIONES ANNO 2009 (€) } \\
\hline & & & & & METROP. & $\begin{array}{l}\text { RESTO } \\
\text { LÍNEAS }\end{array}$ & TOTAL \\
\hline \multirow{7}{*}{ 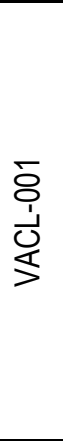 } & \multirow{7}{*}{$\begin{array}{l}\text { Burgos - } \\
\text { Fresneda de la } \\
\text { Sierra }\end{array}$} & \multirow{7}{*}{$\begin{array}{l}\text { Autocares } \\
\text { Castilla-León, } \\
\text { S.A.U. }\end{array}$} & M7 & $\begin{array}{l}\text { Ibeas de Juarros - Urb. Tomillares - } \\
\text { San Medel (M7) }\end{array}$ & 20.000 & \multirow{7}{*}{16.666} & \multirow{7}{*}{89.706} \\
\hline & & & & Burgos - Pradoluengo & & & \\
\hline & & & & Burgos - Fresneda de la Sierra Tirón & & & \\
\hline & & & & Burgos - Arija & & & \\
\hline & & & & Burgos - Santander & & & \\
\hline & & & M5 & $\begin{array}{l}\text { Ubierna - Quintanaortuño - } \\
\text { Sotopalacios - Vivar del Cid - } \\
\text { Quintanilla Vivar (M5) }\end{array}$ & 53.040 & & \\
\hline & & & & Burgos - Bilbao & & & \\
\hline \multirow{2}{*}{ 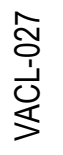 } & \multirow{2}{*}{$\begin{array}{l}\text { Burgos - Aranda } \\
\text { de Duero, con } \\
\text { hijuelas }\end{array}$} & \multirow{2}{*}{$\begin{array}{l}\text { Autocares } \\
\text { Castilla-León, } \\
\text { S.A.U. }\end{array}$} & & Burgos - Aranda de Duero & & \multirow{2}{*}{--} & \multirow{2}{*}{--} \\
\hline & & & & Burgos - Roa & & & \\
\hline \multirow{7}{*}{ 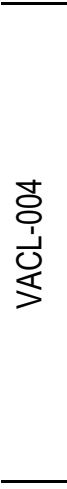 } & \multirow{7}{*}{$\begin{array}{l}\text { Burgos - } \\
\text { Tórtoles de } \\
\text { Esgueva, con } \\
\text { hijuelas }\end{array}$} & \multirow{7}{*}{$\begin{array}{l}\text { Autobuses de } \\
\text { Castilla, S.L. }\end{array}$} & & Arenillas de Río Pisuerga - Burgos & & \multirow{7}{*}{81.911} & \multirow{7}{*}{217.476} \\
\hline & & & M1 & $\begin{array}{c}\text { Villariezo - Arcos - Villagonzalo- } \\
\text { Pedernales (M1) } \\
\end{array}$ & 60.665 & & \\
\hline & & & & Los Balbases - Burgos & & & \\
\hline & & & & Peral de Arlanza - Burgos & & & \\
\hline & & & & Santa María del Campo - Burgos & & & \\
\hline & & & & Tórtoles de Esgueva - Burgos & & & \\
\hline & & & M2 & $\begin{array}{l}\text { Villamiel de Muñó - Albillos - Cayuela } \\
\text { - Cavia - Buniel - Quintanilla de las } \\
\text { Carretas - San Mamés de Burgos - } \\
\text { Villacienzo - Renuncio (M2) }\end{array}$ & 74.900 & & \\
\hline \multirow{2}{*}{ 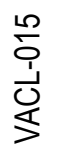 } & \multirow{2}{*}{$\begin{array}{l}\text { Burgos - } \\
\text { Miranda de } \\
\text { Ebro }\end{array}$} & \multirow{2}{*}{$\begin{array}{l}\text { Automóviles } \\
\text { Soto y Alonso, } \\
\text { S.L. }\end{array}$} & & Burgos - Salas de Bureba & & \multirow{2}{*}{25.177} & \multirow{2}{*}{87.278} \\
\hline & & & M6 & $\begin{array}{c}\text { Riocerezo - Hurones - Villayerno } \\
\text { Morquillas (M6) }\end{array}$ & 62.101 & & \\
\hline \multirow{4}{*}{ 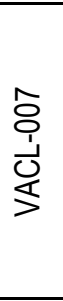 } & \multirow{4}{*}{$\begin{array}{l}\text { Burgos - } \\
\text { Caleruega, con } \\
\text { hijuelas }\end{array}$} & \multirow{4}{*}{$\begin{array}{c}\text { Autocares } \\
\text { Arceredillo, S.L. }\end{array}$} & & Caleruega - Burgos & & \multirow{4}{*}{8.668} & \multirow{4}{*}{63.507} \\
\hline & & & & Santillán del Agua - Burgos & & & \\
\hline & & & & $\begin{array}{l}\text { Sarracín - Ventas de Saldaña - } \\
\text { Saldaña de Burgos - Cojóbar - }\end{array}$ & & & \\
\hline & & & M9 & $\begin{array}{l}\text { Modúbar de la Emparedada - } \\
\text { Humienta - Olmosalbos - Revillarruz } \\
\text { (M9) }\end{array}$ & 54.839 & & \\
\hline \multirow{2}{*}{$\begin{array}{l}\text { 웅 } \\
\text { ì } \\
\text { 온 } \\
\text { > }\end{array}$} & \multirow{2}{*}{$\begin{array}{l}\text { Burgos - } \\
\text { Jaramillo de la } \\
\text { Fuente }\end{array}$} & $\begin{array}{c}\text { Autocares } \\
\text { Arceredillo SI }\end{array}$ & M8 & $\begin{array}{l}\text { Castrillo del Val - Cardeñajimeno - } \\
\text { Urb. Fuentes Blancas - Carcedo de } \\
\text { Burgos - Cardeñadijo (M8) }\end{array}$ & 60.665 & 5.991 & 66.656 \\
\hline & & & & Jaramillo de la Fuente - Burgos & & & \\
\hline & Cervera de & & & Cervera de Pisuerga - Burgos & & & \\
\hline$\grave{0}_{1}$ & Pisuerga - & Autobuses del & & Santibáñez-Zarzaguda - Burgos & & & 00120 \\
\hline 岕 & $\begin{array}{l}\text { Burgos, con } \\
\text { hijuelas } \\
\text { (desviación) }\end{array}$ & Pisuerga, S.L. & M4 & $\begin{array}{l}\text { Villarmero - Sotragero - Arroyal - } \\
\text { Quintanadueñas (M4) }\end{array}$ & 57.243 & 31.893 & 89.136 \\
\hline
\end{tabular}




\begin{tabular}{|c|c|c|c|c|c|c|c|}
\hline \multirow{2}{*}{\multicolumn{2}{|c|}{ CONCESIÓN }} & \multirow{2}{*}{\multicolumn{2}{|c|}{ OPERADOR }} & \multirow[b]{2}{*}{ RUTA } & \multicolumn{3}{|c|}{ SUBVENCIONES AÑO 2009 (€) } \\
\hline & & & & & METROP. & $\begin{array}{l}\text { RESTO } \\
\text { LíNEAS }\end{array}$ & TOTAL \\
\hline 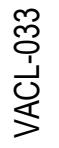 & $\begin{array}{l}\text { Burgos - } \\
\text { Tinieblas de la } \\
\text { Sierra }\end{array}$ & $\begin{array}{c}\text { Arroyo Bus, } \\
\text { S.L. }\end{array}$ & & Cuzcurrita de Juarros - Burgos & & -- & -- \\
\hline \multirow{3}{*}{ 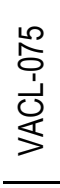 } & \multirow{3}{*}{$\begin{array}{l}\text { Osorno - } \\
\text { Burgos, con } \\
\text { Hijuelas }\end{array}$} & \multirow{3}{*}{$\begin{array}{l}\text { El Noroeste de } \\
\text { Burgos, S.L. }\end{array}$} & & Osorno - Burgos & & \multirow{3}{*}{37.027} & \multirow{3}{*}{43.640} \\
\hline & & & & Melgar de Fernamental - Burgos & & & \\
\hline & & & M3 & $\begin{array}{c}\text { Villalbilla de Burgos - Pol. Ind. Los } \\
\text { Brezos (M3) }\end{array}$ & 13.225 & & \\
\hline \multirow{6}{*}{ 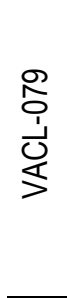 } & \multirow{6}{*}{$\begin{array}{l}\text { Alar del Rey - } \\
\text { Burgos, con } \\
\text { hijuelas }\end{array}$} & \multirow{6}{*}{$\begin{array}{l}\text { Autobuses } \\
\text { Amaya, S.L. }\end{array}$} & & Alar del Rey - Burgos & & \multirow{6}{*}{107.258} & \multirow{6}{*}{113.871} \\
\hline & & & & Frómista - Burgos & & & \\
\hline & & & & Grijalba - Burgos & & & \\
\hline & & & & Herrera de Pisuerga - Burgos & & & \\
\hline & & & & Sasamón - Burgos & & & \\
\hline & & & & Villadiego - Burgos & & & \\
\hline$\frac{0}{\frac{1}{\dot{U}}}$ & $\begin{array}{l}\text { Burgos - } \\
\text { Palencia, con } \\
\text { hijuelas }\end{array}$ & $\begin{array}{l}\text { Moreno Vicente } \\
\text { y Compañía, } \\
\text { S.L. }\end{array}$ & & Burgos - Palencia & & 35.976 & 35.976 \\
\hline 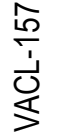 & $\begin{array}{l}\text { Madrid - Irún, } \\
\text { con hijuelas }\end{array}$ & $\begin{array}{l}\text { Nex Continental } \\
\text { Holdings, } \\
\text { S.L.U. }\end{array}$ & & & 20.000 & 16.666 & 89.706 \\
\hline
\end{tabular}


Tabla A6-4. Ingresos de las líneas metropolitanas por venta de bonos en 2009 Fuente: Junta de Castilla y León [87]

\begin{tabular}{cccc}
\hline \multirow{2}{*}{ OPERADOR } & \multicolumn{3}{c}{ AÑO 2009 } \\
\cline { 2 - 5 } & $\mathbf{N}^{\mathbf{0}}$ BONOS 20 & $\mathbf{N}^{\circ}$ BONOS 40 & INGRESOS \\
\hline Autobuses Amaya, S.L. & 5 & 9 & $250,00 €$ \\
\hline Autobuses del Pisuerga, S.A. & 29 & 267 & $5.746,00 €$ \\
\hline Autocares Arceredillo, S.L. & 30 & 190 & $4.220,00 €$ \\
\hline Autocares Castilla y León, S.A. & 195 & 830 & $19.330,00 €$ \\
\hline Automóviles Soto y Alonso, S.L. & 112 & 501 & $11.588,00 €$ \\
\hline Autobuses de Castilla, S.L. & 11200 & & \\
\hline El Noroeste de Burgos, S.L. & 4 & 12 & $296,00 €$ \\
\hline
\end{tabular}

